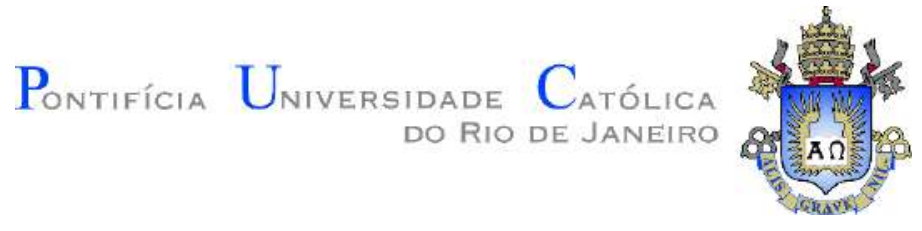

Thomás Lima de Resende

Contribuição dos mecanismos resistentes à força cortante em vigas de concreto armado sem e com fibras de aço

Tese de Doutorado

Tese apresentada como requisito parcial para obtenção do grau de Doutor pelo Programa de Pós-Graduação em Engenharia Civil do departamento de Engenharia Civil e Ambiental da PUC-Rio.

Orientador: Prof. Daniel Carlos Taissum Cardoso Co-orientadora: Lidia da Conceição Domingues Shehata

Rio de Janeiro

Outubro de 2020 
Thomás Lima de Resende

\section{Contribuição dos mecanismos resistentes à força cortante em vigas de concreto armado sem e com fibras de aço}

Tese apresentada como requisito parcial para obtenção do grau de Doutor pelo Programa de Pós-Graduação em Engenharia Civil da PUC-Rio. Aprovada pela Comissão Examinadora abaixo.

Prof. Daniel Carlos Taissum Cardoso

Orientador

Departamento de Engenharia Civil e Ambiental - PUC-Rio

Profa. Lidia da Conceição Domingues Shehata

Co-orientadora

Departamento de Engenharia Civil e Ambiental - PUC-Rio

Prof. Flávio de Andrade Silva

Departamento de Engenharia Civil e Ambiental - PUC-Rio

Prof. Raul Rosas e Silva

Departamento de Engenharia Civil e Ambiental - PUC-Rio

Prof. Joaquim António Oliveira de Barros

Departamento de Engenharia Civil - Universidade do Minho

Prof. Leandro Mouta Trautwein

Departamento de Estruturas - Unicamp

Rio de Janeiro, 30 de outubro de 2020 
Todos os direitos reservados. É proibida a reprodução total ou parcial do trabalho sem autorização da universidade, do autor e do orientador.

\section{Thomás Lima de Resende}

Graduado em Engenharia Civil pela Universidade Federal de Juiz de Fora em 2011. Mestre em Engenharia Civil pela Universidade Federal do Rio de Janeiro/COPPE em 2014. É professor efetivo na Universidade Federal dos Vales do Jequitinhonha e Mucuri.

Ficha Catalográfica

Resende, Thomás Lima de

Contribuição dos mecanismos resistentes à força cortante em vigas de concreto armado sem e com fibras de aço / Thomás Lima de Resende ; orientador: Daniel Carlos Taissum Cardoso ; coorientadora: Lidia da Conceição Domingues Shehata. - 2020.

253 f. : il. color. ; $30 \mathrm{~cm}$

Tese (doutorado)-Pontifícia Universidade Católica do Rio de Janeiro, Departamento de Engenharia Civil e Ambiental, 2020.

Inclui bibliografia

1. Engenharia Civil e Ambiental - Teses. 2. Força cortante. 3. Vigas de concreto. 4. Mecanismos de resistência ao cisalhamento. I. Cardoso, Daniel Carlos Taissum. II. Shehata, Lidia da Conceição Domingues. III. Pontifícia Universidade Católica do Rio de Janeiro. Departamento de Engenharia Civil e Ambiental. IV. Título. 


\section{Agradecimentos}

A Deus, por ter me dado a oportunidade de desenvolver este estudo na Pontifícia Universidade Católica do Rio de Janeiro (PUC-Rio), onde tive o prazer de conviver e trabalhar com profissionais competentes e atenciosos.

Aos meus pais e irmão, por acreditarem neste projeto e terem me dado total apoio em minha jornada estudantil.

À Iandra Galdino, fonte de inspiração, pelo companheirismo e incentivo na condução deste curso.

À Universidade Federal dos Vales do Jequitinhonha e Mucuri (UFVJM), por me permitir dedicação exclusiva a este estudo. Especiais agradecimentos aos colegas do Instituto de Ciência, Engenharia e Tecnologia (ICET/UFVJM), por suprir minha ausência neste período.

Às universidades onde cursei a graduação e mestrado em Engenharia Civil, Universidade Federal de Juiz de Fora (UFJF) e Universidade Federal do Rio de Janeiro (COPPE/UFRJ), por terem me fornecido base e motivação para cursar este Doutorado.

À Pontifícia Universidade Católica do Rio de Janeiro, em especial a todos que compõem o Departamento de Engenharia Civil e Meio Ambiente. Sou muito grato a todos e tenho muito orgulho de ter feito parte da história dessa instituição.

Aos meus orientadores, professores Daniel Cardoso e Lidia Shehata, pelo aceite de orientação, ensinamentos e paciência. Me faltam palavras para expressar a honra e gratidão por tê-los como mestres.

À família que compõe o Laboratório de Estruturas e Materiais da PUC-Rio. Ao professor Flávio Silva, por sua excelente direção; aos técnicos Euclides, José Nilson, Marques, Rogério, Jhansen, Carlos e Bruno, pela dedicação e atenção durante os serviços prestados; aos estagiários e companheiros de labuta, pela ajuda e parceria. Esta família fez o programa experimental acontecer e de uma maneira agradável e descontraída. 
À minha irmã encontrada na PUC-Rio, Danielle Pacheco. Sua amizade e ajuda foram fundamentais na condução deste curso.

Aos colegas de sala de estudo e da "Favelinha", pelos bons momentos compartilhados.

Às senhoras Martha e Claudia Pinheiro, pelo carinhoso acolhimento e receptividade na cidade do Rio de Janeiro.

Às IBRATA e Belgo Bekaert pela doação dos agregados e fibras de aço.

Ao CNPq, à Capes (Código de Financiamento 001) e à FAPERJ pelo apoio financeiro. 


\section{Resumo}

Resende, Thomás Lima de; Cardoso, Daniel Carlos Taissum (Orientador); Shehata, Lidia da Conceição Domingues (Co-orientadora). Contribuição dos mecanismos resistentes à força cortante em vigas de concreto armado sem e com fibras de aço. Rio de Janeiro, 2020. 253 p. Tese de Doutorado Departamento de Engenharia Civil e Ambiental, Pontifícia Universidade Católica do Rio de Janeiro.

O objetivo deste trabalho é contribuir para um melhor entendimento do comportamento à força cortante de vigas de concreto armado sem e com fibras de aço via seus mecanismos resistentes. Para isto, foi feita ampla revisão do estado da arte e, com base nesta revisão, planejado o estudo experimental realizado. Este estudo contemplou quatro composições de concretos que visaram resistência à compressão em torno de 40MPa, variando-se o teor em volume $\left(V_{f}=0,0 \%, 0,5 \%\right.$ ou $1,0 \%)$ e o fator de forma das fibras $\left(l_{f} / d_{f}=45\right.$ ou 80$)$. Além dos ensaios de caracterização dos materiais, realizaram-se ensaios para estudo dos efeitos de pino e de engrenamento dos agregados, além de ensaios de vigas sem estribos com relação entre vão de cisalhamento e altura útil igual a 2,55. Constatou-se influência de $V_{f}\left(l_{f} / d_{f}\right)$ nos efeitos de pino e de engrenamento dos agregados, bem como no comportamento das vigas. O emprego da Correlação de Imagem Digital (CID) permitiu acompanhar a fissuração dos espécimes ensaiados e a obtenção de informações para a proposição de modelos teóricos para análise dos efeitos de pino e de engrenamento dos agregados. Os dados de fotogrametria obtidos nos ensaios das vigas permitiram avaliar a formação e a cinemática da fissura diagonal crítica e, com base nesses dados e nos modelos aqui propostos e em outros apresentados na literatura, buscou-se analisar a contribuição dos mecanismos resistentes em diferentes estágios de carregamento. Foi possível observar que vigas semelhantes podem apresentar posição, forma e cinemática da fissura crítica diferenciadas, embora com respostas globais próximas. Em decorrência disso, as contribuições dos mecanismos resistentes também resultam diferentes.

\section{Palavras-chave}

Força cortante; Vigas de concreto; fibras de aço; Mecanismos de resistência ao cisalhamento; 


\begin{abstract}
Resende, Thomás Lima de; Cardoso, Daniel Carlos Taissum (Orientador); Shehata, Lidia da Conceição Domingues (Co-orientadora). Contribution of shear strength mechanisms of reinforced concrete beams without and with steel fibers. Rio de Janeiro, 2020. 253 p. Tese de Doutorado Departamento de Engenharia Civil e Ambiental, Pontifícia Universidade Católica do Rio de Janeiro.
\end{abstract}

The objective of this work is to contribute to a better understanding of the shear behavior of reinforced concrete beams without and with steel fibers via their resistant mechanisms. For this, a comprehensive review of the state of the art was made and, based on this review, the experimental study carried out was planned. This study contemplated four concrete compositions that aimed a concrete compressive strength around $40 \mathrm{MPa}$, varying the volume content $\left(V_{f}=0.0 \%, 0.5 \%\right.$ or $1.0 \%)$ and the aspect ratio of the fibers $\left(l_{f} / d_{f}=45\right.$ or 80$)$. In addition to the materials characterization tests, tests were carried out to study the dowel action and the aggregate interlock effects and also tests of beams without stirrups with span to effective depth ratio of 2.55. Influence of $V_{f}\left(l_{f} / d_{f}\right)$ in the dowel action and the aggregate interlock effects, as well as in the behavior of the beams was observed. The use of Digital Image Correlation (DIC) allowed monitoring the cracking of the tested specimens and to obtain information that led to theoretical models to analyze the dowel action and the aggregate interlock effects. The obtained photogrammetry data during the beams tests made it possible to follow the formation and kinematics of the critical diagonal crack and, based on these data and on the models proposed here and on others presented in the literature, the contribution of the resistant mechanisms in different loading stages was analyzed. It was possible to observe that similar beams may present differentiated position, shape and kinematics of the critical diagonal crack, although with similar global responses. As a result, the contributions of the resistant mechanisms are also different.

\title{
Keywords
}

Shear strength; Concrete beams; steel fibers; shear strength mechanisms; 


\section{Sumário}

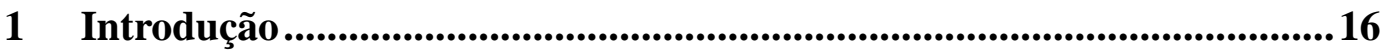

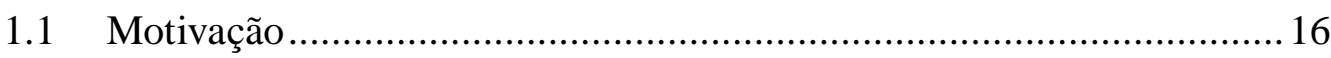

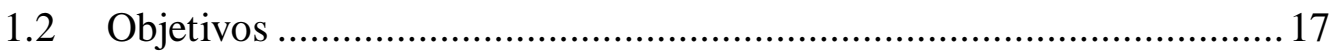

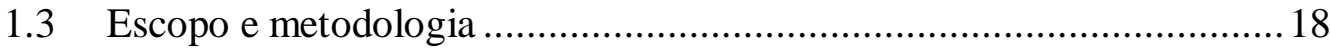

1.4 Estruturação da Tese ............................................................................. 19

2 Revisão bibliográfica...................................................................................20

2.1 Resistência à força cortante de vigas esbeltas de concreto armado sem estribos 20

2.1.1 Vigas sem fibras de aço ……................................................20

2.1.2 Vigas com fibras de aço .......................................................23

2.2 Mecanismos resistentes que contribuem para a resistência à força cortante 27

2.2.1 Efeito de pino da armadura longitudinal de tração...................27

2.2.2 Engrenamento dos agregados ..................................................42

2.2.3 Resistência à tração residual do concreto .................................73

2.2.4 Concreto comprimido não fissurado..........................................76

2.3 Cinemática da fissura diagonal crítica: Investigações experimentais sobre obtenção de deslocamentos entre faces de fissuras utilizando CID e de parcelas referentes a mecanismos resistentes à força cortante de vigas de concreto ............80

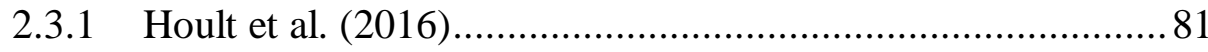

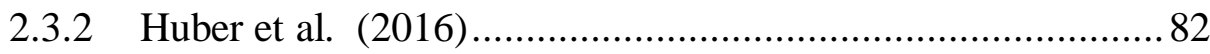

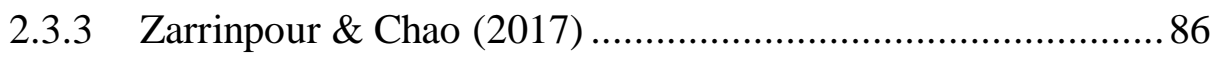

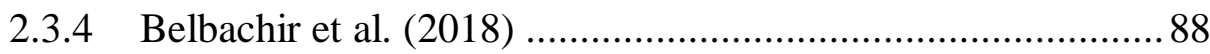

2.3.5 Tambusay et al. (2018) …………………………..............90 
3 Programa experimental ......................................................................97

3.1 Composições e propriedades dos concretos ......................................97

3.1.1 Composições ................................................................. 97

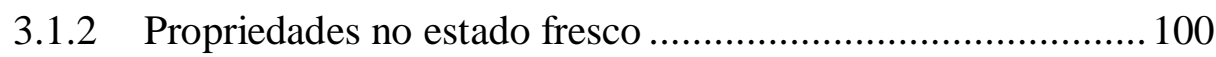

3.1.3 Propriedades no estado endurecido .................................. 101

3.2 Ensaios para estudo do efeito de pino ............................................... 110

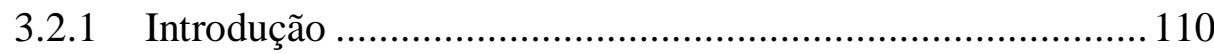

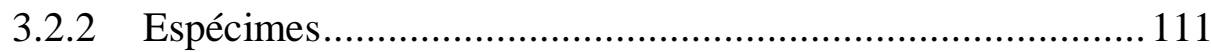

3.2.3 Ensaios sem fotogrametria .............................................. 114

3.2.4 Ensaios com fotogrametria............................................. 116

3.3 Ensaios para estudo do engrenamento dos agregados ....................... 119

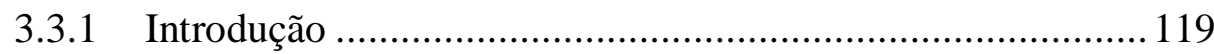

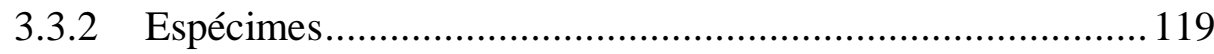

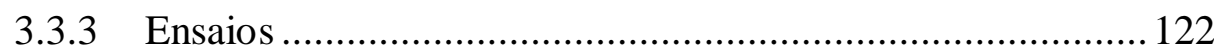

3.4 Ensaios em vigas esbeltas ...................................................... 130

3.4.1 Introdução .............................................................. 130

3.4.2 Características das vigas e esquema de ensaio ..................... 130

3.4.3 Caracterização das barras de aço ........................................ 131

3.4.4 Construção dos espécimes .............................................. 133

3.4.5 Preparação dos espécimes para ensaio.................................. 133

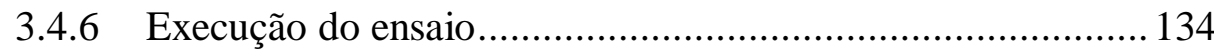

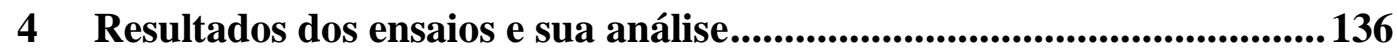

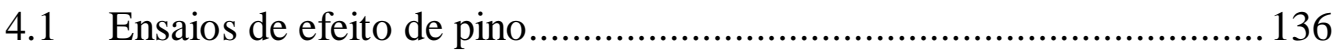

4.1.1 Resultados experimentais ................................................. 136 
4.1.2 Modelo proposto para representar o comportamento dos

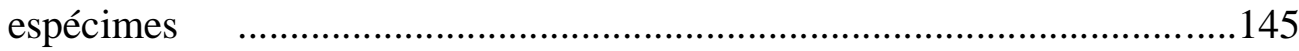

4.1.3 Comparação entre resultados experimentais e calculados ..... 149

4.2 Ensaios de engrenamento dos agregados ...................................... 150

4.2.1 Resultados experimentais ............................................ 150

4.2.2 Comparação dos resultados experimentais obtidos com os dados por equações já propostas....................................................................... 169

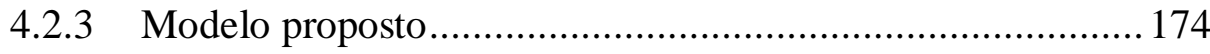

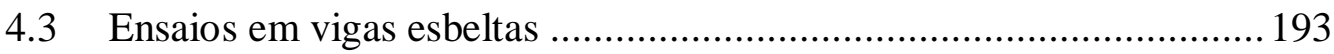

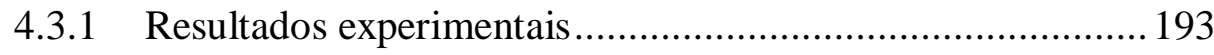

4.3.2 Análises dos mecanismos resistentes................................2212

5 Conclusões e sugestões para trabalhos futuros .......................................229

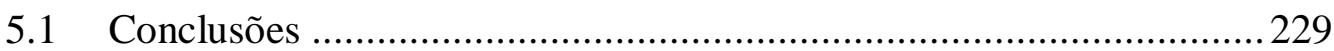

5.2 Sugestões para trabalhos futuros ................................................231

6 Referências bibliográficas......................................................................2233

Apêndice A Técnica óptica de correlação de imagem digital (CID) .245 


\section{Lista de símbolos}

\section{Letras Romanas}

$a$ - Comprimento equivalente (modelo de efeito de pino)

$a / d$ - Relação entre o vão de cisalhamento e a altura útil da viga

$\mathrm{A}_{\text {tot }}$ - Área total por unidade de plano de fissura (modelo densidade de contato)

$b$ - Comprimento correspondente à abertura de fissura artificial (modelo de efeito de pino)

$b_{n}$ - Largura de concreto na seção transversal, no nível da armadura longitudinal

$b_{w}$ - Largura da alma da seção transversal

$c$-Comprimento de trecho fissurado (modelo de efeito de pino)

$d$ - Altura útil

$d_{f}$ - Diâmetro equivalente da fibra de aço

$d l$ - Segmento infinitesimal de um trecho da fissura crítica simplificada

$d_{\max }$ - Dimensão máxima do agregado graúdo

$E_{c}$ - Módulo de elasticidade tangente inicial do concreto

$E_{f}$ - Módulo de elasticidade da fibra de aço

$E_{s}$ - Módulo de elasticidade da barra de aço

F - Carga aplicada

$\mathrm{F}_{\mathrm{z}}-$ Força de compressão de contato

$f_{c}$ - Resistência à compressão do concreto média

$f_{c t}$ - Resistência à tração direta do concreto média

$f_{c t, f l}$ - Resistência à tração na flexão do concreto média

$f_{c t, f l, r}$ - Tensão de tração na flexão residual do concreto

$f_{c t r}$ - Tensão de tração direta residual do concreto

$f_{c t, s p}$ - Resistência à tração por compressão diametral média 
$f_{c u}$ - Resistência à compressão média do concreto obtida dos ensaios de corpos-de-prova cúbicos

$f_{c y}$ - Tensão de contato de compressão do concreto admitido rígido-plástico

$f_{s t}-$ Resistência à tração das barras de aço

$f_{y}$ - Resistência ao escoamento das barras de aço

$G_{F}-$ Energia de fratura do concreto

$h$ - Altura da seção transversal

$h_{c z}$ - Altura da zona comprimida de concreto

$I_{f}$ - Momento de inércia da seção transversal da fibra de aço em relação a eixo que passa por seu centroide

$I_{S}$ - Momento de inércia da seção transversal da barra de aço em relação a eixo que passa por seu centroide

$k$ - Módulo de reação elástico do concreto

$K$ - Parâmetro que leva em consideração a redução da área de contato entre as faces da fissura (modelo densidade de contato)

$K_{s}$ - representa a rigidez de todo o conjunto do aparato metálico para medição da tensão normal nos ensaios do tipo pushoff

$L-$ Fibras de aço com $l_{f}=60 \mathrm{~mm}$ e $l_{f} / d_{f}=80$

$l_{c r}$ - Comprimento total de trecho da fissura crítica simplificada

$l_{d}$ - Comprimento onde tem-se tensão de tração no concreto

$l_{f}$ - Comprimento da fibra de aço

$M$ - Momento fletor

$M_{p l}$ - Momento fletor plástico da fibra

$N$ - Força na direção normal ao plano de cisalhamento

$N^{\prime}$ - Força na direção do eixo longitudinal da fibra

$n$ - Número de barras de aço da armadura longitudinal de tração

$p$-Força por unidade de comprimento nas fibras (modelo de efeito de pino)

$r$ - Razão entre $\Delta$ e $w$

$R_{z}$ - Rugosidade da superfície de concreto

$S$ - Fibras de aço com $l_{f}=30 \mathrm{~mm}$ e $l_{f} / d_{f}=45$

$u$ - Deslocamento na direção do eixo longitudinal da fibra

$v$ - Deslocamento na direção transversal ao eixo longitudinal da fibra

$V$ - Força cortante 
$V^{\prime}$ - Força na direção transversal ao eixo longitudinal da fibra

$V_{a g}$ - Força cortante resistente correspondente ao engrenamento dos agregados entre as faces da fissura diagonal crítica

$V_{c r}$ - Força cortante correspondente ao início da fissura crítica

$V_{c z}$ - Força cortante resistente correspondente ao concreto não fissurado acima da fissura diagonal crítica

$V_{d}$ - Força cortante resistente correspondente ao efeito de pino

$V_{d, c r}$ - Força cortante resistente correspondente ao efeito de pino no início de fissuração ao longo da armadura longitudinal

$V_{d, \max }$ - Força cortante resistente experimental correspondente ao efeito de pino

$V_{d, R}$ - Força cortante de cálculo correspondente a $V_{d}$

$V_{d, R, \max }$ - Força cortante de cálculo correspondente a $V_{d, \max }$

$V_{d, u}-V_{d}$ correspondente a $V=V_{u}$ na viga

$V_{f}$ - Teor de fibras de aço em volume

$V_{f i b}$ - Força cortante resistente correspondente à contribuição das fibras de aço

$V_{i}$ - Força cortante correspondente a um mecanismo resistente

$V_{p}$ - força cortante máxima antes da primeira perda de capacidade resistente

$V_{p l}$ - Força transversal na fibra correspondente à sua plastificação

$V_{R}$ - Força cortante resistente da viga calculada

$V_{\text {res }}$ - Força cortante resistente correspondente à resistência à tração residual do concreto

$V_{u}$ - Força cortante resistente da viga experimental

$w$ - Abertura de fissura

$w_{0}$ - Abertura de fissura a partir de $\sigma_{0}$

$w_{c r}$ - Abertura da fissura a partir da qual a resistência à tração do concreto é nula

$w_{D}-$ Abertura de fissura de controle do modelo de efeito de pino

$w_{\max }-w$ correspondente à carga máxima do ensaio

Z - Módulo resistente plástico da fibra 


\section{Letras gregas}

$\alpha$ - Inclinação da fibra em relação à direção normal à face da fissura

$\alpha_{\mathrm{cr}}$ - Inclinação entre $d l$ e o eixo longitudinal da viga

$\Delta$ - Deslocamento relativo entre as faces da fissura na direção paralela a essas faces

$\Delta_{\mathrm{cr}}-\Delta$ correspondente à $V_{d, c r}$

$\Delta_{\max }-\Delta$ correspondente à carga máxima do ensaio

$\delta_{\mathrm{p}}-$ Deslocamento vertical da viga para a condição $V=V_{p}$

$\delta_{\mathrm{u}}$ - Deslocamento vertical da viga para a condição $V=V_{u}$

$\varepsilon_{\mathrm{cu}}$ - Deformação específica do concreto para a condição $V=V_{u}$

$\varepsilon_{\text {su }}$ - Deformação específica da barra de aço para a condição $V=V_{u}$

$\varepsilon_{\mathrm{x}}$ - Deformação específica na superfície lateral da viga na direção horizontal

$\varepsilon_{y}$ - Deformação específica na superfície lateral da viga na direção vertical

$\varepsilon_{\text {y }}^{*}$ - Deformação específica de escoamento do aço correspondente ao gráfico tensão normal-deformação específica bilinear.

$\eta_{\mathrm{ct}}$ - Número de fibras médio na seção de ruptura do corpo-de-prova dogbone por $\mathrm{mm}^{2}$

$\eta_{\mathrm{f}}$ - Número de fibras estimado por $\mathrm{mm}^{2}$ na seção de cisalhamento do espécime pushoff

$\eta_{\mathrm{f}, \text { viga }}$ - Número de fibras estimado por $\mathrm{mm}^{2}$ na superfície da fissura crítica

$\theta$ - Ângulo entre a direção transversal ao plano de cisalhamento e a direção perpendicular à unidade de contato

$\theta_{\mathrm{s}}-$ Ângulo entre a direção transversal ao plano de cisalhamento e a direção da força $F_{z}$

$\mu$ - coeficiente de atrito entre as unidades de contato da fissura

$\rho$ - Taxa geométrica de armadura longitudinal de tração

$\sigma$ - Tensão normal medida pelas barras de aço externas nos ensaios dos espécimes pushoff

$\sigma_{0}$ - Tensão normal na seção de cisalhamento dos espécimes pushoff no início da zona estável de aquisição de dados 
$\sigma_{e}-$ Tensão normal efetiva na seção de cisalhamento dos espécimes pushoff com fibras

$\sigma_{f}-$ Tensão normal proveniente da ação das fibras de aço na superfície de cisalhamento dos espécimes pushoff e da fissura crítica das vigas

$\sigma_{i}-$ Tensão normal na seção de cisalhamento no início dos ensaios dos espécimes pushoff

$\sigma_{\mathrm{cr}}$ - Tensão normal na seção de cisalhamento correspondente à carga de fissuração dos espécimes pushoff

$\sigma_{\max }-$ Tensão normal na seção de cisalhamento correspondente à carga máxima dos espécimes pushoff

$\sigma_{\mathrm{r}}-$ Tensão normal correspondente ao engrenamento dos agregados de acordo com o modelo proposto

$\sigma_{\text {res }}-$ Tensão de tração residual do concreto

$\tau$ - Tensão cisalhante experimental nos ensaios dos espécimes pushoff

$\tau_{\text {cr }}$ - Tensão de cisalhamento correspondente à carga de fissuração do espécimes pushoff

$\tau_{\max }-$ Tensão de cisalhamento correspondente à carga máxima resistida pelos espécimes pushoff

$\tau_{\mathrm{e}}-$ Tensão de cisalhamento efetiva na seção de cisalhamento dos espécimes pushoff

$\tau_{f}$ - Tensão de cisalhamento proveniente da ação das fibras de aço na superfície de cisalhamento dos espécimes pushoff e da fissura crítica das vigas

$\tau_{\mathrm{r}}-$ Tensão de cisalhamento correspondente engrenamento dos agregados de acordo com o modelo proposto

$\phi$ - Diâmetro da barra de aço

$\Omega$ - Função densidade de probabilidade dos ângulos $\theta$ de contato

$\Omega_{\mathrm{ct}}$ - Função densidade de probabilidade dos ângulos $\alpha$ de inclinação das fibras nos corpos-de-prova dogbone

$\Omega_{\mathrm{f}}$ - Função densidade de probabilidade dos ângulos $\alpha$ de inclinação das fibras nos espécimes pushoff e vigas 


\section{1 \\ Introdução}

\section{1 Motivação}

Embora a resistência à força cortante de elementos de concreto armado venha sendo objeto de investigação há mais de um século, não há consenso a respeito da melhor maneira de avaliá-la e os métodos existentes em normas têm base empírica ou semi-empírica e podem levar a previsões bem diferentes. A dificuldade no estabelecimento de uma abordagem mais racional decorre da complexidade do comportamento do concreto armado, material compósito cujos constituintes possuem comportamento não-linear, e dos diferentes parâmetros que influem no comportamento de elementos desse material à força cortante.

Uma vez formada a fissura diagonal crítica, a resistência à força cortante de elementos de concreto sem estribos é provida pelo concreto não fissurado acima dessa fissura, pela resistência à tração residual do concreto na zona da fissura com menor abertura (parte final da fissura), pelo engrenamento dos agregados e pelo efeito de pino da armadura longitudinal tracionada que atravessa essa fissura. $\mathrm{O}$ adequado entendimento da evolução dessas parcelas resistentes e da sua interação até a ruptura é fundamental para que se chegue a um método racional para avaliação da capacidade resistente à força cortante de vigas de concreto armado e este trabalho visa contribuir para esse entendimento, incluindo o caso de vigas com fibras de aço, onde há também a parcela resistente referente às fibras.

Embora vigas sejam, em geral, providas de pelo menos uma armadura transversal mínima, a resistência à força cortante de vigas sem estribos é de grande interesse, pois serve de base para a definição da armadura transversal mínima, que visa evitar ruptura brusca, bem como para o dimensionamento à força cortante de lajes, elementos que podem ser desprovidos de armadura transversal.

Entre as possíveis aplicações do concreto com fibras de aço (CFA), pode-se citar a substituição parcial ou total de estribos nas vigas, como consta na norma ACI 318:2019 (armadura mínima) e no FIB MC 2010 (2013), sendo que neste é 
apresentada uma equação empírica para o cálculo da resistência ao cisalhamento que inclui a contribuição das fibras. Equações semelhantes aparecem também em recomendações como as RILEM TC 162-TDF (2000) e CNR-DT 2004 (2008).

O recente trabalho de Lantsoght (2019) aponta a ausência de modelos que descrevam o comportamento à força cortante de elementos estruturais de CFA como uma das barreiras para a sua ampla aplicação e ressalta a necessidade de investigação sobre os mecanismos resistentes à força cortante desses elementos.

Atualmente, com a disponibilidade e disseminação do uso da técnica de correlação de imagem digital (CID) nos estudos em estruturas de concreto, passou a ser possível o mapeamento dos campos de deslocamentos e deformações, obtendo-se, assim, informações fundamentais para o adequado entendimento do comportamento à força cortante, como as referentes à cinemática da fissura diagonal crítica.

Essa técnica tem se mostrado promissora, mas sua aplicação a elementos tendo a força cortante como principal causa da ruptura é ainda muito limitada, particularmente para os de CFA (Huber et al., 2016; Zarrinpour \& Chao, 2017; Belbachir et al., 2018; Tambusay et al., 2018; Cavagnis et al., 2018a).

Em face disso, visando a evolução do conhecimento sobre a resistência à força cortante de vigas, foi desenvolvida a tese aqui descrita.

\section{2 \\ Objetivos}

O objetivo geral desta tese é contribuir para o maior conhecimento sobre o comportamento à força cortante de vigas de concreto armado sem estribos e sem e com fibras de aço e as parcelas correspondentes aos diferentes mecanismos resistentes. Devido à abrangência dos aspectos envolvidos, algumas limitações foram estabelecidas para o estudo: vigas esbeltas (relação entre o vão de cisalhamento e a altura útil $a / d \geq 2,5$ ) de altura constante, de concretos com massa específica convencional e resistência à compressão em torno de $40 \mathrm{MPa}$, com armadura longitudinal concentrada junto à face tracionada, sem força normal e sujeitas a carregamento monotônico.

Como objetivos específicos, podem ser citados: 
- Avaliar experimentalmente o efeito de pino e engrenamento dos agregados em vigas de concreto sem e com fibras de aço.

- Desenvolver e validar modelos constitutivos para o efeito de pino e engrenamento dos agregados que levam em consideração a existência ou não de fibras de aço.

- Compreender como diferentes mecanismos contribuem para a resistência da força cortante de vigas de concreto armado e investigar como as fibras de aço afetam essa contribuição.

- Investigar como a forma e a evolução da fissura diagonal crítica influenciam a capacidade resistente à força cortante de vigas de concreto armado.

\section{3}

\section{Escopo e metodologia}

A pesquisa teve como escopo o estudo dos mecanismos resistentes à força cortante em vigas de concreto armado esbeltas sem estribos e sem e com fibras de aço e do comportamento à força cortante destes elementos por meio da associação destes mecanismos resistentes com os campos de deslocamentos do vão de ruptura. Por conta disso, todo o trabalho foi desenvolvido sob o enfoque da ação dos mecanismos resistentes e da cinemática da fissura diagonal crítica.

$\mathrm{Na}$ campanha experimental desenvolvida, foram utilizados concretos com quatro diferentes composições $\operatorname{com} f_{c} \sim 40 \mathrm{MPa}$, tendo-se neles variado o teor em volume $\left(V_{f}=0,0,5 \%\right.$ e $\left.1,0 \%\right)$ e dimensões das fibras de aço (comprimento igual a $30 \mathrm{~mm}$ e $60 \mathrm{~mm}$ e fator de forma de 45 e 80, respectivamente).

A fim de aumentar a compreensão do comportamento dos espécimes ensaiados, aplicou-se a técnica fotogramétrica de Correlação de Imagem Digital (CID) durante alguns dos ensaios.

O estudo englobou as seguintes etapas:

- Ampla pesquisa bibliográfica sobre os mecanismos resistentes à força cortante de vigas esbeltas sem e com fibras de aço e investigações acerca do comportamento à força cortante de vigas, levando em consideração as parcelas resistentes e a cinemática da fissura diagonal crítica. 
- Realização de ensaios de 16 e 12 espécimes para investigação dos efeitos de pino e de engrenamento dos agregados, respectivamente.

- Desenvolvimento e validação de modelos constitutivos para os efeitos de pino e de engrenamento dos agregados.

- Realização de 8 ensaios de vigas, monitorando-se o desenvolvimento da fissura crítica ao longo do carregamento por meio de correlação de imagem digital (CID).

- Com as relações constitutivas propostas para os efeitos de pino e de engrenamento dos agregados e as da literatura para os mecanismos resistentes não investigados neste trabalho, quantificação da parcela de contribuição dos diferentes mecanismos para a resistência à força cortante das vigas ensaiadas.

\section{4 \\ Estruturação da Tese}

Esta tese, além do Capítulo 1, onde consta a parte introdutória, é composta de cinco capítulos, e um apêndice.

No Capítulo 2 é apresentada a revisão bibliográfica sobre comportamento à força cortante de vigas sem e com fibras de aço e os parâmetros que nele influem e sobre as parcelas que contribuem para a resistência à força cortante dessas vigas. São também relatadas investigações sobre resistência à força cortante de vigas em que a técnica de fotogrametria foi utilizada.

O Capítulo 3 descreve o programa experimental desenvolvido.

No Capítulo 4 são analisados e discutidos os resultados do programa experimental. São propostos e validados modelos teóricos para o efeito de pino e do engrenamento dos agregados. Por fim, com estes modelos propostos e os da literatura para os outros mecanismos resistentes, buscou-se avaliar o comportamento à força cortante das vigas ensaiadas.

No capítulo 5 são feitas as considerações finais do trabalho.

No apêndice A são resumidas informações sobre correlação de imagem digital, técnica utilizada na análise do comportamento de espécimes ensaiados. 


\section{2 Revisão bibliográfica}

\section{1 \\ Resistência à força cortante de vigas esbeltas de concreto armado sem estribos}

\subsection{1}

Vigas sem fibras de aço

Em vigas de concreto armado submetidas a momento fletor e força cortante, uma vez atingida a resistência à tração do concreto na face tracionada, formam-se fissuras verticais de flexão espaçadas ao longo do vão e ocorre redistribuição de tensões. Essas fissuras se propagam verticalmente em direção à face comprimida, até uma certa altura, passando, então, a se inclinarem. $\mathrm{O}$ avanço das fissuras inclinadas em direção à face comprimida é acompanhado por sucessivas redistribuições de tensões e pelo despertar dos mecanismos de transferência, até que haja o fendilhamento ao longo da armadura longitudinal (Krefeld \& Thurston, 1966; Chana, 1981). Há de se ressaltar que pesquisas mais recentes, a partir de registros fotográficos com câmera de alta velocidade, indicam que a fissura longitudinal ao longo da armadura longitudinal tracionada e o prolongamento da fissura diagonal crítica na direção da face comprimida são fenômenos pós-pico de carga (Khaja \& Sherwood, 2013; Belbachir, 2018).

Uma vez formada a fissura diagonal crítica, a resistência à força cortante de vigas sem estribos é provida pelo concreto não fissurado acima dessa fissura $\left(V_{c z}\right)$, e pelos mecanismos de transferência de forças ao longo da fissura, isto é, pela resistência à tração residual do concreto $\left(V_{\text {res }}\right)$, pelo efeito de pino da armadura longitudinal tracionada que atravessa a fissura $\left(V_{d}\right)$ e pelo engrenamento dos agregados entre as faces da fissura $\left(V_{a g}\right)$, como mostra o esquema da Figura 2.1 (ACI 445R, 1999). Entretanto, nota-se que é recorrente a desconsideração de $V_{\text {res }}$ (Kim \& Park 1996; Sarkar et al., 1999; Wight \& Macgregor, 2012; Yang, 2014; entre outros). 


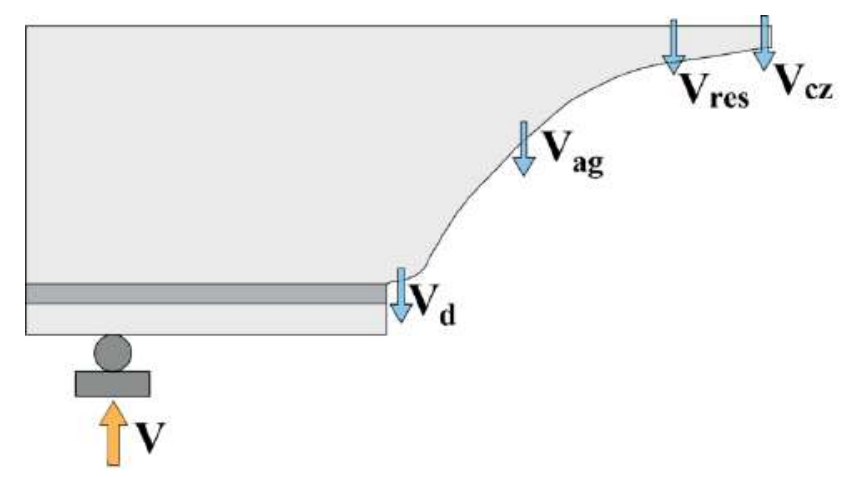

Figura 2.1 - Forças internas de uma viga sem estribos depois do surgimento da fissura diagonal crítica.

A resistência à força cortante depende da altura da linha neutra, da existência de mesa na região comprimida e da taxa de armadura longitudinal de tração, fatores relacionados com o dimensionamento à flexão, e da capacidade de transmissão de cortante na fissura diagonal. Em vigas em que há cargas perto dos apoios (distância até cerca de 2 a 2,5 vezes a altura útil, $d$ ), tem-se o efeito benéfico da transmissão direta dessas cargas para os apoios (Vollum \& Fang, 2015). Nas com carga distribuída, uma parcela do carregamento próxima dos apoios também é para eles transmitida diretamente (Cavagnis et al., 2018a).

Em vigas em que a força cortante é a principal causa de ruptura, a adoção de uma menor taxa de armadura longitudinal, $\rho$, faz com que as fissuras apresentem uma maior profundidade e tamanho de abertura, o que faz reduzir a resistência da parcela de efeito de pino e engrenamento dos agregados, ou seja, há interação entre os mecanismos resistentes à força cortante (Wight \& MacGregor, 2009). Pelo fato da eficiência da ação de pino da armadura longitudinal ser limitada pela resistência à tração do concreto e pela espessura de seu cobrimento, a ação de pino é menos efetiva em elementos sem estribos do que naqueles com estribos (Baumann \& Rüsch, 1970). Segundo Regan (2000), a resistência à força cortante depende também da aderência da armadura longitudinal, mas essa influência pode ser desconsiderada na prática.

De acordo com Khaja \& Sherwood (2013), a resistência à força cortante depende do par $\rho$ e $a / d$ (ou $M / V d$ ) e não de $\rho$ isoladamente. Esse par de parâmetros pode ser considerado por meio da relação $M /(V d \rho)$, que está diretamente ligada à deformação específica da armadura longitudinal, que, por sua vez, define espaçamento e abertura das fissuras. Vigas ensaiadas por esses autores que tinham 
mesma relação $M /(V d \rho)$ apresentaram tensões cisalhantes nominais resistentes semelhantes.

A contribuição do engrenamento dos agregados, cuja importância tem sido mostrada em diferentes estudos desde os anos 60 (Fenwick \& Paulay, 1968, foi um dos trabalhos pioneiros), depende da rugosidade dessas faces e dos deslocamentos relativos entre as faces das fissuras. A rugosidade está relacionada com as partículas de agregados graúdos nas faces da fissura, e com o fato da fissura contornar ou atravessar esses agregados, o que depende das características da pasta de cimento, da interface pasta-agregado e do tipo de agregado. No caso da fissura atravessar os agregados, o que pode ocorrer em concretos de alta resistência e concretos com agregados de calcário ou leves (Regan et al., 2005; Albajar, 2008; Sagaseta \& Vollum, 2011a), as faces das fissuras ficam menos rugosas e a contribuição do engrenamento é menor.

Segundo Walraven (1980), todas as partículas com dimensão máxima maior que duas vezes a abertura da fissura contribuem na transferência de tensões cisalhantes na fissura. Portanto, a dimensão máxima do agregado $\left(d_{\max }\right)$ também é fator influente na contribuição do engrenamento; agregados com maior dimensão tendem a propiciar maior rugosidade nas faces das fissuras. Ensaios de vigas esbeltas de concreto armado com $d=1400 \mathrm{~mm}$ realizados por Sherwood (2008), nos quais foi variada apenas a dimensão máxima do agregado $\left(d_{\max }=9,5 \mathrm{~mm}\right.$, $19 \mathrm{~mm}, 38 \mathrm{~mm}, 51 \mathrm{~mm})$, mostraram a tendência do aumento da resistência à força cortante à medida que se aumentou $d_{\max }$. Isto foi também verificado por Deng et al. (2017), ao ensaiarem vigas com altura de $400 \mathrm{~mm}$ nas quais se variou apenas $d_{\max }$ (10 mm, $20 \mathrm{~mm}, 31,5 \mathrm{~mm}, 40 \mathrm{~mm})$. Ampla revisão bibliografica realizada por Resende (2014) sobre comportamento à força cortante de vigas de concreto autoadensável indicou a tendência dessas vigas terem menor resistência à força cortante que vigas semelhantes de concreto vibrado, por conta do menor teor e/ou menor dimensão máxima do agregado graúdo que esse tipo de concreto costuma ter.

Em vigas de mesma taxa de armadura longitudinal e concreto, o aumento da altura efetiva de vigas com pouca ou nenhuma armadura transversal implica na redução da tensão cisalhante nominal resistente, o que é conhecido como "efeito escala". Com esse aumento da altura, as fissuras inclinadas ficam mais espaçadas e com maior abertura, diminuindo, assim, a parcela resistente ao cortante relativa ao 
engrenamento dos agregados. De acordo com Taylor (1974), aumentando-se a dimensão máxima do agregado proporcionalmente ao aumento das dimensões da seção da viga, a redução da resistência média ao cisalhamento é menor.

O estudo de Sherwood (2008) mostrou que o espaçamento de fissuras a meia altura das vigas e lajes sem armadura transversal tende a ser aproximadamente igual à metade da altura efetiva, independentemente do valor dessa altura. Então, quando essa altura aumenta, o espaçamento longitudinal das fissuras aumenta proporcionalmente e, consequentemente, há aumento da abertura das fissuras e diminuição da capacidade de engrenamento dos agregados. Com a adição de adequada armadura longitudinal distribuída ao longo da altura da viga, controla-se essa fissuração e pode-se eliminar o efeito escala (Sherwood, 2008). Investigação de Yu e Bažant (2011) indicou que estribos diminuem o efeito de escala na resistência à força cortante de vigas com altura de até cerca de $1 \mathrm{~m}$, mas não o eliminam e, nas vigas com altura maior ainda, não alteram esse efeito. Segundo Huber et al. (2016), a adição de estribos, mesmo que em taxa mínima, diminui o efeito escala. Albajar (2008) relatou resultados de estudos que sugerem ser o efeito de escala menos relevante nos casos de vigas curtas do que nos de vigas esbeltas.

As importâncias relativas dos diferentes mecanismos resistentes têm sido objeto de discordância. Isto decorre delas dependerem de vários fatores, inclusive da localização, forma e cinemática da fissura diagonal crítica (Campana, 2013).

Investigações experimentais recentes sobre resistência à força cortante de vigas de concreto têm sido conduzidas com o acompanhamento da cinemática da fissura crítica por correlação de imagem digital (CID). Esta técnica tem se mostrado eficiente e capaz de subsidiar o entendimento do comportamento à força cortante $\mathrm{e}$ dos diferentes mecanismos resistentes por meio da cinemática da fissura crítica, e é enfocada no item 2.3.

\subsection{2 \\ Vigas com fibras de aço}

A adição de fibras de aço, dependendo do teor e das características dessas fibras e também da matriz de concreto, pode promover o aumento de resistência e de ductilidade do concreto submetido à compressão e à tração, principalmente sob tração, pois as fibras funcionam como obstáculo ao desenvolvimento da abertura e 
do comprimento das fissuras. A ruptura por tração do concreto com fibras ocorre com alongamento elástico ou plástico das fibras, por degradação da matriz de concreto na zona de transição fibra-matriz ou por arrancamento ou ruptura das fibras.

Dependendo da sua composição, o concreto com fibras submetido a tração uniaxial pode apresentar ruptura localizada e perda de capacidade resistente imediatamente após a ocorrência da primeira fissura ou ter fissuras múltiplas e resistência à tração maior que a tensão relativa à formação da primeira fissura (FIB MC 2010, 2013).

Para aplicações estruturais, o concreto com fibras é classificado com base na sua resistência residual pós-fissuração obtida de ensaio à flexão padronizado, de mais fácil realização que o de tração direta.

Tendo em vista um mínimo desempenho a garantir, segundo Aguado \& Laranjeira (2007), em elementos com função estrutural, não é recomendável usar teores de fibras de aço inferiores a $0,25 \%$ em volume $\left(20 \mathrm{~kg} / \mathrm{m}^{3}\right)$ e, para não precisar mudar sensivelmente a estrutura granular do concreto, deve-se não ter teores maiores que $1,5 \%$ em volume $\left(118 \mathrm{~kg} / \mathrm{m}^{3}\right)$. Para que as fibras possam atuar como ponte de transferência de tensões nas fissuras, o comprimento das fibras deve ser pelo menos 2 vezes a dimensão máxima do agregado. As recomendações CNRDT 204/2006 indicam que o teor de fibras em aplicações estruturais não deve ser menor que $0,3 \%\left(24 \mathrm{~kg} / \mathrm{m}^{3}\right)$.

Em função do exposto, a resistência à força cortante e a ductilidade de vigas de concreto com fibras de aço é maior que a de vigas de mesmas características de concreto sem fibras, podendo-se, inclusive, dispensar a adoção de taxa de estribos mínima (Prisco et al., 2010). A ACI 318:2019 permite dispensar a armadura mínima para cortante desde que o concreto tenha $f_{c} \leq 40 \mathrm{MPa}$ e pelo menos $0,75 \%$ de fibras de aço e atenda a algumas condições de desempenho quando ensaiado à flexão. De acordo com o FIB MC 2010 (2013), a dispensa de armadura mínima e a substituição total ou parcial da armadura transversal depende apenas desse desempenho.

A resistência à força cortante de vigas de concreto com fibras depende, além dos mesmos fatores que a de vigas de concreto sem fibras, do teor e das características das fibras, o que acarreta, além da adição de uma nova parcela resistente referente às fibras, interferência nos demais mecanismos resistentes. 
Essa interferência dependerá da distribuição e orientação das fibras na viga que, por sua vez, dependerá de fatores como geometria da forma, existência de barras de armadura, maneira de lançamento do concreto na forma e de vibração e fluidez do concreto (Soroushian \& Lee, 1990; Gettu et al., 2005; Zirgulis et al., 2016; Lim et al., 2018; Raju et al., 2020).

A análise das resistências à força cortante de vigas com fibras ensaiadas por diferentes autores realizada por Lantsoght (2019) indicou que, contrariamente ao que acontece nas vigas sem fibras, a diminuição da dimensão máxima do agregado tende a aumentar essa resistência das com fibras. Segundo esse autor, isso se deve ao fato de menor $d_{\max }$ acarretar um concreto mais uniforme e melhor aderência entre as fibras e a matriz.

Como a armadura longitudinal distribuída ao longo da altura e os estribos levam à diminuição ou mesmo à extinção do efeito de escala, era de se esperar que as fibras, dependendo do seu teor e características, também pudessem conduzir a resposta semelhante. Entretanto há conclusões contraditórias sobre a influência das fibras no efeito de escala, possivelmente devido às variações das características das vigas e dos teores e propriedades das fibras adotados nos estudos experimentais realizados. Cuenca (2012), dos ensaios de vigas sem e com fibras de aço $\left(b_{w}=250 \mathrm{~mm}, \rho \approx 1 \%, a / d=3, d_{\max }=16 \mathrm{~mm}\right.$, fibras com $l_{f}=50 \mathrm{~mm}, l_{f} / d_{f}=62,5$, $V_{f}=0,0 \%, 0,64 \%$ ou $1,0 \%, f_{c} \approx 35 \mathrm{MPa}$ ) com alturas iguais a $500 \mathrm{~mm}, 1000 \mathrm{~mm}$ e $1500 \mathrm{~mm}$, concluiu que a adição de fibras tende a diminuir o efeito de escala à medida que se aumenta a tenacidade do concreto. Por outro lado, Shoaib et al. (2014), ao ensaiarem vigas com fibras ( $b_{w} \approx 300 \mathrm{~mm}, a / d=3, d_{\max }=10 \mathrm{~mm}$, fibras com $\left.l_{f}=30 \mathrm{~mm}, l_{f} / d_{f}=55, V_{f}=1,0 \%\right)$, onde se variaram $\rho(\approx 1,4 \%$ a 4,0 \%), $f_{c}(23 \mathrm{MPa}$ a $80 \mathrm{MPa})$ e $h(308 \mathrm{~mm}, 600 \mathrm{~mm}$ ou $1000 \mathrm{~mm})$, chegaram à conclusão de que a diminuição da resistência à força cortante de vigas com fibras quando se aumenta $h$ é da mesma ordem de grandeza que a constatada por outros autores em vigas de concreto sem fibras.

Tem sido constatado que o aumento do teor de fibras até cerca de $1 \%$ leva a aumento considerável da resistência à força cortante de elementos em relação aos de características semelhantes e sem fibras, mas aumentos acima desse teor tendem a proporcionar pouco ganho de desempenho (Dihn et al., 2010; Susetyo \& Vecchio, 2010). O comprimento e o fator de forma $l_{f} d_{f}$ também influenciam o 
comportamento de elementos estruturais à força cortante, sendo a relação $l_{f} / d_{f}$ mais relevante que o comprimento. Elementos tendo fibras com menor comprimento podem ter melhor desempenho que os semelhantes com mesmo teor volumétrico de fibras de maior comprimento e mesma relação $l_{f} d_{f}$. Presume-se que isso ocorra devido ao número de fibras mais curtas ser maior que o das fibras mais longas, levando a maior possibilidade das fibras interceptarem microfissuras, o que acarreta controle do desenvolvimento de microfissuras em macrofissuras (Susetyo \& Vecchio, 2010).

A contribuição das fibras para a resistência à força cortante de vigas é atribuída à sua capacidade de transferir tensões através das fissuras diagonais e de controlar o desenvolvimento e a abertura das fissuras (Parra-Montesinos et al., 2010). Além das fibras contribuírem elas mesmas para a resistência à força cortante, o controle do desenvolvimento das fissuras leva a uma maior altura da região comprimida e consequente maior contribuição dessa região para a resistência ao cortante. Por outro lado, a melhoria do comportamento à tração e o controle da fissuração ao longo da armadura longitudinal implicam numa maior contribuição do efeito de pino (Zarrinpour \& Chao, 2017).

Nas vigas com fibras ensaiadas por Zarrinpour \& Chao (2017), as maiores contribuições para a resistência à força cortante foram aquelas referentes ao efeito de ponte provida pelas fibras ao longo da fissura crítica, à região comprimida não fissurada e ao efeito de pino. Nelas, a parcela referente ao engrenamento dos agregados foi desprezível (ver item 2.3.2.3). Entretanto, mais investigações sobre a influência das fibras de aço nos mecanismos resistentes à força cortante e na sua interação são necessárias.

O estudo de Lantsoght (2019) avaliou várias expressões já propostas para estimar a resistência à força cortante de vigas com fibras, comparando os resultados por elas fornecidas com os experimentais de 488 vigas, concluindo que elas não traduzem o comportamento dessas vigas adequadamente. Pontuou-se a necessidade de estudos sobre os mecanismos resistentes e a cinemática da fissura crítica de vigas com fibras e sem estribos para que se possa vir a desenvolver método de projeto de vigas com fibras mais otimizado. 


\section{2 Mecanismos resistentes que contribuem para a resistência à força cortante}

Neste item é feito resumo do estado da arte sobre os mecanismos resistentes à força cortante de vigas sem estribos, abrangendo investigações experimentais, métodos para sua quantificação e influência da adição de fibras de aço.

\subsection{1}

\section{Efeito de pino da armadura longitudinal de tração}

O "efeito de pino" de uma armadura atravessando uma fissura representa sua capacidade de restringir deslocamento relativo entre as faces da fissura na direção paralela aos planos dessas faces, ou seja, sua capacidade de transmitir força perpendicular ao seu eixo.

No caso de vigas de concreto armado, a restrição provida pela armadura longitudinal de tração ao deslocamento vertical relativo entre as duas faces da fissura que leva à ruptura por força cortante acarreta contribuição para a resistência à força cortante das vigas, que depende da interação entre as forças na armadura nas direções longitudinal e transversal.

Segundo Vintzeleou \& Tassios (1986), nos casos de cobrimentos da armadura maiores que 6 a 7 vezes o diâmetro das barras, o efeito de pino é governado pelo escoamento da armadura e esmagamento do concreto sob essa armadura. Nos casos de cobrimentos menores (caso usual de vigas), em elementos sem estribos e sem fibras, $V_{d}$ atinge seu valor máximo $\left(V_{d, \max }\right)$ quando se inicia fendilhamento do concreto no nível da armadura $\left(V_{d, c r}\right)$, conforme ilustrado na Figura 2.2.

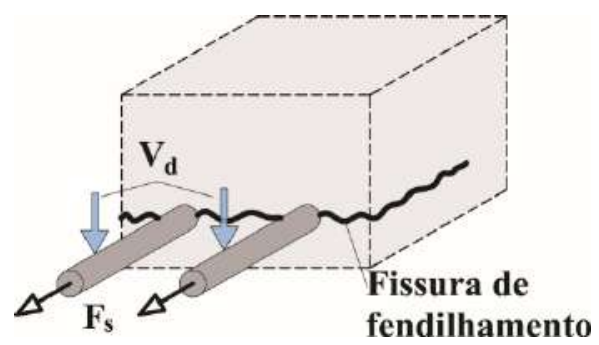

Figura 2.2 - Fissura de fendilhamento ao longo da armadura longitudinal em decorrência do efeito de pino 


\subsubsection{1}

\section{Investigações experimentais}

Vários ensaios foram realizados, principalmente nas décadas de 60 e 70, para investigar a contribuição do efeito de pino da armadura longitudinal na resistência à força cortante de vigas, considerando-se diferentes variáveis. O tipo de ensaio realizado para tal tem sido preferencialmente o adotado por Krefeld \& Thurston (1966), Baumann \& Rüsch (1970) e Taylor $(1969,1974)$. Nele, a força é aplicada a um bloco rígido posicionado no centro de uma viga simplesmente apoiada, separado do resto da viga por uma fissura criada artificialmente, e a carga é transferida de uma parte para a outra apenas pela armadura longitudinal de tração. Desse ensaio é obtida a relação entre a força transversal na armadura longitudinal $\left(V_{d}\right)$ e o deslocamento vertical relativo entre as faces da fissura atravessada pela armadura $(\Delta)$ e o valor máximo de $V_{d}$ e o de $\Delta$ a ele correspondente. Na Figura 2.3 tem-se o esquema de ensaio e dimensões adotadas em trabalhos descritos na literatura.

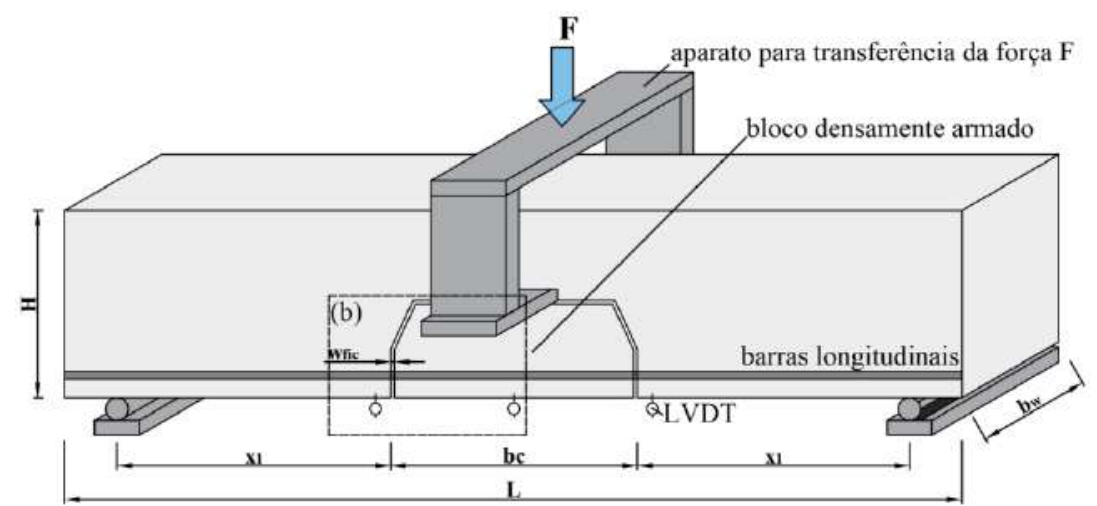

(a)

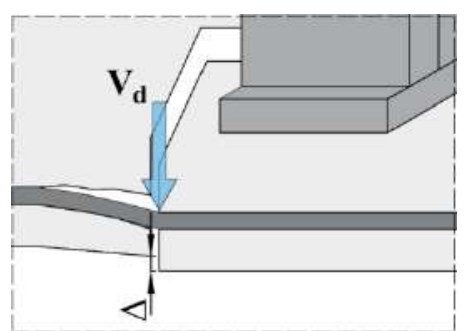

(b)

Figura 2.3 (continua) - Ensaio de efeito de pino: (a) Esquema de ensaio adotado por Krefeld \& Thurston (1966), Taylor (1969) e Baumann \& Rüsch (1970); (b) espécime após o surgimento da fissura de fendilhamento; (c) dimensões adotadas por alguns autores, em mm. 


\begin{tabular}{cccc}
\hline Dimensões (mm) & $\begin{array}{c}\text { Krefeld \& } \\
\text { Thurston (1966) }\end{array}$ & Taylor (1969) & $\begin{array}{c}\text { Baumann \& } \\
\text { Rüsch (1970)* }\end{array}$ \\
\hline$b_{\mathrm{w}}$ & 152 a 206 & 200 & 110 \\
$\mathrm{H}$ & 305 a 381 & 400 & 320 \\
$\mathrm{x}_{1}$ & 305 a 762 & 810 & 450 \\
$\mathrm{~b}_{\mathrm{c}}$ & 610 & 810 & 450 \\
\hline
\end{tabular}

*Para os espécimes sem estribos

(c)

Figura 2.3 (continuação) - Ensaio de efeito de pino: (a) Esquema de ensaio adotado por Krefeld \& Thurston (1966), Taylor (1969) e Baumann \& Rüsch

(1970); (b) espécime após o surgimento da fissura de fendilhamento; (c) dimensões adotadas por alguns autores, em $\mathrm{mm}$.

Nos espécimes ensaiados por Krefeld \& Thurston (1966), todos sem estribos, variaram-se a largura $(152 \mathrm{~mm}$ a $206 \mathrm{~mm})$, o diâmetro das duas barras de aço longitudinais $(22,2 \mathrm{~mm}$ ou $28,7 \mathrm{~mm})$, o cobrimento inferior dessas barras (38 mm a $114 \mathrm{~mm}$ ) e a distância da fissura artificial aos apoios (305 $\mathrm{mm}$ a $762 \mathrm{~mm}$ ). As principais conclusões foram que $V_{d, \max }$ aumentou com o acréscimo do cobrimento e diminuiu com o aumento da distância da fissura diagonal aos apoios.

Taylor (1969, 1974) ensaiou 4 espécimes sem estribos e com armadura longitudinal constituída por duas barras com diâmetro de $22 \mathrm{~mm}$ tendo cobrimentos lateral e inferior iguais a $25 \mathrm{~mm}$, onde a variável foi a abertura da fissura artificial $(0,2 \mathrm{~mm}, 1,5 \mathrm{~mm}$ ou $5,0 \mathrm{~mm})$. A partir de seus resultados, foi proposta a curva idealizada mostrada na Figura 2.4 para relacionar $V_{d}$ e $\Delta$ (equação 2.2) e estabelecido que o valor de $\mathrm{V}_{\mathrm{d}}$ para a formação de fissura ao longo da armadura $\left(V_{d}=V_{d, c r}\right)$ corresponde a $\Delta=0,17 \mathrm{~mm}$.

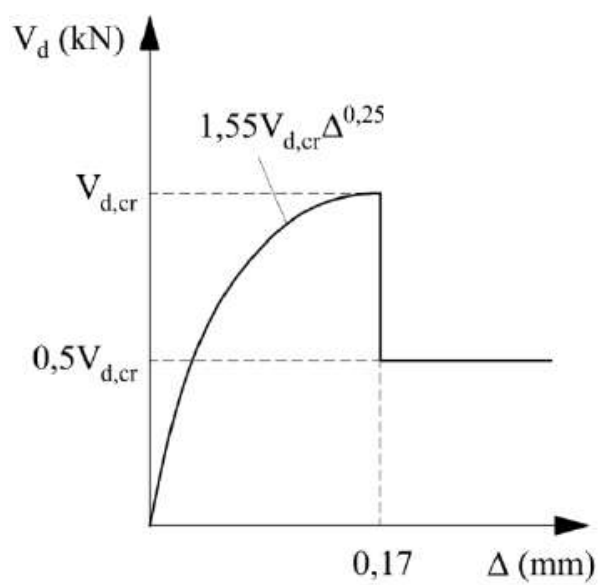

Figura 2.4 - Relação entre $V_{d}$ e $\Delta$ proposta por Taylor $(1969,1974)$. 


$$
V_{d}=\left\{\begin{array}{c}
1,55 V_{d, c r} \Delta^{0,25} \text { para } \Delta \leq 0,17 \\
0,5 V_{d, c r} \text { para } \Delta>0,17
\end{array} \quad \text { (unidades: } \mathrm{mm}\right. \text { e kN) }
$$

Esse autor ensaiou também 8 espécimes com um estribo posicionado a diferentes distâncias da fissura artificial, tendo observado maior efetividade do estribo em aumentar $V_{d, \max }$ com a diminuição dessa distância.

Complementando o estudo, foram ainda ensaiadas 28 vigas projetadas para romper por força cortante mostrando fissura ao longo da armadura longitudinal. Estas vigas visaram investigar a influência em $V_{d}$ de diferentes parâmetros: resistência do concreto, vão de cisalhamento, número, arranjo e cobrimento das barras de aço longitudinais, e abertura da fissura artificial. A partir de seus ensaios, Taylor $(1969,1974)$ concluiu que $V_{d, \max }$ aumenta com o aumento da resistência à tração do concreto e da largura de concreto no nível da armadura longitudinal e depende dessa armadura e de seu cobrimento.

Dos 31 espécimes ensaiados por Baumann \& Rüsch (1970), apenas 4 não tinham estribos. Os demais, a menos de um, que tinha 2 estribos, tinham apenas 1 estribo nas proximidades da fissura fictícia. As variáveis dos espécimes, além do número de estribos, foram: abertura da fissura fictícia; largura e a altura da viga; diâmetro, número de barras e de camadas (uma ou duas), cobrimento inferior e lateral e tipo de aço da armadura longitudinal; diâmetro do estribo e sua distância à fissura fictícia; distância da fissura fictícia aos apoios ( $x_{1}$ na Figura 2.3); resistência do concreto. Dos espécimes sem estribos, as variáveis limitaram-se ao cobrimento de concreto (inferior entre $20 \mathrm{~mm}$ e $51 \mathrm{~mm}$ e lateral entre $15 \mathrm{~mm}$ a $18 \mathrm{~mm}$ ) e ao diâmetro da armadura ( $16 \mathrm{~mm}, 20 \mathrm{~mm}$ ou $26 \mathrm{~mm}$ ). Foi concluído que $V_{d, \max }$ depende da largura de concreto no nível da armadura (largura da viga menos a largura ocupada pelas barras de aço), do diâmetro da armadura e da resistência do concreto e que a capacidade de aumento de $V_{d}$ após o início da fissuração ao longo da armadura longitudinal depende da existência de estribos, cuja eficiência aumenta com a sua maior proximidade da fissura fictícia.

Baumann \& Rüsch (1970) propuseram que, até a formação de fissura ao longo da armadura $\left(V_{d}=V_{d, c r}\right)$, tem-se relação aproximadamente linear entre $V_{d}$ e $\Delta$ até $\Delta=0,08 \mathrm{~mm}$, ou seja, 
$\Delta=0,08 V_{d} / V_{d, c r}$

$(\Delta \mathrm{em} \mathrm{mm})$

eq. (2.1)

Entretanto, conforme apresentado na Figura 2.5, isto não é constatado nas curvas de seus espécimes sem estribos.

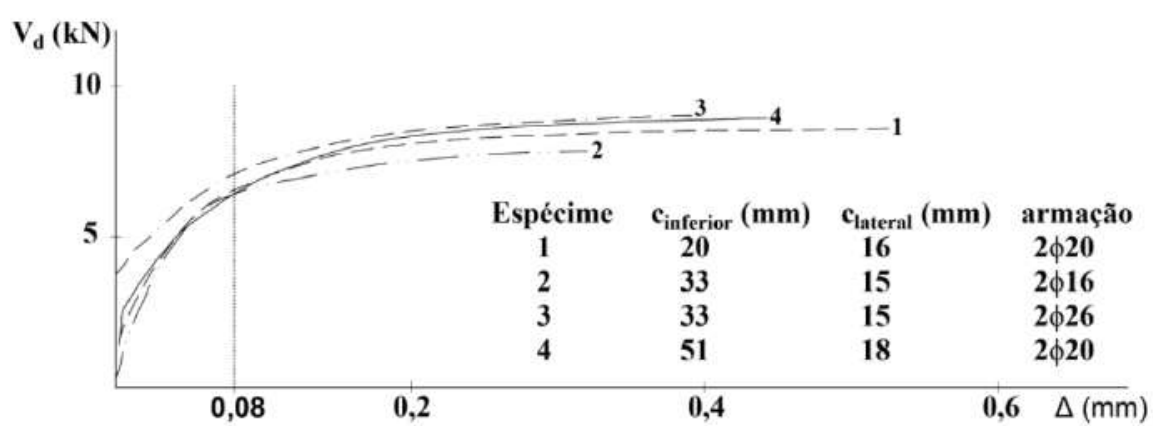

Figura 2.5 - Curvas $V_{d}-\Delta$ para os espécimes sem estribos de Baumann e Rüsch (1970).

Embora a resistência à força cortante de vigas de concreto armado com fibras de aço tenha sido o foco de várias investigações nas últimas décadas, na pesquisa bibliográfica realizada sobre a contribuição da parcela de efeito de pino na resistência à força cortante de vigas de concreto armado com fibras de aço, encontrou-se o relato de apenas um estudo (Xia et al., 2015), que englobou vigas de concreto Ductal ${ }^{\circledR}\left(f_{c} \sim 165 \mathrm{MPa}\right.$, sem agregados graúdos $)$ e barras de aço MMFX ( de tensão de escoamento de aproximadamente $700 \mathrm{MPa}$ ), caso que foge do escopo deste trabalho. Entretanto, é de se esperar aumento de $V_{d, \max }$ ao adicionar fibras de aço, uma vez que há aumento na resistência à tração residual do concreto, controle da fissuração e melhora na aderência barra-concreto, (Dinh, 2009; Lantsoght, 2019).

\subsubsection{2 \\ Métodos para avaliação de $V_{d}\left(V_{d, R}\right.$ e $\left.V_{d, R, \max }\right)$}

Na bibliografia consultada, constatou-se que o modelo mais difundido para estudo do comportamento do efeito de pino da armadura longitudinal de tração de vigas de concreto armado é baseado na analogia de vigas sobre apoio elástico, na qual a viga é representada pela barra de aço e o apoio elástico pelo concreto (Vintzeleou \& Tassios, 1986). Neste modelo, o problema é reduzido a uma análise unidirecional, em que a barra de aço é idealizada como apoiada em uma sequência de molas ao longo de seu eixo e submetida a uma carga perpendicular ao seu eixo 
ou a essa carga e um momento fletor, no caso de haver defasagem entre a seção de aplicação de carga e o início do apoio elástico.

Este modelo apresenta como vantagem a reunião das propriedades do apoio a um único parâmetro, $k$ (constante de mola por unidade de área), que deve expressar as características do concreto e da interface barra-concreto e cuja adequada determinação é fundamental.

Existem métodos para cálculo de $V_{d, R, \max }$, que foram inspirados no comportamento de viga em apoio elástico (Baumann \& Rüsch, 1970; Vintzleou \& Tassios, 1986; Cavagnis et al., 2018b), e de $V_{d, R}$, em que adotaram-se valores de deslocamentos obtidos experimentalmente em ensaios de vigas associados à teoria de barra com comportamento elástico linear (Cavagnis et al., 2018a).

No item 2.2.1.2.1 são apresentados os fundamentos da analogia de viga sobre apoio elástico aplicado ao efeito de pino na armadura longitudinal tracionada de vigas de concreto armado e, no item 2.2.1.2.2, fórmulas já propostas para $V_{d, R} \mathrm{e}$ $V_{d, R, \max }$ que não incluem o caso de concreto com fibras.

\subsubsection{1}

\section{Analogia de viga sobre apoio elástico aplicada ao efeito de pino na armadura longitudinal tracionada de vigas de concreto armado}

Ao ter-se uma força vertical $\left(V_{d}\right)$ e um momento fletor $\left(M_{0}\right)$ na extremidade de uma barra de aço (Figura 2.6), esta flete e aparece uma reação distribuída no apoio. É admitido que haja proporcionalidade entre a intensidade desta reação $(p)$ e o deslocamento vertical ( $y$ ) da barra em qualquer seção transversal, como indica a equação 2.3 .

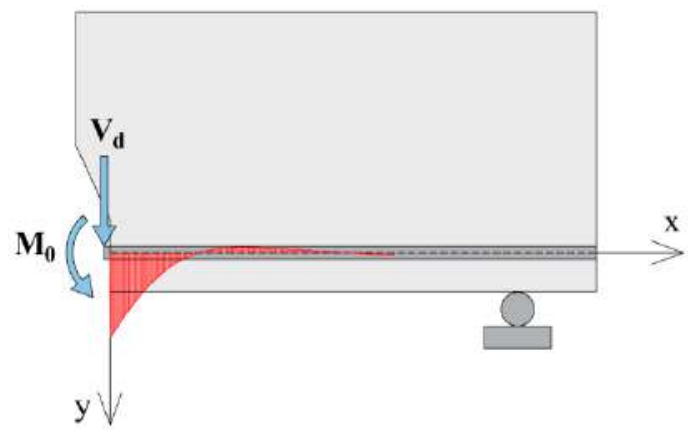

Figura 2.6 - Barra da armadura longitudinal tracionada de viga de concreto submetida a $V_{d}$ e $M_{o}$. Esboço do diagrama de tensão normal no concreto na direção $y$, ao longo do comprimento da barra. Na ausência de defasagem entre a seção de aplicação de $V_{d}$ e o início do apoio elástico, $M_{0}=0$. 
$p=k \phi y$

onde a força $p$ refere-se a cada barra de diâmetro $\phi$.

Como $\frac{d V}{d x}=\frac{d^{2} M}{d x^{2}}=k \phi y$ e $E_{S} I_{S} \frac{d^{2} y}{d x^{2}}=-M$, sendo $V$ a força cortante e $M$ o momento fletor na seção transversal distando $x$ da de onde tem-se $V_{d}$ e $M_{0}$, a equação diferencial da linha elástica da barra de aço é:

$$
E_{s} I_{s} \frac{d^{4} y}{d x^{4}}=-k \phi y
$$

Nesta equação,

$E_{s}$ é o módulo de elasticidade da barra de aço e

$I_{s}$ é o momento de inércia da seção transversal da barra de aço em relação a eixo que passa por seu centroide.

A solução geral da equação 2.4, apresentada por Hetényi (1979), é a equação 2.5 , onde $A, B, C$ e $D$ são constantes. Para o caso objeto deste estudo, em que o carregamento atuante em uma extremidade da barra $(x=0)$ tem efeito desprezível próximo à sua outra extremidade $\left(\beta L>\pi\right.$, sendo $\beta=\sqrt[4]{\frac{k \phi}{4 E_{s} I_{s}}}$ e $L$ o comprimento da barra; Hetényi, 1979), ou seja, tem-se uma barra cujo comprimento pode ser idealizado como sendo semi-infinito, com deslocamento vertical e momento fletor tendendo para zero em seções distantes da de carregamento, deve-se ter $A=B=0$.

$$
y=\mathrm{e}^{\beta \mathrm{x}}(A \cos \beta x+B \operatorname{sen} \beta x)+e^{-\beta x}(C \cos \beta x+D \operatorname{sen} \beta x)
$$

As outras duas constantes de integração $C$ e $D$ são determinadas a partir das condições de contorno na seção transversal em $x=0$ (Figura 2.5):

$$
\begin{aligned}
& E_{S} I_{S}\left(\frac{d^{2} y}{d x^{2}}\right)_{x=0}=-\left(-M_{0}\right)=M_{0} \\
& E_{S} I_{S}\left(\frac{d^{3} y}{d x^{3}}\right)_{x=0}=-V=-\left(-V_{d}\right)=V_{d}
\end{aligned}
$$


Destas condições e da equação $2.5, \operatorname{com} A=B=0$, chega-se a:

$C=\frac{1}{2 \beta^{3} E_{S} I_{s}}\left(V_{d}+\beta M_{0}\right) ; \quad D=-\frac{M_{0}}{2 \beta^{2} E_{S} I_{S}}$

Substituindo $C$ e $D$ na equação 2.5 , para o caso de barra semi-infinita tem-se:

$$
y=\frac{e^{-\beta x}}{2 \beta^{3} E_{s} I_{s}}\left[\beta M_{0}(\cos \beta x-\operatorname{sen} \beta x)+V_{d} \cos \beta x\right]
$$

Da relação $\frac{d V}{d x}=-E_{S} I_{S} \frac{d^{4} y}{d x^{4}}=-p$, obtém-se a força de reação por unidade de comprimento ao longo da barra semi-infinita:

$$
p=-2 \beta e^{-\beta x}\left[\beta M_{0}(\cos \beta x-\operatorname{sen} \beta x)+V_{d} \cos \beta x\right]
$$

Para o caso em que $M_{0}=0$, a equação (2.9) reduz-se a:

$$
p=-2 V_{d} \beta e^{-\beta x} \cos \beta x
$$

Se a barra for analisada como de comprimento finito (como feito por Vintzleou \& Tassios, 1986), segundo Hetényi (1979), para o caso de $M_{0}=0$, temse:

$$
\mathrm{p}=\frac{2 \mathrm{~V}_{\mathrm{d}} \beta\left[\operatorname{sen}(\beta \mathrm{L}) \cosh (\beta \mathrm{x}) \cos \left(\beta \mathrm{x}^{\prime}\right)-\operatorname{senh}(\beta \mathrm{L}) \cos (\beta \mathrm{x}) \cosh \left(\beta \mathrm{x}^{\prime}\right)\right]}{\operatorname{senh}^{2}(\beta \mathrm{L})-\operatorname{sen}^{2}(\beta \mathrm{L})}
$$

onde $x^{\prime}=(L-x)$

Na Figura 2.7 comparam-se os valores de p dados pelas equações 2.10 (barra de comprimento semi-infinito) e 2.11 (barra de comprimento finito), considerando $\phi=10 \mathrm{~mm}, \beta L=5$. Vintzleou \& Tassios (1986) consideraram $L=8 \phi$ e $5 \leq \beta L \leq 6$ (ver item 2.2.1.2.2). Essa figura evidencia a semelhança entre os resultados fornecidos pelas duas equações, para $\beta L>\pi$. 


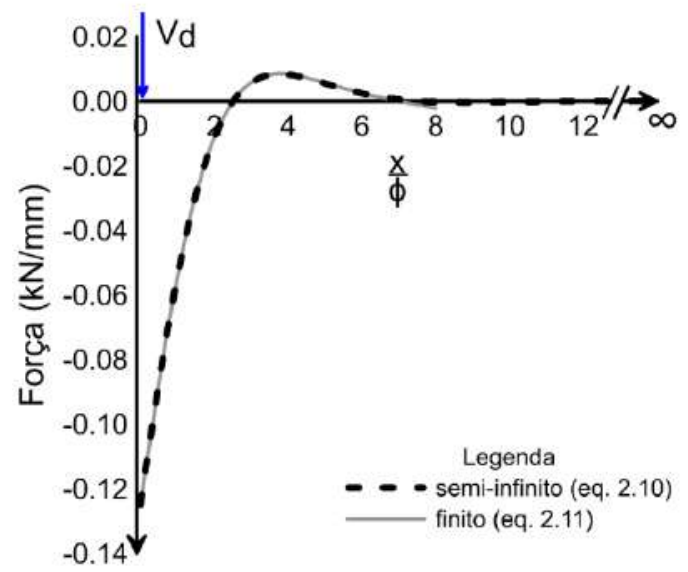

Figura 2.7 - Distribuição de força por unidade de comprimento ao longo de uma barra de aço submetida a $V_{d}=1 \mathrm{kN}$ em uma das extremidades.

\subsubsection{2}

\section{Fórmulas propostas para cálculo de $V_{d, R}$ e $V_{d, R, \max }$}

a) Vintzeleou \& Tassios (1986)

Vintzeleou \& Tassios (1986) apresentaram duas equações para cálculo de $V_{d, R, \text { max }}$ baseadas na analogia de viga finita em apoio elástico submetida a uma força concentrada na extremidade da barra, considerando as possibilidades de ruptura por fendilhamento no nível da armadura ou na região do cobrimento, sendo aqui focada apenas a primeira situação.

A equação foi obtida considerando que a força de reação total $F_{c c}$ (equação 2.12, com $p$ dada pela equação 2.11) deve ser igual à força máxima de tração suportada pela largura de concreto no nível da barra, $F_{c t}$, ao longo do comprimento em que a tração se desenvolve, $l_{d}$ (eq. 2.13), admitida constante e igual a $f_{c t}$ (Figura 2.8).

$$
\begin{aligned}
& F_{c c}=\int_{0}^{l_{d}} p d x \\
& F_{c t}=f_{c t} b_{n} l_{d}
\end{aligned}
$$

onde $b_{n}=b_{w}-\sum \phi_{i}$ é largura de concreto no nível da armadura, igual à largura da viga, $b_{w}$, menos a soma dos diâmetros das barras longitudinais.

O comprimento da barra considerado foi $L=8 \phi$, com base no trabalho experimental de Marcus (1951), e $\beta L=5,0$ (valor não justificado, $>\pi$ ). O valor do 
limite de integração na equação 2.12 foi obtido igualando a equação 2.11 a zero para os valores dos parâmetros adotados, chegando-se a $l_{d}=2,5 \phi$ (Figura 2.8). Com este valor de $l_{d}$ nas equações 2.12 e 2.13 :

$$
\begin{aligned}
& F_{c c}=\int_{0}^{2,5 \phi} p d x=1,22 V_{d} \\
& F_{c t}=2,5 b_{n} \phi f_{c t}
\end{aligned}
$$

Igualando as equações 2.14 e 2.15 obteve-se a força cortante correspondente ao efeito de pino no início de fissuração ao longo da armadura longitudinal $\left(V_{d, c r}\right)$, que, no caso de vigas sem estribos e sem fibras, também corresponde à força cortante resistente referente ao efeito de pino $\left(V_{d, R, \max }\right)$ :

$$
V_{d, R, \max }=V_{d, c r}=2,0 b_{n} \phi f_{c t}
$$

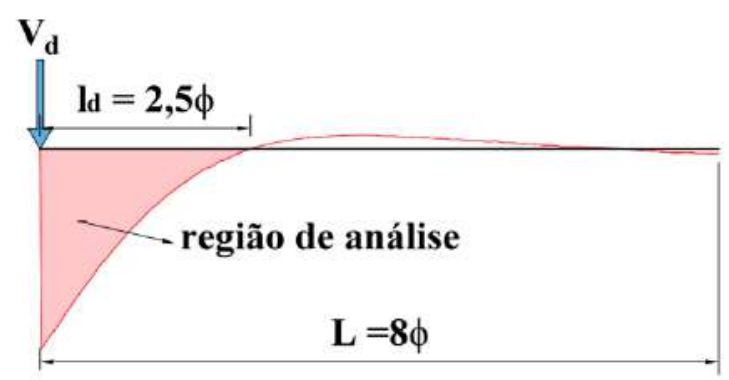

(a)

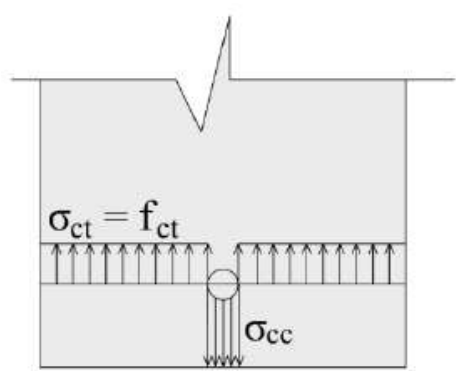

(b)

Figura 2.8 - Analogia de viga sobre apoio elástico e considerações adotadas por Vintzeleou \& Tassios (1986): (a) Diagrama de tensão normal no concreto devido à ação de $V_{d}$, para $L=8 \phi$; (b) Distribuição da tensão de tração $\left(\sigma_{\mathrm{ct}}\right)$ e de compressão $\left(\sigma_{\mathrm{cc}}\right)$ na seção transversal, no nível da armadura.

A partir de $V_{d}=V_{d, c r}$, a barra passa a estar sob a ação da força $V_{d}$ e de um momento fletor por ela gerado, sendo o braço de alavanca definido pelo comprimento da fissura de fendilhamento. Logo, em vigas sem estribos e fibras de aço, para a situação posterior ao início do fendilhamento, $V_{d}<V_{d, c r}$.

\section{b) Taylor $(1969,1974)$}

Taylor $(1969,1974)$, com base nos resultados de seus ensaios e as variáveis neles adotadas, que não incluiram o diâmetro das barras, propôs a equação 2.17: 


$$
V_{d, R, \max }=V_{d, c r}=9,1+0,0001\left[\sum\left(c_{s}+c_{i}\right)\right]^{2} f_{c t, s p}
$$

Nela, $c_{s}=$ cobrimento lateral da armadura, $c_{i}=$ distância livre entre barras consecutivas na direção horizontal, $\sum\left(c_{s}+c_{i}\right)$ é a largura da superfície de ruptura do concreto (equivale $\mathrm{a} \mathrm{b}_{\mathrm{n}}$ ) $\operatorname{com} c_{s}$ e $c_{i} \mathrm{em} \mathrm{mm}, f_{c t, s p}$ é a resistência à tração indireta do concreto em N/mm e $V_{d, R, \max } \mathrm{em} \mathrm{kN}$ (para $\Delta=0,17 \mathrm{~mm}$ ).

\section{c) Baumann \& Rüsch (1970)}

Baumann \& Rüsch (1970) consideraram que a solicitação transversal às barras de aço até a carga de fissuração é transferida para o concreto abaixo das barras, que, por sua vez, solicita à tração o concreto acima delas. Sua expressão é dada em função da força resistente à tração do concreto no nível da armadura longitudinal ao longo de um comprimento $l_{d}$, ficando a equação:

$$
V_{d, R, \max }=f_{c t} b_{n} l_{d}
$$

onde

$V_{d, R, \max }$ é dada em $\mathrm{N}$;

$f_{c t}$ é a resistência à tração direta do concreto em MPa (considerada pelos autores igual a $0,244 f_{c u}{ }^{2 / 3}$, sendo $f_{c u}$ a resistência à compressão do concreto obtida do ensaio de corpos-de-prova cúbicos com dimensão de $200 \mathrm{~mm}$ ).

$b_{n}=b_{w}-\sum \phi_{i}$ é largura de concreto em mm no nível da armadura, em mm.

$l_{d}$ é o comprimento, em mm, onde tem-se tensão de tração do concreto (convertido pela relação $f_{c}=0,8 f_{c u}$ ).

A partir de resultados experimentais, os autores chegaram a equações de $l_{d}$ para os casos de uma e duas camadas de barras de aço, sendo apresentada aqui apenas a para uma camada:

$$
\left.l_{d}=\frac{6,60 \phi}{\sqrt[3]{f_{c u}}} \quad \text { (Unidades: } \mathrm{N}, \mathrm{mm}\right)
$$

Logo, para o caso de camada única de armadura longitudinal de tração, $V_{d, R, \max }$ é dada por: 


$$
V_{d, R, \max }=1,62 b_{n} \phi \sqrt[3]{f_{c}}
$$

\section{d) Cavagnis et al. (2018a e 2018b)}

Cavagnis et al. (2018a) adotaram os deslocamentos verticais no nível das barras, medidos durante os ensaios de suas vigas usando correlação de imagem digital (ver item 2.3.2.6), para avaliar a contribuição do efeito de pino na resistência à força cortante de suas vigas de concreto armado sem estribos, e assumiram comportamento elástico linear das barras.

Eles admitiram que os deslocamentos verticais das barras variaram segundo um polinômio do terceiro grau, chegaram aos valores das constantes do polinômio a partir dos deslocamentos verticais ( $y_{0}$ e $\left.y_{l}\right)$ e rotações medidos ( $y_{0}$ ' e $y_{1}$ ') em pontos distantes de $x_{p}=\phi / 2$ (Figura 2.9) das extremidades do trecho de comprimento da barra $l_{p a}$ definido como sendo a soma do comprimento horizontal atingido pela fissura de efeito de pino $\left(l_{p}\right)$ e do diâmetro da barra $(\phi)$.

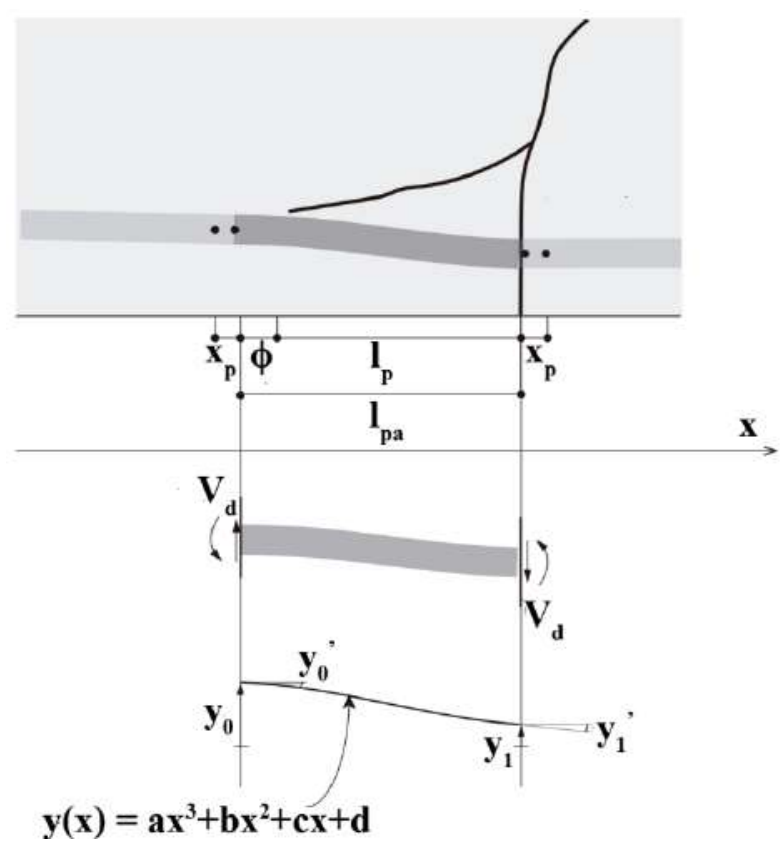

Figura 2.9 - Deslocamentos da armadura longitudinal tracionada na região de fissura de efeito de pino (adaptado Cavagnis et al., 2018a).

$$
V_{d R}=n E_{s} I_{s} \frac{d^{3} y(x)}{d x^{3}}=\frac{6 n E_{s} I_{s}}{l_{d a}^{3}}\left[y_{0}-y_{1}+\frac{l_{p a}}{2}\left(y_{0}^{\prime}+y_{1}^{\prime}\right)\right]
$$

Nesta equação,

$n$ é o número de barras de aço;

$E_{s}$ é módulo de elasticidade da barra de aço; 
$I_{S}$ é o momento de inércia da seção transversal de uma barra de aço em relação ao eixo que passa por seu centroide.

Já Cavagnis et al. (2018b), em sua proposta de equação para a resistência à força cortante de vigas de concreto armado sem estribos via somatório das parcelas dos mecanismos resistentes, considerou a do efeito de pino como sendo a dada pela equação 2.22 proposta por Ruiz et al. (2013) para contribuição do efeito de pino da armadura de flexão na resistência pós-punção de lajes lisas.

$$
V_{d R}=n b_{e f} f_{c t, e f} l_{d}
$$

onde

$n$ é o número de barras de aço;

$f_{c t, e f}=k_{b} f_{c t}$ é a resistência à tração efetiva do concreto; segundo dados experimentais de Ruiz et al. (2010), $k_{b}$ é o menor valor entre $0,063 \varepsilon_{\mathrm{s}}^{-0,25} \leq 1$ $\left(\varepsilon_{\mathrm{s}}=\right.$ deformação específica da armadura de flexão) e $0,063\left(\frac{d-c}{w_{c}}\right)^{0,25} \leq 1$ ( $w_{c}$ é a abertura da fissura crítica no nível da armadura longitudinal);

$b_{e f}$ é a largura efetiva de concreto onde tem-se tensão de tração relativa a cada barra, definida como sendo o menor valor entre $\left(b_{w} / n-\phi\right)$ e $4 c$;

$l_{d}$ é o comprimento de desenvolvimento da força de tração, adotado igual a $2 \phi$ (ensaios de Ruiz et al., 2013).

\subsubsection{3}

Contribuição do efeito de pino para a resistência à força cortante de vigas

Diferentes estudos têm apontado que vários parâmetros podem afetar a contribuição do efeito de pino para a resistência à força cortante de vigas sem estribos: armadura longitudinal (taxa, diâmetro e número de barras e de camadas, propriedades de aderência), cobrimento da armadura, resistência do concreto. Entretanto, há divergências com relação à importância relativa desses parâmetros, como há também com relação à relevância do efeito de pino na resistência à força cortante de vigas.

Sarkar \& Bose (1999) ensaiaram dois grupos de vigas tendo $40 \mathrm{MPa} \leq f_{c} \leq 110 \mathrm{MPa}$ e num deles foi criada uma fissura diagonal lisa por meio da inserção de uma folha metálica $(0,8 \mathrm{~mm}$ de espessura) visando eliminar o 
engrenamento dos agregados. A posição dessa fissura artificial foi definida a partir do que foi observado nas vigas do outro grupo. Tendo sido eliminado o engrenamento dos agregados e obtida a parcela referente ao concreto comprimido a partir do método semi-empírico usado por Taylor (1974) (item 2.2.4, p. 76), a parcela de efeito de pino $\left(V_{d}\right)$ foi considerada como sendo a diferença entre a força cortante última experimental e a parcela relativa ao concreto comprimido. Os resultados levaram à conclusão de que a parcela $V_{d}$ correspondeu a cerca de $50 \%$ da resistência à força cortante das vigas por eles ensaiadas e que tendeu a ser menor com o aumento de $f_{c}$.

Jelic et al. (1999), partindo da premissa de que a parcela de efeito de pino teria relevância se ela estivesse diretamente ligada ao diâmetro da barra, realizaram um programa experimental que incluiu oito vigas de argamassa armada projetadas para terem ruptura por força cortante (seção retangular; $b_{w}=50 \mathrm{~mm} ; h=100 \mathrm{~mm}$; $d=85 \mathrm{~mm} ; a / d=3,5 ; f_{c}$ em torno de $\left.45 \mathrm{MPa}, \rho=3,6 \%\right)$. Nelas mantiveram-se as mesmas dimensões, condições de ensaio e taxa de armadura longitudinal, alterandose apenas o diâmetro das barras $(2 \mathrm{~mm}, 4 \mathrm{~mm}, 8 \mathrm{~mm}, 10 \mathrm{~mm})$, tendo-se duas vigas para cada diâmetro. Como os valores da força cortante das vigas ficaram próximos, concluiu-se que, independentemente do diâmetro e da tensão de escoamento das barras, vigas com mesma área de armadura longitudinal têm a mesma resistência à força cortante e que, portanto, a parcela de efeito de pino é desprezível, raciocínio que é questionável.

Singh \& Chintakindi (2013) ensaiaram 20 vigas (seção retangular; $b_{w}=100 \mathrm{~mm} ; h=150 \mathrm{~mm} ; d=120 \mathrm{~mm} ; a / d=3,0$ ou 4,$5 ; f_{c}$ em torno de $30 \mathrm{MPa}$ a $40 \mathrm{MPa}, d_{\max }=8 \mathrm{~mm}, \rho=1,25 \%, 1,88 \%$ ou 2,50\%; $\phi=3 \mathrm{~mm}, 4 \mathrm{~mm}, 6 \mathrm{~mm}$, $8 \mathrm{~mm}, 10 \mathrm{~mm}, c=30 \mathrm{~mm}$ ), nas quais variaram-se basicamente o vão de cortante $\mathrm{e}$ a taxa e o diâmetro da armadura longitudinal, para investigar a relevância da parcela do efeito de pino e a influência do diâmetro das barras na força cortante resistente. Os autores concluíram que, para uma determinada categoria de aço, taxa e cobrimento da armadura longitudinal, e classe de concreto, o diâmetro da armadura não influencia a capacidade resistente de vigas e, consequentemente, é improvável que a parcela de efeito de pino seja relevante. A maior resistência à força cortante verificada nas vigas com maior taxa de armadura longitudinal foi atribuída ao maior controle da fissuração, que aumenta a parcela resistente relativa ao engrenamento dos agregados. 
O estudo experimental de Panda \& Gangolu (2017) foi realizado para investigar a significância de parâmetros considerados relevantes em relação à resistência à força cortante de vigas sem estribos $\left(\rho, \phi, f_{c}\right.$, cobrimento abaixo da armadura $c$ ) e da sua interação. As 19 vigas tinham seção retangular; $b_{\mathrm{w}}=180 \mathrm{~mm}$; $h$ variável, de maneira a manter $d=150 \mathrm{~mm} ; a / d=2,73 ; f_{c}$ em torno de $49 \mathrm{MPa}$, $62 \mathrm{MPa}$ ou $69 \mathrm{MPa} ; d_{\max }=12 \mathrm{~mm} ; \rho=1,16 \%, 1,49 \%$ ou 2,33 \% (aços de mesma categoria); $\phi=10 \mathrm{~mm}, 16 \mathrm{~mm}$ ou $20 \mathrm{~mm} ; c=25 \mathrm{~mm}, 50 \mathrm{~mm}$ ou $75 \mathrm{~mm}$. Para eliminar o engrenamento dos agregados, foram criadas fissuras diagonais lisas inclinadas a $37^{\circ} \mathrm{com}$ o eixo longitudinal das vigas e distando $d$ dos apoios, por meio da introdução de chapa metálica com $0,5 \mathrm{~mm}$ de espessura, como indicado na Figura 2.10. A contribuição da região de concreto comprimida para resistência à força cortante foi obtida adotando o método semi-empírico usado por Taylor (1974) (item 2.2.4, p. 76), e a diferença entre a força cortante última e essa contribuição levou aos valores de $V_{d}$ para as vigas ensaiadas.

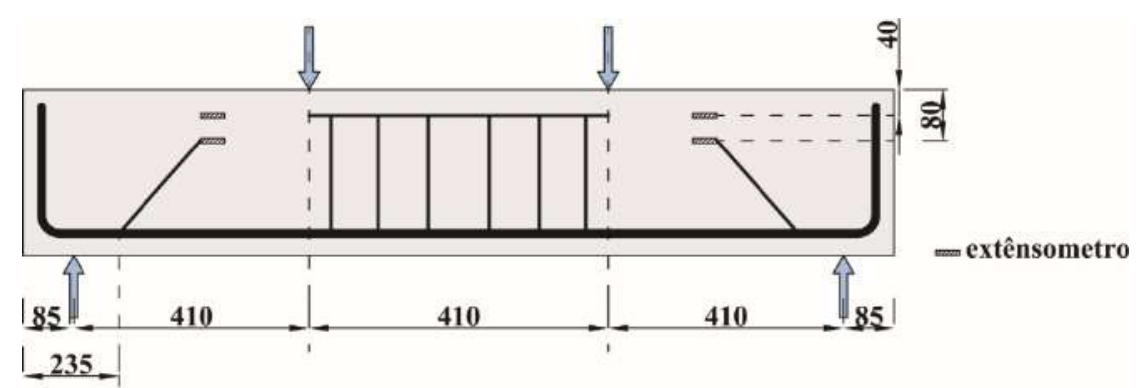

Figura 2.10 - Esquema de ensaio e fissuras produzidas artificialmente (Panda \& Gangolu, 2017). Dimensões em mm.

A regressão múltipla e a análise de variância (ANOVA) aplicadas aos resultados dos ensaios levaram Panda \& Gangolu (2017) a concluir que apenas o cobrimento tem influência individual em $V_{d}$, que aumenta com o aumento do cobrimento. A influência dos outros parâmetros investigados depende da sua interação com os demais, sendo significantes as interações $\rho \phi, \rho f_{c}, \rho \phi f_{c}, \rho \phi c, \rho \phi f_{c} c$, havendo também indícios de que dimensionamentos que levem as vigas a terem comportamento dúctil favorecem o efeito de pino. Na ausência do engrenamento dos agregados, constatou-se parcela média relativa ao efeito de pino de $56 \%$ da força cortante resistente.

Segundo Zarrinpour \& Chao (2017), a melhoria do comportamento à tração e o controle da fissuração ao longo da armadura longitudinal providos pelas fibras 
implicam numa maior contribuição do efeito de pino para a resistência à força cortante (ver item 2.3.2.3), que passa a ser mais relevante nas vigas de concreto com fibras que nas de concreto sem fibras.

\subsection{2}

\section{Engrenamento dos agregados}

Como resultado da rugosidade das faces da fissura, deslocamentos relativos entre essas faces levam ao efeito de engrenamento dos agregados, que é a ação mecânica das partículas que sobressaem de uma face da fissura e reagem contra as partículas da face oposta. Esse efeito depende da área de contato entre os agregados, mostrada na Figura 2.11.

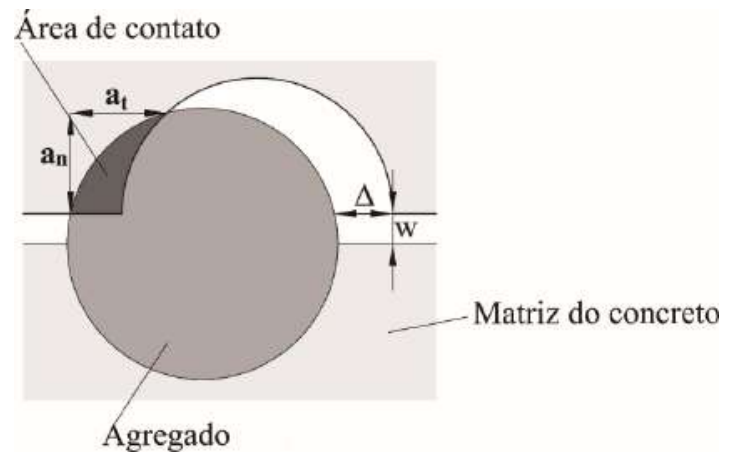

Figura 2.11 - Engrenamento dos agregados (Walraven, 1980).

Este mecanismo é usualmente estudado teoricamente considerando o concreto constituído de duas fases: uma formada pela pasta de cimento e agregados miúdos e outra formada pelos demais agregados. Para os casos em que o agregado graúdo apresenta maior resistência e rigidez do que a argamassa, como nos concretos convencionais de resistência usual, a fissura segue a interface entre os agregados e a matriz. Já para os casos em que a resistência do agregado graúdo é menor do que a da matriz, como nos concretos de alta resistência, de agregado de calcário e nos concretos com agregado graúdo leve, a fissura tende a atravessar os agregados graúdos (Albajar, 2008). A Figura 2.12 ilustra a forma da fissura para estas duas situações. 


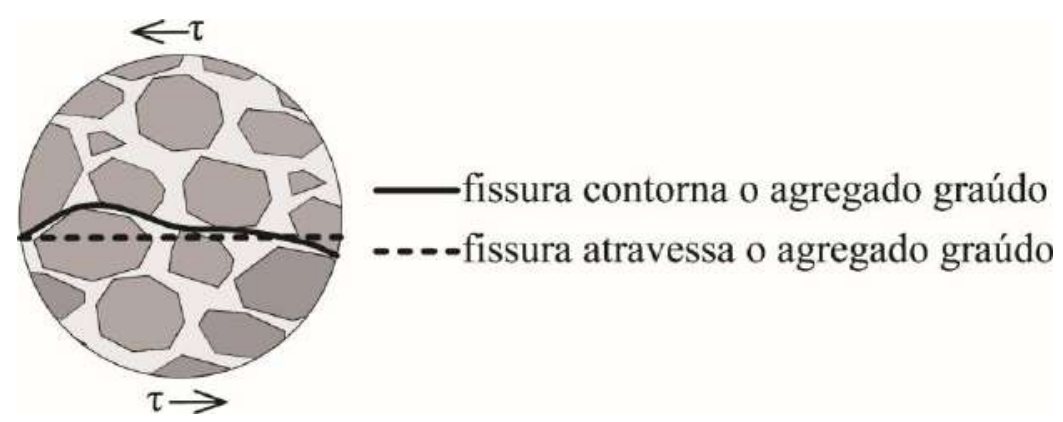

Figura 2.12 - Caminhamento da fissura para a situação em que ela contorna ou atravessa o agregado graúdo.

Na literatura, constatou-se que deslizamento $(\Delta)$ e abertura $(w)$ da fissura, teor e dimensão máxima do agregado graúdo, resistência do concreto e tensões normal e cisalhante estão inter-relacionados na contribuição deste mecanismo resistente à força cortante (Albajar, 2008; Kim et al., 2010).

Dentre os ensaios empregados para investigar o comportamento ao longo da fissura, ou seja, a relação entre tensões e deslocamentos entre faces da fissura, o tipo mais usado é o push-off (ver Figura 2.13). Não há um padrão de dimensões do espécime e nem da metodologia de ensaio e na Tabela 2.1 listam-se dimensões adotadas em alguns estudos. Particularmente para concretos com fibras, outros tipos de ensaios de cisalhamento têm sido também adotados (Boulekbache et al., 2012; Khanlou et al., 2012; Marar et al., 2017).

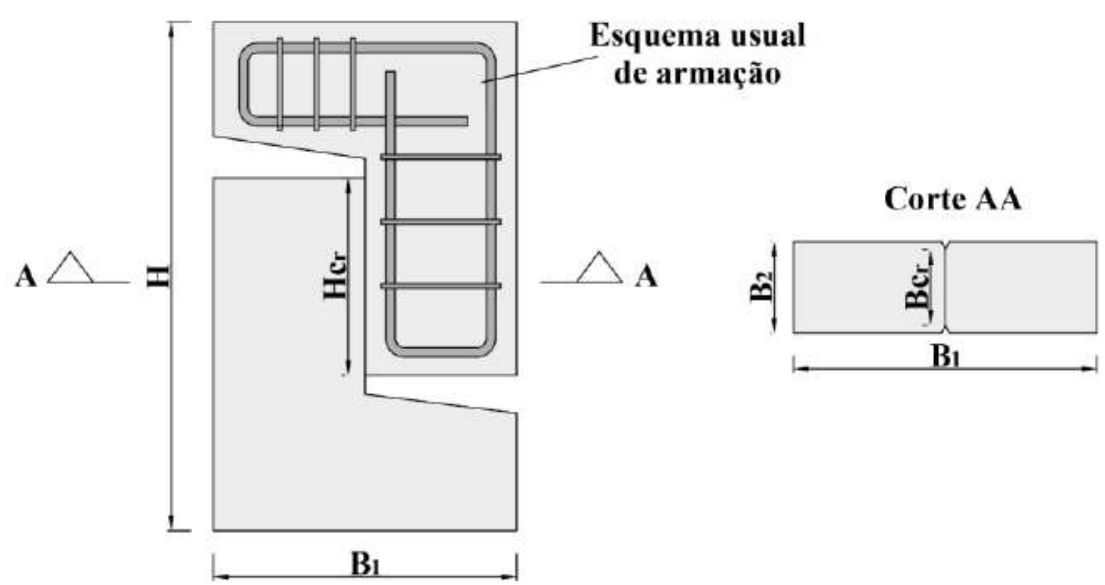

Figura 2.13 - Configuração dos espécimes do tipo push-off. Valores das dimensões adotados em alguns trabalhos são listados na Tabela 2.1. 
Tabela 2.1 - Dimensões dos espécimes, em mm, usadas em alguns ensaios do tipo push-off.

\begin{tabular}{ccccc}
\hline $\begin{array}{c}\text { Dimensões } \\
(\mathrm{mm})\end{array}$ & $\begin{array}{c}\text { Walraven } \\
(1980)\end{array}$ & $\begin{array}{c}\text { Kim et al. } \\
(2010)\end{array}$ & $\begin{array}{c}\text { Sagaseta \& } \\
\text { Vollum }(2011 \mathrm{~b})\end{array}$ & $\begin{array}{c}\text { Echegaray- } \\
\text { Oviedo } \\
(2014)\end{array}$ \\
\hline$H$ & 600 & 660 & 700 & 670 \\
$H_{c r}$ & 300 & 305 & 350 & 260 \\
$B_{1}$ & 400 & 400 & 300 & 400 \\
$B_{2}$ & 120 & 152 & 165 & 120 \\
$B_{c r}$ & 120 & 125 & 135 & 100 \\
\hline
\end{tabular}

O espécime é formado por duas partes em forma de "L" que são densamente armadas e concretadas em conjunto e tem um entalhe ao longo da altura da seção transversal que liga essas partes, que é submetida a cisalhamento durante o ensaio. A armadura serve para garantir rigidez e resistência do "L" e o entalhe é para direcionar a formação de fissura, fazendo com que ela se desenvolva nesse plano. Conforme o interesse de investigação, pode-se colocar barras de aço atravessando a seção de cisalhamento e realizar pré-fissuração nessa seção.

Durante o ensaio, geralmente aplica-se força na direção vertical alinhada com o plano de cisalhamento (seção com entalhe), e fazem-se medições da abertura e do deslizamento entre as faces da fissura formada no referido plano. Para medir a tensão normal na seção de interesse, o espécime é colocado entre duas chapas de aço conectadas entre si por quatro barras de aço externas, pré-tensionadas e instrumentadas com extensômetros elétricos. A partir da deformação específica destas barras de aço é obtido o valor da força normal durante a execução do ensaio. No caso em que os espécimes têm barras de aço atravessando a seção transversal submetida a cisalhamento, estas barras são instrumentadas com extensômetros elétricos e as chapas e barras de aço externas ao espécime não são colocadas. Destes ensaios são tiradas, portanto, informações das tensões normal e cisalhante e do deslizamento e da abertura de fissura no plano de cisalhamento.

Na Figura 2.14 tem-se a representação esquemática do ensaio de espécies sem armadura atravessando a seção de cisalhamento e uma foto do ensaio realizado por Kim et al. (2010), em que a seção de cisalhamento foi pré-fissurada e a tensão normal foi obtida a partir da deformação específica das barras de aço externas ao espécime. 


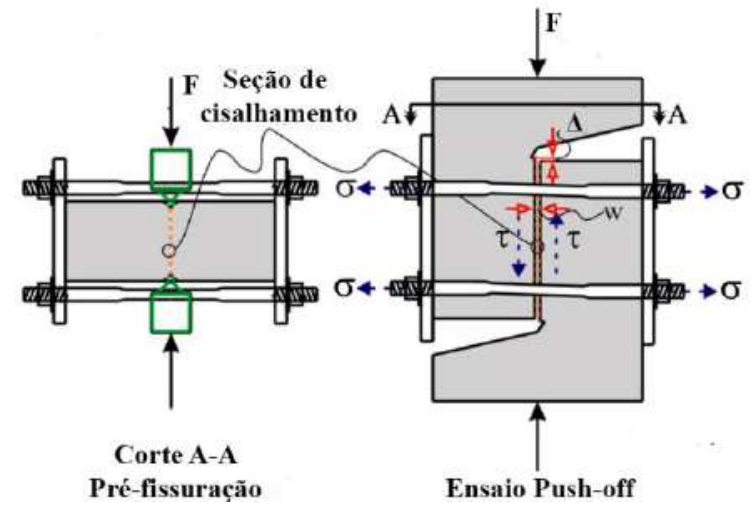

(a)

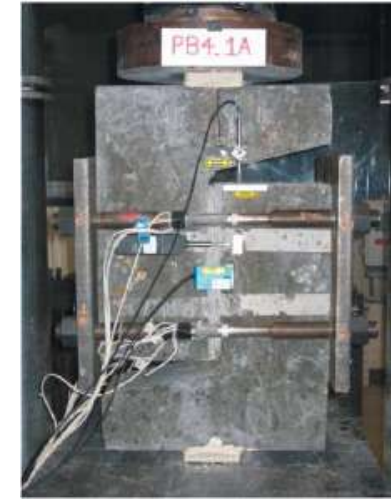

(b)

Figura 2.14 - (a) Esquema de pré-fissuração, ensaio e (b) foto do espécime de Kim et al. (2010) posicionado para ensaio. Dimensões listadas na Tabela 2.1. Adaptado de Kim et al. (2010).

\subsubsection{1}

Investigações experimentais em espécimes sem fibras de aço

Diferentes variáveis têm sido consideradas nos estudos experimentais sobre engrenamento dos agregados, como resistência à compressão do concreto, teor, dimensão máxima e tipo de agregados, taxa de armadura na seção submetida a cisalhamento, pré-fissuração ou não, condições de contorno e metodologia de ensaio. A diversidade de parâmetros envolvidos levou a dificuldades nas análises de resultados e a aparentes contradições.

Walraven (1980) desenvolveu estudo experimental com 83 espécimes do tipo push-off, sendo 32 sem armadura. Para este caso, as variáveis adotadas foram: resistência à compressão do concreto $\left(f_{c u}=13 \mathrm{MPa}, 33 \mathrm{MPa}, 37 \mathrm{MPa}\right.$ e $\left.59 \mathrm{MPa}\right)$, composição do concreto (dimensão máxima do agregado graúdo $16 \mathrm{~mm}$ ou $32 \mathrm{~mm})$, abertura da pré-fissura $(0,0 \mathrm{~mm}, 0,2 \mathrm{~mm}$ e $0,4 \mathrm{~mm})$ e tensão normal imposta pelas barras de aço externas $(0,3 \mathrm{MPa}$ a $6,8 \mathrm{MPa}$ para uma abertura de fissura de referência igual a 0,6 mm). Foi observado em todos os espécimes que, para maior valor da força na barra externa, maior foi a tensão cisalhante e menor abertura de fissura para um determinado deslizamento.

O programa experimental de Kim et al. (2010) compreendeu 48 espécimes push-off sem armadura e pré-fissurados na seção submetida a cisalhamento e visou comparar o comportamento do concreto autoadensável (CAA) de alta resistência com o do concreto vibrado (CV). As variáveis consideradas foram o tipo de agregado graúdo (cascalho de rio e brita de calcário, $d_{\max }=19 \mathrm{~mm}$ ), teor de agregado graúdo ( $28,0 \%$ a $44,3 \%$ em volume), composição de concreto ( $f_{c}$ entre 
$72 \mathrm{MPa}$ e $110 \mathrm{MPa}$ ) e tipo de concreto (CV e CAA). Os espécimes tinham abertura da fissura inicial menor que $0,5 \mathrm{~mm}$ e, para a faixa de abertura inicial adotada, tanto nos CV quanto nos CAA, o tipo e o teor de agregados graúdos influenciaram o engrenamento dos agregados. Maior teor de agregados graúdos tendeu a acarretar maior engrenamento de agregados e os espécimes com cascalho de rio apresentaram maior engrenamento de agregado que os com brita de calcário. Os espécimes de concreto de menor resistência à compressão tiveram maior engrenamento dos agregados que os de concreto de maior resistência.

Echegaray-Oviedo (2014), para investigar o caso de concretos autoadensáveis sem e com fibras de aço, propôs alguns ajustes na metodologia convencional do ensaio do tipo push-off. Foi adotado aparato que permitia deslizamento de uma parte em "L" com relação à outra (Figura 2.15), fazendo com que as barras de aço externas instrumentadas estivessem sujeitas apenas a força axial. Os espécimes foram pré-fissurados na seção de cisalhamento antes do seu posicionamento para o ensaio push-off (abertura em torno de $0,1 \mathrm{~mm}$ a $1,0 \mathrm{~mm}$ ) e o controle da abertura da fissura inicial wo no aparato de ensaio push-off (0 ou $1 \mathrm{~mm})$ foi feito pelo sistema formado pelas barras e placas de aço mostradas na Figura 2.15. As dimensões dos espécimes constam na Tabela 2.1 .

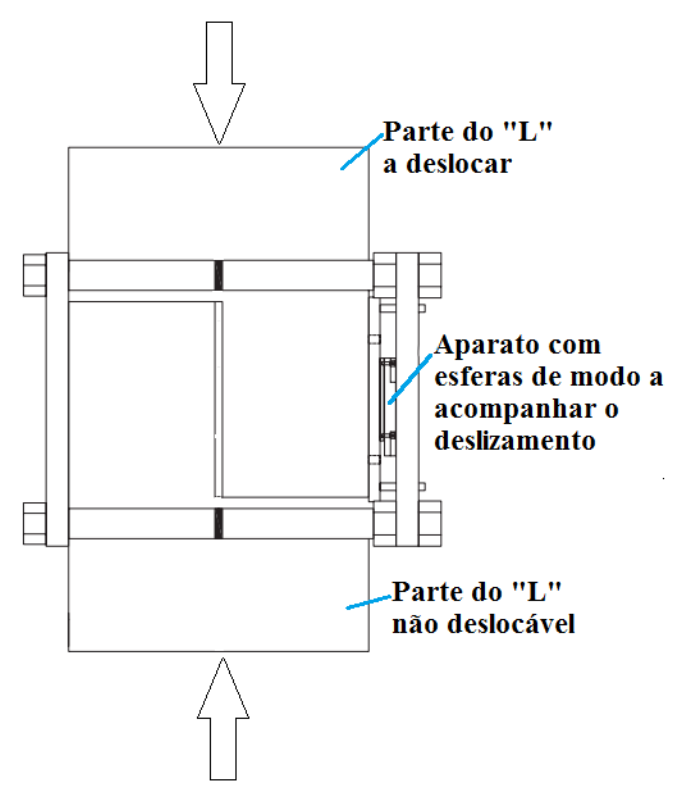

Figura 2.15 - Esquema de ensaio de Echegaray-Oviedo (2014). (Adaptado de Echegaray-Oviedo, 2014)

Foram ensaiados 56 espécimes, sendo 14 sem fibras de aço e sem armadura na seção de cisalhamento e os demais com fibras. Os com fibras são comentados 
no item 2.2.2.2. As variáveis dos 14 espécimes foram: pré-tensão normal na seção de cisalhamento (espécimes confinados, para que se tivesse abertura de fissura inicial no ensaio push-off $w_{0}=0$, ou não confinados para que se tivesse $w_{0}=1 \mathrm{~mm}$ ), resistência à compressão do concreto $\left(f_{c}\right.$ em torno de $40 \mathrm{MPa}, 50 \mathrm{MPa}$ ou $\left.60 \mathrm{MPa}\right)$ e dimensão máxima do agregado graúdo (12 mm ou $20 \mathrm{~mm})$.

A Figura 2.16 mostra os resultados dos ensaios push-off de EchegarayOviedo (2014) em espécimes de concreto de mesma composição $\left(f_{c}=40 \mathrm{MPa}\right.$ e $d_{\max }=12 \mathrm{~mm}$ ) e diferentes tensões de confinamento. Foi observado que esta tensão influi expressivamente no comportamento dos espécimes. $\mathrm{O}$ espécime com $w_{0}=0$ apresentou maior resistência ao cisalhamento para determinados deslizamento e abertura de fissura em comparação ao espécime de concreto de mesma composição, porém com $w_{0}=1$, havendo redução da diferença com o aumento do deslizamento (Figuras 2.16a e 2.16b). Notou-se também que o espécime com $w_{0}=0$ apresentou maior deslizamento para uma determinada abertura de fissura (Figura 2.16c) e diferença no padrão de curva tensão normal - abertura de fissura para $w_{0}=0$ e para $w_{0}=1$ (Figura 2.15d).

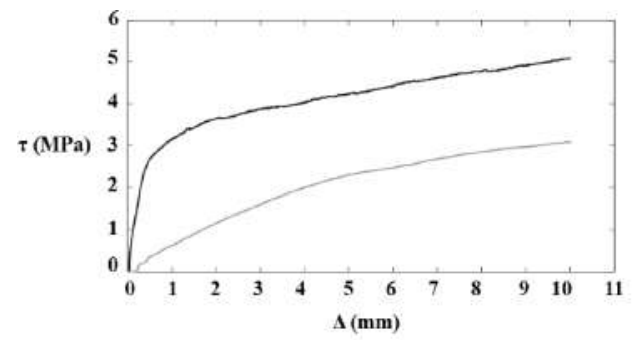

(a)

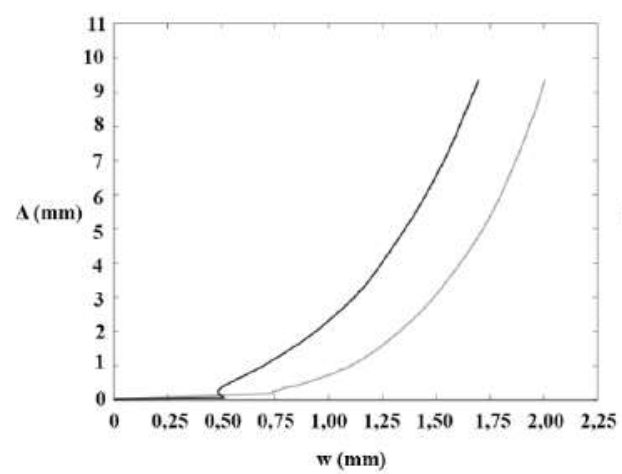

(c)

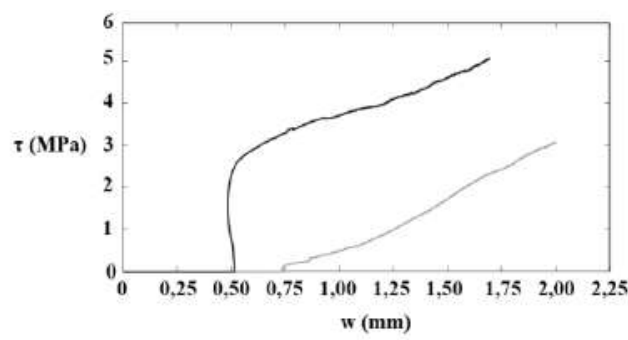

(b)

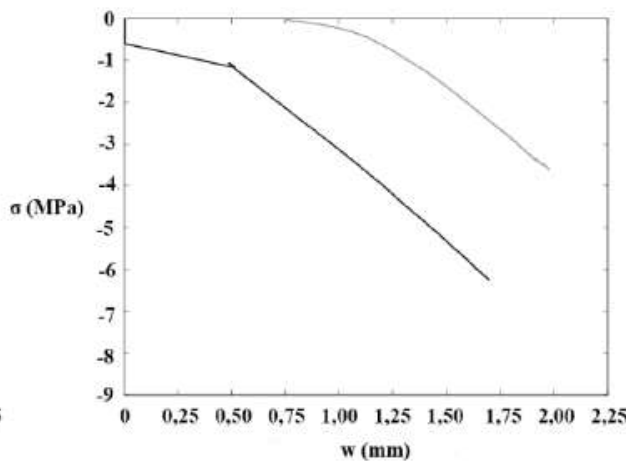

(d)

$$
\text { legenda } w_{0}=0
$$

Figura 2.16 - Resultados dos ensaios push-off de Echegaray-Oviedo (2014) para espécimes de concreto de mesma composição e diferente tensão normal confinante. (Adaptado de Echegaray-Oviedo, 2014) 
Foi verificado também que o aumento da dimensão máxima do agregado graúdo levou ao aumento da resistência ao cisalhamento, tanto para $w_{0}=0$ (Figura 2.17) e quanto para $w_{0}=1$. A influência da resistência à compressão do concreto não foi esclarecida.
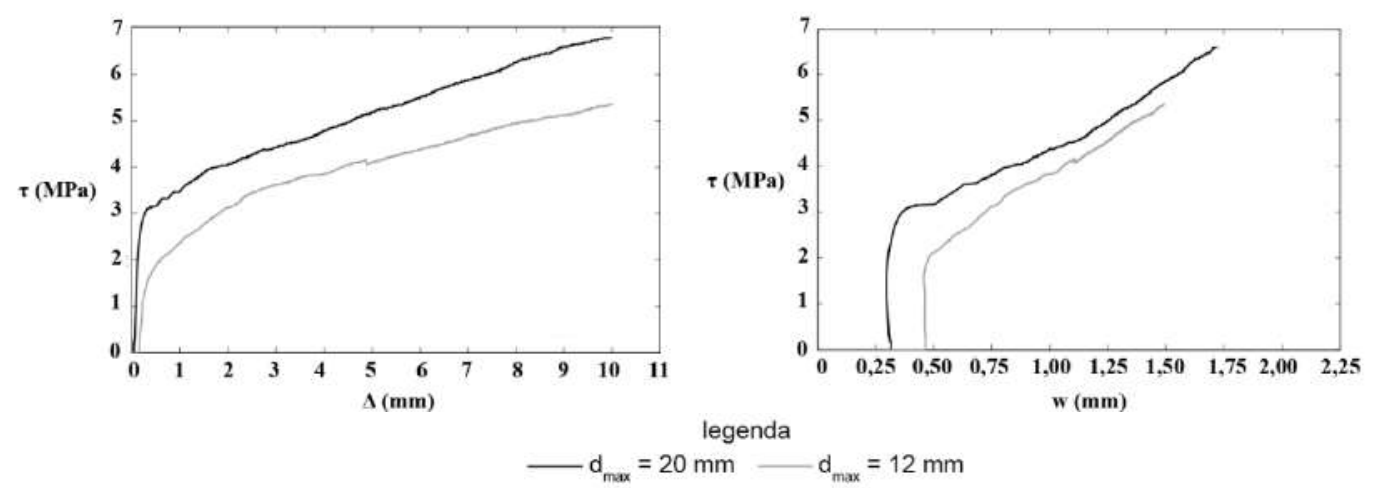

Figura 2.17 - Curvas médias $\tau-\Delta$ e $\tau$-w obtidas dos ensaios push-off em espécimes $\operatorname{com~} \mathrm{f}_{\mathrm{c}}=60 \mathrm{MPa}$ e diferentes dimensões máximas do agregado graúdo e $w_{0}=0$.

(Adaptado de Echegaray-Oviedo, 2014)

Nos ensaios de vigas de concreto armado sem estribos $(a / d=3,4 ; \rho=1 \%$; $d_{\max }=10 \mathrm{~mm}$ ) realizados por Sagaseta \& Vollum (2011a), feitas com concretos tendo dois tipos de agregado graúdo: seixo rolado marinho e brita de calcário, observou-se que as com agregado de calcário $\left(f_{c}=68,4 \mathrm{MPa}\right)$ tiveram todo o agregado das superfícies da fissura diagonal fraturado e menor capacidade resistente à força cortante que as com seixo $\left(f_{c}=80,2 \mathrm{MPa}\right)$, nas quais notou-se fratura de cerca de $30 \%$ dos agregados na fissura crítica. Os autores concluíram que a resistência à força cortante depende da rugosidade da fissura e de $f_{c}$. Tendo também ensaiado vigas com estribos, Sagaseta \& Vollum (2011a) constataram que apenas as vigas esbeltas sem estribos têm sua resistência à força cortante reduzida pela fratura dos agregados.

\subsubsection{2}

\section{Investigações experimentais em espécimes com fibras de aço}

Khaloo \& Kim (1997) realizaram ensaios em 28 espécimes do tipo push-off sem armadura atravessando a seção de cisalhamento, sem entalhe e nenhum tipo de sistema para controle da tensão normal na seção de cisalhamento. Neles variaramse $f_{c}(28 \mathrm{MPa}, 44 \mathrm{MPa}, 54 \mathrm{MPa}$ ou $72 \mathrm{MPa})$, teor $\left(V_{f}=0 \%, 0,5 \%, 1,0 \%\right.$ ou 1,5\%) e fator de forma /comprimento das fibras de aço (29/16 ou 58/32). No geral, foi observado que o aumento de $f_{c}, V_{f}$ e $l_{f} / d_{f}$ levaram ao aumento da capacidade 
resistente ao cisalhamento. Para um mesmo valor de $V_{f}$ e $l_{f} / d_{f}$, esse aumento foi maior para os espécimes de maior $f_{c}$. Ao comparar a resistência ao cisalhamento dos espécimes com $V_{f}=1,0 \%$ e $l_{f} / d_{f}=58$ com os de mesmo $f_{c}$ sem fibras, constatouse um aumento de $39 \%\left(f_{c}=28 \mathrm{MPa}\right), 47 \%\left(f_{c}=44 \mathrm{MPa}\right), 59 \%\left(f_{c}=54 \mathrm{MPa}\right) \mathrm{e}$ $86 \%\left(f_{c}=78 \mathrm{MPa}\right)$. Nos espécimes com $f_{c}$ de $28 \mathrm{MPa}$ e $44 \mathrm{MPa}$, houve arrancamento das fibras ligando as faces da fissura e, nos com $f_{c}$ de $54 \mathrm{MPa}$ e $78 \mathrm{MPa}$, observou-se rompimento de fibras, o que indica maior aderência entre as fibras e a matriz de concreto nos casos de maior $f_{c}$.

Barragán et al. (2006) analisaram o comportamento à força cortante em elementos de concreto com fibras de aço usando espécimes do tipo push-off com dois entalhes (Figura 2.18), extraídos de prismas de concretos já ensaiados à flexão para caracterização dos concretos (RILEM TC 162 - TDF). Os espécimes não possuíam nenhum tipo de armadura e não foram providos de um sistema para controle da tensão normal na seção de cisalhamento. Outra característica distinta foi a altura de $60 \mathrm{~mm}$ adotada para a seção de cisalhamento, bem inferior à de espécimes já ensaiados (ver Tabela 2.1). As dimensões dos espécimes foram definidas a partir de análises visando garantir ruptura por cortante e não por fendilhamento.

Foram utilizados concretos $\operatorname{com} f_{c}=30 \mathrm{MPa}$ ou $70 \mathrm{MPa}$. No primeiro caso, foram utilizadas fibras com comprimento de $60 \mathrm{~mm}$ e, no segundo, fibras com comprimento de $30 \mathrm{~mm}$, ambas com $l_{f} / d_{f}=80$, e, nos dois casos, $V_{f}=0 \%, 0,25 \%$ ou $0,51 \%$. As fibras de menor comprimento tinham resistência à tração de cerca do dobro da daquela de maior comprimento. O número limitado de ensaios e a diferença nas propriedades das fibras acarretaram dificuldades de análise.
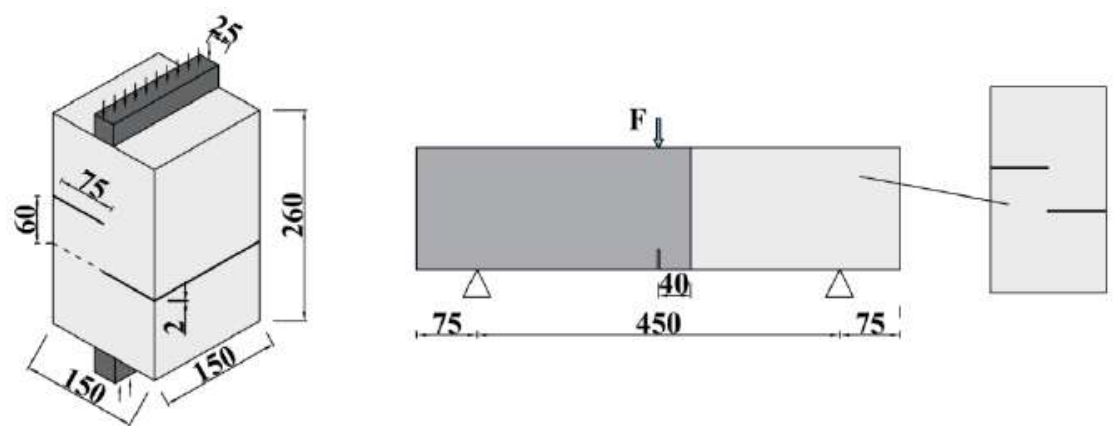

Figura 2.18 - Tipo de ensaio realizado por Barragán et al. (2006) e viga de onde foi retirado espécime, em região não afetada pela ruptura à flexão. Dimensões em $\mathrm{mm}$. 
Para os espécimes de referência, sem fibras, a curva tensão cisalhante versus deslizamento foi praticamente linear até a fissuração (pico da curva), quando houve perda instantânea de resistência. No caso dos espécimes de concreto de menor resistência e com fibras, após o primeiro pico houve perda gradual da capacidade resistente. No espécime de maior $f_{c}$, houve perda de resistência após o primeiro pico seguida de pequeno ganho antes da perda contínua de resistência. Segundo os autores, isso pode ser atribuído ao maior número de fibras na seção de cisalhamento (menor $l_{f}$ ).

Nos 30 espécimes de concreto autoadensável com fibras de aço ensaiados por Echegaray-Oviedo (2014), com $f_{c}$ em torno de $50 \mathrm{MPa}$, as principais variáveis foram: pré-tensão normal na seção cisalhante (confinado, com $w_{0}=0$ ou não confinado, com $\left.w_{0}=1\right)$, tipo $\left(\left(l_{f} / d_{f}\right) / l_{f}\right)=65 / 35,80 / 30$ ou 80/50) e teor $\left(V_{f}=0,0 \%\right.$, $0,51 \%, 0,64 \%$ ou $0,89 \%)$ de fibras de aço com gancho. Não foi constatada influência relevante dos tipos de fibras usados na carga referente ao primeiro pico da curva tensão cisalhante - deslizamento para a situação $w_{0}=0$, mas os espécimes com fibras $80 / 30$ e $V_{f}=0,51 \%$ apresentaram maior resistência pós primeiro pico, fato justificado pela maior quantidade de fibras para um mesmo volume (menor comprimento). Já nos casos com $w_{0}=1$, a tensão referente ao primeiro pico variou conforme o tipo de fibras.

De modo geral, foi observada tendência de aumento da resistência ao cisalhamento com o aumento do teor de fibras, embora para o menor incremento de fibras de aço $\left(V_{f}=0,51 \%\right.$ para $\left.V_{f}=0,64 \%, \Delta V_{f}=0,13 \%\right)$ isto não tenha sido constatado e, para o maior incremento $\left(V_{f}=0,51 \%\right.$ para $\left.V_{f}=0,89 \%, \Delta V_{f}=0,38 \%\right)$, tenha ocorrido oscilação na relação tensão cisalhante - deslizamento para a situação $w_{0}=1$.

Mirasay \& Banthia (2002), Boulekbache et al. (2012) e Soetens \& Matthys (2017) realizaram ensaios adotando o procedimento de ensaio japonês JSCE-SF6 (1990), no qual duas seções de um prisma são submetidas a cisalhamento (Figura 2.19), com algumas modificações, tendo em vista o recorrente desvio do plano de ruptura e o invalidamento de resultados. No programa experimental de Mirasay \& Banthia (2002) foram utilizados prismas com dimensões $150 \mathrm{~mm} \times 150 \mathrm{~mm}$ x $500 \mathrm{~mm}$ e entalhe de $15 \mathrm{~mm}$ no entorno da seção de cisalhamento; no de Boulekbache et al. (2012) as dimensões foram $100 \mathrm{~mm}$ x $100 \mathrm{~mm}$ x $350 \mathrm{~mm}$ e entalhe de $10 \mathrm{~mm}$ e no de Soetens \& Matthys 
(2017) adotaram-se as dimensões de $150 \mathrm{~mm}$ x $150 \mathrm{~mm}$ x $600 \mathrm{~mm}$ e entalhe de $30 \mathrm{~mm}$. O trabalho de Mirasay \& Banthia (2002) foi o único a seguir o sistema de apoio do procedimento original. De modo a garantir que o espécime não rotacionasse durante o carregamento, Boulekbache et al. (2012) e Soetens \& Matthys (2017) utilizaram um suporte em volta das regiões anterior e posterior aos planos de cisalhamento (Figura 2.20). A fim de investigar a influência da tensão normal no plano de cisalhamento, Soetens \& Matthys (2017), para alguns espécimes, adicionaram em seu esquema de ensaio um sistema de ação-reação na direção horizontal (Figura 2.20.b).

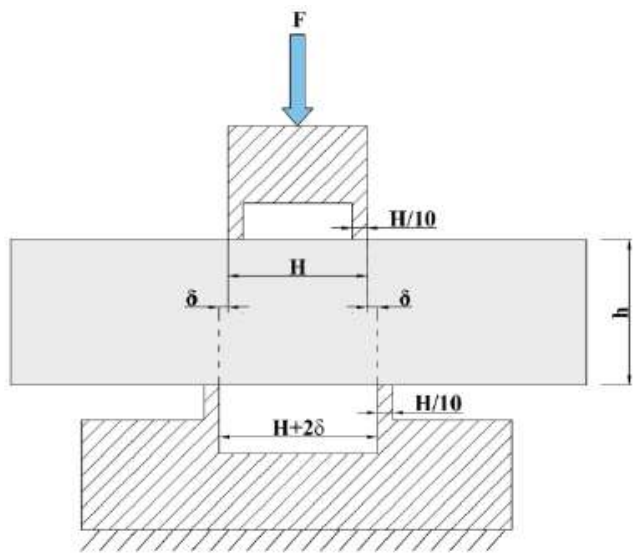

Figura 2.19 - Esquema de ensaio e proporção das dimensões $(0 \mathrm{~mm} \leq \delta \leq 1 \mathrm{~mm})$ do ensaio JSCE-SF6 (1990).

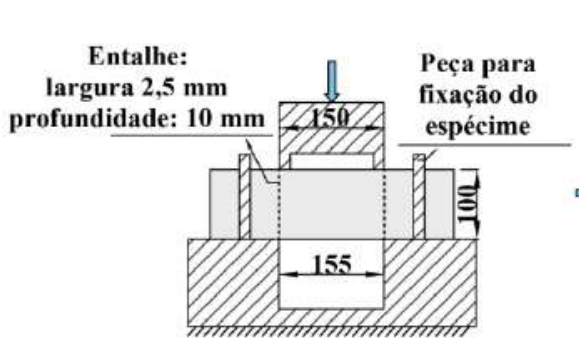

(a)

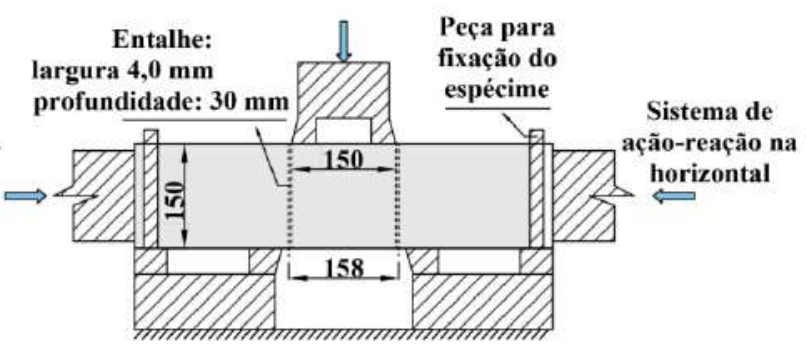

(b)

Figura 2.20 - Esquema de ensaio adotado (a) Boulekbache et al. (2012) e (b) Soetens \& Matthys (2017). Dimensões em mm.

No programa experimental de Mirasay \& Banthia (2002) foi investigada a influência do tipo e do teor de fibras de aço. Mantiveram-se constantes a resistência à compressão do concreto $\left(f_{c}=47 \mathrm{MPa}\right)$ e o comprimento e o fator de forma das fibras $\left(l_{f}=50 \mathrm{~mm}, l_{f} d_{f}=50\right)$ e variaram-se o teor $\left(V_{f}=0,0 \%\right.$ a $\left.2,0 \%\right)$ e o tipo das fibras (uma com seção circular e extremidades planas - FE e outra corrugada - CR). Foi constatado aumento da resistência ao cisalhamento com a adição dos dois tipos 
de fibras; os com as fibras FE apresentaram maior aumento de resistência em relação ao sem fibras que os com fibras CR ( $88 \%$ FE e 51,7 \% CR), para $V_{f}=1,5 \%$ (Figura 2.21). Enquanto os espécimes com fibras FE apresentaram resistência tendendo a aumentar linearmente com o aumento do teor de fibras, os com fibras CR indicaram tendência de limitação do aumento de resistência com o aumento de $V_{f}$, conforme mostra a Figura 2.22.

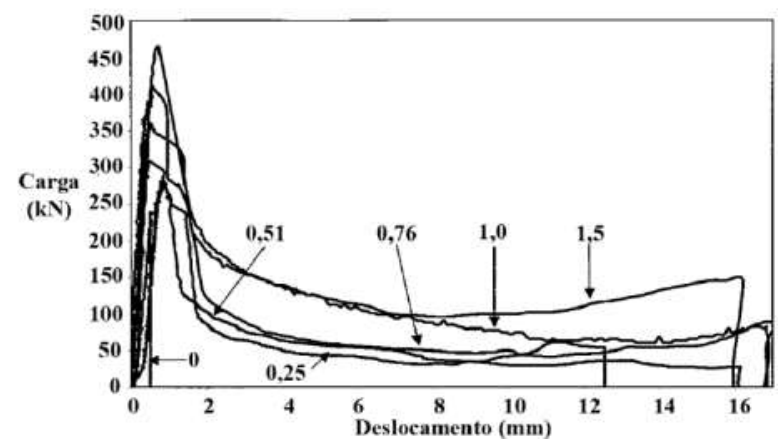

(a)

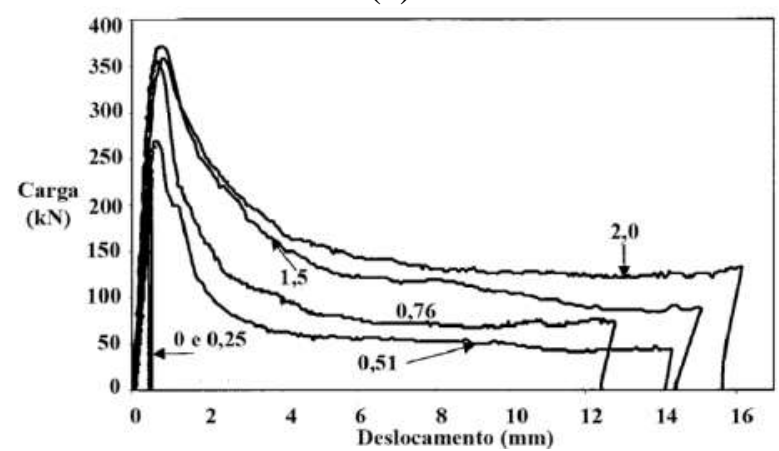

(b)

Figura 2.21 - Curvas carga - deslocamento vertical para os espécimes com diferentes volumes percentuais de fibras de aço: (a) fibras FE e (b) fibras CR.

(Adaptado de Mirasay \& Banthia, 2002)

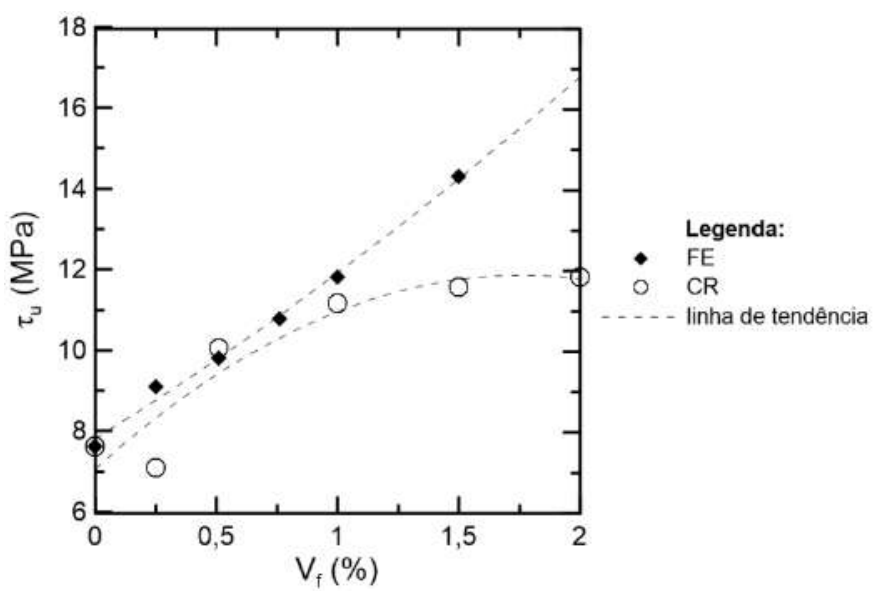

Figura 2.22 - Resistência ao cisalhamento $\left(\tau_{\mathrm{u}}\right)$ em função do volume percentual de fibras de aço para os espécimes com fibras FE e CR de Mirasay \& Banthia (2002). 
O programa experimental de Boulekbache et al. (2012) teve como variáveis o tipo de concreto (convencional com $f_{c}=30 \mathrm{MPa}-\mathrm{OC}$; autoadensável com $f_{c}=60 \mathrm{MPa}-\mathrm{SCC}$; de alta resistência com $f_{c}=80 \mathrm{MPa}-$ HSC), volume de fibras $\left(\mathrm{V}_{\mathrm{f}}=0,0 \%, 0,5 \%\right.$ e $\left.1,0 \%\right)$ e fator de forma/comprimento das fibras $(65 / 35 \mathrm{ou}$ 80/60). Verificou-se que maior alinhamento ou direção mais aleatória e distribuição das fibras dependem da fluidez do concreto. A mudança do concreto de $f_{c}=30 \mathrm{MPa}$ para o de $f_{c}=80 \mathrm{MPa}$ nos espécimes sem fibras acarretou um aumento de $123 \%$ na capacidade resistente ao cisalhamento. Nos espécimes com $f_{c}$ baixo, fibras atravessando a fissura na seção de cisalhamento foram arrancadas da matriz, enquanto nos com $f_{c}$ maior, principalmente nos com maior valor de $V_{f} l_{f} d_{f}$, houve ruptura de algumas fibras. Constatou-se baixa influência do fator de forma das fibras na capacidade resistente; houve apenas $5 \%$ de aumento ao mudar $l_{f} / d_{f}$ de 65 para 80. Verificou-se resistência ao cisalhamento variando linearmente com $V_{f} l_{f} / d_{f}$ e, para $V_{f}=0,5 \%$, registrou-se aumento de $44 \%$ nessa resistência e, para $V_{f}=1,0 \%$, aumento de $65 \%$ em relação aos espécimes sem fibras.

Soetens \& Matthys (2017) ensaiaram 69 prismas (16 diferentes modelos), nos quais variaram-se o tipo de concreto (CAA ou CV com $\mathrm{f}_{\mathrm{c}} \sim 64 \mathrm{MPa}$ ), teor $\left(V_{f}=0,0 \%, 0,25 \%, 0,50 \%\right.$ e $\left.0,75 \%\right)$ e comprimento de fibras de aço com gancho nas extremidades $\left(l_{f}=30 \mathrm{~mm}\right.$ e $60 \mathrm{~mm}$, de mesmo $\left.l_{f} / d_{f}\right)$ e tensão de confinamento no plano de cisalhamento (0 MPa, $5 \mathrm{MPa}, 10 \mathrm{MPa}$ e $25 \mathrm{MPa})$. Os espécimes romperam na região de entalhe, com efeitos secundários que indicam nela não ter havido cisalhamento puro. A adição de fibras teve influência positiva na resistência ao cisalhamento, e ligeiramente maior nos espécimes de CAA que nos de CV e nos de fibras de maior comprimento. Não houve influência do teor e tipo de fibras de aço no padrão da curva abertura de fissura - deslizamento. Verificou-se relação entre a resistência ao cisalhamento e o número de fibras interceptando a seção de cisalhamento. A existência de tensão de confinamento aumentou a resistência ao cisalhamento, mas em menor proporção que o aumento dessa tensão.

Khanlou et al. (2012) desenvolveram um programa experimental adotando ensaio de cisalhamento padronizado pela FIP (1978) (Figura 2.23) para avaliar a resistência à força cortante entre elementos pré-fabricados e moldados no local. Foram utilizados concretos $\operatorname{com} f_{c}=35 \mathrm{MPa}$ ou $60 \mathrm{MPa}$, e fibras de aço $\left(l_{f}=60 \mathrm{~mm}\right.$ e $\left.l_{f} / d_{f}=80\right)$ nos teores em volume iguais a $0,0 \%, 0,25 \%, 0,51 \%, 0,76 \%$ ou $1,0 \%$. Para cada combinação de variáveis foram moldados três espécimes. 


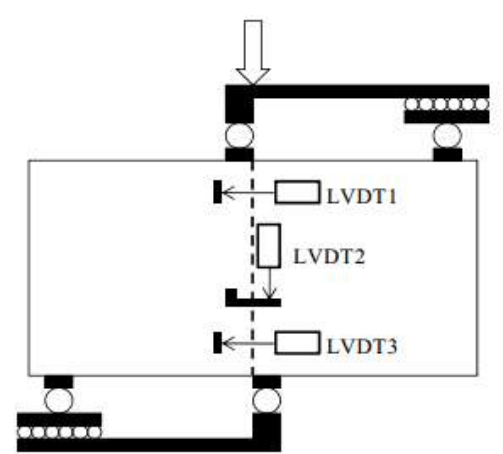

(a)

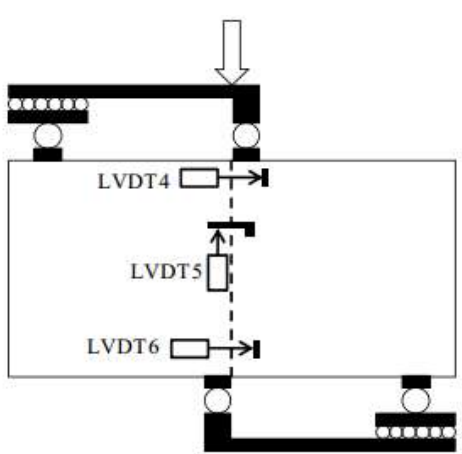

(b)

Figura 2.23 - Esquema de ensaio e instrumentação. (a) e (b) vistas opostas do espécime (Khanlou et al., 2012).

Assim como observado por Barragán et al. (2006), para os espécimes sem fibras, a curva tensão cisalhante - deslizamento foi linear até a fissuração, quando houve perda total de resistência. Para os $\operatorname{com} f_{c}=35 \mathrm{MPa}$ e $V_{f}=0,25 \%$ e $0,51 \%$ e $\operatorname{com} f_{c}=60 \mathrm{MPa}$ e $V_{f}=0,25 \%$, após a fissuração, houve perda gradual de resistência ao cisalhamento, enquanto, para os demais casos, após pequena perda de resistência depois da fissuração houve recuperação da capacidade resistente de maneira a atingir valores de tensão maiores que aquela relativa à fissuração antes de haver perda gradual de capacidade resistente. A adição de fibras levou ao aumento das tensões cisalhantes de fissuração e última.

Marar et al. (2017) realizaram ensaios de cisalhamento em prismas com duplo entalhe (Figura 2.24), sem o controle da tensão normal no plano de cisalhamento. Nos espécimes variaram-se a resistência à compressão do concreto $\left(f_{c}=30 \mathrm{MPa}\right.$ ou $50 \mathrm{MPa})$, volume $\left(V_{f}=0 \%, 0,5 \%, 1,0 \%\right.$ ou $\left.1,5 \%\right)$ e o fator de forma das fibras de aço (65 ou 80, para um mesmo comprimento). Constatou-se aumento da resistência ao cisalhamento com o aumento do volume de fibras (até $146 \%$ ) e resistência do concreto (até $29 \%$ ). Para os espécimes de $l_{f} d_{f}=65$, o aumento da tensão cisalhante última dos com $V_{f}=0,5 \%, 1,0 \%$ e $1,5 \%$ em relação aos com $V_{f}=0,0 \%$ foi, em média, $43 \%, 89 \%$ e $116 \%$, respectivamente. Para estes mesmos teores de fibras e $l_{f} / d_{f}=80$, os aumentos foram de $23 \%, 79 \%$ e $129 \%$, respectivamente, concluindose que não houve influência do fator de forma (Figura 2.25). 


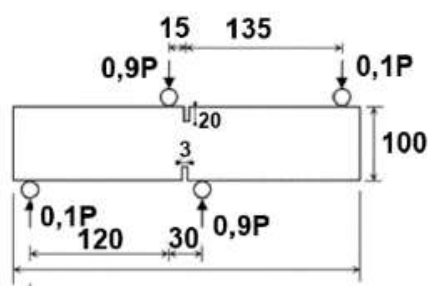

Figura 2.24 - Prisma simétrico com duplo entalhe (100 mm x $100 \mathrm{~mm} \times 300 \mathrm{~mm})$. Dimensões em mm. (Adaptado Marar et al., 2017)

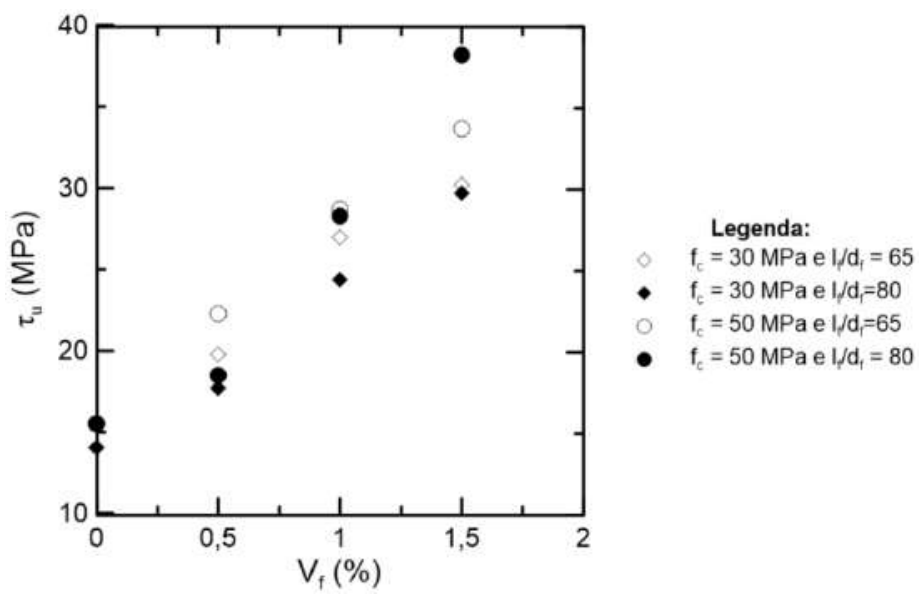

Figura 2.25 - Resistência ao cisalhamento $\left(\tau_{\mathrm{u}}\right)$ em função do volume percentual de fibras de aço para os espécimes de Marar et al., (2017).

A revisão bibliográfica realizada indicou que houve concentração das investigações sobre o engrenamento dos agregados em elementos de concretos com fibras de aço nas últimas duas décadas, com uma intensificação nos últimos anos. Diferentemente dos estudos experimentais de espécimes sem fibras de aço, em que houve principalmente ensaios do tipo push-off e tanto a tensão cisalhante quanto a normal no plano de cisalhamento foram reportadas, no caso dos concretos com fibras de aço, outros tipos de ensaios também foram empregados e, em sua maioria, não foi feita medição da tensão normal ao plano de cisalhamento. Em todos os trabalhos analisados verificou-se o aumento na capacidade resistente ao cisalhamento e aumento de ductilidade para crescente aumento de $V_{f}$. Quanto à influência de $l_{f} / d_{f}$, os resultados mostraram-se contraditórios. 


\subsubsection{3 \\ Métodos para avaliação das relações entre tensões e deslocamentos nas fissuras}

Alguns dos modelos adotados para analisar o engrenamento dos agregados são baseados no princípio da dilatância da fissura, que considera as tensões normal e cisalhante nas faces da fissura em função dos deslocamentos relativos entre elas.

Nesse contexto, os dois modelos (teórico e empírico) de Walraven (1980) (e Walraven \& Reinhardt, 1981), Bazant \& Gambarova (1980), Gambarova \& Karakoç (1983); Li \& Maekawa (1987) (e Li et al., 1989), Ulaga (2003) e Guidotti (2010) usados na literatura para avaliar a contribuição do engrenamento dos agregados na resistência à força cortante de vigas de concreto armado (Campana et al., 2013; Yang, 2014; Huber et al., 2016; Cavagnis 2017; Belbachir et al., 2018; etc.), são abordados nas primeiras seções, onde é adotado o sinal positivo para a tensão normal de compressão. Por último, é comentado o modelo de Matos et al. (2020) para o caso de concreto com fibras.

\subsubsection{1 Modelos de duas fases}

No modelo de Walraven (1980) e Walraven \& Reinhardt (1981), os autores admitiram que o concreto é composto por duas fases; uma constituída por pasta de cimento e agregados com dimensão máxima de $0,25 \mathrm{~mm}$, de comportamento rígidoplástico, e a outra por agregados com dimensão máxima maior que 0,25 mm e considerados rígidos. Os agregados foram assumidos como posicionados aleatoriamente e com forma simplificada de esferas para que se pudesse considerar que eles poderiam ser interceptados pela fissura em toda altura com a mesma probabilidade e projetando-se para fora do plano da fissura de uma forma arbitrária. Considerou-se que a microrrugosidade da fissura, causada pela parte dos agregados que ficam para fora das faces da fissura é a dominante e, por conta disso, a macrorrugosidade, decorrente da ondulação das faces da fissura, foi ignorada. Admitiu-se que a fissura contorna os agregados (Figura 2.26) e que o deslizamento entre as faces da fissura ocorre depois da abertura ter seu valor final. 


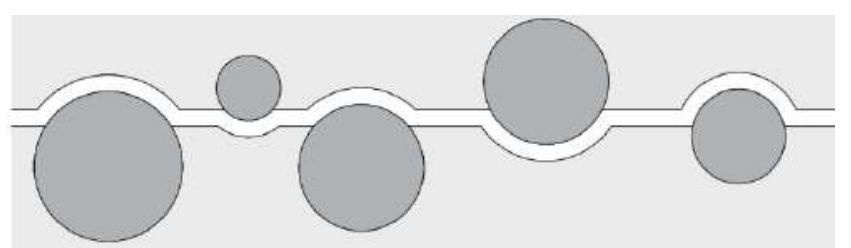

Figura 2.26 - Forma idealizada das superfícies da fissura considerada por Walraven \& Reinhardt (1981).

Quando ocorre deslizamento entre as faces da fissura, as partículas de agregado entram em contato com a matriz, que plastifica localmente, e em cada área de contato tem-se uma tensão normal $\sigma_{\mathrm{pu}}$ e uma tensão tangencial $\tau_{\mathrm{pu}}=\mu \sigma_{\mathrm{pu}}$, como mostrado na Figura 2.27. Nesta figura, $a_{t}$ e $a_{n}$ são as projeções das áreas de contato nas direções paralela e normal ao plano da fissura, respectivamente. A partir de resultados experimentais, o coeficiente de atrito $\mu$ entre a matriz e os agregados e a tensão de plastificação $\sigma_{\mathrm{pu}}$ foram definidos como sendo $\mu=0,5$ e $\sigma_{\mathrm{pu}}=6,39 f_{c u}{ }^{0,56}$.
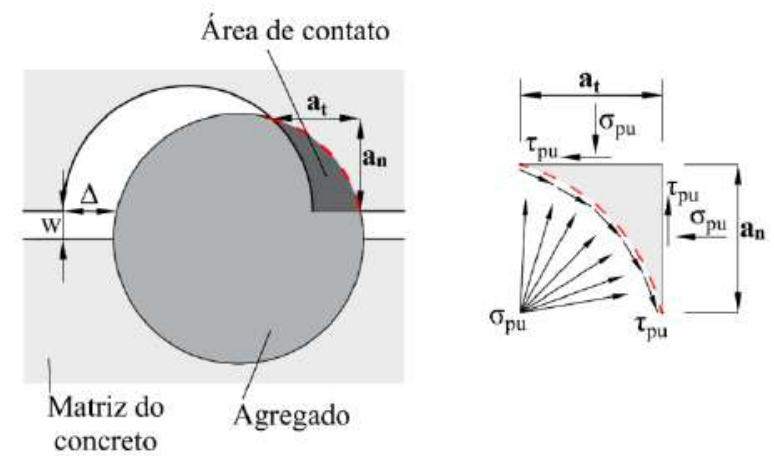

Figura 2.27 - Área de contato de uma partícula de agregado com a matriz e tensões nessa área, segundo o modelo de duas fases proposto por Walraven (1980).

Considerando as condições de equilíbrio em cada partícula e que $\Sigma a_{t}$ e $\Sigma a_{n}$ são o somatório das áreas de contato de todas as partículas numa unidade de área da superfície da fissura, chegou-se a:

$$
\begin{gathered}
\sigma=\sigma_{\mathrm{pu}}\left(\Sigma a_{t}-\mu \Sigma a_{n}\right) \\
\tau=\sigma_{\mathrm{pu}}\left(\Sigma a_{n}+\mu \Sigma a_{t}\right)
\end{gathered}
$$

As expressões para cálculo de $A_{t}=\Sigma a_{t}$ e $A_{n}=\Sigma a_{n}$ dependem de $w, \Delta$ e da granulometria, $d_{\max }$ e volume porcentual dos agregados e foram obtidas considerando a probabilidade de os agregados serem interceptados pelo plano de 
fissura e a distância do centro dos agregados à face da fissura ( $u$ na Figura 2.28). Foi admitida granulometria contínua de Füller, definida por $p=\sqrt{\frac{D}{d_{\max }}}$, em que $p$ representa a porcentagem passante em uma malha de abertura diametral igual a $D$ e $d_{\max }$ é a dimensão máxima do agregado. A probabilidade de um ponto qualquer no concreto ser um agregado foi definida como sendo $p=p_{k}$, sendo $p_{k}$ a razão entre os volumes de agregados e de concreto.

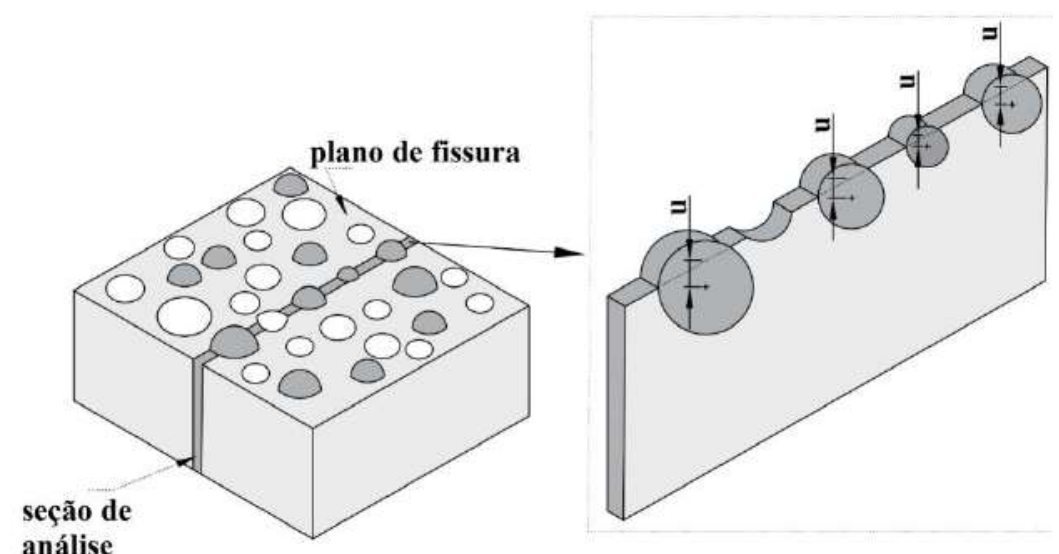

Figura 2.28 - Ilustração de um plano de fissura e de uma seção deste plano, a partir do qual se deu a modelagem do comportamento de toda a fissura, de acordo com Walraven \& Reinhardt (1981).

Ulaga (2003) e Guidotti (2010) propuseram modificações no modelo de duas fases de Walraven (1980). Ulaga (2003) admitiu que a abertura e o deslizamento na fissura se desenvolvem simultaneamente a um ângulo constante $\gamma=\operatorname{arctg}(w / \Delta) \mathrm{e}$ Guidotti (2010) considerou que parte da abertura de fissura total se desenvolve antes do início do deslizamento $\left(w_{0}\right)$, tendo-se a seguir o crescimento de $w$ e $\Delta$ a um ângulo $\gamma_{\mathrm{T}}=\operatorname{arctg}\left[\left(w-w_{0}\right) / \Delta\right]$. Tanto a cinemática da fissura do modelo de Walraven (1980) quanto a de Ulaga (2003) são casos particulares da de Guidotti (2010). A de Walraven (1980) considera $w_{0}=w\left(\gamma_{\mathrm{T}}=0\right)$ e a de Ulaga (2003) $w_{0}=0$, como mostrado na Figura 2.29. 


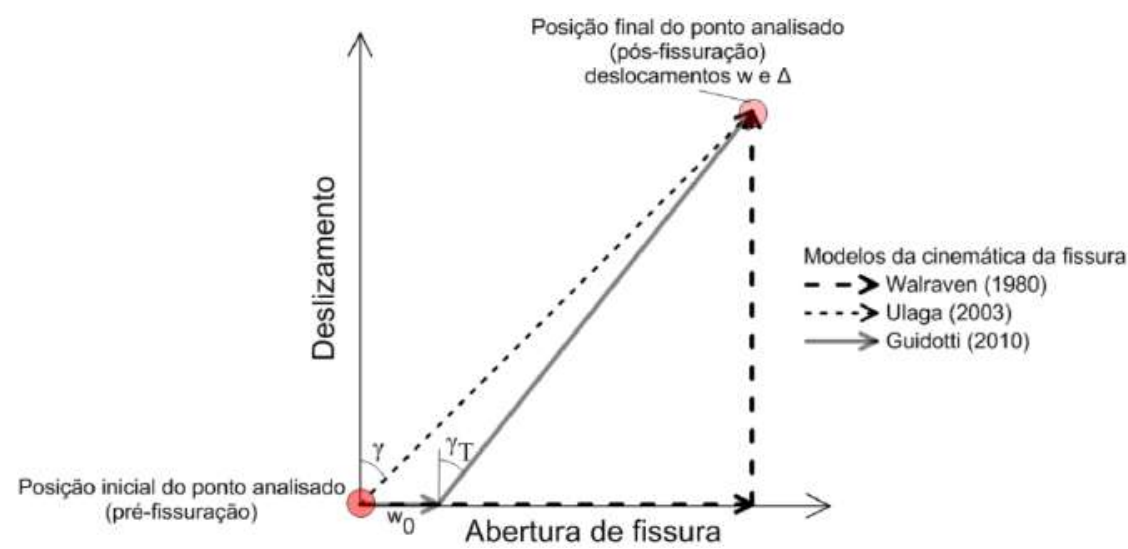

Figura 2.29 - Modelos de desenvolvimento da cinemática da fissura de Walraven (1980), Ulaga (2003) e Guidotti (2010).

Por simplificação, é apresentado no Quadro 2.1 apenas o caso geral das equações de $A_{t}$ e $A_{n}$, dadas por Guidotti (2010). As expressões para os modelos de Walraven \& Reinhardt (1981) e Ulaga (2003) são obtidas fazendo-se $w_{0}=w$ e $w_{0}=0$, respectivamente. As equações 2.25 a 2.28 apresentam coeficientes ligeiramente diferentes da de Walraven \& Reinhardt (1981), porém as duas levam a resultados praticamente iguais. 
60

Quadro 2.1 - Caso geral das equações de $A_{t}$ e $A_{n}$, dadas por Guidotti (2010).

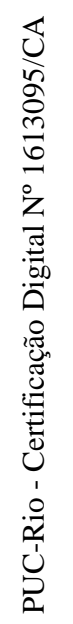

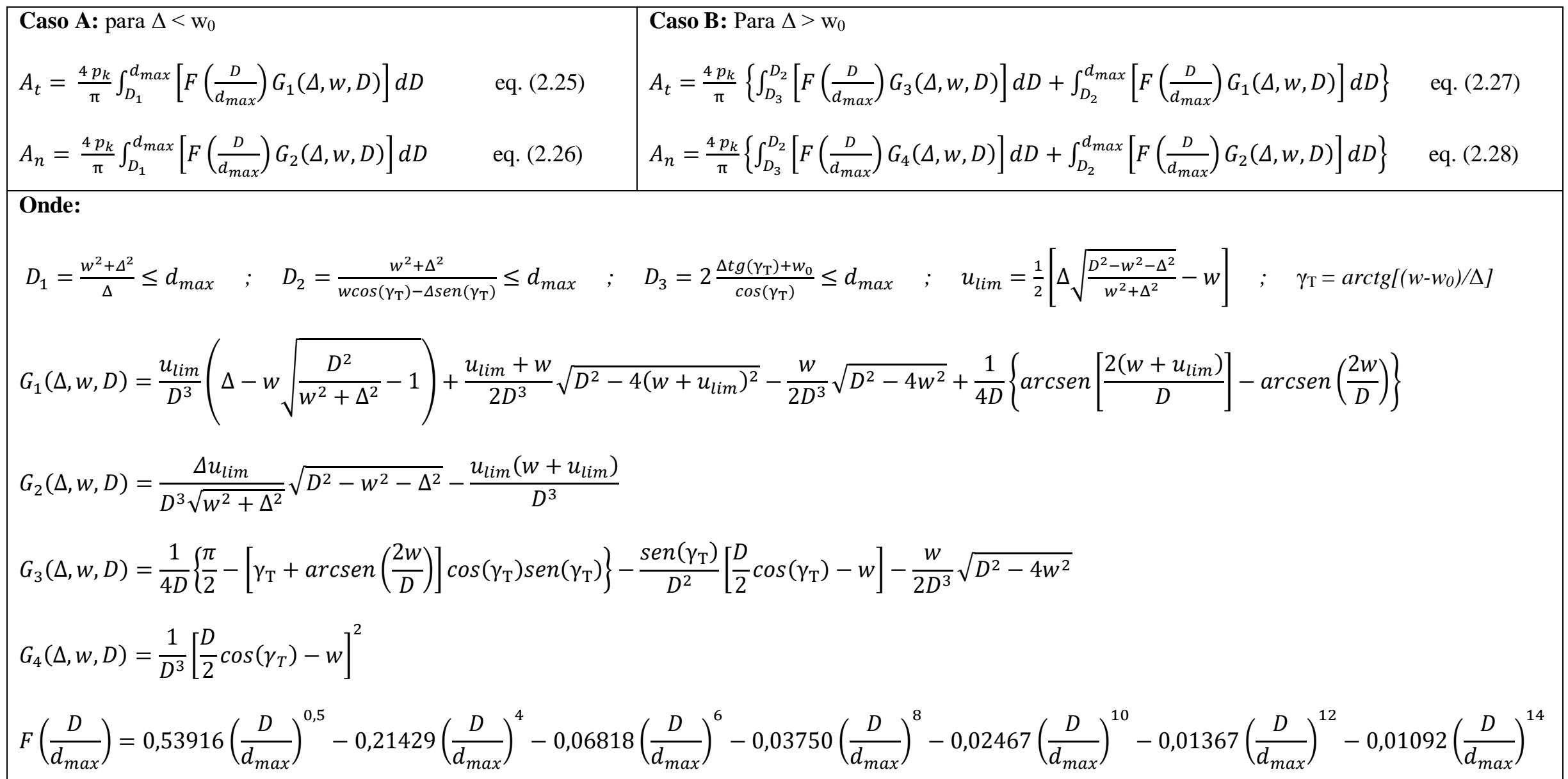


Na Figura 2.30 são apresentadas curvas tensão cisalhante - deslizamento na fissura para o caso de um concreto com $d_{\max }=16 \mathrm{~mm}, p_{k}=0,75$ e $f_{c}=40 \mathrm{MPa}$ $\left(f_{c u}=50 \mathrm{MPa}\right)$, para diferentes aberturas de fissura, de acordo com os modelos de Walraven \& Reinhardt (1981), Ulaga (2003) e Guidotti (2010) com wo arbitrado igual a $w / 5$. Nesta figura é possível observar que, para determinado par de valores de $w$ e $\Delta$, o modelo de Walraven (1980) fornece os maiores valores de tensões na fissura e o de Ulaga (2003) os menores.

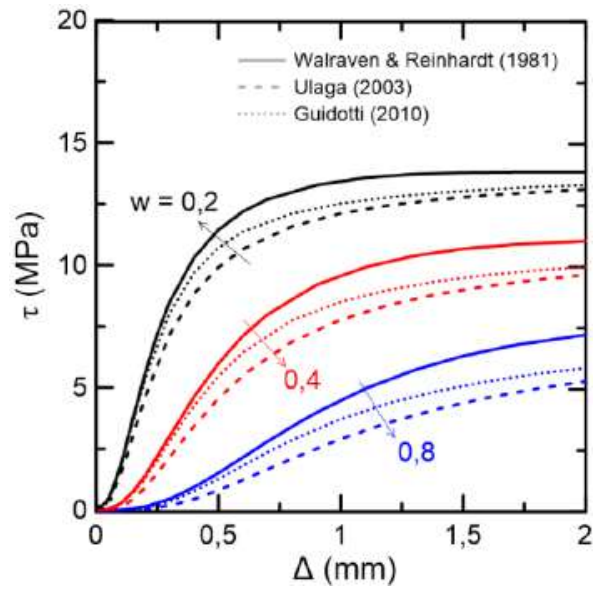

(a)

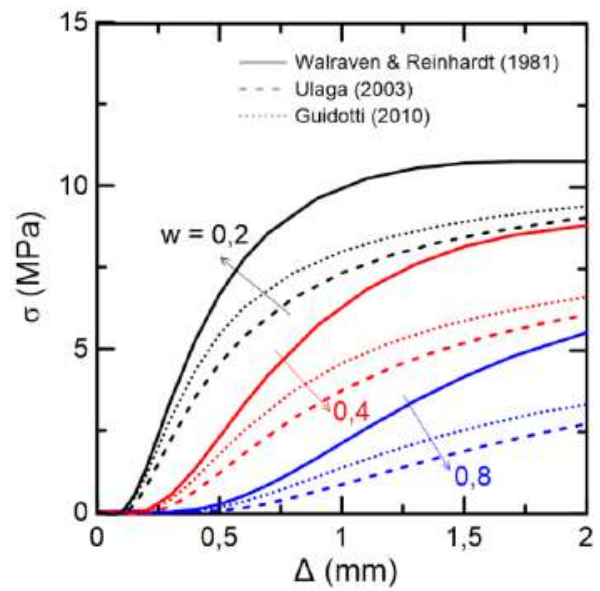

(b)

Figura 2.30 - Curvas (a) tensão cisalhante - deslizamento na fissura e (b) tensão normal - deslizamento na fissura de acordo com Walraven \& Reinhardt (1981), Ulaga (2003) e Guidotti (2010) (adotado $w_{0}=w / 5$ ) para diferentes aberturas de fissura $\mathrm{w}$ em $\mathrm{mm}$. Setas indicam curvas referentes à mesma abertura de fissura.

Além de ser de aplicação trabalhosa, o modelo de duas fases foi baseado nas premissas de ter-se granulometria contínua, fissura contornando os agregados e macrorrugosidade desprezível, o que pode não corresponder ao caso em análise. Há evidência de que, mesmo que haja fratura de grande parte dos agregados, pode haver engrenamento por conta da macrorrugosidade (Sagaseta \& Vollum, 2011b).

Tendo em vista as desvantagens desse método, Cavagnis et al. (2018b) sugeriram simplificações, considerando a cinemática da fissura de Guidotti (2010) e inserindo parâmetro para levar em conta a rugosidade média da superfície da fissura. Sua formulação leva em consideração a superposição da parcela de engrenamento dos agregados e da resistência à tração residual do concreto ao longo da fissura crítica (trecho onde há $w$ e $\Delta$ ) e de apenas resistência à tração residual do concreto onde houver exclusivamente abertura de fissura $(\operatorname{sem} \Delta$, no topo da fissura) e foram calibradas de acordo com os seus resultados experimentais em vigas esbeltas apresentadas em Cavagnis et al. (2015). 
$\sigma=\sqrt{f_{c}} \frac{c_{4} \bar{\Delta}^{7 / 3}}{\left(c_{2} \bar{w}\right)^{3+c_{2} \bar{\Delta}}}-\sigma_{\mathrm{res}}$

$$
\tau=\sqrt{f_{c}} \frac{c_{3} \bar{\Delta}^{4 / 3}}{\left(c_{2} \bar{w}\right)^{1,8+c_{2} \bar{\Delta}}}
$$

Unidades em $\mathrm{N}$ e mm.

Nestas equações, $\sigma_{\text {res }}$ é a tensão de tração residual do concreto calculada de acordo com Reinhardt (1984) (ver Quadro 2.2 no item 2.2.3); $c_{2}=40, c_{3}=35$ e $\mathrm{c}_{4}=400 ; \bar{\Delta}=\Delta / d_{m}$ e $\bar{w}=w / d_{m}$ são o deslizamento e a abertura de fissura normalizados, respectivamente, e $d_{m}$ é a rugosidade média. Para $f_{c} \leq 60 \mathrm{MPa}, d_{m}$ é o menor valor entre $40 \mathrm{~mm}$ e $\left(16+d_{\max }\right)$ e, para maior $f_{c}$, o menor valor entre $40 \mathrm{~mm}$ $\mathrm{e}\left[16+d_{\max }\left(60 / f_{c}\right)^{2}\right]$.

Na Figura 2.31 são apresentadas curvas tensão cisalhante versus deslizamento na fissura, para diferentes valores de abertura da fissura, obtidas a partir dessas equações e considerando concreto igual ao adotado para traçado das curvas da Figura 2.30. Para efeito de comparação, nela constam também as curvas dadas pelo modelo de Guidotti (2010), com $w_{0}$ arbitrado igual a $w / 5$.

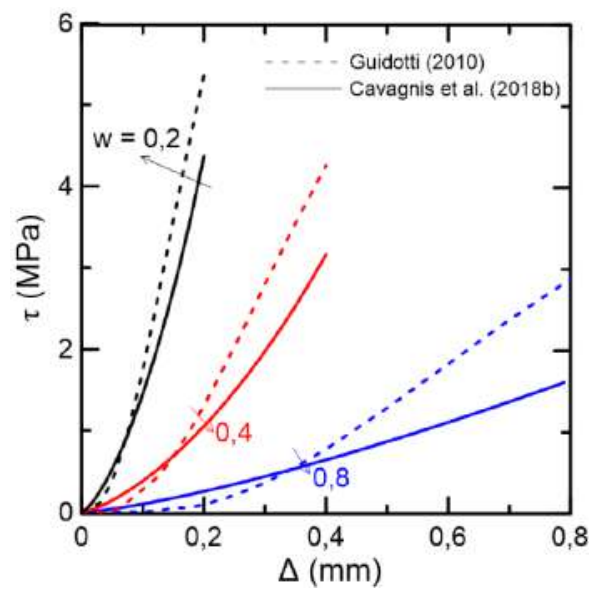

(a)

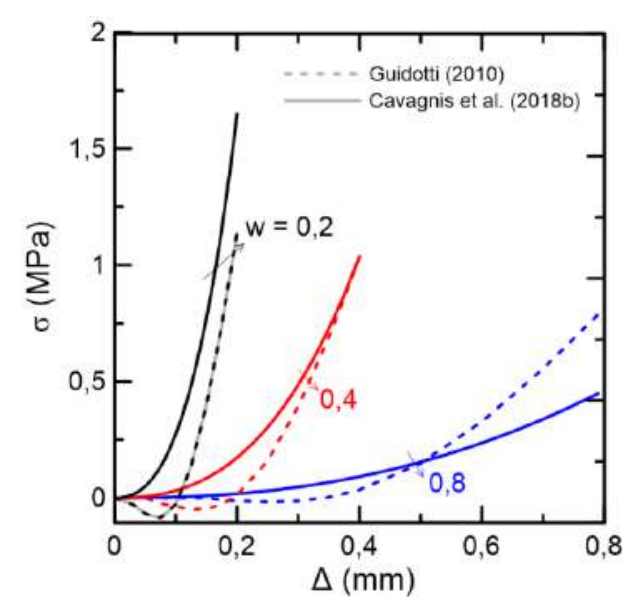

(b)

Figura 2.31 - Curvas (a) tensão cisalhante - deslizamento na fissura e (b) tensão normal - deslizamento na fissura para diferentes valores de abertura de fissura $w$ em mm, de acordo com propostas de Cavagnis et al. (2018b) e de Guidotti (2010), considerando $w_{0}=w / 5$. Setas indicam curvas referentes à mesma abertura de fissura. 


\subsubsection{2}

\section{Modelo de densidade de contato}

O modelo de densidade de contato de Li \& Maekawa (1987), apresentado também em Li et al. (1989) com alguns ajustes, objetivou representar a rugosidade da superfície de contato da fissura por meio de várias unidades de contato, em que foi considerada uma distribuição probabilística "função densidade de contato" dos ângulos de contato entre as partículas. O modelo contempla os casos de carregamento cíclico e monotônico, sendo resumido aqui apenas o último caso.

A área unitária da superfície da fissura foi idealizada como composta por potenciais planos de contato $\left(d A_{\theta}\right)$, dada pela equação 2.31 , com inclinação $\theta$ em relação ao eixo $\mathrm{Y}$ coincidente com o ângulo da tensão normal de contato $\theta_{\mathrm{s}}$ (Figura 2.32). Em cada área de contato, de comportamento elasto-plástico, há transferência de tensões normal e cisalhante.

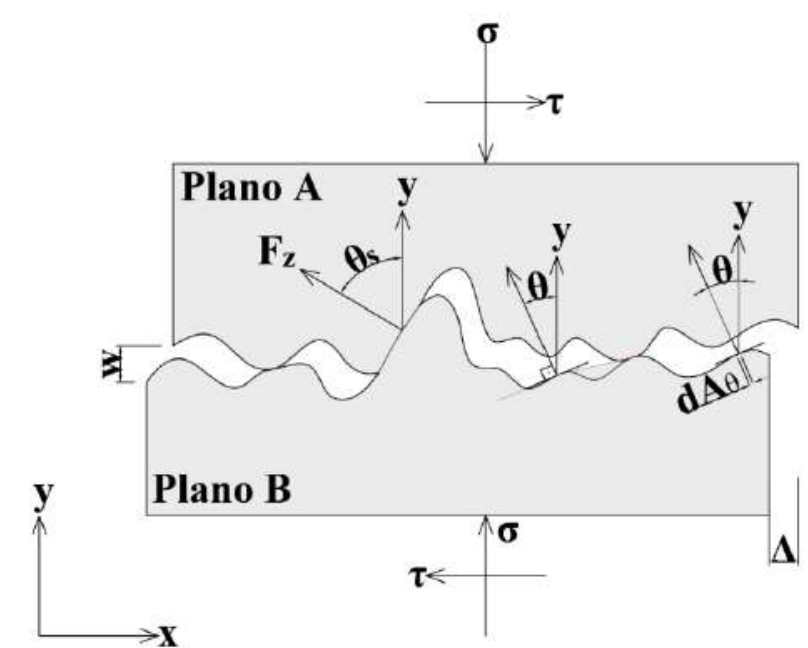

Figura 2.32 - Idealização da geometria da fissura de acordo com Li \& Maekawa (1987). Adaptado de Li et al. (1989).

$d A_{\theta}=A_{t o t} \Omega(\theta) d \theta$ eq. (2.31)

Nesta equação, $A_{t o t}$ é a área total por unidade de plano de fissura e $\Omega(\theta)$ é a função que descreve a densidade de probabilidade dos ângulos de contato e que satisfaz a equação 2.32 .

$$
\int_{-\pi / 2}^{\pi / 2} \Omega(\theta) d \theta=1
$$


Por compatibilidade geométrica, tem-se que a integral da projeção da área unitária de contato de $d A_{\theta}$ no plano de fissura (eixo x da Figura 2.32) é igual a 1:

$$
\int_{-\pi / 2}^{\pi / 2} \mathrm{dA}_{\theta} \cos \theta=1
$$

Substituindo a eq. (2.31) na eq. (2.33) chegou-se a $A_{\text {tot }}$ :

$$
A_{\text {tot }}=\frac{1}{\int_{-\pi / 2}^{\pi / 2} \Omega(\theta) \cos \theta \mathrm{d} \theta}
$$

A função densidade de contato $\Omega(\theta)$ foi, a partir de um conjunto de resultados experimentais, simplificada para a função trigonométrica dada pela equação 2.35 (para concretos com $f_{c} \leq 50 \mathrm{MPa}$ ), que independe da dimensão máxima e granulometria dos agregados (Figura 2.33).

$$
\Omega(\theta)=0,5 \cos (\theta)
$$

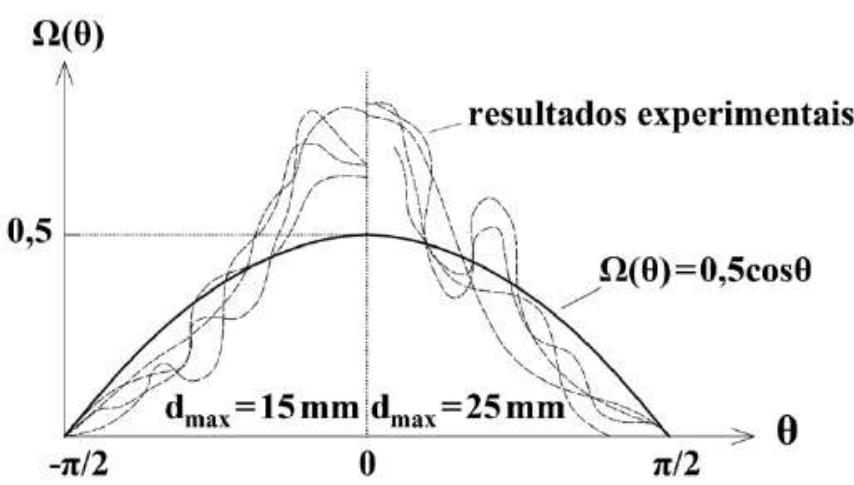

Figura 2.33 - Curvas $\Omega(\theta)$ experimentais de espécimes de concretos com diferentes dimensões máximas de agregados graúdos e idealizada.

Com a equação 2.35 em 2.34, chegou-se a $A_{t o t}=1,27$, ou seja, a área da superfície da fissura é 1,27 vezes a área do plano de fissura.

A força de compressão normal a cada contato $F_{z}(w, \Delta, \theta) \mathrm{d} \theta$, indicada na Figura 2.32, é obtida multiplicando a tensão normal de contato pela área efetiva de contato:

$$
F_{z}(w, \Delta, \theta) \mathrm{d} \theta=\sigma_{\text {con }}(\theta) K(w) A_{t o t} \Omega(\theta) \mathrm{d} \theta
$$


onde as grandezas $\sigma_{\text {con }}$ e $K(w)$ são as definidas a seguir.

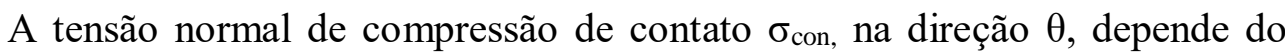
deslocamento relativo normal $\left(w^{\prime}\right)$ a essa direção e do carregamento. Essa tensão tem o limite $f_{c y}=R_{s} w_{\text {lim }}^{\prime}$, sendo $w_{\text {lim }}^{\prime}$ definido empiricamente como sendo $0,04 \mathrm{~mm}$. $\mathrm{O}$ valor de $\mathrm{R}_{\mathrm{s}}$ não foi diretamente definido pelos autores, tendo-se apenas chegado empiricamente ao produto $R_{s} A_{\text {tot }}=436 f_{c}^{1 / 3}$, com $f_{c}$ em MPa. Como simplificação para o caso de carregamento monotônico, os autores consideraram o concreto tendo comportamento rígido-plástico (Figura 2.34), tendo em vista que a abertura e o deslizamento na fissura são expressivamente maiores que $w^{\prime}$ 'lim e que a componente de deformação elástica é desprezível se comparada com a plástica.

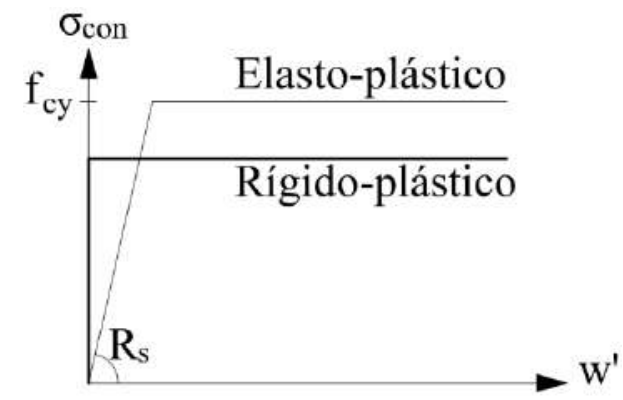

Figura 2.34 - Mudança de comportamento do concreto de elasto-plástico para rígido-plástico, no caso de carregamento monotônico. Adaptado de Li et al. (1989).

O parâmetro $K(w)$, dado pela equação 2.37 , leva em consideração a redução da área de contato entre as faces da fissura, uma vez que a rugosidade da superfície da fissura reduz a área de contato.

$$
K(w)=1-\exp \left(1-\frac{2 w}{d_{\max }}\right) \geq 0
$$

Sendo a abertura de fissura expressivamente menor que a dimensão máxima do agregado graúdo, o valor de $K(w)$ é aproximadamente igual a 1.

O somatório das forças de contato em todas as áreas unitárias da fissura fornece as equações de tensões normal e cisalhante: 


$$
\begin{aligned}
& \sigma=\int_{-\pi / 2}^{\pi / 2} F_{z}(w, \Delta, \theta) \cos \theta \mathrm{d} \theta \\
& \tau=\int_{-\pi / 2}^{\pi / 2} F_{z}(w, \Delta, \theta) \operatorname{sen} \theta \mathrm{d} \theta
\end{aligned}
$$

Considerando $\sigma_{\text {con }}$ de comportamento rígido-plástico, $K(w)=1$ e apenas o intervalo de integração das equações 2.38 e 2.39 em que há tensão de contato, ou seja:

$$
w^{\prime}>0 \text { se } \theta>\operatorname{arctg}(w / \Delta)
$$

Assim, chegou-se às equações 2.41 .

$$
F_{z}=f_{c y} A_{t o t} \Omega(\theta) \mathrm{d} \theta \quad \text { para } \theta>\operatorname{arctg}(w / \Delta)
$$

E as equações 2.38 e 2.39 se transformaram nas 2.42 e 2.43 , respectivamente, que levaram às equações 2.44 e 2.45 .

$$
\begin{aligned}
& \sigma=\int_{\operatorname{arctg}(w / \Delta)}^{\pi / 2} 0,5 f_{c y} A_{t o t} \cos ^{2} \theta \mathrm{d} \theta \\
& \tau=\int_{\operatorname{arctg}(w / \Delta)}^{\pi / 2} 0,5 f_{c y} A_{t o t} \cos \theta \operatorname{sen} \theta \mathrm{d} \theta
\end{aligned}
$$

$$
\begin{aligned}
\sigma & =k^{\prime}\left[\frac{\pi}{2}-\operatorname{cotg}^{-1}(r)-\frac{r}{1+r^{2}}\right] \\
\tau & =k^{\prime} \frac{r^{2}}{1+r^{2}}
\end{aligned}
$$

Nas equações 2.44 e 2.45, $\quad r=\Delta / w$ e $k^{\prime}$, que seria igual a $0,25 A_{\text {tot }} f_{c y}=0,25\left(A_{t o t} R_{s} w_{\text {lim }}^{\prime}\right)=4,36 f_{c}^{1 / 3}$, passou a ser dado pela equação 2.46. Esta redução visou fazer com que, face às aproximações feitas, essas equações não superestimassem os valores de $\sigma$ e $\tau$. 
$k^{\prime}=3,83 f_{c}^{1 / 3}$

Na Figura 2.35 tem-se curvas tensão versus deslizamento na fissura de acordo com o modelo de densidade de contato, junto com as curvas dadas pelo modelo de Walraven \& Reinhardt (1981) anteriormente apresentadas na Figura 2.30. As curvas das Figuras 2.35 e 2.30 mostram tendência de, para determinados valores de $w$ e $\Delta$, o modelo de contato levar a maiores valores de tensões que os modelos de duas fases, com aumento nas diferenças para maiores aberturas de fissura.

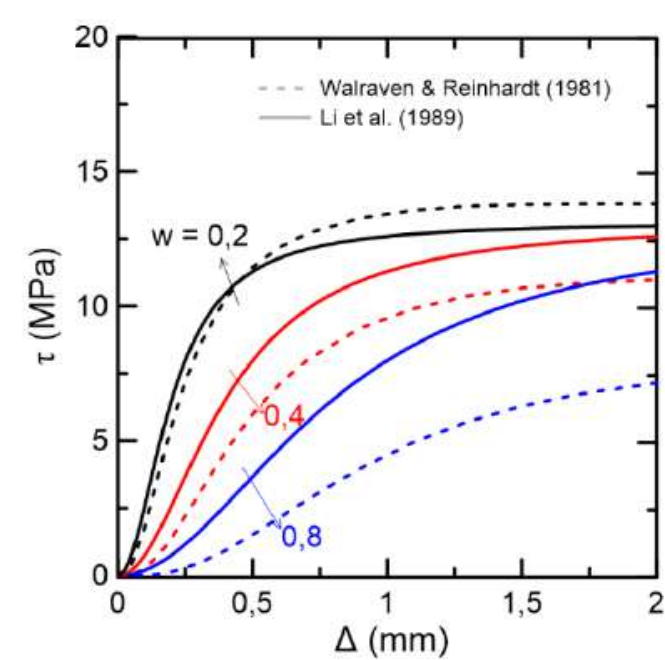

(a)

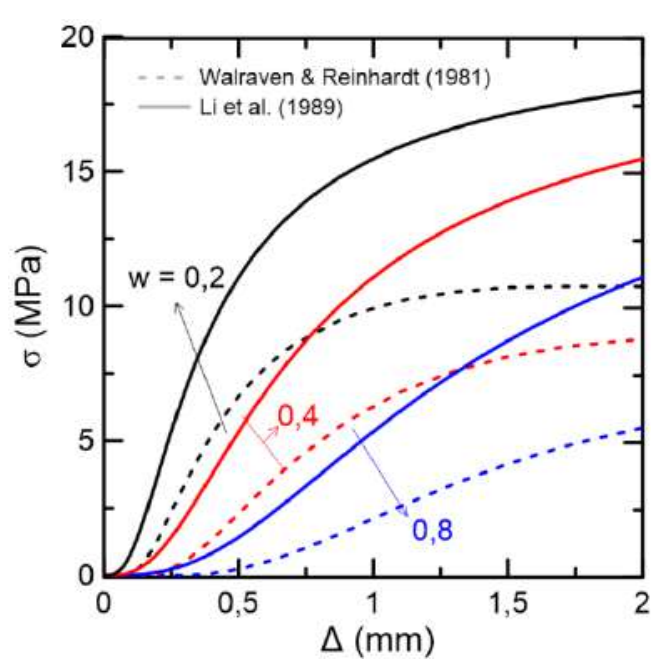

(b)

Figura 2.35 - Curvas (a) tensão cisalhante - deslizamento e (b) tensão normal deslizamento de acordo com os modelos de Li et al. (1989) e de Walraven \& Reinhardt (1981), para diferentes aberturas de fissura $w$ em mm. Setas indicam curvas referentes à abertura de fissura.

\subsubsection{3}

\section{Métodos com base empírica}

Embora os modelos simplificado linear de Walraven \& Reinhardt (1981) e o de rugosidade de fissura de Bazant \& Gambarova (1980) e sua modificação feita por Gambarova \& Karakoç (1983) sejam essencialmente empíricos, eles foram empregados no estudo da contribuição da parcela de engrenamento dos agregados na resistência à força cortante de vigas de concreto armado (Huber et al., 2016; Belbachir et al., 2018) e o simplificado de Walraven \& Reinhardt (1981) aparece, inclusive, nas recomendações FIB MC 2010 (2013). Por conta disso e da sua facilidade de aplicação, esses modelos são aqui resumidos. 
Walraven \& Reinhardt (1981), a partir dos resultados de seu programa experimental, chegaram às equações 2.47 e 2.48 .

$$
\begin{aligned}
& \sigma=-\frac{f_{c u}}{20}+\left[1,35 w^{-0,63}+\left(0,191 w^{-0,552}-0,15\right) f_{c u}\right] \Delta \\
& \tau=-\frac{f_{c u}}{30}+\left[1,8 w^{-0,8}+\left(0,234 w^{-0,707}-0,20\right) f_{c u}\right] \Delta
\end{aligned}
$$

sendo $w$ e $\Delta$ em mm; $\sigma, \tau$ e $f_{c u}$ em MPa.

Em FIB MC 2010 (2013), estas equações foram acrescidas do fator de correção $\left(\mathrm{C}_{\mathrm{f}}\right)$, para levar em conta a rugosidade entre as faces da fissura de diferentes tipos de concreto, e $\mathrm{f}_{\mathrm{cu}}$ foi substituída por $\mathrm{f}_{\mathrm{c}}$, ficando:

$$
\begin{aligned}
& \sigma=C_{f}\left\{-0,06 f_{c}+\left[1,35 w^{-0,63}+\left(0,242 w^{-0,55}-0,19\right) f_{c}\right] \Delta\right\} \\
& \tau=C_{f}\left\{-0,04 f_{c}+\left[1,8 w^{-0,8}+\left(0,292 w^{-0,7}-0,25\right) f_{c}\right] \Delta\right\}
\end{aligned}
$$

em que $C_{f}$ é adotado igual a 0,35 , para elementos de concreto de alta resistência ou com agregados de baixa resistência (a maioria dos agregados será atravessada pela fissura) ou, caso contrário, $C_{f}=1,0$ e as unidades são $\mathrm{N}$ e mm.

Na Figura 2.36 constam curvas tensão cisalhante e tensão normal versus deslizamento na fissura, para um concreto $\operatorname{com} f_{c}=40 \mathrm{MPa}$ e diferentes aberturas de fissura, obtidas adotando as expressões simplificadas de Walraven \& Reinhardt (1981) e do FIB MC 2010 (2013), com $C_{f}=1$,0, e também as relativas ao modelo de duas fases de Walraven \& Reinhardt (1981), com $d_{\max }=16 \mathrm{~mm}, p_{k}=0,75 \mathrm{e}$ $f_{c}=40 \mathrm{MPa}$. Nela evidencia-se a equivalência entre as expressões simplificadas quando $C_{f}=1,0$ e que, para um par de valores de $\Delta$ e $w$, os de $\sigma$ e $\tau$ dados por essas expressões podem diferir consideravelmente daqueles obtidos com o modelo de duas fases. 


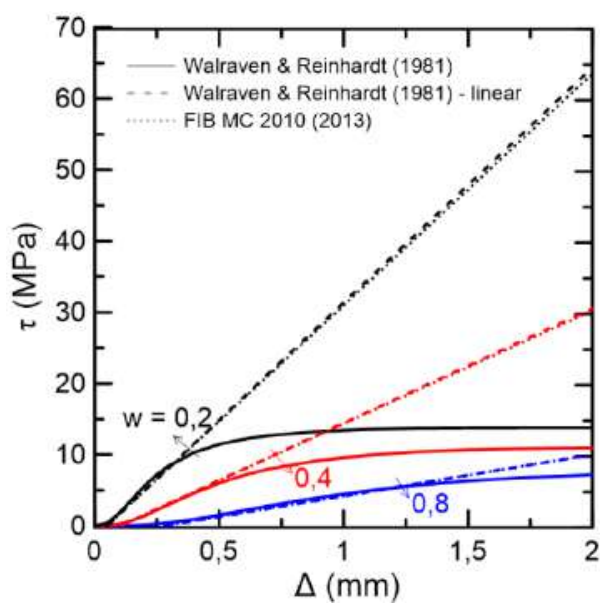

(a)

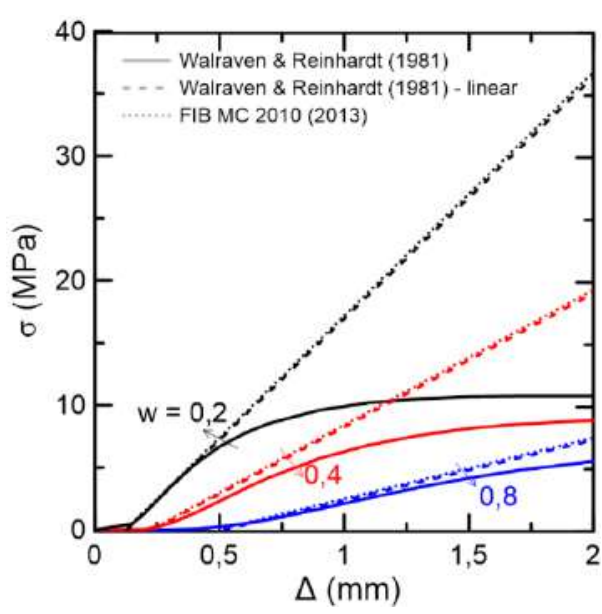

(b)

Figura 2.36 - Curvas (a) tensão cisalhante - deslizamento na fissura e (b) tensão normal - deslizamento na fissura de acordo com o modelo de duas fases e linear de Walraven \& Reinhardt (1981) e a expressão do FIB MC 2010 (2013), com

$C_{f}=1$, para diferentes aberturas de fissura $w$ em $\mathrm{mm}$. Setas indicam curvas referentes à mesma abertura de fissura.

Bazant \& Gambarova (1980), em seu modelo de rugosidade de fissura, com

base em simplificações admitidas para a microrrugosidade das faces da fissura e em observações experimentais de diferentes investigações, principalmente a de Paulay \& Loeber (1974), e em condições que deveriam ser atendidas pelas relações entre tensões e deslocamentos nas fissuras, chegaram a equações para representá-las. Entre outras características dessas relações, constatou-se a influência de $r=\Delta / w$ na curva $\tau$ - $\Delta$ para um valor de $w$ constante; há aumento de $\tau$ até $r=1,2$, mantendo-se essa tensão constante para maiores valores de $r$. As equações propostas por esses autores para cálculo de $\sigma$ e $\tau$ dependem de $w, \Delta, r, f_{c}$, e $d_{\text {max }}$ :

$$
\begin{aligned}
& \sigma=\frac{a_{1}}{w}\left(a_{2} \tau\right)^{p} \\
& \tau=\tau_{\mathrm{u}} r \frac{a_{3}+a_{4}|r|^{3}}{1+a_{4} r^{4}}
\end{aligned}
$$

onde as unidades são $\mathrm{N}$ e mm e:

$$
p=1,3\left(1-\frac{0,231}{1+0,185 w+5,63 w^{2}}\right)
$$




$$
\begin{aligned}
& \tau_{\mathrm{u}}=\frac{\tau_{0} a_{0}}{a_{0}+w^{2}} ; \quad \tau_{0}=0,245 f_{c} ; \quad r=\frac{\Delta}{w} \\
& a_{0}=0,01 d_{\text {máx }}^{2} ; \quad a_{1}=0,000534 ; \quad a_{2}=145 ; \quad a_{3}=\frac{2,45}{\tau_{0}} ; \quad a_{4}=2,44\left(1-\frac{4}{\tau_{0}}\right)
\end{aligned}
$$

Posteriormente, Gambarova \& Karakoç (1983), valendo-se de uma base de resultados experimentais maior, refinaram o modelo de Bazant \& Gambarova (1980), introduzindo modificações nas relações entre $\sigma, \tau, \Delta$ e $w$ para melhor representá-las. Para a situação em que $w>0,5 d_{\max }$, foi considerado que não há mais contato entre as faces da fissura. As equações 2.51 e 2.52 foram modificadas para:

$$
\begin{aligned}
& \sigma=a_{1} a_{2} \sqrt{w} \frac{r}{\left(1+r^{2}\right)^{0,25}} \tau \\
& \tau=\tau_{0}\left(1-\sqrt{\frac{2 w}{d_{\text {máx }}}}\right) r \frac{a_{3}+a_{4}|r|^{3}}{1+a_{4} r^{4}}
\end{aligned}
$$

com:

$$
a_{1} a_{2}=0,62 ; \quad a_{3}=\frac{2,45}{\tau_{0}} ; \quad a_{4}=2,44\left(1-\frac{4}{\tau_{0}}\right) ; \quad \tau_{0}=(0,25 a 0,30) f_{c}
$$

onde as unidades são $\mathrm{N}$ e mm.

As curvas tensão - deslizamento para diferentes aberturas na fissura obtidas adotando as equações propostas por Bazant \& Gambarova (1980) e Gambarova \& Karakoç (1983), para um concreto de $f_{c}=40 \mathrm{MPa}$ e $d_{\max }=16 \mathrm{~mm}$, podem ser vistas na Figura 2.37. Elas mostram que, dependendo de $w$ e $\Delta$, os dois grupos de equações podem fornecer valores de $\tau$ e $\sigma$ próximos ou não, havendo tendência de maior concordância entre os valores de $\tau$ do que entre os de $\sigma$. 


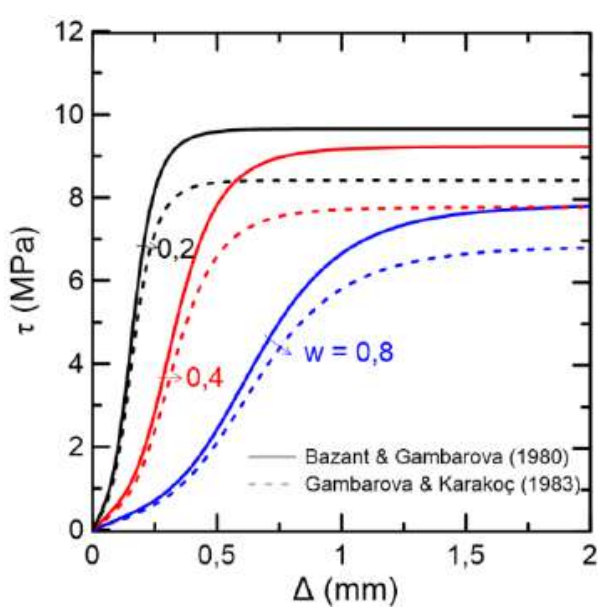

(a)

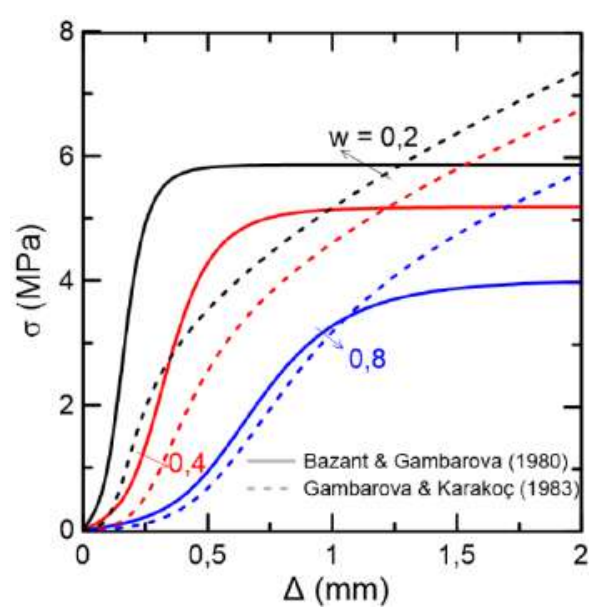

(b)

Figura 2.37 - Curvas (a) tensão cisalhante - deslizamento na fissura e (b) tensão normal - deslizamento na fissura de acordo com Bazant \& Gambarova (1980) e Gambarova \& Karakoç (1983), para diferentes aberturas de fissura $w$ em mm.

Setas indicam curvas relativas à mesma abertura de fissura.

\subsubsection{4 \\ Modelo para concretos com fibras}

Matos et al. (2020) propuseram um modelo constitutivo para o caso de concretos com fibras, em que as parcelas de engrenamento dos agregados e a das fibras são combinadas.

Para a contribuição de engrenamento dos agregados, foram considerados os modelos de densidade de contato de Li \& Maekawa (1987) ( $\sigma$ e $\tau$, eq. 2.44 e 2.45, respectivamente) e o de rugosidade de fissura modificado de Gambarova \& Karakoç (1983) ( $\sigma$ e $\tau$, eq. 2.53 e 2.54, respectivamente). Para a parcela das fibras $\left(\sigma_{\mathrm{fn}}\right)$, foram testados três modelos de arrancamento: de Pfyl (2003), Htut (2010) e Lee et al. (2010). A resistência à tração residual da matriz do concreto $\left(\sigma_{\text {res }}\right)$ foi levada em consideração pela equação apresentada em Voo \& Foster (2003).

O equacionamento proposto considerou a decomposição dessas tensões nas direções normal e paralela ao plano de fissura, conforme ilustra a Figura 2.38. Deste modo, as equações finais de tensão normal $\left(\sigma_{\text {tot }}\right)$ e tangencial $\left(\tau_{\text {tot }}\right)$ no plano de cisalhamento são definidas como: 


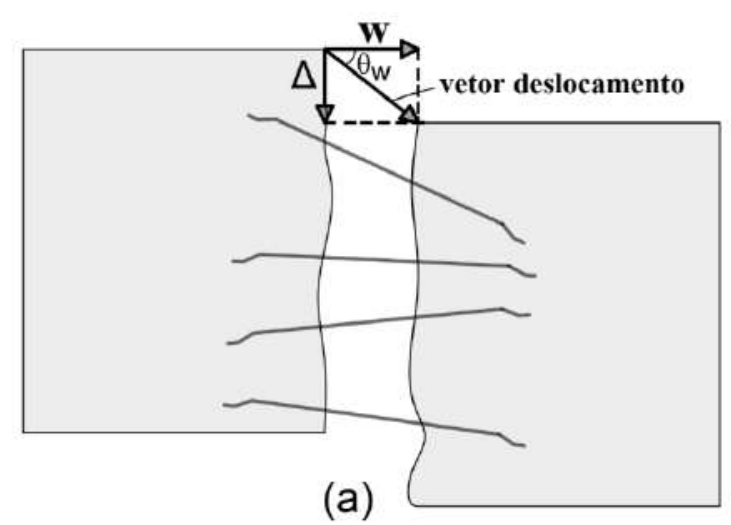

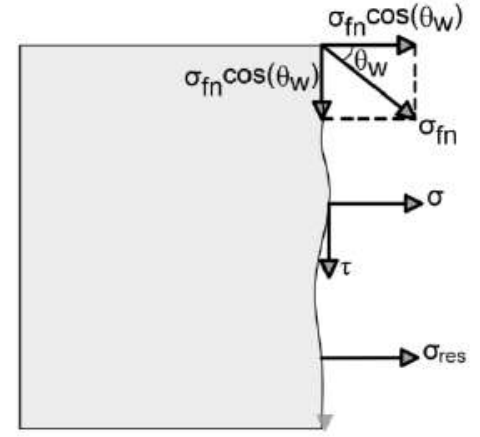

(b)

Figura 2.38 - Esquema do modelo: (a) idealização da fissura e representação da cinemática da fissura; (b) representação simplificada dos mecanismos resistentes na superfície de cisalhamento.

$$
\begin{aligned}
& \sigma_{t o t}=\sigma_{f n} \cos \theta_{w}+\sigma+\sigma_{r e s} \\
& \tau_{t o t}=\sigma_{f n} \operatorname{sen} \theta_{w}+\tau
\end{aligned}
$$

\section{Onde:}

$\theta_{\mathrm{w}}$ é o ângulo entre a direção normal ao plano de cisalhamento e o vetor de deslocamento entre as faces da fissura, ou seja,

$$
\theta_{w}=\operatorname{arctg}\left(\frac{\Delta}{w}\right)
$$

Para avaliar os modelos de engrenamento dos agregados e de arrancamento de fibras adotados e validar os equacionamentos propostos (eq. 2.55 e eq. 2.56), diferentes combinações de modelos foram aplicadas nessas equações, comparandose os resultados obtidos com os experimentais de Khanlou et al. (2012), Soltanzadeh et al. (2015) e Soetens \& Matthys (2017).

O equacionamento proposto mostrou ser capaz de capturar razoavelmente as tensões de cisalhamento e normal máximas experimentais, mas não o comportamento pós-fissuração (exemplo na Figura 2.39). Os melhores ajustes ocorreram com a adoção dos modelos de engrenamento dos agregados e de fibras de Gambarova \& Karakoç (1983) e Pfyl (2003), respectivamente. Os autores atribuiram a inconsistência na previsão do comportamento pós-fissuração ao fato dos modelos de engrenamento dos agregados terem sido originalmente desenvolvidos para o caso de concretos sem fibras, nos quais os deslocamentos relativos entre as faces da fissura atingidos são menores. 
Para levar isso em consideração e representar um comportamento pósfissuração mais realista, os autores propuseram a consideração de um coeficiente de degradação do engrenamento dos agregados com o aumento dos deslocamentos. As equações dos modelos originais foram multiplicadas por um coeficiente definido por uma função Gompertz (tipo de função sigmoide), onde seus parâmetros foram ajustados baseando-se nos resultados experimentais adotados. Com esta modificação, o comportamento pós-fissuração previsto ficou mais próximo do experimental, independentemente do modelo de engrenamento dos agregados utilizado (exemplo na Figura 2.39).

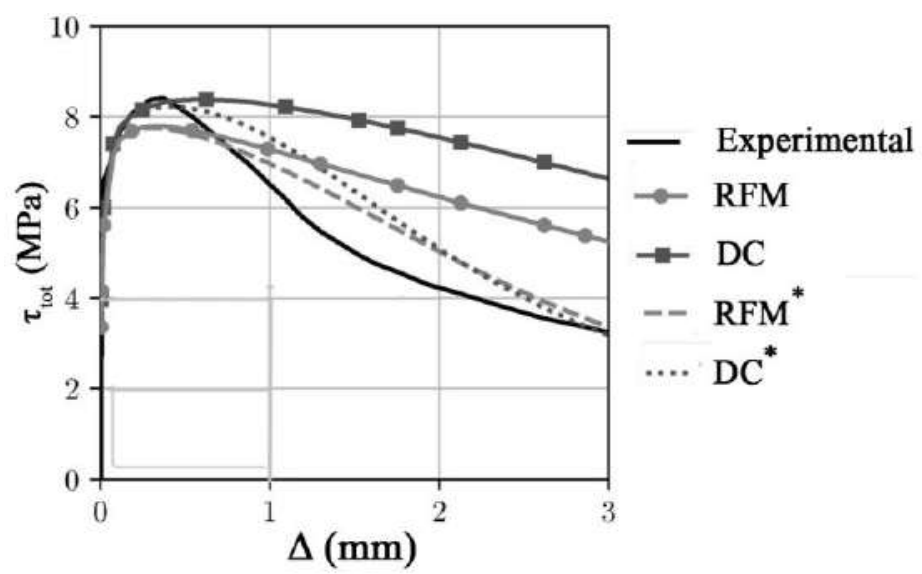

Figura 2.39 - Comparação entre a curva experimental para espécime com $V_{f}=1 \%$ de Khanlou et al. (2012) e as previstas pelo modelo de Matos et al. (2020) adotando para o engrenamento dos agregados os modelos de densidade de contato (DC) e de rugosidade de fissura modificados (RFM), sem e com (*) coeficiente de degradação. Adaptado de Matos et al. (2020).

\subsection{3}

\section{Resistência à tração residual do concreto}

Este mecanismo resistente está associado à capacidade residual do concreto de transmitir tensões de tração no estado fissurado até uma determinada abertura de fissura (Hilleborg et al., 1976). Ao ser atingida a resistência à tração do concreto e iniciar-se a formação de fissura, há uma queda da capacidade resistente até que $w=w_{c r}$, quando ela se torna nula. A região onde há queda da capacidade resistente à tração do concreto, denominada de zona de processos de fratura (ZPF), é ilustrada na Figura 2.40. A área sob o gráfico $\sigma_{\text {res }}$ versus $w$ visto nessa figura representa a energia de fratura $\left(G_{F}\right)$, que é a energia necessária para propagar uma fissura por unidade de área. 


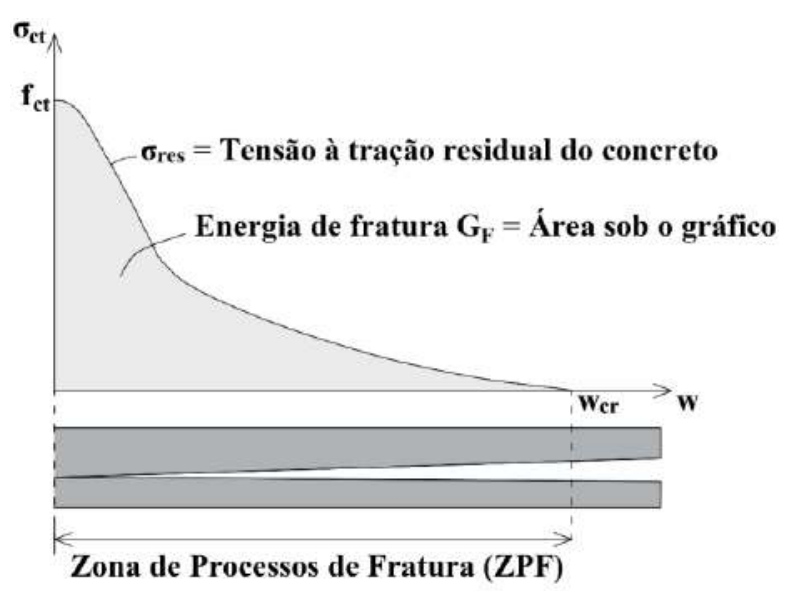

Figura 2.40 - Tensão à tração residual do concreto em função da abertura de fissura.

Quando da ruptura de vigas de concreto armado por força cortante, a ZPF é desenvolvida na região superior da fissura crítica e a contribuição da tensão residual à tração nessa zona para a resistência ao cortante nem sempre é considerada. Yang (2014), por exemplo, desconsiderou essa parcela no procedimento proposto para avaliar a resistência à força cortante de vigas de concreto armado sem estribos, que leva em conta o somatório de parcelas referentes aos mecanismos resistentes, com a justificativa dela ser desprezível. Entretanto, estudos recentes que adotaram a técnica de correlação de imagem digital para obtenção dos campos de deslocamentos mostraram que essa contribuição pode ser relevante em vigas sem estribos; no estudo de Huber et al. (2016) verificou-se contribuição de $18 \%$ a $38 \%$ de $V_{u}$ e no de Cavagnis et al. (2018a) até $32 \%$ de $V_{u}$.

A relação experimental entre tensão de tração residual e abertura de fissura deveria ser obtida por meio de ensaios de tração direta, mas, em decorrência da sua dificuldade de execução, ela costuma ser determinada indiretamente a partir de ensaios de tração na flexão (EN 14651, 2005; RILEM TC 162-TDF).

$\mathrm{Na}$ falta de ensaios, existem diferentes propostas para relacionar a tensão de tração residual com a abertura de fissura; na Quadro 2.2 encontram-se as de Reinhardt (1984), Hordijk (1992) e FIB MC 2010 (2013). Delas, a de Hordijk (1992) é a que tem sido adotada em trabalhos mais recentes sobre o comportamento à força cortante de vigas de concreto via análise de seus mecanismos resistentes (Campana et al., 2013, Huber et al., 2016; Cavagnis et al., 2018a).

No exemplo de aplicação dessas relações para um concreto de $f_{c}=40 \mathrm{MPa}$ apresentado na Figura 2.41, $\operatorname{com} f_{c t}$ e energia de fratura $G_{F}$ estimados de acordo com o FIB MC 2010 (2013), pode-se observar a proximidade das curvas da tensão 
residual em função da abertura de fissura e das de abertura de fissura crítica em função da resistência à compressão do concreto de Hordijk (1992) e FIB MC 2010 (2013).

Vale observar que há propostas de relação entre tensão de tração residual e abertura de fissura mais simples, definidas por uma única reta, como a de Hillerborg et al. (1976), que considera $w_{c r}$ entre $0,01 \mathrm{~mm}$ e $0,02 \mathrm{~mm}$. Esta faixa de valores para $w_{c r}$, a que consta em ACI 445R-99 (ACI, 1999), que é entre 0,05 mm e 0,15 mm, e a mostrada na Figura 2.41b, bem como a diferença entre as curvas da Figura 2.41a, evidenciam a falta de consenso sobre o assunto.

Quadro 2.2 - Equações de tensão residual de tração em função da abertura de fissura de Reinhardt (1984), Hordijk (1992) e FIB MC 2010 (2013).

\section{Reinhardt (1984)}

$$
\sigma_{\mathrm{res}}=f_{c t}\left[1-\left(\frac{w}{w_{c r}}\right)^{0,31}\right]
$$

$w_{c r}=4,226 \frac{G_{F}}{f_{c t}}$

\section{Hordijk (1992)}

$\sigma_{\text {res }}=f_{c t}\left\{\left[1+\left(3 \frac{w}{w_{c r}}\right)^{3}\right] e^{-6,93\left(w / w_{c r}\right)}-0,0274 \frac{w}{w_{c r}}\right\}$

$w_{c r}=5,14 \frac{G_{F}}{f_{c t}}$

FIB MC 2010 (2013)

$\sigma_{\text {res }}=f_{c t}\left(1-0,8 \frac{w}{w_{1}}\right)$ para $w \leq w_{1}$

eq. $(2.59 \mathrm{a})$

$\sigma_{\text {res }}=f_{c t}\left(0,25-0,05 \frac{w}{w_{1}}\right)$ para $1<w \leq w_{1}$

$w_{1}=\frac{G_{F}}{f_{c t}} \quad w_{c r}=5 \frac{G_{F}}{f_{c t}} \quad G_{F}=0,073 f_{c}^{0,18}$

$\sigma_{\text {res }}$ é a resistência à tração residual do concreto, $w$ é a abertura de fissura, $G_{F}$ é a energia de fratura do concreto. Unidades: $\mathrm{N}$ e $\mathrm{mm}$. 


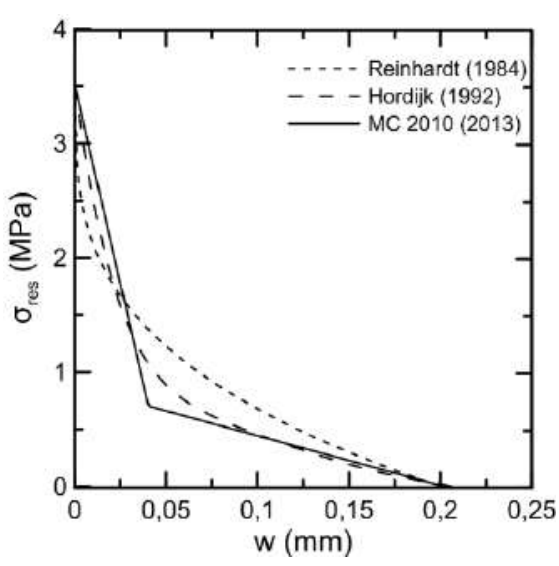

(a)

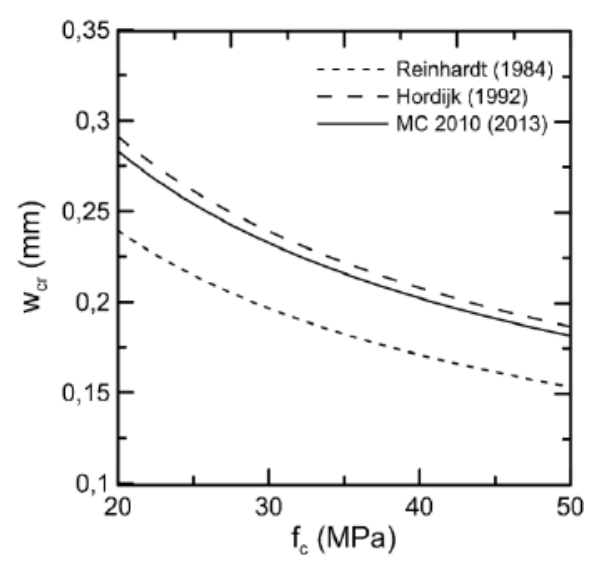

(b)

Figura 2.41 - (a) Curvas tensão residual de tração - abertura de fissura para concreto $\operatorname{com} f_{c}=40 \mathrm{MPa}$ e (b) Curvas abertura de fissura crítica - resistência à compressão do concreto; de acordo com Reinhardt (1984), Hordijk (1992) e FIB

MC 2010 (2013). Valores de $f_{c t}$ e $G_{F}$ calculados de acordo com FIB MC 2010 (2013).

\subsection{4}

\section{Concreto comprimido não fissurado}

Este mecanismo representa a capacidade de transmissão de força cortante na região de concreto comprimido não fissurado acima da fissura diagonal crítica. A contribuição desse mecanismo para a resistência à força cortante de vigas não tem sido objeto de muitas investigações. Com o advento da técnica de correlação de imagem digital para aquisição dos campos de deslocamentos e deformações da superfície lateral de vigas de concreto armado submetidas a força cortante, acreditase haver possibilidade de melhor investigar esse mecanismo, embora haja ainda alguns desafios com relação à acurácia dos resultados obtidos (ver item 2.3).

Uma das maneiras de avaliar a parcela $V_{c z}$ é a partir de uma distribuição de tensão cisalhante admitida ao longo da altura da seção. Mörsch (1909), considerando a seção no estádio II e comportamento elástico-linear do concreto e desprezando a resistência à tração do concreto, chegou à distribuição parabólica acima da linha neutra e constante abaixo dela (Figura 2.42). 


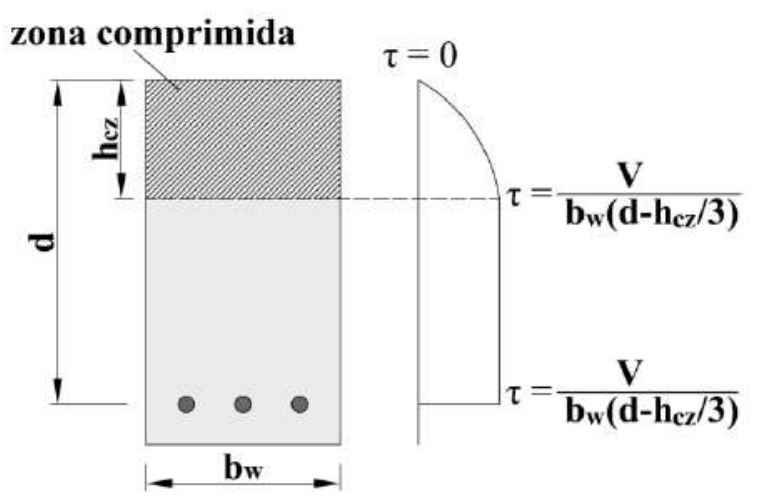

Figura 2.42 - Distribuição da tensão de cisalhamento na seção transversal de acordo com Mörsch (1909).

A partir dessa distribuição, chega-se a

$$
V_{c z}=\frac{2}{3} \frac{h_{c z}}{\left(d-\frac{h_{c z}}{3}\right)} V
$$

Embora tipos de distribuição de tensão cisalhante um pouco diferentes do de Mörsch (1909) tenham sido propostos posteriormente (Hamadi \& Regan, 1980, por exemplo), ele ainda é considerado adequado e capaz de levar a boa estimativa de $V_{c z}$ (Sherwood, 2008).

Taylor (1974) adotou um método semi-empírico para avaliar a distribuição de tensão cisalhante na região comprimida e a parcela $V_{c z}$, que foi posteriormente usado por outros autores, como Sarkar et al. (1999) e Sherwood (2008). Em vigas de concreto armado por ele ensaiadas foram colados extensômetros elétricos na direção longitudinal, em seções no entorno da de carregamento e em diferentes níveis da região comprimida (exemplo na Figura 2.43), e, admitindo relação linear entre tensões normais e deformações específicas, a partir das deformações específicas medidas e da equação 2.61, chegou à tensão cisalhante em cada nível e, por integração dessa tensão na área comprimida, à contribuição para a resistência à força cortante $V_{c z}$.

$$
\tau_{\mathrm{cz}}=\int_{0}^{y} \frac{\delta \sigma}{\delta \mathrm{M}} \frac{\delta \mathrm{M}}{\delta \mathrm{x}} d y
$$

Nessa equação, $\tau_{c z}$ é a tensão de cisalhamento na altura $y$ a partir do bordo comprimido; $\sigma$ é a tensão normal na direção longitudinal e $M$ é o momento fletor 
na seção transversal distante $x$ do apoio. Em cada nível onde medem-se deformações específicas, obtem-se $\frac{\delta \varepsilon}{\delta \mathrm{M}}$ e, consequentemente, $\frac{\delta \sigma}{\delta \mathrm{M}}$ e também a força cortante total $\frac{\delta \mathrm{M}}{\delta \mathrm{X}}$.

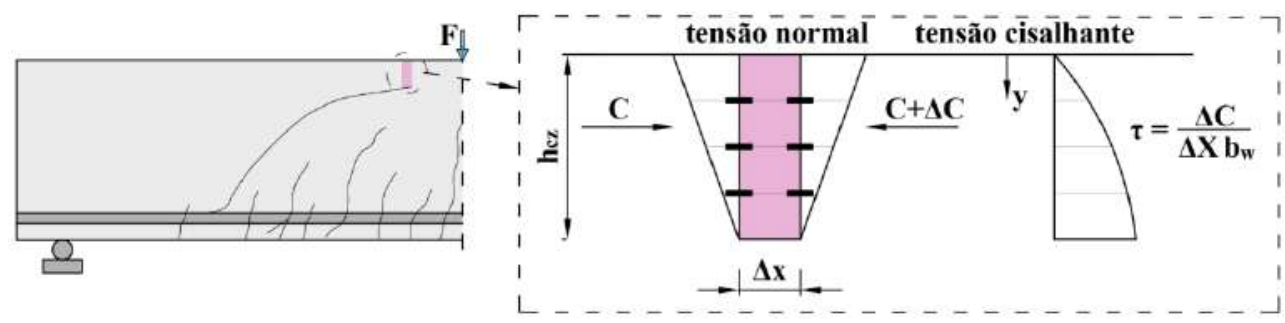

Figura 2.43 - Distribuições de tensão normal, obtidas de deformações específicas medidas na zona comprimida da viga, e de tensão cisalhante, determinada a partir das de tensão normal.

Sherwood (2008), em um dos espécimes de seu programa experimental de maiores dimensões, onde foi possível medir deformações específicas em maior número de níveis na região acima da fissura crítica, encontrou $V_{c z}=0,24 V_{u}$, enquanto o valor de $V_{c z}=0,21 V_{u}$ seria obtido segundo o método de Mörsch (1909). Daí concluiu-se que a clássica teoria de Mörsch (1909) leva a bons resultados mesmo para situações próximas da de ruptura.

Em vigas ensaiadas por Cavagnis (2018a), a parcela $V_{c z}$ foi avaliada na região acima do final da fissura crítica, a partir das deformações específicas principais obtidas usando correlação de imagem digital da superfície lateral das vigas. As tensões principais foram consideradas como tendo a mesma direção das deformações principais e seus valores foram determinados a partir das equações constitutivas do concreto. A integração da tensão cisalhante na zona comprimida levou a $V_{c z}$.

As tensões principais de tração foram calculadas assumindo comportamento elástico-linear até tensão igual à resistência à tração $\left(\sigma_{1}=E_{c} \varepsilon_{1}\right.$ para $E_{c} \varepsilon_{1} \leq f_{c t}$; caso contrário, $\sigma_{1}=0$ ) e as de compressão a partir das relações tensão-deformação de Ruiz et al. (2007) mostradas na Figura 2.44a e dadas pela equação 2.62.

$$
\sigma_{2}=\frac{E_{c} \varepsilon_{2}}{1+\left(\frac{\varepsilon_{2}}{\varepsilon_{0}}\right)^{\alpha}}
$$

$$
\text { Com: } \varepsilon_{0}=\frac{\alpha f_{c, e f}}{E_{c}(\alpha-1)^{\left(1-\frac{1}{\alpha}\right)}} \text { e } \alpha=0,5+\frac{f_{c, e f}}{20}+\frac{f_{c, e f}^{2}}{1500}
$$


Nessa equação, $\sigma_{2}(\mathrm{MPa})$ e $\varepsilon_{2}$ são a tensão e a deformação principal de compressão, respectivamente; $f_{c, e f}(\mathrm{MPa})$ é a resistência à compressão do concreto levando em consideração o estado biaxial de tensão e a simplificação bilinear do critério de ruptura de Mohr-Coulomb adotando ângulo de atrito igual a $37^{\circ}$ (Figura 2.44b).

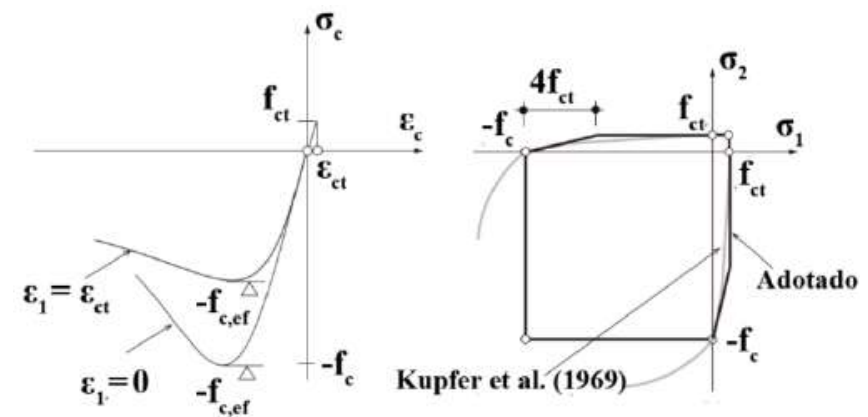

(a)

(b)

Figura 2.44 - (a) Curvas tensão normal-deformação específica do concreto adotadas (Ruiz et al., 2007); (b) Superfícies de ruptura de Kupfer et al. (1969) e considerada. Adaptado de Cavagnis (2018a).

Para as vigas onde observou-se fissuração na zona comprimida (não associada à fissura crítica), a resistência à tração foi desconsiderada e adotado $\mathrm{f}_{\mathrm{c}, \mathrm{ef}}$ conforme proposto por Vecchio \& Collins (1986):

$$
f_{c, e f}=f_{c} \frac{1}{0,8+170 \varepsilon_{1}} \leq f_{c}
$$

onde $\varepsilon_{1}$ é a deformação principal de tração.

Cavagnis et al. (2018b), considerando os resultados de seus ensaios e os constantes de um banco de dados de vigas esbeltas e assumindo a distância entre o eixo do apoio e a seção onde a fissura crítica passa pela armadura longitudinal de tração igual a $0,5 a$ (Figura 2.45), concluiram que a contribuição da parcela $V_{c z}$ depende da relação $r_{f} / h_{c z}$, sendo $r_{f}$ a distância horizontal entre o topo da fissura crítica e o eixo de aplicação de carga e $h_{c z}$ a altura da zona comprimida medida (Figura 2.45). Os valores de $V_{c z} / V_{R}$ em função de $r_{f} / h_{c z}$ vistos no gráfico da Figura 2.45 indicam que $V_{c z}$ não passa de cerca de $20 \%$ de $V_{R}$. 

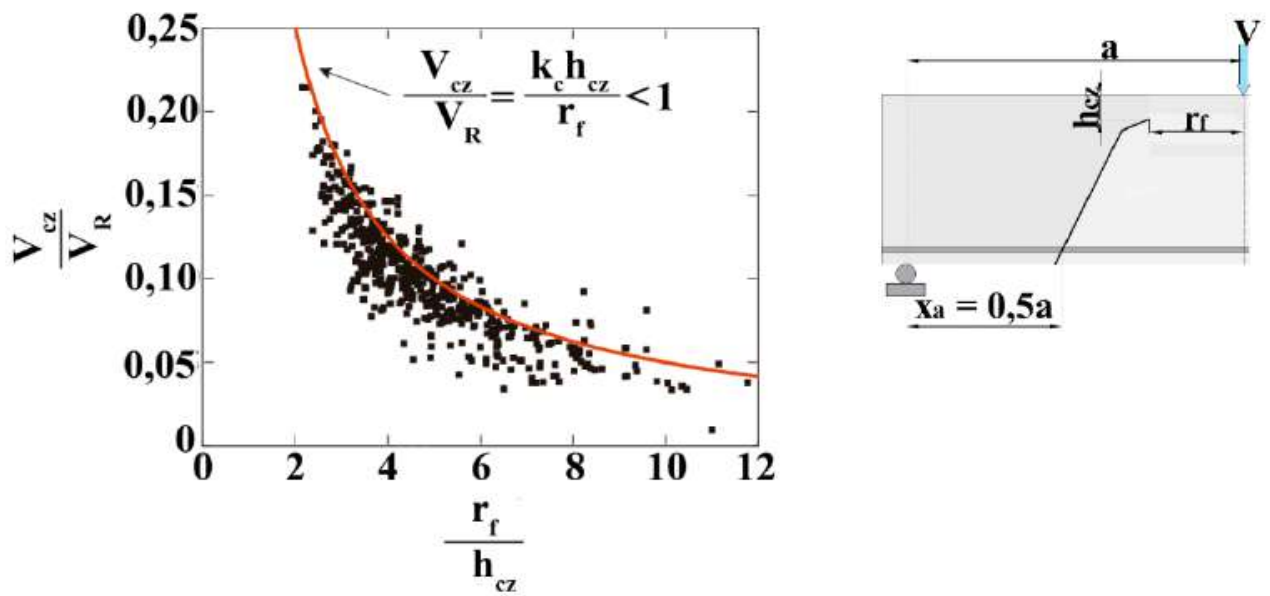

Figura 2.45 - Relação $V_{c z} / V_{R}$ em função de $r_{f} / h_{c z}$ para as 629 vigas analisadas, considerando a distância entre o apoio e o encontro da fissura crítica com a armadura longitudinal igual a $0,5 a$. Parâmetro $k_{c}=0,5$ obtido a partir dos resultados experimentais. Adaptado de Cavagnis et al. (2018b).

A principal influência da adição de fibras de aço na parcela $V_{c z}$ parece estar associada à maior altura da zona comprimida $\left(h_{c z}\right)$ que no caso de vigas de concreto sem fibras para uma determinada solicitação. Isto decorre do retardamento do aumento do comprimento e da abertura das fissuras causado pelas fibras (Lantsoght, 2019; Zarrinpour \& Chao, 2017 - ver item 2.3.3, p. 86).

\section{3 \\ Cinemática da fissura diagonal crítica: Investigações experimentais sobre obtenção de deslocamentos entre faces de fissuras utilizando CID e de parcelas referentes a mecanismos resistentes à força cortante de vigas de concreto}

Neste item são resumidos seis trabalhos encontrados na literatura que focaram na obtenção de deslocamentos entre faces de fissuras usando correlação de imagem digital e, a partir desses deslocamentos, de parcelas relativas a diferentes mecanismos resistententes à força cortante de vigas sem e com fibras de aço. Desses trabalhos, apenas um englobou vigas com fibras de aço.

Para auxiliar no entendimento da técnica de correlação de imagem digital, no apêndice A são apresentadas algumas informações básicas sobre esta técnica. 


\subsection{1}

\section{Hoult et al. (2016)}

Hoult et al. (2016) apresentaram discussão sobre a influência da curvatura de vigas na obtenção dos deslocamentos entre as faces de fissuras por meio de CID e propuseram método para minimizar essa influência.

Para determinar a abertura e o deslizamento entre as faces da fissura são selecionados subsets de cada lado da fissura, como mostrado na Figura 2.46, mas, em elementos com curvatura, a influência da curvatura na determinação desses deslocamentos pode não ser desprezível.

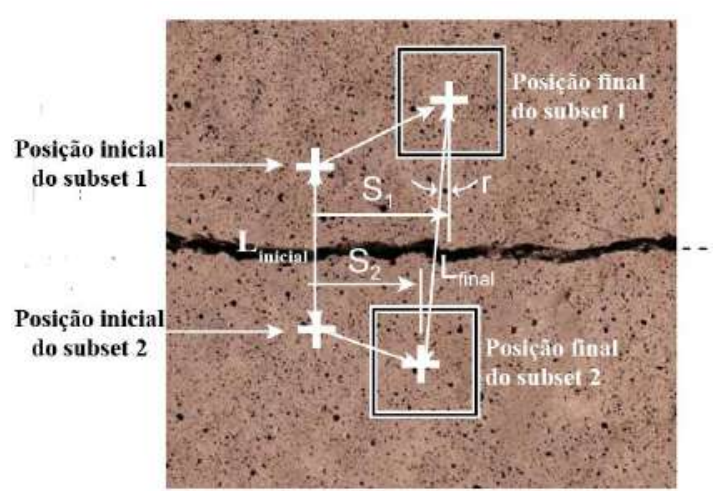

$$
\begin{gathered}
w=L_{\text {final }} \cos r-L_{\text {inicial }} \\
\Delta=S_{2}-S_{1}
\end{gathered}
$$

Figura 2.46 - Determinação de deslocamentos entre faces de fissura a partir de subsets nessas faces. Adaptado (Hoult et al., 2016).

Na Figura 2.47 está representado trecho de viga antes e depois de ser submetido a flexão pura, com os pares de subsets $A-A^{\prime}$ e $B-B^{\prime}$ posicionados em direção perpendicular a um plano inicialmente vertical. Observam-se nessa figura os deslocamentos verticais $S_{A}$ e $S_{B}$ após a flexão, cuja diferença, no caso de aparecimento de uma fissura de flexão, corresponderá a um "deslizamento" não associado a movimentos entre as faces de fissura, mas sim à curvatura da viga decorrente da flexão.

Para eliminar esse efeito no cálculo do deslizamento entre as faces de fissura e obter o deslizamento efetivo, esses autores propuseram adotar duas linhas de subsets de cada lado da fissura (1, 2 e 3, 4 mostradas na Figura 2.47), em vez de apenas uma (2 e 3). Em não havendo fissura entre os planos 1 e 2 e os 3 e 4, qualquer deslocamento relativo medido entre eles é decorrente apenas da curvatura. Pode-se, portanto, obter os deslizamentos aparentes entre os planos 1 e 2 e os 3 e 4 e a média de seus valores é o deslocamento referente à curvatura entre os planos 2 e 3. Finalmente, subtraindo-se este deslocamento relativo do deslocamento relativo 
total determinado entre os planos 2 e 3 , chega-se ao deslizamento real entre as faces da fissura. Embora com a curvatura se tenha alteração nas distâncias entre os subsets $A-A^{\prime}$ e $B-B^{\prime}$, o que leva também a uma influência na abertura de fissura medida, segundo Hoult et al. (2016), ela pode ser desconsiderada devido à ordem de grandeza dessa influência em relação à da abertura da fissura.

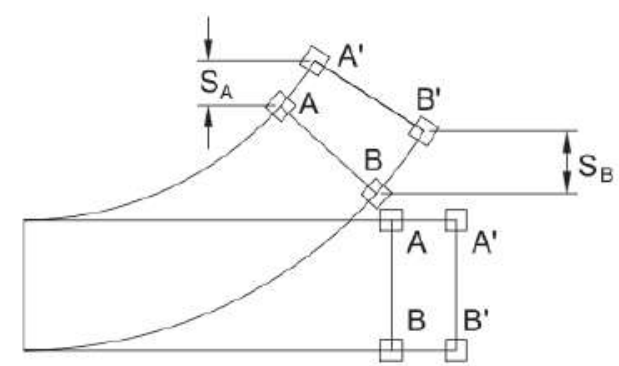

(a)

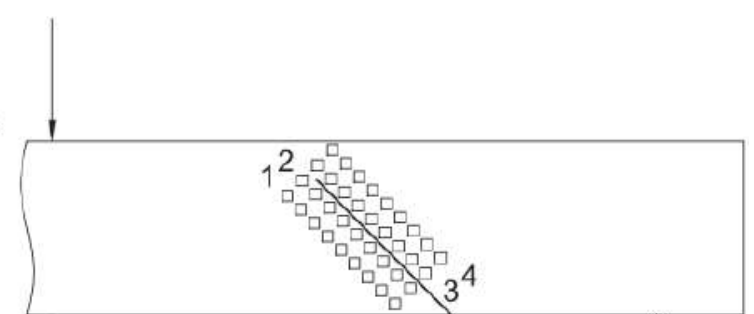

(b)

Figura 2.47 - (a) Deslocamento vertical entre os subsets A-A' e B-B' devido à curvatura da viga: $S_{B}-S_{A}$; (b) Uso de duas linhas de pontos em cada lado da fissura para poder eliminar o efeito da curvatura. Adaptado de Hoult et al. (2016)

Os autores desenvolveram também um programa experimental de 6 vigas ensaiadas à flexão por quatro pontos divididas em dois grupos: (1) com deslizamento muito pequeno em relação à abertura de fissura - ruptura por flexão; (2) deslizamento da mesma ordem de grandeza da abertura de fissura - ruptura por força cortante. Detalhes dos ensaios dessas vigas podem ser encontrados na tese de Dutton (2012), um dos autores do artigo de Hoult et al. (2016).

Uma viga de cada um desses grupos teve a cinemática da fissura de ruptura avaliada. Para carga próxima da de ruptura da viga do grupo (1), sem a consideração do efeito da curvatura encontrou-se deslizamento em torno de $0,35 \mathrm{~mm}$, maior que a abertura, enquanto ao considerar esse efeito o deslizamento passou a ficar próximo de zero. Para a viga do grupo (2), com a consideração do efeito da curvatura, encontrou-se abertura de fissura maior que o deslizamento, mas da mesma ordem de grandeza.

\subsection{2}

\section{Huber et al. (2016)}

Huber et al. (2016) desenvolveram um programa experimental de 20 vigas de concreto armado sem e com estribos com o acompanhamento da cinemática da diagonal crítica. A associação dos dados obtidos com equações existentes na 
literatura levou à avaliação da contribuição dos diferentes mecanismos resistentes à força cortante das vigas por eles ensaiadas.

Todas as vigas tiveram o esquema de ensaio à flexão por três pontos com carga aplicada no centro do vão e com dimensões de modo a obter a relação $a / d=3,04$. As vigas tiveram $\rho \approx 1,2 \%$ (uma camada com 4 barras) e as com estribos tiveram a taxa de armadura transversal mínima de acordo com o FIB MC 2010 (2013). As variáveis dos ensaios foram: tipo de seção transversal (retangular "R" ou " $T$ " com mesa tendo largura $b_{f}$ igual a 2 vezes a da alma $b_{w}$ e altura igual a $b_{f} / 3$ - T), largura de alma (75 mm a $300 \mathrm{~mm})$, altura da seção transversal (250 mm a $1000 \mathrm{~mm}$ ), tipo de concreto (vibrado com $d_{\max }=22 \mathrm{~mm}-\mathrm{CV}-$ ou autoadensável $\operatorname{com} d_{\max }=16 \mathrm{~mm}-\mathrm{CAA}$ ) e sua resistência (CAA: $51 \mathrm{MPa}$ a $61 \mathrm{MPa}$; CV: $30 \mathrm{MPa}$ a $38 \mathrm{MPa}$ ). Na Tabela 2.2 apresentam-se apenas dados das vigas sem estribos, que são o foco deste trabalho.

As vigas sem estribos tiveram ruptura frágil, com a fissura diagonal crítica se estendendo até a região comprimida e incipiente fissura ao longo da armadura longitudinal (fendilhamento).

Para análise dos deslocamentos entre as faces da fissura diagonal crítica, esta fissura foi idealizada como sendo composta por vários segmentos de reta com comprimento aproximado de 45 pixels, para os quais foi determinada a inclinação com relação ao eixo longitudinal da viga. Consideraram-se cerca de 50 pontos ao longo da fissura para determinar a abertura e deslizamento entre suas faces ao longo do ensaio. Por conta da acurácia desejada, a dimensão horizontal do campo de medições foi limitada a $1,2 \mathrm{~m}$, o que implicou na impossibilidade de obter a cinemática em todo comprimento da fissura de algumas vigas.

A fissura diagonal crítica das vigas $\mathrm{R}(300 \times 1000), \mathrm{T}(150 \times 500)$ e T(300x1000) se desenvolveu a partir de várias fissuras e uma taxa maior de aquisição de dados teria sido necessária para detectar o instante em que elas se juntaram para formar a fissura crítica.

A partir dos deslocamentos relativos ao longo da fissura diagonal crítica e de equações disponíveis foram obtidas as parcelas resistentes à força cortante. Para a do efeito de pino, adotou-se a equação de Baumann \& Rüsch (1970); a parcela referente ao engrenamento dos agregados foi avaliada considerando quatro diferentes equações: linear de Walraven (1980), duas fases de Walraven \& Reinhardt (1981), Gambarova \& Karakoç (1983) e de FIB MC 2010 (2013); e a 
correspondente à tensão de tração residual na zona de processamento de fratura foi obtida com a equação de Hordijk (1992), adotando energia da fratura $G_{F}$ determinada conforme Marí et al. (2014). Devido ao tamanho de imagem escolhido, as medições obtidas não tinham acurácia suficiente para interpretação do estado de deformações da região comprimida não fissurada, o que impediu a obtenção da parcela resistente relativa a essa região, sendo ela, então, desprezada.

As parcelas de mecanismos resistentes $\left(V_{i}\right)$ obtidas para a força cortante última $\left(V_{u}\right)$ e para a força cortante correspondente à última imagem registrada antes da propagação instável da fissura ( $V_{I p} \leq V_{u}$, ramo descendente) estão listadas na Tabela 2.2, assim como os valores de $V_{u}$ e $V_{I p}$. Nela nota-se que os valores da parcela de engrenamento dos agregados dados por diferentes equações podem diferir bastante, podendo ser mesmo maiores que $V_{u}$, e que a de Gambarova \& Karakoç (1983) forneceu os maiores valores. Nessa tabela é dada também a relação $V_{u} / \Sigma V_{i}$ e $V_{I p} / \Sigma V_{i}$, tendo sido considerada na soma de $V_{i}$ a parcela do engrenamento dos agregados que consta na coluna 4 da tabela. Pode-se notar que $V_{u} / \Sigma V_{i}$ varia de 0,92 a 2,29 e $V_{I P} \curvearrowright V_{i}$ varia de 0,92 a 1,34

A contribuição dos diferentes mecanismos resistentes dependeu da forma da fissura diagonal crítica e dos deslocamentos relativos de suas faces. Fissuras com maior inclinação com relação ao eixo longitudinal das vigas tiveram relevantes deslizamentos, enquanto as com menor inclinação tiveram predominância de abertura.

A parcela relativa ao engrenamento dos agregados se mostrou relevante quando se considerou a força cortante $V_{I p}$. As contribuições do engrenamento dos agregados e da tensão residual do concreto mostraram efeito de escala e a influência da mesa das vigas em $V_{u}$ teve relação com a contribuição da tensão residual do concreto. A contribuição do efeito de pino da armadura longitudinal foi pequena, em face da largura de concreto no nível da armadura $\left(b_{n}\right)$ ser pequena. 
Tabela 2.2-Resumo de características e resultados das vigas de Huber et al. (2016).

\begin{tabular}{|c|c|c|c|c|c|c|c|c|c|c|c|}
\hline \multirow{2}{*}{$\begin{array}{c}\text { Viga } \\
\text { seção }\left(b_{w} \times h\right)\end{array}$} & \multicolumn{2}{|c|}{ Concreto } & \multirow{2}{*}{$\begin{array}{c}V_{u} \\
(\mathbf{k N})\end{array}$} & \multirow{2}{*}{$\begin{array}{r}V_{I p} \\
(\mathbf{k N}) \\
\end{array}$} & \multicolumn{7}{|c|}{ Mecanismos resistentes $V_{i}(\mathbf{k N})$ correspondente a $V_{u}$ ou $\left(V_{I p}\right)$} \\
\hline & Tipo & $f_{c}(\mathrm{MPa})$ & & & 1 & 2 & 3 & 4 & 5 & 6 & $V_{u} / \Sigma V_{i}\left(V_{I p} / \Sigma V_{i}\right)$ \\
\hline $\mathrm{R}(75 \times 250)$ & CAA & 58,10 & 19,6 & 19,6 & $4,1(5,4)$ & $5,3(9,2)$ & $26,7(27,0)$ & $12,7(13,0)$ & $6,1(5,5)$ & 2,4 & $0,92(0,94)$ \\
\hline $\mathrm{R}(75 \times 250)$ & $\mathrm{CV}$ & 37,90 & 16,0 & 15,2 & $0(13,7)$ & $0(12,3)$ & $5,1(21,2)$ & $0(12,0)$ & $5,0(2,5)$ & 2,0 & $2,29(0,92)$ \\
\hline $\mathrm{R}(150 \times 500)$ & CAA & 58,10 & 67,2 & & & & & & & & \\
\hline $\mathrm{R}(150 \times 500)$ & $\mathrm{CV}$ & 36,00 & 72,4 & 66,9 & $4,6(27,8)$ & $0(25,2)$ & $23,8(54,3)$ & $24,8(29,1)$ & $13,1(12,7)$ & 8,0 & $1,58(1,34)$ \\
\hline $\mathrm{R}(300 \times 1000)$ & CAA & 60,30 & 214,5 & 204 & $154(254)$ & $248(442)$ & $464(656)$ & $206(229)$ & $0(0)$ & 38 & $0,88(0,76)$ \\
\hline $\mathrm{R}(300 \times 1000)$ & $\mathrm{CV}$ & 35,60 & 177,1 & & & & & & & & \\
\hline $\mathrm{T}(75 \times 250)$ & CAA & 58,10 & 23,5 & 23,0 & $4,4(7,0)$ & $7,6(10,2)$ & $20(36,1)$ & $8,1(12,9)$ & $9,0(9,5)$ & 2,4 & $1,2(0,93)$ \\
\hline $\mathrm{T}(150 \times 500)$ & CAA & 60,30 & 71,0 & 62,5 & $10(12,3)$ & $8,1(19,5)$ & $60(86)$ & $18(33,4)$ & $20(16,6)$ & 9,5 & $1,5(1,1)$ \\
\hline $\mathrm{T}(300 \mathrm{x} 1000)$ & CAA & 56,60 & 216,7 & & & & & & & & \\
\hline
\end{tabular}




\subsection{3}

\section{Zarrinpour \& Chao (2017)}

Zarrinpour \& Chao (2017) desenvolveram um programa experimental que incluiu 12 vigas sem estribos, sendo 10 com e 2 (referência) sem fibras de aço, visando investigar os seus mecanismos resistentes à força cortante. Exceto por duas vigas com fibras de aço em que se variou apenas a largura da alma da seção transversal $\left(b_{w}\right)$, nos demais pares de vigas variou-se também a altura da seção transversal $(h)$. As duas vigas nas quais só se variou $b_{w}$ serviram para constatar que, como nas vigas sem fibras, a largura das vigas não afeta a tensão cisalhante nominal. Planejou-se ter resistência à compressão do concreto $f_{c}=42 \mathrm{MPa}$, mas ela variou entre $29 \mathrm{MPa}$ e $50 \mathrm{MPa}$.

Foram constantes destes ensaios: relação $a / d \approx 3,5$, taxa de armadura longitudinal $\rho \approx 2,7 \%$, e volume e tipo de fibras de aço $V_{f}=0,75 \%$ (com ganchos, comprimento $l_{f}=51 \mathrm{~mm}$ e fator de forma $l_{f} / d_{f}=67$ ). Exceto para as vigas não duplicadas $\left(\mathrm{h}=305 \mathrm{~mm}\right.$ e $b_{\mathrm{w}}=152 \mathrm{~mm}$ e $\left.610 \mathrm{~mm}\right)$, variou-se $h(h=457 \mathrm{~mm}$, $610 \mathrm{~mm}, 915 \mathrm{~mm}$ e $1220 \mathrm{~mm})$ e a largura da alma $\left(b_{w}\right)$ na proporção de $b_{w}=h / 3$. O esquema de ensaio foi o de flexão por três pontos, sendo a carga aplicada no meio do vão ou a uma distância de um dos apoios igual a um terço do vão das vigas com e sem fibras de aço, respectivamente. Na Tabela 2.3 são listados os valores das dimensões da seção das vigas, de $f_{c}$, tensões cisalhantes correspondentes ao início da fissura crítica de cisalhamento $\left(V_{c r}\left(b_{w} d\right)\right)$ e última $\left(V_{u} /\left(b_{w} d\right)\right)$ e abertura máxima da fissura crítica para $V_{u}\left(w_{\max }\right)$.

Observou-se que as fibras de aço retardaram o desenvolvimento das fissuras de flexão e de cisalhamento, o que possibilitou a região da zona comprimida não fissurada manter-se com maior altura até alto valor de carregamento, levando a maior contribuição dessa região para a resistência à força cortante. Exceto nas vigas 610x305 e 152x457b, o início da fissura crítica deu-se na alma da viga e a aproximadamente $45^{\circ}$ com o eixo longitudinal da viga, enquanto usualmente essa fissura ocorre como continuação de uma fissura de flexão.

Depois do início da fissuração ao longo da armadura longitudinal, as fibras foram capazes de retardar o seu desenvolvimento e o aumento da sua abertura e de manter as barras de aço no seu lugar original, permitindo maior contribuição do efeito de pino dessas barras. 
Segundo Zarrinpour \& Chao (2017), em ensaios de vigas sem fibras realizados por outros autores, na ruptura constataram-se aberturas máximas da fissura diagonal crítica variando entre cerca de $0,05 \mathrm{~mm}$ e $0,5 \mathrm{~mm}$, sendo elas maiores para vigas de maior altura. Nas vigas de Zarrinpour \& Chao (2017) sem fibras, a Tabela 2.3 mostra que $w_{\max }$ ficou também nessa faixa; nas com fibras $w_{\max }$ foi sempre maior que $1,0 \mathrm{~mm}$.

Tabela 2.3 - Resultados e análise para as vigas.

\begin{tabular}{cccccccc}
\hline $\begin{array}{c}\text { Viga } \\
\left(b_{w} \times h\right)\end{array}$ & $\begin{array}{c}\boldsymbol{f}_{\boldsymbol{c}} \\
(\mathrm{MPa})\end{array}$ & $\begin{array}{c}\boldsymbol{V}_{\boldsymbol{c} r}\left(\boldsymbol{b}_{\boldsymbol{w}} \boldsymbol{d}\right) \\
(\sqrt{\mathrm{MPa})}\end{array}$ & $\boldsymbol{V}_{\boldsymbol{u}} /\left(\boldsymbol{b}_{\boldsymbol{w}} \boldsymbol{d}\right)$ & $\begin{array}{c}\boldsymbol{w}_{\max } \\
(\mathrm{mm})\end{array}$ & $\begin{array}{c}\boldsymbol{V}_{\boldsymbol{f i b}} / \boldsymbol{V}_{\boldsymbol{u}} \\
\boldsymbol{V}_{\boldsymbol{c} z} / \boldsymbol{V}_{\boldsymbol{u}}\end{array}$ & $\boldsymbol{V}_{\boldsymbol{d}} / \boldsymbol{V}_{\boldsymbol{u}}$ \\
$152 \times 305$ & 29 & 2,41 & 3,10 & 1,32 & 20,4 & 69,2 & 10,4 \\
$610 \times 305$ & 29 & 2,09 & 3,10 & 3,28 & 34,2 & 55,8 & 10,0 \\
$152 \times 457_{\mathrm{a}}$ & 39 & 1,70 & 2,70 & 1,37 & 24,2 & 64,3 & 11,5 \\
$152 \times 457_{\mathrm{b}}$ & 39 & 1,10 & 3,20 & 1,66 & 23,9 & 52,6 & 23,5 \\
$203 \times 610_{\mathrm{a}}$ & 50 & 1,60 & 2,40 & 1,52 & & & \\
$203 \times 610_{\mathrm{b}}$ & 50 & 1,20 & 3,50 & 2,03 & & & \\
$254 \times 915_{\mathrm{a}}$ & 50 & 0,90 & 3,30 & 2,03 & & & \\
$254 \times 915_{\mathrm{b}}$ & 50 & 1,30 & 3,40 & 1,04 & 22,5 & 45,0 & 32,5 \\
$305 \times 1220_{\mathrm{a}}$ & 50 & 1,00 & 3,10 & 1,96 & 14,7 & 50,5 & 34,8 \\
$305 \times 1220_{\mathrm{b}}$ & 50 & 0,90 & 3,00 & 2,56 & 29,8 & 36,0 & 34,2 \\
REF 152X457a & 38 & 1,00 & 1,40 & 0,04 & & & \\
REF 152X457a & 38 & 0,80 & 1,20 & 0,35 & & & \\
\hline
\end{tabular}

Zarrinpour \& Chao (2017) consideraram que a resistência à força cortante foi dada pelas parcelas do concreto da zona comprimida $\left(V_{c z}\right)$, do efeito de pino da armadura longitudinal $\left(V_{d}\right)$ e das fibras que atravessaram a fissura diagonal crítica $\left(V_{f i b}\right)$. A contribuição da parcela de engrenamento dos agregados foi desconsiderada, uma vez que ensaios do tipo push-off realizados por eles identificaram que o valor da abertura de fissura imediatamente anterior à ruptura foi de 0,2 $\mathrm{mm}$ e que, aplicando a equação de engrenamento dos agregados de Walraven e Reinhardt (1981) ao longo da fissura diagonal crítica com abertura até este valor, a contribuição dessa parcela na resistência foi menor que $5 \%$, uma vez que a abertura da fissura diagonal crítica foi majoritariamente maior que 0,2 $\mathrm{mm}$.

Segundo esses autores, a ruptura das vigas se iniciou por tração na região comprimida. A contribuição da parcela do concreto acima da linha neutra $\left(V_{c z}\right)$ foi estimada por meio da associação do critério de ruptura de Rankine e de dados 
obtidos da curva tensão normal de compressão versus deformação específica do concreto, constatando-se que essa contribuição em relação à força cortante última decresceu conforme aumentou-se $h$.

Para avaliar a contribuição das fibras de aço que atravessaram a fissura crítica na região abaixo da linha neutra $\left(V_{f i b}\right)$, relacionou-se o valor da abertura de fissura em cada ponto com a tensão normal a partir da curva tensão normal versus abertura de fissura obtida do ensaio do concreto à tração direta.

A parcela de efeito de pino $\left(V_{d}\right)$ foi dada pela diferença entre a força cortante última e o somatório das parcelas dos demais mecanismos resistentes.

Na Tabela 2.3 é listada a porcentagem de contribuição de cada um desses mecanismos resistentes em relação à força cortante última, onde pode ser constatado que a maior contribuição avaliada foi a do concreto acima da linha neutra.

\subsection{4}

\section{Belbachir et al. (2018)}

O programa experimental de Belbachir et al. (2018) teve o acompanhamento da cinemática da fissura diagonal crítica de vigas de concreto armado sem estribos e, utilizando fórmulas existentes na literatura para avaliação da parcela do engrenamento dos agregados na resistência à força cortante, investigou-se a influência do efeito escala nessa parcela.

Foram ensaiadas 6 vigas com 3 diferentes alturas da seção transversal retangular ( $h=250 \mathrm{~mm}$, nas vigas D11 e D12; $450 \mathrm{~mm}$, nas vigas D21 e D22 e $650 \mathrm{~mm}$, nas vigas D31 e D32; $d=h-50 \mathrm{~mm}$ ). Mantiveram-se constantes a largura da seção (200 mm), as taxas de armaduras longitudinais de tração ( $\rho=1,5 \%$, uma ou duas camadas de 3 barras) e de compressão ( $\rho^{\prime}=0,5 \%$, uma camada de duas ou três barras), relação $a / d=2,5$ e tipo de concreto $\left(f_{c}=28,5 \mathrm{MPa}\right)$. O esquema de ensaio foi o de flexão por três pontos com a força aplicada no meio do vão.

Nas vigas menores, a fissura diagonal crítica foi formada para carga mais próxima da última do que nas vigas maiores. A comparação de abertura e deslizamento numa mesma posição ao longo da fissura diagonal crítica mostrou ser a abertura entre as faces da fissura o deslocamento relativo predominante. Nas vigas de menor altura D11 e D21 constataram-se maiores deslocamentos relativos na 
parte inferior e o decréscimo desses deslocamentos ao longo do comprimento da fissura, enquanto na viga D32, de maior altura, verificou-se a ocorrência de maiores deslocamentos a meia altura. Daí depreendeu-se que nessa viga a contribuição do efeito de pino da armadura longitudinal seria menor que a das vigas D11 e D21.

Observou-se que o perfil da fissura diagonal tem efeito de escala (vigas maiores apresentaram fissura com trechos mais íngremes e curvos, enquanto as menores mostraram tendência de fissura com forma linear) e que a inclinação da fissura com relação ao eixo longitudinal da viga tem papel importante na ativação do engrenamento dos agregados. Fissuras mais inclinadas apresentaram maior deslizamento e quase todo engrenamento se desenvolveu nas partes mais inclinadas das fissuras.

A partir da cinemática da fissura diagonal crítica e das fórmulas de Walraven \& Reinhardt (1981) e Gambarova \& Karakoç (1983), foram avaliadas as parcelas $V_{a g}$ referentes a $V_{u}, 0,95 V_{u}$ e $0,87 V_{u}$ (pós-pico) das vigas D11, D21 e D32 mostradas na Tabela 2.4, onde constam também os valores de $V_{u}$ dessas vigas. Os valores de $V_{a g}$ obtidos pela fórmula de Walraven \& Reinhardt (1981) foram maiores que os dados pela fórmula de Gambarova \& Karakoç (1983), principalmente para as cargas pós-pico, quando o engrenamento foi mais ativado, sendo ambos em alguns casos superiores ao da resistência experimental. Foi verificado que, para a carga de pico, o engrenamento dos agregados não foi um mecanismo dominante, havendo a tendência do aumento de sua contribuição com o aumento da altura da viga.

Tabela 2.4 - Avaliação da contribuição da parcela de engrenamento dos agregados.

\begin{tabular}{ccccccc}
\hline & & & \multicolumn{2}{c}{$V_{a g}(\mathbf{k N})$} & \multicolumn{2}{c}{$V_{a g} / \boldsymbol{V}_{\boldsymbol{u}}$} \\
\cline { 4 - 7 } Viga & \% $\boldsymbol{V}_{\boldsymbol{u}}$ & $\left.\boldsymbol{V}_{\boldsymbol{u}} \mathbf{( k N}\right)$ & $\mathbf{1}$ & $\mathbf{2}$ & $\mathbf{1}$ & $\mathbf{2}$ \\
\hline \multirow{4}{*}{ D11 } & 100 & 60,46 & 7,99 & 5,68 & 0,13 & 0,09 \\
& 95 & 58,45 & 33,88 & 17,29 & 0,58 & 0,29 \\
& 87 & 52,75 & 51,79 & 30,30 & 0,98 & 0,57 \\
& 100 & 97,30 & 21,32 & 22,68 & 0,27 & 0,23 \\
D21 & 95 & 92,07 & 73,87 & 55,06 & 0,82 & 0,59 \\
& 87 & 85,19 & 97,24 & 88,24 & 1,14 & 1,03 \\
& 100 & 131,0 & 46,46 & 19,80 & 0,35 & 0,15 \\
D32 & 95 & 125,3 & 115,3 & 62,35 & 0,88 & 0,50 \\
& 87 & 116,5 & 116,6 & 87,47 & 1,00 & 0,75 \\
\hline \multicolumn{3}{c}{ Walraven $(1980) ;{ }^{2}$ Gambarova \& Karakoç (1983) }
\end{tabular}




\subsection{5}

Tambusay et al. (2018)

Tambusay et al. (2018) apresentaram o resultado de apenas uma viga $\left(b_{w}=100 \mathrm{~mm} ; h=150 \mathrm{~mm} ; d=128 \mathrm{~mm} ; a / d=2,5 ; \rho=\rho^{\prime}=2,38 \%\right.$, uma camada; $f_{c u}=43,4 \mathrm{MPa} ; V_{u} \sim 32 \mathrm{kN}$ ) de concreto armado sem estribos ensaiada à flexão por três pontos com a força aplicada no meio do vão e com o uso de CID.

As análises por CID foram limitadas ao processo de fissuração por meio de observações do campo de deformação longitudinal da viga. Na Figura 2.48 é mostrada a evolução da fissuração conforme aumentou-se o carregamento.
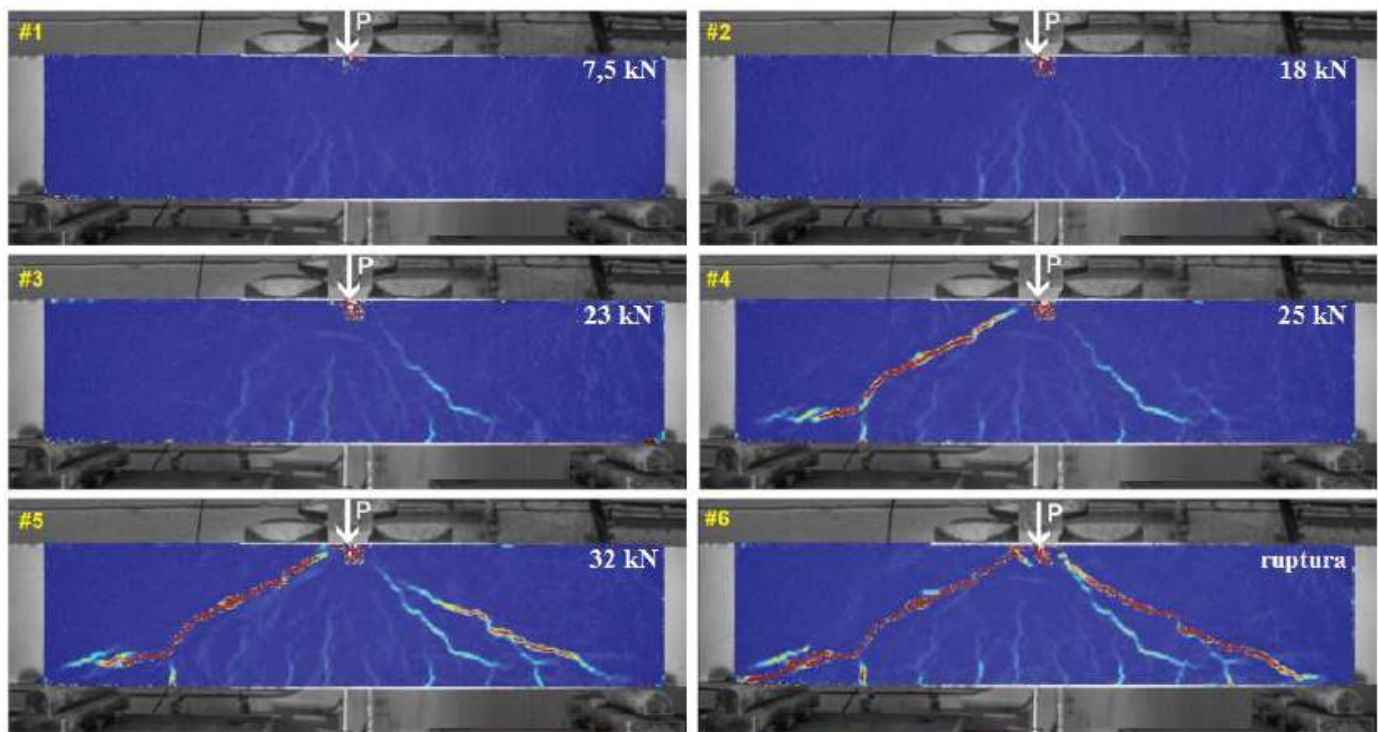

Escala de cores

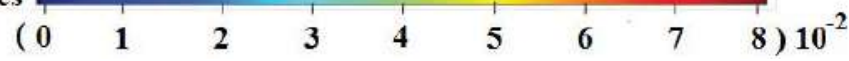

Figura 2.48 - Campo de deformação longitudinal para algumas etapas de carregamento (adaptado de Tambusay et al., 2018).

Estes mesmos autores apresentaram em outro artigo (Suryanto et al., 2017) mais três vigas com as mesmas dimensões e ensaiadas no mesmo esquema estrutural, sendo duas com estribos e uma sem estribos, mas não apresentaram os resultados da CID para a viga sem estribos.

\subsection{6}

Cavagnis et al. (2018a)

Cavagnis et al. (2018a) realizaram uma campanha experimental contendo 20 vigas de concreto armado sem estribos ( 25 ensaios realizados, pois algumas tiveram parte reforçada depois do primeiro ensaio e ensaiadas novamente até ocorrer ruptura 
na outra parte) com diferentes esquemas estruturais e condições de carregamento (vigas de vão único, contínuas e em balanço, de carregamento distribuído e concentrado, este último para o caso de viga em balanço). As vigas tinham seção retangular com dimensões $250 \mathrm{~mm}$ x $600 \mathrm{~mm}$, relação $M / V d$ no apoio da direita entre 1,7 a 6,9, $f_{c} \sim 34 \mathrm{MPa}$ e duas taxas de armadura longitudinal: $\rho=\rho^{\prime}=0,54 \%$ (uma camada, $d=559 \mathrm{~mm}$ ) ou $\rho=\rho^{\prime}=0,89 \%$ (uma camada, $d=556 \mathrm{~mm}$ ).

$\mathrm{Na}$ Tabela 2.5 resumem-se dados das vigas que tiveram os resultados da cinemática da fissura crítica adequadamente obtidos (vigas contínuas e em balanço). A menos de uma (viga 66), elas tinham relação $M / V d \geq 2,5$. Na Figura 2.49 mostra-se o esquema estrutural adotado para estas vigas.

Tabela 2.5 - Resumo de dados de algumas vigas ensaiadas.

\begin{tabular}{cccccccccc}
\hline Viga & $\begin{array}{c}\ell \\
(\mathbf{m})\end{array}$ & $\begin{array}{c}\boldsymbol{a} \\
(\mathbf{m})\end{array}$ & $\boldsymbol{M} / \boldsymbol{V d}$ & $\begin{array}{c}\boldsymbol{f}_{\boldsymbol{c}} \\
(\mathbf{M P a})\end{array}$ & $\begin{array}{c}\boldsymbol{\rho} \\
(\boldsymbol{\%})\end{array}$ & $\begin{array}{c}\boldsymbol{q} \\
(\mathbf{k N} / \mathbf{m})\end{array}$ & $\begin{array}{c}\boldsymbol{V}_{\boldsymbol{e s q}} \\
(\mathbf{k N})\end{array}$ & $\begin{array}{c}\boldsymbol{V}_{\boldsymbol{d i r}} \\
(\mathbf{k N})\end{array}$ & $\begin{array}{c}\boldsymbol{V}_{u} / \boldsymbol{b}_{\boldsymbol{w}} \boldsymbol{d}{ }_{\boldsymbol{c}} \boldsymbol{c} \\
(\sqrt{ } \mathbf{M P a})\end{array}$ \\
\hline 53 & 5,60 & & 2,88 & 33,2 & 0,886 & 40,2 & 68 & 158 & 0,197 \\
54 & 5,60 & & 3,78 & 36,5 & 0,886 & 40,6 & 46 & 182 & 0,217 \\
55 & 5,60 & & 4,48 & 33,7 & 0,886 & 33,4 & 19 & 168 & 0,208 \\
57 & 4,90 & & 4,41 & 33,2 & 0,886 & 30,0 & & 147 & 0,184 \\
58 & 4,20 & & 3,78 & 36,1 & 0,886 & 50,6 & & 213 & 0,254 \\
59 & 3,50 & & 3,15 & 35,5 & 0,886 & 52,3 & & 183 & 0,221 \\
62 & 2,80 & & 2,52 & 35,8 & 0,886 & 62,1 & & 174 & 0,209 \\
66 & 2,10 & & 1,89 & 31,2 & 0,886 & 91,4 & & 192 & 0,247 \\
63 & 3,50 & & 3,13 & 33,6 & 0,544 & 60,8 & & 213 & 0,263 \\
60 & 2,80 & & 2,50 & 36,9 & 0,544 & 58,9 & & 165 & 0,194 \\
70 & & 3,85 & 6,92 & 33,3 & 0,886 & & & 114 & 0,142 \\
69 & & 3,15 & 5,67 & 32,9 & 0,886 & & & 107 & 0,134 \\
61 & & 2,45 & 4,41 & 35,3 & 0,886 & & & 103 & 0,125 \\
64 & & 1,75 & 3,13 & 35,6 & 0,886 & & 108 & 0,131 \\
68 & & 1,40 & 2,52 & 32,6 & 0,886 & & 124 & 0,156 \\
65 & & 1,75 & 3,13 & 35,5 & 0,544 & & 102 & 0,123 \\
\hline
\end{tabular}

Esquema estrutural, $q, \ell, a$, e local de $V_{e s q}$ e $V_{d i r}$ estão indicados na Figura 2.49; $M / V d$ refere-se ao apoio da direita. 


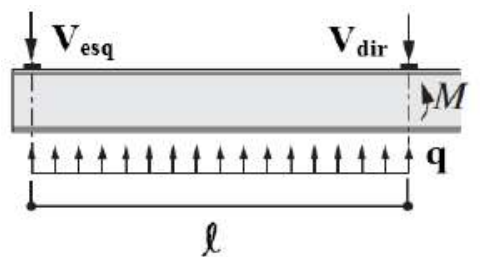

(a)

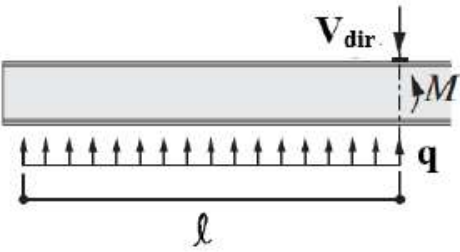

(b)

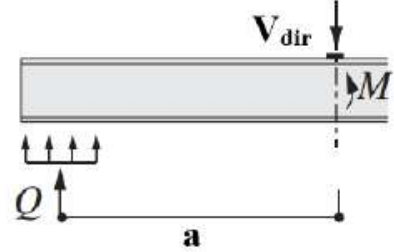

(c)

Figura 2.49 - Esquema estrutural das vigas (Tabela 2.5): (a) vigas contínuas com carregamento distribuído: 53, 54, 55; (b) vigas em balanço com carregamento distribuído: 57, 58, 59, 62, 66, 63, 60; (c) vigas em balanço com carregamento concentrado: 70, 69, 61, 64, 68 e 65. Adaptado (Cavagnis et al., 2018a)

Para avaliar o comportamento estrutural e os mecanismos resistentes à força cortante, os ensaios foram conduzidos utilizando-se a técnica de CID, com a obtenção dos dados da cinemática da fissura crítica por trechos de comprimento de no máximo ao equivalente à dimensão máxima do agregado graúdo $\left(d_{\max }=16 \mathrm{~mm}\right)$. Os resultados obtidos foram associados aos mecanismos de transferência de força de engrenamento dos agregados na fissura crítica $\left(V_{a g}\right)$, resistência à tração residual do concreto $\left(V_{r e s}\right)$, efeito de pino das armaduras longitudinais tracionada $\left(V_{d, t}\right)$ e comprimida $\left(V_{d, c}\right)$, no caso da fissura crítica atingir essa armadura, concreto comprimido não fissurado na altura $h_{c z}$ mostrada na Figura $2.50\left(V_{c z}\right)$ e, para as vigas submetidas a carregamento distribuído, parcela de força transmitida diretamente para os apoios sem interceptar a fissura crítica $\left(V_{q}\right.$, resultante da carga distribuída entre a seção do apoio e a onde a fissura crítica encontra a armadura, como mostra a Figura 2.50).

Exemplo do desenvolvimento da fissuração obtido usando CID pode ser visto na Figura 2.51.

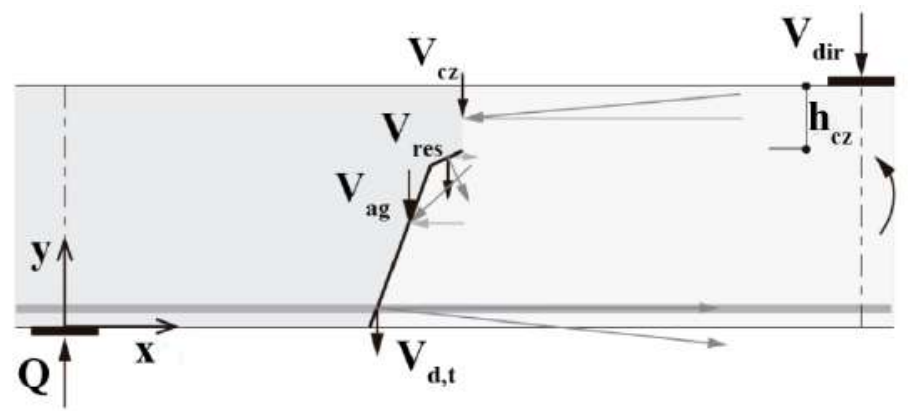

(a)

Figura 2.50 (continua) - Parcelas de transferência de cortante. (a) balanço com carga concentrada (b) balanço com carga distribuída. Adaptado Cavagnis et al. 


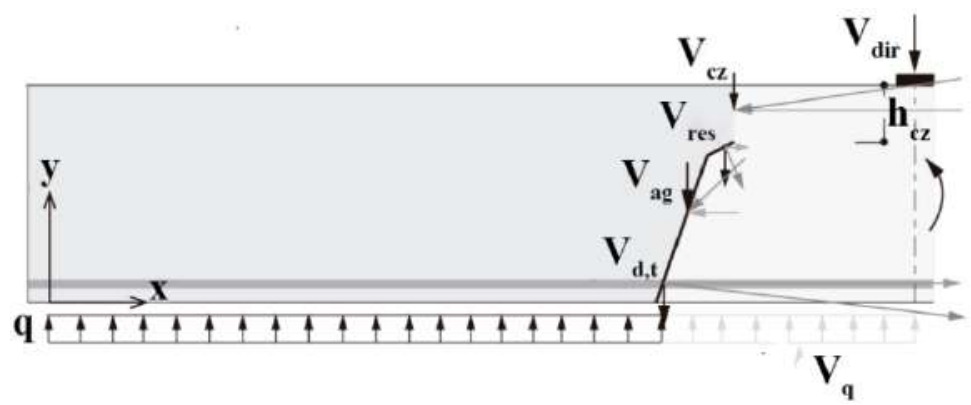

(b)

Figura 2.50 (continuação) - Parcelas de transferência de cortante. (a) balanço com carga concentrada (b) balanço com carga distribuída. Adaptado Cavagnis et al. (2018a)
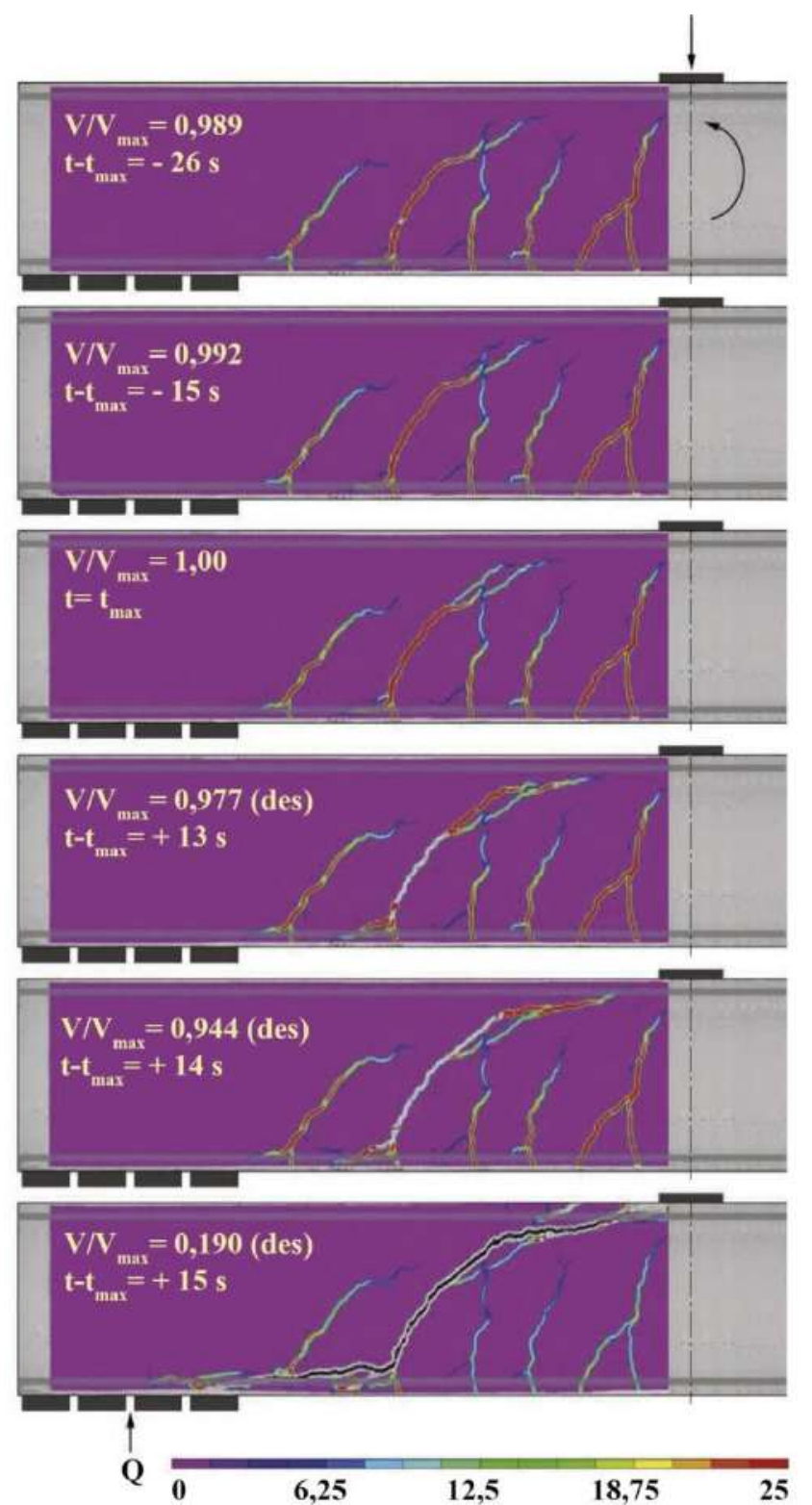

Figura 2.51 - Fissuração da viga 65 para diferentes valores de $V / V_{\max }$. Ramo descendente indicado por (des). Adaptado Cavagnis et al. (2015). 
Os autores identificaram os diferentes tipos de fissuras mostrados na Figura 2.52. As fissuras de flexão $B$ e $C$ surgiram para cargas mais avançadas que as $P$. Fissuras $D^{\prime}$ apareceram antes da ruptura, para deslocamentos verticais no nível da armadura longitudinal da ordem de $0,15 \mathrm{~mm}$, enquanto as $D$ ' e $D$ ', apareceram depois da carga de ruptura. As E decorreram do engrenamento dos agregados; as $F$ do prolongamento de uma fissura primária na região comprimida, com menor inclinação em relação ao eixo longitudinal da viga; as $G$ de flexão ou grande compressão e/ou cortante no banzo comprimido.

A fissura $P-E$ ou $P-F$ nem sempre correspondeu à superfície final de ruptura depois da carga máxima, devido a ser interceptada ou fundida com outra durante a ruptura, mas pelo menos coincidiu em parte com ela. Exemplo disso pode ser visto na Figura 2.53, que mostra, além da fissuração, deslocamentos entre as faces da fissura que levou à ruptura.

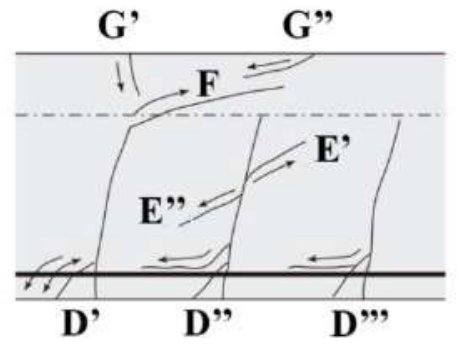

(b)

Figura 2.52 - (a) Fissuras primárias $P$ e secundárias $B$ e $C$ de flexão. (b) Fissuras relacionadas com mecanismos de transferência de força. Adaptado Cavagnis et al., (2015).

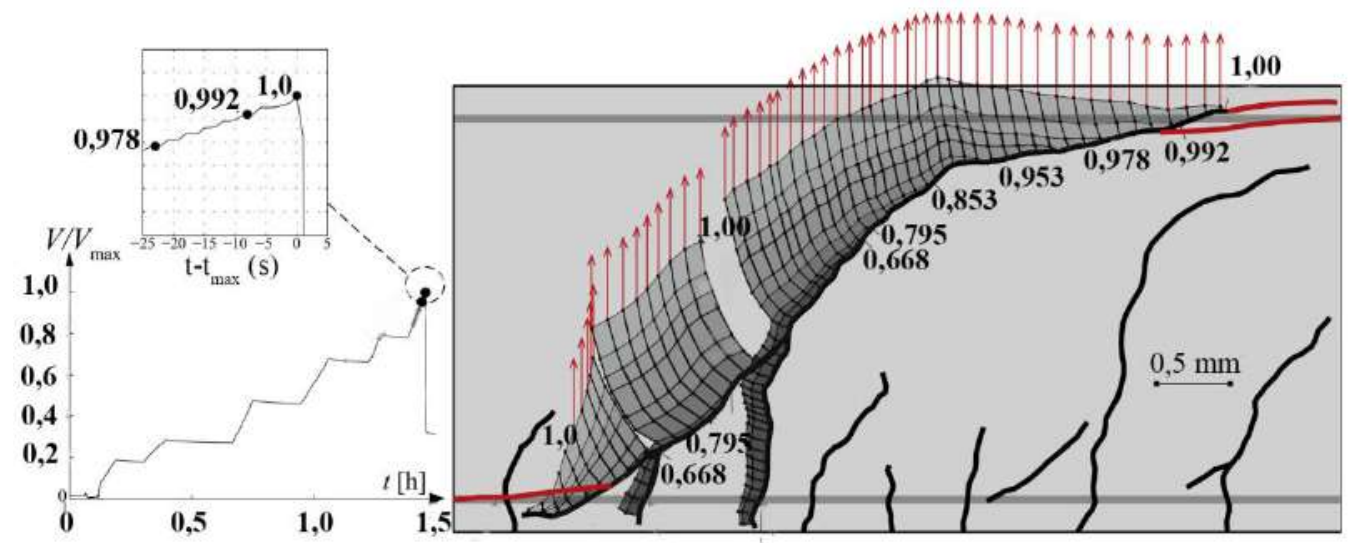

Figura 2.53 - Desenvolvimento da fissuração e dos deslocamentos entre faces de fissura da viga 59 para diferentes valores de $V / V_{\max }$ (cor preta). Vetores de deslocamento verticais e fissuras em vermelho referem-se ao processo de ruptura instável. Adaptado Cavagnis et al., (2015). 
A parcela referente ao engrenamento dos agregados foi avaliada considerando as equações de Walraven (1980) e de Ulaga (2003), tendo-se adotado a de Ulaga (2003), que representava melhor o ocorrido nas vigas e fornecia tensões mais conservadoras. A referente à tensão de tração residual na zona de processamento de fratura foi obtida com a equação de Hordijk (1992), adotando energia da fratura $\mathrm{G}_{\mathrm{F}}$ determinada conforme o FIB MC 2010 (2013). A contribuição do efeito de pino foi obtida a partir de deslocamentos verticais e rotações medidos nas extremidades de determinado comprimento na vizinhança da armadura (ver item 2.2.1.2.2d, p. 38). A parcela relativa ao concreto comprimido não fissurado foi estimada a partir de deformações principais obtidas pela CID ao longo da altura $h_{c z}$, das equações constitutivas do concreto e considerando-se que as direções das deformações e tensões principais coincidiam (eq. 2.62, p. 78).

Na Figura 2.54 listam-se as parcelas da tensão cisalhante última relativa das vigas correspondentes aos diferentes mecanismos de transferência de força. $\mathrm{O}$ valor do somatório das parcelas resistentes $\left(\Sigma V_{i}\right)$ apresentou coerência com o da força cortante última $\left(V_{u}\right)$, tendo-se para ele coeficiente de variação de $9 \%$ e média da relação $V_{u} / \Sigma V_{i}$ igual a 1,01 .

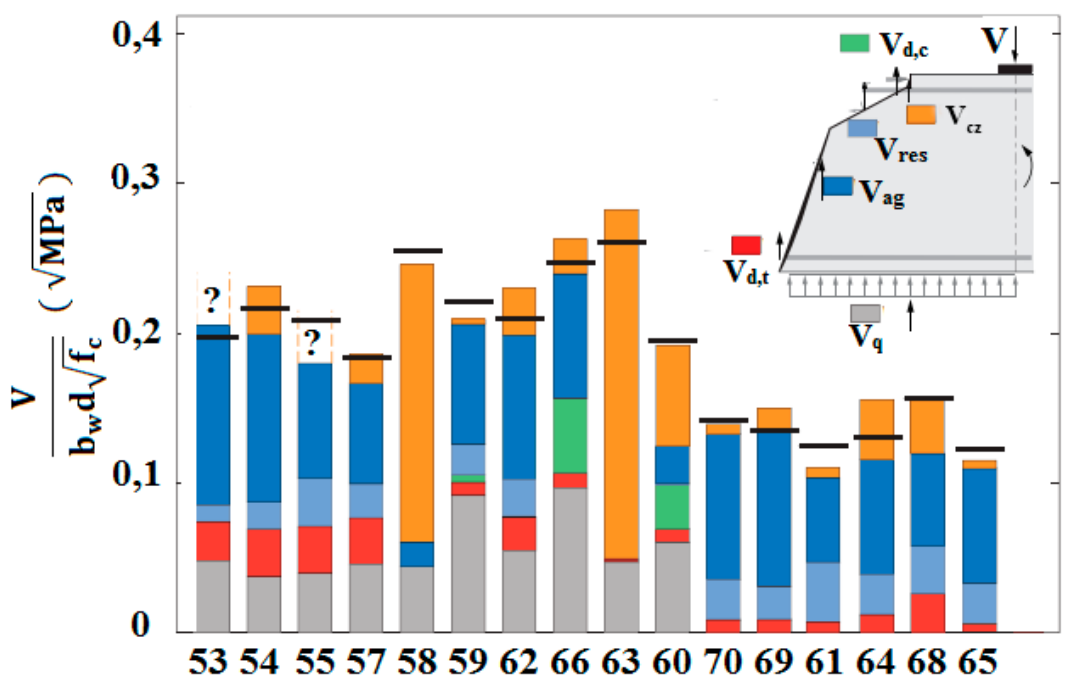

Figura 2.52 - Contribuição das parcelas resistentes para cada viga. (?) Vigas sem informações detalhadas das deformações principais na zona comprimida. Adaptado Cavagnis et al. (2018a).

As análises mostraram que cada parcela resistente dependeu da posição, geometria e cinemática da fissura crítica. Nas vigas que tiveram a posição da fissura crítica distante do apoio à direita, o engrenamento dos agregados foi o mecanismo 
resistente dominante, com principal mobilização na região íngreme e superior da fissura crítica. Nas vigas em que a posição da fissura crítica ficou próxima a este apoio, devido ao restrito deslizamento na fissura, a participação do engrenamento dos agregados foi limitada, tendo-se como parcela resistente dominante a do concreto comprimido não fissurado (vigas 58, 63 e 60).

A contribuição do efeito de pino da armadura longitudinal tracionada mostrou-se mais relevante para as vigas com carregamento distribuído; para as com carregamento concentrado, ela foi influenciada pela posição da fissura crítica. A referente à armadura longitudinal comprimida mostrou-se relevante para as cargas pós-pico quando a fissura crítica se desenvolveu nessa região.

A parcela relativa à resistência à tração residual do concreto dependeu principalmente da abertura e do comprimento e inclinação do trecho quasehorizontal da fissura crítica. 


\section{3 \\ Programa experimental}

Este capítulo descreve o programa experimental desenvolvido para investigar mecanismos resistentes à força cortante de vigas de concreto sem e com fibras de aço.

Dentro das limitações estabelecidas para o estudo, explicitadas no item 1.3, foram considerados quatro diferentes concretos: um sem fibras, um com teor de fibras em volume $V_{f}=0,5 \%\left(l_{f}=30 \mathrm{~mm}\right.$ e $\left.l_{f} / d_{f}=45\right)$ e os outros dois com $V_{f}=1,0 \%\left(l_{f}=30 \mathrm{~mm}\right.$ e $60 \mathrm{~mm}$ e $l_{f} / d_{f}=45$ e 80$)$. A seguir são apresentadas as composições desses concretos e os resultados dos ensaios realizados para sua caracterização.

São descritos os ensaios que visaram investigar o efeito de pino (16 espécimes sem e com fibras de aço) e o engrenamento dos agregados (12 espécimes sem e com fibras de aço). São também relatados os ensaios de 12 vigas sem e com fibras de aço, cujos resultados, junto com os dos ensaios sobre os mecanismos resistentes e informações obtidas de estudos realizados por outros autores e resumidas na revisão bibliográfica, possibilitaram analisar a contribuição dos diferentes mecanismos para a resistência à força cortante das vigas.

\section{1}

\section{Composições e propriedades dos concretos}

\subsection{1}

\section{Composições}

Nas composições dos concretos, empregaram-se cimento CPII-E, água do sistema de abastecimento da cidade, aditivo superplastificante MasterGlenium 51, da $\mathrm{BASF}^{\circledR}$, de base éter policarboxílica, areia artificial e agregados graúdos classificados macroscopicamente como gnaisse-granítico (pedreira Ibrata ${ }^{\circledR}$, do município de Itaboraí, RJ). Na Figura 3.1 são apresentadas imagens destes agregados 


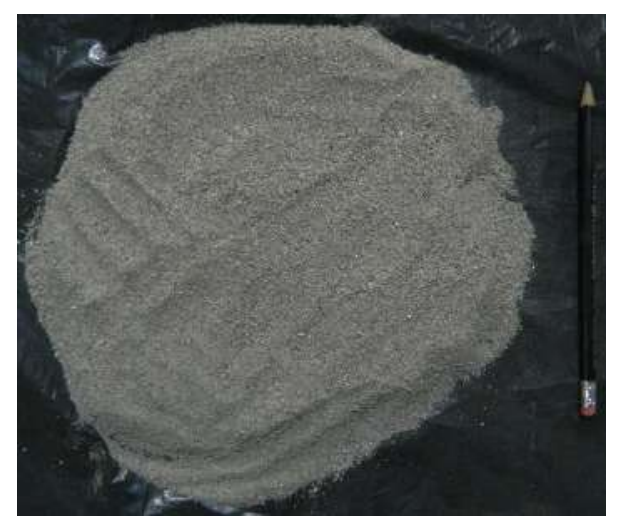

(a)

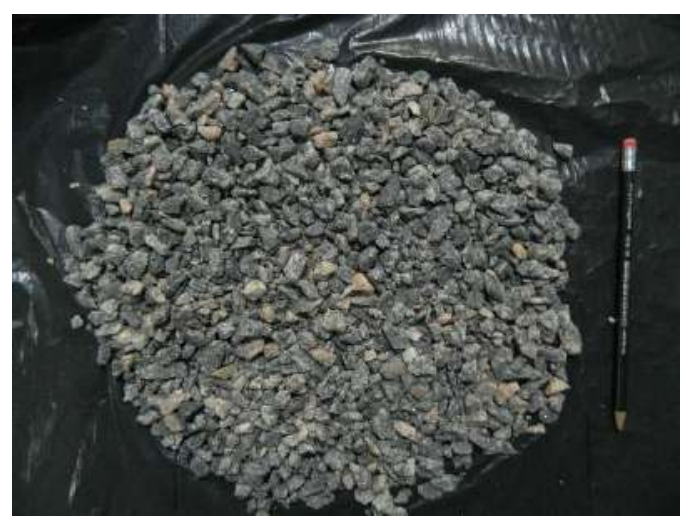

(b)

Figura 3.1 - Amostras dos agregados utilizados nas composições dos concretos: (a) areia artificial; (b) agregados graúdos.

As curvas granulométricas dos agregados e o índice de forma dos graúdos foram obtidos de ensaios realizados de acordo com a ABNT NBR NM 248 (2003) e ABNT NBR 7809 (2019), respectivamente. As curvas granulométricas, juntamente com os limites impostos pela ABNT NBR 7211 (2009) são apresentadas na Figura 3.2.

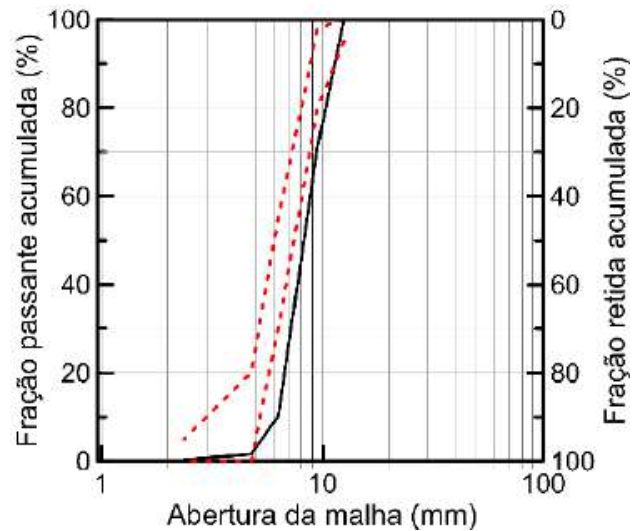

(a)

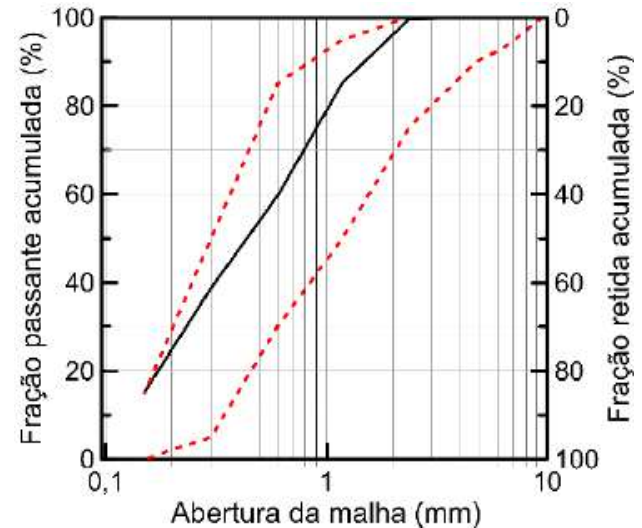

(b)

Figura 3.2 - Curvas granulométricas: (a) agregado graúdo e (b) areia artificial. Linhas tracejadas indicam limites utilizáveis da ABNT NBR 7211 (2009).

A distribuição granulométrica da areia artificial ficou dentro dos limites da zona utilizável da ABNT NBR 7211 (2009). Já a do agregado graúdo, que se encontrou na zona granulométrica 4,75/12,5 mm, não atendeu aos limites das peneiras com abertura de 6,3 mm e 9,5 mm. Ribeiro (2006), em seu trabalho sobre caracterização de agregados graúdos da região metropolitana da cidade do Rio de Janeiro, mostrou que, para esta zona granulométrica, $24 \%$ das 25 pedreiras que 
foram incluídas no estudo não tiveram suas amostras coletadas atendendo aos limites dados pela norma.

A areia artificial e os agregados graúdos tinham dimensão máxima de 2,36 mm e 12,5 mm e módulo de finura de 2,02 e 6,25, respectivamente. O índice de forma dos agregados graúdos foi de 2,24, o que atende ao limite $(\leq 3)$ da ABNT NBR 7809 (2019).

As fibras de aço utilizadas tinham ganchos nas extremidades (Figura 3.3). Suas características informadas pelo fabricante e a nomenclatura usada neste trabalho para referenciá-las (“S” ou "L") são as apresentadas na Tabela 3.1.

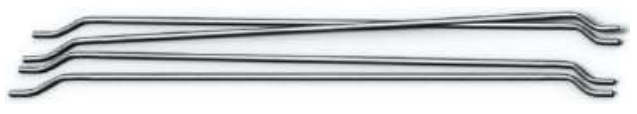

Fibras do tipo "S"

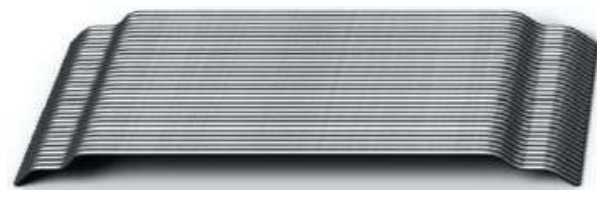

Fibras do tipo "L"

Figura 3.3 - Aspecto das fibras utilizadas. As fibras do tipo "S" foram fornecidas soltas e as do tipo "L" coladas (catálogo da Belgo Bekaert Arames. Disponível em: < http://www.belgobekaert.com.br>).

Tabela 3.1 - Características das fibras de aço fornecidas pelo fabricante.

\begin{tabular}{ccc}
\hline \multirow{2}{*}{ Características } & Tipo de fibra \\
& S & L \\
\hline Comprimento $(\mathrm{mm})$ & 30 & 60 \\
Diâmetro equivalente $(\mathrm{mm})$ & 0,62 & 0,75 \\
Fator de forma & 45 & 80 \\
Massa específica $\left(\mathrm{g} / \mathrm{cm}^{3}\right)$ & 7,85 & 7,85 \\
Resistência à tração $(\mathrm{MPa})$ & 1270 & 1225 \\
Módulo elástico $(\mathrm{GPa})$ & 210 & 210 \\
\hline
\end{tabular}

As composições dos concretos são apresentadas na Tabela 3.2. Em relação aos sem fibras, os concretos com fibras de aço tiveram o volume de agregados modificado por conta da inserção das fibras. 
Tabela 3.2 - Composições dos concretos.

\begin{tabular}{cccc}
\hline \multirow{2}{*}{ Material } & \multicolumn{3}{c}{$\mathbf{k g} / \mathbf{m}^{\mathbf{3}}$} \\
\cline { 2 - 4 } & $V_{f}=0 \%$ & $V_{f}=0,5 \%$ & $V_{f}=1,0 \%$ \\
\hline Cimento CPII-E & 412 & 412 & 412 \\
Areia artificial & 856 & 856 & 856 \\
Agregado graúdo & 957 & 941 & 929 \\
Água & 185 & 185 & 185 \\
Aditivo superplastificante & 8,24 & 12,4 & 12,4 \\
Fibras de aço & 0 & 39,3 & 78,5 \\
\hline
\end{tabular}

\section{1 .2}

\section{Propriedades no estado fresco}

Para a caracterização dos concretos no estado fresco, foi realizado o ensaio de consistência pelo abatimento do tronco de cone da ABNT NBR NM 67 (1998). Os valores de abatimento são apresentados na Tabela 3.3.

Tabela 3.3 - Consistência dos concretos.

\begin{tabular}{ccc}
\hline $\boldsymbol{V}_{\boldsymbol{f}}(\boldsymbol{\%})$ & tipo de fibra & Abatimento $(\mathbf{m m})$ \\
\hline 0 & 0 & 230 \\
0,5 & $\mathrm{~S}$ & 245 \\
1,0 & $\mathrm{~S}$ & 235 \\
1,0 & $\mathrm{~L}$ & 135 \\
\hline
\end{tabular}

Exceto pelo concreto com fibras tipo "L", os concretos atingiram a classe mais alta de abatimento, $\geq 220$ mm (ABNT NBR 8953, 2015). Observação visual indicou que os concretos apresentaram leve exsudação e que não houve segregação. Na Figura 3.4 é apresentada a fotografia do concreto com maior abatimento.

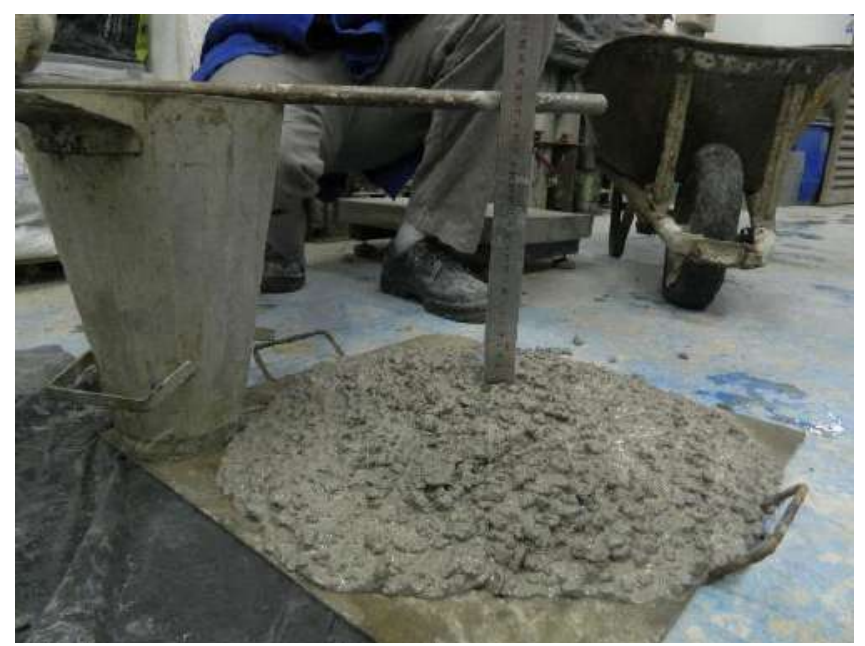

Figura 3.4 - Concreto de maior abatimento $\left(V_{f}=0,5 \%(S)\right.$, abatimento $=245 \mathrm{~mm}$ ). 


\subsection{3}

\section{Propriedades no estado endurecido}

Para determinar as propriedades dos concretos no estado endurecido, foram realizados ensaios de resistência à compressão $\left(f_{c}\right)$, módulo de elasticidade $\left(E_{c}\right)$, resistência à tração por compressão diametral $\left(f_{c t, s p}\right)$, resistência à tração direta $\left(f_{c t}\right)$ e resistência à tração na flexão $\left(f_{c t, f l}\right)$.

Todos os corpos-de-prova de concreto receberam "adensamento" por vibração decorrente de golpes de martelo de borracha na superfície externa das formas. Após a concretagem, eles foram molhados e cobertos com filme plástico por 24 ou 48 horas, sendo, então, desmoldados e deixados sob as condições ambientais do laboratório até a data de ensaio.

Para a obtenção da resistência à compressão, foram ensaiados no mínimo 3 corpos-de-prova para cada betonada; para obter as demais propriedades, foram ensaiados no mínimo três corpos-de-prova para cada tipo de concreto. Os corposde-prova foram ensaiados com a idade entre 28 a 31 dias.

Na Tabela 3.4 são listados os tipos de ensaios realizados para cada concreto.

Tabela 3.4 - Tipos de ensaios realizados para cada concreto (X).

\begin{tabular}{lcc} 
Tipo de ensaio & $\boldsymbol{V}_{\boldsymbol{f}}=\mathbf{0}$ & $\boldsymbol{V}_{\boldsymbol{f}} \neq \mathbf{0}$ \\
\hline Compressão & $\mathrm{x}$ & $\mathrm{x}$ \\
Módulo de elasticidade & $\mathrm{x}$ & - \\
Tração por compressão diametral & $\mathrm{x}$ & - \\
Tração na flexão & $\mathrm{x}$ & $\mathbf{x}$ \\
Tração direta & - & $\mathbf{x}$ \\
\hline
\end{tabular}

\subsubsection{1}

Resistência à compressão, módulo de elasticidade e resistência à tração por compressão diametral

Antes de serem ensaiados em máquina CONTROLS, modelo MCC8, com capacidade máxima de 2000 kN, os corpos-de-prova cilíndricos com diâmetro de $100 \mathrm{~mm}$ e altura de $200 \mathrm{~mm}$ tiveram suas extremidades planificadas por meio da máquina retificadora mostrada na Figura 3.5a.

Os ensaios de resistência à compressão, resistência à tração por compressão diametral e módulo de elasticidade foram executados em conformidade com a 
ABNT NBR 5739 (2018), ABNT NBR 7222 (2011) e ABNT NBR 8522 (2017), respectivamente. A medição de variação de comprimento no ensaio do módulo de elasticidade foi realizada por meio de dois transdutores de deslocamentos. As ilustrações da realização de um dos ensaios para a obtenção do módulo de elasticidade e da resistência à tração por compressão diametral são apresentadas nas Figuras 3.5b-c.

O valor médio e o desvio padrão dos resultados dos ensaios à compressão, módulo de elasticidade e resistência à tração por compressão diametral são apresentados na Tabela 3.5.

Tabela 3.5 - Valores médios e (desvio padrão) dos resultados dos ensaios de $f_{c}, E_{c}$ e $f_{c t, s p}$ de acordo com o tipo de concreto.

\begin{tabular}{ccccc}
\hline \multirow{2}{*}{ Ensaio } & \multicolumn{4}{c}{$V_{\boldsymbol{f}} \%$ (tipo de fibra) } \\
\cline { 2 - 5 } & $\mathbf{0}$ & $\mathbf{0 , 5}(\mathbf{S})$ & $\mathbf{1 , 0}(\mathbf{S})$ & $\mathbf{1 , 0}(\mathbf{L})$ \\
\hline$f_{c}(\mathrm{MPa})$ & $36,1(2,7)$ & $36,2(2,3)$ & $40,4(2,4)$ & $39,8(2,7)$ \\
$E_{c}(\mathrm{GPa})$ & $24,5(0,40)$ & & & \\
$f_{c t, s p}(\mathrm{MPa})$ & $2,88(0,48)$ & & \\
\hline
\end{tabular}

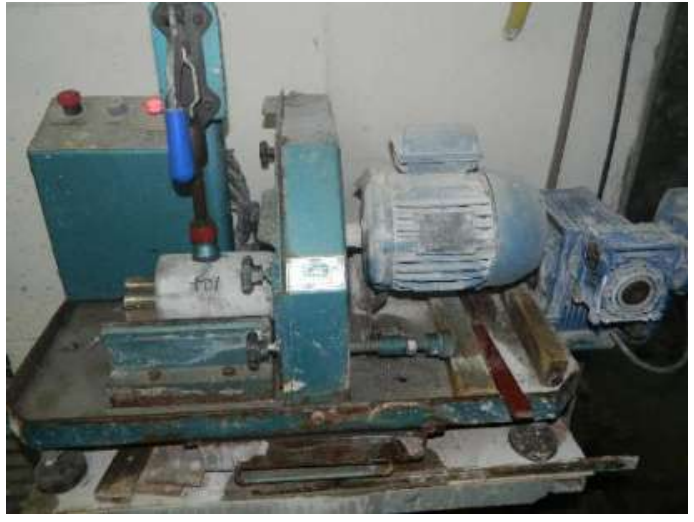

(a)

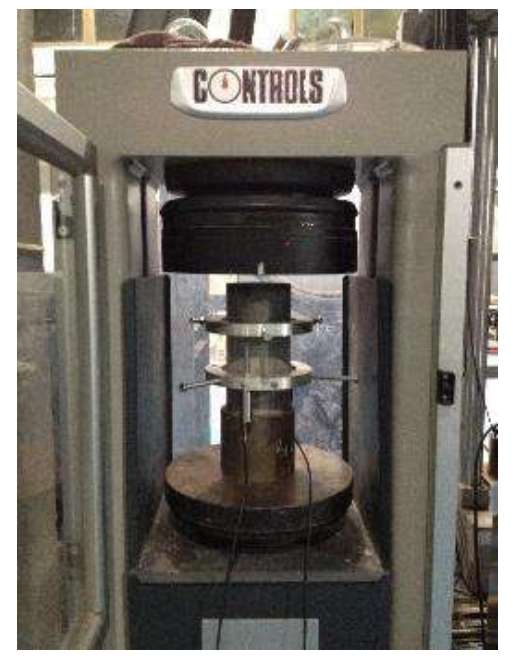

(b)

Figura 3.5 (continua) - Preparação dos corpos-de-prova e ensaios para obtenção das propriedades mecânicas do concreto no estado endurecido. (a) máquina para planificar as extremidades dos corpos-de-prova; (b) Corpo-de-prova posicionado na CONTROLS para o ensaio de determinação do módulo de elasticidade;

(c) Corpo-de-prova posicionado para ensaio de tração por compressão diametral. 


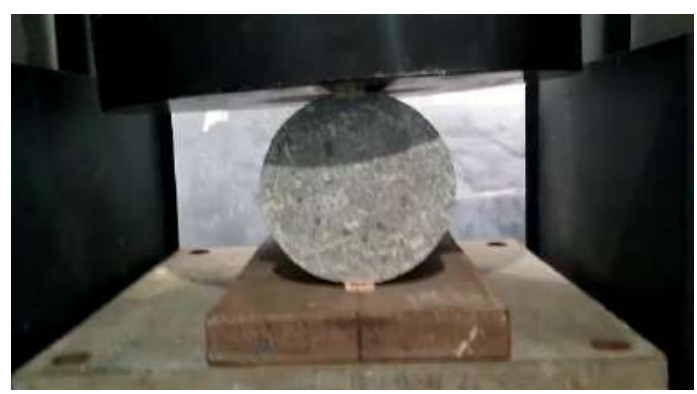

(c)

Figura 3.5 (continuação) - Preparação dos corpos-de-prova e ensaios para obtenção das propriedades mecânicas do concreto no estado endurecido. (a) máquina para planificar as extremidades dos corpos-de-prova; (b) Corpo-de-prova posicionado na CONTROLS para o ensaio de determinação do módulo de elasticidade; (c) Corpo-de-prova posicionado para ensaio de tração por compressão diametral.

\subsubsection{2}

\section{Resistência à tração direta (corpos-de-prova tipo "osso-de-cachorro")}

Os corpos-de-prova ensaiados à tração direta, do tipo "osso-de-cachorro" (dogbone), tinham partes diferenciadas: uma central com comprimento de $300 \mathrm{~mm}$ e seção circular tendo diâmetro variando de $68 \mathrm{~mm}$ a $150 \mathrm{~mm}$ e extremidades com comprimento de 100 mm e seção circular com diâmetro de 150 mm, como mostra a Figura 3.6.

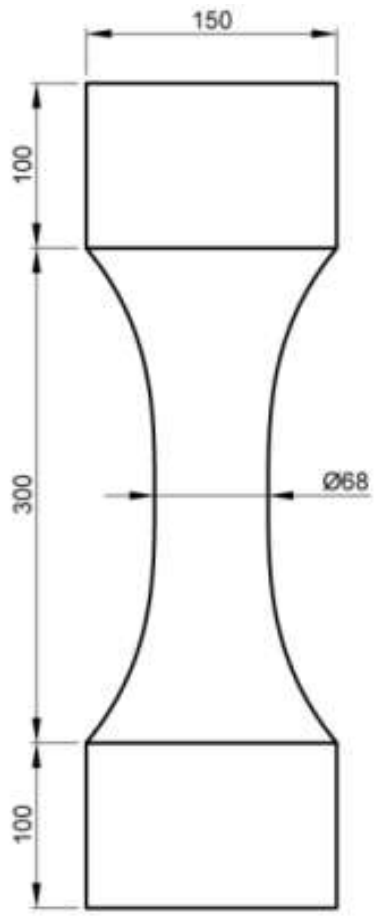

Figura 3.6 - Dimensões do corpo-de-prova do tipo "osso de cachorro"

(Adaptado de Pereira, 2017) 
A concretagem foi realizada com o corpo-de-prova na posição vertical.

Para fins de fixação do corpo-de-prova na garra da máquina de ensaios, foi feito um furo na região central das duas extremidades do corpo-de-prova (Figura 3.7a), com profundidade de $100 \mathrm{~mm}$ e diâmetro $12 \mathrm{~mm}$, para posterior posicionamento de uma barra de aço CA-50 de $\phi=10 \mathrm{~mm}$ e comprimento de 200 mm, colada com epóxi Sikadur 32.

A máquina de ensaios utilizada foi uma universal MTS modelo 311, com capacidade de carga de $1000 \mathrm{kN}$. Para medir a variação de comprimento foi montado no corpo-de-prova um aparato para suporte de um par de LVDT HBM com o limite de medição de $50 \mathrm{~mm}$, como mostrado na Figura 3.7b. A média das variações de comprimento obtidas com o par de LVDT foi, simplificadamente, considerada como sendo a abertura da única fissura constatada visualmente na região de menor seção transversal.

O controle do ensaio foi por deslocamento, à taxa de $0,1 \mathrm{~mm} / \mathrm{min}$ e os dados registrados foram: carga, deslocamento do atuador e variação de comprimento medida pelos LVDT 1 e 2 . O critério de parada do ensaio foi o deslocamento de 2,5 mm do atuador. Em PEREIRA (2017), é possível obter maiores informações acerca deste ensaio.

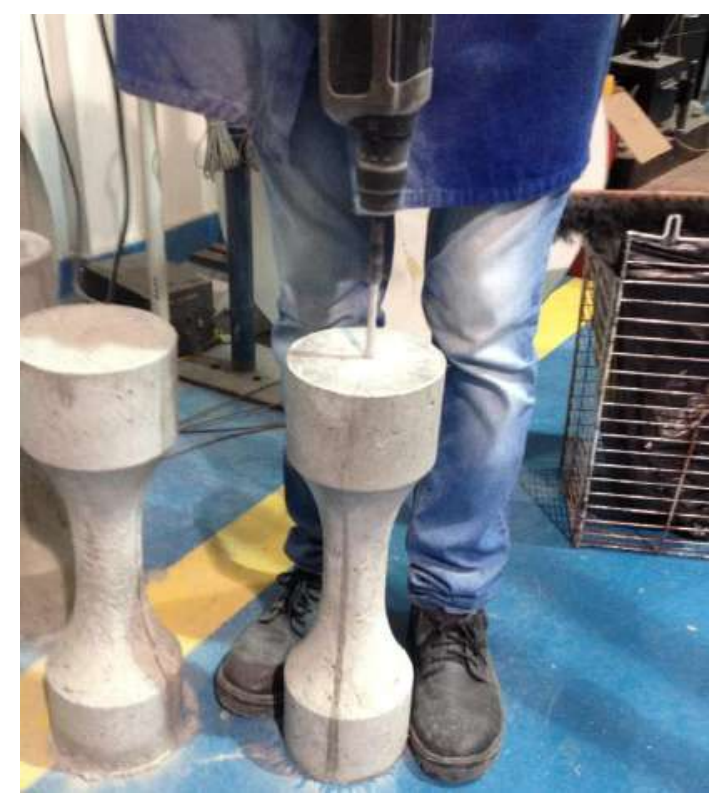

(a)

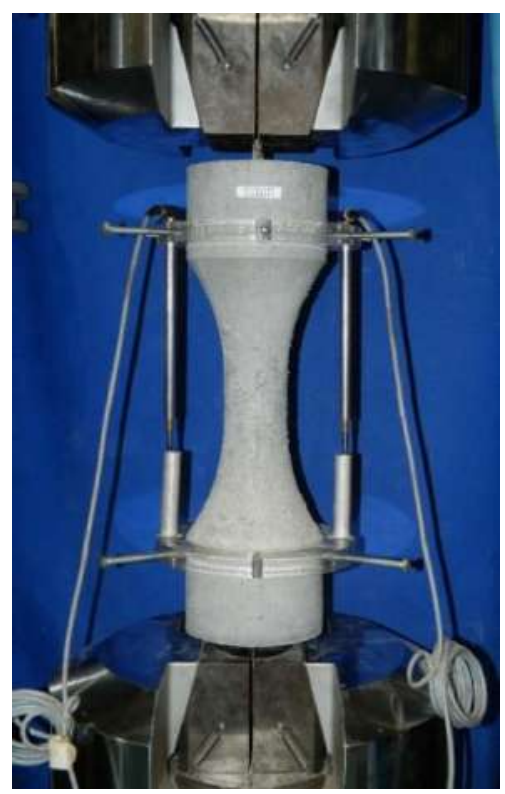

(b)

Figura 3.7 - Detalhes do ensaio à tração direta: (a) Processo de furação da extremidade para a inserção da barra de aço e (b) posicionamento do corpo-deprova na máquina de ensaios. 
Dos 9 corpos-de-prova ensaiados, apenas 7 tiveram seus resultados aproveitados, tendo em vista problemas na execução de 2 deles. Na Tabela 3.6 é apresentada a resistência à tração para cada corpo-de-prova e o número de fibras na seção transversal de ruptura. Observou-se que, em média, na seção transversal de ruptura dos corpos-de-prova com $V_{f}=1,0 \%$ havia em torno de 46 fibras, enquanto na dos com $V_{f}=0,5 \%$ havia 16 fibras, ou seja, a quantidade de fibras nessa seção não variou na mesma proporção que o teor em volume de fibras.

Tabela 3.6 - Número de fibras na seção de ruptura e $f_{c t}$ para cada corpo-de-prova e valores médios referentes aos de mesmo teor e tipo de fibras.

\begin{tabular}{ccccc}
$\boldsymbol{V}_{\boldsymbol{f}} \%$ (tipo de fibra) & \multicolumn{2}{c}{$\mathbf{n}^{\mathbf{0}}$ de fibras } & \multicolumn{2}{c}{$\boldsymbol{f}_{\boldsymbol{c t}}(\mathbf{M P a})$} \\
\multirow{2}{*}{$\mathbf{0 , 5}(\mathbf{S})$} & 14 & & 2,54 & 2,51 \\
& 17 & 16 & 2,48 & \\
& 17 & & - & \\
\hline \multirow{3}{*}{$\mathbf{1}(\mathbf{S})$} & 29 & & - & \\
& 64 & 47 & 3,34 & 3,34 \\
& 47 & & 3,34 & \\
\hline & 49 & & 3,19 & \\
$\mathbf{1}(\mathbf{L})$ & 54 & 46 & 3,15 & 3,15 \\
& 36 & & 3,10 & \\
\hline
\end{tabular}

Na Figura 3.8 são apresentados os gráficos de tensão normal residual na seção de menor diâmetro - abertura de fissura obtidos. Neles constam os números de fibras de aço observadas na seção transversal de ruptura. 


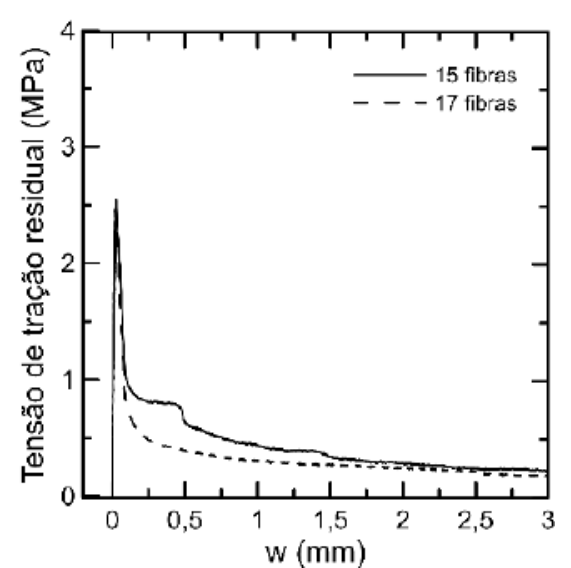

(a)

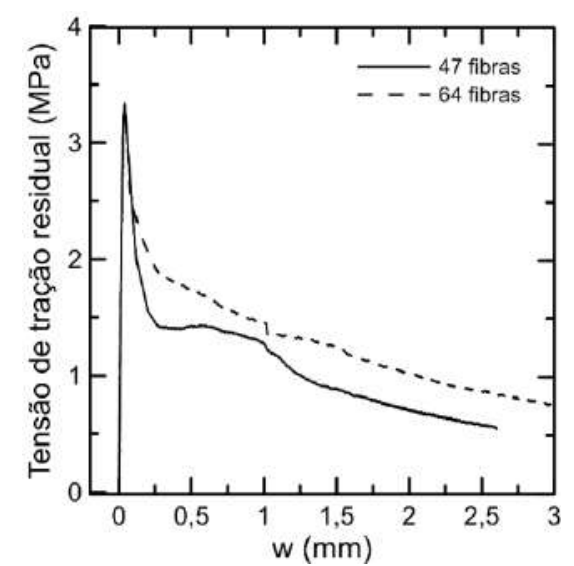

(b)

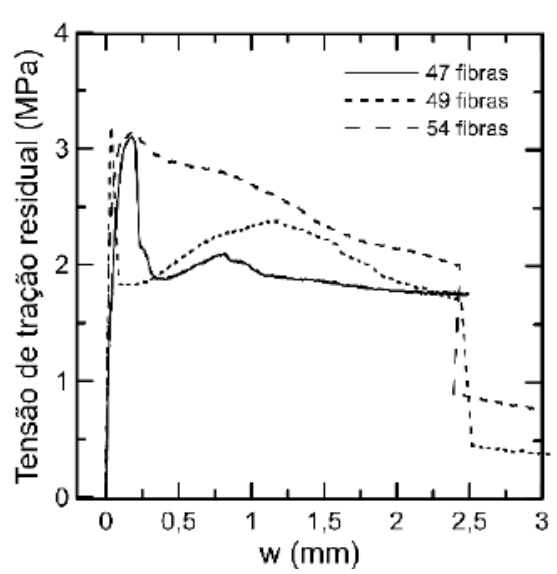

(c)

Figura 3.8 - Gráficos tensão normal de tração residual na seção de menor diâmetro - abertura de fissura. Corpos-de-prova com (a) $V_{f}=0,5 \%$ (S), (b) $V_{f}=1,0 \%(\mathrm{~S})(\mathrm{c}) V_{f}=1,0 \%(\mathrm{~L})$.

Observa-se na Figura 3.8 a relação entre o número de fibras na seção transversal de ruptura e o comportamento pós-fissuração. Maior número de fibras de aço na seção transversal de ruptura levaram a perda de capacidade resistente mais gradual. Nessa figura pode-se notar também tendência de perda de capacidade resistente mais gradual nos concretos com fibras de maior comprimento.

Em todos os ensaios foi observado o arrancamento de fibras. Na Figura 3.9 é apresentado o aspecto de um dos corpos-de-prova após o ensaio. 


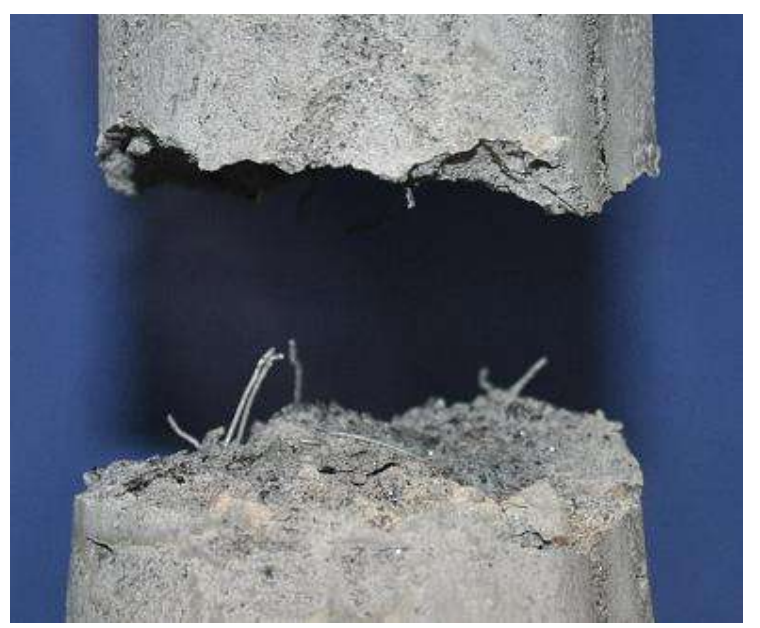

Figura 3.9 - Aspecto após o ensaio de corpo-de-prova de concreto com $V_{f}=0,5 \%(\mathrm{~S})$.

\subsubsection{3}

\section{Resistência à tração na flexão}

Para a caracterização dos concretos com fibras e adicionais informações para o concreto sem fibras, foram realizados ensaios de resistência à tração por flexão de acordo com a norma EN 14651 (2005) (para concretos com fibras).

As dimensões dos corpos-de-prova utilizados foram $150 \mathrm{~mm}$ x $150 \mathrm{~mm}$ x $550 \mathrm{~mm}$, com largura do entalhe de $3 \mathrm{~mm}(\leq 5 \mathrm{~mm})$ e profundidade de $25 \mathrm{~mm} \pm 1 \mathrm{~mm}$, conforme ilustra a Figura 3.10.

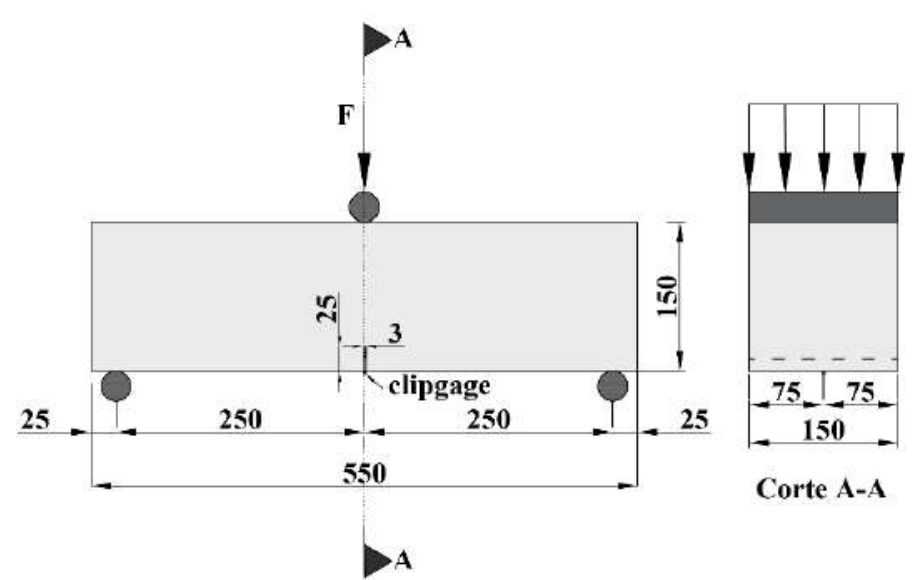

Figura 3.10 - Dimensões em mm e esquema de ensaio.

Os ensaios foram controlados pela abertura do entalhe (CMOD - crack mouth opening displacement) medida por meio de um clipgage posicionado na extremidade inferior do entalhe (Fig 3.10 e 3.11a). A fim de checar o uso da técnica de CID e obter informações adicionais para trabalhos futuros, esta técnica foi 
utilizada nestes ensaios. Na Figura 3.11b são comparadas as aberturas de fissura obtidas ao longo de um dos ensaios por meio de clipgage e CID.

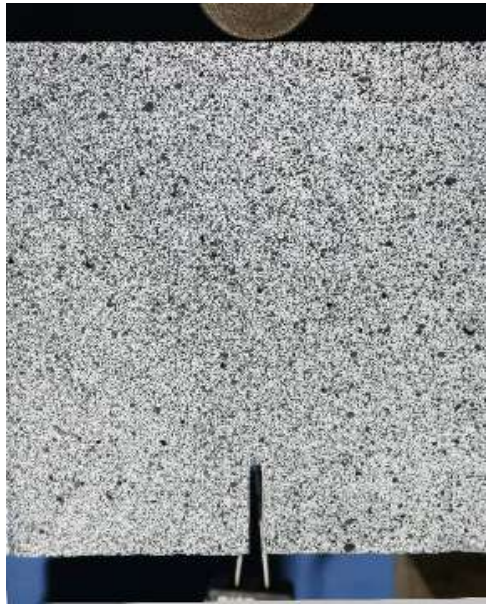

(a)

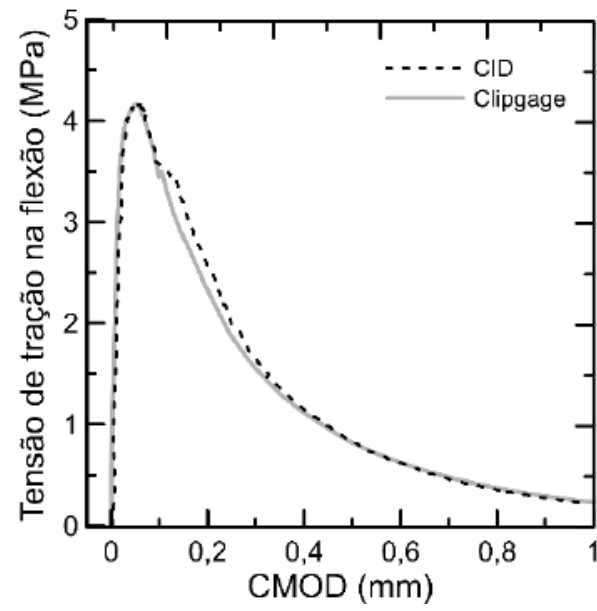

(b)

Figura 3.11 - Ensaio à tração na flexão: (a) região do entorno da seção de aplicação de carga. (b) comparação entre valores de abertura de fissura obtidos por meio de clipgage e CID durante um ensaio de concreto sem fibras (Fig. 3.12a).

A velocidade de ensaio adotada foi de $0,05 \mathrm{~mm} / \mathrm{min}$ até $\mathrm{CMOD}=0,1 \mathrm{~mm}$, a partir da qual ela passou a ser $0,2 \mathrm{~mm} / \mathrm{min}$, e o critério de parada foi $\mathrm{CMOD}=4 \mathrm{~mm}$, conforme prescreve a norma. Utilizou-se um atuador hidráulico com capacidade de $100 \mathrm{kN}$ montado em um pórtico rígido e controlado por um sistema de ensaios MTS. Problemas durante o ensaio dos corpos-de-prova CP3 dos concretos com $V_{f}=0,5 \%(\mathrm{~S})$ e $V_{f}=1,0 \%(\mathrm{~S})$ levaram ao término do ensaio para $\mathrm{CMOD} \approx 2,5 \mathrm{~mm} \mathrm{e} \approx 1,5 \mathrm{~mm}$, respectivamente (Figuras 3.12b e c).

$\mathrm{Na}$ Figura 3.12 são apresentadas as curvas tensão de tração na flexão-CMOD agrupadas por concretos com mesmos teor e tipo de fibras, enquanto na Figura 3.13 são juntadas as curvas referentes a todos os concretos, para fins de comparação global. Na Tabela 3.7 são listadas a resistência à tração na flexão $\left(f_{c t, f l}\right)$, a abertura (CMOD) correspondente $\mathrm{e}$ as tensões para CMOD $=0,5 \mathrm{~mm}, 1,5 \mathrm{~mm}, 2,5 \mathrm{~mm}$ e 3,5 $\mathrm{mm}$ e os valores das relações da FIB MC 2010 (2013) para verificação da possibilidade do uso destes concretos com fibras em substituição parcial ou total da armadura convencional.

Nessas figuras e tabela, pode-se observar que, exceto pela CMOD do CP1 de $V_{f}=0,5 \%(\mathrm{~S})$, para os concretos com $V_{f}=0$ e $V_{f}=0,5 \%(\mathrm{~S})$ a tensão de pico e correspondente CMOD foram similares. Entretanto, para determinado valor de 
CMOD, observou-se tensão residual menor nos com $V_{f}=0$. Os concretos com $V_{f}=1 \%$ tiveram maiores valores de resistência e correspondente CMOD e perda mais gradativa de resistência residual, notando-se a tendência de maiores valores para os concretos com fibras de maiores comprimento e fator de forma.

Todos os espécimes com fibras listados na Tabela 3.7 atendem os requisitos impostos pela FIB MC 2010 (2013) para seu uso em substituição parcial ou total da armadura convencional, que são:

$$
\begin{aligned}
& \frac{f_{c t, f l . r(C M O D=0,5 \mathrm{~mm})}}{f_{c t, f l}}>0,4 \\
& \frac{\left.f_{c t, f l, r(C M O D}=2,5 \mathrm{~mm}\right)}{f_{c t, f l, r(C M O D=0,5 \mathrm{~mm})}}>0,5
\end{aligned}
$$

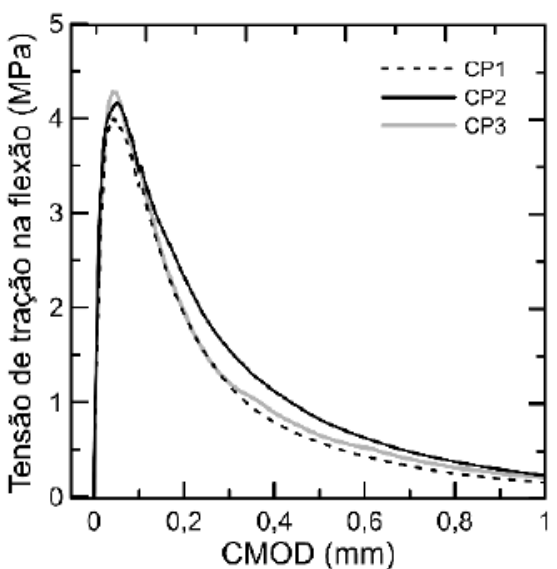

(a)

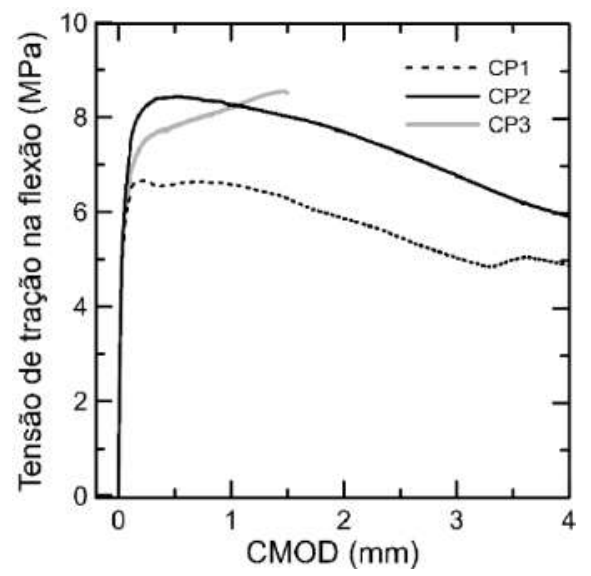

(c)

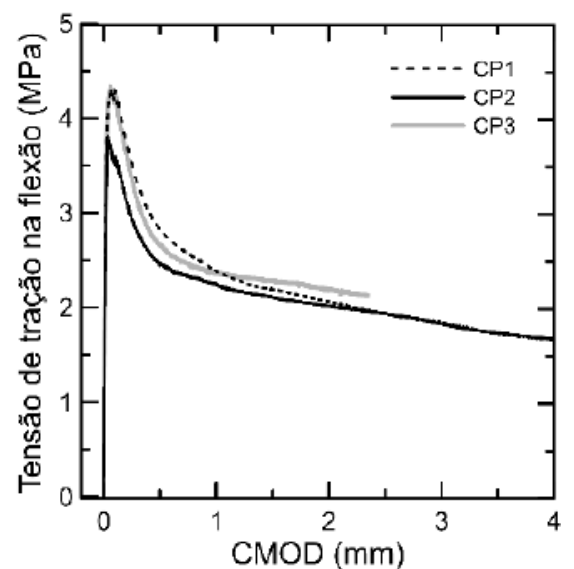

(b)

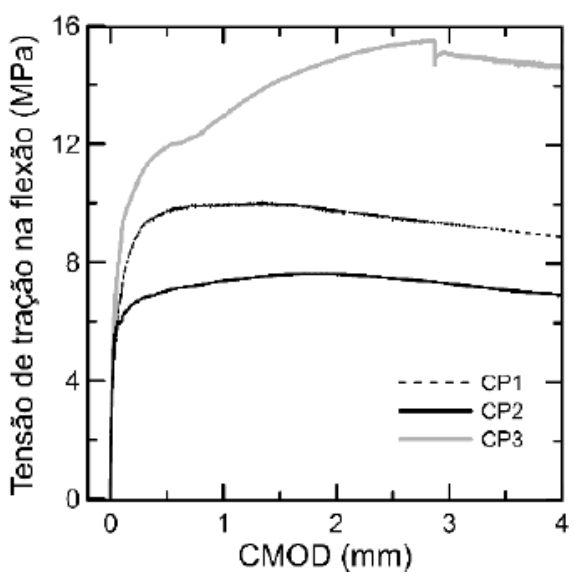

(d)

Figura 3.12 - Curvas tensão de tração na flexão - CMOD para os corpos de prova agrupados conforme teor e tipo de fibras: (a) $V_{f}=0 \%$; (b) $V_{f}=0,5 \%$ (S); (c) $V_{f}=1,0 \%(\mathrm{~S})$; (d) $V_{f}=1,0 \%(\mathrm{~L})$. 


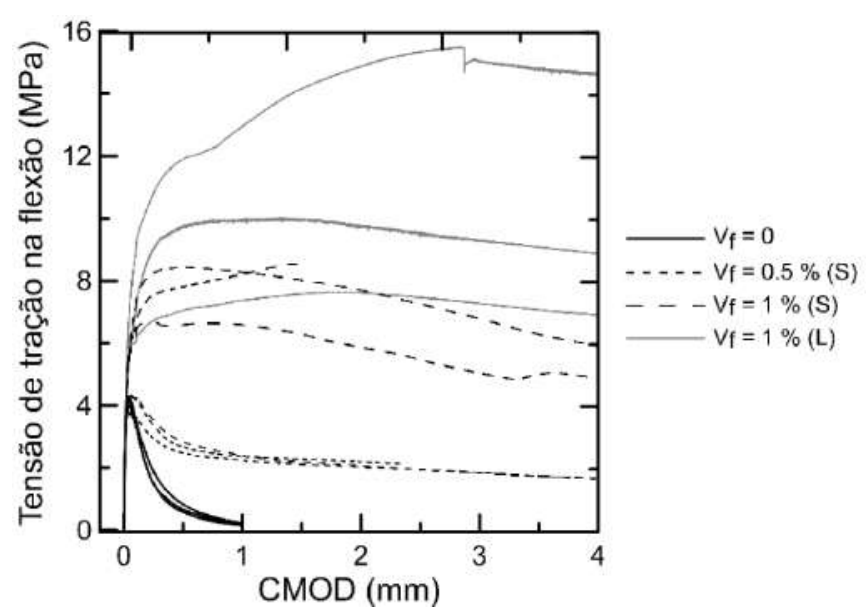

Figura 3.13 - Curvas tensão de tração na flexão - CMOD para todos os corposde-prova.

Tabela 3.7 - Valores da resistência à tração na flexão e correspondente CMOD, da tensão de tração residual $\left(f_{c t, f l, r}\right)$ para CMOD igual a $0,5,1,5,2,5$ e 3,5 mm e razões das inequações 3.1 e 3.2 (FIB MC 2010, 2013).

\begin{tabular}{|c|c|c|c|c|c|c|c|c|}
\hline$V_{f}(\%)$ & $\begin{array}{c}f_{c t, f l} \\
(\mathbf{M P a})\end{array}$ & $\begin{array}{c}\mathbf{C M O D}_{\mathrm{fct}, \mathrm{fl}} \\
\quad(\mathbf{m m})\end{array}$ & 0,5 & $\begin{array}{c}1,5 \\
f_{c t, f l, r}(1\end{array}$ & $\begin{array}{r}2,5 \\
\mathrm{MPa})\end{array}$ & 3,5 & ineq (3.1) & ineq $(3.2)$ \\
\hline $\mathbf{0}$ & 3,99 & 0,0442 & 0,579 & & & & & \\
\hline 0 & 4,16 & 0,0513 & 0,652 & & & & & \\
\hline $\mathbf{0}$ & 4,28 & 0,0427 & 0,819 & & & & & \\
\hline 0,5 (S) & 4,30 & 0,106 & 2,82 & 2,19 & 1,94 & 1,73 & 0,656 & 0,688 \\
\hline 0,5 (S) & 3,80 & 0,0373 & 2,47 & 2,11 & 1,94 & 1,73 & 0,650 & 0,785 \\
\hline 0,5 (S) & 4,34 & 0,0572 & 2,66 & 2,28 & & & 0,613 & \\
\hline $1(\mathrm{~S})$ & 6,67 & 0,229 & 6,58 & 6,28 & 5,46 & 4,98 & 0,987 & 0,830 \\
\hline $1(S)$ & 8,44 & 0,522 & $8,42 *$ & 8,01 & 7,25 & 6,27 & $0,998^{*}$ & $0,861^{*}$ \\
\hline $1(\mathrm{~S})$ & 8,54 & 1,46 & 7,81 & & 5,29 & 4,56 & & \\
\hline $1(\mathrm{~L})$ & 10,0 & 1,339 & $9,73 *$ & 9,94 & 9,51 & 9,08 & $0,973^{*}$ & 0,977 \\
\hline $1(\mathrm{~L})$ & 7,62 & 1,92 & $7,04 *$ & $7,57 *$ & 7,46 & 7,06 & $0,924^{*}$ & $1,06^{*}$ \\
\hline $1(\mathrm{~L})$ & 15,5 & 2,83 & $11,9 *$ & $14,2^{*}$ & $15,3 *$ & 14,8 & $0,768^{*}$ & $1,29^{*}$ \\
\hline
\end{tabular}

* Corpo-de-prova sem atingir $f_{c t, f l}$.

\section{2}

\section{Ensaios para estudo do efeito de pino}

\subsection{1}

\section{Introdução}

Com o objetivo de investigar experimentalmente a influência do efeito de pino na resistência à força cortante de vigas de concreto armado sem e com fibras de aço, foi desenvolvido um programa experimental contendo 16 espécimes. $\mathrm{O}$ modelo adotado para estes ensaios foi do mesmo tipo do usado por Krefeld \& 
Thurston (1966), Baumann \& Rush (1970) e Taylor (1974), que, dentre os que têm sido usados, parece melhor simular as condições em vigas.

Foram variáveis dos espécimes os seguintes parâmetros: diâmetro $(\phi=12,5 \mathrm{~mm}$ ou $16 \mathrm{~mm}$ ) e tipo e teor de fibras ( $\mathrm{S}$ ou L, cujas propriedades estão na Tabela 3.1, p. 99; $V_{f}=0 \%, 0,5 \%$ ou $1 \%$ ). Foram mantidos constantes geometria, número de barras de aço da armadura de tração longitudinal $(n=2)$, abertura fictícia $\left(w_{f i c}=5 \mathrm{~mm}\right)$ e os cobrimentos lateral $\left(c_{s}=3,0 \mathrm{~mm}\right)$ e de fundo $\left(c_{b}=25 \mathrm{~mm}\right)$.

Para o caso dos concretos sem fibras, foi fabricado um exemplar para cada determinado conjunto de parâmetros variados, e, para o dos com fibras, dois espécimes. Para os espécimes sem fibras e com fibras (tipo $\mathrm{S}, V_{f}=1 \%$ ) e $\phi=12,5 \mathrm{~mm}$ e $16 \mathrm{~mm}$, foram repetidos os ensaios com instrumentação adicional à usada nos demais ensaios: maior número de transdutores de deslocamento e câmeras para mapeamento completo do campo de deslocamentos por meio da Correlação de Imagem Digital (CID).

\section{2 .2 \\ Espécimes}

\subsubsection{1 \\ Características}

Os espécimes tinham geometria prismática, com $0,15 \mathrm{~m}$ de largura, 0,25 m de altura e 1,20 m de comprimento. A região central inferior tinha um bloco densamente armado, isolado e distando $5 \mathrm{~mm}$ da outra parte do espécime, que, carregado no seu topo, transmitia carga à armadura longitudinal, elemento de ligação entre as duas partes do espécime. Acima do topo do bloco havia uma região vazada, a fim de dar apoio ao sistema de transmissão de carga para o bloco.

Na Tabela 3.8 são listadas as características dos espécimes ensaiados, que são nomeados de acordo com o diâmetro das barras de aço da armadura longitudinal de tração e teor e tipo de fibra (entre parênteses). Os que foram ensaiados com o emprego de fotogrametria, têm sua identificação iniciada com a letra " $\mathrm{D}$ ”. As letras a e b identificam espécimes com mesmas características. 
Tabela 3.8 - Características dos espécimes.

\begin{tabular}{ccccc}
\hline Espécime & $\boldsymbol{l}_{\boldsymbol{f}} / \boldsymbol{d}_{\boldsymbol{f}}$ & $\left(\boldsymbol{V}_{\boldsymbol{f}} \boldsymbol{l}_{\boldsymbol{f}} / \boldsymbol{d}_{\boldsymbol{f}}\right) \boldsymbol{\%} \boldsymbol{f}_{\boldsymbol{c} t} \mathbf{\text { ou }} \boldsymbol{f}_{\boldsymbol{c t}, \boldsymbol{s} \boldsymbol{p}}{ }^{*}(\mathbf{M P a})$ & $\boldsymbol{b}_{\boldsymbol{n}}(\mathbf{m m})$ \\
\hline $\mathbf{1 2 , 5}$ & - & - & $2,88^{*}$ & 125 \\
$\mathbf{D 1 2 , 5}$ & - & - & $2,88^{*}$ & 125 \\
$\mathbf{1 6}$ & - & - & $2,88^{*}$ & 118 \\
$\mathbf{D 1 6}$ & - & - & $2,88^{*}$ & 118 \\
$\mathbf{1 2 , 5 ( 0 , 5 S ) a}$ & 45 & 22,5 & 2,51 & 125 \\
$\mathbf{1 2 , 5 ( 0 , 5 S ) b}$ & 45 & 22,5 & 2,51 & 125 \\
$\mathbf{1 2 , 5 ( 1 S ) a}$ & 45 & 45 & 3,34 & 125 \\
$\mathbf{1 2 , 5 ( 1 S ) b}$ & 45 & 45 & 3,34 & 125 \\
$\mathbf{D 1 2 , 5 ( 1 S )}$ & 45 & 45 & 3,34 & 125 \\
$\mathbf{1 2 , 5 ( 1 L ) a}$ & 80 & 80 & 3,15 & 125 \\
$\mathbf{1 2 , 5 ( 1 L ) b}$ & 80 & 80 & 3,15 & 125 \\
$\mathbf{1 6}(\mathbf{0 , 5 S}) \mathbf{a}$ & 45 & 22,5 & 2,51 & 118 \\
$\mathbf{1 6 ( 0 , 5 S ) b}$ & 45 & 22,5 & 2,51 & 118 \\
$\mathbf{1 6}(\mathbf{1 S}) \mathbf{a}$ & 45 & 45 & 3,34 & 118 \\
$\mathbf{1 6}(\mathbf{1 S}) \mathbf{b}$ & 45 & 45 & 3,34 & 118 \\
$\mathbf{D 1 6}(\mathbf{1 S})$ & 45 & 45 & 3,34 & 118 \\
\hline
\end{tabular}

Duas barras de aço CA-50; $b_{w}=150 \mathrm{~mm} \mathrm{e} h=250 \mathrm{~mm} ; c_{s}=30 \mathrm{~mm}, c_{b}=25 \mathrm{~mm} \mathrm{e} w_{f i c}=5 \mathrm{~mm}$; $b_{n}=$ largura de concreto no nível da armadura $\left(b_{w}-2 \phi\right)$

As Figuras 3.14 e 3.15 mostram as dimensões do espécime e o detalhamento da armadura do bloco.
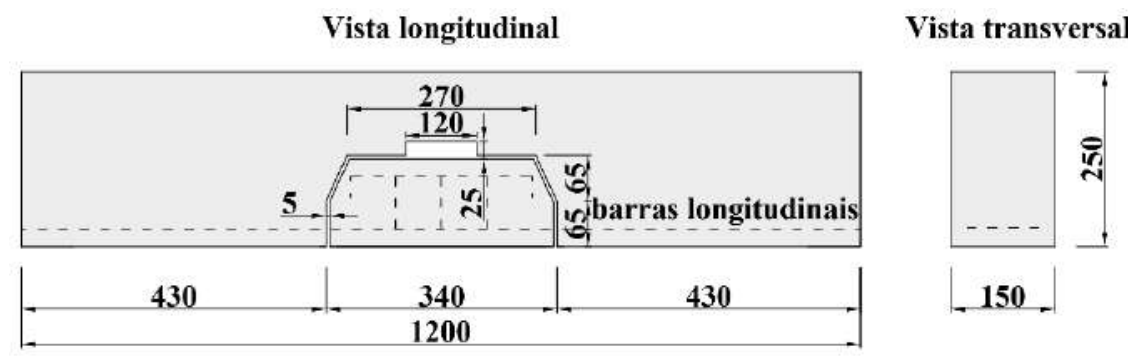

Figura 3.14 - Dimensões do espécime em mm.

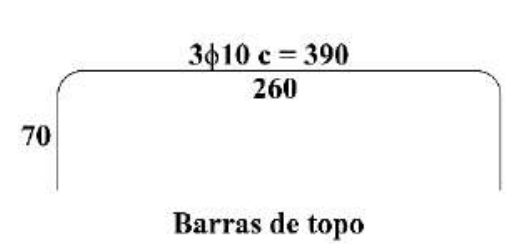

(a)

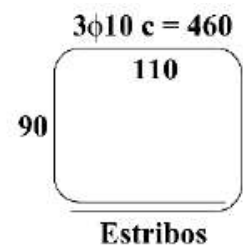

Estribos

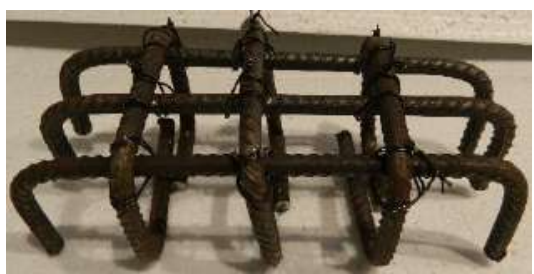

(b)

Figura 3.15 - Armaduras do bloco central: (a) Detalhamento (dimensões em mm);

(b) gaiola de armaduras do bloco. 


\subsubsection{2 Construção}

Foram utilizados madeira de compensado naval para a elaboração das formas, poliestireno expandido para a região de vazios, espaçadores de plástico para garantir os cobrimentos, e betoneira com capacidade de $400 \mathrm{~L}$ para confeccionar o concreto.

A fabricação dos espécimes se deu em duas etapas: a primeira etapa consistiu no posicionamento da gaiola de armaduras (armaduras do bloco amarradas com as barras longitudinais da viga) na forma do espécime (Figura 3.16a) e a montagem da forma do bloco (Figura 3.16b). Com esta forma devidamente vedada e desmoldante aplicado, procedeu-se à concretagem do bloco. Na segunda etapa, 24 horas após a concretagem do bloco, foram feitas a retirada da forma do bloco e a cobertura da superfície do bloco com poliestireno expandido envolvido por filme plástico (Figura 3.16c). Feito isto e aplicado desmoldante na forma, foi feita a concretagem do restante do espécime. A fim de facilitar seu manuseio no estado endurecido, ganchos foram posicionados nas extremidades do espécime com o concreto ainda fresco (Figura 3.16d).

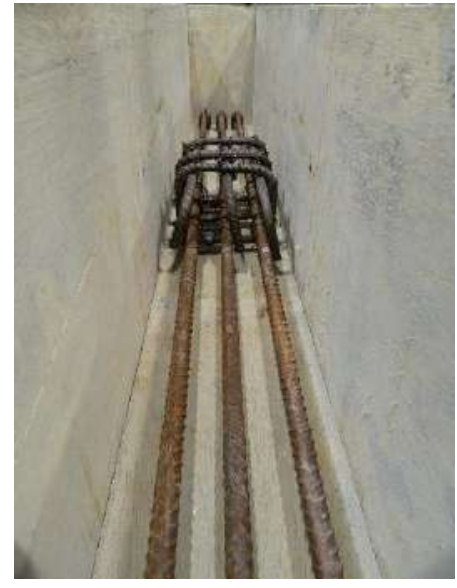

(a)

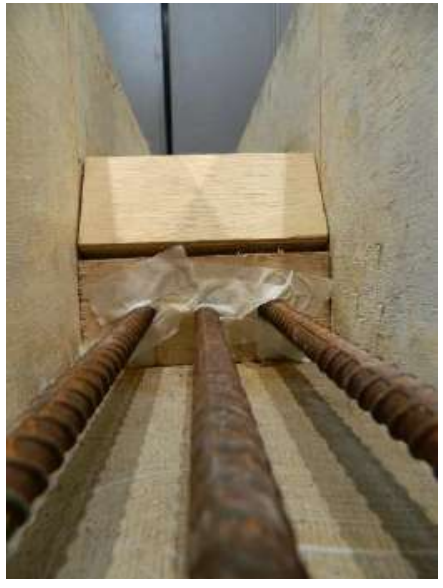

(b)

Figura 3.16 (continua) - Principais etapas de moldagem dos espécimes: (a) gaiola de armaduras no interior da forma; (b) forma do bloco devidamente montada e vedada; (c) bloco concretado e envolvido por poliestireno expandido; (d) concretagens finalizadas. 


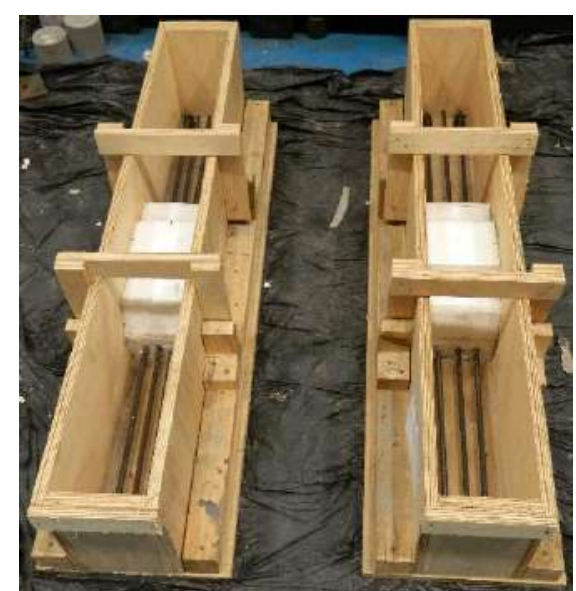

(c)

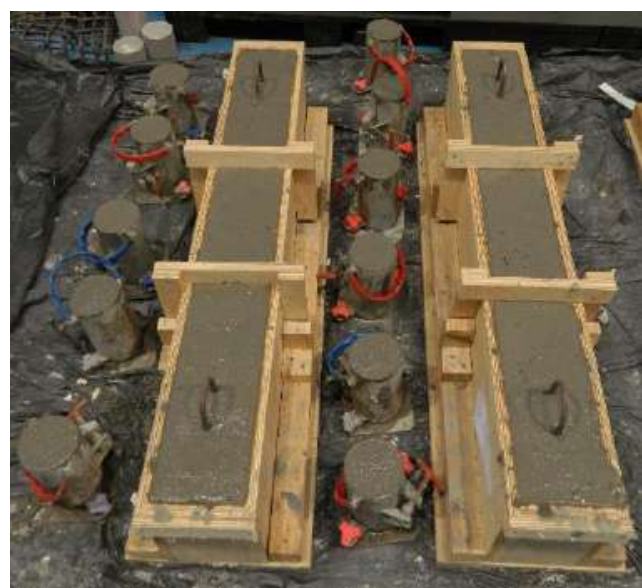

(d)

Figura 3.16 (continuação) - Principais etapas de moldagem dos espécimes: (a) gaiola de armaduras no interior da forma; (b) forma do bloco devidamente montada e vedada; (c) bloco concretado e envolvido por poliestireno expandido; (d) concretagens finalizadas.

Os espécimes receberam adensamento por vibração decorrente de golpes de martelo de borracha na superfície externa das formas. Eles foram molhados e cobertos com filme plástico nas primeiras 24 horas e, após 72 horas, foram desmoldados e deixados sob as condições ambientais do laboratório.

\subsection{3 \\ Ensaios sem fotogrametria}

\subsubsection{1}

\section{Esquema de ensaio}

Os espécimes foram simplesmente apoiados e submetidos a carga única no topo do bloco. Para obter o deslocamento vertical relativo da barra longitudinal $(\Delta)$, dois transdutores de deslocamento foram posicionados na região central do bloco e outros quatro fora dele, sendo um par imediatamente antes e um par imediatamente depois da fissura fictícia, totalizando 6 transdutores. O esquema de ensaio é apresentado na Figura 3.17.

O aparato metálico para a transferência de carga do atuador para o topo do bloco foi construído pela soldagem de chapas de aço em forma de U (Figura 3.18a) que se apoiavam em outra chapa simplesmente apoiada no topo do bloco. $\mathrm{Na}$ Figura 3.18 b é apresentado detalhe deste aparato. 

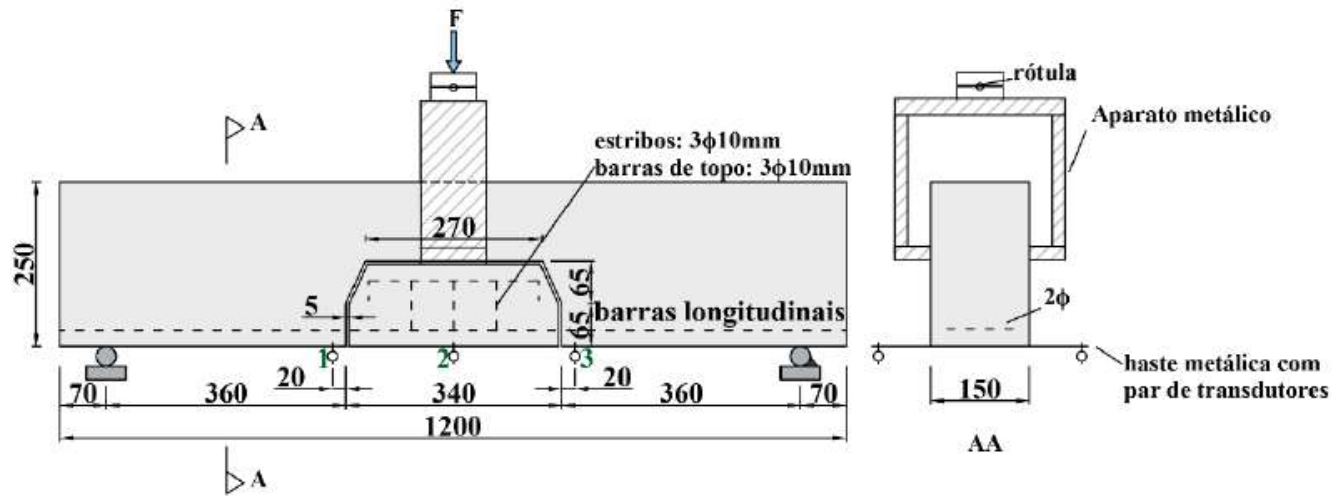

Figura 3.17 - Esquema de ensaio de efeito de pino sem fotogrametria e numeração dos transdutores de deslocamento. Dimensões em mm.

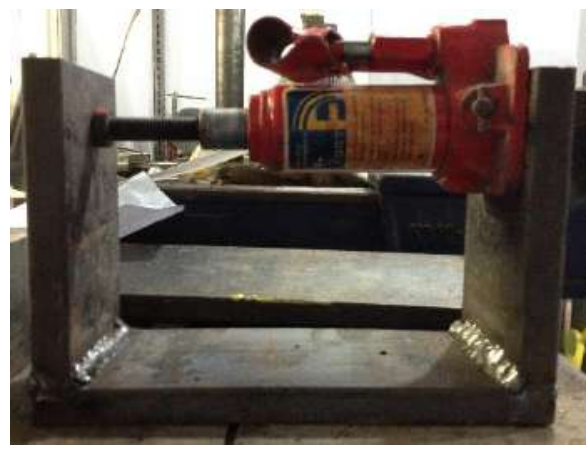

(a)

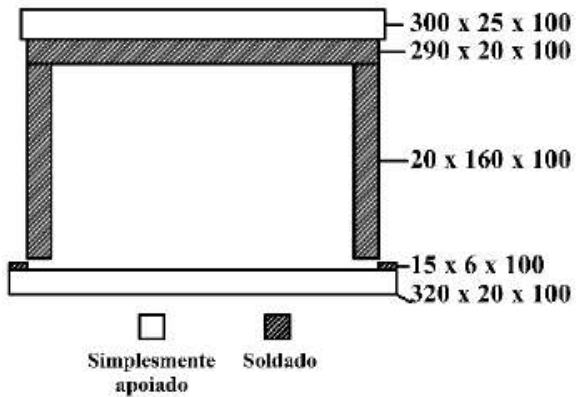

(b)

Figura 3.18 - Sistema de aplicação de carga: (a) Chapas de aço soldadas em forma de U; (b) Detalhamento. Dimensões em mm.

\subsubsection{2 \\ Preparação dos espécimes para ensaio}

Injetou-se acetona nas peças de poliestireno expandido a fim de removê-las e pedaços remanescentes foram retirados com o auxílio de espátula. A seguir, foram feitos o posicionamento do espécime no local de ensaio e seu alinhamento em relação ao atuador, nas duas direções, e instalados os transdutores de deslocamento.

\subsubsection{3}

\section{Execução do ensaio}

Para aplicação de carga, foi utilizado um atuador hidráulico com capacidade de $500 \mathrm{kN}$ controlado por um sistema MTS.

Os ensaios foram controlados por deslocamento, a uma taxa de $0,3 \mathrm{~mm} / \mathrm{min}$ e conduzidos até o deslocamento do atuador atingir no mínimo $6 \mathrm{~mm}$ e $11 \mathrm{~mm}$ para 
os espécimes sem e com fibras de aço, respectivamente. A duração aproximada dos ensaios dos espécimes de concretos sem e com fibras foi de 30 minutos e 45 minutos, respectivamente.

Os transdutores de deslocamento tiveram o registro das medições feitas com um sistema de aquisição HBM QuantumX MX440B.

Na Figura 3.19 mostra-se um espécime posicionado para ensaio sem fotogrametria.

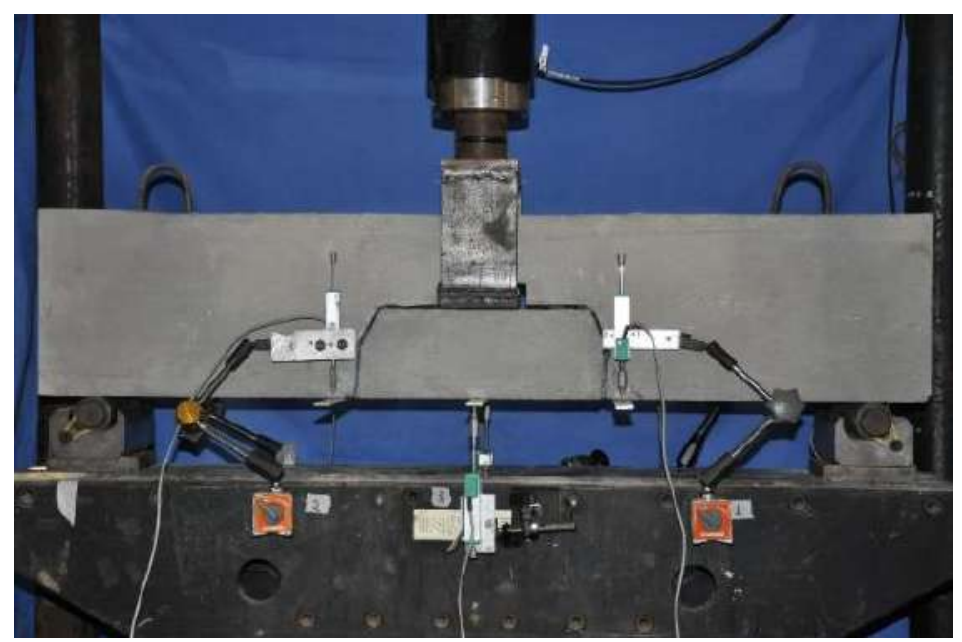

Figura 3.19 - Esquema de ensaio de efeito de pino sem fotogrametria.

\subsection{4 \\ Ensaios com fotogrametria}

\subsubsection{1}

\section{Esquema de ensaio}

À instrumentação adotada nos ensaios sem fotogrametria (item 3.2.3.1) adicionaram-se dois pares de transdutores para medir deslocamento vertical nas extremidades do bloco. Uma face lateral foi preparada para o acompanhamento do campo de deslocamentos por duas câmeras (Canon EOS Rebel T6i e Nikon D3300, ambas com 24 megapixels e lente 18-55 mm f/3.5-5.6), sendo cada uma responsável pelo registro fotográfico de metade do espécime.

Na Figura 3.20 é ilustrado o esquema de ensaio com fotogrametria. 


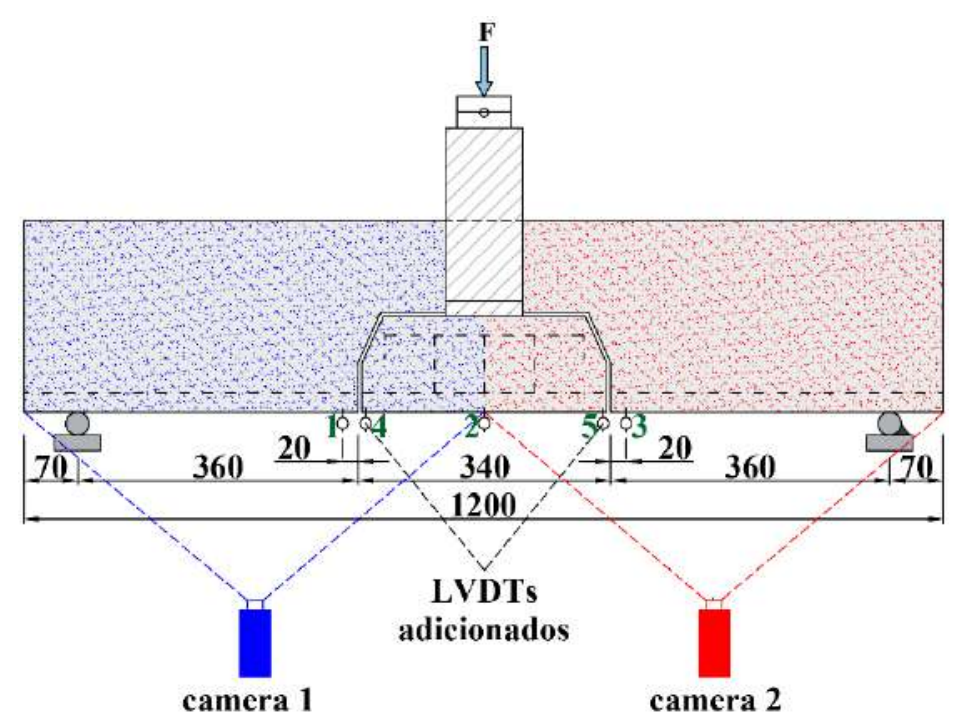

Figura 3.20 - Esquema de ensaio de efeito de pino com fotogrametria e numeração dos transdutores de deslocamento. Dimensões em mm.

\subsubsection{2}

\section{Preparação dos espécimes para ensaio}

Posteriormente à remoção do poliestireno expandido da fissura fictícia, iniciou-se o processo de pintura dos espécimes para a fotogrametria. Foi aplicado primeiramente um padrão de fundo branco fosco e, depois de sua secagem, um padrão de pontos pretos foscos espaçados aleatoriamente. $\mathrm{O}$ processo foi manual $\mathrm{e}$ com tinta spray. Depois da secagem da pintura, foram realizados o posicionamento e o alinhamento do espécime em relação ao atuador, nas duas direções. Por último, instalaram-se os transdutores de deslocamento.

\subsubsection{3}

\section{Execução do ensaio}

O procedimento de execução dos ensaios foi o mesmo descrito no item 3.2.3.3, com a adição do relativo à fotogrametria. A Figura 3.21 mostra uma viga preparada para ser ensaiada. 


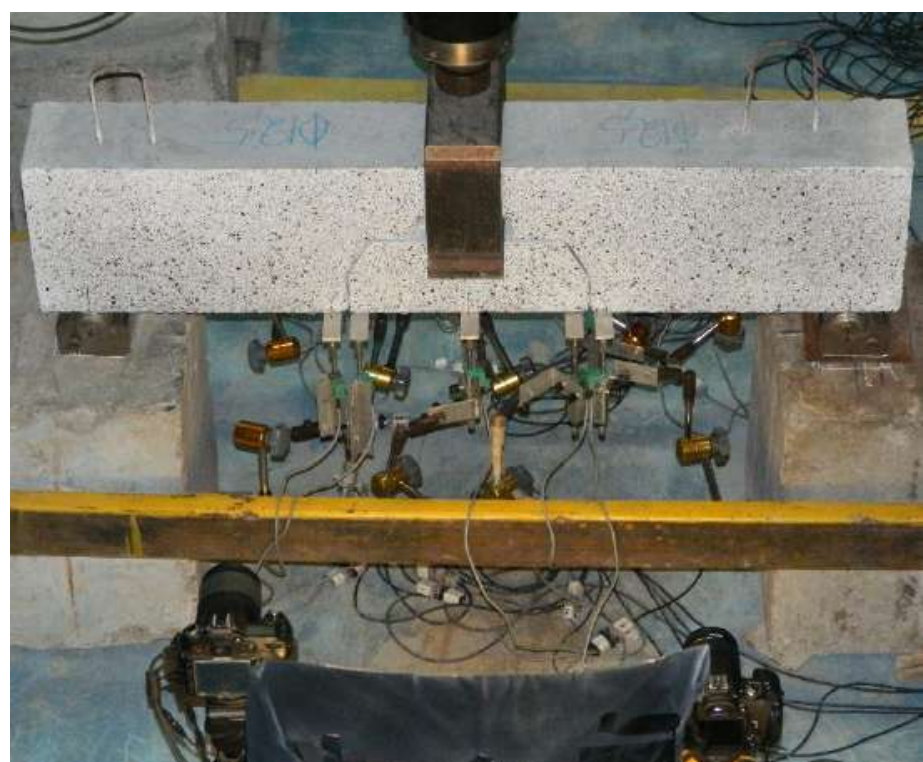

Figura 3.21 - Viga preparada para ensaio com fotogrametria.

As fotografias foram tiradas em uma resolução mínima de 6,9 megapixels e a uma frequência de $0,50 \mathrm{~Hz}$. A aquisição destas fotos foi realizada pelo software digiCamControl, de modo independente da dos demais dados.

As câmeras foram ajustadas em um tripé para registrar a área de interesse (600 mm x $250 \mathrm{~mm}$ ) durante o ensaio. Para evitar variação de luminosidade na superfície fotografada, foi utilizada uma fonte luminosa composta por duas lâmpadas amarelas de potência de $12,5 \mathrm{~W}$ antepostas a um tecido TNT, de modo a ter-se uma luminosidade difusa. Na Figura 3.22 mostra-se a região do espécime fotografada por cada câmera. A duração dos ensaios foi a mesma do caso sem fotogrametria.

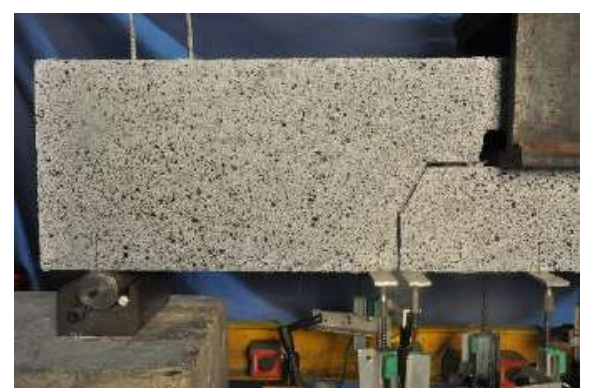

(a)

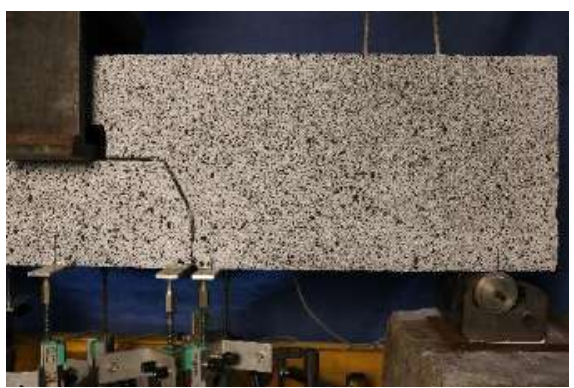

(b)

Figura 3.22 - Regiões dos espécimes registradas pelas câmeras: (a) esquerda e (b) direita. 


\section{3 Ensaios para estudo do engrenamento dos agregados}

\subsection{1}

Introdução

A fim de investigar experimentalmente a parcela de engrenamento dos agregados na resistência à força cortante de vigas de concreto sem e com fibras de aço, foram produzidos 12 espécimes, sendo 3 para cada tipo de concreto. $\mathrm{Na}$ Tabela 3.9 são listados os espécimes ensaiados.

Tabela 3.9 - Espécimes ensaiados.

\begin{tabular}{|c|c|c|c|}
\hline Espécime & $l_{f} / d_{f}$ & $\left.l_{f} / d_{f}\right)$ & $f_{c t, s p}{ }^{*}(\mathrm{MPa})$ \\
\hline $\mathrm{P}(0) \mathrm{a}$ & & & \\
\hline $\mathrm{P}(0) \mathrm{b}$ & - & - & $2,88^{*}$ \\
\hline$P(0) c$ & & & \\
\hline $\mathrm{P}(0,5 \mathrm{~S}) \mathrm{a}$ & & & \\
\hline $\mathrm{P}(0,5 \mathrm{~S}) \mathrm{b}$ & 45 & 22,5 & 2,51 \\
\hline $\mathrm{P}(0,5 \mathrm{~S}) \mathrm{c}$ & & & \\
\hline $\mathrm{P}(1 \mathrm{~S}) \mathrm{a}$ & & & \\
\hline $\mathrm{P}(1 \mathrm{~S}) \mathrm{b}$ & 45 & 45 & 3,34 \\
\hline $\mathrm{P}(1 \mathrm{~S}) \mathrm{c}$ & & & \\
\hline $\mathrm{P}(1 \mathrm{~L}) \mathrm{a}$ & & & \\
\hline$P(1 L) b$ & 80 & 80 & 3,15 \\
\hline $\mathrm{P}(1 \mathrm{~L}) \mathrm{c}$ & & & \\
\hline
\end{tabular}

O modelo de ensaio adotado foi o do tipo pushoff, uma vez que ele permite a obtenção das tensões e dos deslocamentos nas direções normal e tangencial ao plano de cisalhamento (item 2.2.2).

\subsection{2}

\section{Espécimes}

\subsubsection{1}

\section{Características}

Os espécimes tinham seção de cisalhamento retangular de dimensões $100 \mathrm{~mm}$ x $260 \mathrm{~mm}$, partes em "L" armadas com barras de diâmetro de 12,5 mm no contorno e 6 estribos de diâmetro $6,3 \mathrm{~mm}$, e um entalhe nas duas faces laterais 
opostas contornando a seção de cisalhamento. Nas Figuras 3.23 e 3.24 mostram-se geometria e armaduras dos espécimes, respectivamente.

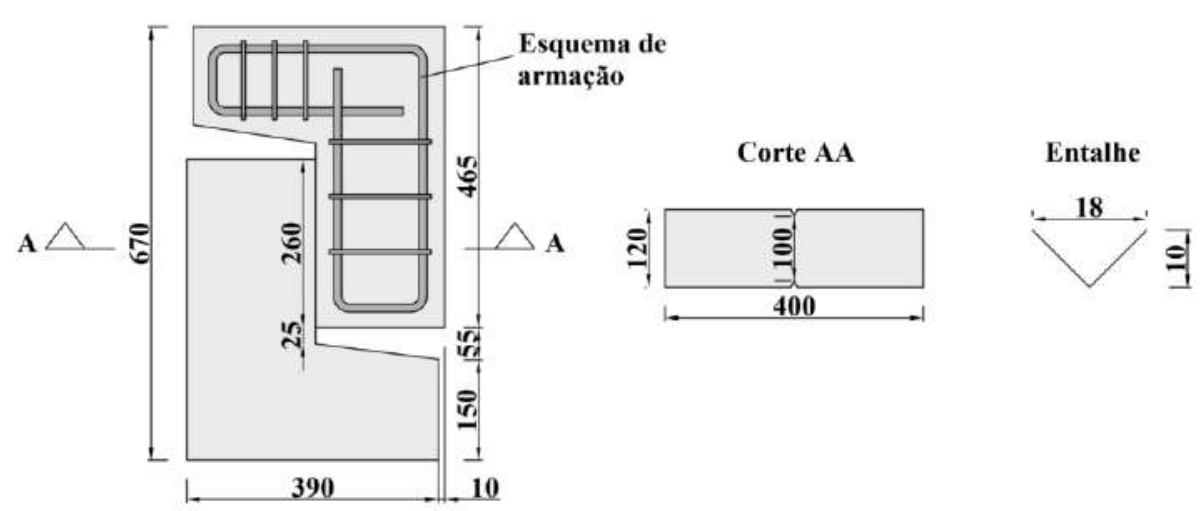

Figura 3.23 - Geometria dos espécimes. Dimensões em mm.

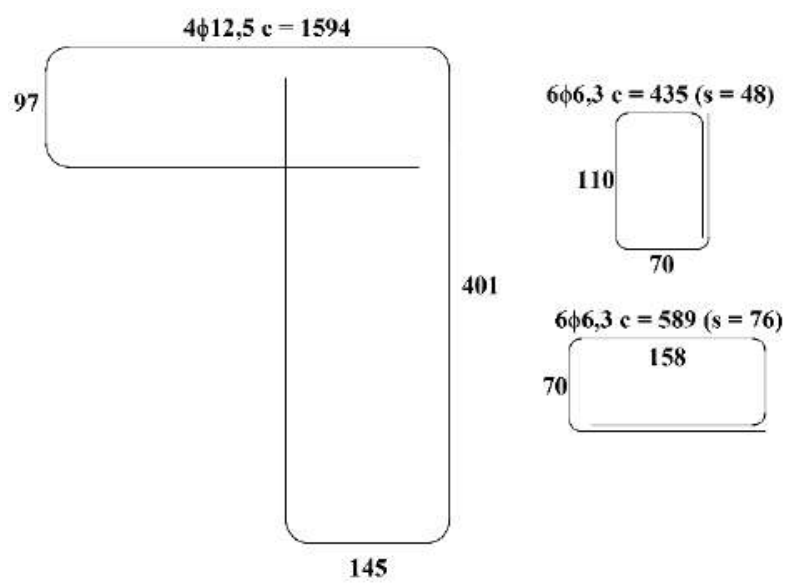

Figura 3.24 - Detalhamento das armaduras (CA-50). Dimensões em mm.

\subsubsection{2 \\ Construção}

Foram utilizados madeira de compensado naval para a elaboração das formas, cantoneira de alumínio para produzir o entalhe, espaçadores de plástico para garantir o cobrimento de $25 \mathrm{~mm}$, e betoneira com capacidade de $400 \mathrm{~L}$ para confeccionar o concreto.

Para obter a redução do comprimento de um dos lados do trecho "L" do espécime, na forma foi colado poliestireno expandido com espessura de $10 \mathrm{~mm}$ envolto por filme plástico (Figuras 3.23 e 3.25). O entalhe de um lado foi realizado pela colagem de fita crepe na cantoneira de alumínio e na forma; no outro lado foi feito após a concretagem, com o posicionamento da cantoneira sobre o concreto 
ainda fresco. Previamente ao lançamento do concreto foi aplicado desmoldante na forma. Na Figura 3.25 são ilustradas as situações anterior e posterior à moldagem do espécime.

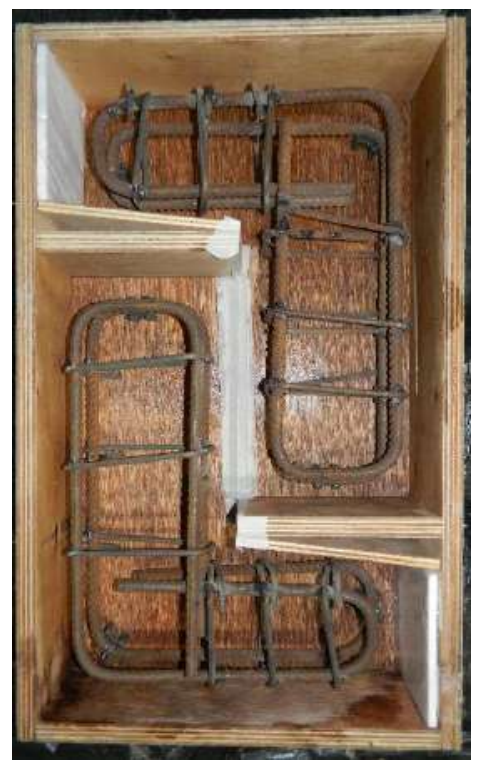

(a)

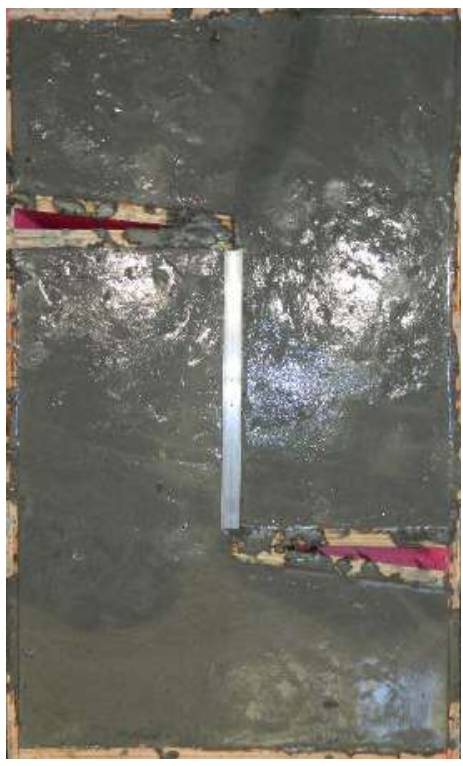

(b)

Figura 3.25 - Construção do espécime: (a) Forma com armaduras e cantoneira para formação do entalhe na face inferior; (b) Espécime após concretagem com cantoneira para formação do entalhe na face superior.

Os espécimes receberam adensamento por vibração decorrente de golpes de martelo de borracha na superfície externa das formas, a não ser os com fibras de maior comprimento, nos quais foi utilizado vibrador de imersão, tendo em vista a dificuldade deste concreto fluir por entre as armaduras. Após a concretagem, os espécimes foram molhados e cobertos com filme plástico durante as primeiras 24 horas e, após 72 horas, foram desmoldados e deixados sob as condições ambientais do laboratório. 


\subsection{3}

\section{Ensaios}

\subsubsection{1}

\section{Esquema de ensaio}

O esquema de ensaio foi tal que permitisse obter simultaneamente as tensões cisalhante $(\tau)$ e normal $(\sigma)$ e os deslocamentos relativos transversal $(w)$ e longitudinal $(\Delta)$ ao longo do plano de cisalhamento.

Para obtenção da tensão normal, o espécime foi colocado entre duas chapas de aço suficientemente rígidas ( $\mathrm{n}^{\circ} 2$ na Fig 3.26) conectadas entre si por quatro barras de aço externas instrumentadas com extensômetros elétricos. Estas barras rosqueadas tinham diâmetro de $\phi=25 \mathrm{~mm}$ (diâmetro interno de $20 \mathrm{~mm}$ ) e foram instrumentadas com dois extensômetros elétricos colados em posições diametralmente opostas na região do plano de cisalhamento ( $n^{\circ} 3$ na Fig 3.26). A ligação entre as barras e a chapa de aço se deu por meio de uma porca em cada extremidade. De modo a evitar esforços nas barras não relacionados à força normal, foi colocado um sistema deslizante composto por quatro roletes ( $\phi=19 \mathrm{~mm}$ ) ao lado do "L" deslizante ( $\mathrm{n}^{\circ} 4$ na Fig 3.26) entre uma das chapas conectadas pelas barras e a chapa do mesmo lado em contato com o espécime ( ${ }^{\circ} 5$ na Fig 3.26, de dimensões iguais às da seção de cisalhamento).

Este sistema de aço foi projetado visando deixar a altura da seção de cisalhamento desobstruída durante o ensaio, para viabilizar a aquisição dos campos de deslocamentos via fotogrametria em uma face e, na outra, a fixação dos transdutores de deslocamento no espécime.

Para não impor restrição à abertura de fissura, roletes foram usados entre duas chapas de aço no sistema ação-reação de carga vertical (n 1 na Fig 3.26).

A Figura 3.26 mostra o esquema de ensaio, peças usadas na montagem e posicionamento da instrumentação. 


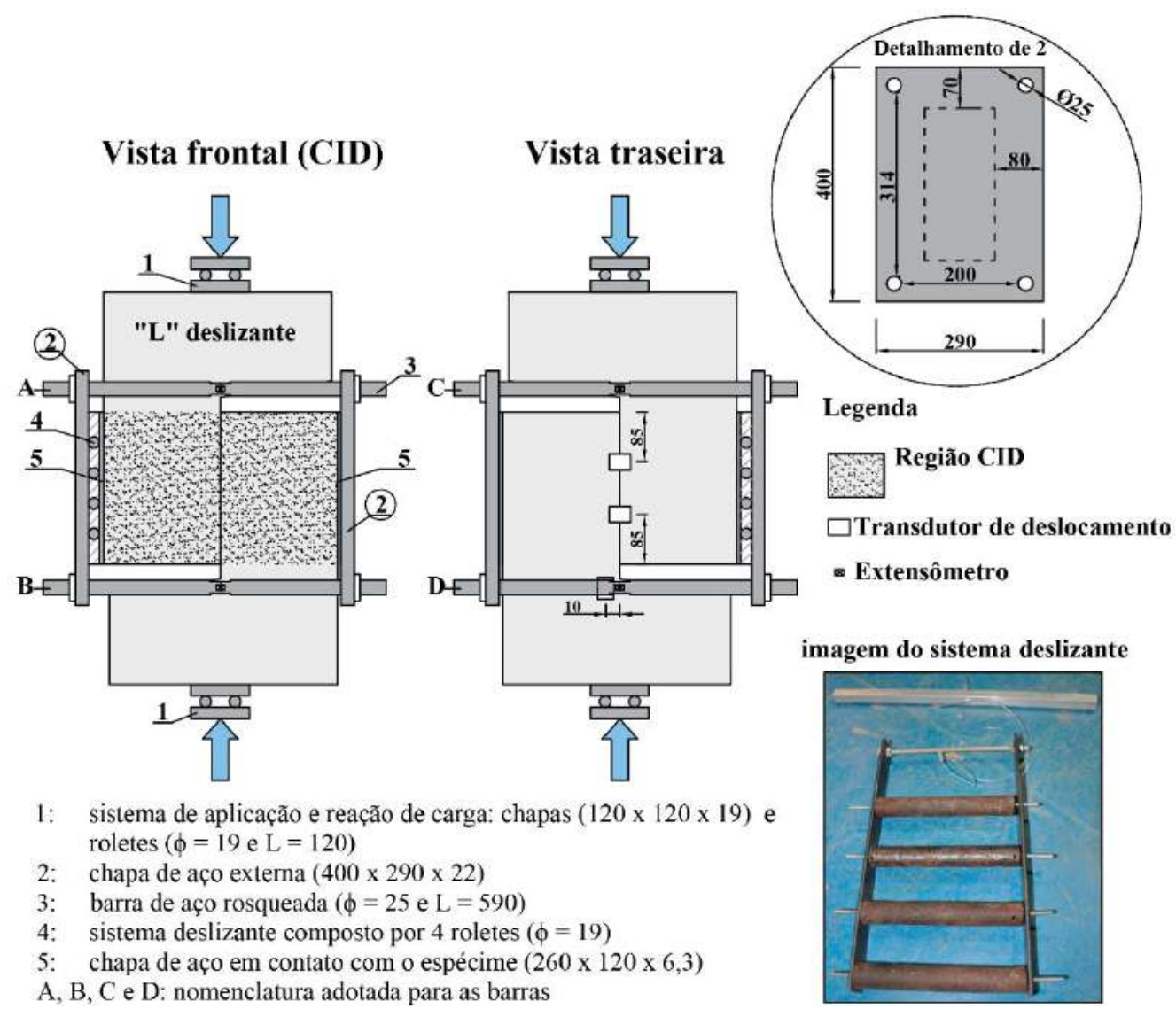

Figura 3.26 - Esquema de ensaio, peças usadas e posicionamento dos transdutores de deslocamento. Dimensões em mm.

\subsubsection{2}

\section{Caracterização e calibração das barras rosqueadas}

Para obter as curvas tensão normal de tração - deformação específica, foram ensaiadas três barras rosqueadas do mesmo lote que as usadas no ensaio pushoff, com comprimento de $50 \mathrm{~cm}$. Na sua região central foi retirada a rosca para possibilitar a colagem de dois extensômetros elétricos de resistência em posições diametralmente opostas. Nos ensaios, feitos com controle de deslocamento à velocidade de 0,5 mm/min, foi utilizada uma máquina universal MTS modelo 311 com capacidade de carga de $1000 \mathrm{kN}$. Na Figura 3.27 vê-se uma das barras posicionada para o ensaio e na Figura 3.28 as curvas tensão normal - deformação específica. 


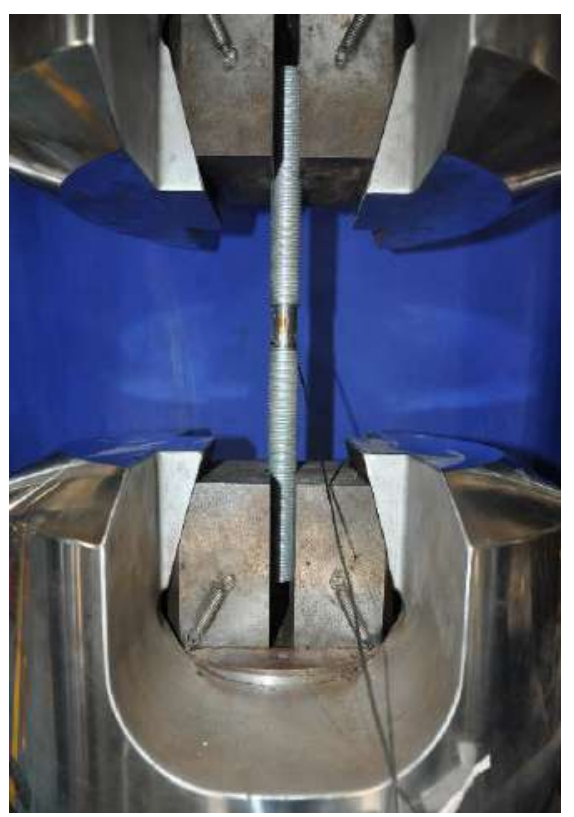

Figura 3.27 - Barra de aço rosqueada posicionada para o ensaio.

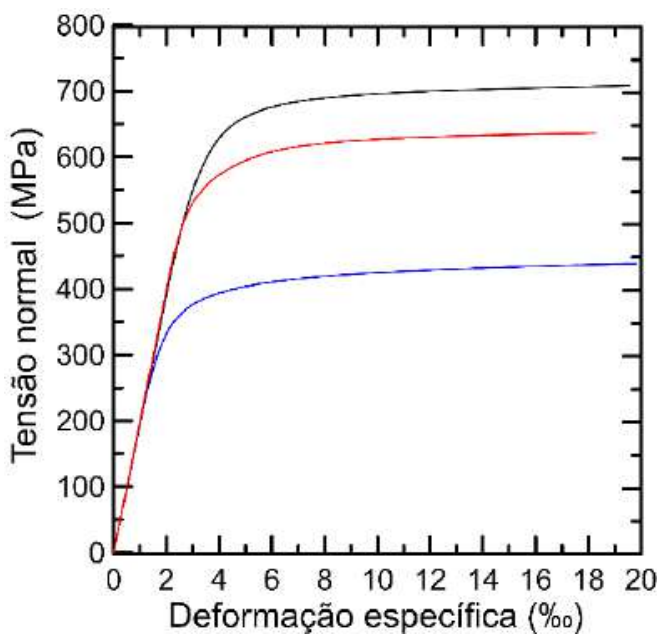

Figura 3.28 - Curvas tensão normal de tração - deformação específica das barras rosqueadas.

Face à expectativa de que a força máxima em cada barra durante o ensaio pushoff não superaria $50 \mathrm{kN}$, ou seja, tensão normal de cerca de $176 \mathrm{MPa}$ (para $\phi_{\mathrm{e}}=19 \mathrm{~mm}$ ), concluiu-se que as barras trabalhariam em regime linear elástico, permitindo, assim, uma correlação linear entre deformação específica e força.

Com o intuito de calibrar as 4 barras a serem usadas nos ensaios pushoff para medição indireta de força normal atuando na seção de cisalhamento, elas foram ensaiadas à tração para o intervalo de carga de 0 a $50 \mathrm{kN}$. Cada barra foi submetida a quatro ciclos de carga e descarga, até $50 \mathrm{kN}$ a uma velocidade de $5 \mathrm{kN} / \mathrm{min}$ e descarga a uma velocidade de $25 \mathrm{kN} / \mathrm{min}$. 
De modo a evitar dano nas extremidades das barras rosqueadas se em contato com as garras da máquina de ensaio, elas foram ligadas a outras barras como mostra a Figura 3.29.

As relações força - deformação específica obtidas estão na Figura 3.30.

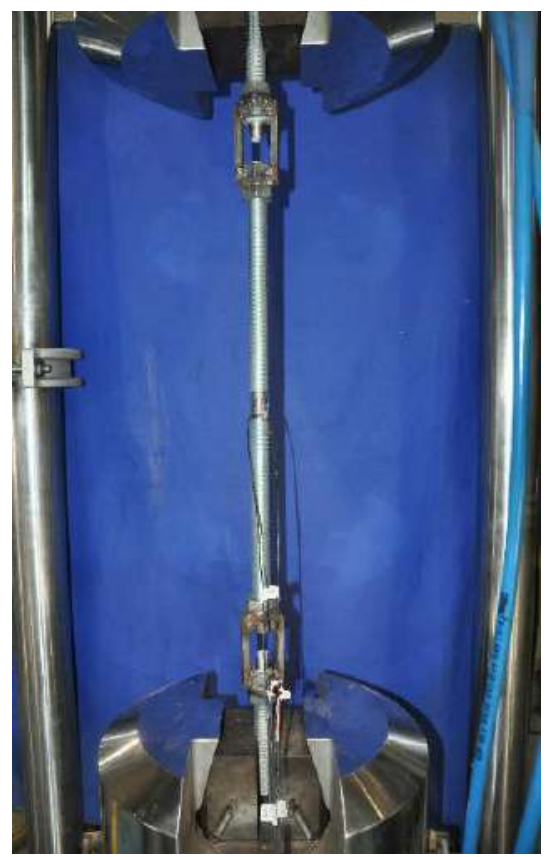

Figura 3.29 - Esquema de ensaio para calibração das barras rosqueadas utilizadas no ensaio pushoff.

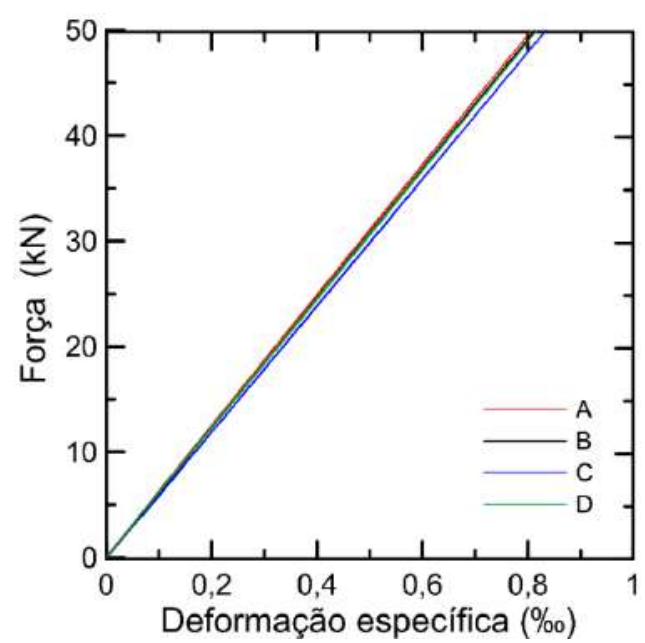

Figura 3.30 - Curvas força de tração - deformação específica para as barras rosqueadas usadas no ensaio de pushoff. As barras "A", "B", "C" e "D" são indicadas na Figura 3.26. 


\subsubsection{3}

\section{Preparação dos espécimes para ensaio}

Cerca de uma semana antes da execução do ensaio iniciou-se o processo de pintura dos espécimes para a CID. Foi aplicado primeiramente um padrão de fundo branco fosco e, depois de sua secagem, um padrão de pontos pretos foscos espaçados aleatoriamente (Figura 3.31). O processo foi manual e com tinta spray.

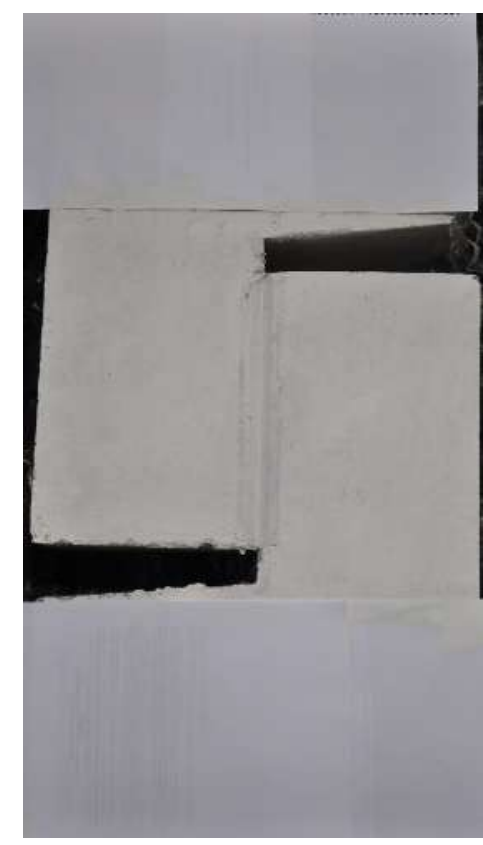

(a)

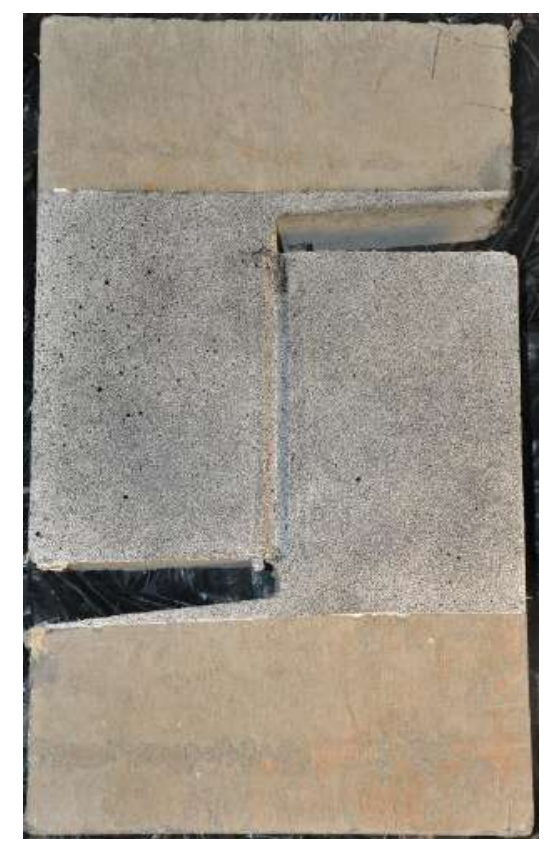

(b)

Figura 3.31 - Pintura do espécime para CID: (a) padrão de fundo branco fosco aplicado; (b) padrão completo.

O processo de montagem e posicionamento de cada espécime para ensaio foi feito em duas etapas. Em um dia posicionaram-se os transdutores de deslocamento e as chapas do lado "L" não deslizante (Fig 3.26: vista frontal, chapas à direita). No outro, foi colada a chapa de contato com o espécime do lado "L" deslizante (Fig 3.26: vista frontal, peça $n^{\circ} 5$ à esquerda), encaixado o sistema deslizante (Fig 3.26: peça $n^{\circ} 4$ ), a chapa externa (Fig 3.26: vista frontal, peça $n^{\circ} 2$ à esquerda) e feitos o posicionamento e pré-tensionamento das barras e o alinhamento do espécime em relação ao atuador, nas duas direções.

Na Figura 3.32 estão as vistas frontal e traseira de um espécime posicionado para o ensaio. 


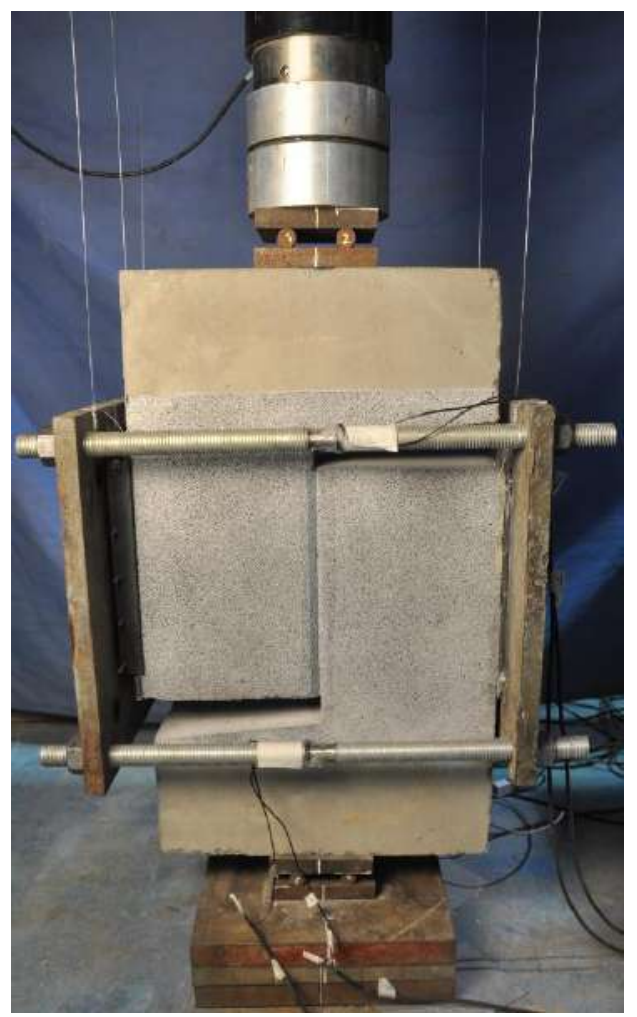

(a)

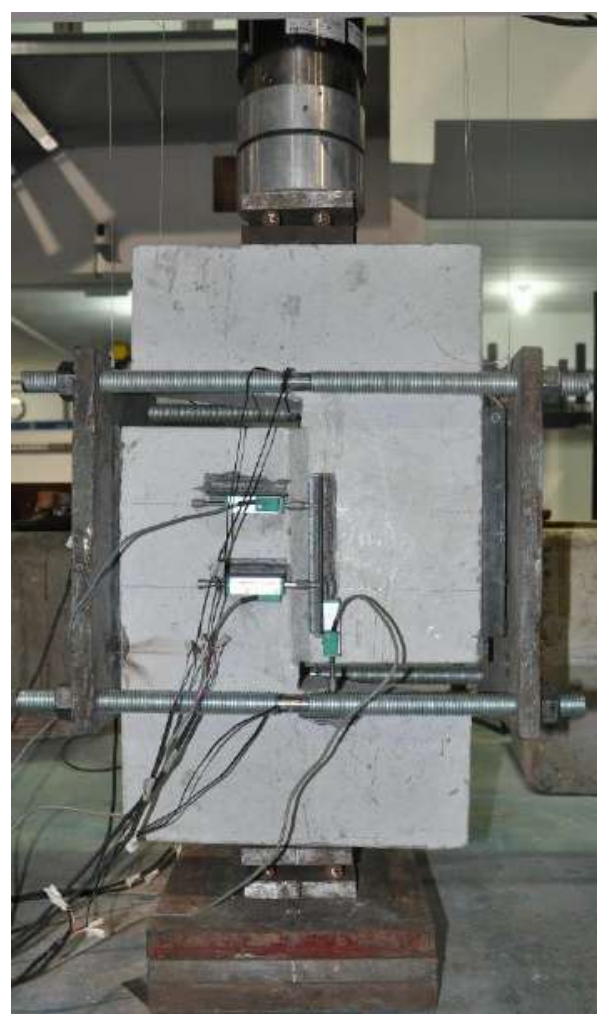

(b)

Figura 3.32 - Espécime posicionado para o ensaio: (a) vista frontal; (b) vista traseira.

\subsubsection{4 \\ Execução do ensaio}

Para aplicação de carga, foi utilizado um atuador hidráulico com capacidade de $500 \mathrm{kN}$ controlado por um sistema MTS. O ensaio foi controlado pelo deslocamento do atuador, a uma taxa de $0,1 \mathrm{~mm} / \mathrm{min}$, e interrompido a um deslocamento do atuador não menor que $9 \mathrm{~mm}$. A duração aproximada dos ensaios dos espécimes de concretos sem e com fibras foi de 1 hora e 2 horas, respectivamente.

Os transdutores de deslocamentos e extensômetros tiveram o registro das medições feitas com um sistema de aquisição HBM QuantumX MX440B.

A câmera utilizada para o registro fotográfico para as análises por CID foi uma Canon EOS Rebel T6i com lente 18-55 mm f/3.5-5.6. As fotografias foram tiradas em uma resolução mínima de 5,9 megapixels e a uma frequência de $0,50 \mathrm{~Hz}$ e $0,14 \mathrm{~Hz}$ para os espécimes sem e com fibras, o que levou a um mínimo de 2400 fotos e 900 fotos por cada espécime sem e com fibras, respectivamente. A aquisição destas fotos foi realizada pelo software digiCamControl, de modo independente da dos demais dados. 
A câmera foi apoiada em um bloco de concreto e ajustada para registrar a área de interesse (400 mm x 260 mm; ver Fig 3.26) durante o ensaio. Para evitar variação de luminosidade na superfície fotografada, foi utilizado uma fonte luminosa composta por duas lâmpadas amarelas de potência de $12,5 \mathrm{~W}$ antepostas a um tecido TNT, de modo a ter-se uma luminosidade difusa.

Com o espécime posicionado e equipamentos ajustados para o ensaio (Figura 3.33), as porcas das barras rosqueadas foram afrouxadas de modo a permitir medições referentes à carga zero. Feito isto, as porcas foram apertadas gradualmente de modo a poder iniciar o ensaio com uma baixa tensão normal no plano de cisalhamento $\left(0,0771 \mathrm{MPa} \leq \sigma_{\mathrm{i}} \leq 0,289 \mathrm{MPa}\right)$.

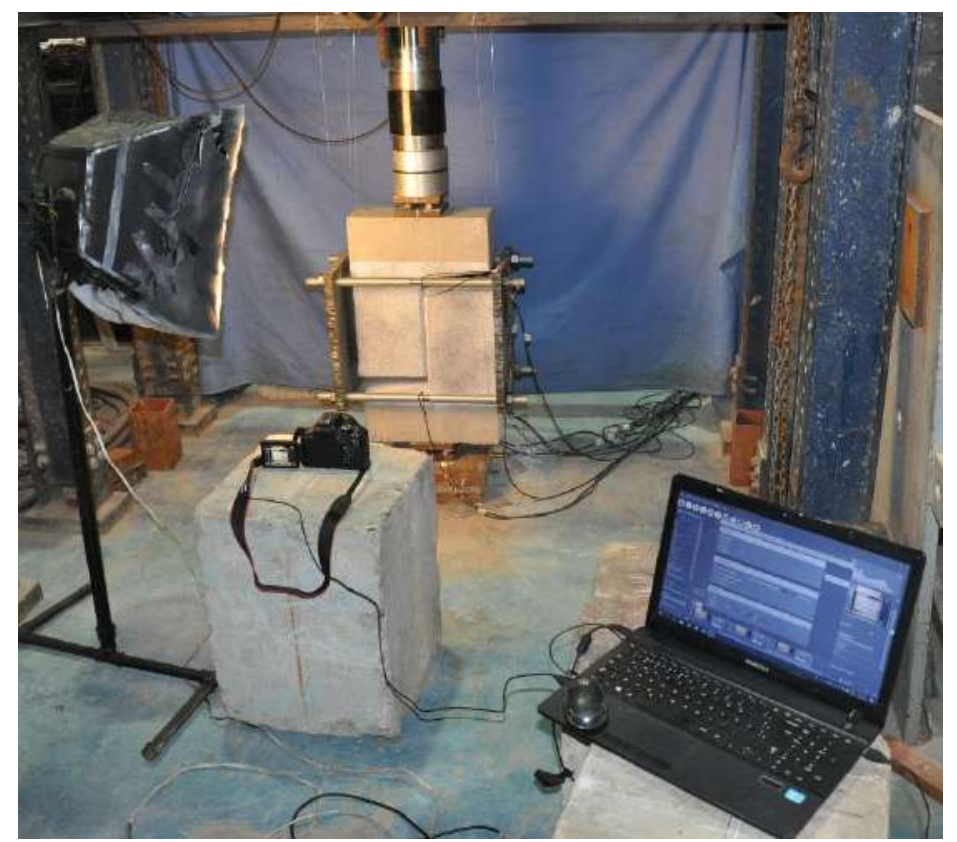

Figura 3.33 - Espécime posicionado e equipamentos ajustados para o ensaio.

\subsubsection{5 \\ Caracterização das superfícies de ruptura}

Finalizados os ensaios dos espécimes sem fibras, nos quais houve separação entre as partes "L" do espécime na região de cisalhamento (o que não ocorreu nos com fibras), iniciaram-se os preparativos para a caracterização das superfícies de ruptura.

Esta caracterização se deu pelo mapeamento das ondulações das superfícies de ruptura de cada "L" por meio de CID em três dimensões. Para isto, estas 
superfícies foram pintadas com um fundo branco fosco e um padrão de pontos pretos foscos espaçados aletoriamente (Figura 3.34).

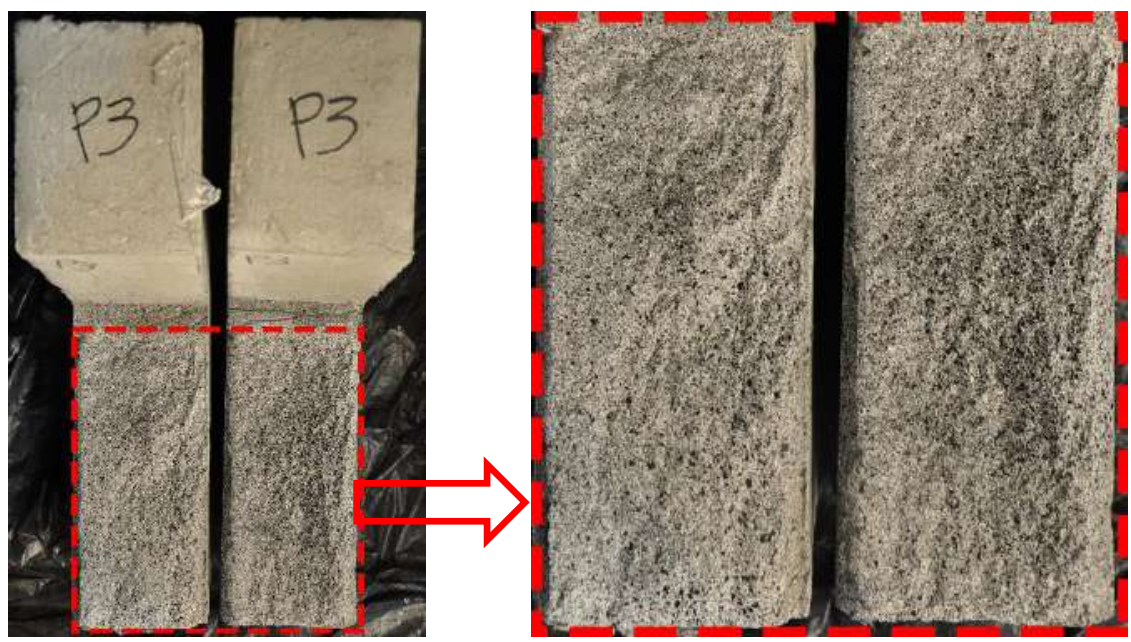

Figura 3.34 - Superfície de ruptura com o padrão de pontos aplicado.

Com o equipamento fotográfico montado (duas câmeras monocromáticas, modelo Basler acA1920-155 $\mu$ m de 2,3 megapixels de resolução), cada elemento "L" foi posicionado sobre um apoio estável e iluminado por uma luz difusa. Assim, o sistema foi preparado e calibrado, para, então, registrar uma fotografia. $\mathrm{Na}$ Figura 3.35 é ilustrado o esquema para o registro fotográfico.

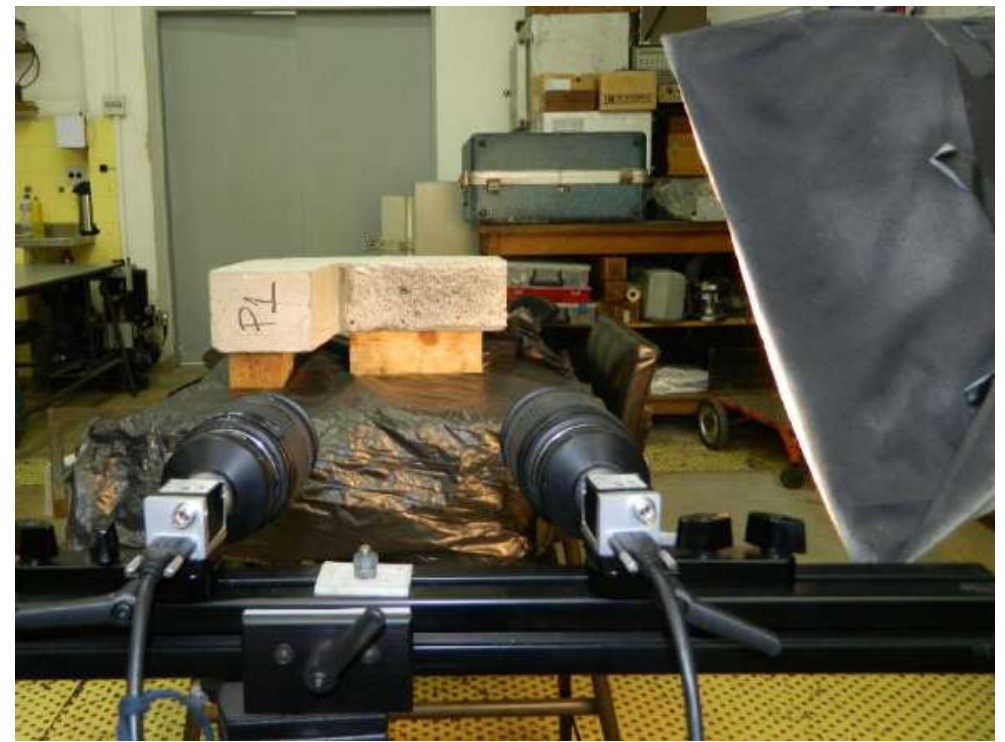

Figura 3.35 - Esquema para a aquisição de imagem para a caracterização da superfície de ruptura. 


\section{4 \\ Ensaios em vigas esbeltas}

\subsection{1}

Introdução

Para investigar o comportamento à força cortante em vigas esbeltas de concreto armado sem estribos e sem e com fibras de aço por meio do acompanhamento da cinemática da fissura diagonal crítica, foi realizado um programa experimental contendo 8 vigas. Nele utilizou-se a técnica de fotogrametria no vão de cisalhamento onde ocorreria a ruptura.

O único parâmetro variável das vigas foi o teor e tipo de fibras dos concretos (Tabela 3.2, p. 100). Com cada tipo de concreto foram moldadas duas vigas, que receberam as nomenclaturas listadas na Tabela 3.10.

Tabela 3.10 - Vigas ensaiadas.

\begin{tabular}{cccc}
\hline Viga & $\boldsymbol{l}_{\boldsymbol{f}} / \boldsymbol{d}_{\boldsymbol{f}}$ & $\left(\boldsymbol{V}_{\boldsymbol{f}} \boldsymbol{l}_{\boldsymbol{f}} / \boldsymbol{d}_{\boldsymbol{f}}\right) \boldsymbol{\%}$ & $\boldsymbol{f}_{\boldsymbol{c} \boldsymbol{c}}$ ou $\boldsymbol{f}_{\boldsymbol{c t}, \boldsymbol{s p}}{ }^{*}(\mathrm{MPa})$ \\
\hline $\begin{array}{l}\mathrm{B}(0) \mathrm{a} \\
\mathrm{B}(0) \mathrm{b}\end{array}$ & - & - & $2,88^{*}$ \\
\hline $\begin{array}{l}\mathrm{B}(0,5 \mathrm{~S}) \mathrm{a} \\
\mathrm{B}(0,5 \mathrm{~S}) \mathrm{b}\end{array}$ & 45 & 22,5 & 2,51 \\
\hline $\begin{array}{l}\mathrm{B}(1 \mathrm{~S}) \mathrm{a} \\
\mathrm{B}(1 \mathrm{~S}) \mathrm{b}\end{array}$ & 45 & 45 & 3,34 \\
\hline $\begin{array}{l}\mathrm{B}(1 \mathrm{~L}) \mathrm{a} \\
\mathrm{B}(1 \mathrm{~L}) \mathrm{b}\end{array}$ & 80 & 80 & 3,15 \\
\hline
\end{tabular}

\subsection{2}

\section{Características das vigas e esquema de ensaio}

As vigas tinham seção transversal retangular com largura de $0,15 \mathrm{~m}$ e $0,20 \mathrm{~m}$ de altura e comprimento de 1,20 m. A armadura longitudinal (Figura 3.36) era composta de $4 \phi 12,5 \mathrm{~mm}(\rho=1,94 \%)$ de CA-50, com cobrimentos inferior e lateral de $25 \mathrm{~mm}$, e a altura útil era $169 \mathrm{~mm}$.

As vigas foram ensaiadas à flexão, sendo simplesmente apoiadas e submetidas a carga concentrada fora do meio do vão (Figura 3.36), visando definir o vão de cisalhamento onde haveria a ruptura $(\mathrm{a} / \mathrm{d}=2,55)$. A força cortante para a 
região à esquerda e à direita da seção transversal de aplicação de carga “ $F$ ” era de $0,594 F$ e $0,406 F$, respectivamente.

A deformação específica da armadura longitudinal foi medida por meio de dois extensômetros elétricos de resistência colados em posições diametralmente opostas de uma das barras de aço (barra não próxima da face lateral da viga), na seção transversal de aplicação de carga, e a deformação específica do concreto na face superior da viga foi medida usando um extensômetro (base de medição de $50 \mathrm{~mm}$ ) colado a $2 \mathrm{~cm}$ dos dois lados da seção de aplicação de carga. Para medir o deslocamento vertical na seção transversal de aplicação de carga, foram utilizados dois transdutores de deslocamento. Para obter o campo de deslocamentos de todo o vão de cisalhamento de ruptura, foi utilizada a técnica de fotogrametria em uma de suas faces.

Na Figura 3.36 são apresentados detalhes da viga e seu esquema de ensaio.

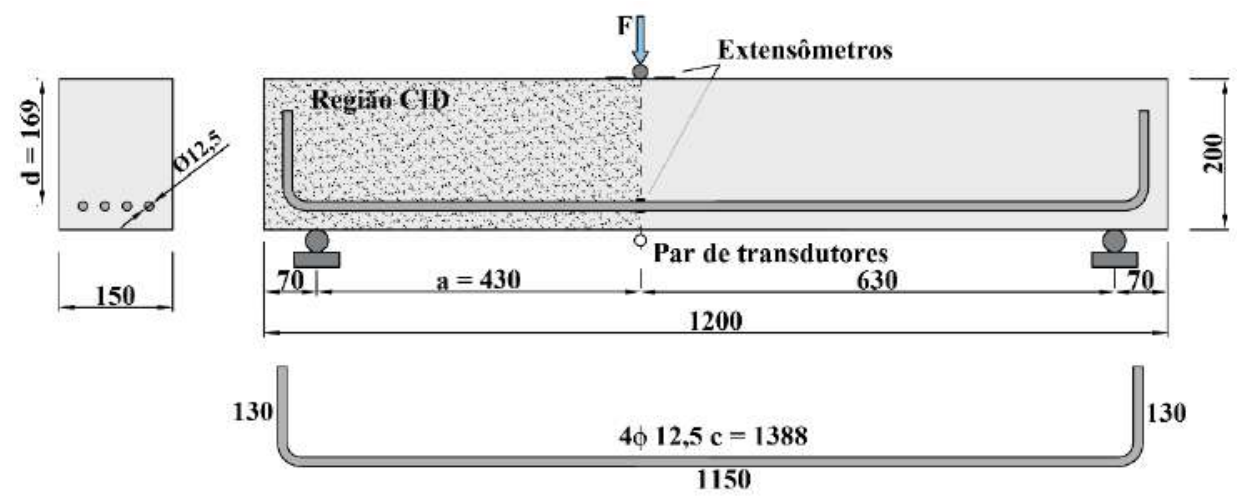

Figura 3.36 - Detalhamento da viga, esquema de ensaio e instrumentação. Dimensões em mm.

\subsection{3}

\section{Caracterização das barras de aço}

Para a determinação das propriedades mecânicas das barras de aço de CA-50 com diâmetro de $12,5 \mathrm{~mm}$, foram ensaiadas à tração três amostras com comprimento de $500 \mathrm{~mm}$, de acordo com a ABNT NBR ISO 6892-1:2013.

Os ensaios foram realizados em uma máquina universal MTS modelo 311, com capacidade de carga de $1000 \mathrm{kN}$, medindo-se a deformação específica do aço utilizando um clip gauge (Figura 3.37a). As amostras romperam na região de medição do clip gauge (Figura 3.37b) e atenderam aos requisitos da ABNT NBR 7480 (2007). 


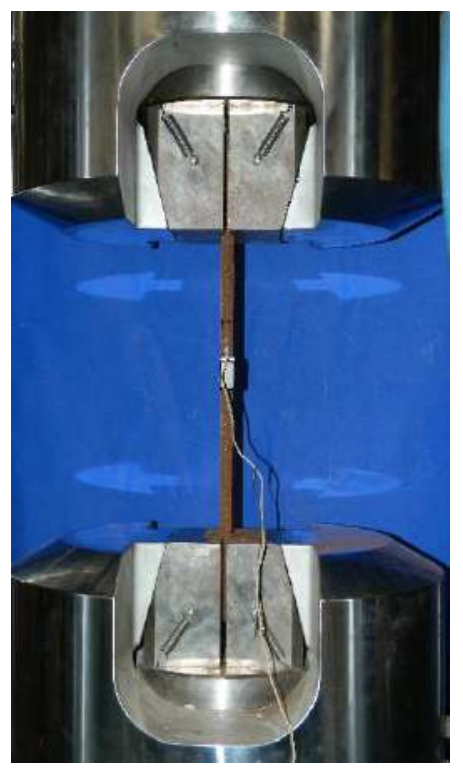

(a)

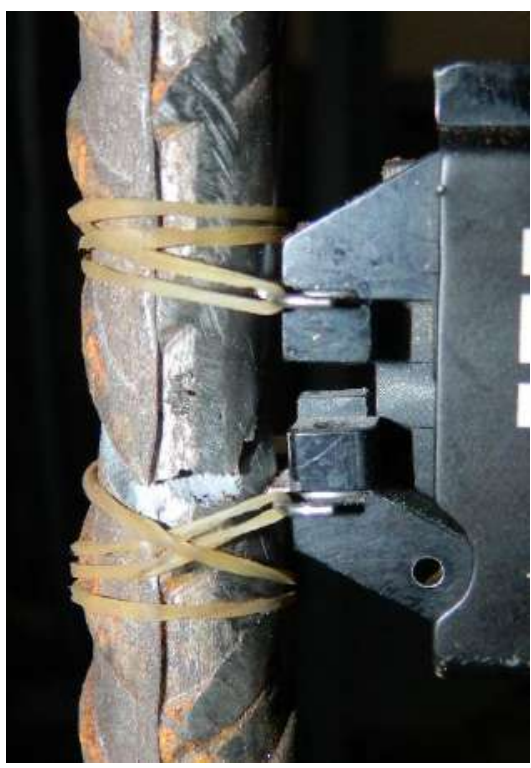

(b)

Figura 3.37 - Ensaio de caracterização à tração das barras de aço: (a) barra de aço posicionada para o ensaio; (b) região de ruptura entre os suportes do clip gauge.

A Tabela 3.11 resume as propriedades mecânicas obtidas e a Figura 3.38 apresenta as curvas tensão normal - deformação específica.

Tabela 3.11 - Resumo das propriedades mecânicas das barras de aço utilizadas.

\begin{tabular}{ccccc} 
Amostra & $f_{y}(\mathrm{MPa})$ & $\varepsilon_{\mathrm{y}}^{*}(\% \mathrm{o})$ & $f_{\text {st }}(\mathrm{MPa})$ & $f_{s t} / f_{y}$ \\
\hline 1 & 560 & 3,22 & 705 & 1,26 \\
2 & 530 & 2,95 & 682 & 1,25 \\
3 & 574 & 3,02 & 719 & 1,25 \\
Média & 555 & 3,06 & 702 & 1,25 \\
\hline
\end{tabular}

$\varepsilon_{\text {y: }}^{*}$ Deformação específica de escoamento correspondente ao gráfico tensão normal-deformação específica bilinear.

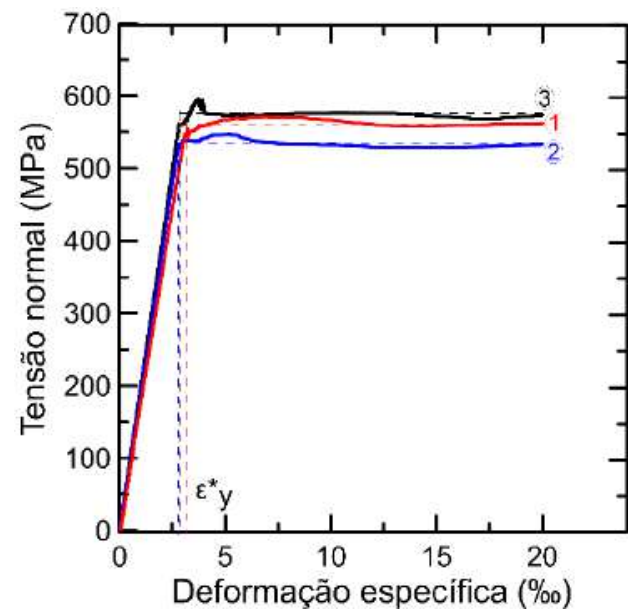

Figura 3.38 - Curvas tensão normal de tração - deformação específica das amostras de aço. 


\subsection{4}

\section{Construção dos espécimes}

Foram utilizados madeira de compensado naval para a elaboração das formas, espaçadores de plástico para garantir o cobrimento de $25 \mathrm{~mm}$, e betoneira com capacidade de 400 L para confeccionar o concreto.

Com a forma montada e desmoldante aplicado, as barras de aço foram posicionadas no fundo da forma sobre os espaçadores, para então proceder à concretagem (Figura 3.39a).

As vigas receberam adensamento por vibração decorrente de golpes de martelo de borracha na superfície externa das formas. Com o concreto ainda fresco, ganchos foram posicionados nas extremidades da viga a fim de facilitar seu manuseio no estado endurecido (Figura 3.39b). As vigas foram molhadas e cobertas com filme plástico durante as primeiras 24 horas e, após 72 horas, foram desmoldados e deixados sob as condições ambientais do laboratório.

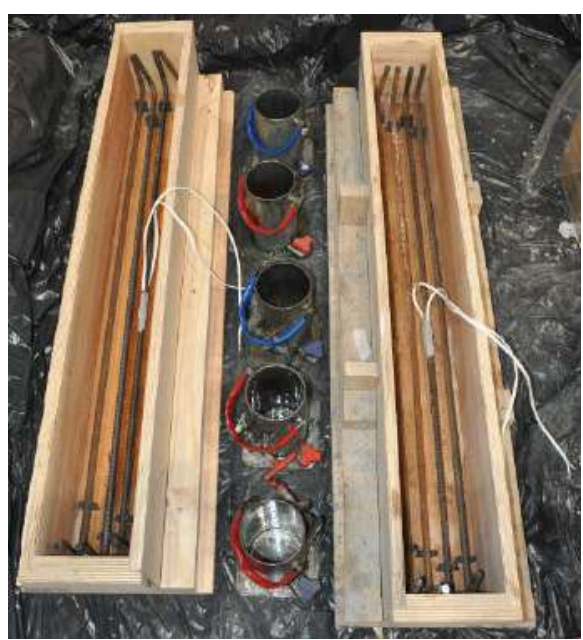

(a)

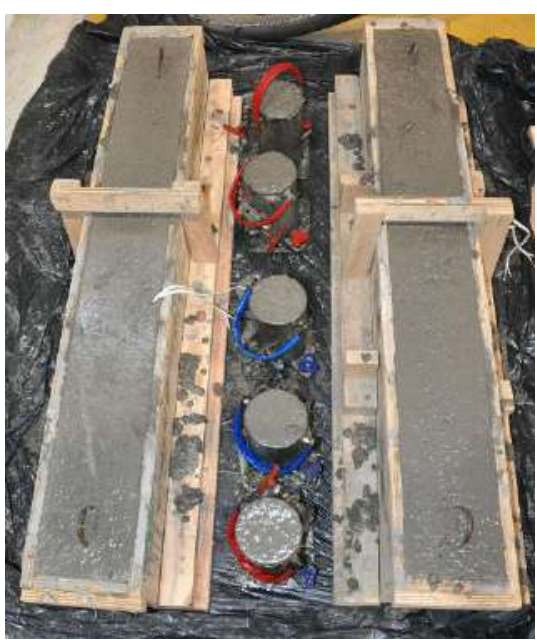

(b)

Figura 3.39 - Construção da viga: (a) Formas preparadas para a concretagem; (b) Vigas logo após serem concretadas.

\subsection{5}

Preparação dos espécimes para ensaio

Cerca de uma semana antes da execução do ensaio iniciou-se o processo de pintura dos espécimes para a CID. Foi aplicado primeiramente um padrão de fundo branco fosco e, depois de sua secagem, um padrão de pontos pretos foscos espaçados aleatoriamente (Figura 3.40). O processo foi manual e com tinta spray. 


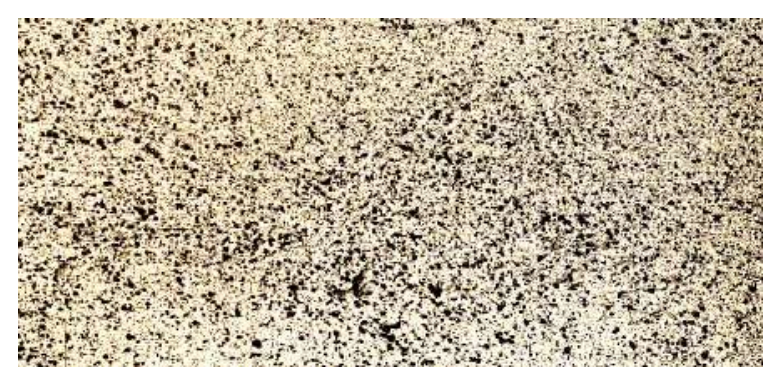

Figura 3.40 - Padrão de pontos aplicados na viga $\mathrm{B}(1 \mathrm{~L}) \mathrm{b}$.

Posteriormente, procedeu-se à colagem dos extensômetros elétricos na face superior da viga. No dia seguinte, a viga foi posicionada e alinhada em relação ao atuador, nas duas direções.

\subsection{6 Execução do ensaio}

Para aplicação de carga, foi utilizado um atuador hidráulico com capacidade de $500 \mathrm{kN}$ controlado por um sistema MTS. O ensaio foi realizado com controle do deslocamento do atuador, a uma taxa de $0,3 \mathrm{~mm} / \mathrm{min}$, e interrompido a um deslocamento do atuador não menor que $10 \mathrm{~mm}$ (vigas sem fibras de aço) ou $15 \mathrm{~mm}$ (vigas com fibras de aço).

Os transdutores de deslocamento e extensômetros tiveram o registro das medições feitas com um sistema de aquisição HBM QuantumX MX440B.

A câmera utilizada para o registro fotográfico foi uma Nikon D90 com lente 18-55 mm f/3.5-5.6. As fotografias foram tiradas em uma resolução mínima de 3,0 megapixels e a uma frequência de $0,50 \mathrm{~Hz}$. A aquisição destas fotos foi realizada pelo software digiCamControl, de modo independente da dos demais dados.

A câmera foi apoiada em um tripé e ajustada para registrar a área de interesse (500 mm x 200 mm; ver Fig 3.36) durante o ensaio. Para evitar variação de luminosidade na superfície fotografada, foi utilizado uma fonte luminosa composta por duas lâmpadas amarelas de potência de $12,5 \mathrm{~W}$ antepostas a um tecido TNT, de modo a ter-se uma luminosidade difusa.

Na Figura 3.41 mostra uma viga e a instrumentação usada em seu ensaio. 


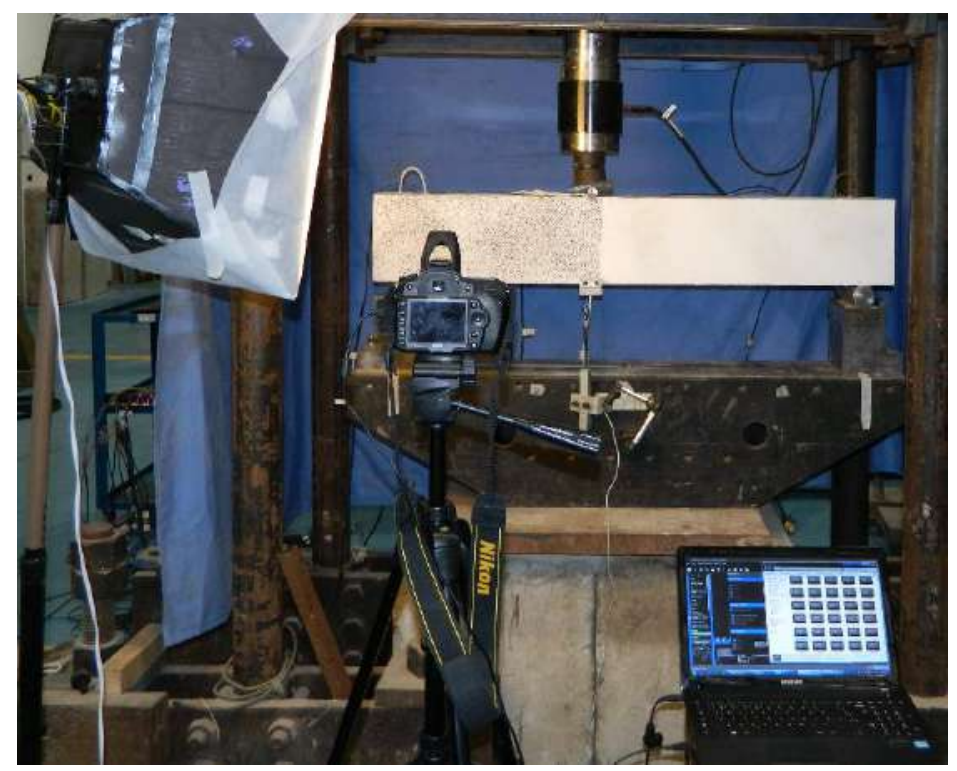

Figura 3.41 - Viga e instrumentação.

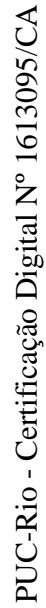




\section{Resultados dos ensaios e sua análise}

Este capítulo apresenta os resultados dos ensaios realizados, bem como sua análise. Para a Correlação de Imagem Digital 2D (todas as análises fotogramétricas, exceto as dos planos de engrenamento dos agregados) foi utilizado o software Gom Correlate $^{\circledR}$, com subset de tamanho 25 x 25 pixels e passo de 8 pixels, enquanto que para a de Correlação de Imagem Digital 3D (análise da superfície de engrenamento dos agregados) foi utilizado o software $V I C-3 D^{\circledR}$.

\section{1}

\section{Ensaios de efeito de pino}

\subsection{1}

\section{Resultados experimentais}

Para verificar os deslocamentos obtidos por meio da CID, eles foram comparados com os obtidos com os transdutores de deslocamento. A Figura 4.1, que exemplifica uma dessas comparações, mostra a boa concordância entre os deslocamentos determinados segundo os dois procedimentos.

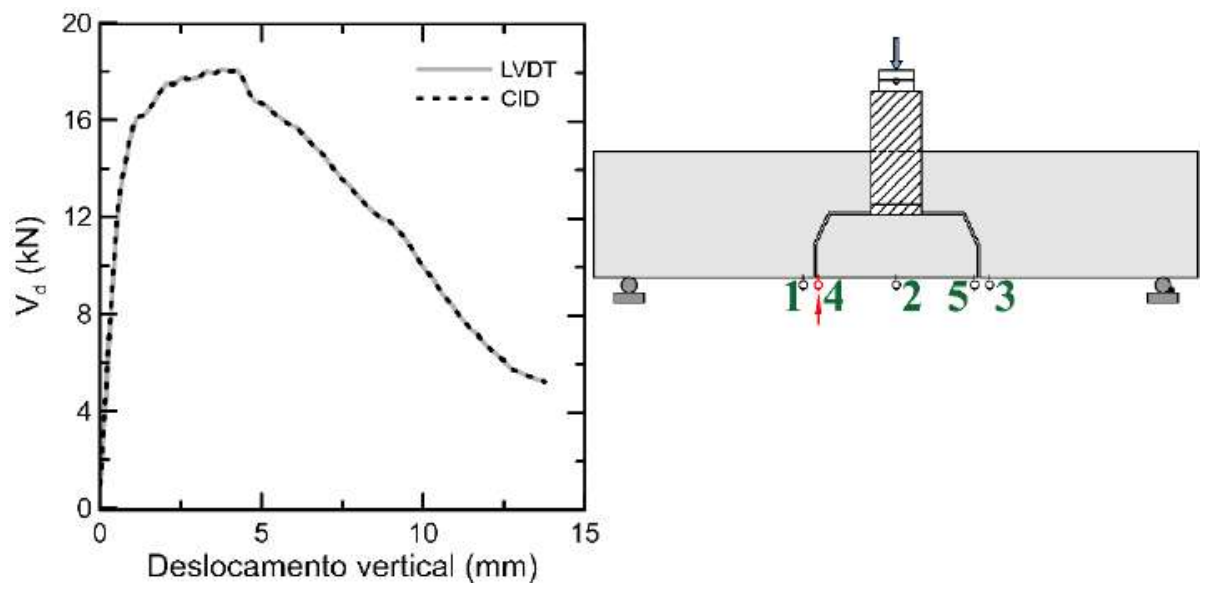

Figura 4.1 - Deslocamento vertical na posição 4 do espécime D16(1S) obtido por meio de transdutor de deslocamento e CID.

Para se ter uma noção do erro da abertura de fissura de fendilhamento ao longo da armadura longitudinal obtida por meio de fotogrametria, foi verificada a 
variação de comprimento na direção vertical entre os pontos de controle utilizados para a medição de abertura de fissura (pares de pontos opostos na região onde se formaria a fissura, a cada $10 \mathrm{~mm}$, como ilustrado na Figura 4.2), para duas imagens fotográficas consecutivas (a de referência e a de comparação) para o estágio imediatamente anterior ao início do ensaio (força do atuador nula). Constatou-se um erro absoluto médio de $\left(3,69 \times 10^{-3}\right) \mathrm{mm}$.
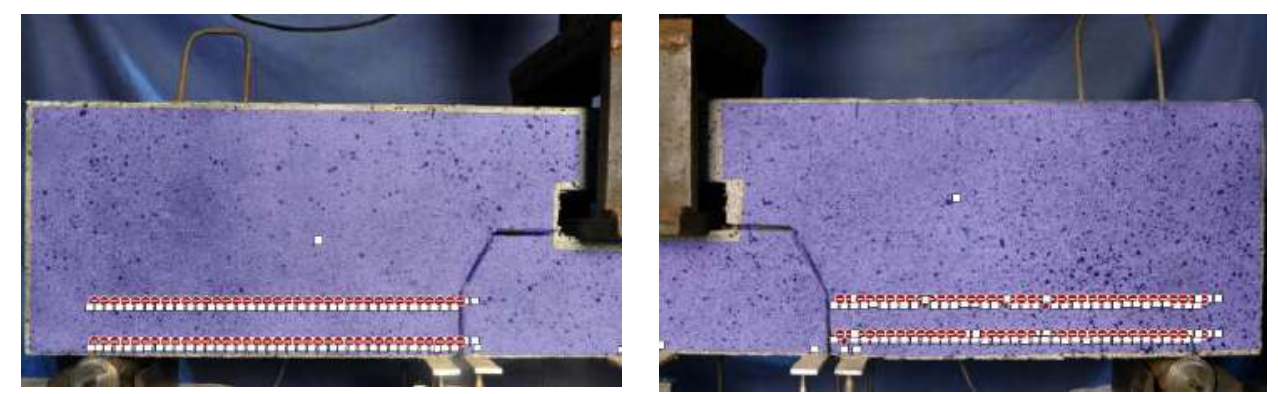

Figura 4.2 - Distribuição de pares de pontos a cada $10 \mathrm{~mm}$ para controle do valor da abertura de fissura de fendilhamento.

Todos os espécimes tiveram ruptura por fendilhamento ao longo da armadura. Na Figura 4.3 podem ser vistos os aspectos dos espécimes " $D$ " ao final dos ensaios, junto com os respectivos campos de deslocamento vertical. Nela constata-se que, ao final do ensaio, o bloco central do espécime D12,5(1S) apresentou maior rotação. Observou-se início da fissuração nos dois lados das vigas quase que ao mesmo tempo, mas, posteriormente, elas apresentaram alguma assimetria em seu comportamento. Na Figura 4.4, que mostra o deslocamento vertical do bloco dado pelos transdutores posicionados no seu centro e nas suas extremidades esquerda e direita em função de $V_{d}$, nota-se que a assimetria de deslocamento vertical do bloco central ocorreu apenas para valores de $V_{d}$ próximos de $V_{d, \max }$ e na fase pós-pico. 


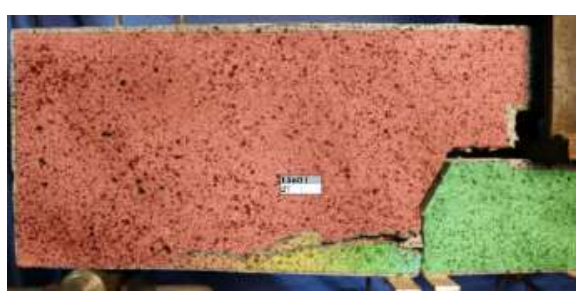

(a)

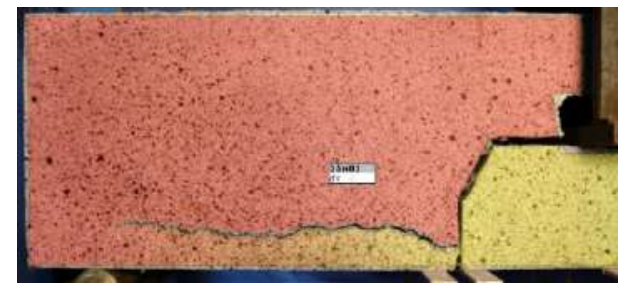

(c)

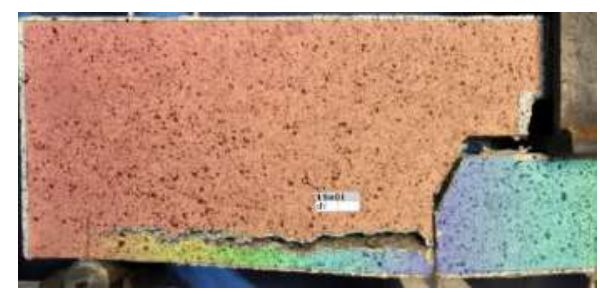

(e)

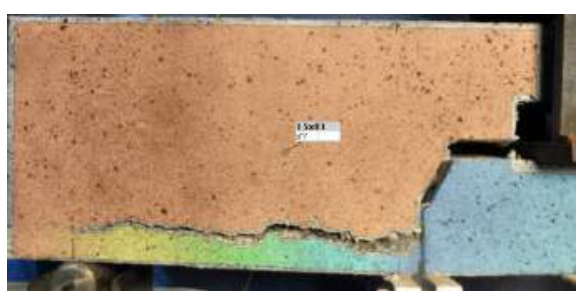

(g)

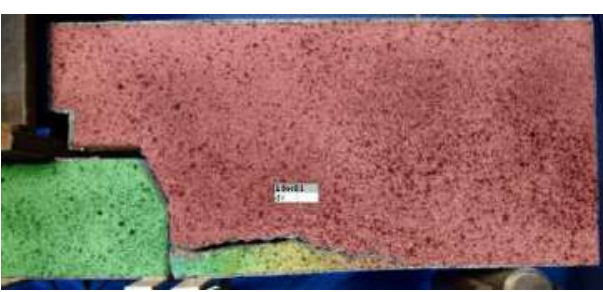

(b)

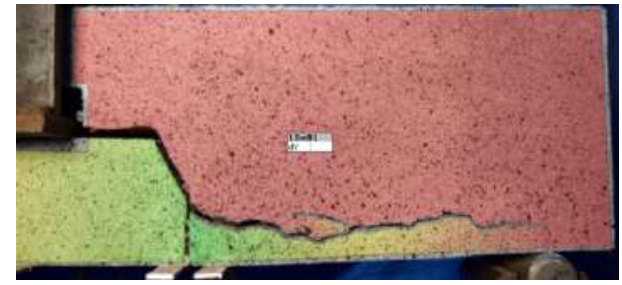

(d)

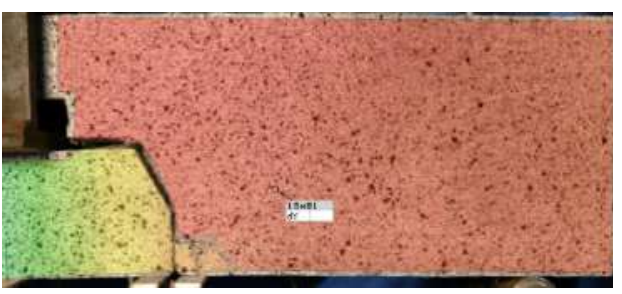

(f)

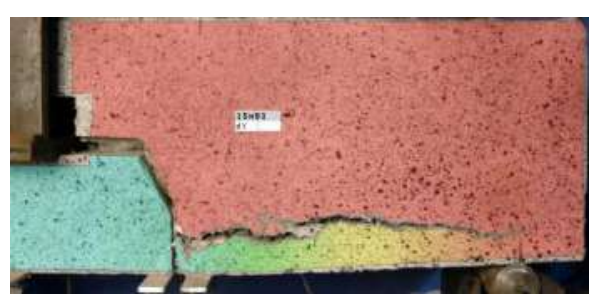

(h)

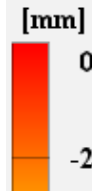

Figura 4.3 - Campo de deslocamento vertical dos espécimes " $\mathrm{D}$ " ao final dos ensaios: (a-b) D12,5; (c-d) D16; (e-f) D12,5(1S); (g-h) D16(1S). 


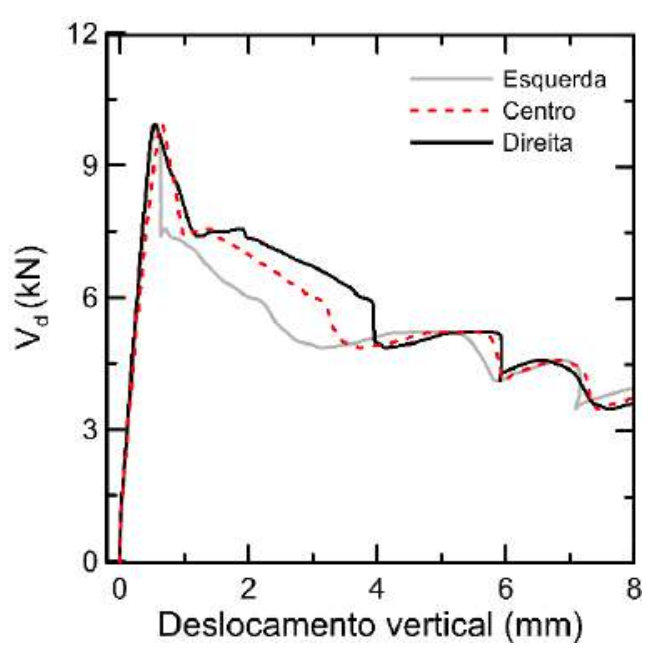

(a)

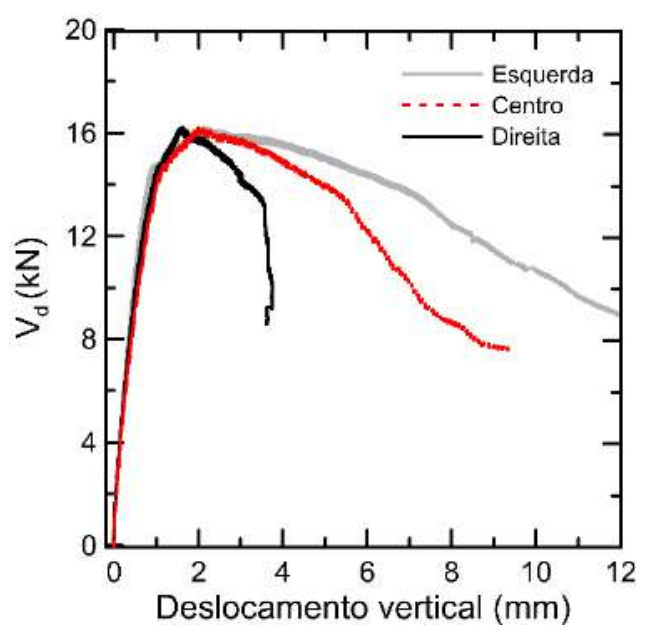

(c)

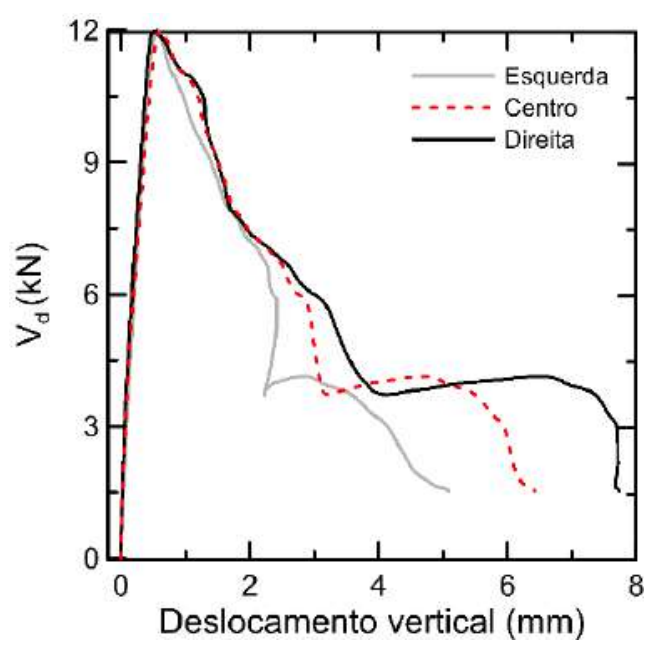

(b)

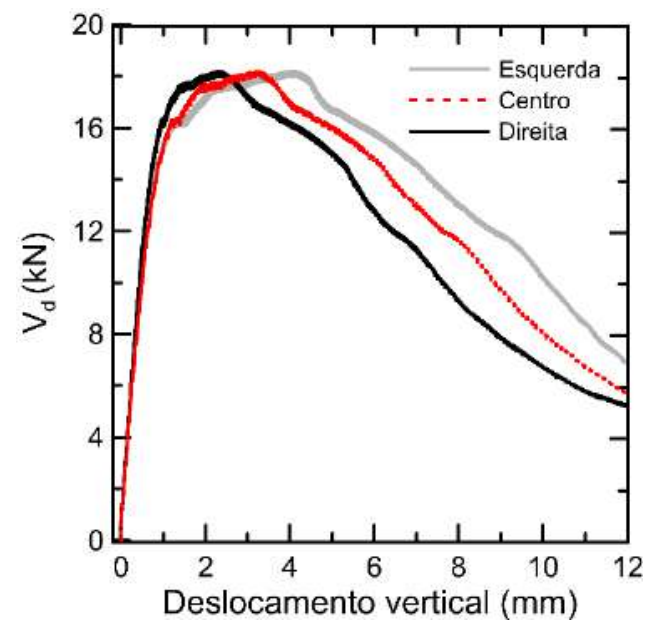

(d)

Figura 4.4 - Relação entre $\mathrm{V}_{\mathrm{d}}$ e o deslocamento vertical do bloco no seu centro e nas suas extremidades: (a) D12,5; (b) D16; (c) D12,5(1S); (d) D16(1S).

A Tabela 4.1 lista a força correspondente à fissuração $V_{d, c r}$ (espécimes sem fibras e os "D" com fibras) e a máxima $V_{d, \max }$ e os correspondentes deslocamentos verticais relativos $\Delta_{c r}$ e $\Delta_{\max }$. Estes deslocamentos foram calculados subtraindo a média dos deslocamentos verticais medidos pelos dois LVDT colocados no lado da viga onde ocorreu ruptura (posição 1 ou 3 na Figura 4.1 ou Figura 3.17 na p. 115) da média dos deslocamentos acusados pelos dois LVDT na posição 2. 
Tabela 4.1 - Resultados dos ensaios.

\begin{tabular}{|c|c|c|c|c|}
\hline Espécime & $\begin{array}{l}V_{d, c r} \\
(\mathbf{k N})\end{array}$ & $\begin{array}{c}V_{d, \max } \\
(\mathbf{k N})\end{array}$ & $\begin{array}{c}\Delta_{c r} \\
(\mathbf{m m})\end{array}$ & $\begin{array}{r}\Delta_{\max } \\
(\mathbf{m m})\end{array}$ \\
\hline 12,5 & 9,31 & 9,31 & 0,293 & 0,293 \\
\hline D12,5 & 9,94 & 9,94 & 0,298 & 0,298 \\
\hline 16 & 11,5 & 11,5 & 0,257 & 0,257 \\
\hline D16 & 12,0 & 12,0 & 0,216 & 0,216 \\
\hline $12,5(0,5 \mathrm{~S}) \mathrm{a}$ & - & 10,8 & - & 0,49 \\
\hline $12,5(0,5 \mathrm{~S}) \mathrm{b}$ & - & 10,7 & - & 0,585 \\
\hline $12,5(1 \mathrm{~S}) \mathrm{a}$ & - & 14,5 & - & 0,913 \\
\hline $12,5(1 \mathrm{~S}) \mathrm{b}$ & - & 17,3 & - & 1,05 \\
\hline $\mathrm{D} 12,5(1 \mathrm{~S})$ & 9,81 & 16,2 & 0,237 & 0,846 \\
\hline $12,5(1 \mathrm{~L}) \mathrm{a}$ & - & 18,6 & - & 1,41 \\
\hline $12,5(1 \mathrm{~L}) \mathrm{b}$ & - & 16,2 & - & 1,15 \\
\hline $16(0,5 \mathrm{~S}) \mathrm{a}$ & - & 16,9 & - & 0,684 \\
\hline $16(0,5 S) b$ & - & 13,8 & - & 0,613 \\
\hline $16(1 \mathrm{~S}) \mathrm{a}$ & - & 18,3 & - & 0,733 \\
\hline $16(1 S) b$ & - & 19,3 & - & 0,774 \\
\hline D16(1S) & 11,6 & 18,2 & 0,196 & 1,39 \\
\hline
\end{tabular}

Na Figura 4.5 constam os gráficos da abertura da fissura de fendilhamento junto à fictícia, $w_{D}$ (ver Figura 4.10a, p. 146), em função de $V_{d}$ obtidos para os espécimes "D". Essa figura e a Tabela 4.1 mostram que $V_{d, c r}=V_{d, \max }$ para os espécimes sem fibras e como as fibras melhoram o comportamento pós-fissuração. Na Tabela 4.1 pode-se notar que vigas de mesma armadura sem e com fibras têm valores de $V_{d, c r}$ similares.
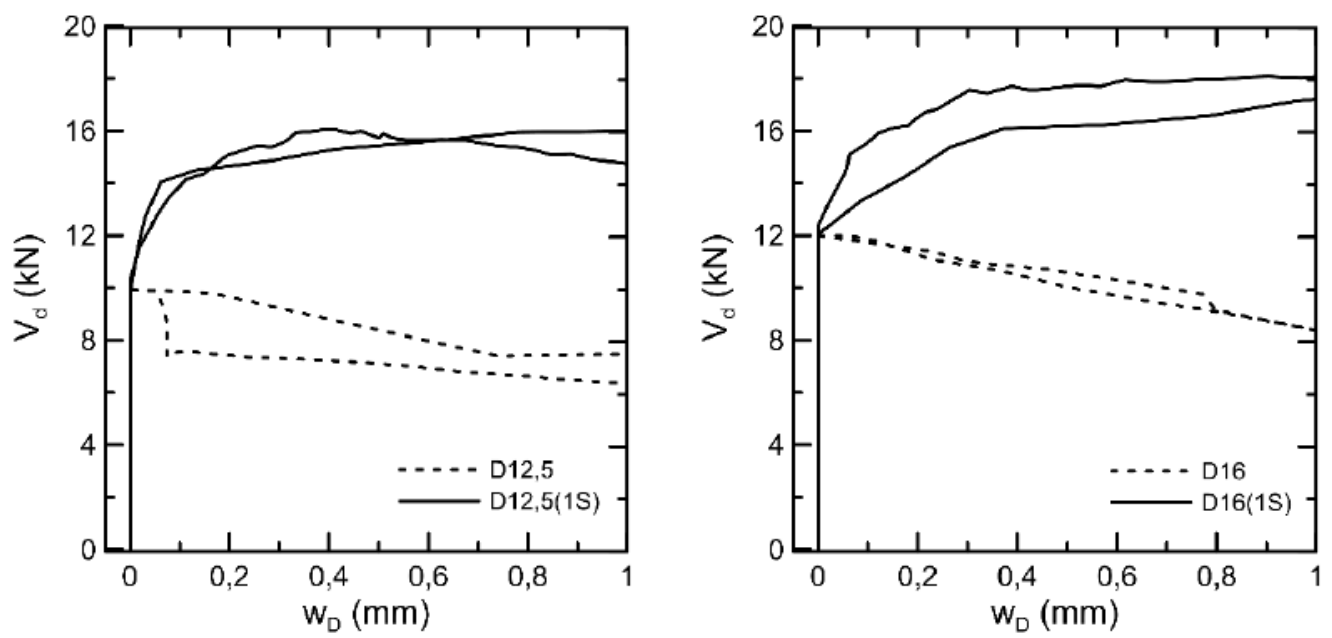

Figura 4.5 - Relação entre $w_{D}$ e $V_{d}$ para ambos os lados dos espécimes "D". 
As relações entre $V_{d, \max } e V_{f}\left(l_{f} / d_{f}\right)$ e entre $\Delta_{\max }$ e $V_{f}\left(l_{f} / d_{f}\right)$ mostradas na Figura 4.6 evidenciam o aumento de $V_{d, \max }$ e de $\Delta_{\max }$ com o aumento de $V_{f}\left(l_{f} / d_{f}\right)$. Para o mesmo valor de $V_{f}\left(l_{f} / d_{f}\right)$, pode-se notar nessa figura tendência de maiores valores de $V_{d, \max }$ para as vigas com barras de aço de maior diâmetro $(\phi=16 \mathrm{~mm})$, mas não de $\Delta_{\max }$.

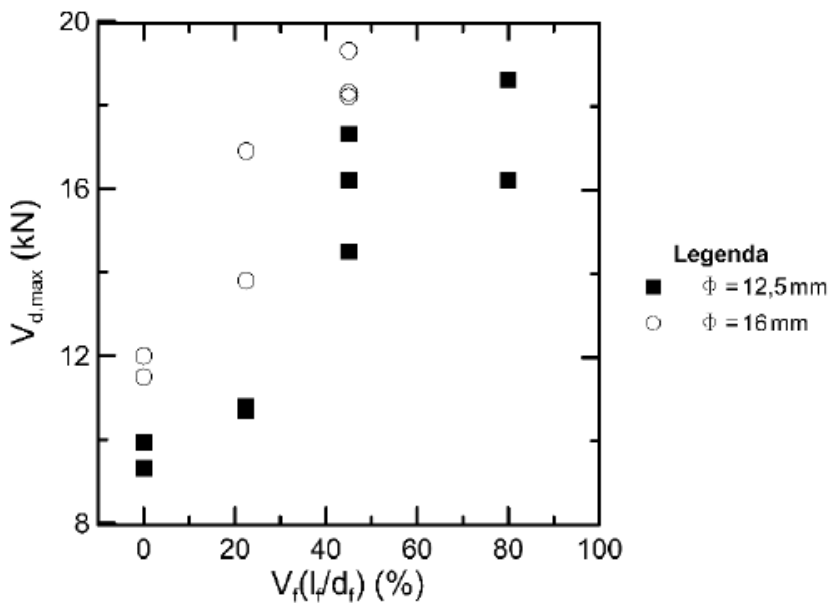

(a)

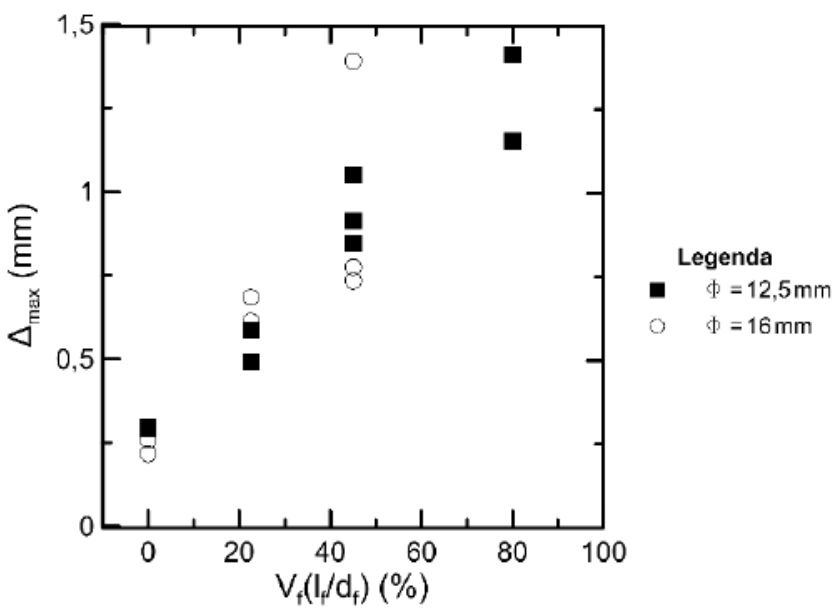

(b)

Figura 4.6 - Relações entre: (a) $V_{f}\left(l_{f} / d_{f}\right)$ e $V_{d, \max }$ e (b) $V_{f}\left(l_{f} / d_{f}\right)$ e $\Delta_{\max }$.

$\mathrm{Na}$ Tabela 4.2, onde constam as relações entre os valores médios de $V_{d, \max } \mathrm{e}$ $\Delta_{\max }$ das vigas com fibras e os valores médios obtidos para as sem fibras com mesma armadura, nota-se maior aumento de $\Delta_{\max }$ do que de $V_{d, \max }$ com o aumento de $V_{f}$ e de $l_{f} / d_{f}$. 
Tabela 4.2 - Razões entre os valores médios de $V_{d, \max }$ e $\Delta_{\max }$ das vigas com e sem fibras.

\begin{tabular}{c|ccc|cc|ccc|cc}
\hline \multicolumn{5}{c}{$\phi$} & \multicolumn{3}{c}{$\phi 16 \mathbf{~ m m}$} \\
\multicolumn{4}{c}{$V_{d, \max }$} & \multicolumn{3}{c|}{$\Delta_{\max }$} & \multicolumn{3}{c}{$V_{d, \max }$} & \multicolumn{2}{c}{$\Delta_{\max }$} \\
\hline Referência & $\mathbf{0 , 5}(\mathbf{S})$ & $\mathbf{1}(\mathbf{S})$ & $\mathbf{1}(\mathbf{L})$ & $\mathbf{0 , 5}(\mathbf{S})$ & $\mathbf{1}(\mathbf{S})$ & $\mathbf{1 ( L )}$ & $\mathbf{0 , 5}(\mathbf{S})$ & $\mathbf{1}(\mathbf{S})$ & $\mathbf{0 , 5}(\mathbf{S})$ & $\mathbf{1 ( S )}$ \\
(sem fibras) & 1,12 & 1,66 & 1,81 & 1,82 & 3,17 & 4,33 & 1,31 & 1,58 & 2,74 & 4,08 \\
\hline
\end{tabular}

As relações entre $V_{d}$ e $\Delta$ para os espécimes com mesma armadura estão reunidas na Figura 4.7. Nela nota-se que, em geral, os com maior valor de $V_{f}\left(l_{f} d_{f}\right)$ tendem a ter maior valor de $V_{d}$ para um dado $\Delta$. Nota-se também que a distribuição aleatória das fibras no concreto pode levar espécimes similares a terem resistência e comportamento pós-pico diferenciados.

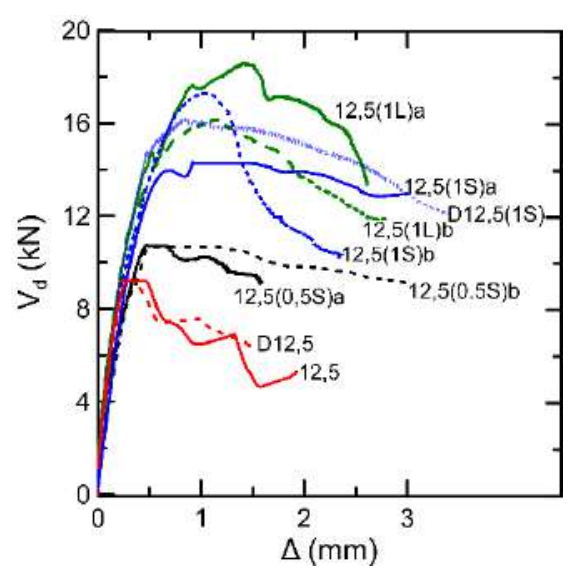

(a)

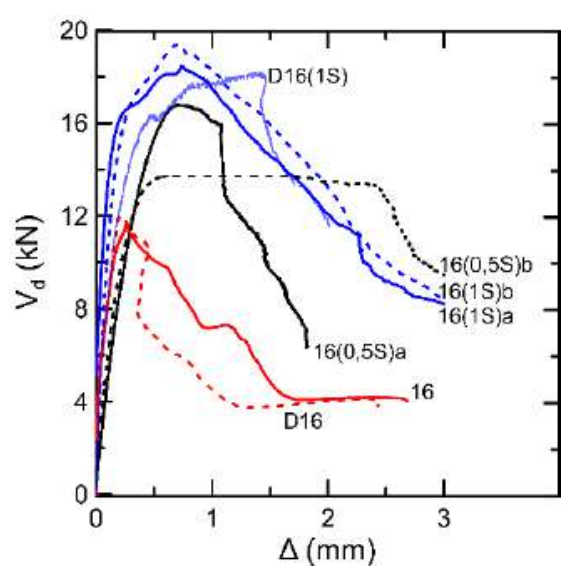

(b)

Figura 4.7 - Relações entre $V_{d}$ and $\Delta$ : (a) $\phi=12,5 \mathrm{~mm}$; (b) $\phi=16 \mathrm{~mm}$.

As relações da Figura 4.7 para os espécimes sem fibras não mostram o comportamento quase plástico relatado por Baumann e Rüsch (1970) nem a relação sugerida por Taylor $(1969,1974)$, que considera uma súbita perda de resistência após fissuração e estabilização para valor de $V_{d}$ igual a $V_{d, c r} / 2$ (Figura 2.4, p. 29).

Para comparar quantitativamente o comportamento dos espécimes na parte descendente das curvas mostradas na Figura 4.7, foram escolhidos os valores de $V_{d}$ correspondentes a $\Delta=1,5 \mathrm{~mm}$. Na Figura 4.8, que mostra a relação entre esses valores e $V_{f}\left(l_{f} / d_{f}\right)$, nenhuma tendência diferenciada é observada para os espécimes com diferentes diâmetros das barras de aço. 


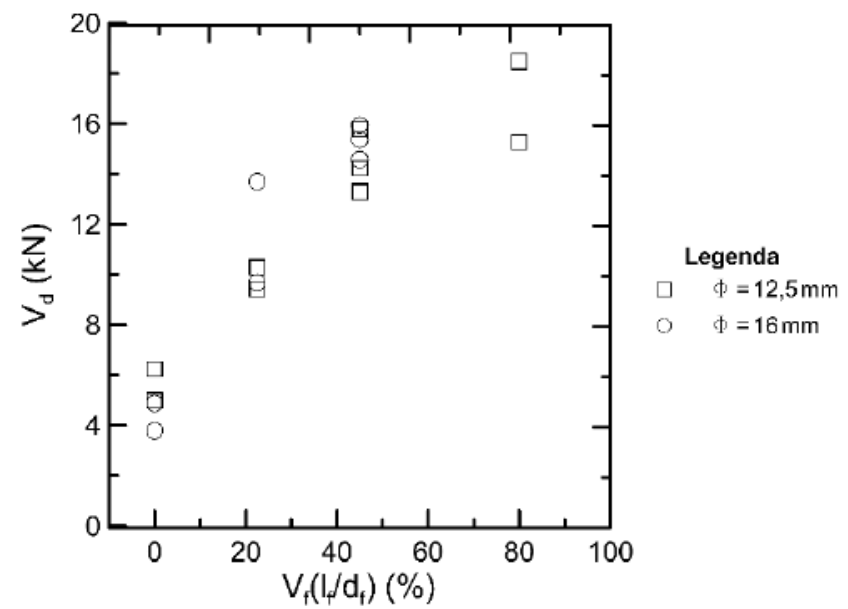

Figura 4.8 - Relações entre $V_{d}$ correspondente a $\Delta=1,5 \mathrm{~mm}$ e $V_{f}\left(l_{f} d_{f}\right)$.

As análises por meio de CID possibilitaram, para um dado valor da força $V_{d}$ (antes ou depois de $V_{d, m a x}$ ), obter a abertura da fissura $w$ ao longo de seu comprimento, como mostra a Figura 4.9. Esta figura e a 4.7 mostram a diferença de comportamento entre as vigas sem e com fibras. 


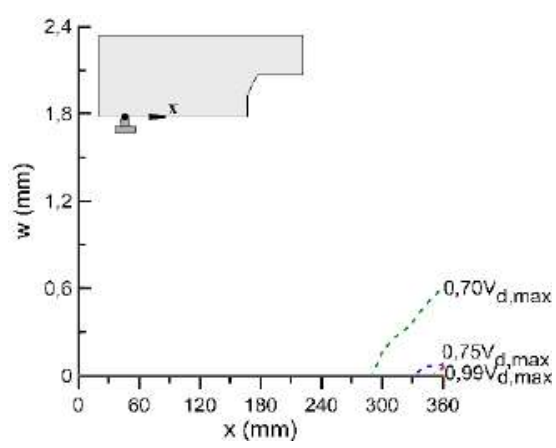

Lado esquerdo

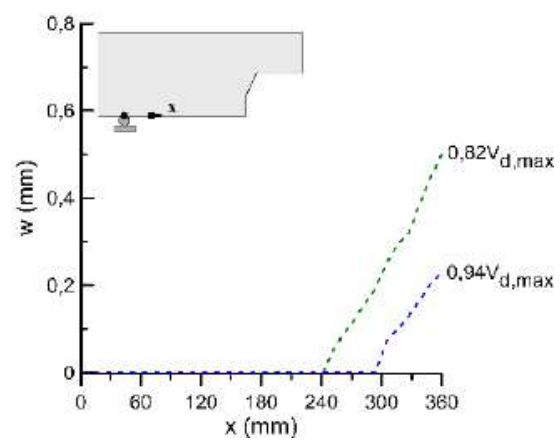

Lado esquerdo

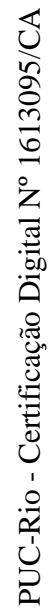

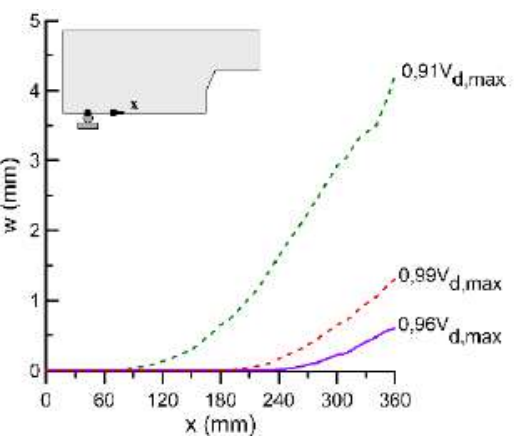

Lado esquerdo

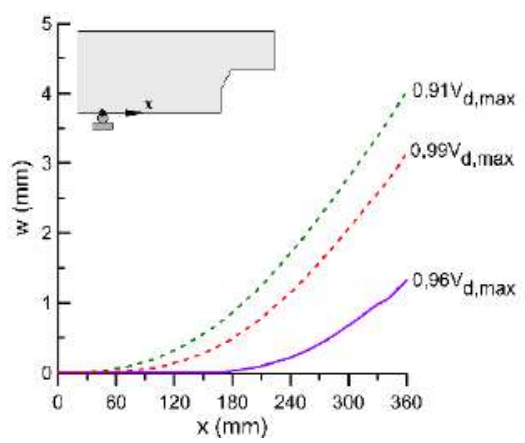

Lado esquerdo

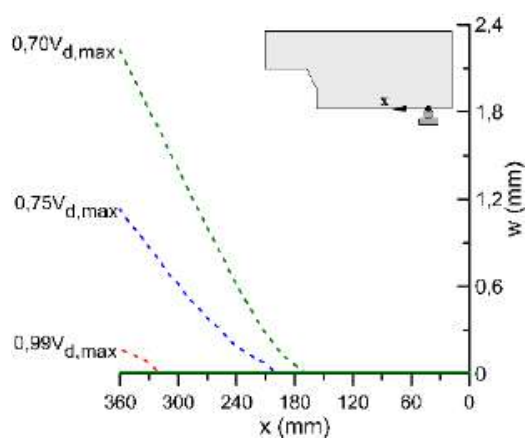

Lado direito

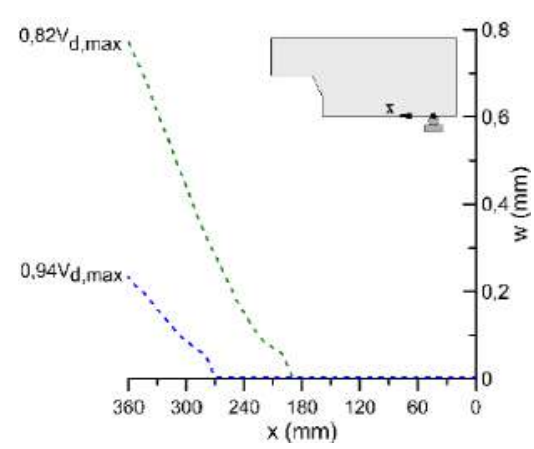

Lado direito

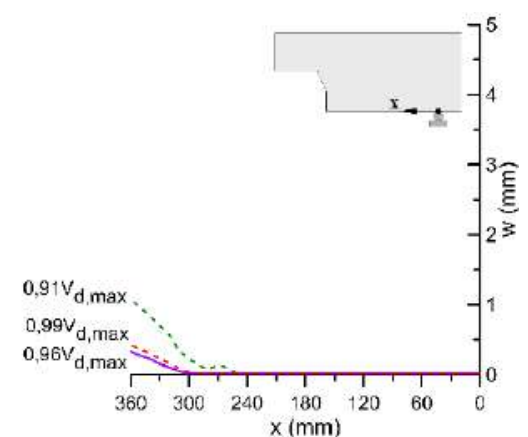

Lado direito

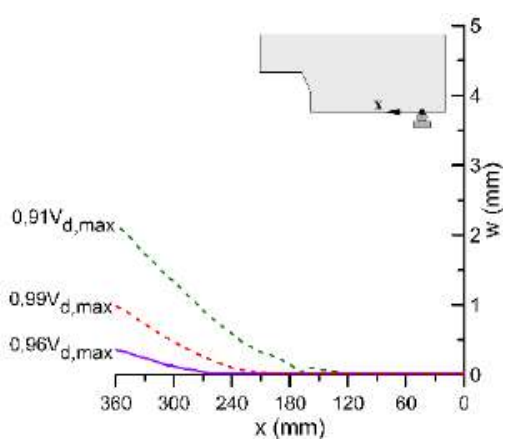

Lado direito

Figura 4.9 - Abertura e comprimento da fissura de fendilhamento para diferentes estágios de carregamento antes (linhas contínuas) e depois (linhas tracejadas) de $V_{d, \max }$ : (a) D12,5; (b) D16; (c) D12,5(1S); d) D16(1S). 


\subsection{2}

\section{Modelo proposto para representar o comportamento dos espécimes}

O modelo proposto para analisar o efeito de pino nos ensaios realizados considera três diferentes trechos; um sem abertura de fissura de fendilhamento, outro com abertura de fissura e o terceiro correspondente à abertura de fissura artificial $(5 \mathrm{~mm})$. Assume-se que i) o cobrimento é suficientemente pequeno para ter sua influência no efeito de pino ignorada; ii) as barras de aço têm comportamento linear-elástico e são engastadas na extremidade lateral do bloco central; iii) as tensões radiais devido à transferência por atrito são pequenas quando comparadas às tensões resultantes do efeito de pino (consideração implícita nos trabalhos anteriores de Baumann \& Rüsch (1970) e Vintzeleou \& Tassios (1986)); iv) a influência das tensões de tração decorrentes da flexão global e da força cortante podem ser desconsideradas, ou seja, as fissuras de flexão e inclinadas não se formam na região de interesse e a abertura de fissura artificial permanece sendo a seção de controle durante o ensaio. Esta última hipótese foi confirmada durante os ensaios.

Para o trecho sem abertura de fissura, é adotada a analogia de viga em apoio elástico, mas substituindo as molas com coeficiente constante que representam o meio elástico em que as barras de aço se encontram por um comprimento equivalente com uma extremidade engastada (comprimento $a$ na Figura 4.10), procedimento simplificado adotado por Davisson \& Robinson (1965) para analisar estacas parcialmente enterradas submetidas a carregamento lateral. Este comprimento depende da rigidez à flexão das barras de aço $\left(E_{s} I_{s}\right)$ e do módulo do meio elástico em que estão embutidas $(k)$. Uma larga faixa de valores para $k$ tem sido encontrada na literatura (Dei Poli et al. (1992); Tanaka \& Murakoshi (2011)), tendo ela que ser determinada experimentalmente. Segundo revisão bibliográfica realizada por Tanaka \& Murakoshi (2011), $k$ parece aumentar com o aumento do módulo de elasticidade do concreto e diminuir com o aumento do diâmetro das barras de aço. Uma vez definido o valor de $k$, o comprimento equivalente $a$ pode ser calculado (Davisson \& Robinson (1965)): 


$$
a=1,4 \sqrt[4]{\frac{E_{s} I_{s}}{k \phi}}
$$

A resistência à tração do concreto é assumida constante ao longo da largura de concreto da viga no nível da armadura (largura da viga $b_{\mathrm{w}}$ menos o número de barras $n$ multiplicada pelo diâmetro da barra $\left.\phi: b_{n}=b_{w}-n \phi\right)$ e igual a $f_{c t}$. Logo, o deslocamento na ponta da fissura (seção C na Figura 4.10) é:

$$
y_{C}=\frac{f_{c t}\left(b_{w}-n \phi\right)}{n k \phi}
$$

No trecho com abertura de fissura (comprimento $c$ na Figura 4.10), embora a tensão normal residual no concreto com fibras dependa da abertura da fissura (Figura 4.10a), ela é admitida com valor constante ao longo da fissura e determinada a partir da relação entre tensão normal residual e abertura de fissura obtida no ensaio à tração direta do concreto, assumindo abertura de fissura igual à metade da abertura na posição D indicada na Figura 4.10, para levar em consideração, de maneira aproximada, que as tensões residuais do concreto não são constantes. Portanto, assumindo a tensão residual constante ao longo da largura $b_{n}$ da viga, a força das fibras $p$ é obtida multiplicando a tensão de tração residual $\left(f_{c t r}\right)$ correspondente a uma abertura de fissura igual a $w_{D} / 2$ por $b_{n}$.

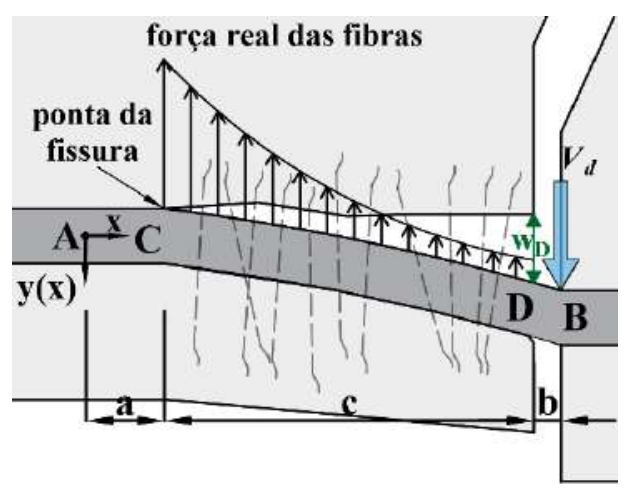

(a)

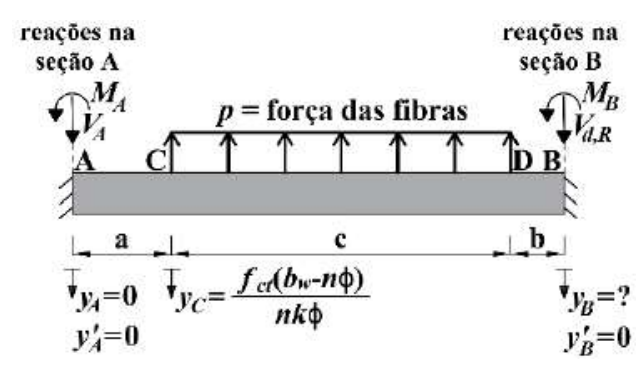

(b)

Figura 4.10 - Efeito de pino nas vigas ensaiadas: (a) comportamento real; (b) modelo proposto 
No modelo proposto na Figura 4.10b, há um deslocamento prescrito $\left(y_{B}\right)$ na seção $\mathrm{B}$, de modo que o deslocamento $\left(y_{A}\right)$ e a rotação $\left(y_{A}^{\prime}\right)$ na seção A e a rotação na seção $\mathrm{B}\left(y_{B}^{\prime}\right)$ são zero e o deslocamento na ponta da fissura $\mathrm{C}$ tem o valor definido na equação (4.2).

A partir da curva elástica da barra, o deslocamento na seção C pode ser obtido:

$$
y_{C}=\frac{M_{A} \frac{a^{2}}{2}+V_{A} \frac{a^{3}}{6}}{E_{S} I_{S}}
$$

As reações de apoio podem ser encontradas sobrepondo os efeitos de $y_{B}$ e do carregamento $p$ (Figura 4.10b):

$$
M_{A}=\frac{-12 a b^{2} c p-12 a b c^{2} p-4 a c^{3} p-6 b^{2} c^{2} p-4 b c^{3} p-c^{4} p+72 \mathrm{E}_{\mathrm{S}} \mathrm{I}_{\mathrm{s}} y_{B}}{12(a+b+c)^{2}}
$$

$$
V_{A}=\frac{6 a b^{2} c p+6 a b c^{2} p+2 a c^{3} p+2 b^{3} c p+6 b^{2} c^{2} p+4 b c^{3} p+c^{4} p-24 E_{S} I_{S} y_{B}}{2(a+b+c)^{3}}
$$

$$
M_{B}=\frac{12 a^{2} b c p+6 a^{2} c^{2} p+12 a b c^{2} p+4 a c^{3} p+4 b c^{3} p+c^{4} p+72 \mathrm{E}_{\mathrm{S}} \mathrm{I}_{\mathrm{s}} y_{B}}{12(a+b+c)^{2}}
$$

$$
V_{d, R}=\frac{0,5 p c\left(2 a^{3}+6 a^{2} b+6 a^{2} c+6 a b c+4 a c^{2}+2 b c^{2}+c^{3}\right)+12 E_{S} I_{S} y_{B}}{(a+b+c)^{3}}
$$

Com as equações (4.4) e (4.5) em (4.3) e, posteriormente, fazendo (4.3) igual a (4.2), é obtido $y_{B}$ e, consequentemente, $V_{d, R}$.

$$
y_{B}=\frac{p C_{1}+24 E_{s} I_{s} y_{C} C_{2}}{24 a^{2} E_{s} I_{S}(a+3 b+3 c)}
$$

onde $C_{1}=a^{2} c\left[8 a b^{3}+18 a b^{2} c+12 a b c^{2}+3 a c^{3}+6 b^{3} c+10 b^{2} c^{2}+5 b c^{3}+c^{4}\right] \mathrm{e}$ $C_{2}=a^{3}+3 a^{2} b+3 a^{2} c+3 a b^{2}+6 a b c+3 a c^{2}+2 b^{3}+3 b^{2} c+3 b c^{2}+c^{3}$.

Na Figura 4.10, pode-se verificar que: 


$$
w_{D}=y_{D}-y_{C}
$$

E $y_{D}$ pode ser obtido da equação elástica da barra:

$$
y_{D}=y_{B}-\frac{\left(M_{B} \frac{b^{2}}{2}-V_{d, R} \frac{b^{3}}{6}\right)}{E_{S} I_{S}}
$$

Usando as equações (4.9) e (4.10), $V_{d, R}$ também pode ser expressa em função da abertura da fissura de fendilhamento junto à fissura fictícia $w_{D}$ :

$$
V_{d, R}=\frac{3\left[M_{B} b^{2}+2 \mathrm{E}_{\mathrm{s}} \mathrm{I}_{\mathrm{s}}\left(w_{D}+y_{C}-y_{B}\right)\right]}{b^{3}}
$$

Com as equações dadas anteriormente, é possível obter a relação entre $V_{d, R}$ e $w_{D}$. Inicialmente, os valores conhecidos são: comprimento $b$, largura da viga $b_{w}$, número $n$ e diâmetro $\phi$ das barras de aço, e relação entre resistência à tração residual $f_{c t r}$ e abertura da fissura $w$ obtida no ensaio de tração direta do concreto.

O valor de $k$ deve ser definido. Para os espécimes deste estudo, o valor que levou a uma boa concordância entre curvas calculadas e experimentais e que também se encontrou no intervalo reportado na literatura (Dei Poli et al. (1992); Kwan et al. (2010); Tanaka \& Murakoshi (2011)) foi $k=E_{c} /(2,2 \phi)$. Com o $k$ definido, são determinados o comprimento $a$ (Eq. 4.1) e o deslocamento $y_{C}$ (eq. 4.2).

Para um dado valor de $w_{D}$, a partir da curva da resistência à tração residual do concreto em função da abertura de fissura, é obtida a resistência à tração residual correspondente à abertura de fissura igual a $w_{D} / 2$. Multiplicando essa resistência residual por $b_{n}=\left(b_{w}-n \phi\right)$, o valor de $p$ é encontrado. Então, o único valor desconhecido das equações (4.4) a (4.8) é o do comprimento $c$. E ele pode ser encontrado a partir da eq. 4.9, porque para cada valor $\mathrm{w}_{\mathrm{D}}$ existe apenas um valor possível de $c$. Com $c, V_{d, R}$ pode ser obtido com a Eq. (4.7) ou Eq. (4.11). 


\subsection{3}

\section{Comparação entre resultados experimentais e calculados}

$\mathrm{Na}$ Figura 4.11, a relação entre $V_{d}$ e $w_{D}$ experimental é comparada com a dada pelo modelo proposto (relação entre $V_{d, R} \mathrm{e} w_{D}$ ) para o lado onde ocorreu ruptura nos espécimes D12,5(1S) e D16(1S). As duas curvas de tensão normal residual abertura de fissura obtidas para o concreto com $V_{f}=1,0 \%$ de fibras $\mathrm{S}$ (Figura 3.8b, p. 106) foram usadas para calcular $p$.

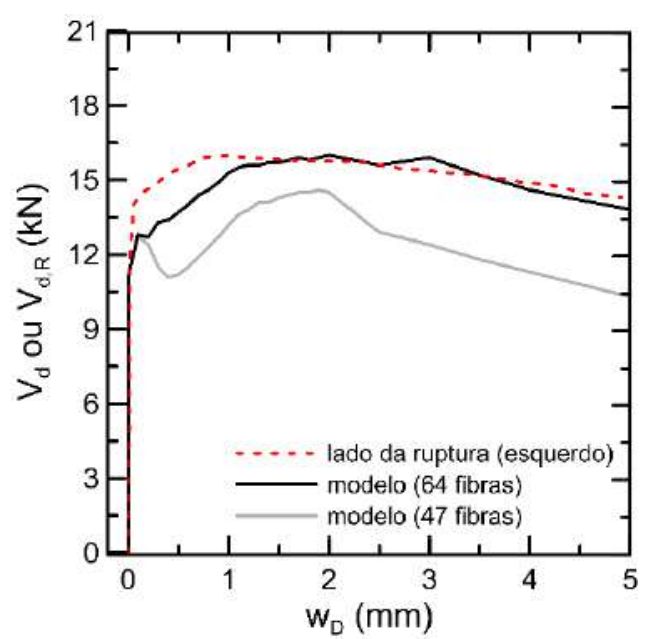

(a)

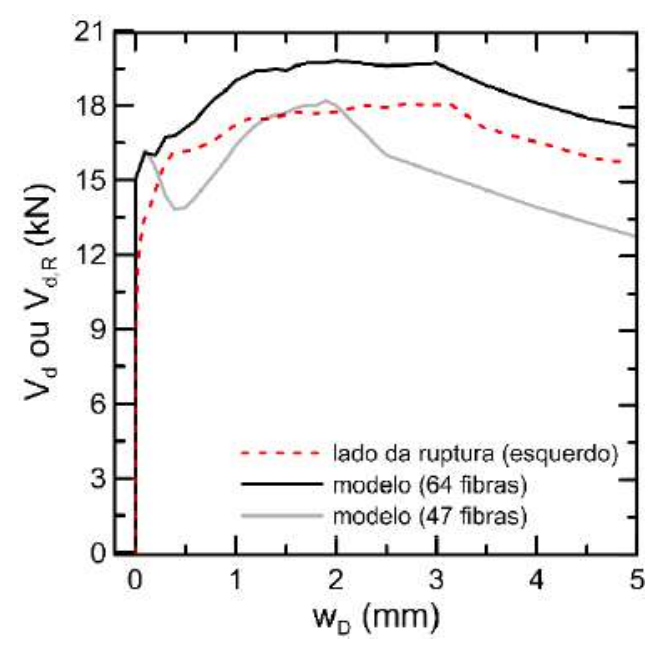

(b)

Figura 4.11 - Comparação entre as relações $V_{d}-w_{D}$ e $V_{d, R}-w_{D}$ : (a) D12,5(1S); (b) D16(1S).

A Tabela 4.3 apresenta a relação entre $V_{d, \max }$ e $V_{d, R, \max }\left(V_{d, R}\right.$ máximo) dos espécimes sem fibras e dos "D" com fibras. Para resistência à tração direta dos concretos sem fibras considerou-se $f_{c t}=0,9 f_{c t, s p} \quad(\mathrm{EN} \mathrm{1992-1-1:2004)}$ onde $f_{c t, s p}=2,88 \mathrm{MPa}$ (Tabela 3.5). Como observado experimentalmente, o modelo proposto fornece $V_{d, R, \max }$ maior para os espécimes com barras de aço de maior diâmetro $(\phi=16 \mathrm{~mm})$.

Tabela 4.3 - Razão entre $V_{d, \max }$ e $V_{d, R, \max }$.

\begin{tabular}{lccc}
\hline Espécime & $\boldsymbol{V}_{\boldsymbol{d}, \max }(\mathbf{k N})$ & $\boldsymbol{V}_{\boldsymbol{d}, \boldsymbol{R}, \max }(\mathbf{k N})$ & $\boldsymbol{V}_{\boldsymbol{d}, \max } / \boldsymbol{V}_{\boldsymbol{d}, \boldsymbol{R}, \boldsymbol{m a x}}$ \\
\hline $\mathbf{1 2 , 5}$ & 9,31 & 9,11 & 1,02 \\
$\mathbf{D 1 2 , 5}$ & 9,94 & 9,11 & 1,09 \\
$\mathbf{1 6}$ & 11,5 & 12,3 & 0,935 \\
D16 & 12,0 & 12,3 & 0,976 \\
D12,5(1S) & 16,2 & 14,4 e $15,9^{*}$ & 1,13 e $1,02^{*}$ \\
D16(1S) & 18,2 & 17,1 e $19,5^{*}$ & 1,06 e $0,932^{*}$ \\
\hline
\end{tabular}

*calculados considerando as curvas da Figura 3.8b relativas a 47 e 64 fibras na seção de ruptura. 
Considerando a Tabela 4.3 e a Figura 4.11, que a quantidade e a direção das fibras são aleatoriamente distribuídas e como isto afeta o comportamento pósfissuração dos elementos com fibras, pode-se dizer que a correlação entre resultados experimentais e calculados é satisfatória.

\section{2}

\section{Ensaios de engrenamento dos agregados}

\subsection{1}

\section{Resultados experimentais}

As análises fotogramétricas mostraram que a fissuração ocorreu no plano do entalhe, mas alguns espécimes apresentaram também fissuras fora deste plano.

Verificou-se que, ao longo dos ensaios, as forças nas quatro barras de aço externas foram aproximadamente iguais, havendo maior diferença entre elas na fase de perda de capacidade resistente. A Figura 4.12, referente ao ensaio do espécime $\mathrm{P}(1 \mathrm{~L}) \mathrm{c}$, exemplifica isso.
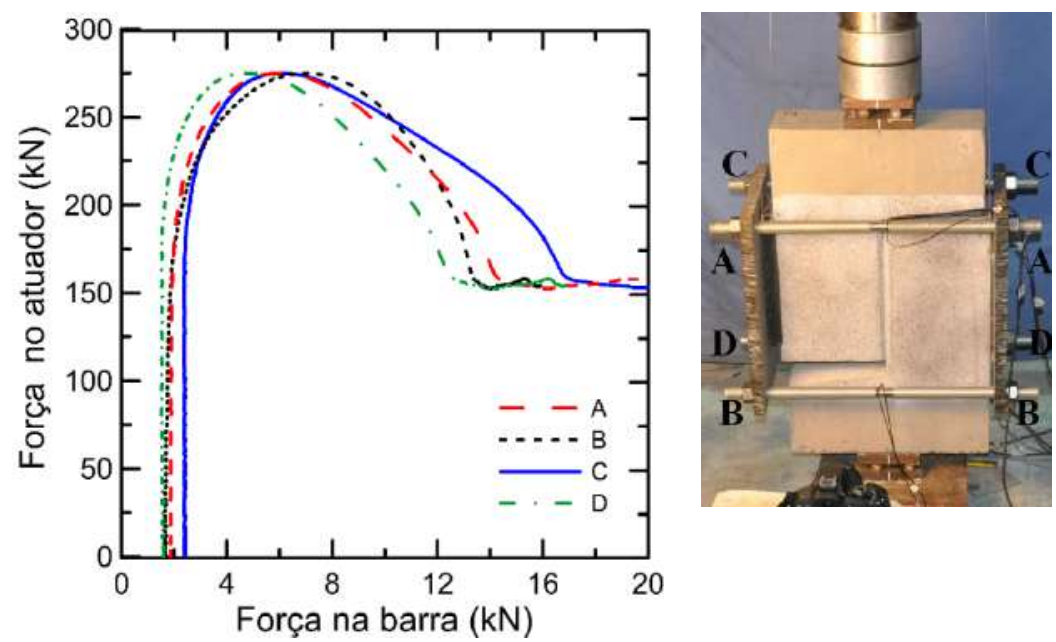

Figura 4.12 - Força nas barras de aço externas ao longo do ensaio do espécime $\mathrm{P}(1 \mathrm{~L}) \mathrm{c}$.

Devido ao fato dos ensaios terem sido controlados pelo deslocamento do atuador, os espécimes sem fibras apresentaram aumento brusco dos deslocamentos relativos nas direções paralela $(\Delta)$ e transversal ao plano de cisalhamento $(w)$ imediatamente após a fissuração. A região do comportamento caracterizada por esse 'salto' nos resultados com aquisição reduzida de dados é aqui denominada “zona instável”. Logo a seguir, voltou-se ao registro adequado de dados, tendo-se 
novamente a aqui chamada "zona estável", de interesse para as análises do engrenamento dos agregados (item 4.2.3). A Figura 4.13, que mostra a relação entre a tensão cisalhante $\tau$ e a abertura da fissura no entalhe $w$ verificada no espécime $\mathrm{P}(0) \mathrm{a}$, ilustra essas zonas.

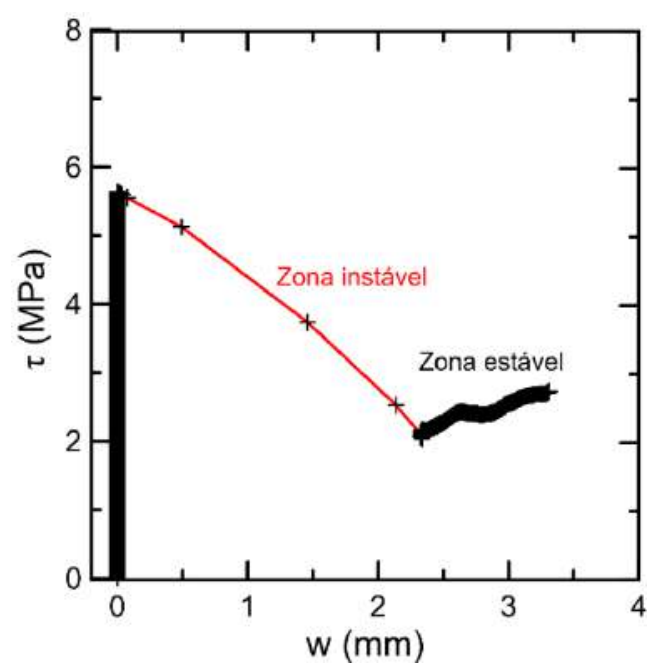

Figura 4.13 - Curva $\tau$ - $w$ para o espécime $\mathrm{P}(0) \mathrm{a}$.

Na Figura 4.14 é apresentado o campo de deformação específica na direção horizontal para um estágio pós-fissuração (com abertura de fissura estabilizada) dos espécimes sem fibras e, na Figura 4.15, para o estágio de tensão de cisalhamento máxima $\left(\tau_{\max }\right)$ dos espécimes com fibras. Nestas imagens, pode-se ver o estado geral de fissuração dos espécimes. Os espécimes $\mathrm{P}(0,5 \mathrm{~S}) \mathrm{a}, \mathrm{P}(1 \mathrm{~L}) \mathrm{a}$ e $\mathrm{P}(1 \mathrm{~L}) \mathrm{b}$ apresentaram fissuras fora da região do entalhe, sendo as dos $\mathrm{P}(0,5 \mathrm{~S})$ a e $\mathrm{P}(1 \mathrm{~L}) \mathrm{a}$ paralelas ao plano do entalhe e as do $\mathrm{P}(1 \mathrm{~L}) \mathrm{b}$ paralelas e inclinadas em relação a esse plano, o que pode ser justificado principalmente pelas características inerentes de concreto com fibras: distribuição e ação heterogênea das fibras no elemento estrutural.

Já nas Figuras 4.16 a 4.19 são mostrados os campos de deslocamentos horizontal e vertical para o estágio final do ensaio de cada espécime, onde pode ser observado que as partes em " $\mathrm{L}$ " tiveram movimento de corpo rígido. 


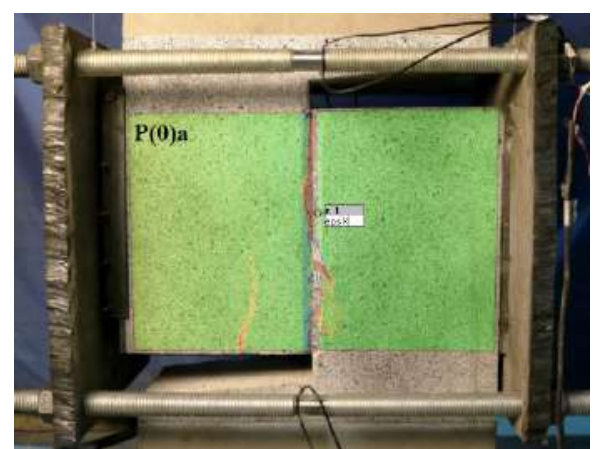

(a)

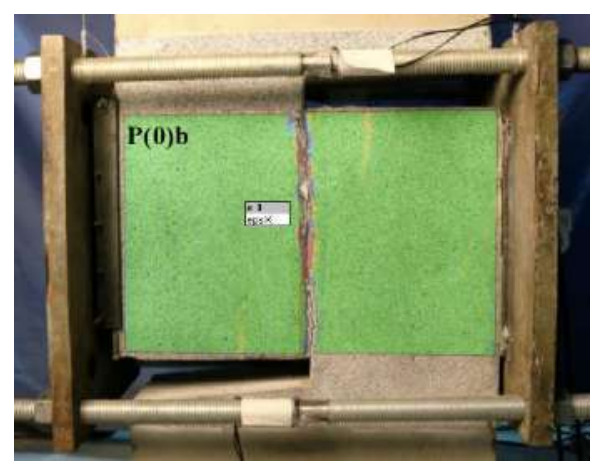

(b)

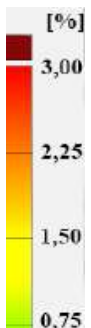

0,75

0,00

$-0,75$

$-1,50$

$-2,25$

$-3,00$

(c)

Figura 4.14 - Campo de deformação na direção horizontal para os espécimes sem fibras no estágio pós-fissuração e com abertura de fissura estabilizada: (a) $\mathrm{P}(0) a$; (b) $\mathrm{P}(0) \mathrm{b} ;(\mathrm{c}) \mathrm{P}(0) \mathrm{c}$. 


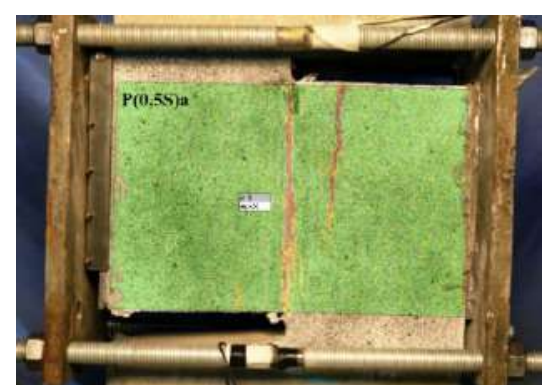

(a)

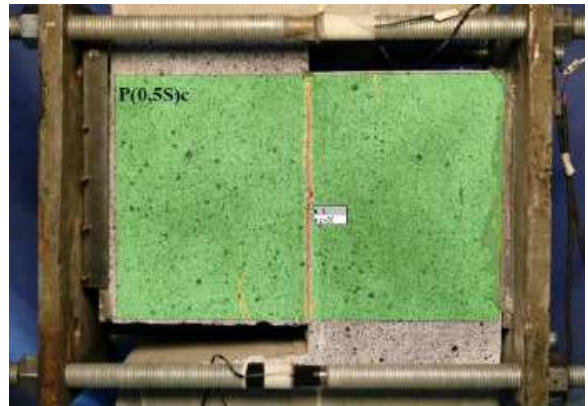

(c)

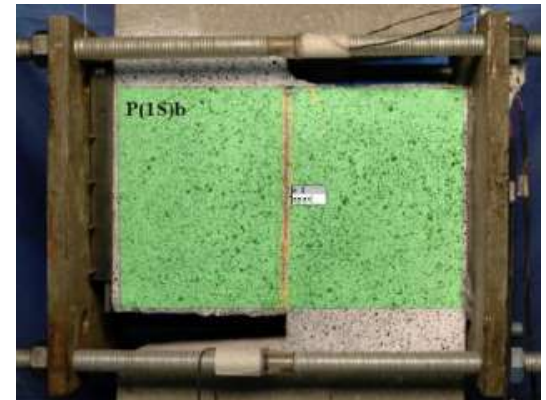

(e)

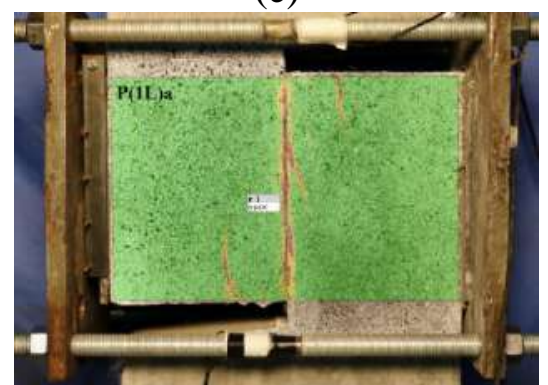

(g)

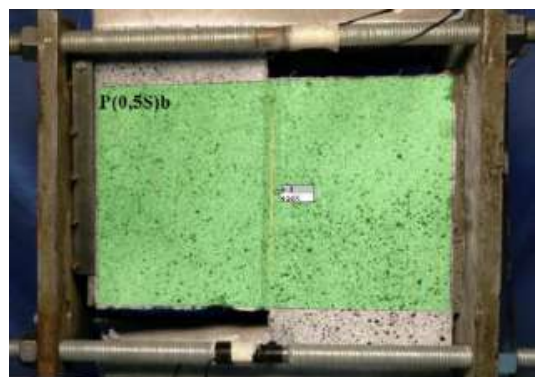

(b)

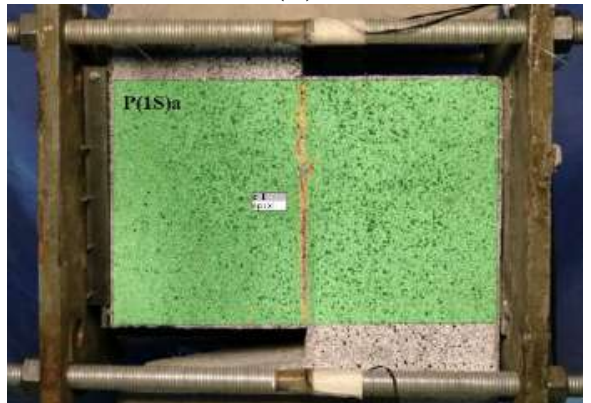

(d)

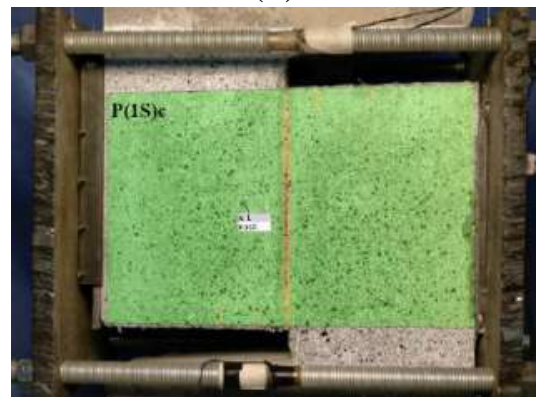

(f)

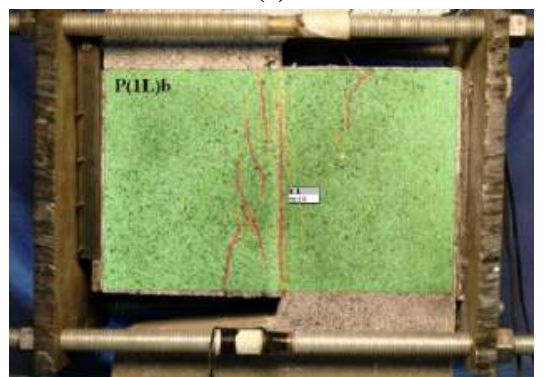

(h)
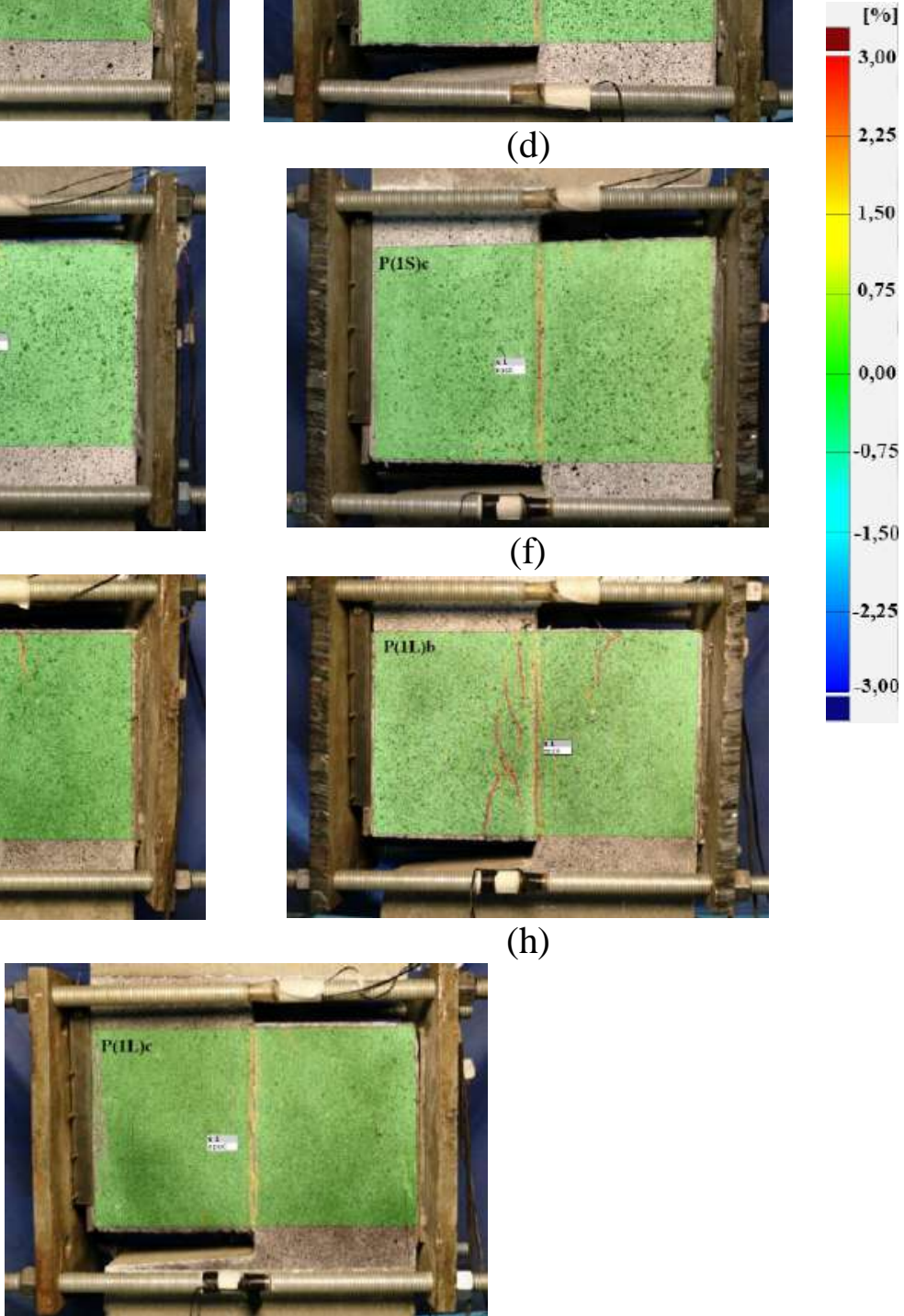

2,25

Figura 4.15 - Campo de deformação na direção horizontal para os espécimes com fibras no estágio de tensão de cisalhamento máxima: (a) $\mathrm{P}(0,5 \mathrm{~S}) \mathrm{a}$; (b) $\mathrm{P}(0,5 \mathrm{~S}) \mathrm{b}$; (c) $\mathrm{P}(0,5 \mathrm{~S}) \mathrm{c}$; (d) $\mathrm{P}(1 \mathrm{~S}) \mathrm{a}$; (e) $\mathrm{P}(1 \mathrm{~S}) \mathrm{b}$; (f) $\mathrm{P}(1 \mathrm{~S}) \mathrm{c}$; (g) $\mathrm{P}(1 \mathrm{~L}) \mathrm{a}$; (h) $\mathrm{P}(1 \mathrm{~L}) \mathrm{b}$; (i) $\mathrm{P}(1 \mathrm{~L}) \mathrm{c}$; 


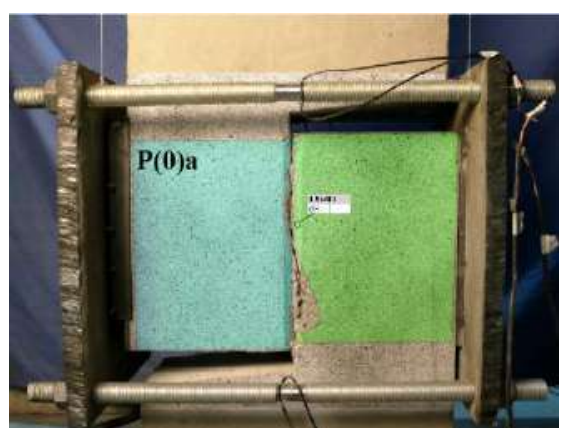

(a)

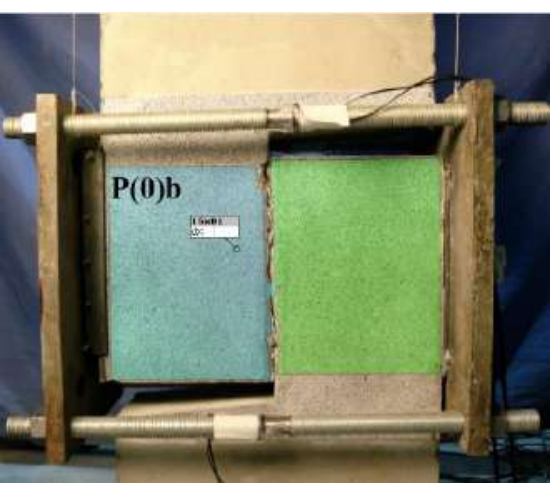

(c)

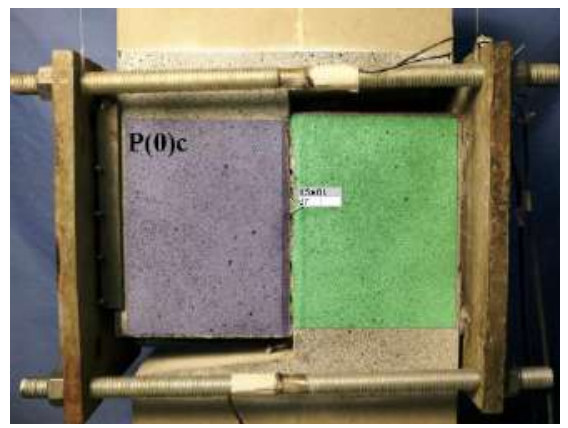

(e)

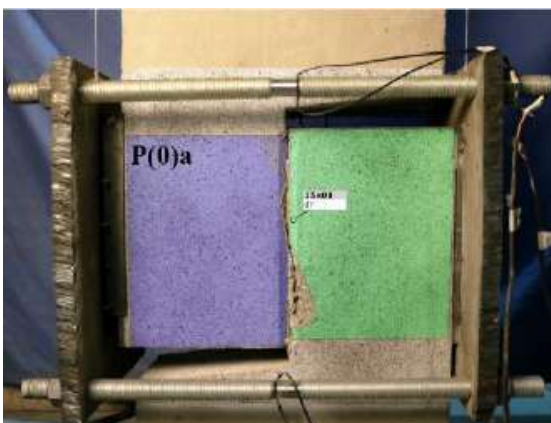

(b)

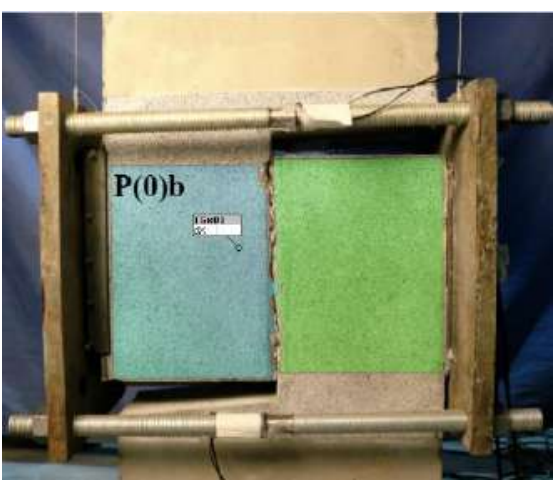

(d)

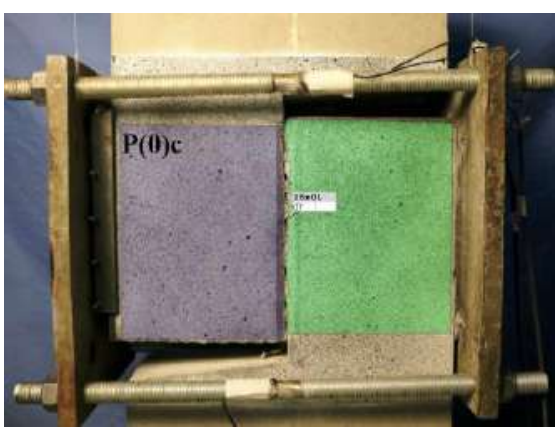

(f)

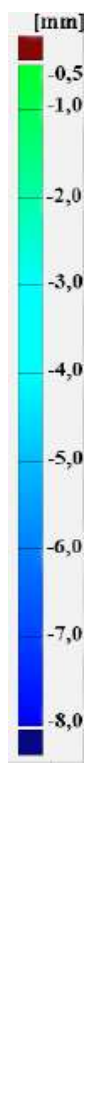

Figura 4.16 - Campos de deslocamentos na direção horizontal (à esquerda) e vertical (à direita), no estágio final dos ensaios dos espécimes sem fibras: (a-b) $\mathrm{P}(0) \mathrm{a} ;(\mathrm{c}-\mathrm{d}) \mathrm{P}(0) \mathrm{b}$; (e-f) $\mathrm{P}(0) \mathrm{c}$. 


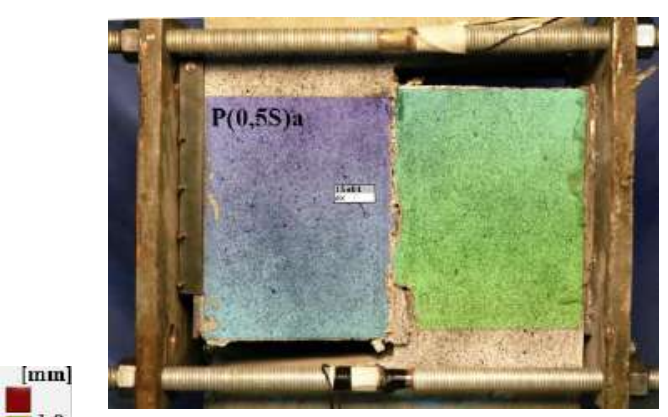

(a)

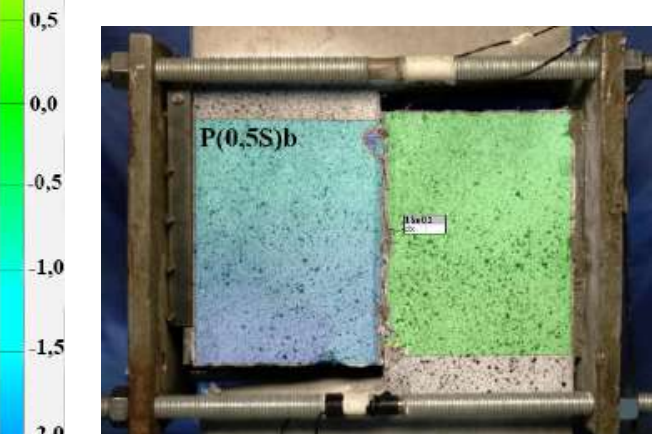

(c)

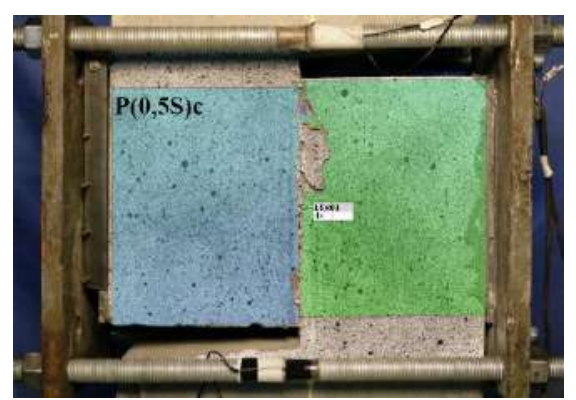

(e)

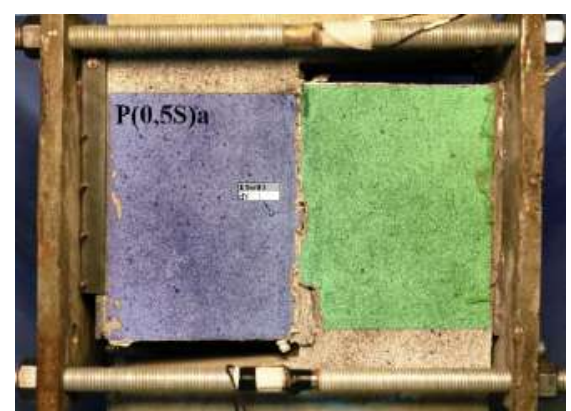

(b)

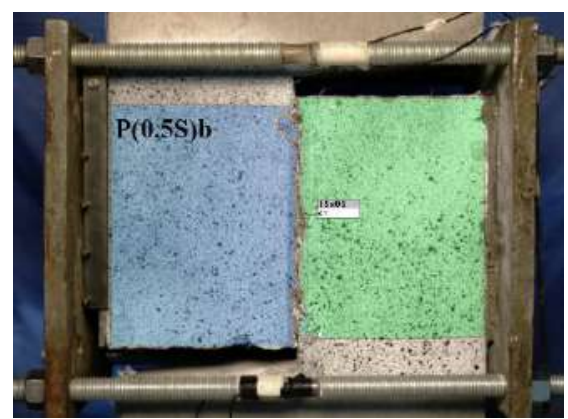

(d)

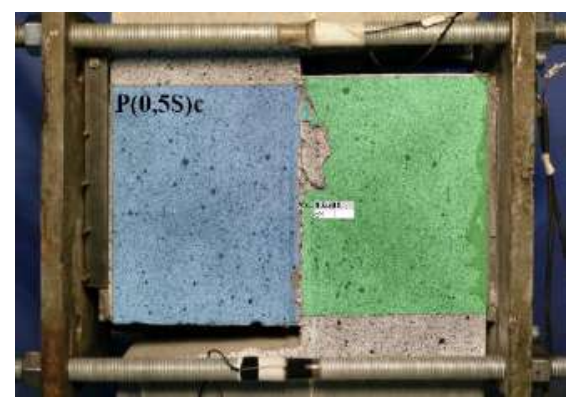

(f)
${ }_{0,0}^{[\mathrm{mm}]}$

$-1,5$

$-3,0$

$-4,5$

$-6,0$

$-7,5$

$-9,0$

$-10,5$

$-12,0$

Figura 4.17 - Campos de deslocamentos na direção horizontal (à esquerda) e vertical (à direita), no estágio final dos ensaios dos espécimes com $V_{f}=0,5 \%$ (S): (a-b) $\mathrm{P}(0,5 \mathrm{~S}) \mathrm{a}$; (c-d) $\mathrm{P}(0,5 \mathrm{~S}) \mathrm{b}$; (e-f) $\mathrm{P}(0,5 \mathrm{~S}) \mathrm{c}$. 


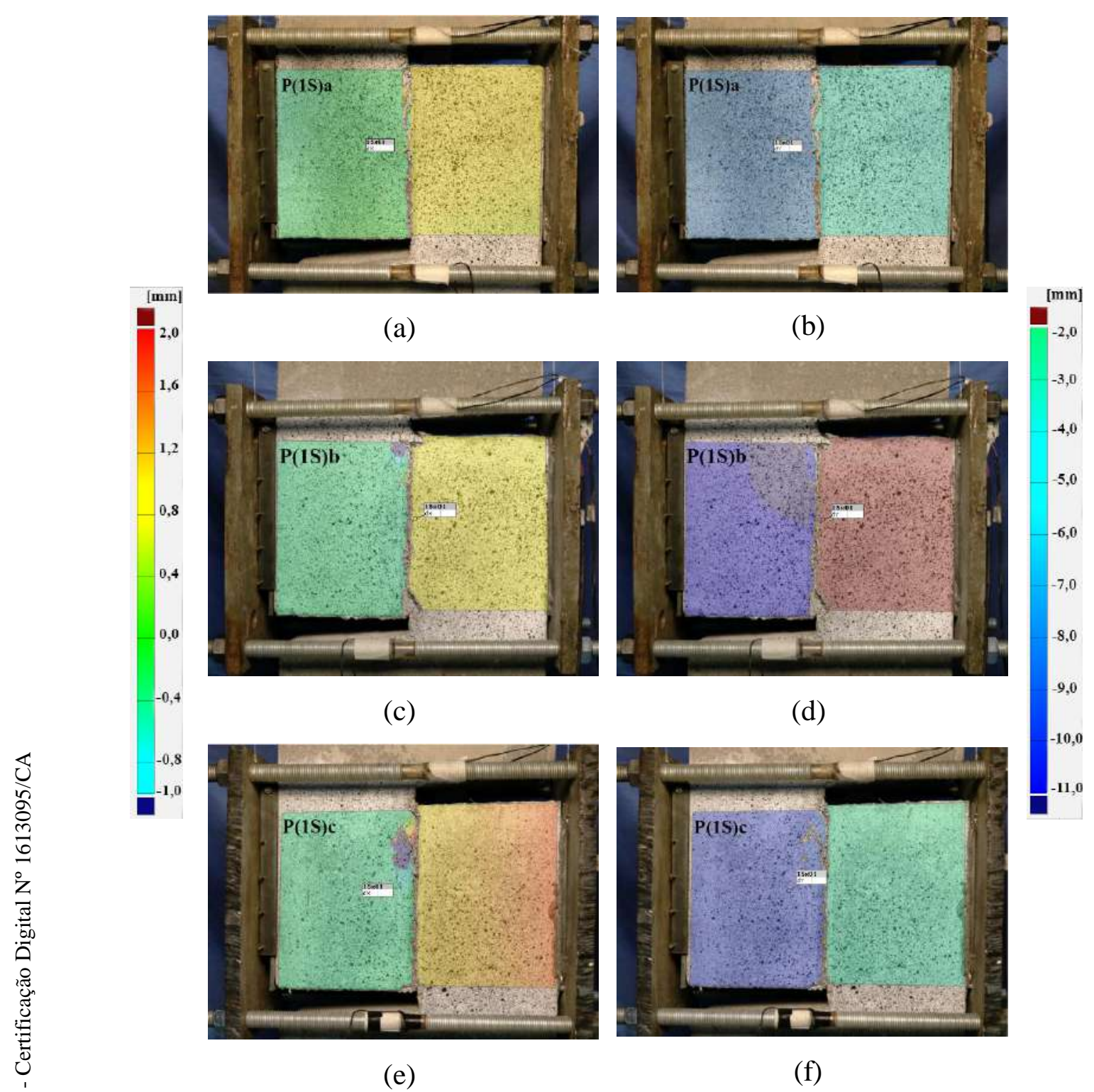

Figura 4.18 - Campos de deslocamentos na direção horizontal (à esquerda) e vertical (à direita), no estágio final dos ensaios dos espécimes com $V_{f}=1,0 \%$ (S): (a-b) P(1S)a; (c-d) P(1S)b; (e-f) P(1S)c. 


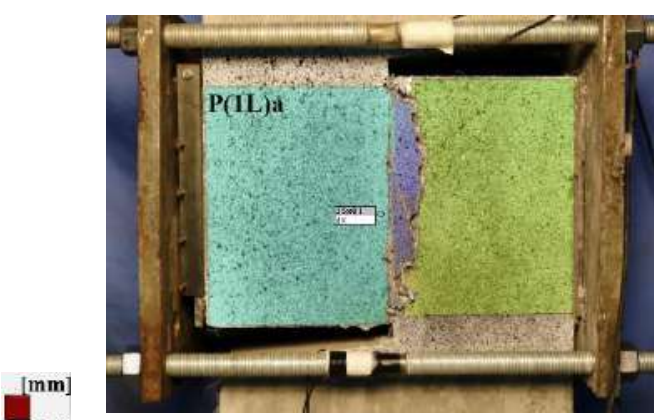

(a)

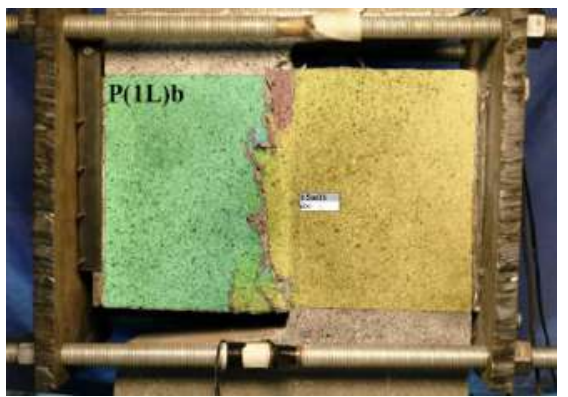

(c)

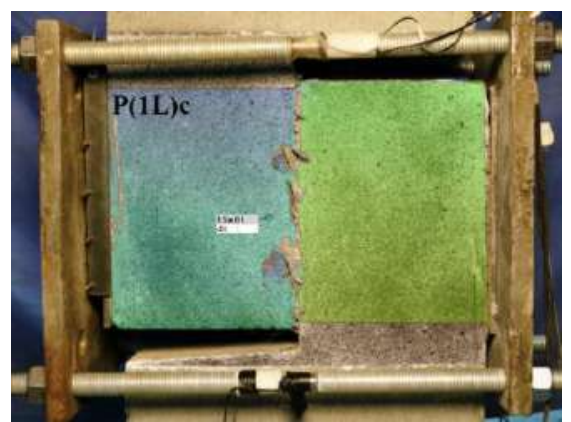

(e)

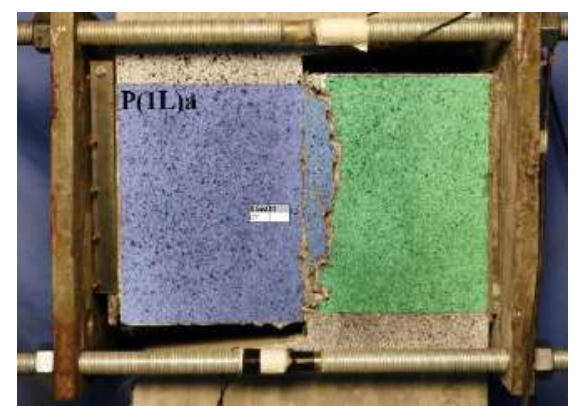

(b)

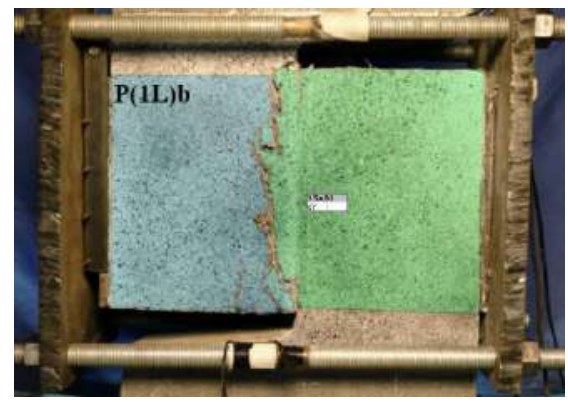

(d)

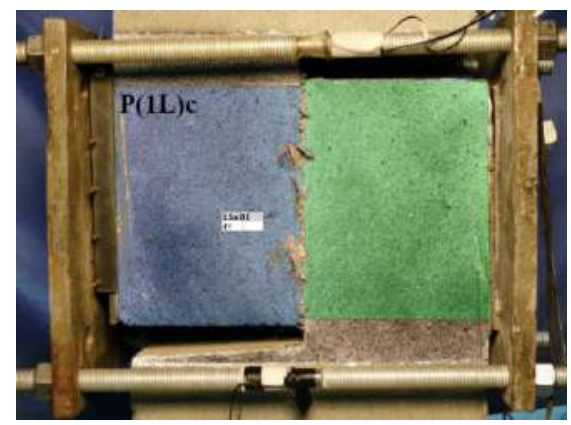

(f)
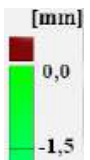

$-4,5$

$-6,0$

$-7,5$

9,0

10,5

Figura 4.19 - Campos de deslocamentos na direção horizontal (à esquerda) e vertical (à direita), no estágio final dos ensaios dos espécimes com $V_{f}=1,0 \%$ (L): (a-b) P(1L)a; (c-d) P(1L)b; (e-f) P(1L)c.

Nas Figuras 4.20 a 4.23 são apresentadas as curvas $\tau-w, \tau-\Delta, \sigma-w, \sigma-\Delta, \tau-\sigma \mathrm{e}$ $\Delta-w$ obtidas para os espécimes, de acordo com o seu teor e tipo de fibras. $\mathrm{Na}$ Figura 4.24, as curvas dos espécimes com diferentes teores de fibras são agrupadas visando uma análise global.

A Tabela 4.4 lista os valores da tensão normal no início do ensaio $\left(\sigma_{i}\right)$, das tensões normais e cisalhantes correspondentes à carga de fissuração e à carga máxima $\left(\sigma_{c r}, \sigma_{\max }\right)$ e $\left(\tau_{c r}, \tau_{\max }\right)$ e os deslocamentos relativos $\left(\Delta_{\max }\right)$ e $\left(w_{\max }\right)$ para a carga máxima. Nela nota-se que os valores de $\tau_{c r}$ dos espécimes com e sem fibras foram próximos, que os de $\sigma_{c r}$ pouco diferiram de $\sigma_{i}$ e que $w_{\max }>\Delta_{\max }$ $\left(0,309 \leq \Delta_{\max } / w_{\max } \leq 0,952\right)$. 
Como mostrado nas curvas $\tau-w$ dos espécimes sem fibras (Figura 4.20), os espécimes $\mathrm{P}(0)$ a e $\mathrm{P}(0) \mathrm{c}$ apresentaram perda de capacidade resistente contínua após a fissuração. $\mathrm{O} P(0) b$, entretanto, depois de alguma perda de capacidade resistente após a fissuração (até $w$ em torno de $0,3 \mathrm{~mm}$ ), recuperou essa capacidade e atingiu $\tau_{\max }>\tau_{\text {cr }}$ e $\sigma_{\max }>\sigma_{c r}$ e $w_{\max }=0,621 \mathrm{~mm}$ e $\Delta_{\max }=0,508 \mathrm{~mm}$, o que mostra que o aumento dos deslocamentos relativos não necessariamente se traduz em diminuição de capacidade resistente. Após atingir $\tau_{c r}$, os espécimes sem fibras tiveram queda brusca de capacidade resistente ("zona instável"), seguida de um gradativo aumento de $\tau$ e de $\sigma$ ("zona estável"), havendo relações $\tau-\Delta$ e $\sigma-w$ aproximadamente lineares. Embora tenha havido alguma variabilidade entre os ensaios no que se refere aos valores de $\tau, \sigma, w$ e $\Delta$ no início da "zona estável", principalmente relacionada à instabilidade da formação da fissura no entalhe, pode-se ver que as curvas mostradas na Figura 4.20 têm tendências parecidas.

Nos espécimes com fibras, a menos do $\mathrm{P}(0,5 \mathrm{~S})$ a, verificou-se tensão de cisalhamento no início de fissuração superior à dos sem fibras. O comportamento dos espécimes com fibras diferenciou-se daquele dos sem fibras após $\tau_{c r}$ (Figura $4.24 \mathrm{a}-\mathrm{b}$ ), quando passou a haver aumento de $\tau$ até que fosse atingida $\tau_{\max }$, a partir da qual ocorreu a perda contínua de capacidade resistente.

Em geral, as curvas das Figuras 4.21 a 4.23 dos espécimes com fibras mostram mesma tendência de comportamento, embora o espécime $\mathrm{P}(1 \mathrm{~L}) \mathrm{b}$ tenha apresentado $w_{\max }=1,12 \mathrm{~mm}$, valor bem maior que o encontrado nos demais espécimes com fibras $\left(0,147 \mathrm{~mm} \leq \mathrm{w}_{\max } \leq 0,616 \mathrm{~mm}\right)$. 


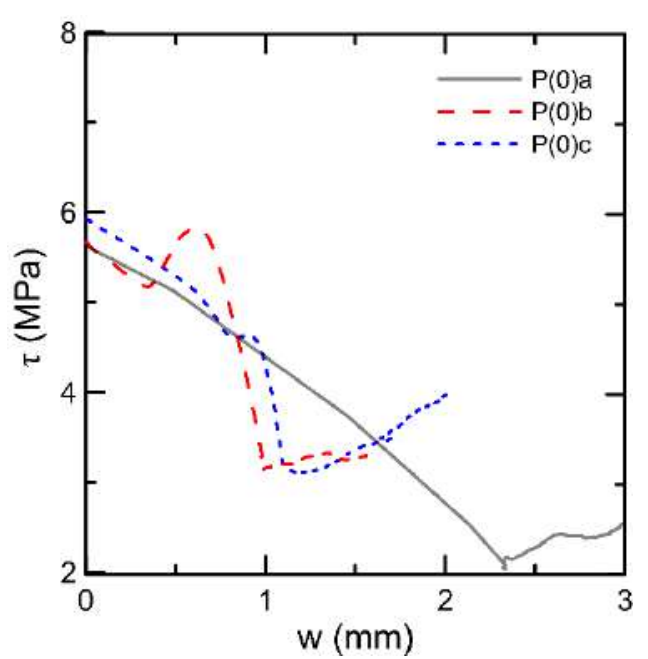

(a)

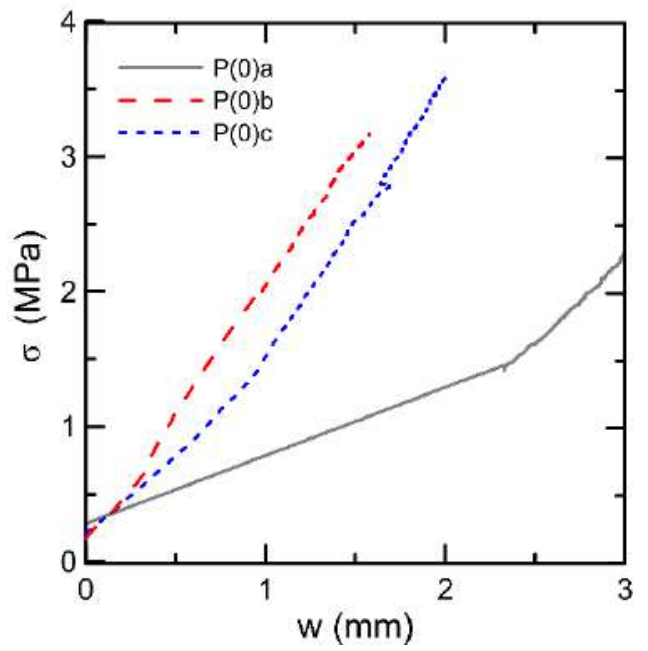

(c)

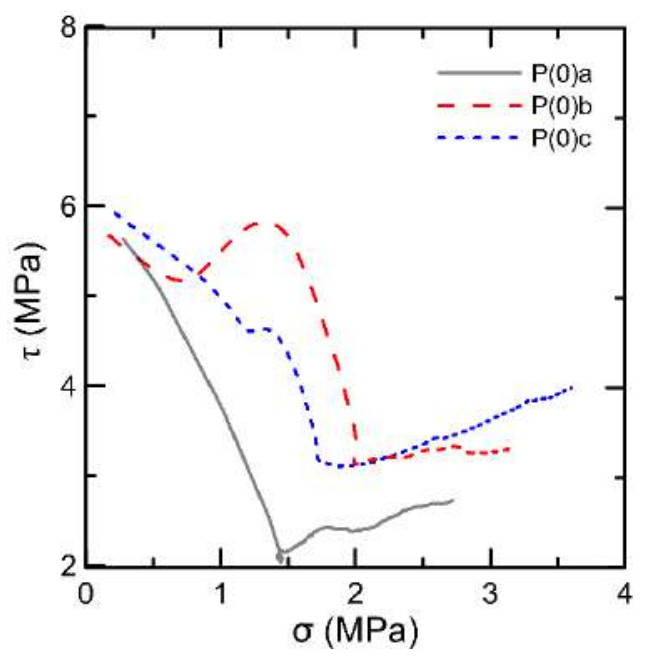

(e)

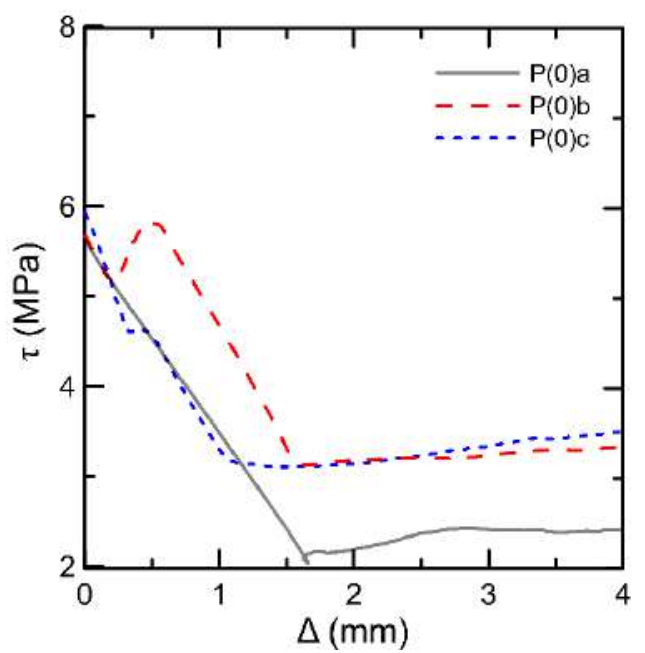

(b)

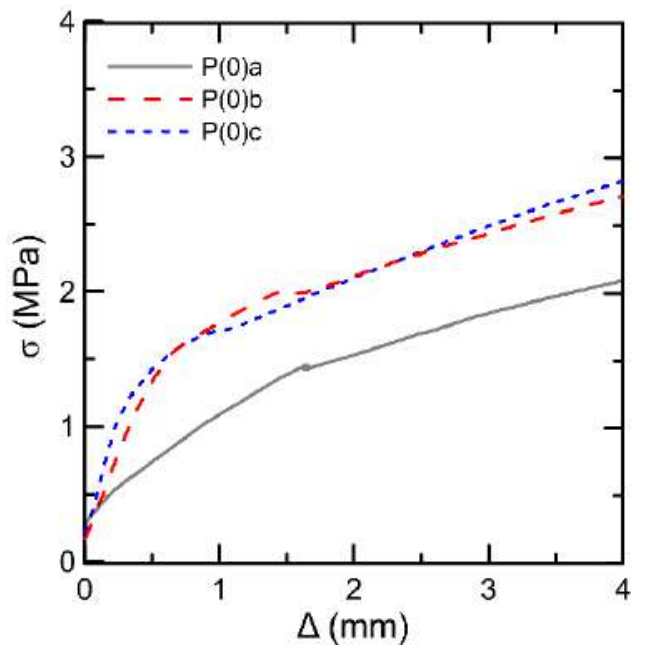

(d)

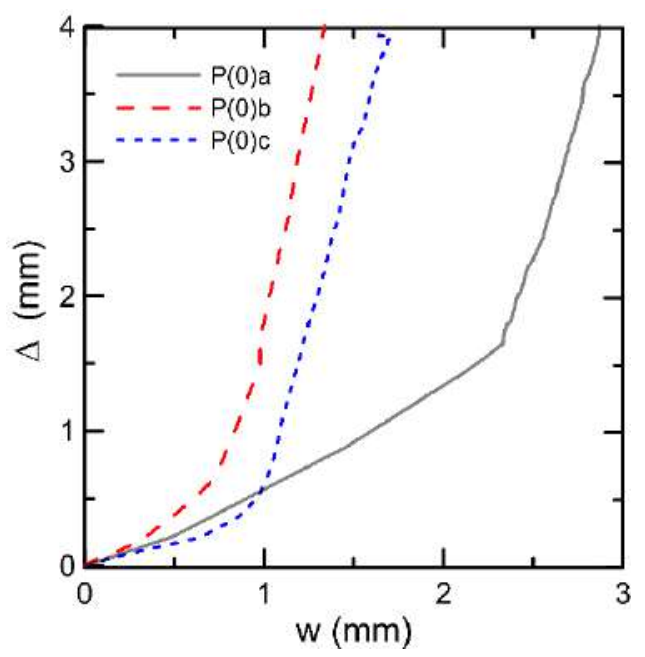

(f)

Figura 4.20 - Resultados dos espécimes sem fibras de aço: (a) $\tau-w$; (b) $\tau-\Delta$; (c) $\sigma-w$; (d) $\sigma-\Delta$; (e) $\tau-\sigma$; (f) $\Delta-w$. 


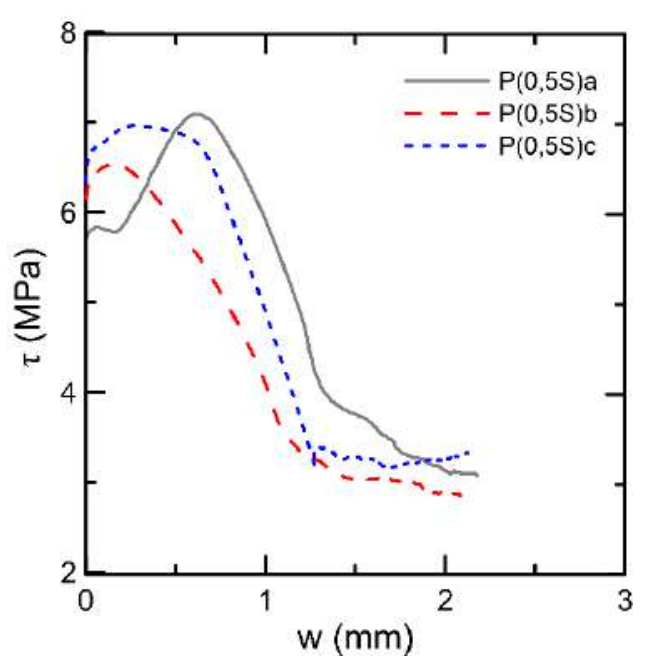

(a)

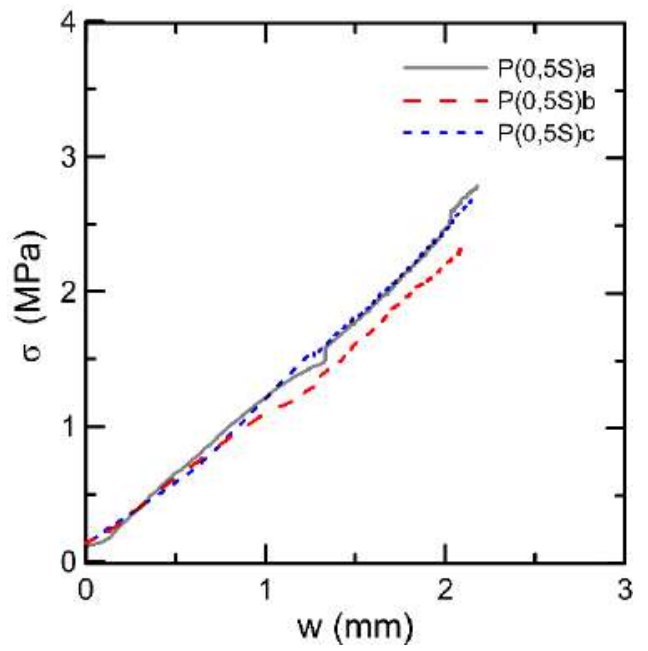

(c)

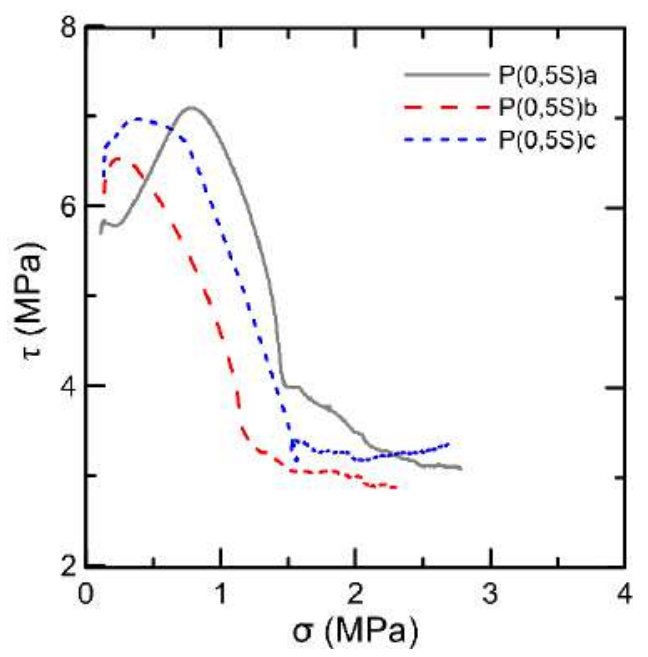

(e)

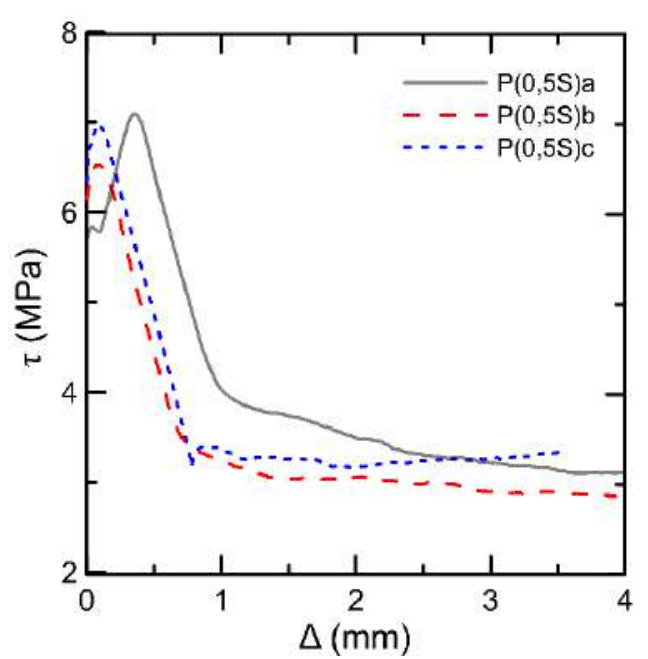

(b)

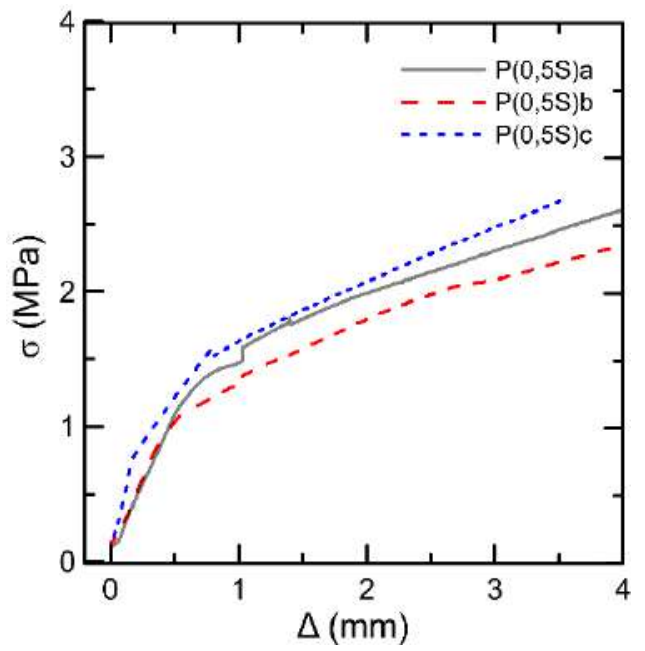

(d)

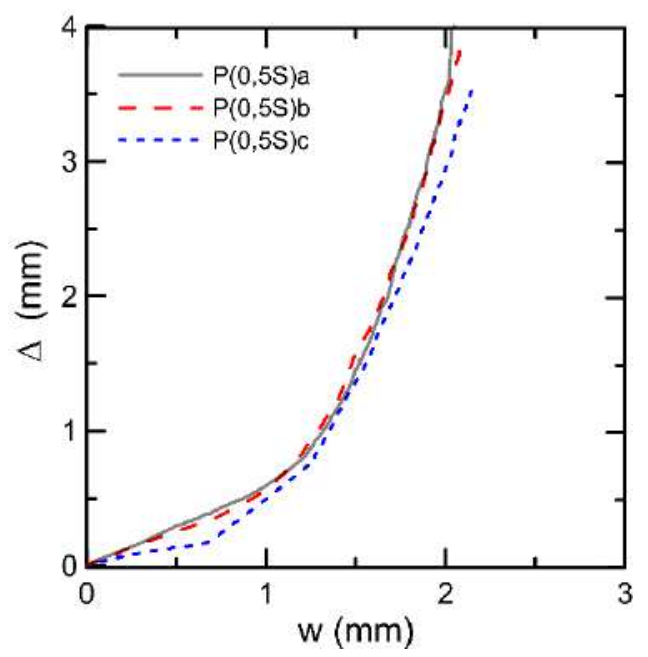

(f)

Figura $4.21-$ Resultados dos espécimes com $V_{f}=0,5 S$ : (a) $\tau-w$; (b) $\tau-\Delta$; (c) $\sigma-w$; (d) $\sigma-\Delta$; (e) $\tau-\sigma$; (f) $\Delta-w$. 


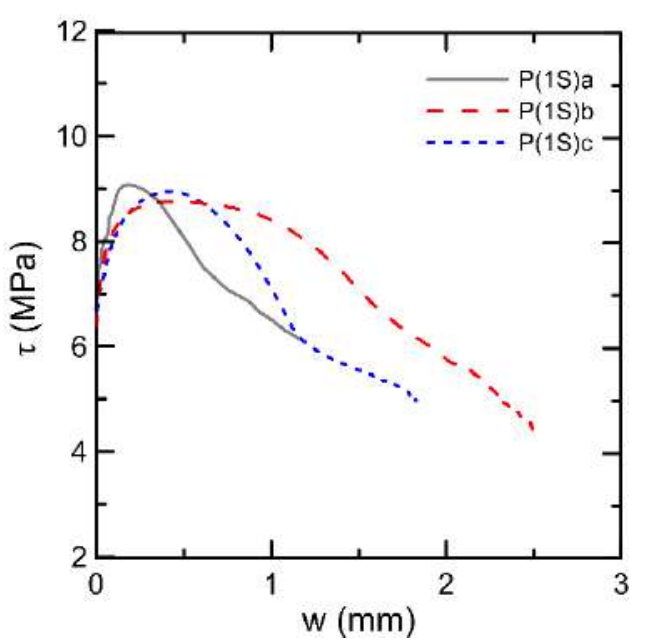

(a)

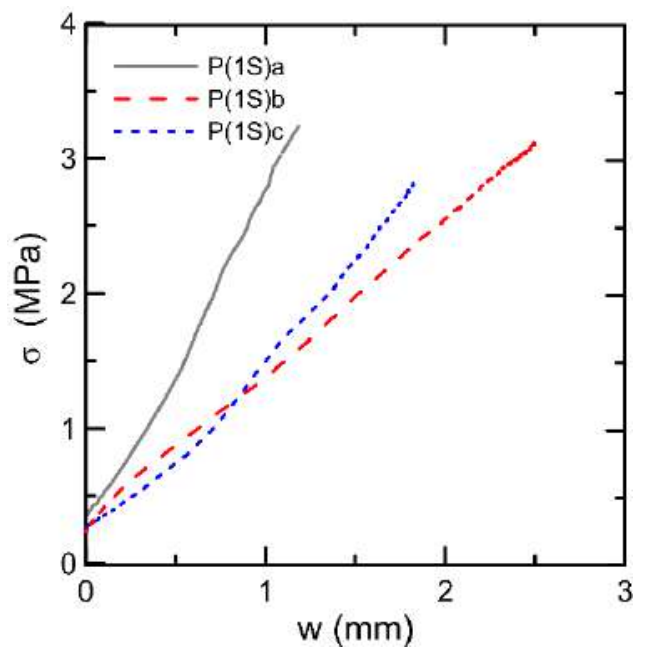

(c)

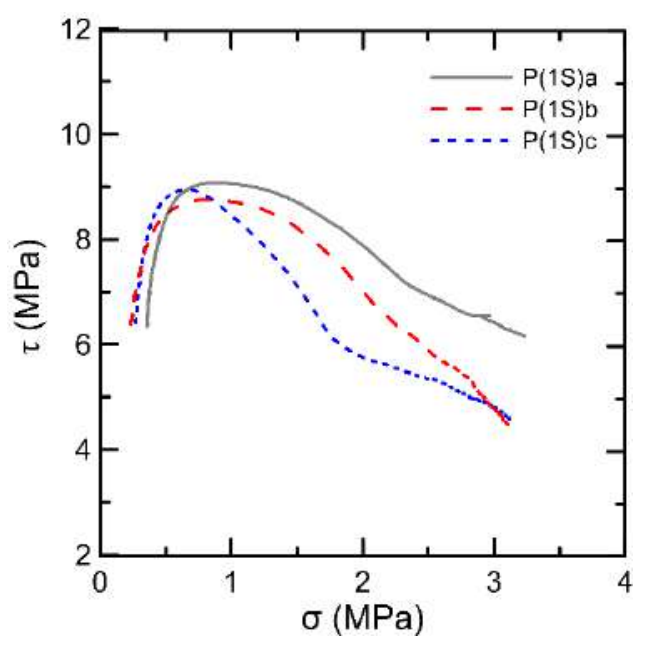

(e)

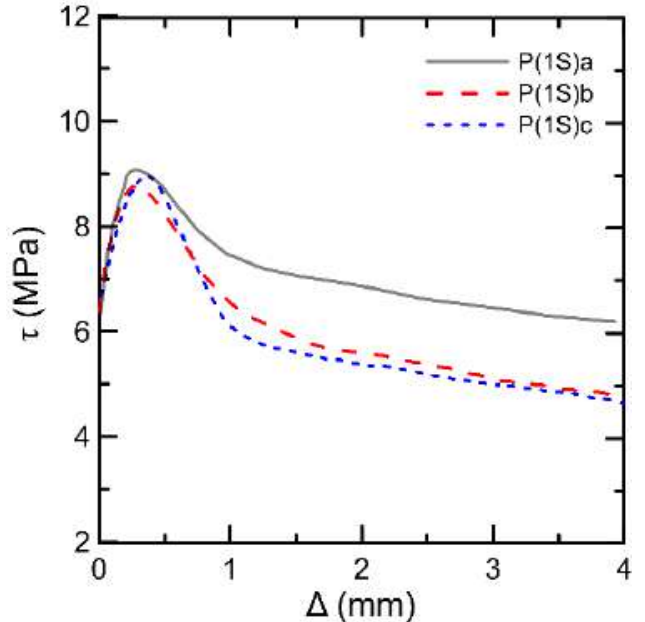

(b)

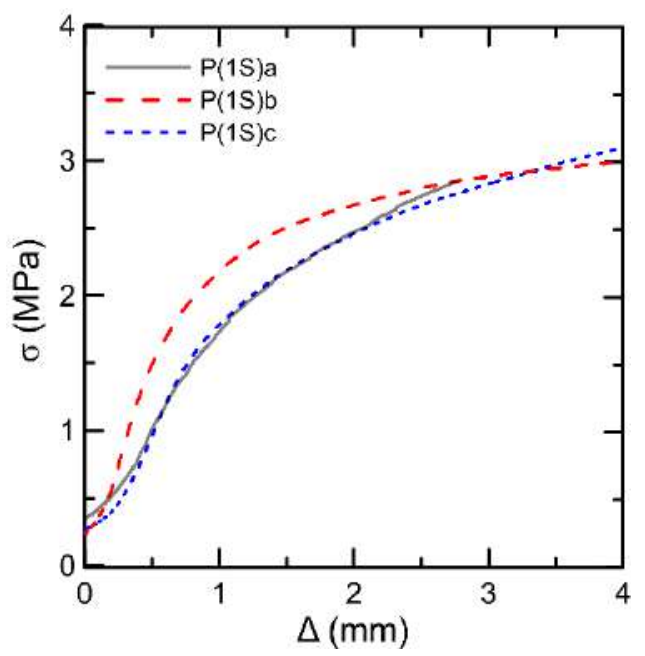

(d)

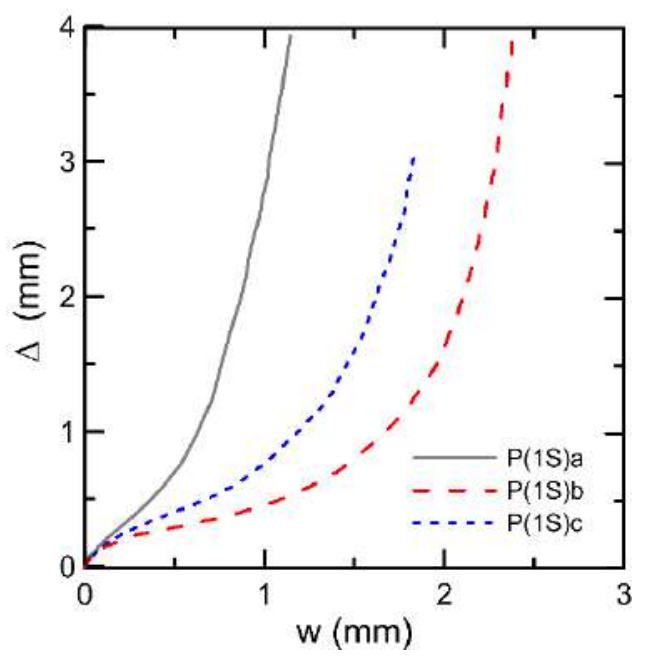

(f)

Figura 4.22 - Resultados dos espécimes com $V_{f}=1 S$ : (a) $\tau$-w; (b) $\tau-\Delta$; (c) $\sigma-w$; (d) $\sigma-\Delta$; (e) $\tau-\sigma$; (f) $\Delta-w$. 


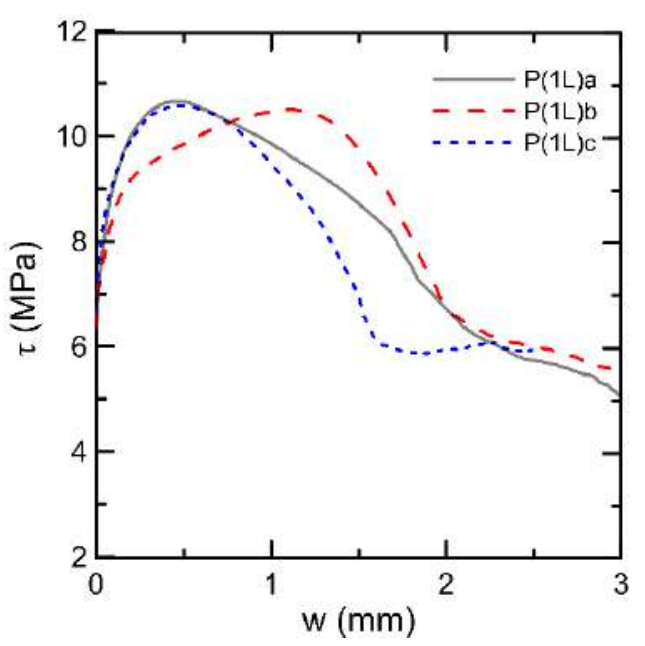

(a)

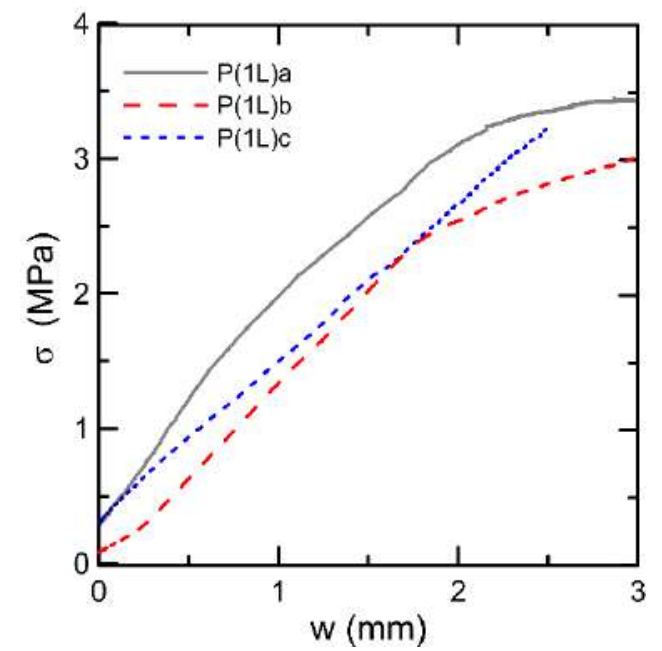

(c)

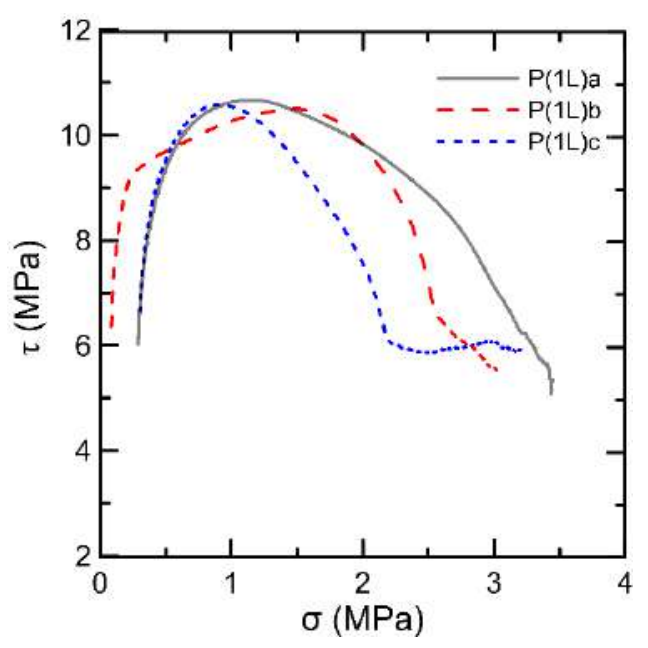

(e)

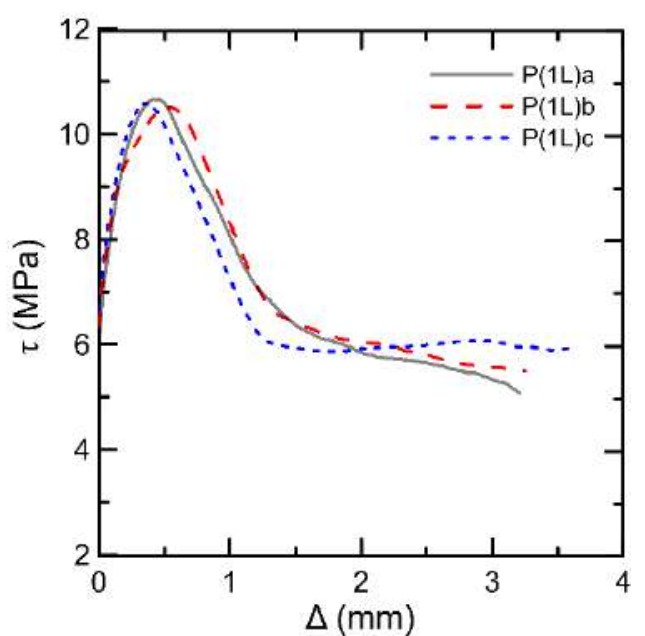

(b)

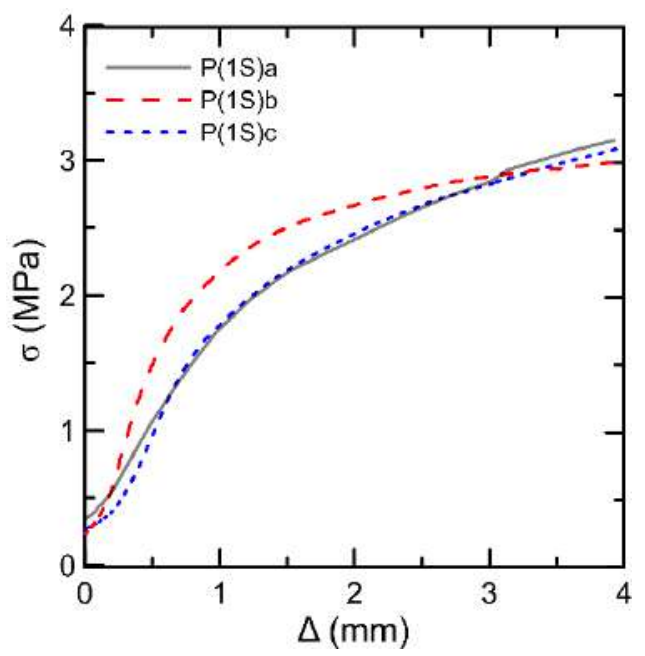

(d)

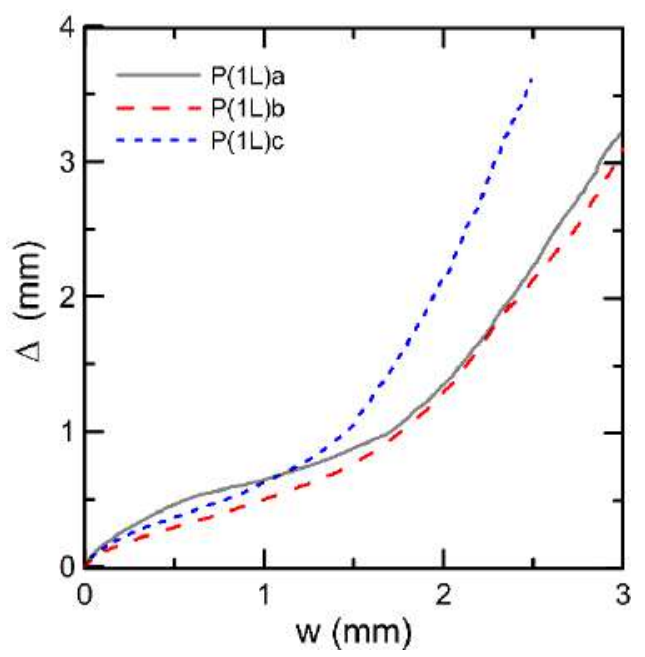

(f)

Figura 4.23 - Resultados dos espécimes com $V_{f}=1 L$ : (a) $\tau-w$; (b) $\tau-\Delta$; (c) $\sigma-w$; (d) $\sigma-\Delta$; (e) $\tau-\sigma$; (f) $\Delta-w$. 


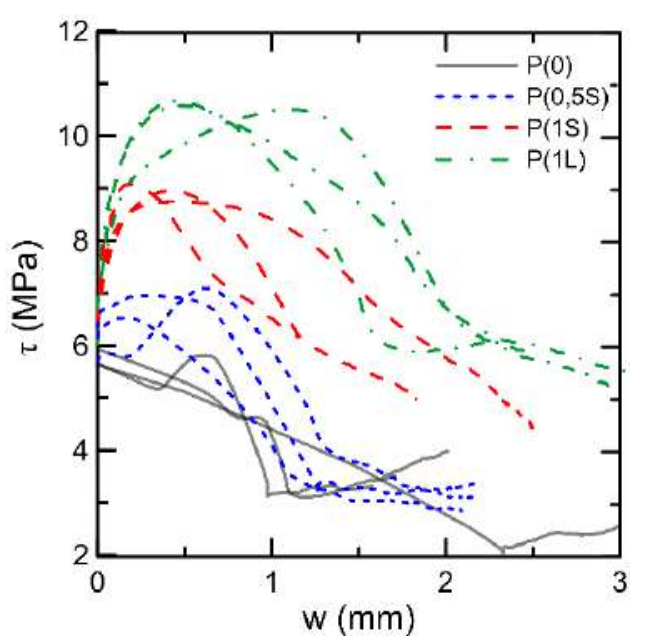

(a)

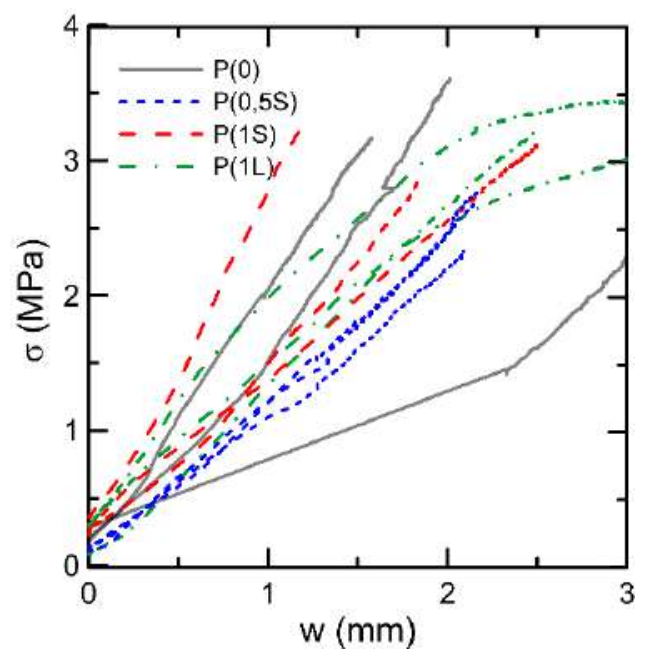

(c)

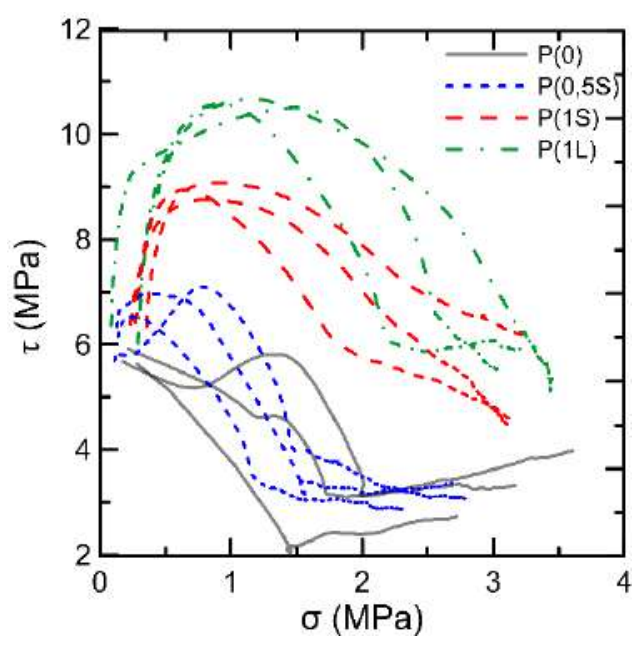

(e)

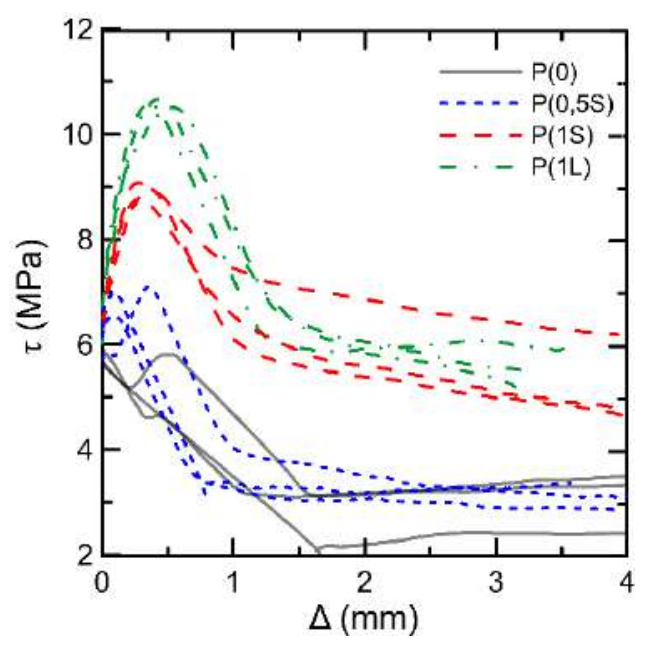

(b)

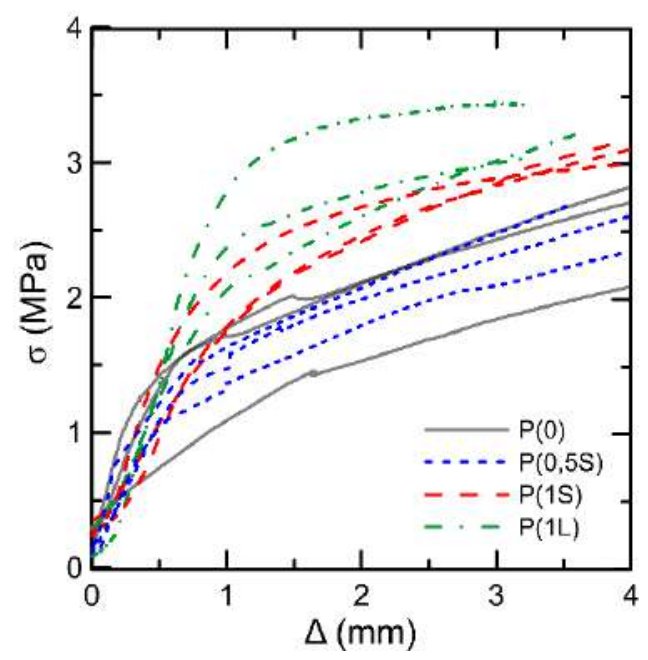

(d)

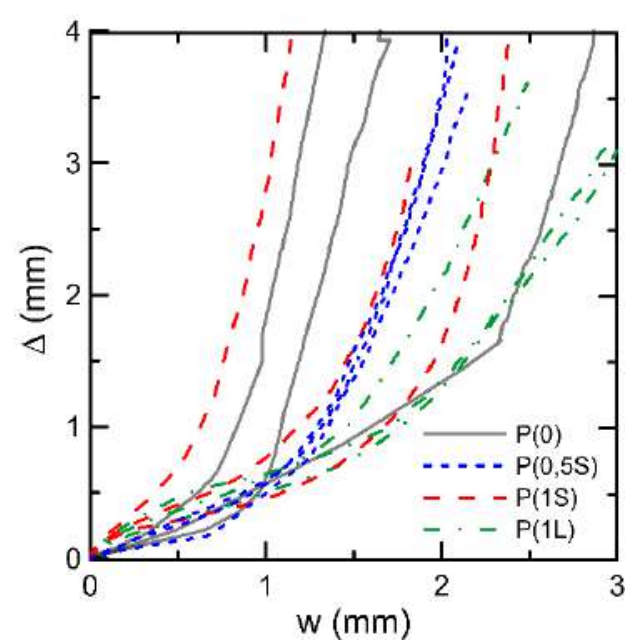

(f)

Figura 4.24 - Resultados dos espécimes com diferentes teores de fibras agrupados: (a) $\tau-w$; (b) $\tau-\Delta$; (c) $\sigma-w$; (d) $\sigma-\Delta$; (e) $\tau-\sigma$; (f) $\Delta-w$. 
Tabela 4.4 - Valores da tensão normal no início do ensaio $\left(\sigma_{i}\right)$, das tensões normais e cisalhantes correspondentes à carga de fissuração e à carga máxima $\left(\sigma_{c r}, \sigma_{\max }\right)$ e $\left(\tau_{c r}, \tau_{\max }\right)$ e os deslocamentos relativos $\left(\Delta_{\max }\right)$ e $\left(w_{\max }\right)$ para a carga máxima.

\begin{tabular}{cccccccc}
\hline Espécime & $\begin{array}{c}\boldsymbol{\sigma}_{\mathbf{i}} \\
(\mathbf{M P a})\end{array}$ & $\begin{array}{c}\boldsymbol{\sigma}_{\mathbf{c r}} \\
(\mathbf{M P a})\end{array}$ & $\begin{array}{c}\boldsymbol{\sigma}_{\max } \\
(\mathbf{M P a})\end{array}$ & $\begin{array}{c}\boldsymbol{\tau}_{\mathbf{c r}} \\
(\mathbf{M P a})\end{array}$ & $\begin{array}{c}\boldsymbol{\tau}_{\max } \\
(\mathbf{M P a})\end{array}$ & $\begin{array}{c}\boldsymbol{w}_{\max } \\
(\mathbf{m m})\end{array}$ & $\begin{array}{c}\boldsymbol{\Delta}_{\max } \\
(\mathbf{m m})\end{array}$ \\
\hline $\mathbf{P}(\mathbf{0}) \mathbf{a}$ & 0,250 & 0,280 & 0,280 & 5,63 & 5,63 & 0 & 0 \\
$\mathbf{P}(\mathbf{0}) \mathbf{b}$ & 0,148 & 0,172 & 1,34 & 5,67 & 5,81 & 0,621 & 0,508 \\
$\mathbf{P}(\mathbf{0}) \mathbf{c}$ & 0,154 & 0,215 & 0,215 & 5,92 & 5,92 & 0 & 0 \\
\hline $\mathbf{P}(\mathbf{0 , 5 S}) \mathbf{a}$ & 0,0865 & 0,111 & 0,777 & 5,70 & 7,09 & 0,616 & 0,350 \\
$\mathbf{P}(\mathbf{0 , 5 S}) \mathbf{b}$ & 0,101 & 0,137 & 0,242 & 6,15 & 6,53 & 0,147 & 0,0763 \\
$\mathbf{P}(\mathbf{0 , 5 S}) \mathbf{c}$ & 0,124 & 0,132 & 0,383 & 6,34 & 6,96 & 0,279 & 0,0861 \\
\hline $\mathbf{P}(\mathbf{1 S}) \mathbf{a}$ & 0,338 & 0,356 & 0,877 & 6,35 & 9,08 & 0,463 & 0,439 \\
$\mathbf{P}(\mathbf{1 S}) \mathbf{b}$ & 0,194 & 0,236 & 0,812 & 6,38 & 8,75 & 0,437 & 0,269 \\
$\mathbf{P}(\mathbf{1 S}) \mathbf{c}$ & 0,247 & 0,273 & 0,661 & 6,40 & 8,95 & 0,423 & 0,366 \\
\hline $\mathbf{P}(\mathbf{1 L}) \mathbf{a}$ & 0,282 & 0,290 & 1,15 & 6,02 & 10,7 & 0,462 & 0,440 \\
$\mathbf{P}(\mathbf{1 L}) \mathbf{b}$ & 0,0771 & 0,083 & 1,50 & 6,36 & 10,5 & 1,120 & 0,555 \\
$\mathbf{P}(\mathbf{1 L}) \mathbf{c}$ & 0,289 & 0,303 & 0,925 & 6,66 & 10,6 & 0,490 & 0,360 \\
\hline
\end{tabular}

A Figura 4.25 mostra relação linear entre $\tau_{\max }$ e $V_{f}\left(l_{f} / d_{f}\right)$.

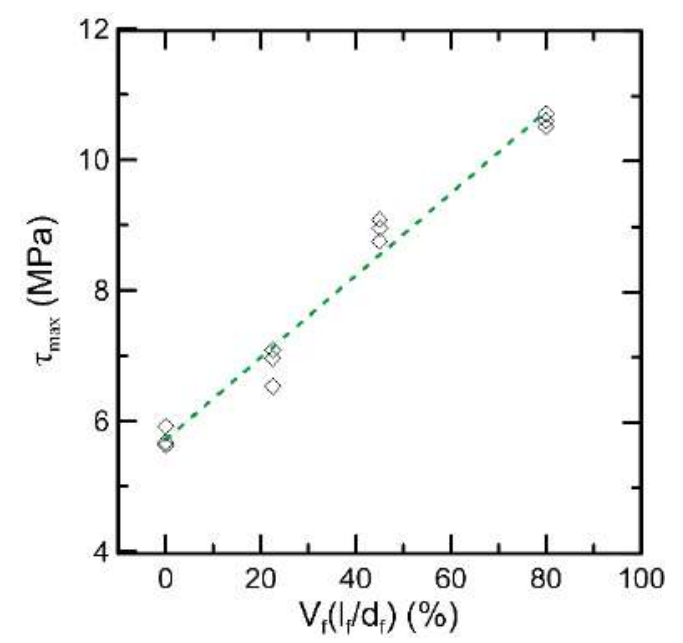

Figura 4.25 - Relação entre $V_{f}\left(l_{f} / d_{f}\right)$ e $\tau_{\max }$.

Para cada parte em "L" dos espécimes sem fibras foi feita análise fotogramétrica em três dimensões (CID-3D) a fim de verificar a topografia de suas superfícies de ruptura, como mostra o exemplo da Figura 4.26a. Para uma análise quantitativa dos perfis das superfícies de ruptura, foram escolhidos os três planos equidistantes entre si e paralelos à direção de deslizamento da superfície de ruptura (eixo x), conforme mostrado na Figura 4.26b. Na Figura 4.27 constam os perfis 
obtidos para cada espécime sem fibras, cada um deles obtido a partir da análise de 200 pontos.

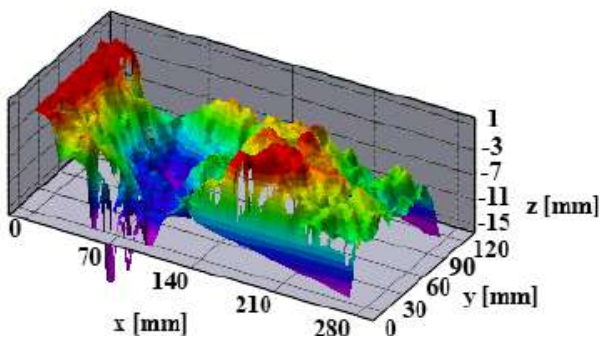

(a)

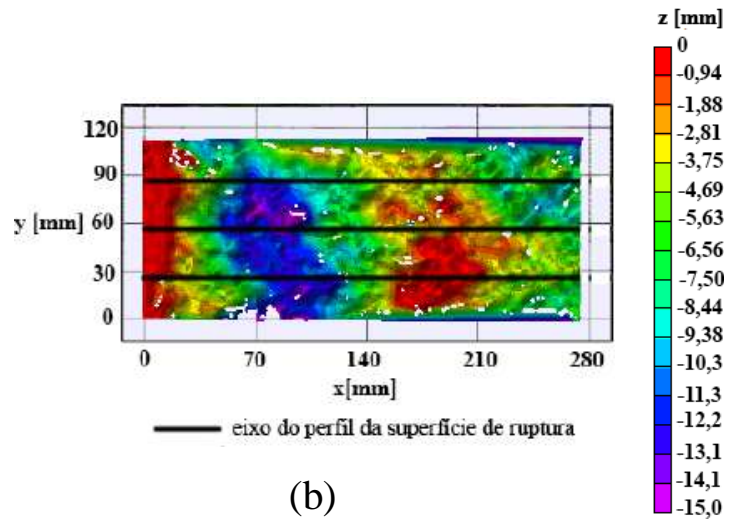

Figura 4.26 - Análise fotogramétrica em 3D (CID-3D). Exemplo para um lado do espécime $\mathrm{P}(0) \mathrm{a}$ : (a) mapa 3D da superfície de ruptura; (b) mapa 2D da superfície de ruptura, com planos utilizados para análise de perfis assinalados. 


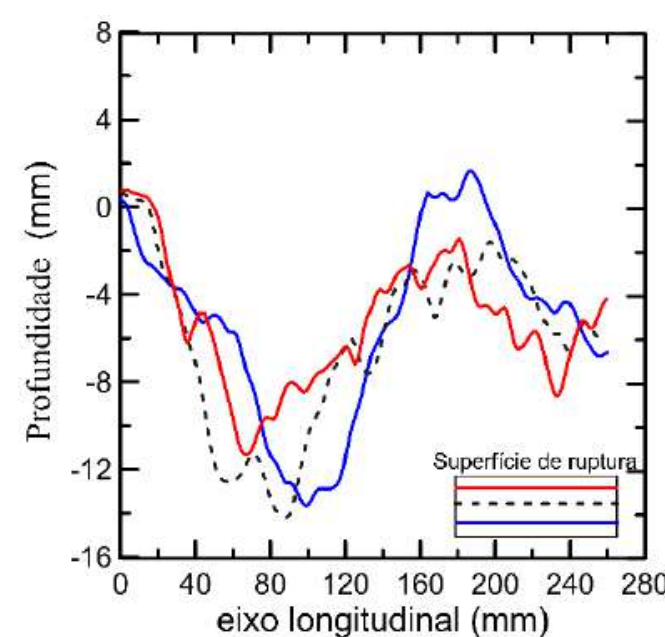

(a)

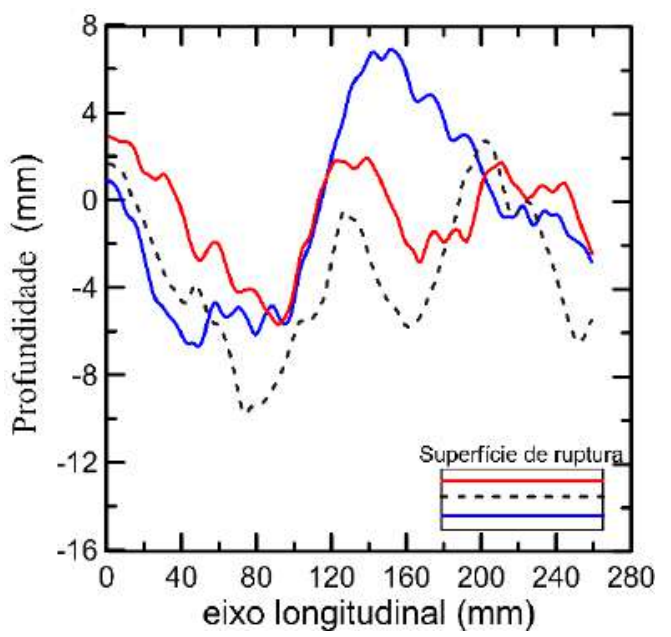

(c)

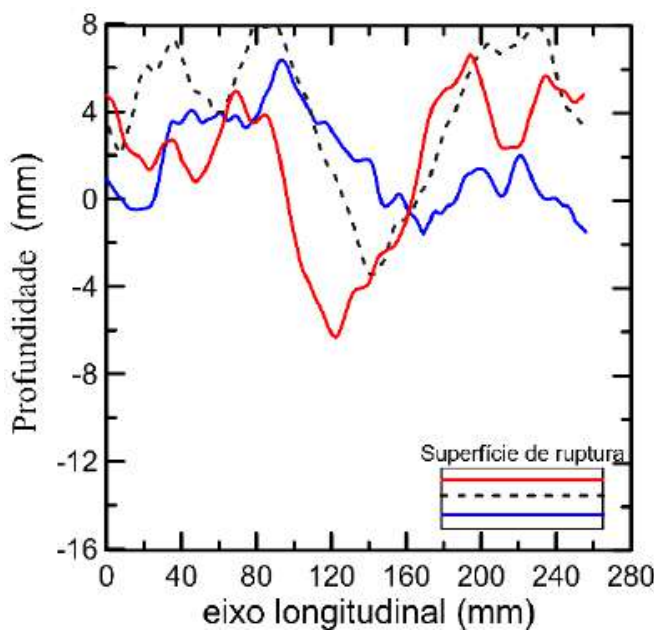

(e)

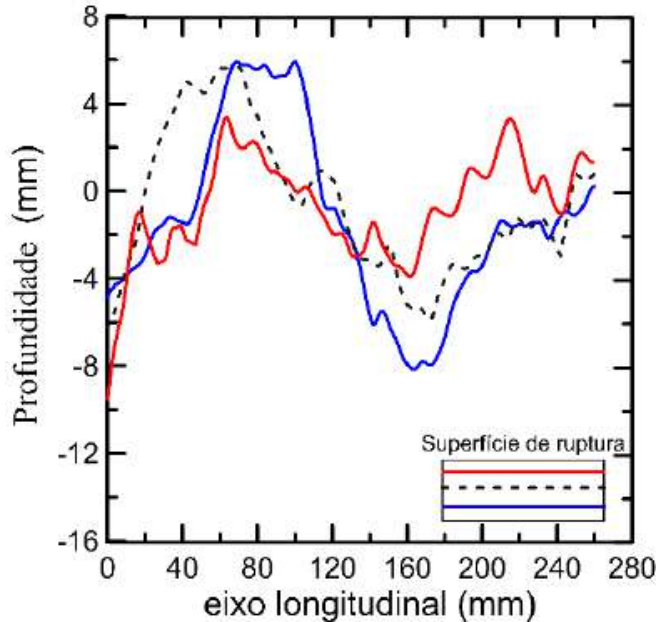

(b)

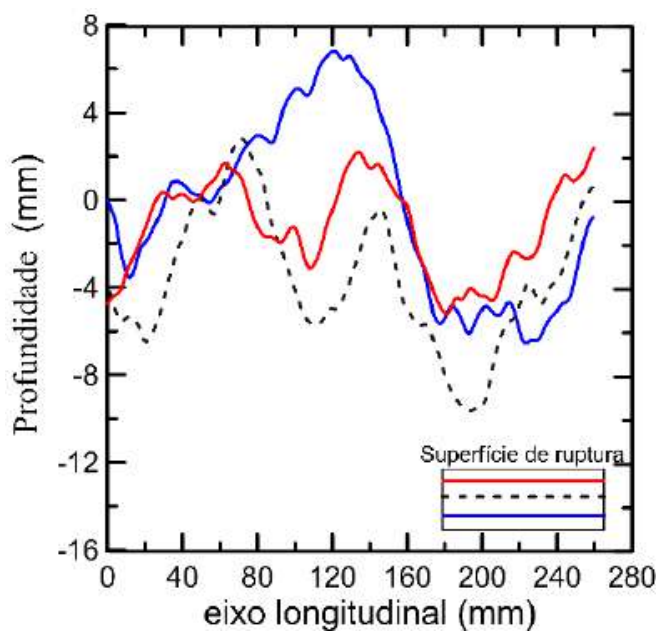

(d)

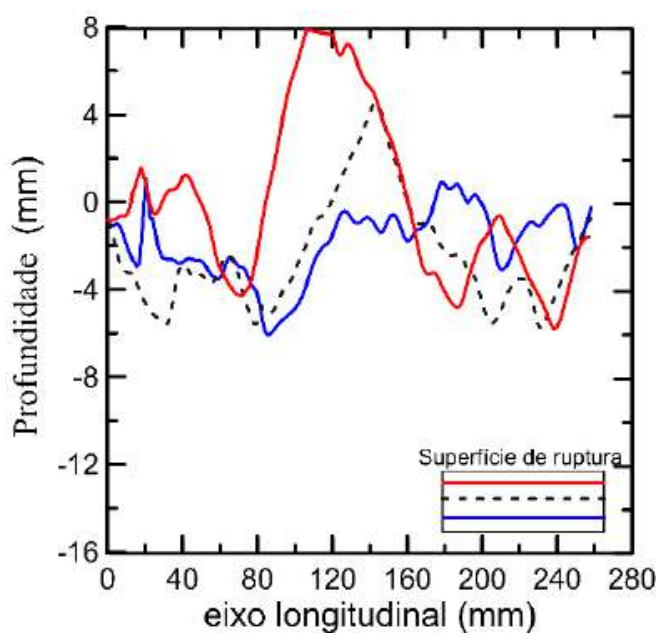

(f)

Figura 4.27 - Perfis da superfície de ruptura nas duas partes em "L": (a) P(0)a; (b) $\mathrm{P}(0) \mathrm{b}$; (c) $\mathrm{P}(0) \mathrm{c}$. 
O FIB MC 2010 (2013) apresenta como uma das formas de quantificar a rugosidade de uma superfície de concreto o valor médio da variação máxima de profundidade $\left(R_{z}\right)$ medida para $n$ trechos do comprimento total de interesse, conforme ilustrado na Figura 4.28. Não é especificado o valor de $n$ a adotar, porém considerou-se $n=5$ para exemplificação, ficando então:

$$
R_{z}=\frac{1}{5} \sum_{i=1}^{n=5} R_{z i}
$$

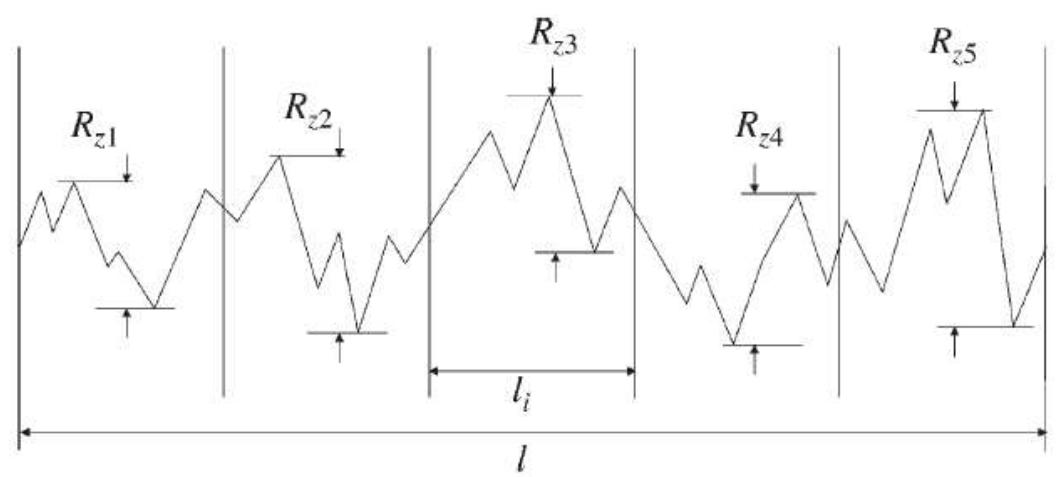

Figura 4.28 - Variação máxima de profundidade $\left(R_{z i}\right)$ para cada trecho $\left(l_{i}=l / 5\right)$. Adaptado de FIB MC 2010 (2013).

Para cada espécime ensaiado, obtiveram-se cinco valores de $R_{z i}$ e um valor médio $R_{z}$ para cada perfil e considerou-se para $R_{z}$ do espécime a média dos valores dos seis perfis analisados, chegando-se a $R_{z}=6,4 \mathrm{~mm}, 6,0 \mathrm{~mm}$ e $5,4 \mathrm{~mm}$ para os espécimes $\mathrm{P}(0) \mathrm{a}, \mathrm{P}(0) \mathrm{b}$ e $\mathrm{P}(0 \mathrm{c})$, respectivamente. Adicionalmente, a Tabela 4.5 apresenta os valores das maiores distâncias entre os picos observados nos perfis de cada espécime.

Tabela 4.5 - Amplitude de profundidade máxima em cada eixo de medição, em $\mathrm{mm}$.

\begin{tabular}{ccc}
\hline $\mathrm{P}(0) \mathrm{a}$ & $\mathrm{P}(0) \mathrm{b}$ & $\mathrm{P}(0) \mathrm{c}$ \\
\hline 12,5 & 8,31 & 7,53 \\
13,3 & 12,5 & 11,1 \\
14,7 & 13,5 & 13,9 \\
\hline
\end{tabular}

Segundo o FIB MC 2010 (2013), considerando-se $R_{t} \approx R_{z} / 2$, é adotada a classificação de superfície suave, rugosa e muito rugosa para $R_{t}<1,5 \mathrm{~mm}$, $R_{t} \geq 1,5 \mathrm{~mm}$ e $R_{t} \geq 3 \mathrm{~mm}$, respectivamente e, portanto, as superfícies de ruptura 
desses espécimes seriam consideradas rugosas ou muito rugosas, o que leva a crer que o coeficiente de atrito da superfície não seja desprezível.

Vale a pena observar que a composição granulométrica dos agregados graúdos usada nos concretos dos espécimes indicou dimensão máxima de 12,5 mm, mas também que $61,2 \%$ e $28,3 \%$ deles ficaram retidos nas peneiras com abertura de $6,3 \mathrm{~mm}$ e $9,5 \mathrm{~mm}$, respectivamente, ou seja, a maioria dos agregados possuía dimensão menor do que os valores apresentados na Tabela 4.5 e próxima a $R_{z}$ ou menor. Tais fatos apontam que a macrorugosidade decorrente das ondulações das faces da fissura não deve ser ignorada na análise de engrenamento dos agregados desses espécimes, o que vai de encontro à premissa do modelo de duas fases de Walraven (1980).

Os perfis das superfícies de ruptura foram também utilizados para obter a densidade de frequência do ângulo de contato $\theta$ para cada lado do espécime, para comparação com a proposta por Li \& Maekawa (1987). Sendo $\theta$ o ângulo entre a direção transversal ao plano de cisalhamento e a direção perpendicular à reta que une dois pontos de controle consecutivos e fazendo o histograma de frequência destes ângulos, a densidade de contato foi obtida pela interpolação de uma curva cujos pontos têm a abscissa sendo o valor médio do intervalo de cada classe de frequência e a ordenada dada pela divisão de cada frequência angular pela amplitude do intervalo de sua classe, sendo a área abaixo deste gráfico unitária.

$\mathrm{Na}$ Figura 4.29, que compara a densidade de contato obtida a partir dos espécimes sem fibras ensaiados com a proposta por Li \& Maekawa (1987), nota-se a considerável diferença entre elas. Neles houve predominância de pequenos valores angulares (ao menos $78 \%$ entre $-12,5^{\circ} \leq \theta \leq 12,5^{\circ}$ ). Vale a pena ressaltar que as densidades de contato experimentais de Li \& Maekawa (1987), que serviram de base para a sua proposta, foram obtidas de ensaios de corpos-de-prova fissurados e não dos espécimes utilizados nos ensaios de engrenamento, não tendo ficado claro o procedimento adotado. É de se esperar que a adoção da própria superfície de ruptura do ensaio de engrenamento, e utilizando meios que não alterem as características de sua superfície (fotogrametria), leve a uma representação mais fiel da superfície a ser considerada em análises. 


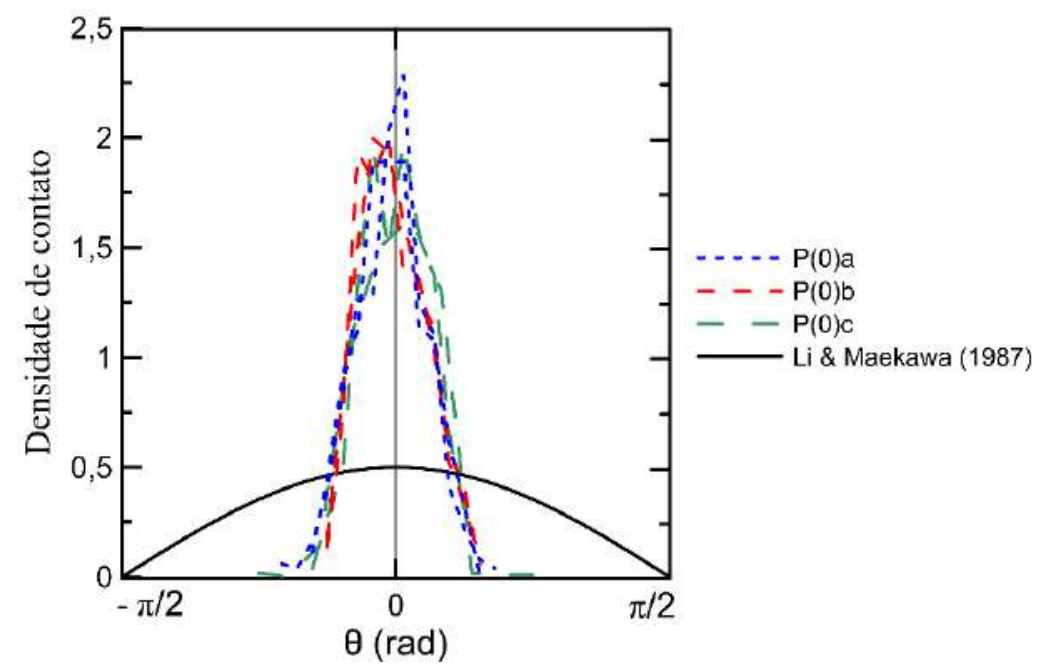

Figura 4.29 - Densidade de contato experimental para os espécimes sem fibras e a proposta por Li \& Maekawa (1987).

\subsection{2 Comparação dos resultados experimentais obtidos com os dados por equações já propostas}

As relações $\tau-w, \tau-\Delta, \sigma-w$ e $\sigma-\Delta$ obtidas para os espécimes sem fibras de aço foram comparadas com as dadas pelo modelo de duas fases de Walraven (1980) e os dele derivados, propostos por Ulaga (2003) e Guidotti (2010), bem como as baseadas no modelo de densidade de contato proposto por Li \& Maekawa (1987) e na proposta empírica de Gambarova \& Karakoç (1983).

As comparações para os espécimes $\mathrm{P}(0) \mathrm{a}, \mathrm{P}(0) \mathrm{b}$ e $\mathrm{P}(0)$ c são apresentadas nas Figuras 4.30 a 4.32. Nelas pode-se observar que o modelo de duas fases e os dele derivados (Walraven, 1980; Ulaga, 2003; Guidotti, 2010) foram os que, em geral, para determinados valores $w$ e $\Delta$, forneceram valores de $\tau$ e $\sigma$ menores que os experimentais. O modelo de Li \& Maekawa (1987) levou a valores de $\tau$ e $\sigma$ bem maiores que os experimentais e o de Gambarova \& Karakoç (1983), embora tendendo também a superavaliar $\tau$ e $\sigma$, forneceu valores mais próximos dos experimentais.

Essas figuras evidenciam a discrepância relevante entre as avaliações feitas usando diferentes equações propostas, fato já comentado por Huber et al. (2016) e Belbachir et al. (2018), e também a diferença que pode haver entre os valores gerados por essas equações e os experimentais.

Algumas das razões para as diferenças entre os resultados experimentais e os obtidos com o modelo de Walraven (1980) podem ser a desconsideração da 
macrorugosidade (ondulação das faces da fissura) da superfície de engrenamento dos agregados no modelo e dele ter sido baseado em ensaios de espécimes de concreto com granulometria contínua, que não é o caso dos concretos deste trabalho.

No caso das fórmulas de Li \& Maekawa (1987), além de ser desprezado o atrito entre as unidades de contato, a função densidade de contato adotada pelos autores é bem diferente da verificada no programa experimental deste estudo (Figura 4.29).

Na próxima seção é apresentada modificação do modelo de Li \& Maekawa (1987), com ajustes dos parâmetros utilizados condizentes com o programa experimental realizado e levando em consideração o atrito entre as superfícies. A escolha desse modelo deveu-se ao fato dele poder ser ajustado para diferentes funções de densidade de contato, ao passo que a hipótese do modelo de Walraven (1980) de que as fissuras permanecem planas a não ser ao encontrar um agregado, quando o contorna, não se aplica a todos os tipos de situação (Albajar, 2008; Cavagnis, 2017). 


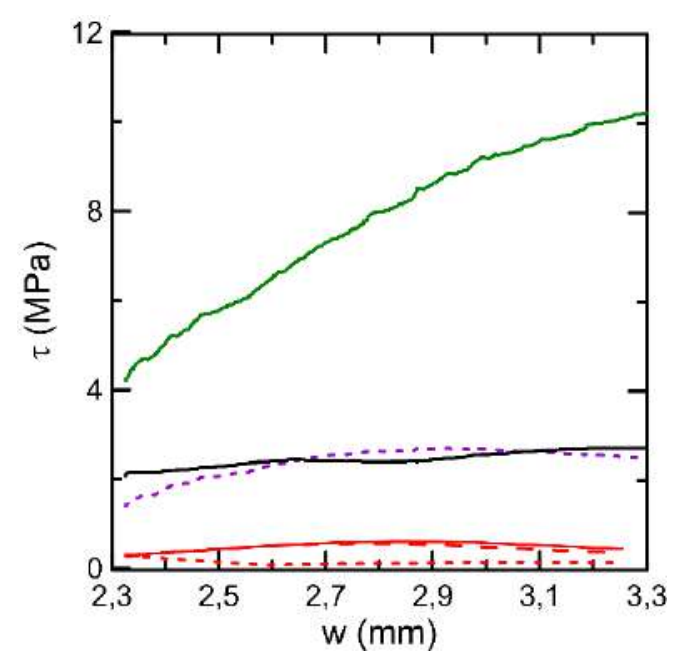

(a)

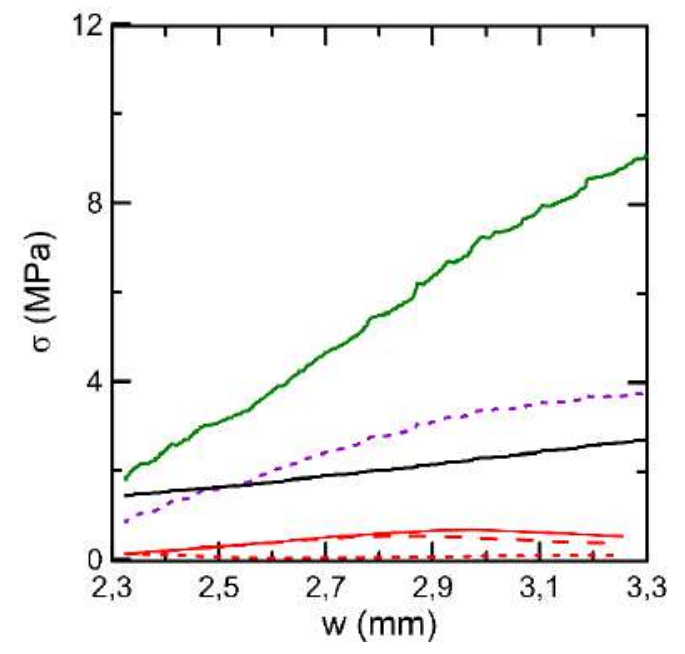

(c)

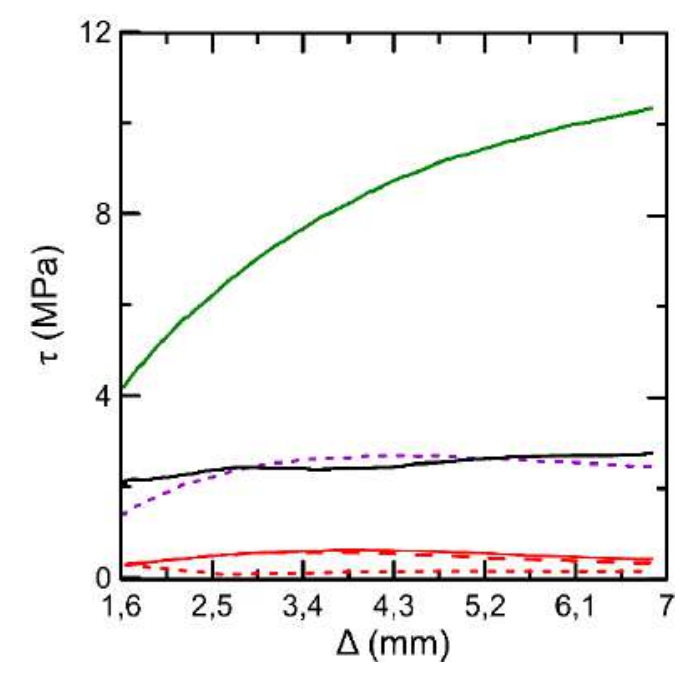

(b)

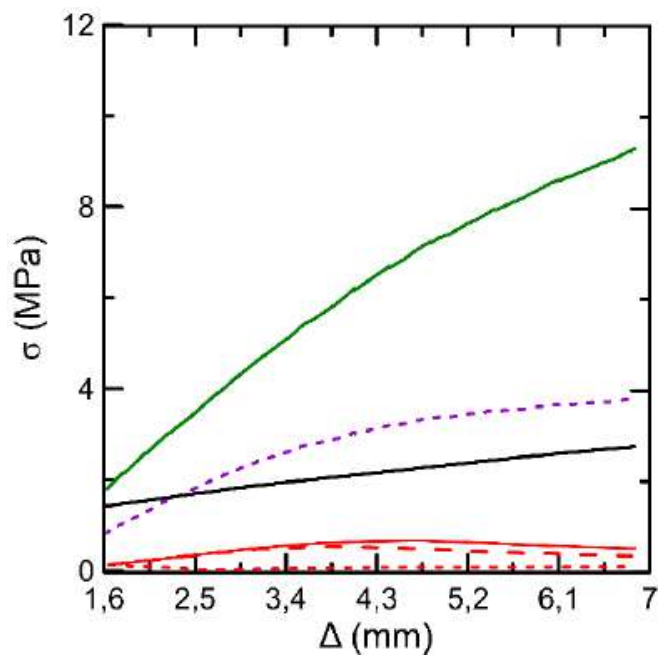

(d)

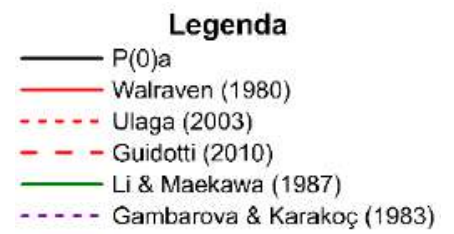

Figura 4.30 - Curvas experimentais e obtidas usando diferentes relações propostas, para o espécime $\mathrm{P}(0) \mathrm{a}$ : (a) $\tau-w$; (b) $\tau-\Delta$; (c) $\sigma-w$; (d) $\sigma-\Delta$. 


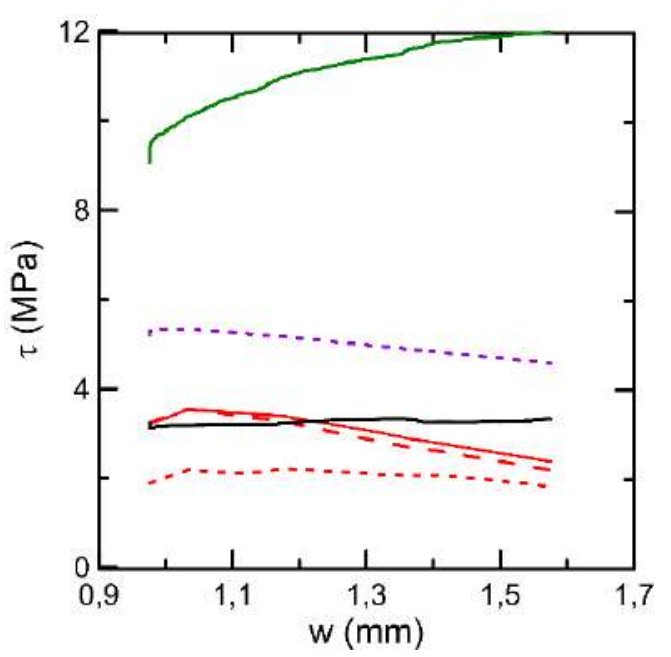

(a)

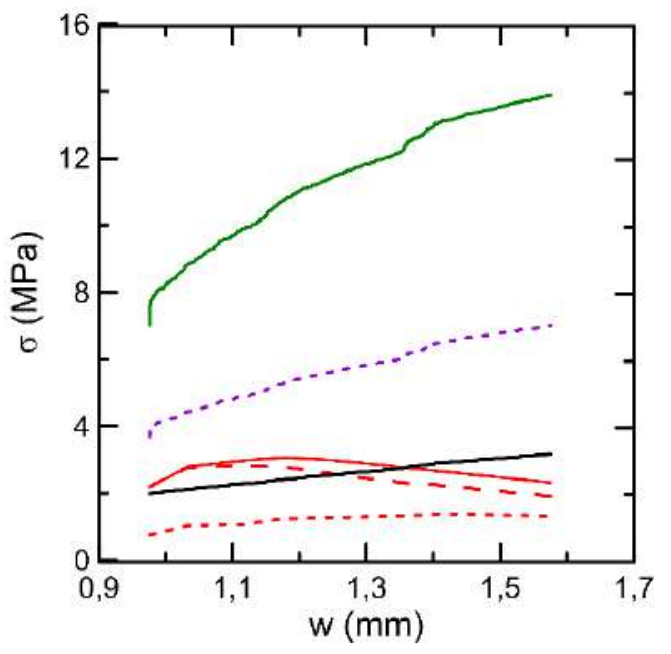

(c)

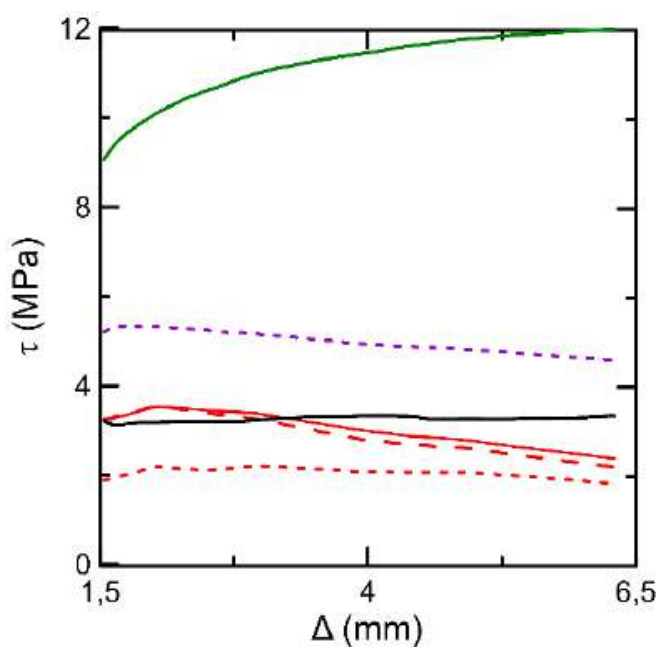

(b)

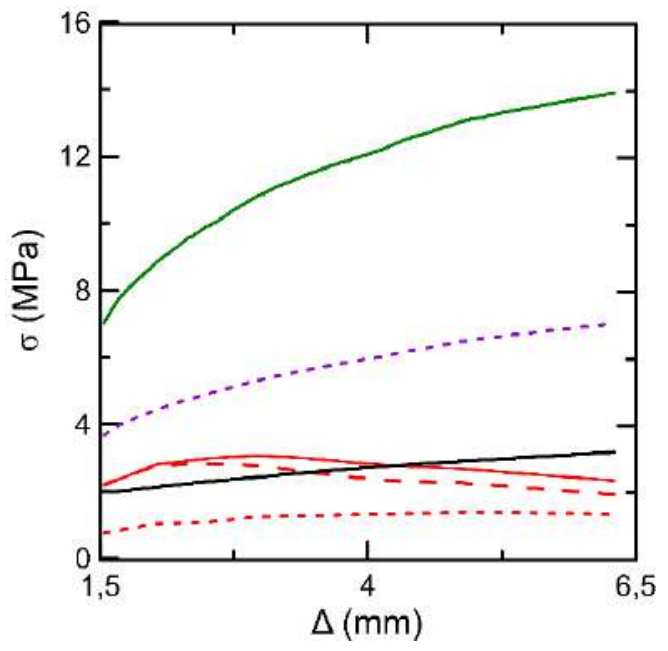

(d)

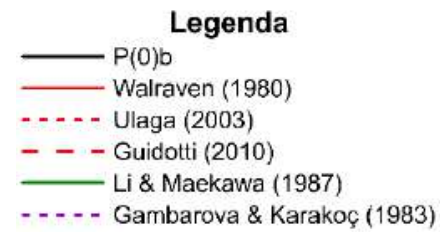

Figura 4.31 - Curvas experimentais e obtidas usando diferentes relações propostas, para o espécime $\mathrm{P}(0) \mathrm{b}$ : (a) $\tau-w$; (b) $\tau-\Delta$; (c) $\sigma-w$; (d) $\sigma-\Delta$. 


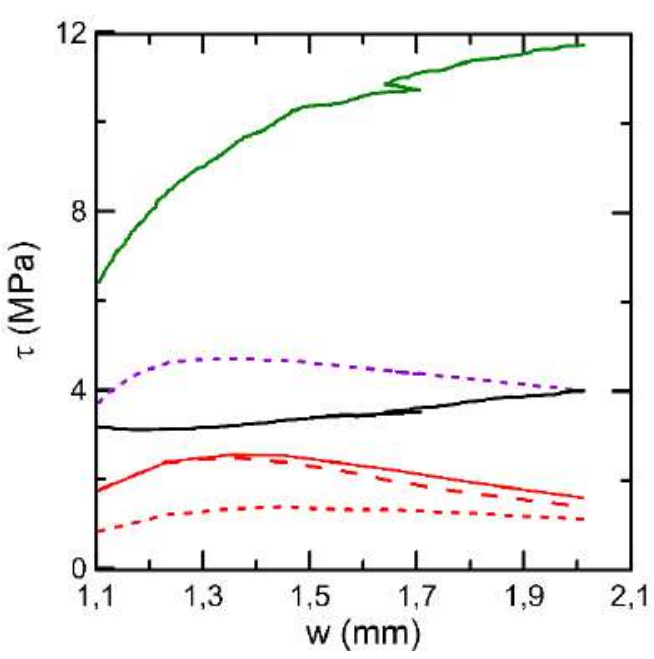

(a)

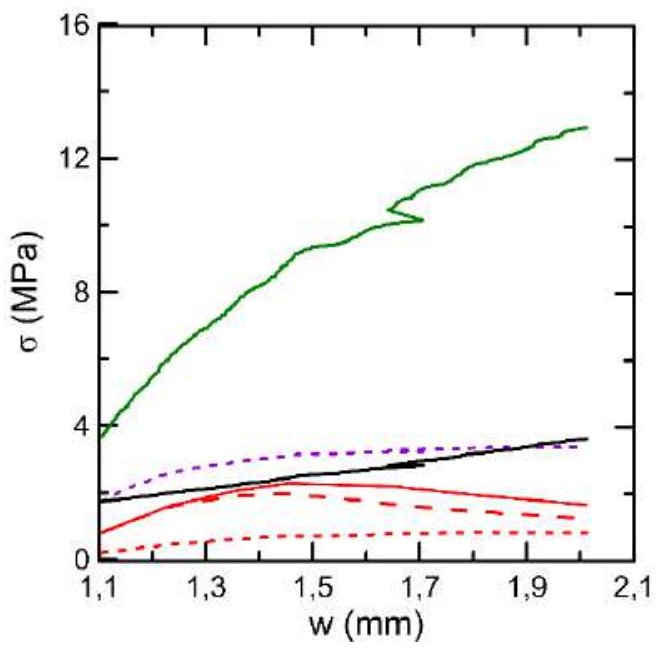

(c)

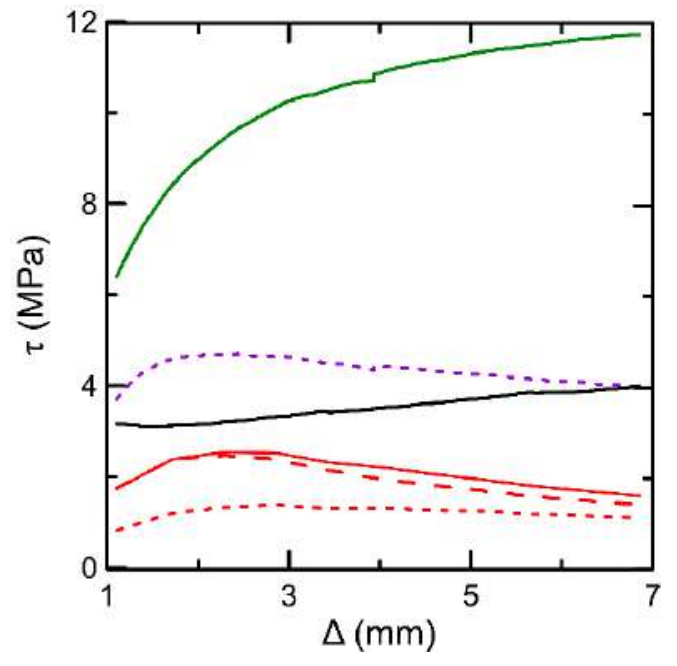

(b)

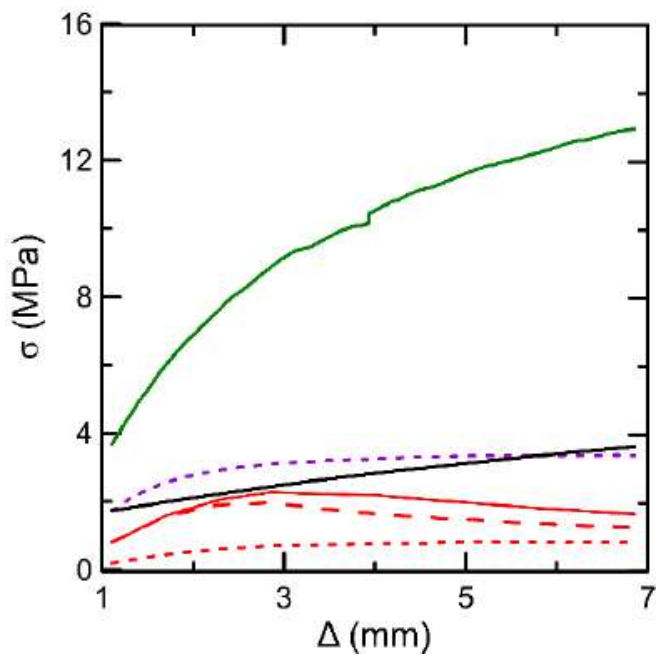

(d)

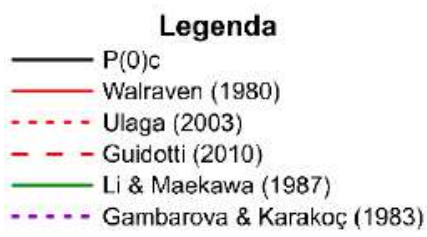

Figura 4.32 - Curvas experimentais e obtidas usando diferentes relações propostas, para o espécime $\mathrm{P}(0) \mathrm{c}$ : (a) $\tau-w$; (b) $\tau-\Delta$; (c) $\sigma-w$; (d) $\sigma-\Delta$. 


\subsection{3}

\section{Modelo proposto}

O modelo de engrenamento dos agregados adotado no presente trabalho é baseado no apresentado em Li \& Maekawa (1989), com as seguintes considerações: i) a função densidade de contato utilizada $(\Omega)$ foi calibrada com os resultados dos perfis da superfície de ruptura dos espécimes sem fibras (eq. 4.13 e Figura 4.33); ii) $\mathrm{o}$ atrito entre as unidades de contato foi considerado de modo que o ângulo da tensão normal de contato $\left(\theta_{\mathrm{s}}\right)$ é a soma do ângulo de contato $(\theta)$ com o ângulo cuja tangente é o coeficiente de atrito ( $\mu$ ) entre as unidades de contato (eq. 4.14); e iii) o valor $k$ ' relacionado com o produto da área total de contato $\left(\mathrm{A}_{\text {tot }}\right)$ pela tensão de contato de compressão do concreto admitido rígido-plástico $\left(\mathrm{f}_{\mathrm{cy}}\right)$, e expresso em Li \& Maekawa (1989) pela relação $k^{\prime}=0,25 A_{t o t} f_{c y}$ (e adotada igual a $3,83 \mathrm{f}_{\mathrm{c}}{ }^{1 / 3}$ ), foi ajustado com base nos resultados deste programa experimental; iv) assim como na formulação final das equações de engrenamento dos agregados de Li \& Maekawa (1989), a diminuição da área de contato entre as faces da fissura para $w$ crescente foi desprezada $(K(w)=1$, eq. 2.37 na p. 65$)$;

$$
\Omega=1,98 \cos (\theta)^{24}
$$

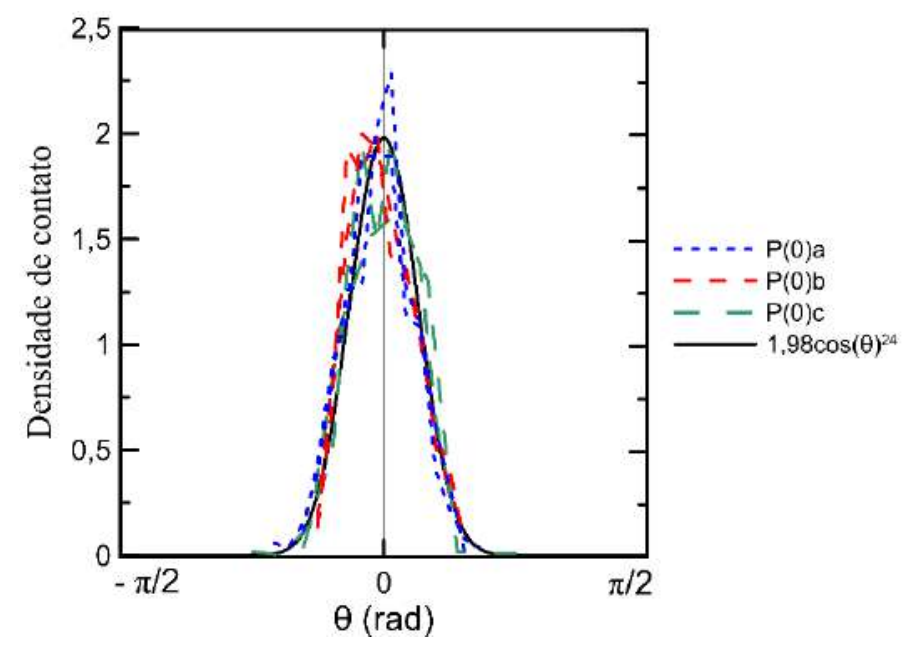

Figura 4.33 - Densidade de contato experimental para os espécimes sem fibras e a curva trigonométrica ajustada para estes resultados.

$\theta_{s}=\theta+\operatorname{arctg}(\mu)$ 
Considerando-se apenas o intervalo onde há contato entre as superfícies, as equações de tensões normal $\left(\sigma_{\mathrm{r}}\right)$ e de cisalhamento $\left(\tau_{\mathrm{r}}\right)$ de Li \& Maekawa (1989) são expressas como:

$$
\begin{aligned}
& \sigma_{r}=\int_{\operatorname{arctg}(w / \Delta)}^{\pi / 2} F_{z}(w, \Delta, \theta) \cos \theta_{s} \mathrm{~d} \theta \\
& \tau_{r}=\int_{\operatorname{arctg}(w / \Delta)}^{\pi / 2} F_{z}(w, \Delta, \theta) \operatorname{sen} \theta_{s} \mathrm{~d} \theta
\end{aligned}
$$

onde $\mathrm{F}_{\mathrm{z}}$ é a força normal de contato.

Mantendo a hipótese original de comportamento rígido-plástico para o concreto, com tensão $\left(f_{\mathrm{cy}}\right)$ e área total de contato constante $\left(\mathrm{A}_{\mathrm{tot}}\right)$, tem-se:

$$
F_{z}=f_{c y} A_{t o t} \Omega(\theta) \mathrm{d} \theta
$$

Considerando as equações 4.13 e 4.14 , e com a eq. 4.17 em eq. 4.15 e eq. 4.16 , chega-se a:

$$
\begin{aligned}
& \sigma_{r}=7,92 k^{\prime} \int_{\operatorname{arctg}(1 / r)}^{\pi / 2}\left\{\cos \theta^{24} \cos [\theta+\operatorname{arctg}(\mu)]\right\} \mathrm{d} \theta \\
& \tau_{r}=7,92 k^{\prime} \int_{\operatorname{arctg}(1 / r)}^{\pi / 2}\left\{\cos \theta^{24} \operatorname{sen}[\theta+\operatorname{arctg}(\mu)]\right\} \mathrm{d} \theta
\end{aligned}
$$

onde $k^{\prime}=0,25 A_{\text {tof }} f_{c y}$ e $r=\Delta / w$

Resolvendo as eq. 4.18 e 4.19, chega-se às seguintes soluções exatas: 


$$
\begin{aligned}
\sigma_{r}=-198 \mathrm{k}^{\prime}[ & 676039 \mu r-4194304 r\left(r^{-2}+1\right)^{12,5} \\
& +739024\left(r^{-2}+1\right)^{2}+777920\left(r^{-2}+1\right)^{3} \\
& +823680\left(r^{-2}+1\right)^{4}+878592\left(r^{-2}+1\right)^{5} \\
& +946176\left(r^{-2}+1\right)^{6}+1032192\left(r^{-2}+1\right)^{7} \\
& +1146880\left(r^{-2}+1\right)^{8}+1310720\left(r^{-2}+1\right)^{9} \\
& +1572864\left(r^{-2}+1\right)^{10}+2097152\left(r^{-2}+1\right)^{11} \\
& +4194304\left(r^{-2}+1\right)^{12}+705432 r^{-2} \\
& +1381471] \\
& /\left[422524375 r\left(\mu^{2}+1\right)^{0,5}\left(r^{-2}+1\right)^{12,5}\right] \\
& \\
\tau_{r}=198 \mathrm{k}^{\prime}\left\{\left[\begin{array}{l}
\left.194304 \mu\left(\left(r^{2}+1\right) / r^{2}\right)^{12,5}+676039\right] \\
\end{array}\right.\right. & /\left[422524375\left(\mu^{2}+1\right)^{0,5}\left(\left(r^{2}+1\right) / r^{2}\right)^{12,5}\right] \\
& -\left[\mu \left(16900975 r^{24}+135207800 r^{22}\right.\right. \\
& +594914320 r^{20}+1699755200 r^{18} \\
& +3399510400 r^{16}+4944742400 r^{14} \\
& +5325107200 r^{12}+4260085760 r^{10} \\
& +2505932800 r^{8}+1055129600 r^{6} \\
& \left.\left.+301465600 r^{4}+52428800 r^{2}+4194304\right)\right] \\
& \left./\left[422524375 r^{25}\left(\mu^{2}+1\right)^{0,5}\left(1 / r^{2}+1\right)^{12,5}\right]\right\}
\end{aligned}
$$

Para validar o modelo proposto e calibrar as constantes $\mu$ e $k^{\prime}$, as eq. 4.20 e 4.21 foram confrontadas com os resultados experimentais.

Nos espécimes sem fibras, devido à zona de instabilidade logo após a formação de fissura e possíveis acomodações no aparato metálico de controle da tensão normal, decidiu-se desprezar os resultados no domínio instável, considerando-se apenas o trecho denominado estável (Figura 4.13).

A relação entre a tensão normal $(\sigma)$ e a abertura de fissura $(w)$ experimental, para o trecho estável, pode ser representada por uma equação linear do tipo:

$$
\sigma=K_{s} w_{0}+\sigma_{0}
$$


em que:

$K_{s}$ representa a rigidez de todo o conjunto do aparato metálico para medição da tensão normal;

$\sigma_{0}$ é a tensão normal no início da zona estável;

$w_{0}$ é a abertura de fissura a partir de $\sigma_{0}$;

Na Figura 4.34 são apresentadas as curvas de ajustes da eq. 4.22 para cada espécime sem fibras, juntamente com os valores de $K_{s}$ e $\sigma_{0}$.

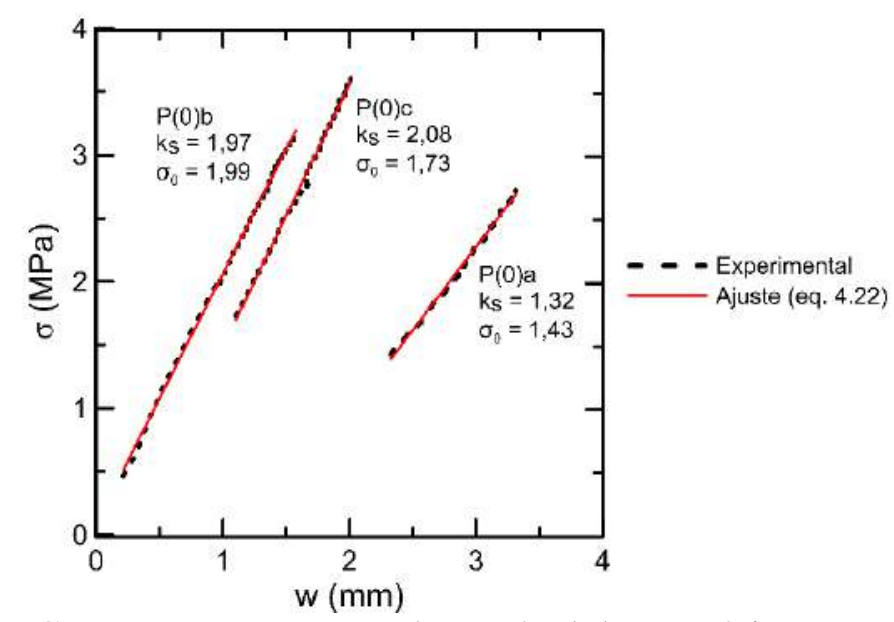

Figura 4.34 - Curvas $\sigma-w$ para o trecho estável dos espécimes sem fibras com a curvas de ajuste (eq. 4.22) e respectivos coeficientes.

Sabe-se que a eq. 4.20 tem de ser igual à 4.22. Dessa igualdade podem-se obter os valores para $\mu$ e $k^{\prime}$ que resultem em uma boa correlação entre as duas equações.

Para os espécimes sem fibras, o valor do coeficiente de atrito que levou ao melhor ajuste foi $\mu=0,6$, próximo ao valor adotado no modelo de duas fases $(\mu=0,5)$ de Walraven (1980), e o valor de $k$ ' foi $6 \mathrm{MPa}$ para o espécime $\mathrm{P}(0)$ a e $12 \mathrm{MPa}$ para os demais, este último valor aproximadamente igual ao previsto por Li \& Maekawa (1989), que foi 12,6 MPa. O valor menor de $k$ ' para o espécime $\mathrm{P}(0)$ a pode ser justificado pelo fato da abertura de fissura no início da zona estável ser aproximadamente o dobro da dos demais espécimes, levando, portanto, a $A_{\text {tot }}$ menor. Conhecidos os valores desses parâmetros, as equações 4.20 e 4.21 puderam ser aplicadas para determinação das tensões normais e cisalhantes correspondentes a determinados valores de abertura e deslizamento. 
$\mathrm{Na}$ Figura 4.35 são apresentadas as curvas de $\sigma_{\mathrm{r}}$ e $\tau_{\mathrm{r}}$ em função de $r$, para $\mu=0,6$ e $k^{\prime}=12 \mathrm{MPa}$. É possível notar que $\sigma_{\mathrm{r}}$ e $\tau_{\mathrm{r}}$ são aproximadamente nulos até $r \approx 1,5$, a partir da qual elas crescem de forma semelhante, porém com $\tau_{\mathrm{r}}>\sigma_{\mathrm{r}}$. Para esses valores de $\mu$ e $k^{\prime}$, as eq. 4.20 e eq. 4.21 podem ser simplificadas por um ajuste de polinômio de grau 3 em função de $r$ (coeficiente de determinação $\mathrm{R}^{2}=0,995$ ), resultando as eq. 4.23 e eq. 4.24 .

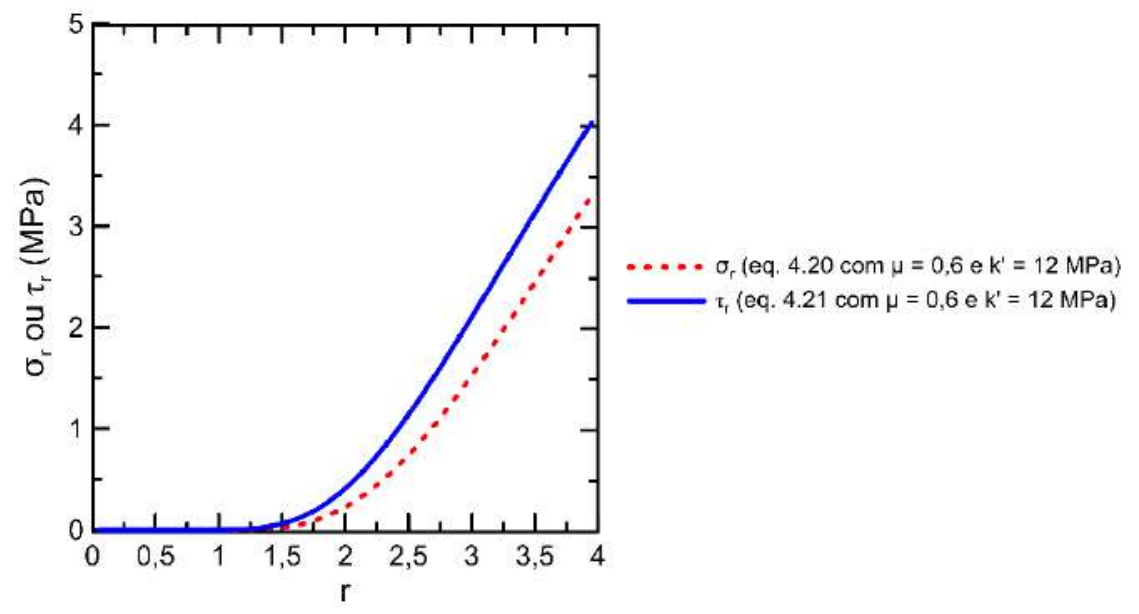

Figura 4.35 - Equações de $\tau_{\mathrm{r}}$ e $\sigma_{\mathrm{r}}$ em função de $r$ propostas para o caso de elementos sem fibras $\left(\operatorname{com} \mu=0,6\right.$ e $\left.k^{\prime}=12 \mathrm{MPa}\right)$.

$$
\begin{aligned}
& \sigma_{r}=0,0576 r^{3}+0,0363 r^{2}-0,147 r \\
& \tau_{r}=0,0283 r^{3}+0,254 r^{2}-0,355 r
\end{aligned}
$$

$\operatorname{com} 0<r \leq 4$

Nas Figuras 4.36 a 4.38, as curvas experimentais para cada espécime sem fibras são confrontadas com as dadas pelo modelo proposto. As curvas teóricas de $\sigma-w$ foram as que melhor se ajustaram às experimentais, uma vez que a eq. 4.20 foi igualada à eq. 4.22. As curvas $\sigma-\Delta$ teórica $\left(\operatorname{com} \mu=0,6\right.$ e $\left.k^{\prime}=6 \mathrm{MPa}\right)$ e experimental do espécime $\mathrm{P}(0)$ a se sobrepuseram. Nos demais casos, houve alguma diferença entre as curvas teóricas e experimentais. 


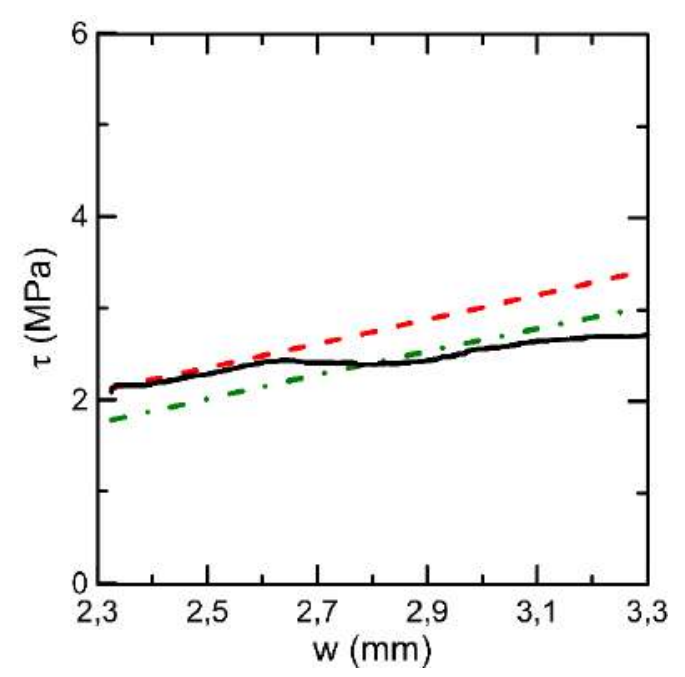

(a)

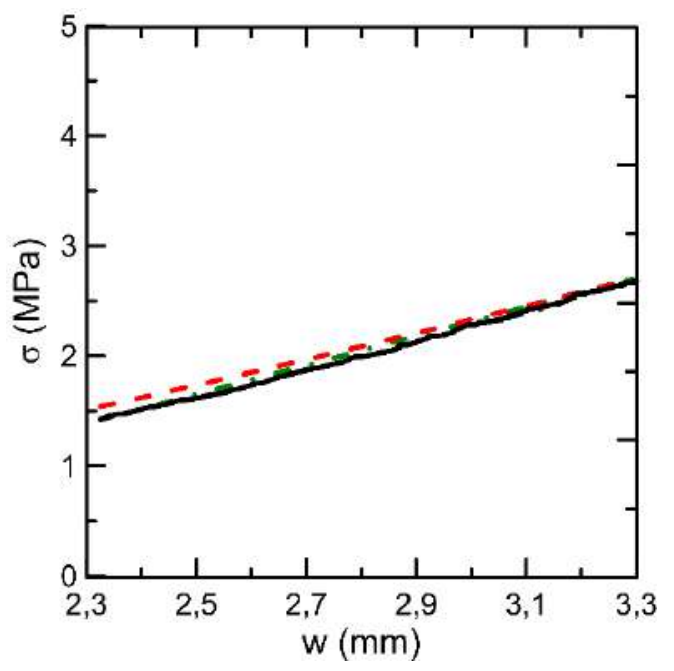

(c)

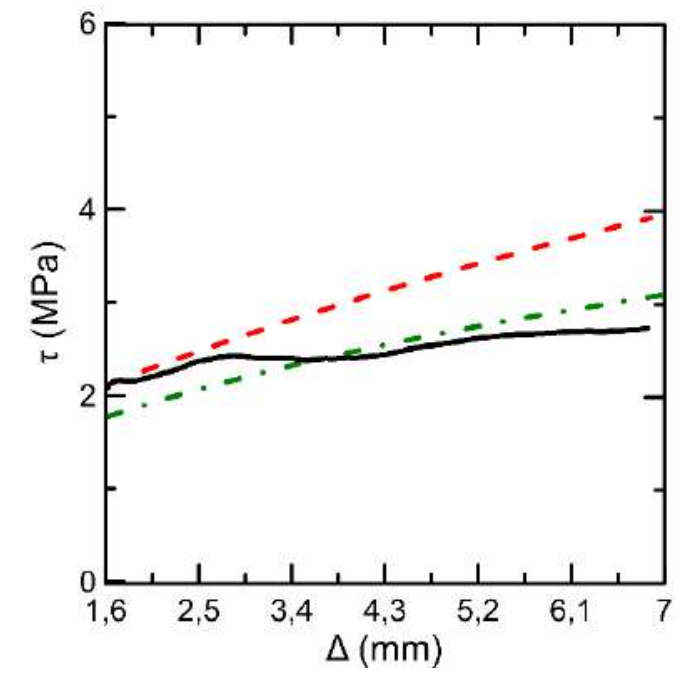

(b)

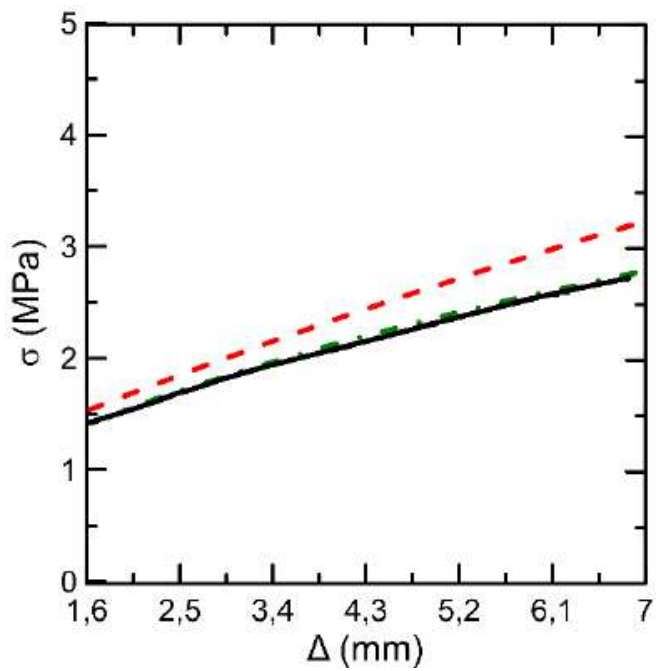

(d)

\section{Legenda}

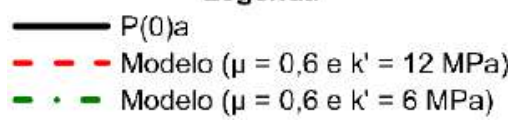

Figura 4.36 - Curvas experimentais e dadas pelo modelo proposto (eq. $4.20 \mathrm{e}$ eq. 4.21), para o espécime P(0)a: (a) $\tau-w$; (b) $\tau-\Delta$; (c) $\sigma-w$; (d) $\sigma-\Delta$. 


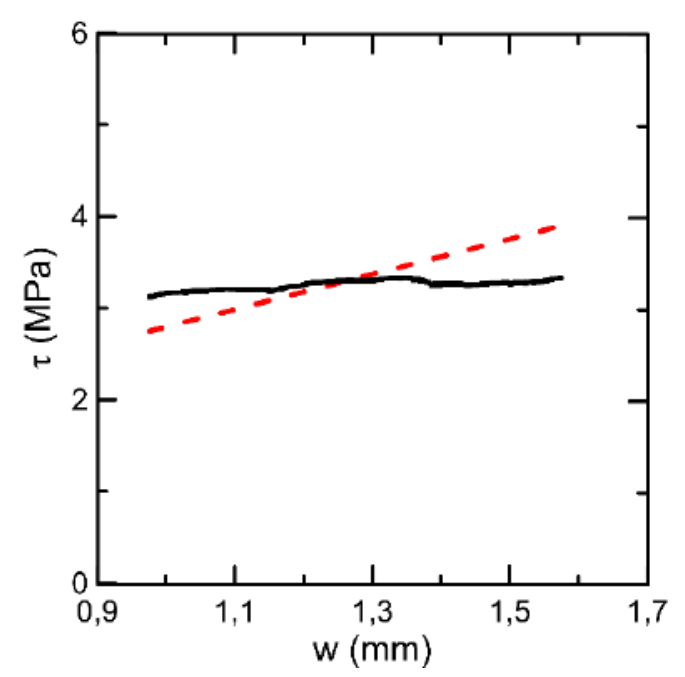

(a)

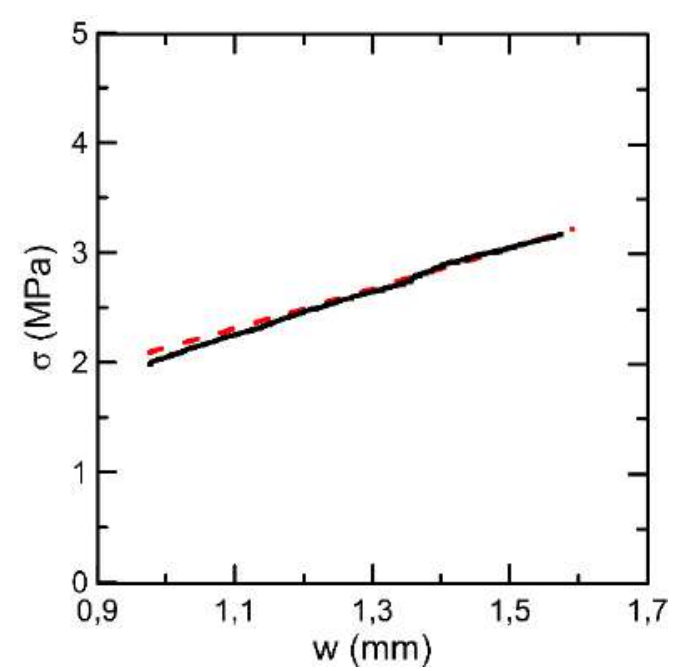

(c)

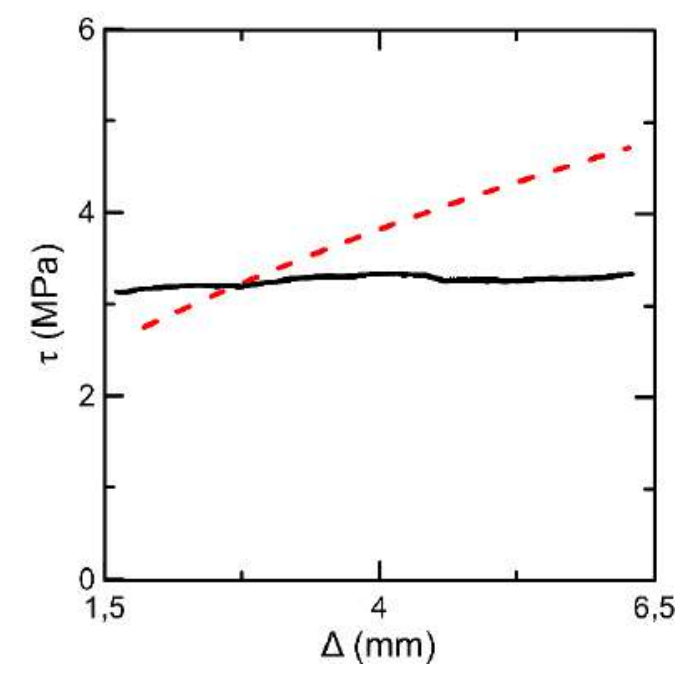

(b)

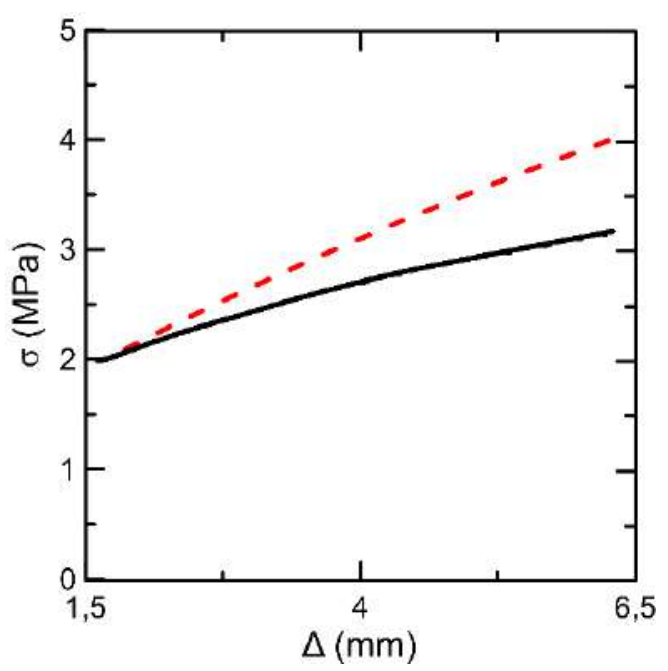

(d)

\section{Legenda$$
\text { - - Modelo }\left(\mu=0,6 \text { e } \mathrm{k}^{\prime}=12 \mathrm{MPa}\right)
$$

Figura 4.37 - Curvas experimentais e dadas pelo modelo proposto (eq. $4.20 \mathrm{e}$ eq. 4.21), para o espécime $\mathrm{P}(0) \mathrm{b}$ : (a) $\tau-w$; (b) $\tau-\Delta$; (c) $\sigma-w$; (d) $\sigma-\Delta$. 


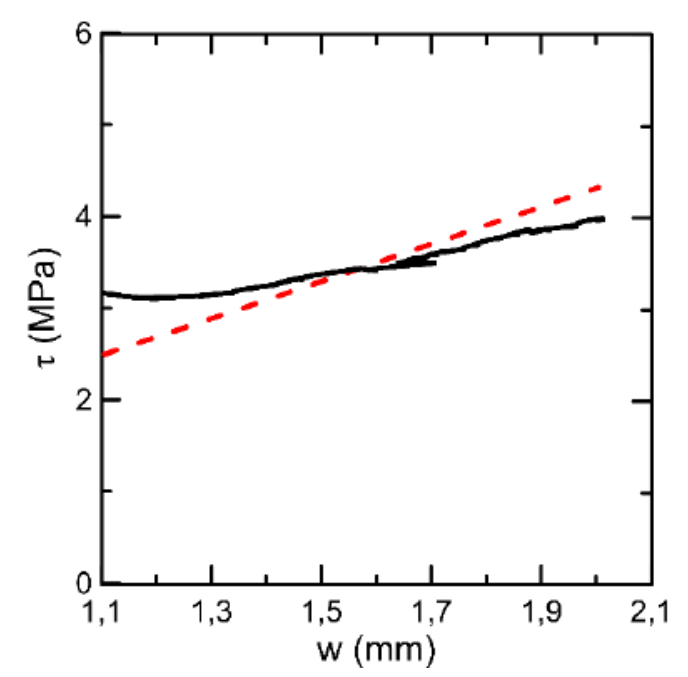

(a)

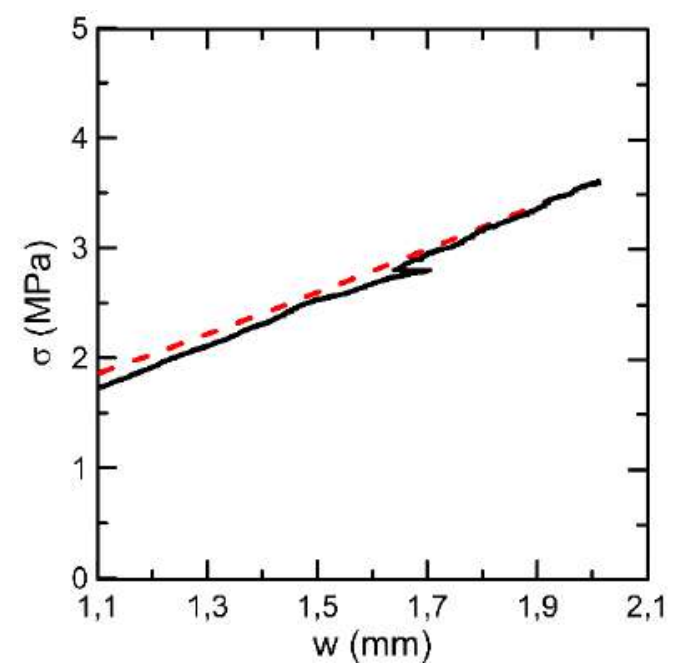

(c)

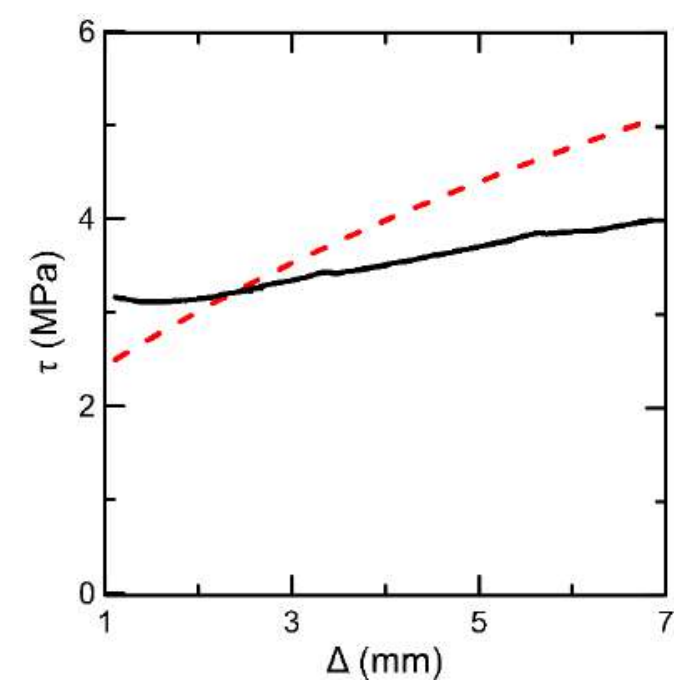

(b)

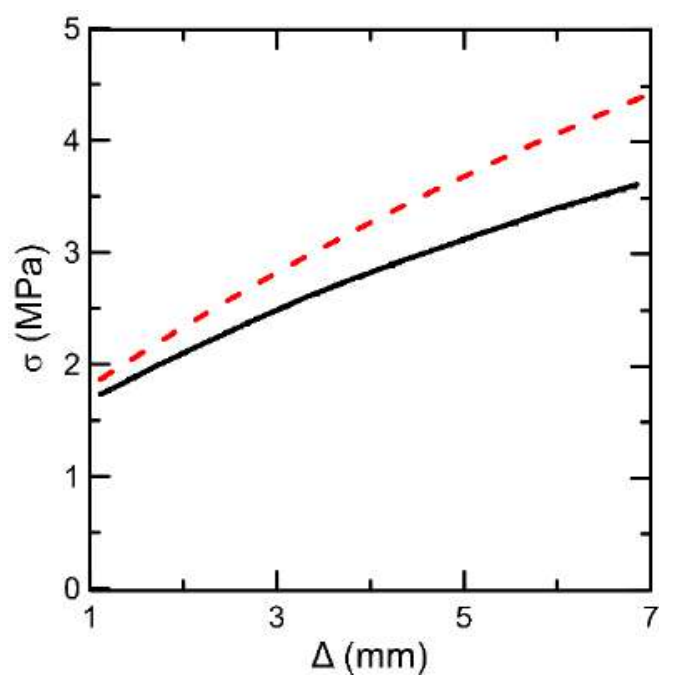

(d)

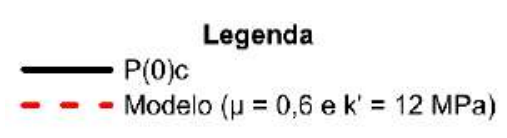

Figura 4.38 - Curvas experimentais e dadas pelo modelo proposto (eq. $4.20 \mathrm{e}$ eq. 4.21), para o espécime $\mathrm{P}(0) \mathrm{c}$ : (a) $\tau-w$; (b) $\tau-\Delta$; (c) $\sigma-w$; (d) $\sigma-\Delta$.

Para os espécimes com fibras, considerou-se que a tensão normal efetiva na seção de cisalhamento $\left(\sigma_{e}\right)$ é dada pela soma da tensão normal medida pelas barras de aço externas $(\sigma)$ com a tensão normal proveniente da ação das fibras de aço $\left(\sigma_{f}\right)$. $\sigma_{e}=\sigma+\sigma_{f}$

E, portanto, a eq. 4.25 é que deve ser igual à eq. 4.20 : $\sigma_{r}=\sigma_{e}$ 
Por dificuldades de ordem prática, não foram avaliadas experimentalmente as superfícies de ruptura dos espécimes com fibras, que podem diferir daquelas dos espécimes sem fibras, pois as fibras podem acarretar ruptura da matriz que as circunda e, consequentemente, alterar a superfície de contato (Isla et al., 2015). Na falta dessa avaliação, admitiram-se a mesma função densidade de contato e os mesmos $\mu$ e $k$ ' adotados para os espécimes sem fibras. Os espécimes $\mathrm{P}(1 \mathrm{~L})$ foram desconsiderados para estas análises, uma vez que neles a fissuração não ocorreu exclusivamente no plano do entalhe.

Conhecendo $\sigma_{\mathrm{f}}$, é possível obter $r$ teórico a partir da eq. 4.26, e assim, determinar a parcela de tensão de cisalhamento correspondente ao engrenamento dos agregados $\left(\tau_{\mathrm{r}}\right.$, eq. 4.21), que, somada com a parcela referente às fibras $\left(\tau_{\mathrm{f}}\right)$, fornece a tensão de cisalhamento resistente efetiva $\left(\tau_{\mathrm{e}}\right)$.

$$
\tau_{e}=\tau_{r}+\tau_{f}
$$

Para determinar as tensões normal $\left(\sigma_{\mathrm{f}}\right)$ e de cisalhamento $\left(\tau_{\mathrm{f}}\right)$ conferidas pelas fibras de aço, adotou-se o critério de densidade de orientação das fibras na seção de cisalhamento.

Para um determinado deslocamento relativo no sistema de referência do ensaio (SRE), tem-se um deslocamento e uma força no sistema de referência local de cada fibra com inclinação $\alpha$ em relação à direção normal à face da fissura (SRF), conforme ilustra a Figura 4.39 para apenas uma fibra.

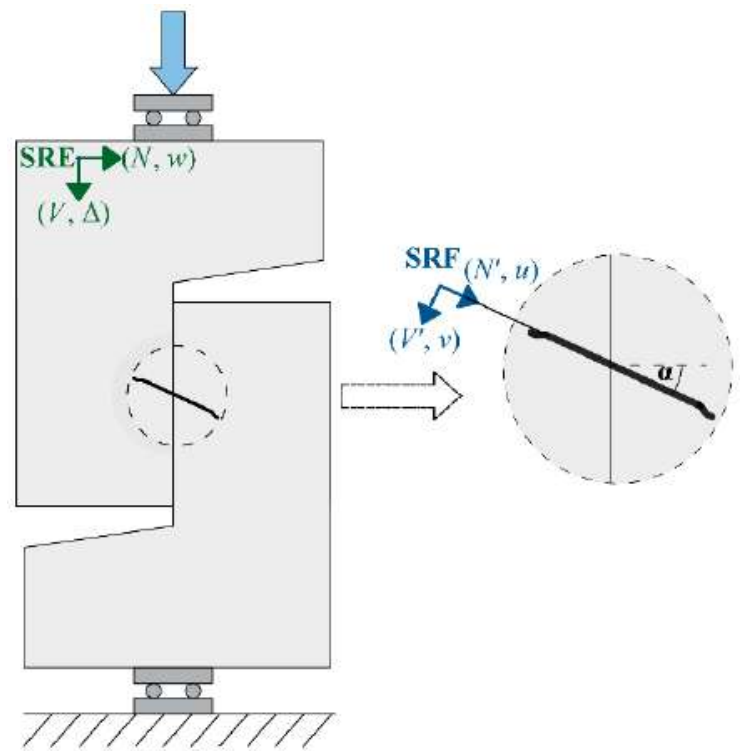

Figura 4.39 - Sistemas de referência do ensaio (SRE) e local da fibra (SRF) e forças atuantes $\left(N, V\right.$ e $\left.N^{\prime}, V^{\prime}\right)$ e deslocamentos relativos $(w, \Delta$ e $u, v)$. Esquema fora de escala. 
Na Figura 4.39, $u$ e $v$ são os deslocamentos nas direções longitudinal e transversal ao eixo da fibra, respectivamente. Estes deslocamentos se relacionam com o sistema de referência do ensaio conforme a eq. 4.28.

$$
\begin{aligned}
& u=w \cos \alpha+\Delta \operatorname{sen} \alpha \\
& v=\Delta \cos \alpha-w \operatorname{sen} \alpha
\end{aligned}
$$

$\mathrm{E}$ as forças normal e cortante no sistema de referência da fibra se relacionam com essas forças no SRE segundo a eq. 4.29. Nesta equação, $N$ e $V$ são as forças nas direções perpendicular e paralela ao plano de cisalhamento (SRE), e $N^{\prime}$ e $V$ ' são as forças nas direções normal e transversal à fibra. Elas são funções dos deslocamentos $u(w, \Delta)$ e $v(w, \Delta)$, podendo variar o seu sinal conforme a orientação destes deslocamentos.

$$
\begin{aligned}
& N=N^{\prime} \cos \alpha-V^{\prime} \sin \alpha \\
& V=N^{\prime} \sin \alpha+V^{\prime} \cos \alpha
\end{aligned}
$$

Devido à ineficiência da ação das fibras com inclinações em relação ao plano de cisalhamento perto de $90^{\circ}$, foram consideradas, arbitrariamente, apenas as fibras contidas no intervalo entre $-70^{\circ}(-1,22 \mathrm{rad})$ e $70^{\circ}(1,22 \mathrm{rad})$, de modo que as tensões resultantes das fibras no S.R.E são dadas por:

$$
\begin{aligned}
& \sigma_{f}=\int_{-1,22}^{1,22} \eta_{f} \Omega_{f}\left[N^{\prime} \cos \alpha-V^{\prime} \sin \alpha\right] d \alpha \\
& \tau_{f}=\int_{-1,22}^{1,22} \eta_{f} \Omega_{f}\left[N^{\prime} \sin \alpha+V^{\prime} \cos \alpha\right] d \alpha
\end{aligned}
$$

onde:

$\eta_{\mathrm{f}}$ é o número de fibras por unidade de área de cisalhamento;

$\alpha$ é o ângulo da fibra com relação à direção normal à face da fissura;

$\Omega_{\mathrm{f}}$ é a densidade de probabilidade dos ângulos $\alpha$ das fibras em uma área de cisalhamento unitária.

Não se podendo obter $\eta_{\mathrm{f}}$ real, seu valor tem que ser estimado. Considerando que todas as fibras existentes num prisma de concreto paralelo ao plano de cisalhamento e de espessura igual ao comprimento da fibra que cruza esse plano 
(Figura 4.40) e que, de acordo com o fabricante, para as fibras tipo $S$, tem-se 13311 fibras $/ \mathrm{m}^{3}$, chega-se a $\eta_{\mathrm{f}}=0,0157$ fibras $/ \mathrm{mm}^{2}$ e 0,0313 fibras $/ \mathrm{mm}^{2}$ para os espécimes $\mathrm{P}(0,5 \mathrm{~S})$ e $\mathrm{P}(1 \mathrm{~S})$, respectivamente.

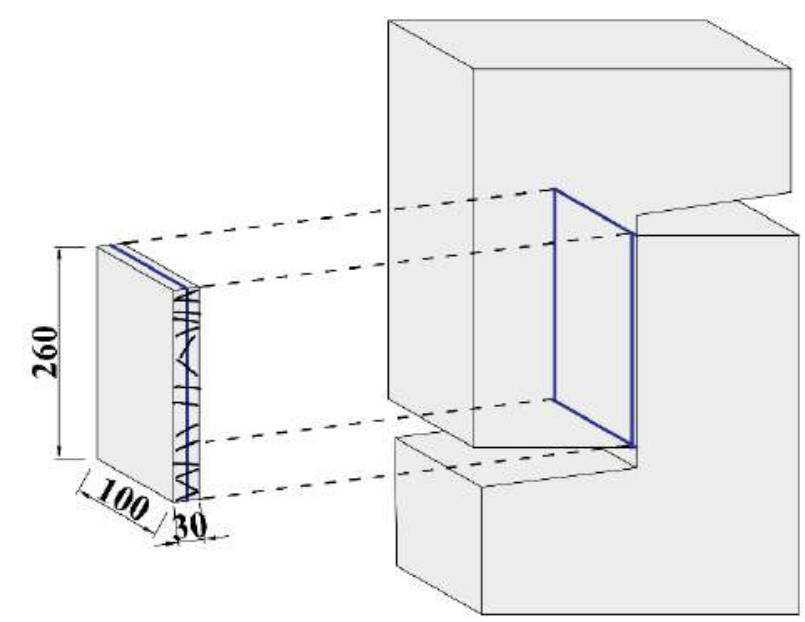

Figura 4.40 - Esquema considerado para obter $\eta_{\mathrm{f} .}$ Dimensões em mm.

Nos espécimes pushoff, foi considerada igual probabilidade de orientação das fibras entre $-\pi / 2$ a $\pi / 2$, ou seja, $\Omega_{\mathrm{f}}=1 / \pi$. A Figura 4.41 mostra esta função densidade de probabilidade de orientação, onde a área hachurada representa a faixa de ângulo $\alpha$ considerada para que as fibras efetivamente atuem como mecanismo resistente.

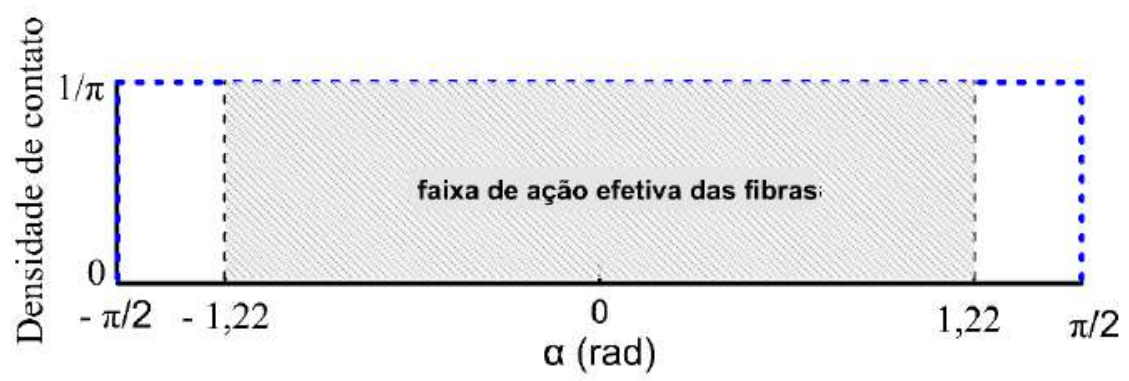

Figura 4.41 - Densidade de probabilidade de orientação das fibras e faixa de ação efetiva das fibras (- 1,22 $\mathrm{rad} \leq \alpha \leq 1,22 \mathrm{rad})$.

Para determinação da força transversal $V$, foi considerado modelo rígidoplástico, com força transversal mobilizada correspondente à plastificação total da fibra $\left(V_{p l}\right)$. O sentido da força $V$ ' depende do sentido do deslocamento $v$.

$$
\begin{cases}V^{\prime}=+V_{p l} & \text { se } v>0 \\ V^{\prime}=-V_{p l} & \text { se } v<0\end{cases}
$$


Analogamente ao que foi adotado no modelo de efeito de pino proposto (item 4.1.2), foi considerado que os trechos da fibra separados pela seção de cisalhamento podem ser substituídos por um comprimento equivalente $a$ (eq. 4.1) e suas extremidades são engastadas (Figura 4.42).

$$
a=1,4 \sqrt[4]{\frac{E_{f} I_{f}}{k d_{f}}}
$$

onde $E_{f} I_{f}$ é a rigidez à flexão da fibra, $d_{f}$ é o diâmetro equivalente da fibra e $k=E_{c} /\left(2,2 d_{f}\right)$ é o módulo de reação elástico do concreto.

Uma vez que um dos lados "L" do pushoff se mantém fixo e o outro deslocável, aplicando-se um deslocamento unitário transversal ao eixo da fibra em uma de suas extremidades engastadas, tem-se as seguintes reações de apoio nas extremidades do trecho de comprimento $2 a$ (Figura 4.42):

$$
\begin{aligned}
& M_{\text {unit }}=\frac{3 E_{f} I_{f}}{2 a^{2}} \\
& F_{\text {unit }}=\frac{3 E_{f} I_{f}}{2 a^{3}}
\end{aligned}
$$

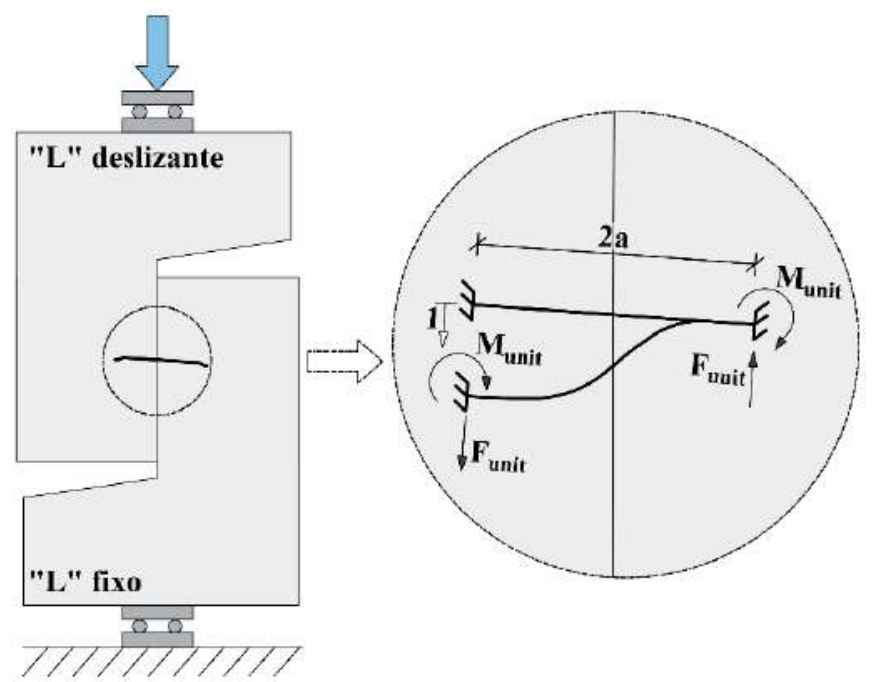

Figura 4.42 - Consideração de trecho da fibra atravessando a seção de cisalhamento, de comprimento $2 a$, como sendo biengastado e com deslocamento transversal unitário no lado do "L" deslizante. Esquema fora de escala.

Assumindo a fibra como esbelta, a força transversal na fibra $\left(V_{p l}\right)$ pode ser correlacionada com o seu momento plástico $\left(M_{p l}\right)$ e as reações de apoio apresentadas nas eq. 4.33 e 4.34 : 


$$
V_{p l}=M_{p l} \frac{F_{\text {unit }}}{M_{\text {unit }}}
$$

ou seja, substituindo eq. 4.33 e eq. 4.34 em eq. 4.35 :

$$
V_{p l}=\frac{M_{p l}}{a}
$$

onde

$$
M_{p l}=f_{y} Z
$$

e:

$f_{y}$ é a tensão de escoamento da fibra. Uma vez que o fabricante fornece apenas a resistência à tração, $f_{s t}, f_{y}$ dos fios de aço de baixo carbono trefilados da fibra foi estimada considerando-se que a relação $f_{s t} / f_{y}$ é aproximadamente 1,20.

$Z$ é o módulo resistente plástico da fibra $\left(Z=d_{f}^{3} / 6\right)$.

Portanto, para os espécimes $\mathrm{P}(0,5 \mathrm{~S})$ e $\mathrm{P}(1 \mathrm{~S})$, onde $d_{f}=0,62 \mathrm{~mm}$, considerando $a=0,841 \mathrm{~mm}$ (eq. 4.1) e assumindo $f_{y}$ igual a $1060 \mathrm{MPa}$, obtém-se $V_{p l}=50$ Newtons.

A força longitudinal $N^{\prime}$ foi obtida de forma indireta, ajustando-se a tensão normal obtida por meio da eq. 4.30 com a tensão residual obtida experimentalmente no ensaio de tração direta (Figura 4.43), ou seja, fazendo:

$$
f_{\text {res }}=\int_{-1,22}^{1,22} \eta_{c t} \Omega_{c t}\left[N^{\prime} \cos \alpha-V^{\prime} \sin \alpha\right] d \alpha
$$

onde:

$f_{\text {res }}$ é a tensão residual de tração direta no concreto para um determinado $w$, em MPa;

$\eta_{\mathrm{ct}}$ é o número de fibras médio na seção de ruptura do corpo-de-prova dogbone (Tabela 3.6, p. 105) por $\mathrm{mm}^{2}$. Para $V_{f}=0,5 \%(S)$ e $1,0 \%(S)$, foram obtidos os valores $\eta_{\mathrm{ct}}=0,00441$ fibras $/ \mathrm{mm}^{2}$ e 0,0129 fibras $/ \mathrm{mm}^{2}$ respectivamente;

$\Omega_{\mathrm{ct}}$ é a densidade de probabilidade dos ângulos das fibras no corpo-de-prova dogbone, também admitida com igual probabilidade de ocorrência, porém limitando-os à faixa entre $-70^{\circ}$ (- 1,22 rad) e $70^{\circ}$ (1,22 rad), uma vez que as fibras não efetivas não foram contabilizadas nos valores de $\eta_{\mathrm{ct}}$, i.e. $\Omega_{\mathrm{ct}}=0,409$; 
$V^{\prime}$ é dado pela eq. 4.32 .

Resolvendo a eq. 4.38 para os resultados dos ensaios à tração direta dos concretos com $V_{f}=0,5 \%(S)$ e 1,0 \% (S), ajustou-se uma função bilinear de $N^{\prime}$ para cada um destes concretos, definidas respectivamente por:

$$
\begin{aligned}
N^{\prime}= & \left\{\begin{array}{r}
-3600 w+740 \quad \text { se } w \leq 0,15 \mathrm{~mm} \\
-64,9 w+210 \text { se } 0,15 \mathrm{~mm}<w \leq 3 \mathrm{~mm}
\end{array}\right. \\
N^{\prime}= & \left\{\begin{array}{c}
-950 w+336 \text { se } w \leq 0,20 \mathrm{~mm} \\
-46,8 w+155 \text { se } 0,20 \mathrm{~mm}<w \leq 3 \mathrm{~mm}
\end{array}\right. \\
& N^{\prime} \text { em Newton }
\end{aligned}
$$

Na Figura 4.43 são comparadas as curvas de tensão residual de tração direta experimental com as obtidas por meio eq. 4.38.

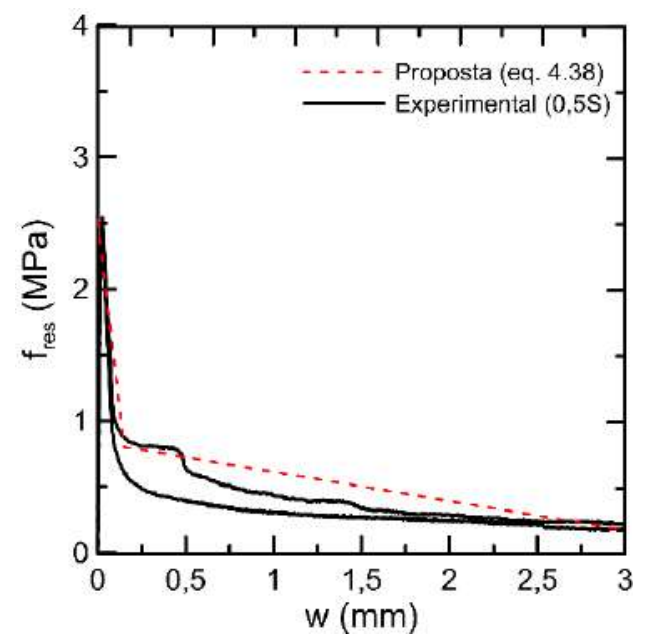

(a)

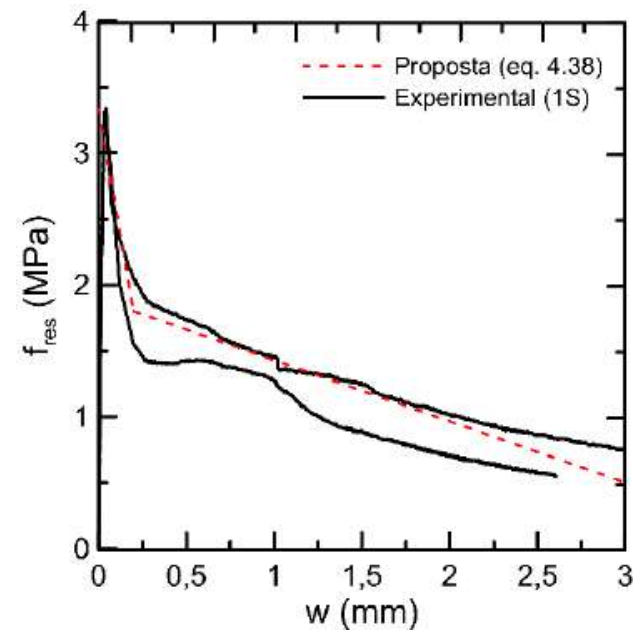

(b)

Figura 4.43 - Curvas de tensão residual de tração direta no concreto experimental e estimada $v s$ abertura de fissura: (a) $V_{f}=0,5 \%(S)$; (b) $V_{f}=1,0 \%(S)$.

Para o caso em que $\mathrm{u}<0$, as fibras atuam sob compressão. No presente trabalho, assume-se que as fibras podem atuar tanto à compressão quanto à tração, seguindo a mesma lei força-deslizamento. Em geral, as fibras são confinadas pelo concreto e, para aberturas de fissura suficientemente pequenas, não estão sujeitas a instabilidade. Assim, para valores de $\mathrm{u}<0$, as eq. 4.39 e eq. 4.40 são multiplicadas por -1 .

Com os parâmetros definidos: $\eta_{\mathrm{f}}\left(0,0157\right.$ fibras $/ \mathrm{mm}^{2}$ ou 0,0313 fibras $\left./ \mathrm{mm}^{2}\right)$, $\Omega_{\mathrm{f}}(1 / \pi), V^{\prime}$ (eq. 4.32) e $N^{\prime}$ (eq. 4.39 e eq. 4.40) para os espécimes $\mathrm{P}(0,5 \mathrm{~S})$ e $\mathrm{P}(1 \mathrm{~S})$, respectivamente, foram calculadas $\sigma_{\mathrm{f}}$ (eq. 4.30) e $\tau_{\mathrm{f}}$ (eq. 4.31). A partir de então, 
procedeu-se ao cálculo das tensões normal e de cisalhamento teóricas dos espécimes $\mathrm{P}(0,5 \mathrm{~S})$ e $\mathrm{P}(1 \mathrm{~S})$ por meio das eq. 4.26 e 4.27 . Nas Figuras 4.44 e 4.45 são apresentadas, para os espécimes $\mathrm{P}(0,5 \mathrm{~S})$ e $\mathrm{P}(1 \mathrm{~S})$ respectivamente, as curvas de tensão normal conforme a relação da eq. 4.25. Nestas figuras, pode-se observar que, em geral, para o trecho de início dos deslocamentos relativos a parcela de contribuição das fibras $\left(\sigma_{f}\right)$ é maior que a parcela medida pelas barras externas $(\sigma)$. Entretanto, para maiores valores, há uma tendência de redução da relação $\sigma_{\mathrm{f}} / \sigma_{\mathrm{e}}$, sendo ela mais expressiva nos espécimes $\mathrm{P}(0,5 \mathrm{~S})$.

Nas Figuras 4.46 e 4.47 são comparadas as curvas da tensão de cisalhamento prevista e experimental. Em geral, nota-se que as curvas teóricas ficaram abaixo das experimentais, sendo que as curvas $\tau_{\mathrm{e}}-\Delta$ teóricas ficaram mais próximas das experimentais e as curvas $\tau_{\mathrm{e}}-w$ teóricas tiveram formas diferentes das experimentais. Isto se justifica pelo fato do valor de $r$ obtido pela eq. 4.26 nem sempre ser aproximadamente igual ao experimental.

Embora seja desejável uma correlação melhor entre as curvas teóricas e experimentais para os elementos com fibras, o aumento do número de variáveis que têm relevante influência em seu comportamento em relação ao caso dos elementos sem fibras aumenta a complexidade do problema.

Diante disto, entende-se que o modelo apresentado para os elementos sem e com fibras de aço é capaz de representar razoavelmente o engrenamento dos agregados constatado. Entretanto, é desejável ter acesso a mais informações experimentais, principalmente para os espécimes com fibras, para conseguir modelagens mais realistas do engrenamento dos agregados. 


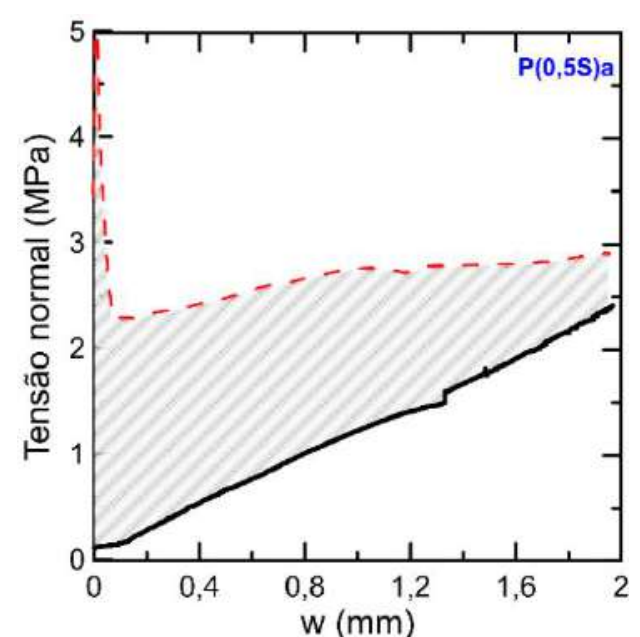

(a)

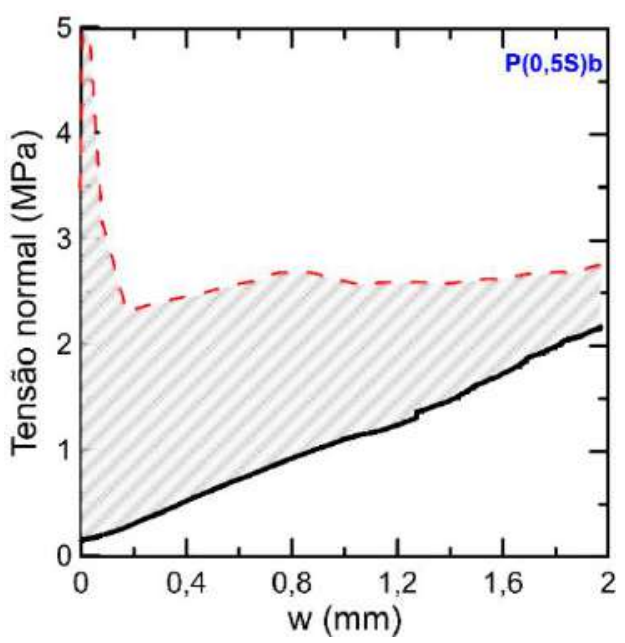

(c)

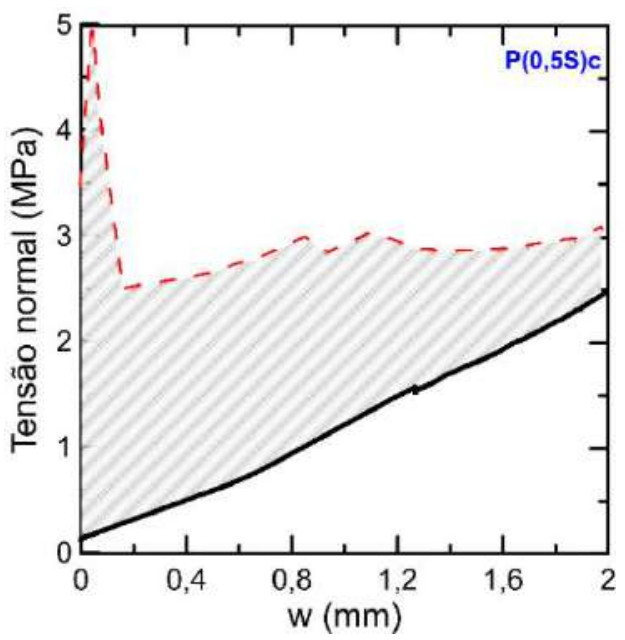

(e)

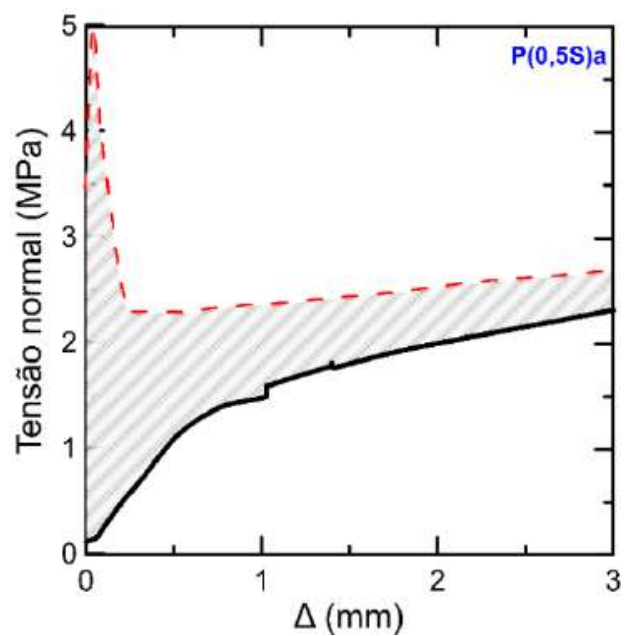

(b)

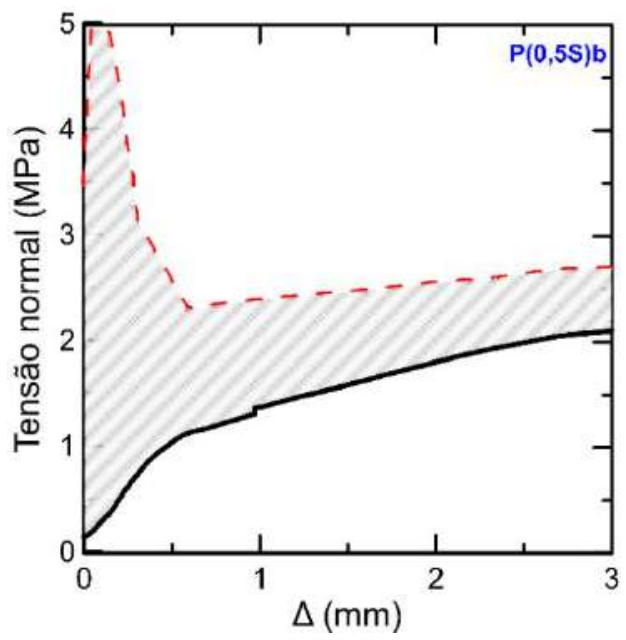

(d)

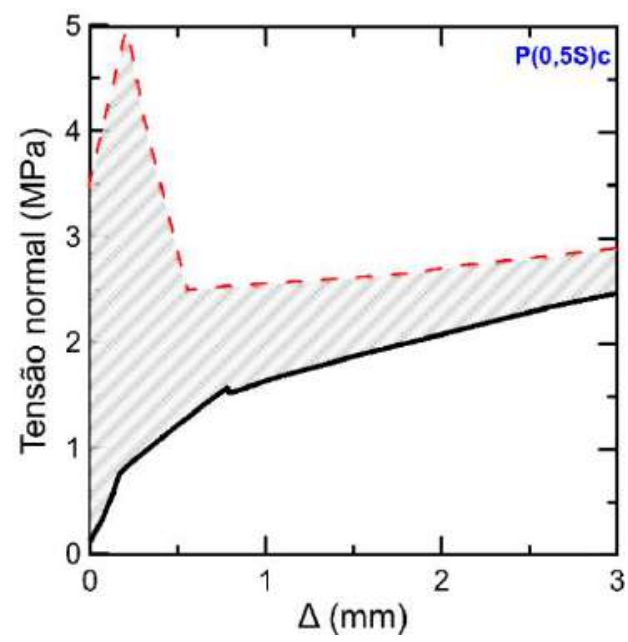

(f)

$$
--\sigma_{0} \longrightarrow \text { Legenda } \sigma W / / / / /, \sigma f
$$

Figura 4.44 -Tensão normal efetiva na seção de cisalhamento $\left(\sigma_{e}\right)$ e parcela de contribuição das barras externas $(\sigma)$ e das fibras $\left(\sigma_{\mathrm{f}}\right) v s$ abertura e deslizamento de fissura dos espécimes $\mathrm{P}(0,5 \mathrm{~S})$. 


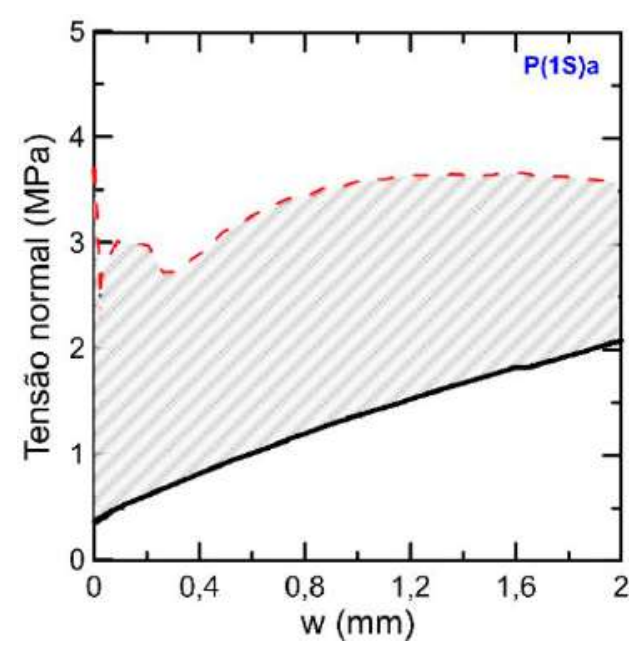

(a)

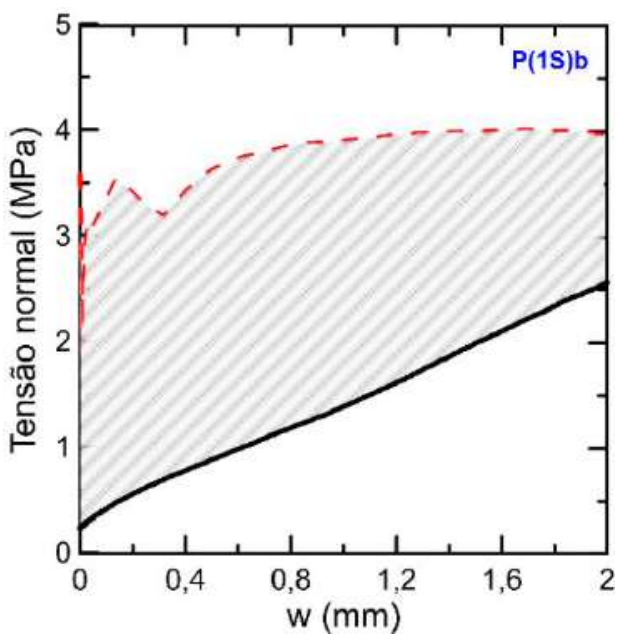

(c)

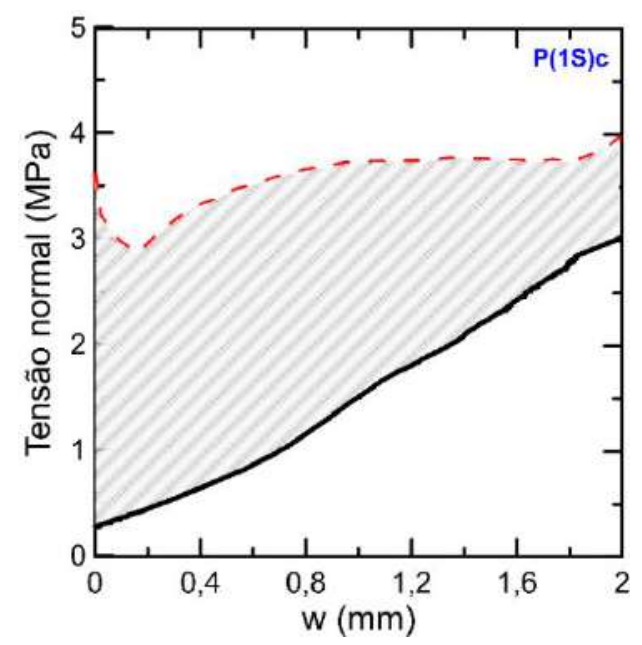

(e)

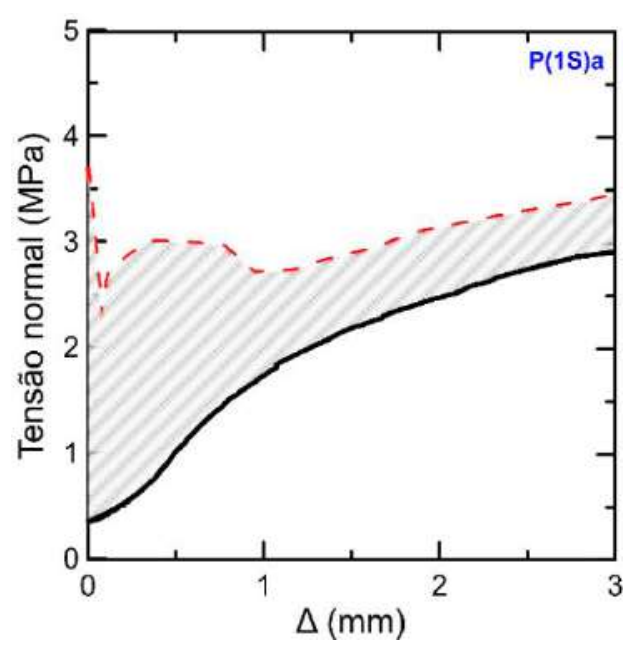

(b)

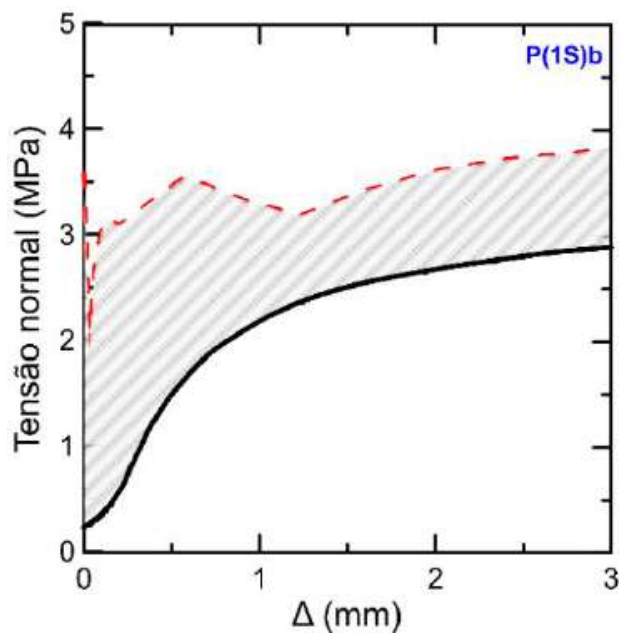

(d)

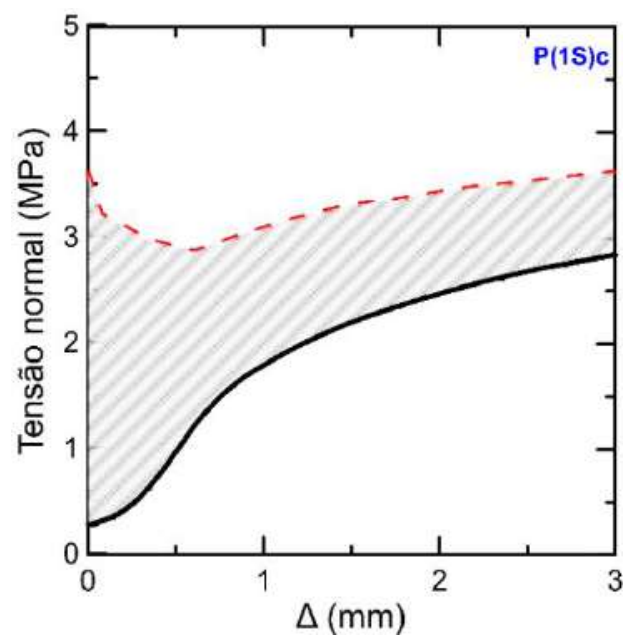

(f)

$$
--\sigma_{0} \stackrel{\text { Legenda }}{\sigma} \mathrm{W} / / / / / / \text {, } \text { of }
$$

Figura 4.45 -Tensão normal efetiva na seção de cisalhamento $\left(\sigma_{e}\right)$ e parcela de contribuição das barras externas $(\sigma)$ e das fibras $\left(\sigma_{\mathrm{f}}\right) v s$ abertura e deslizamento de fissura dos espécimes $\mathrm{P}(1 \mathrm{~S})$. 


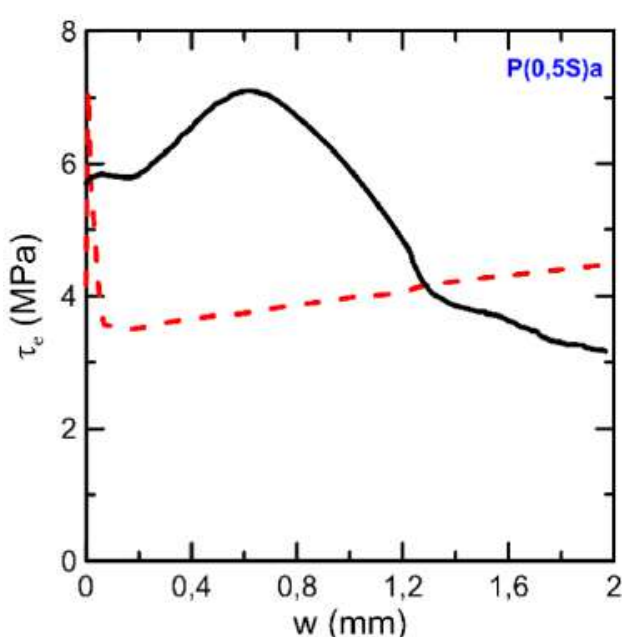

(a)

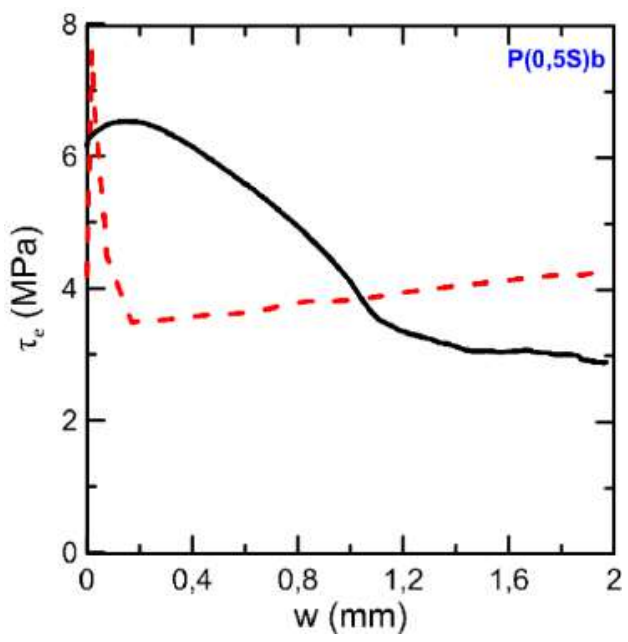

(c)

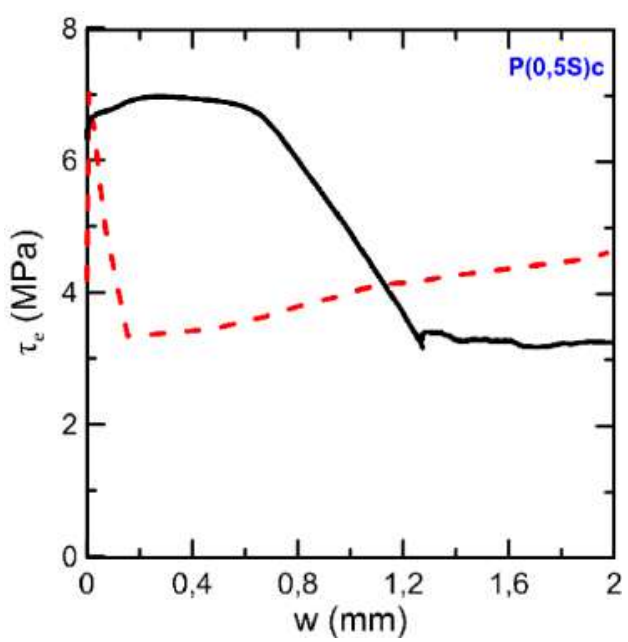

(e)

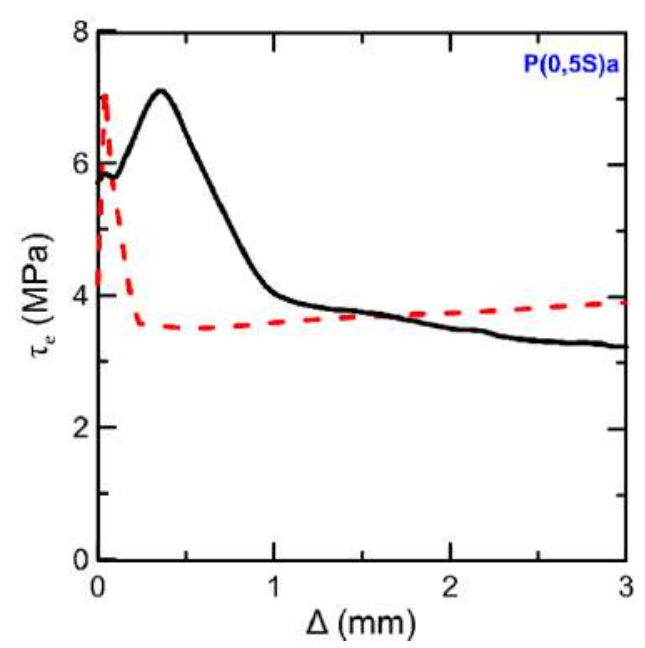

(b)

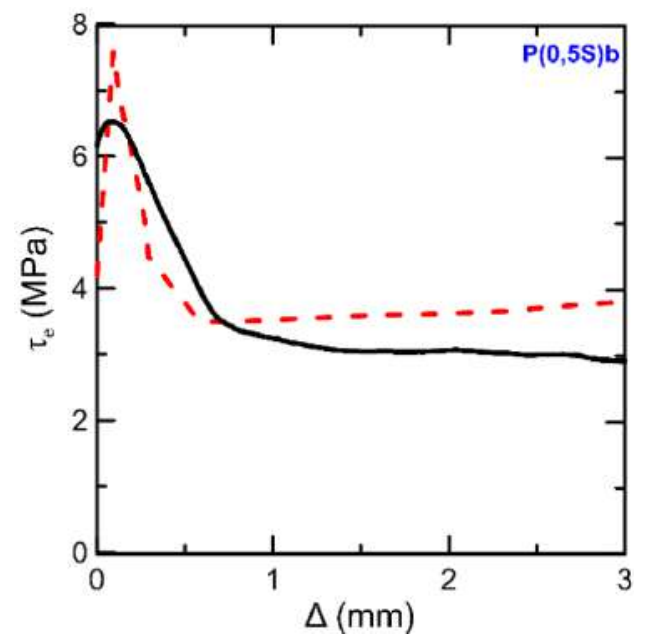

(d)

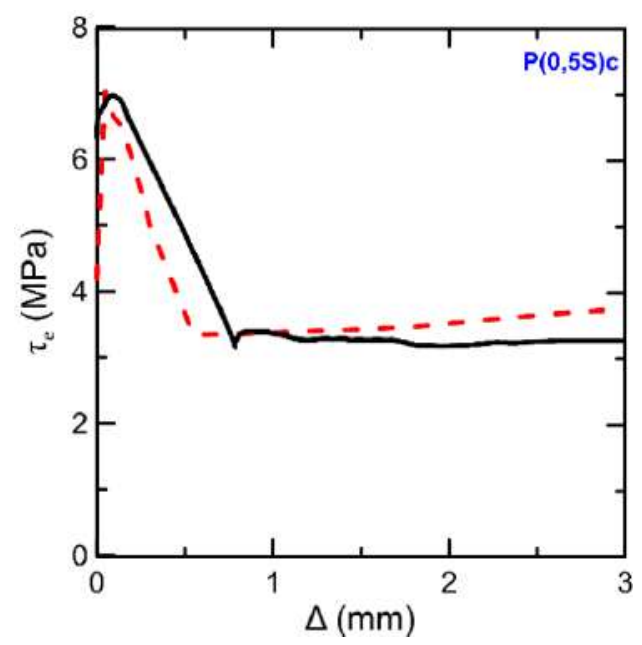

(f)

Legenda

Experimental - - - Modelo

Figura 4.46 - Curvas de tensão de cisalhamento vs abertura e deslizamento de fissura experimentais e previstas pelo modelo proposto (eq. 4.27) para os espécimes $\mathrm{P}(0,5 \mathrm{~S})$. 


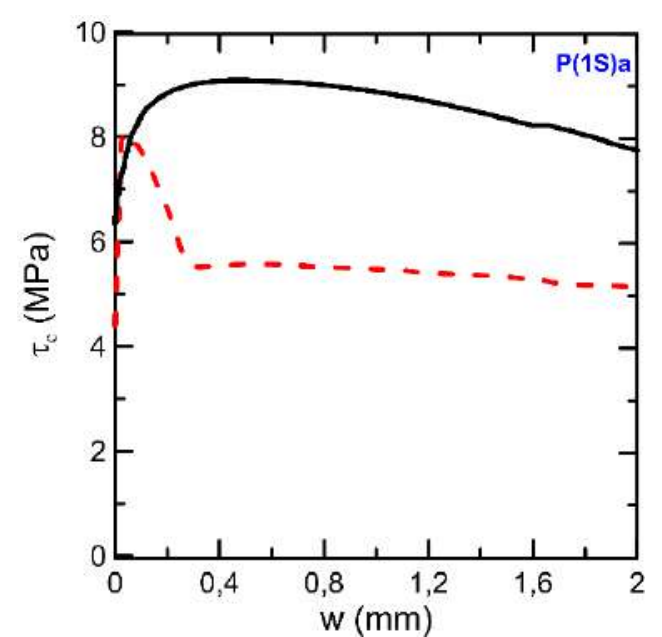

(a)

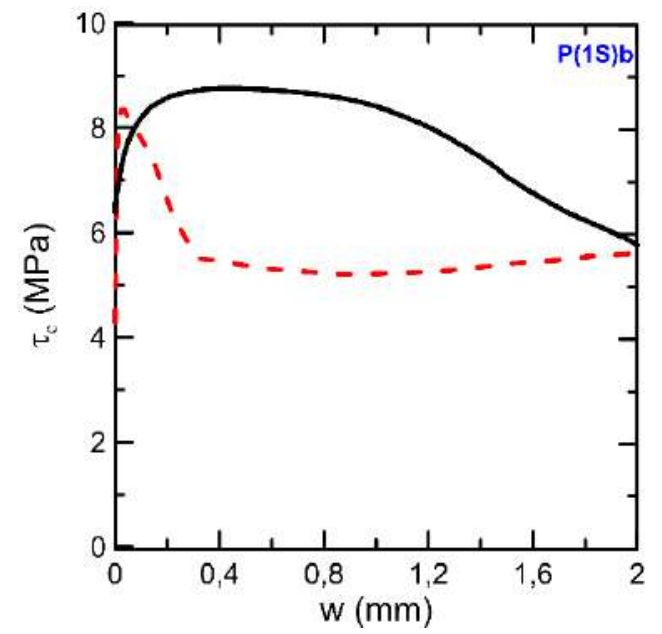

(c)

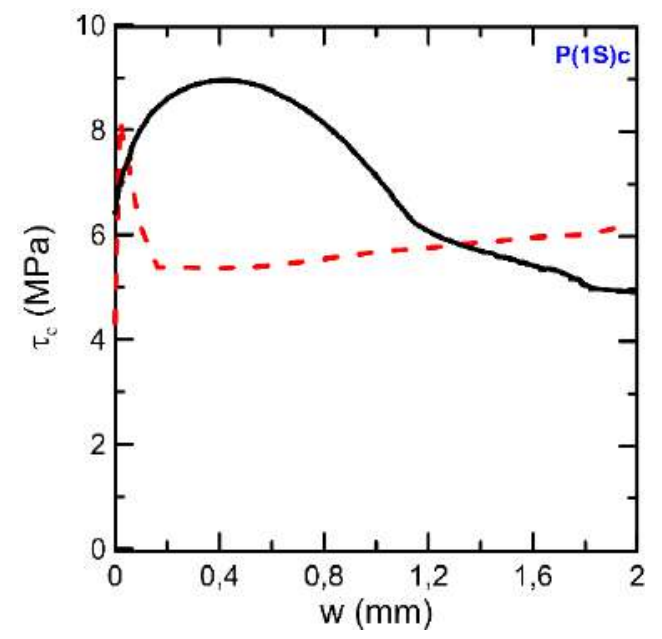

(e)

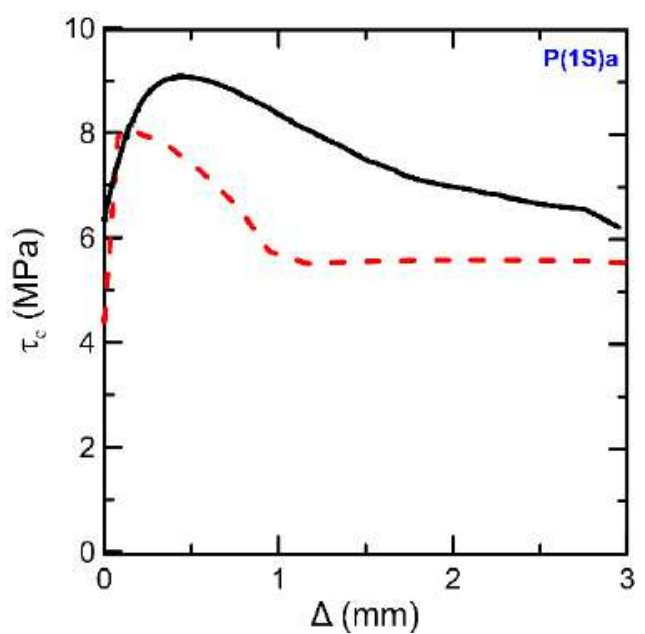

(b)

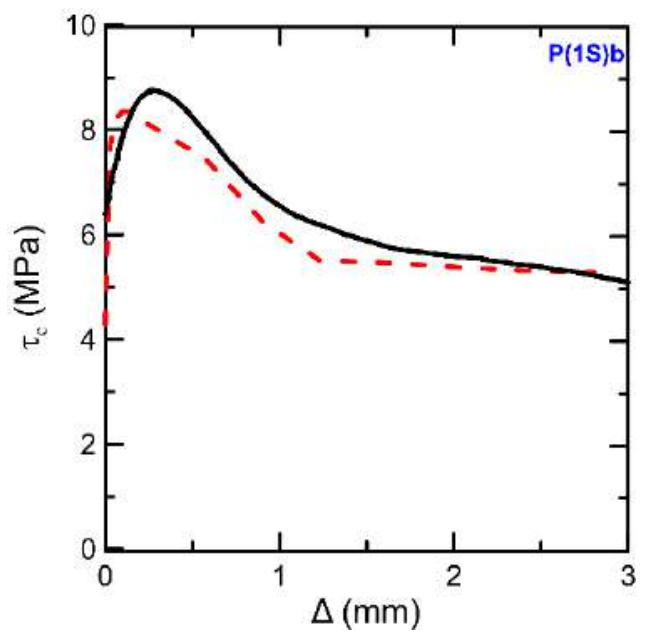

(d)

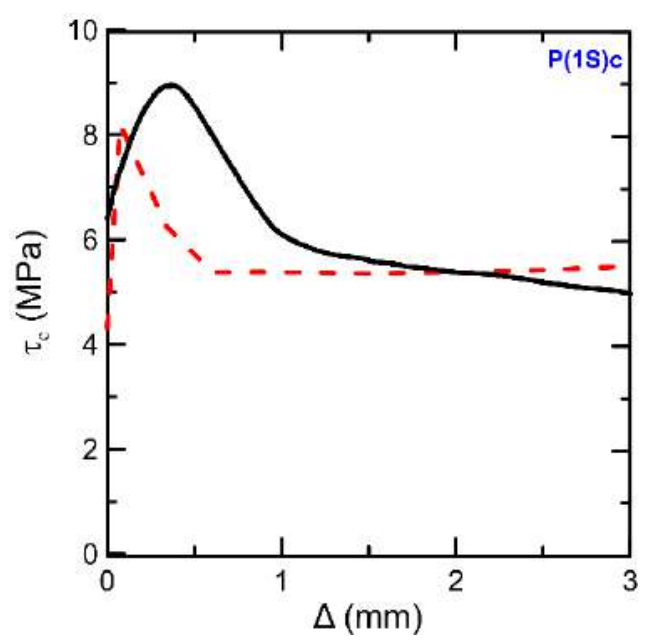

(f)

\section{Legenda}

Experimental - - - Modelo

Figura 4.47 - Curvas de tensão de cisalhamento $v s$ abertura e deslizamento de fissura experimentais e previstas pelo modelo proposto (eq. 4.27) para os espécimes $\mathrm{P}(1 \mathrm{~S})$. 


\section{3 \\ Ensaios em vigas esbeltas}

\subsection{1 \\ Resultados experimentais}

Em todas as vigas houve ruptura por força cortante, sem escoamento da armadura longitudinal de tração e sem esmagamento do concreto. As curvas força cortante-deslocamento vertical, força cortante-deformação específica do concreto e força cortante-deformação específica do aço são apresentadas nas Figuras 4.48 a 4.51, sendo os resultados das vigas agrupados de acordo com o teor e tipo de fibras de seu concreto. Os valores de deslocamento e deformações específicas reportados são as médias de seus pares obtidos pelos transdutores de deslocamento e extensômetros elétricos, respectivamente. Devido a falha no sistema de aquisição de deslocamento dos transdutores da viga $\mathrm{B}(0,5 \mathrm{~S}) \mathrm{b}$ e dos extensômetros colados na armadura longitudinal da viga $\mathrm{B}(1 \mathrm{~L}) \mathrm{b}$, para o deslocamento da viga $\mathrm{B}(0,5 \mathrm{~S}) \mathrm{b}$ foram utilizados os dados da correlação de imagem digital (CID), enquanto que a deformação específica do aço da viga $\mathrm{B}(1 \mathrm{~L}) \mathrm{b}$ foi desconsiderada.

Para uma análise global, na Figura 4.52 são apresentados os resultados de todas as vigas agrupados por grandeza medida. Na Tabela 4.6 são listadas a força cortante referente ao valor máximo de carga antes da primeira perda de capacidade resistente $\left(V_{p}\right)$ e da força cortante última $\left(V_{u}\right)$, correspondente ao valor máximo de carga antes da perda acentuada de capacidade resistente. Essa tabela lista também o deslocamento correspondente a $V_{p}$ e $V_{u}$ e as deformações específicas do concreto e do aço correspondentes a $V_{u}$. A menos das vigas sem fibras, $V_{u}=V_{p}$.

Nas Figura 4.48a e Tabela 4.6, observa-se que os valores de $V_{p}$ das vigas sem fibras ficaram próximos $(35,0 \mathrm{kN}$ e $36,7 \mathrm{kN}$ para $\mathrm{B}(0)$ a e $\mathrm{B}(0) \mathrm{b}$, respectivamente). Entretanto, $V_{u} \approx V_{p}$ para $\mathrm{B}(0) \mathrm{b}$, mas $V_{u} / V_{p}=1,23$ para $\mathrm{B}(0)$ a, que também apresentou deslocamento e deformações maiores que a $\mathrm{B}(0) \mathrm{b}$ para $V_{u}$.

Já para as vigas com fibras, observa-se a tendência de comportamento similar entre as vigas do mesmo grupo nas curvas apresentadas nas Figuras 4.49 a 4.51 . Na Figura 4.52 pode-se ver a tendência de maior força cortante para um determinado deslocamento e de, para um mesmo carregamento, menores deformações para os espécimes com maior teor de fibras. 


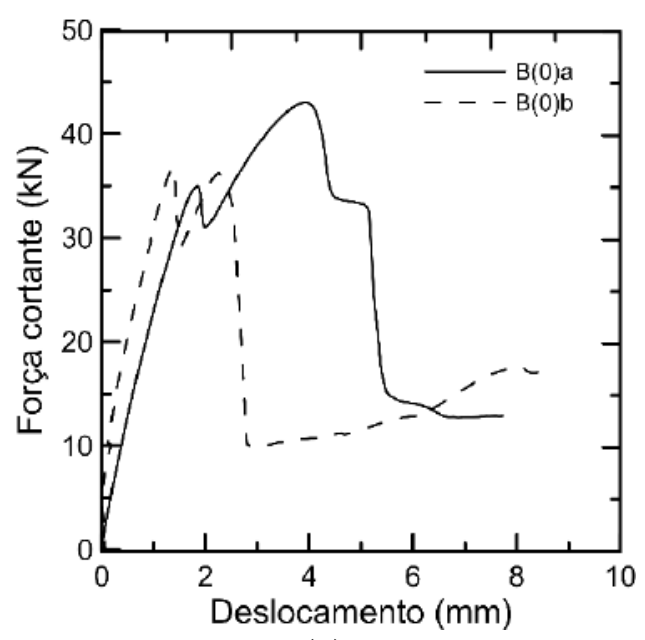

(a)

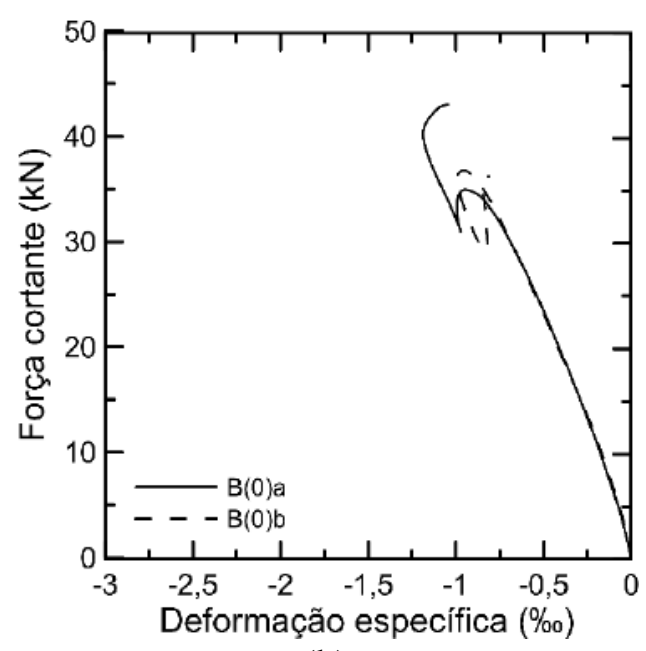

(b)

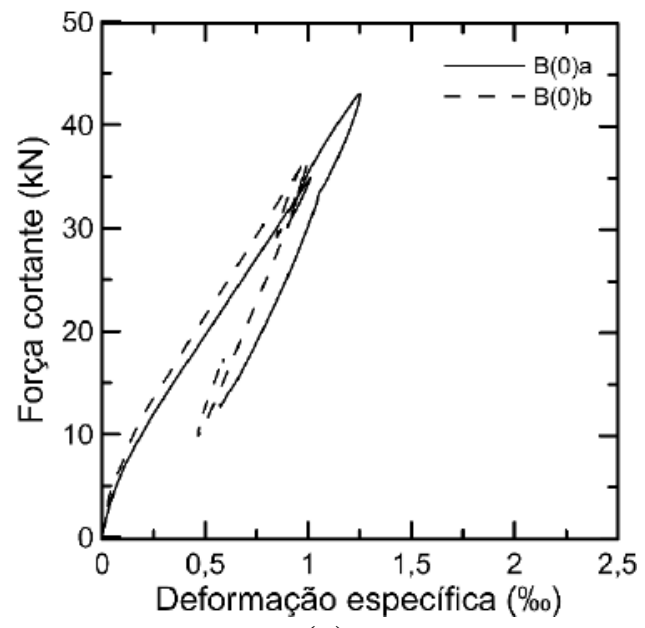

(c)

Figura 4.48 - Vigas do grupo B(0): (a) Curvas força cortante-deslocamento vertical; (b) força cortante-deformação específica do concreto; (c) força cortantedeformação específica do aço. 


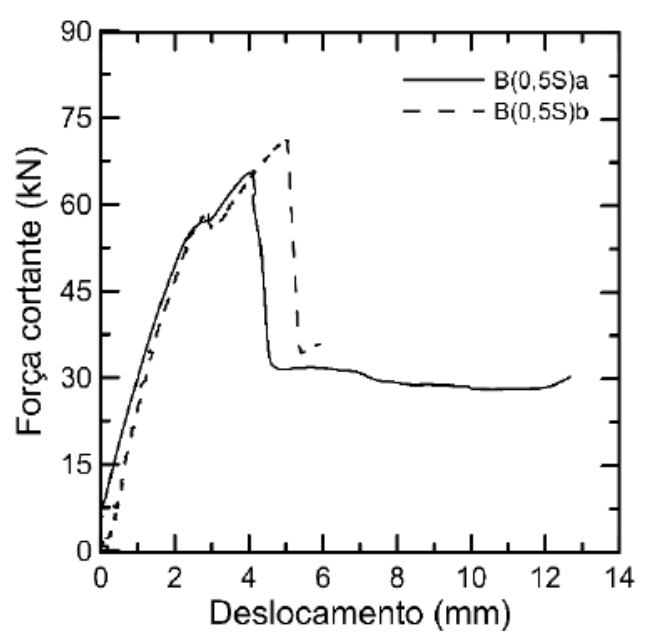

(a)

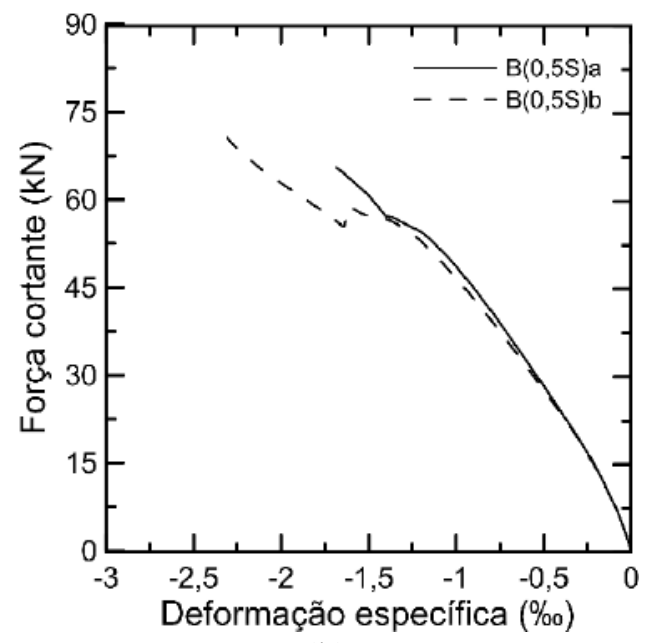

(b)

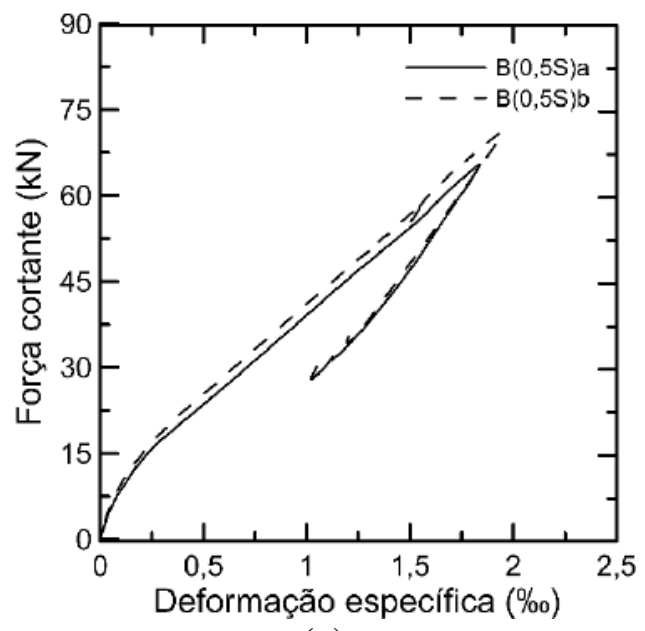

(c)

Figura 4.49 - Vigas do grupo B(0,5S): (a) Curvas força cortante-deslocamento vertical; (b) força cortante-deformação específica do concreto; (c) força cortantedeformação específica do aço. 


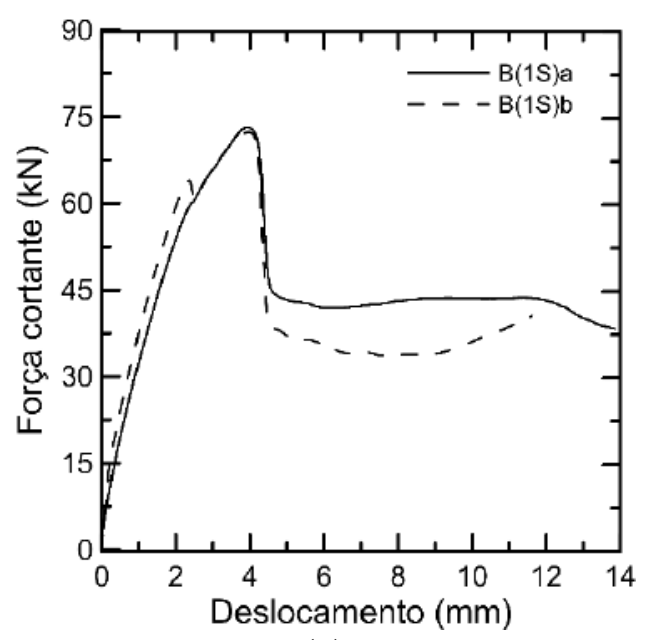

(a)

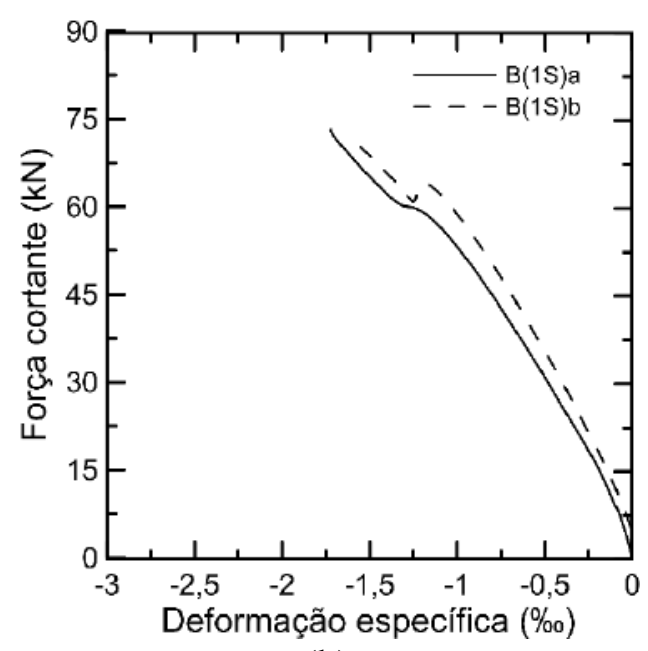

(b)

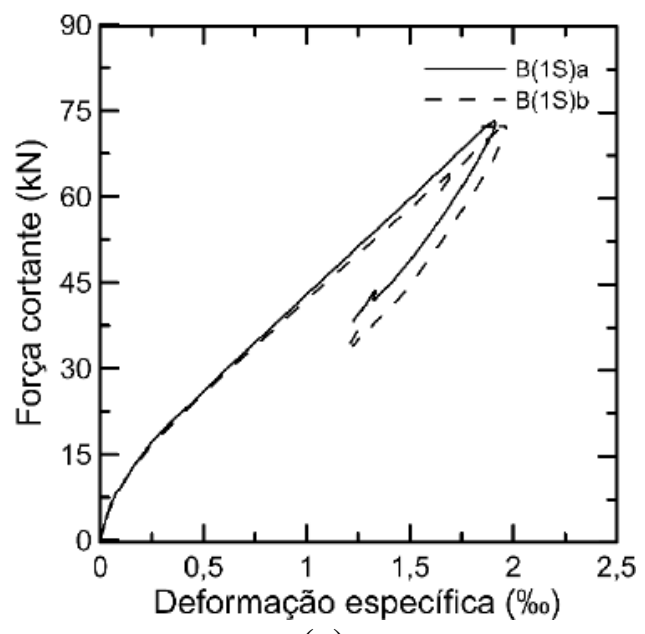

(c)

Figura 4.50 - Vigas do grupo B(1S): (a) Curvas força cortante-deslocamento vertical; (b) força cortante-deformação específica do concreto; (c) força cortantedeformação específica do aço. 


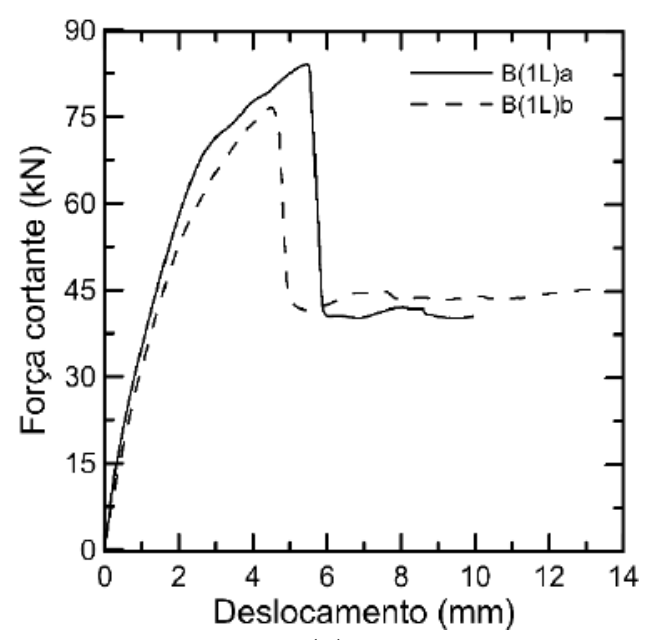

(a)

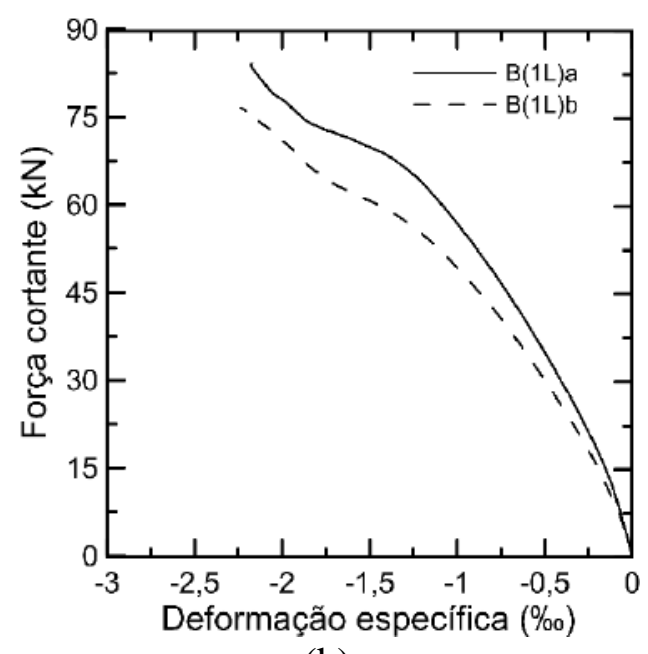

(b)

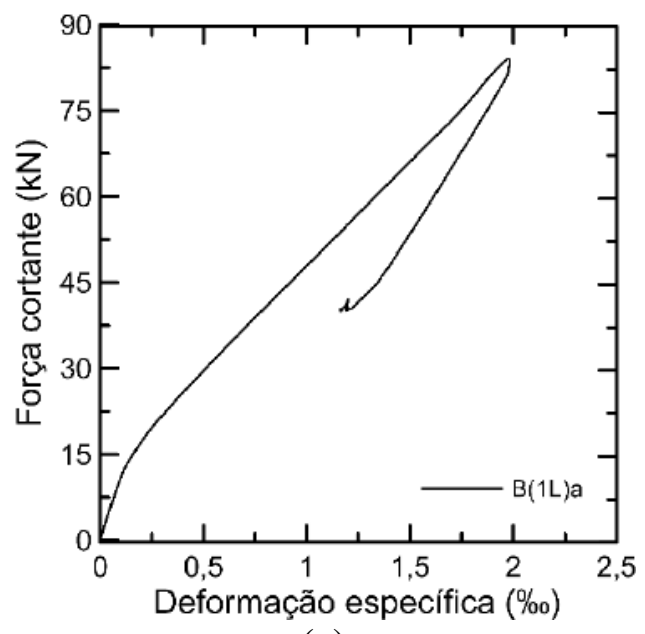

(c)

Figura 4.51 - Vigas do grupo B(1L): (a) Curvas força cortante-deslocamento vertical; (b) força cortante-deformação específica do concreto; (c) força cortantedeformação específica do aço. 


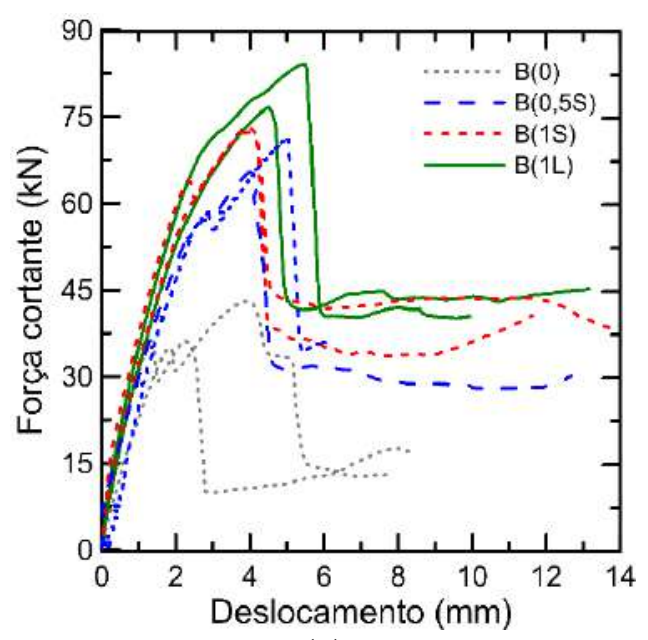

(a)

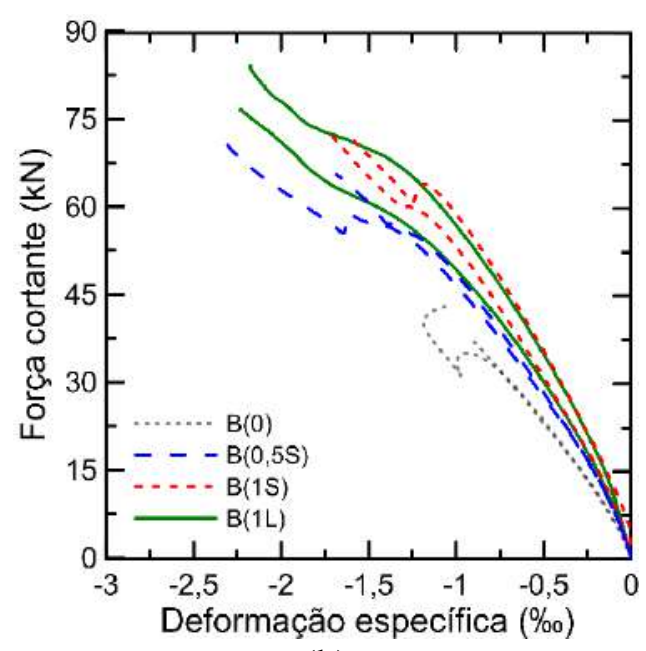

(b)

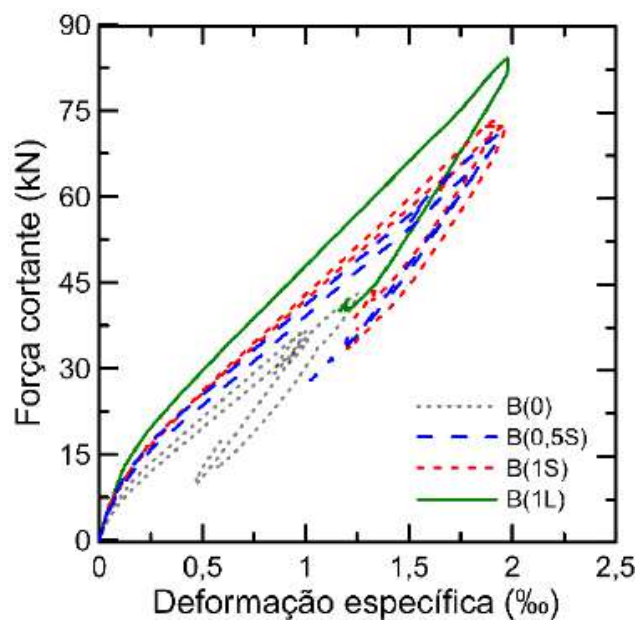

(c)

Figura 4.52 - Curvas para todas as vigas: (a) Curvas força cortante-deslocamento vertical; (b) força cortante-deformação específica do concreto; (c) força cortantedeformação específica do aço.

Tabela 4.6 - Valores de $\boldsymbol{V}_{\boldsymbol{p}}$ e $\boldsymbol{V}_{\boldsymbol{u}}$, deslocamentos verticais $\delta_{\mathrm{p}}$ e $\delta_{\mathrm{u}}$ e deformações específicas no concreto e no aço $\varepsilon_{\mathrm{cu}}$ e $\varepsilon_{\mathrm{su}}$ correspondentes a $V_{p}$ e $V_{u}$.

\begin{tabular}{ccccccc}
\hline Espécime & $\boldsymbol{V}_{\boldsymbol{p}}(\mathbf{k N})$ & $\boldsymbol{V}_{\boldsymbol{u}}(\mathbf{k N})$ & $\boldsymbol{\delta}_{\mathbf{p}}(\mathbf{m m})$ & $\boldsymbol{\delta}_{\mathbf{u}}(\mathbf{m m})$ & $\boldsymbol{\varepsilon}_{\mathbf{c u}}(\mathbf{\% o})$ & $\boldsymbol{\varepsilon}_{\mathbf{s u}}(\mathbf{\% o})$ \\
\hline $\mathrm{B}(0) \mathrm{a}$ & 35,0 & 43,0 & 1,84 & 3,93 & $-1,05$ & 1,25 \\
$\mathrm{~B}(0) \mathrm{b}$ & 36,7 & 36,2 & 1,34 & 2,24 & $-0,811$ & 0,973 \\
$\mathrm{~B}(0,5 \mathrm{~S}) \mathrm{a}$ & 65,5 & 65,5 & 4,04 & 4,04 & $-1,68$ & 1,84 \\
$\mathrm{~B}(0,5 \mathrm{~S}) \mathrm{b}$ & 71,1 & 71,1 & 5,01 & 5,01 & $-2,29$ & 1,95 \\
$\mathrm{~B}(1 \mathrm{~S}) \mathrm{a}$ & 73,1 & 73,1 & 3,92 & 3,92 & $-1,72$ & 1,91 \\
$\mathrm{~B}(1 \mathrm{~S}) \mathrm{b}$ & 72,3 & 72,3 & 3,98 & 3,98 & $-1,58$ & 1,96 \\
$\mathrm{~B}(1 \mathrm{~L}) \mathrm{a}$ & 84,1 & 84,1 & 5,46 & 5,46 & $-2,17$ & 1,98 \\
$\mathrm{~B}(1 \mathrm{~L}) \mathrm{b}$ & 76,5 & 76,5 & 4,49 & 4,49 & $-2,23$ & - \\
\hline
\end{tabular}

A Figura 4.53, que mostra a relação entre $V_{u}$ e $V_{f}\left(l_{f} / d_{f}\right)$, evidencia a influência da adição, teor e tipo de fibras na força cortante última. Ao fazer a média de $V_{u}$ entre as vigas do mesmo grupo de fibras, observa-se um aumento de $71 \%, 82 \%$ e $101 \%$ 
para vigas com $V_{f}=0,5 \%(\mathrm{~S}), 1,0 \%(\mathrm{~S})$ e $1,0 \%(\mathrm{~L})$, respectivamente, com relação às vigas sem fibras.

Exceto pelo $\delta_{\mathrm{u}}$ da viga $\mathrm{B}(1 \mathrm{~S})$, as vigas com fibras de aço apresentaram maior valor de $\delta_{\mathrm{p}}, \delta_{\mathrm{u}}, \varepsilon_{\mathrm{cu}} \mathrm{e} \varepsilon_{\mathrm{su}}$ que as sem fibras, embora não seja clara sua variação de acordo com o teor e tipo de fibras (Tabela 4.6). Ao analisar a relação entre $V_{p}$ e $\delta_{\mathrm{p}}$ (Figura 4.54), verifica-se a tendência de aumento de $\delta_{\mathrm{p}}$ com o aumento de $V_{p}$. O mesmo acontece para a relação entre $V_{u}$ e $\delta_{\mathrm{u}}$ (Figura 4.55), a não ser para a viga $\mathrm{B}(0) \mathrm{a}$.

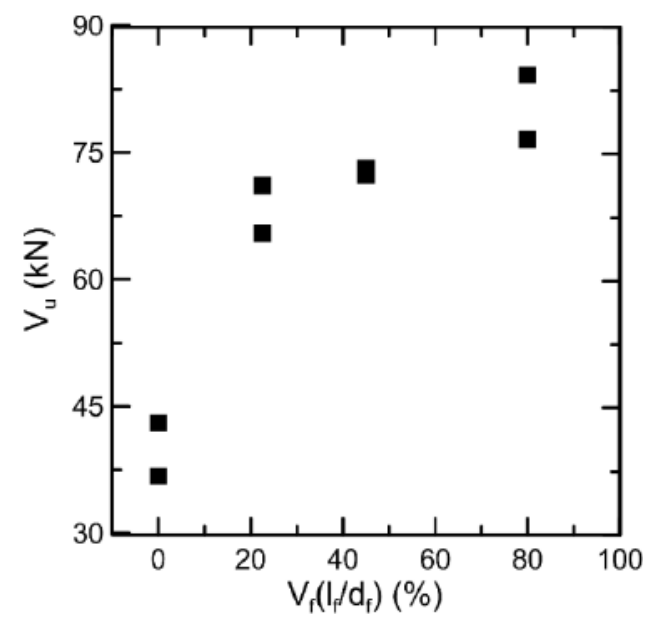

Figura 4.53 - Relação entre $V_{u}$ e $V_{f}\left(l_{f} d_{f}\right)$ das vigas ensaiadas.

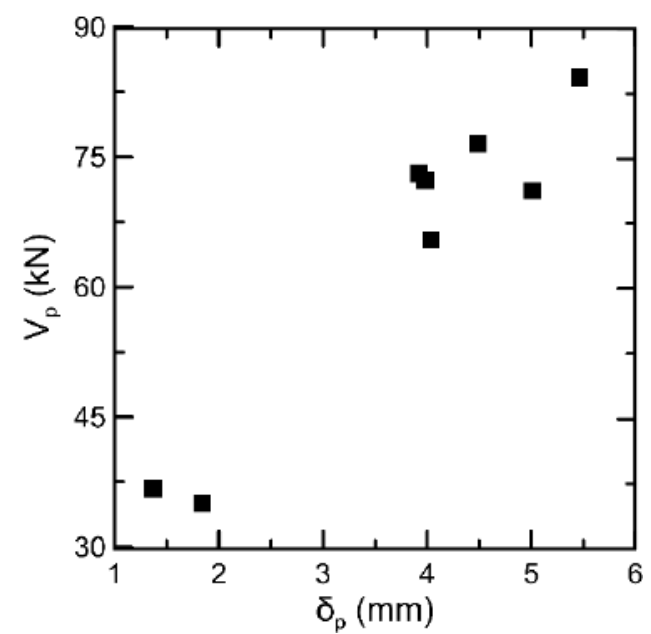

Figura 4.54 - Relação entre $V_{p}$ e $\delta_{p}$ das vigas ensaiadas. 


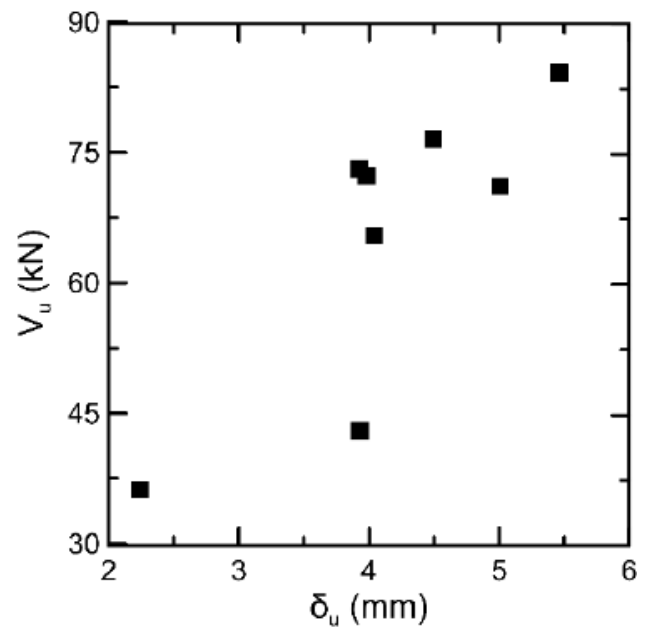

Figura 4.55 - Relação entre $V_{u}$ e $\delta_{u}$ das vigas ensaiadas.

Para verificação dos deslocamentos obtidos por meio da CID, eles foram comparados com os obtidos por meio dos transdutores de deslocamento. As comparações para todas as vigas (exceto para $\mathrm{B}(0,5 \mathrm{~S}) \mathrm{b}$, para a qual não se teve as medições com os transdutores registradas) mostraram boa concordância entre os deslocamentos obtidos das duas maneiras. Na Figura 4.56 é apresentada a comparação para a viga $\mathrm{B}(0) \mathrm{a}$.

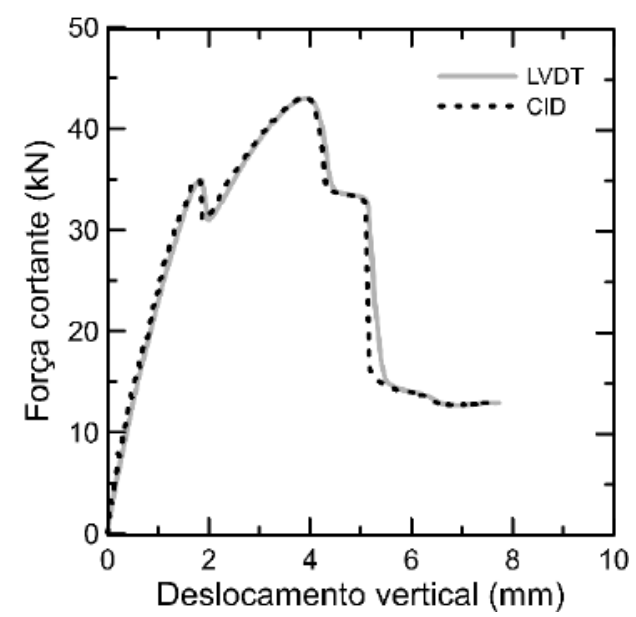

Figura 4.56 - Comparação entre a média dos deslocamentos medidos com os transdutores e o obtido por CID para o espécime B(0)a.

Na Figura 4.57 é apresentada uma imagem das vigas imediatamente antes do término dos ensaios, com o mapeamento do campo de deslocamento na direção vertical obtido pela CID. Nessa figura, é possível ver o padrão de fissuração das vigas, assim como a tendência de deslocamento relativo entre as partes das vigas separadas pela fissura crítica. 
Na região onde estava o gancho colocado para içamento da viga $\mathrm{B}(0) \mathrm{a}$, verificou-se fissuração pós-ruptura (Figura 4.57a).

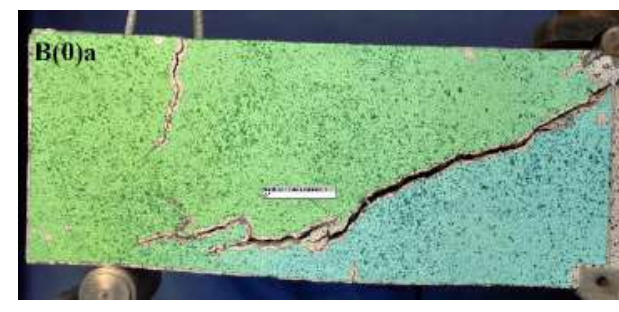

(a)

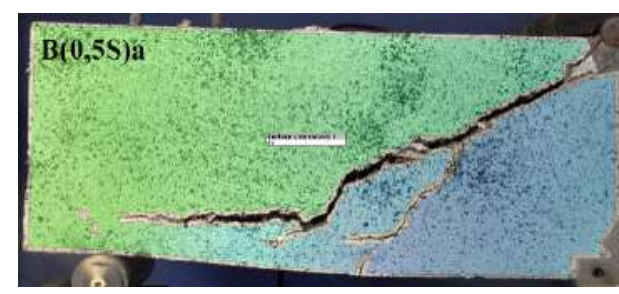

(c)

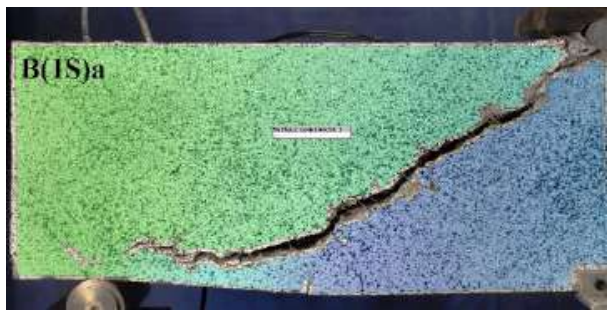

(f)

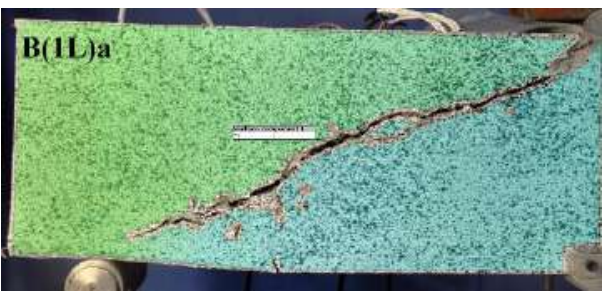

(h)

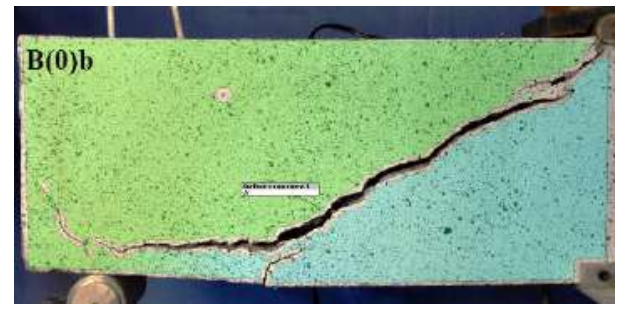

(b)

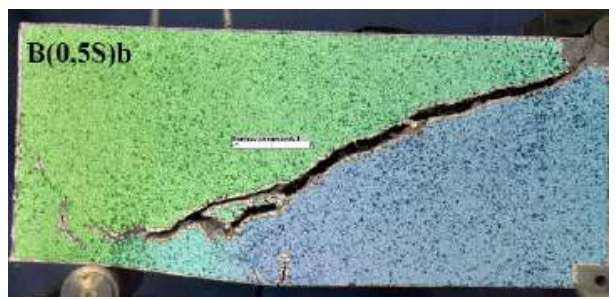

(d)

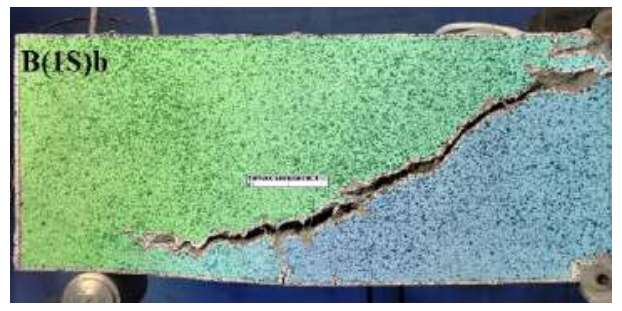

$(\mathrm{g})$

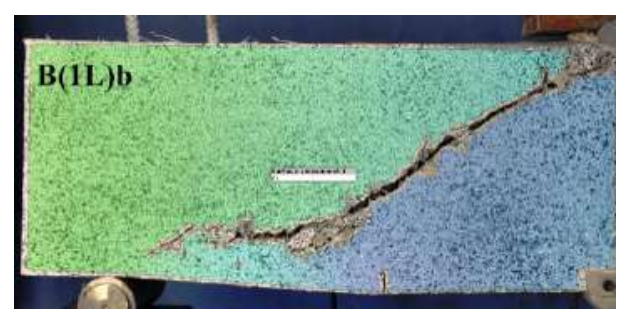

(i)

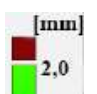

0,0
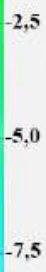

$-10,0$

$-12,5$

$-15,0$

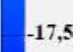

$-20,0$

Figura 4.57 - Campo de deslocamento na direção vertical após o término dos ensaios: (a) $\mathrm{B}(0) \mathrm{a}$; (b) $\mathrm{B}(0) \mathrm{b}$; (c) $\mathrm{B}(0,5 \mathrm{~S}) \mathrm{a}$; (d) $\mathrm{B}(0,5 \mathrm{~S}) \mathrm{b}$; (e) $\mathrm{B}(1 \mathrm{~S}) \mathrm{a}$; (f) $\mathrm{B}(1 \mathrm{~S}) \mathrm{b}$; (g) B(1L)a; (h) B(1L)b

Para efeito de análises, a forma da fissura crítica foi simplificada, adotandose o menor número de trechos retilíneos ( 3 a 5) que representassem razoavelmente a forma verificada, como mostra a Figura 4.58. Esta figura mostra também o ângulo de inclinação desses trechos com o eixo longitudinal das vigas. Os trechos inclinados de maior comprimento tiveram esse ângulo entre $24^{\circ}$ e $36^{\circ}$. 

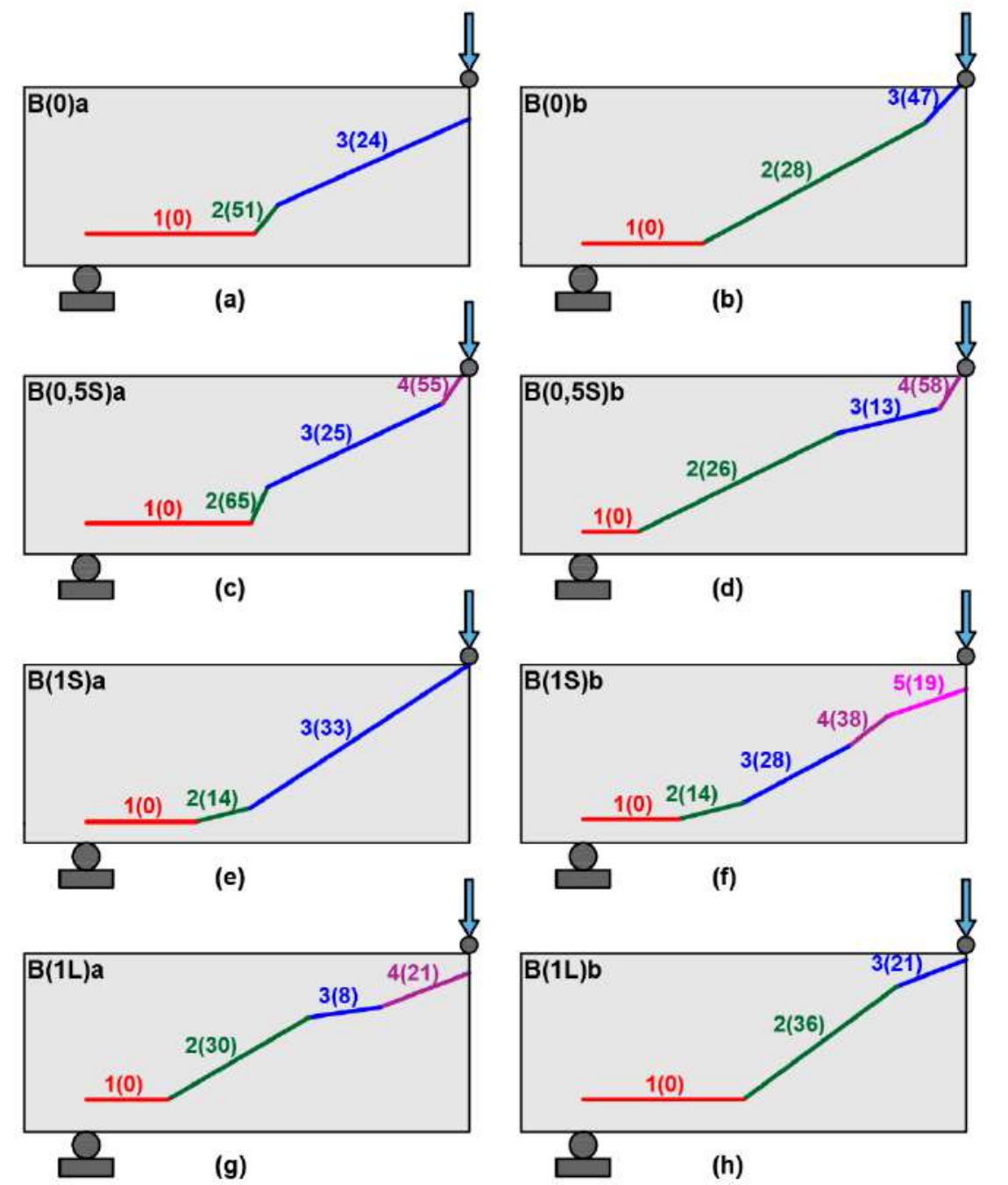

Figura 4.58 - Forma simplificada da fissura crítica das vigas. Numeração dos trechos seguida pelo valor de seu ângulo com a direção horizontal em graus entre parênteses: (a) B(0)a; (b) B(0)b; (c) B(0,5S)a; (d) B(0,5S)b; (e) B(1S)a; (f) $\mathrm{B}(1 \mathrm{~S}) \mathrm{b} ;(\mathrm{g}) \mathrm{B}(1 \mathrm{~L}) \mathrm{a} ;(\mathrm{h}) \mathrm{B}(1 \mathrm{~L}) \mathrm{b}$.

Por meio da análise fotogramétrica, foi possível acompanhar a cinemática da fissura crítica mostrada na Figura 4.58 durante todo o ensaio. A obtenção da abertura e do deslizamento ao longo da fissura usando o software Gom Correlate $^{\circledR}$ seguiu a simplificação indicada na Figura 4.58, sendo utilizados cerca de 90 pontos auxiliares, metade acima e metade abaixo da fissura e situados perpendicularmente à fissura, como mostrado na Figura 4.59. 


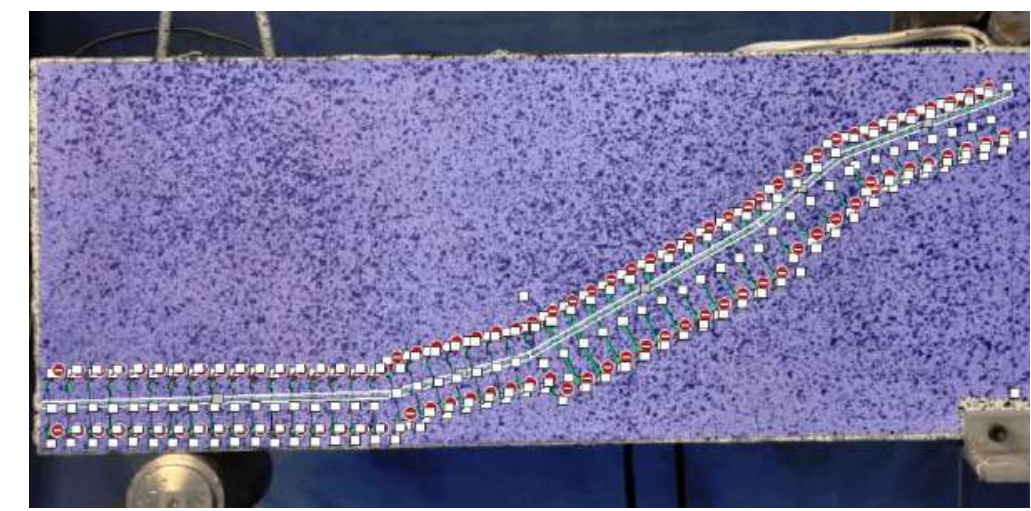

Figura 4.59 - Viga B(1S)b com pontos auxiliares lançados para obter a cinemática da fissura de cisalhamento ao longo do ensaio.

Para estimar a magnitude dos erros de medição dos delocamentos relativos entre as faces da fissura (abertura e deslizamento), eles foram avaliados entre duas fotografias consecutivas imediatamente antes do início do ensaio (deslocamentos relativos teóricos nulos). Constatou-se um erro absoluto médio na faixa de $\left(2,69 \times 10^{-3}\right) \mathrm{mm}$ a $\left(1,02 \times 10^{-3}\right) \mathrm{mm}$, sendo maior para as vigas sem fibras, provavelmente associado ao padrão de pontos menos denso que estas vigas tiveram em relação às com fibras. Para avaliar uma possível influência da curvatura das vigas na obtenção dos deslocamentos entre as faces da fissura crítica conforme mencionado por Hoult et al. (2016), foi adotada a verificação proposta por esses autores (item 2.3.1, p. 81) e concluiu-se que ela foi desprezível.

Em nenhuma das vigas o início da fissuração se deu pelo fendilhamento ao longo da armadura longitudinal (trecho 1, Figura 4.38). O início da fissura crítica ocorreu para a força cortante de $30 \mathrm{kN}(\mathrm{B}(0) \mathrm{a})$ e $35 \mathrm{kN}(\mathrm{B}(0) \mathrm{b})$ paras as vigas sem fibras, enquanto que este valor tendeu a ser maior (entre $39 \mathrm{kN}$ e $51 \mathrm{kN}$ ) para as vigas com fibras. Nas vigas sem fibras, a fissura crítica ocorreu após atingir-se $V_{p}$ e, em todas as vigas, todos os trechos mostrados na Figura 4.58 foram formados antes de $V_{u}$. Na Tabela 4.7 é listado o valor da força cortante quando do início de fissuração de cada trecho. 
Tabela 4.7 - Força cortante correspondente ao início de fissuração de cada trecho da Figura 4.58, em kN.

\begin{tabular}{cccccc}
\hline Viga & 1 & 2 & 3 & 4 & 5 \\
\hline $\mathrm{B}(0) \mathrm{a}$ & $35^{*}$ & $35^{*}$ & $35^{*}$ & - & - \\
$\mathrm{B}(0) \mathrm{b}$ & $30^{*}$ & $30^{*}$ & $30^{*}$ & - & - \\
$\mathrm{B}(0,5 \mathrm{~S}) \mathrm{a}$ & 52 & 41 & 52 & 52 & - \\
$\mathrm{B}(0,5 \mathrm{~S}) \mathrm{b}$ & 56 & 44 & 56 & 56 & - \\
$\mathrm{B}(1 \mathrm{~S}) \mathrm{a}$ & 70 & 59 & 51 & - & - \\
$\mathrm{B}(1 \mathrm{~S}) \mathrm{b}$ & 63 & 49 & 39 & 52 & 64 \\
$\mathrm{~B}(1 \mathrm{~L}) \mathrm{a}$ & 57 & 48 & 68 & 68 & - \\
$\mathrm{B}(1 \mathrm{~L}) \mathrm{b}$ & 53 & 45 & 58 & - & - \\
*alor entre $V_{p}$ e $V_{u}$. Demais valores são anteriores a $V_{u}$.
\end{tabular}

Para visualizar o estado de fissuração do vão de ruptura em diferentes etapas do ensaio, foram geradas imagens dos campos de deformações horizontal $\left(\varepsilon_{\mathrm{x}}\right) \mathrm{e}$ vertical $\left(\varepsilon_{\mathrm{y}}\right)$ do vão de ruptura para diferentes etapas de ensaio. Na Figura 4.60 mostram-se estes campos para as vigas sem fibras no estágio de força cortante $(V)$ igual a $V_{p}$ e $V_{u}$. Para as vigas com fibras, nas Figuras 4.61 a 4.63, esses campos são mostrados para os estágios de força cortante igual a $0,65 V_{u}, 0,80 V_{u}$ e $V_{u}$.

Na Figura 4.60 pode-se ver que, para $V=V_{p}$, as vigas sem fibras já apresentavam fissuras de flexão prolongando-se, com parte inclinada ou não, até cerca de metade da altura das vigas.

Nas vigas com fibras, no estágio de $V=0,65 V_{u}$ as vigas já apresentavam fissuras de flexão (Figuras 4.61 a 4.63), tendo elas maiores abertura e comprimento nas vigas $\mathrm{B}(0,5 \mathrm{~S}) \mathrm{b}$ e $\mathrm{B}(1 \mathrm{~S}) \mathrm{b}$. Para $V=0,80 V_{u}$, todas já apresentavam fissuras inclinadas. Para $V=V_{u}$, nessas figuras pode-se ver que, diferentemente das demais vigas, as $\mathrm{B}(0,5 \mathrm{~S})$ apresentaram junção da fissura crítica com outra, a cerca de meia altura da viga $(\mathrm{B}(0,5 \mathrm{~S}) \mathrm{a})$ ou na proximidade do topo da viga $(\mathrm{B}(0,5 \mathrm{~S}) \mathrm{b})$. 


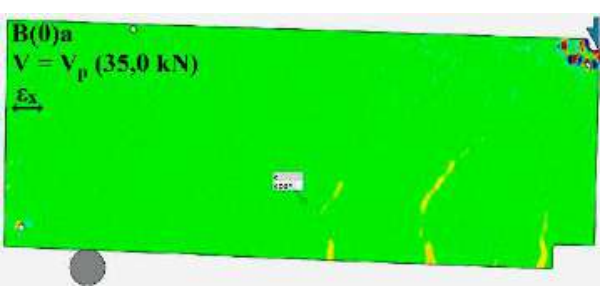

(a)

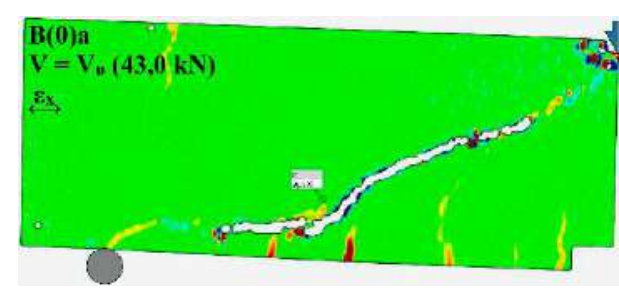

(c)

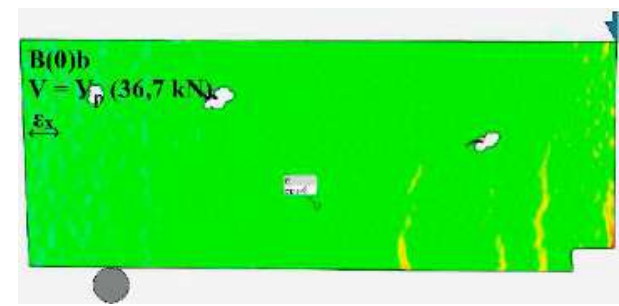

(e)

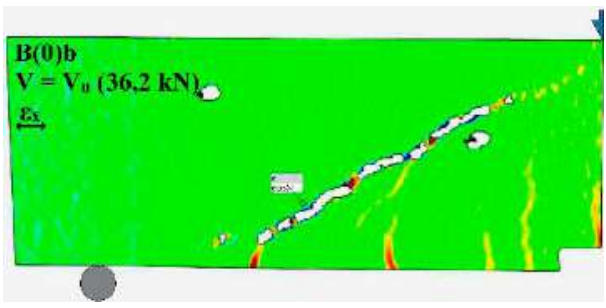

(g)

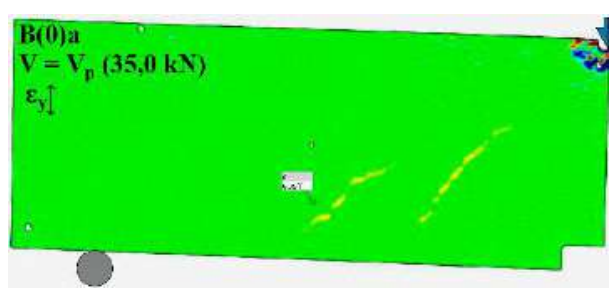

(b)

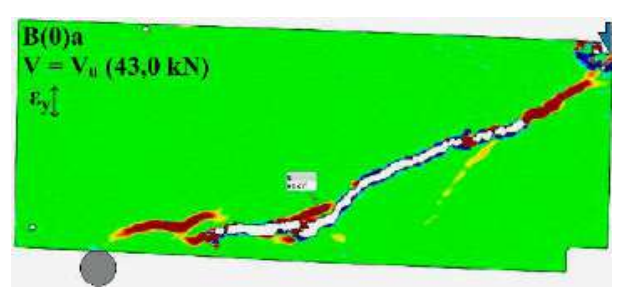

(d)

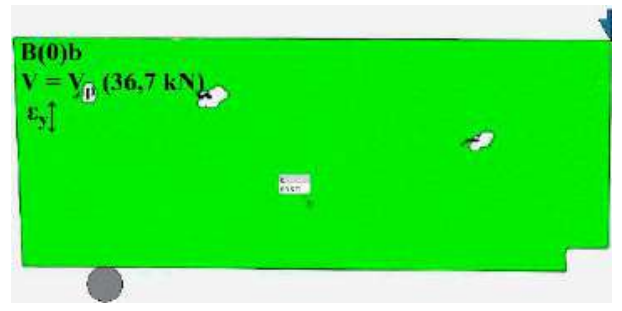

(f)

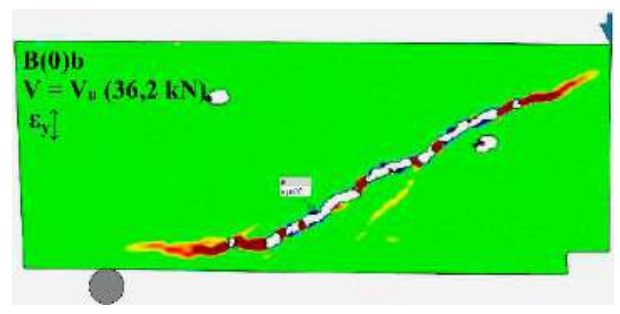

(h)

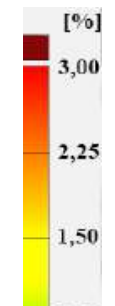

0,75

Figura 4.60 - Campo de deformação específica nas direções horizontal $\left(\varepsilon_{x}\right)$ e vertical $\left(\varepsilon_{y}\right)$ das vigas $\mathrm{B}(0)$ para o estágio de carregamento $V_{p}$ e $V_{u}$. 


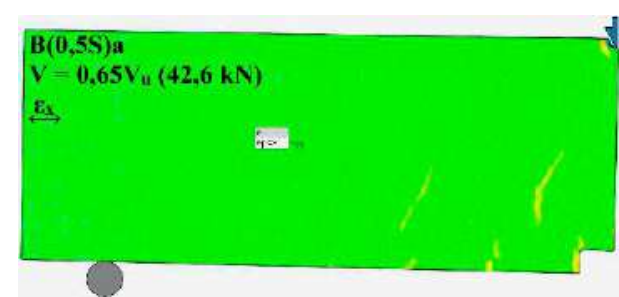

(a)

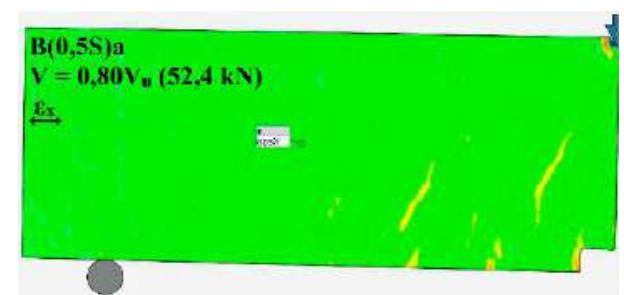

(c)

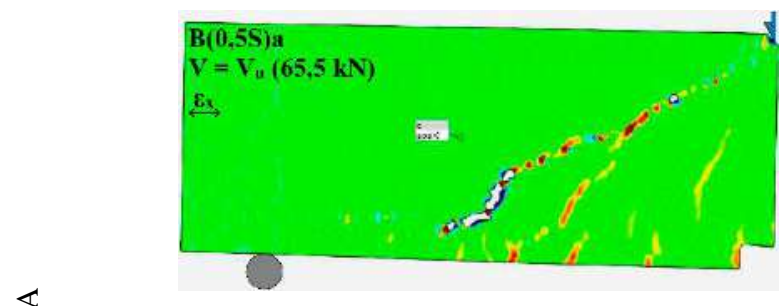

(e)

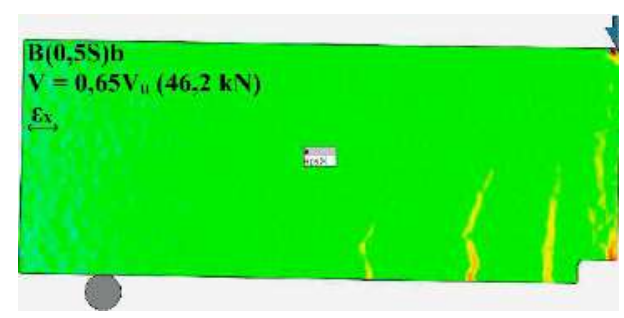

(g)

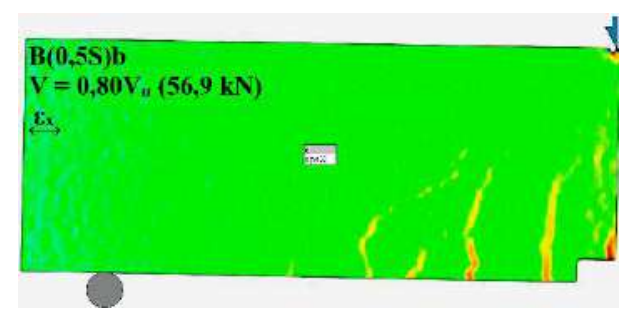

(i)

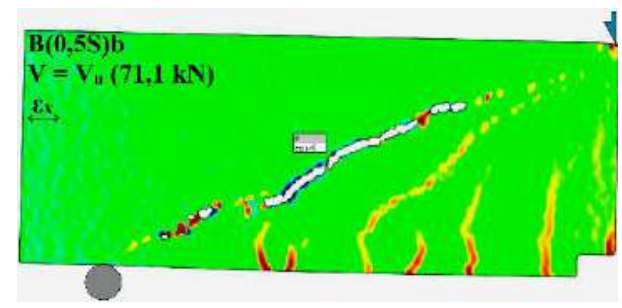

(k)

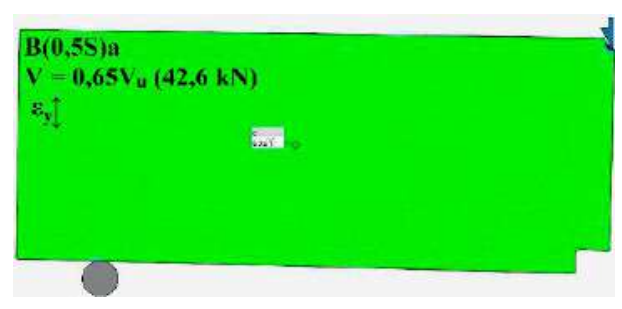

(b)

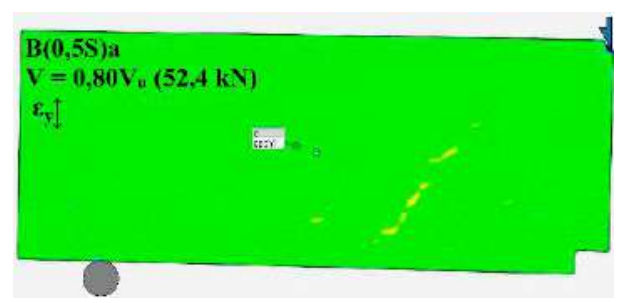

(d)

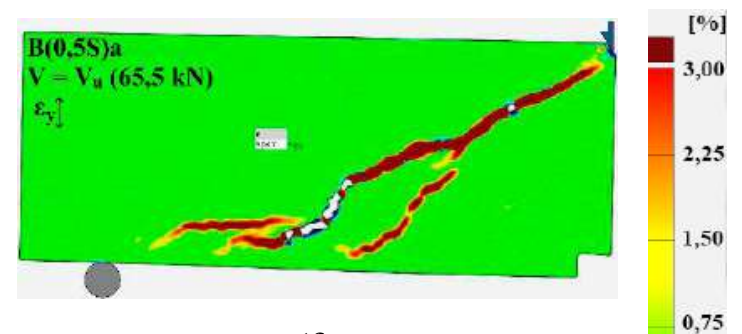

(f)

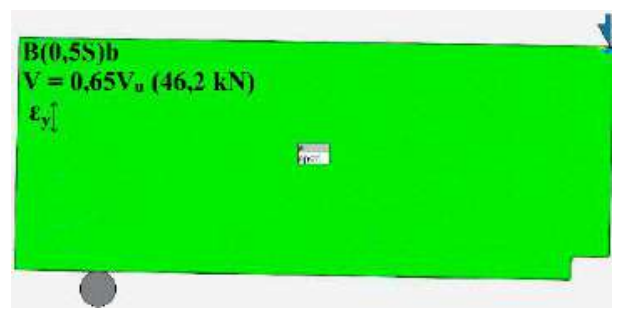

(h)

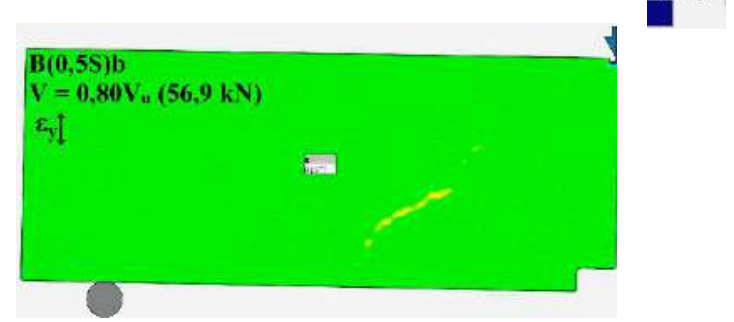

(j)

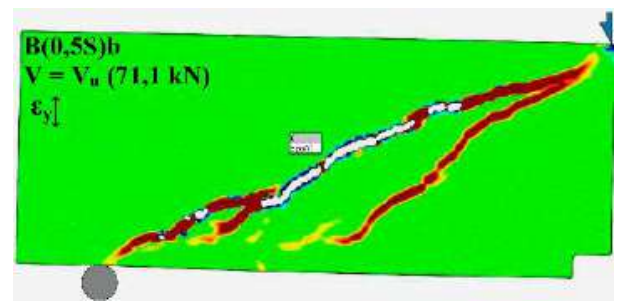

(1)

Figura 4.61 - Campo de deformação específica nas direções horizontal $\left(\varepsilon_{x}\right)$ e vertical $\left(\varepsilon_{y}\right)$ das vigas $\mathrm{B}(0,5 \mathrm{~S})$ para o estágio de carregamento $0,65 V_{u}, 0,80 V_{u}$ e $V_{u}$. 


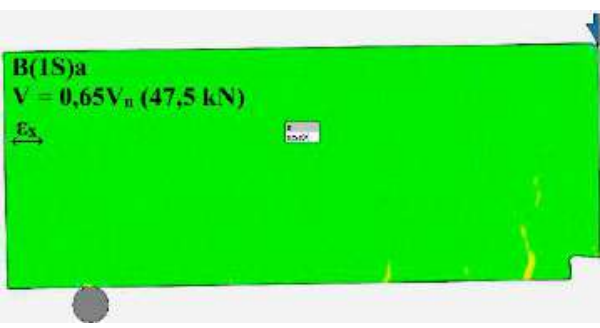

(a)

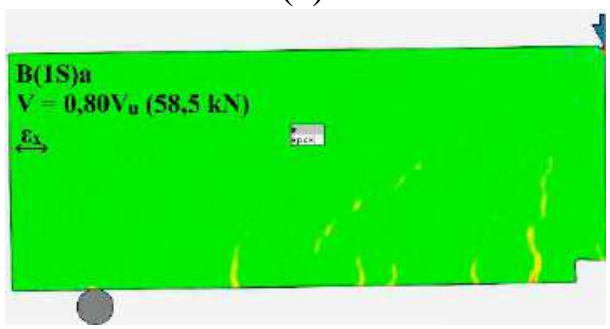

(c)

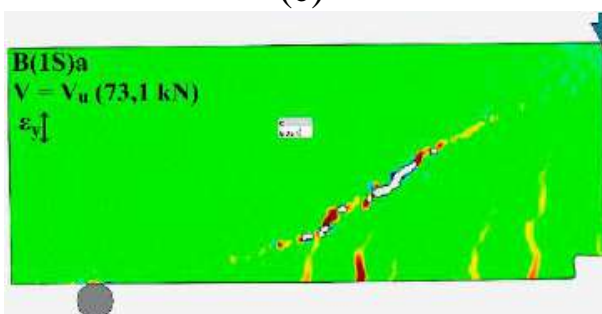

(e)

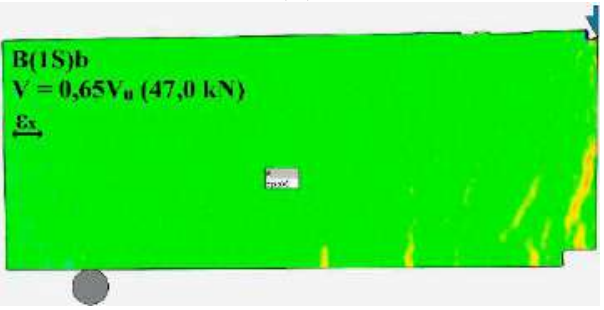

(g)

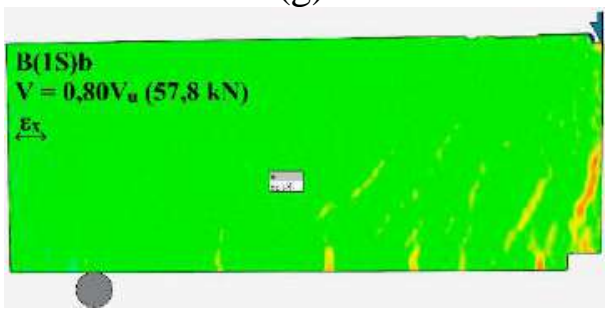

(i)

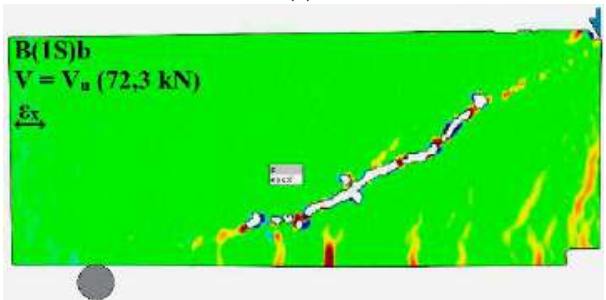

(k)

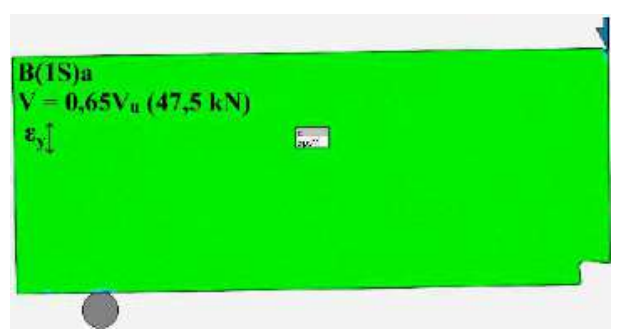

(b)

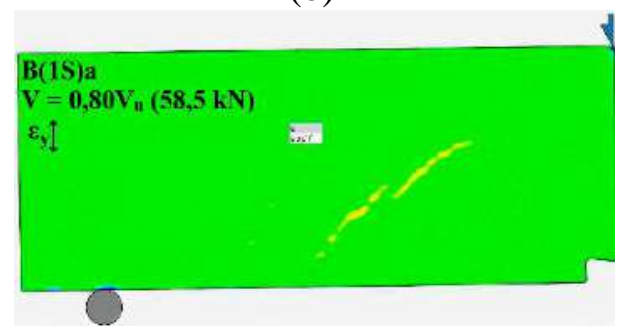

(d)

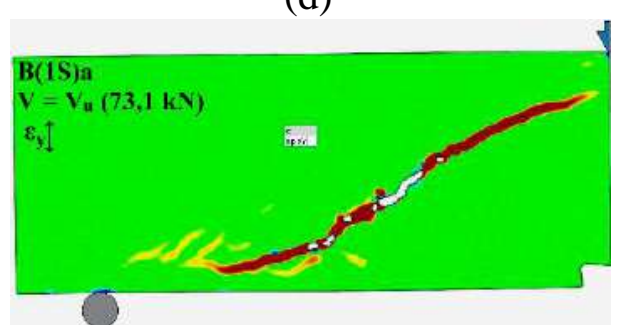

(f)

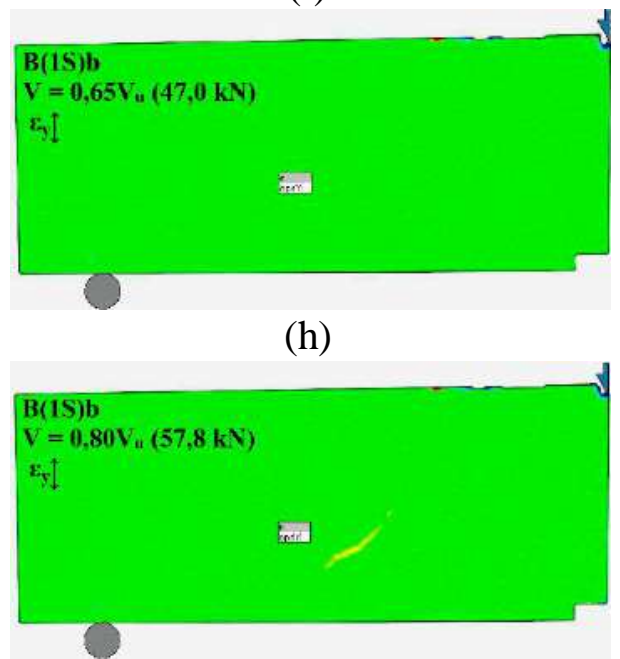

(j)

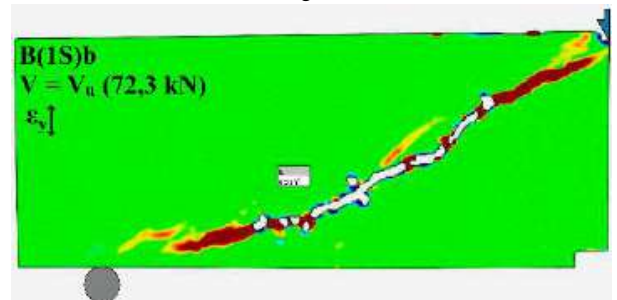

(1)

Figura 4.62 - Campo de deformação específica nas direções horizontal $\left(\varepsilon_{x}\right)$ e vertical $\left(\varepsilon_{y}\right)$ das vigas $\mathrm{B}(1 \mathrm{~S})$ para o estágio de carregamento $0,65 V_{u}, 0,80 V_{u}$ e $V_{u}$. 


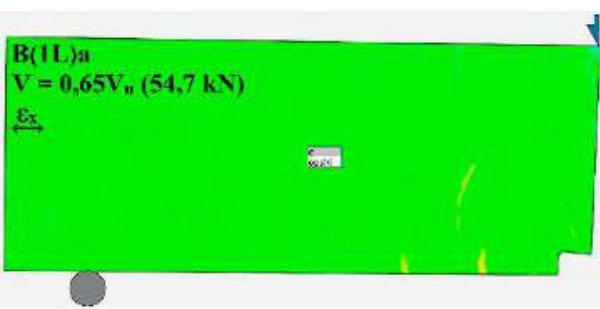

(a)

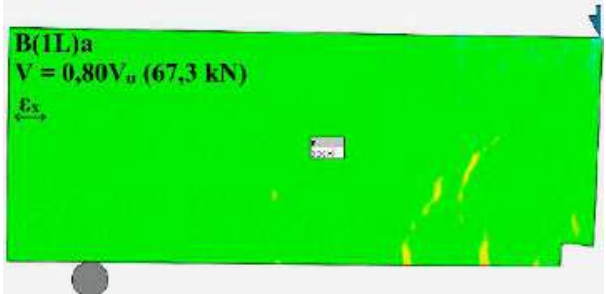

(c)

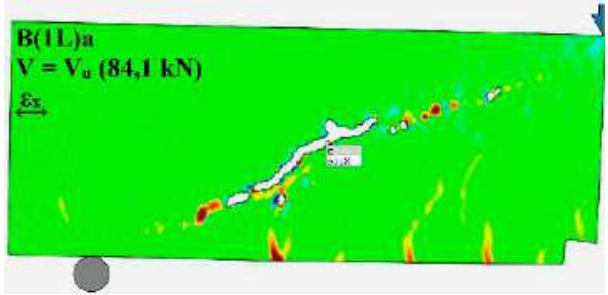

(e)

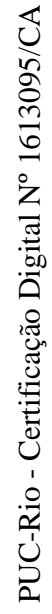

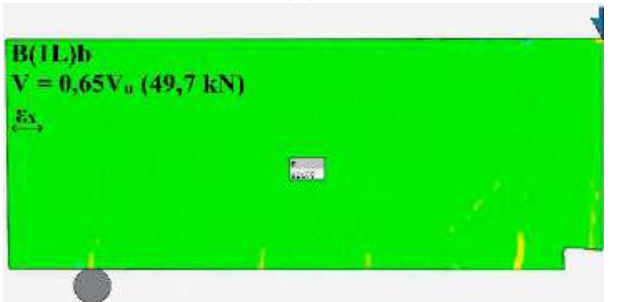

(g)

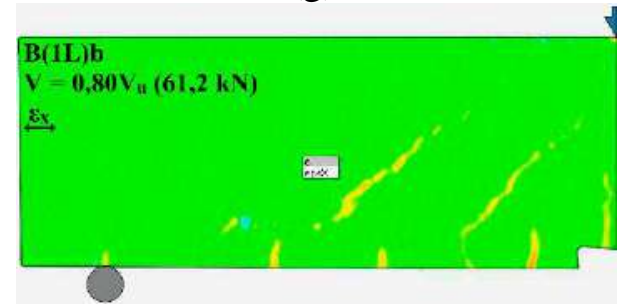

(i)

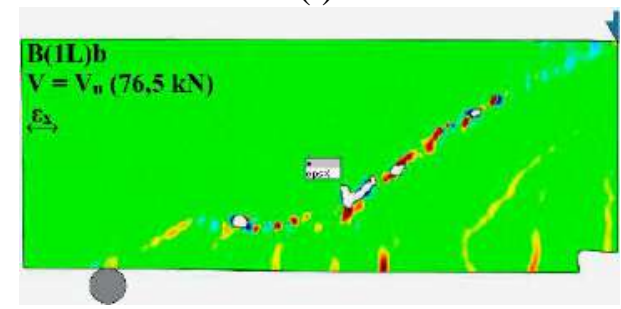

$(\mathrm{k})$

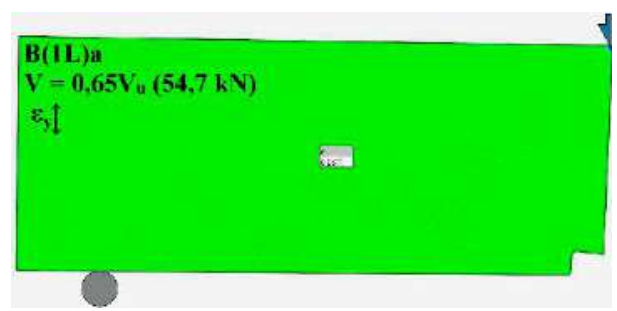

(b)

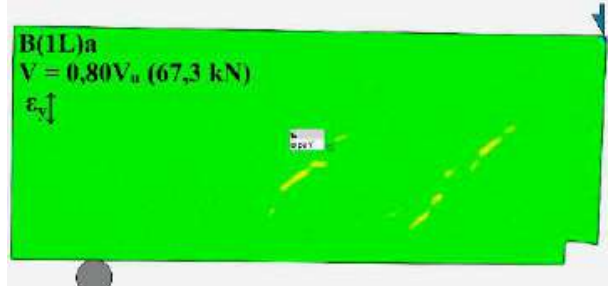

(d)

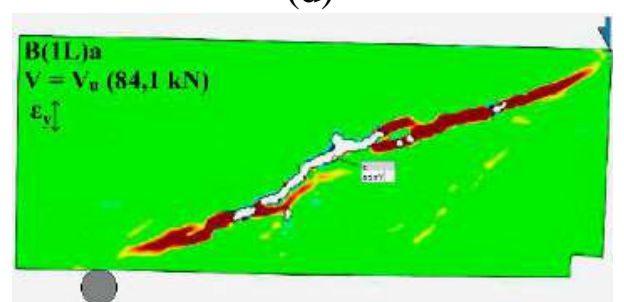

(f)

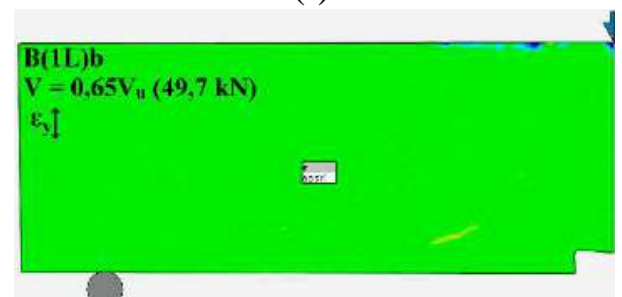

(h)

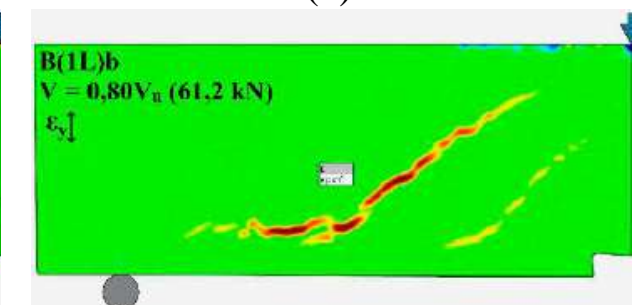

(j)

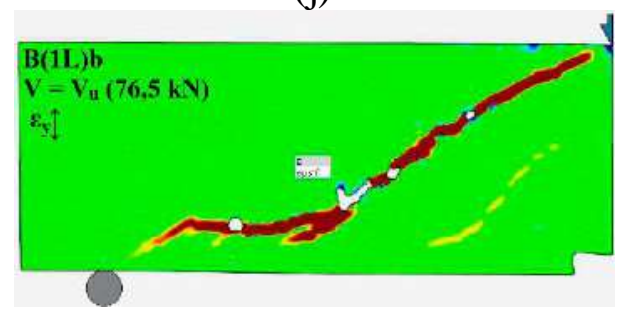

(1)

Figura 4.63 - Campo de deformação específica nas direções horizontal $\left(\varepsilon_{x}\right)$ e vertical $\left(\varepsilon_{y}\right)$ das vigas $\mathrm{B}(1 \mathrm{~L})$ para o estágio de carregamento $0,65 V_{u}, 0,80 V_{u}$ e $V_{u}$.

Com base no padrão de fissura apresentado na Figura 4.58 e nos resultados das análises fotogramétricas, chegou-se à cinemática da fissura no estágio de $V_{u}$ 
mostrada na Figura 4.64. Pode-se observar que, predominantemente, w $>\Delta$ e que não há uma tendência clara de valores de abertura e de deslizamento próximos nas vigas similares. Embora as vigas $\mathrm{B}(1 \mathrm{~S})$ sejam as que tiveram valores de $V_{u}$ mais próximos entre si $(73,1 \mathrm{kN}$ e $72,3 \mathrm{kN})$, a $\mathrm{B}(1 \mathrm{~S}) \mathrm{b}$ apresentou deslocamentos relativos entre as faces da fissura expressivamente maiores que os da $\mathrm{B}(1 \mathrm{~S}) \mathrm{a}$, que, entre todas as vigas, teve menor abertura e prolongamento de fissura no trecho 1 .

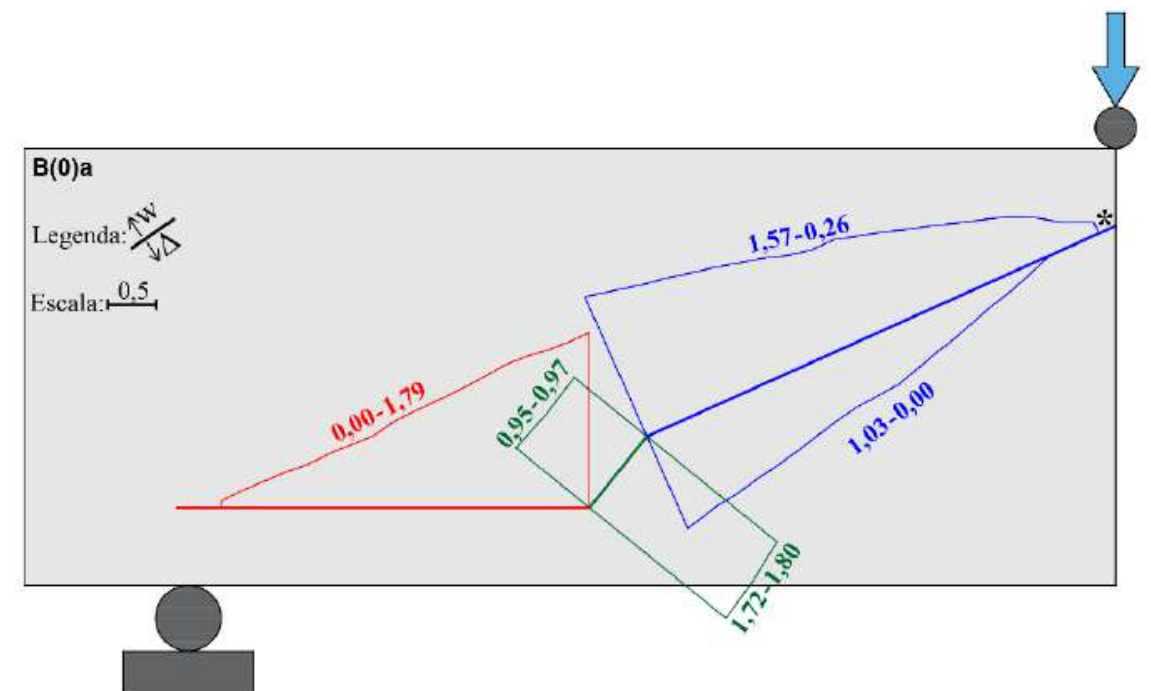

(a)

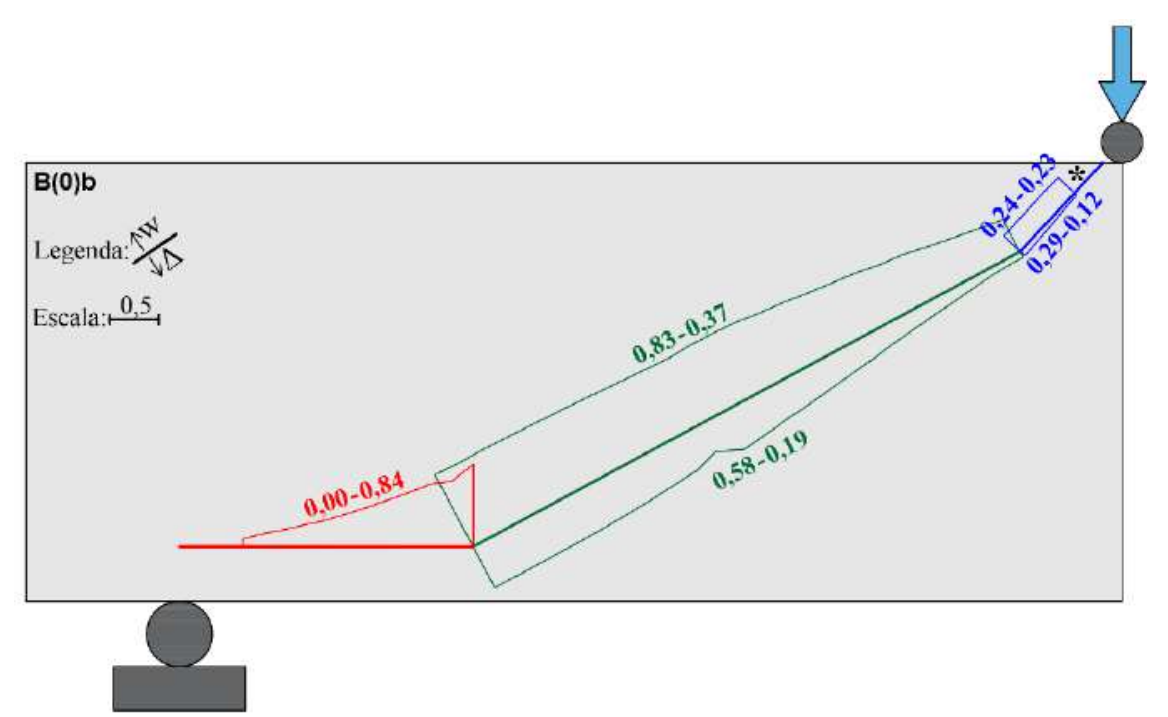

(b)

Figura 4.64 (continua) - Deslocamentos relativos, em mm, ao longo da fissura correspondentes a $V_{u}$. Abertura $(w)$ e deslizamento $(\Delta)$ da fissura representados acima e abaixo, respectivamente, da fissura (trechos retilíneos mostrados na Figura 4.38): (a) B(0)a; (b) B(0)b; (c) B(0,5S)a; (d) B(0,5S)b; (e) B(1S)a; (f) $\mathrm{B}(1 \mathrm{~S}) \mathrm{b}$; (g) B(1L)a; (h) B(1L)b. * Indica região sem possibilidade de análise dos deslocamentos. 


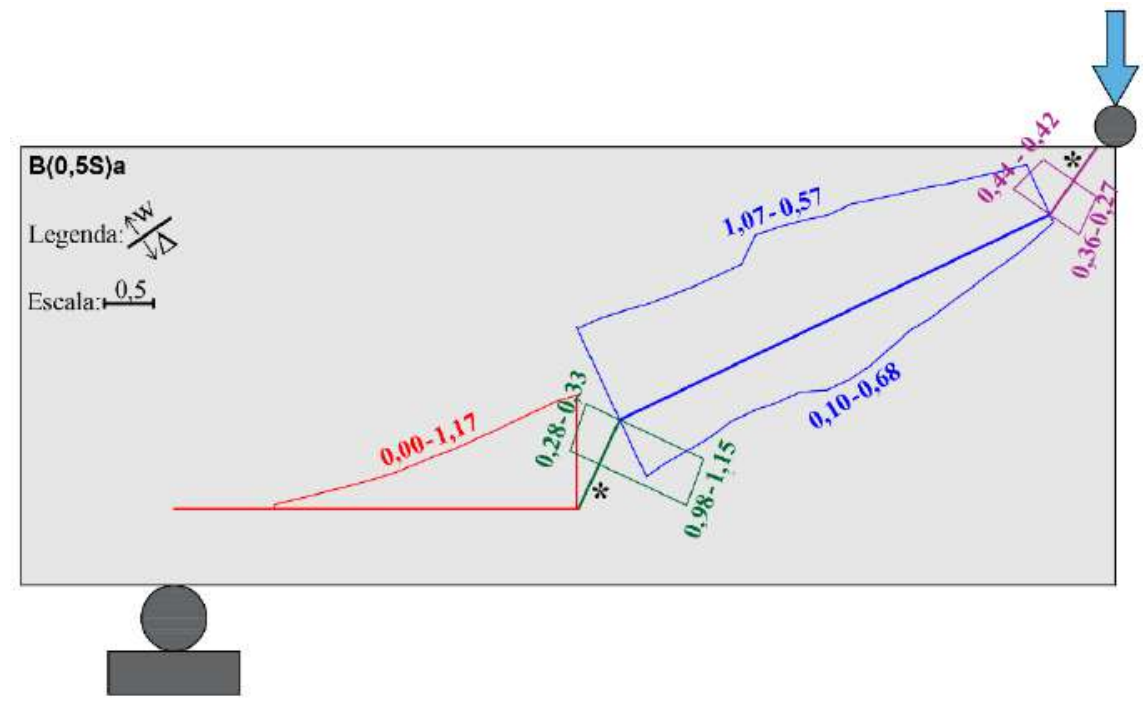

(c)

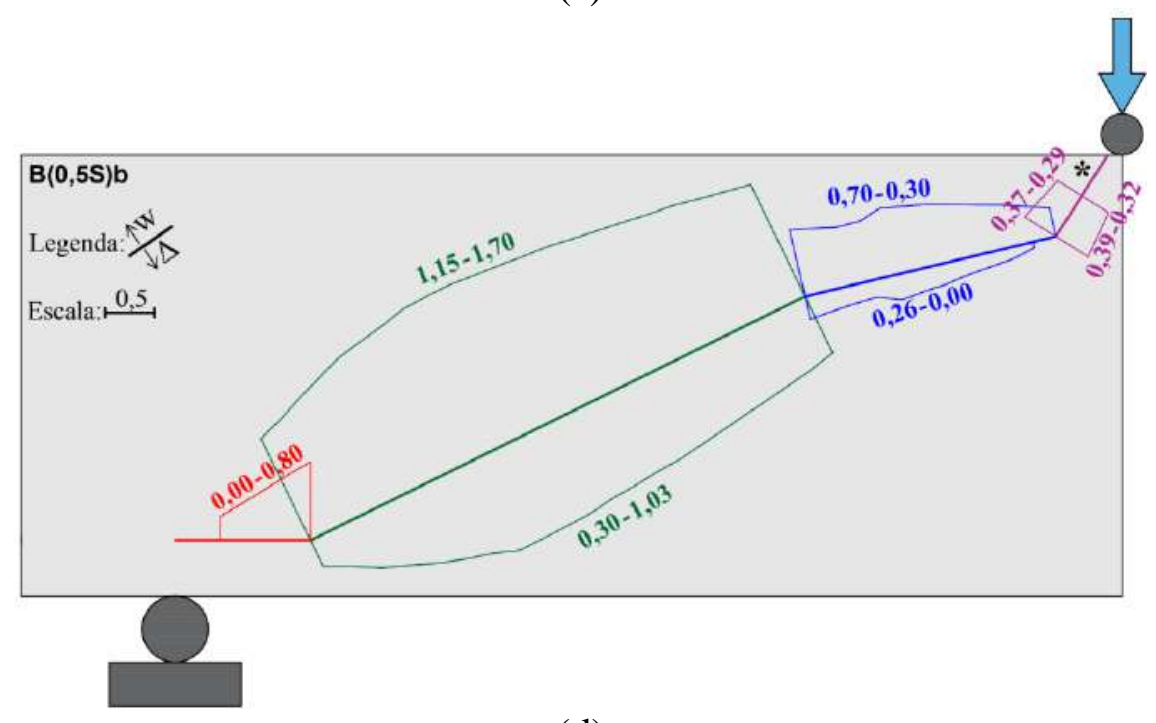

(d)

Figura 4.64 (continua) - Deslocamentos relativos, em mm, ao longo da fissura correspondentes a $V_{u}$. Abertura $(w)$ e deslizamento $(\Delta)$ da fissura representados acima e abaixo, respectivamente, da fissura (trechos retilíneos mostrados na

Figura 4.38): (a) B(0)a; (b) B(0)b; (c) B(0,5S)a; (d) B(0,5S)b; (e) B(1S)a;

(f) $\mathrm{B}(1 \mathrm{~S}) \mathrm{b}$; (g) B(1L)a; (h) B(1L)b. * Indica região sem possibilidade de análise dos deslocamentos. 


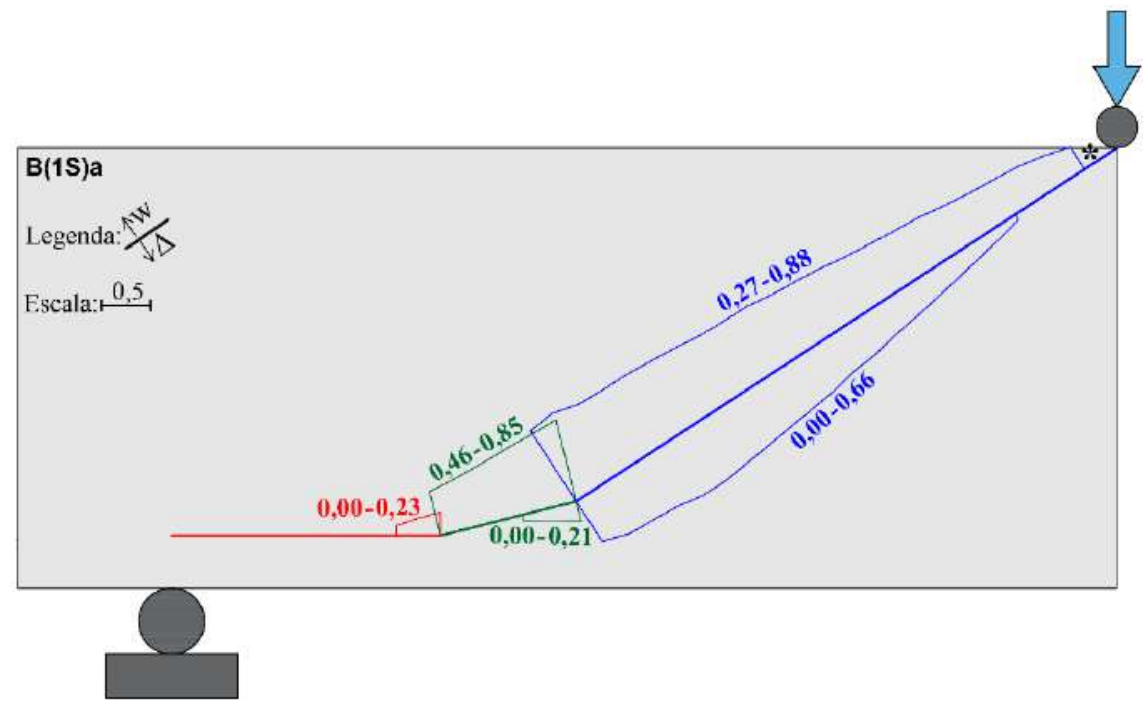

(e)

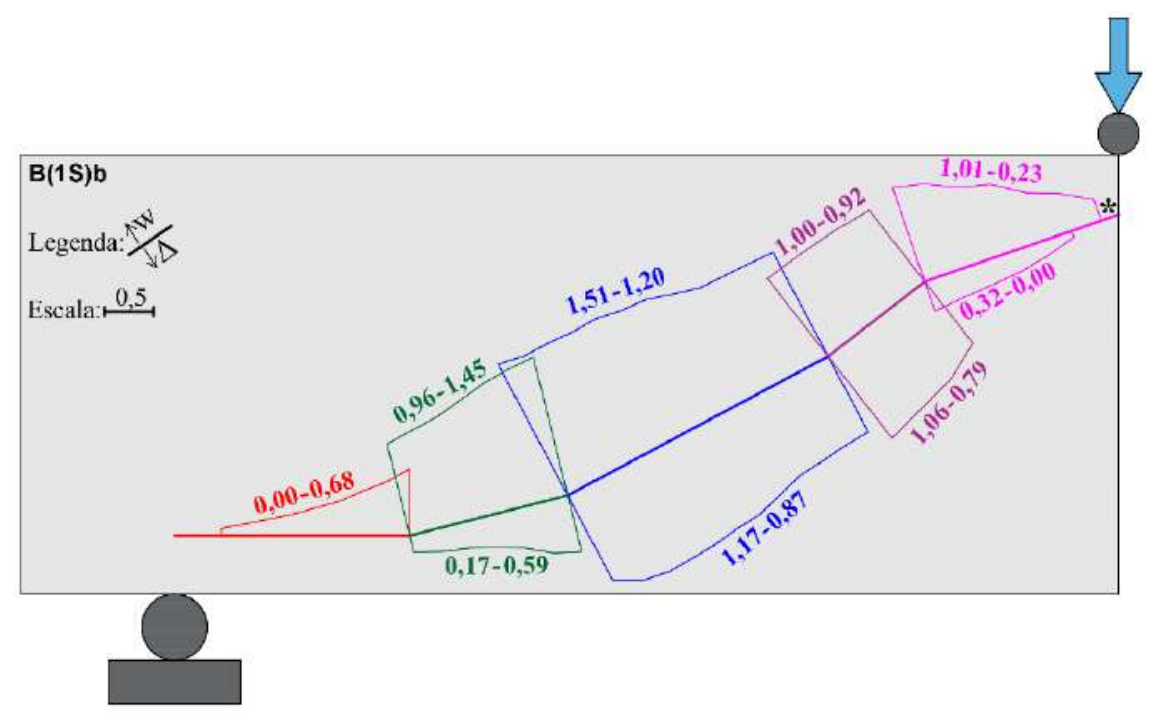

(f)

Figura 4.64 (continua) - Deslocamentos relativos, em mm, ao longo da fissura correspondentes a $V_{u}$. Abertura $(w)$ e deslizamento $(\Delta)$ da fissura representados acima e abaixo, respectivamente, da fissura (trechos retilíneos mostrados na Figura 4.38): (a) B(0)a; (b) B(0)b; (c) $\mathrm{B}(0,5 \mathrm{~S}) \mathrm{a}$; (d) $\mathrm{B}(0,5 \mathrm{~S}) \mathrm{b}$; (e) $\mathrm{B}(1 \mathrm{~S}) \mathrm{a}$; (f) $\mathrm{B}(1 \mathrm{~S}) \mathrm{b}$; (g) B(1L)a; (h) B(1L)b. * Indica região sem possibilidade de análise dos deslocamentos. 


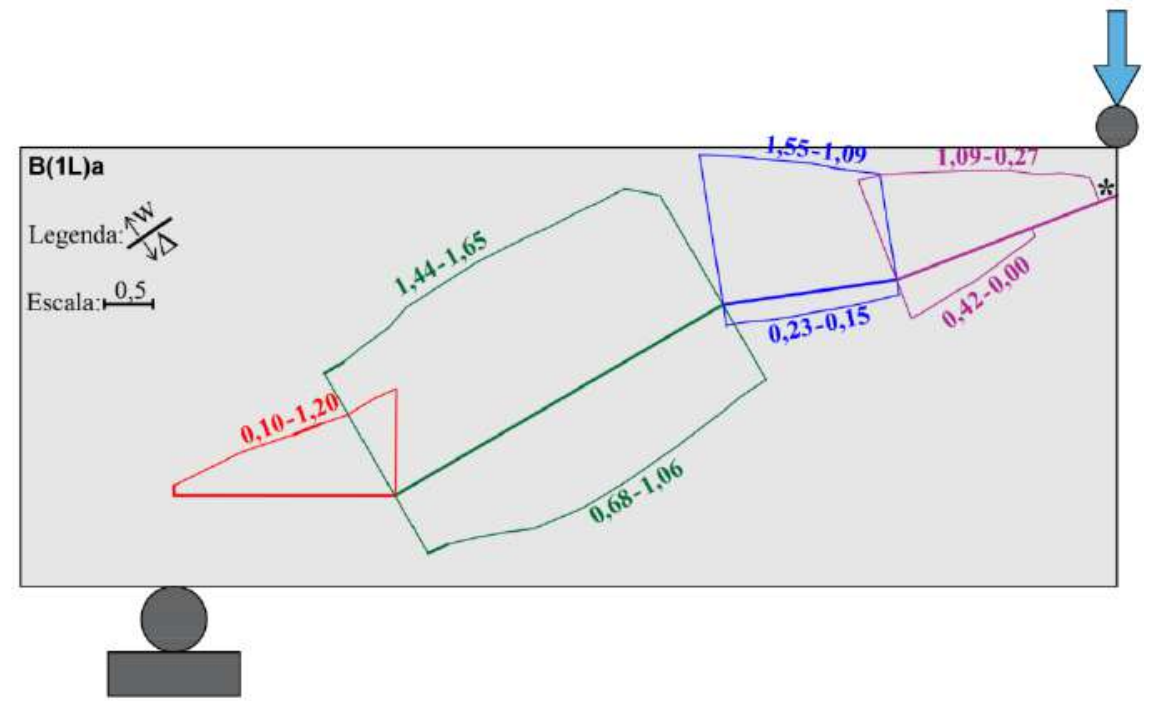

$(\mathrm{g})$

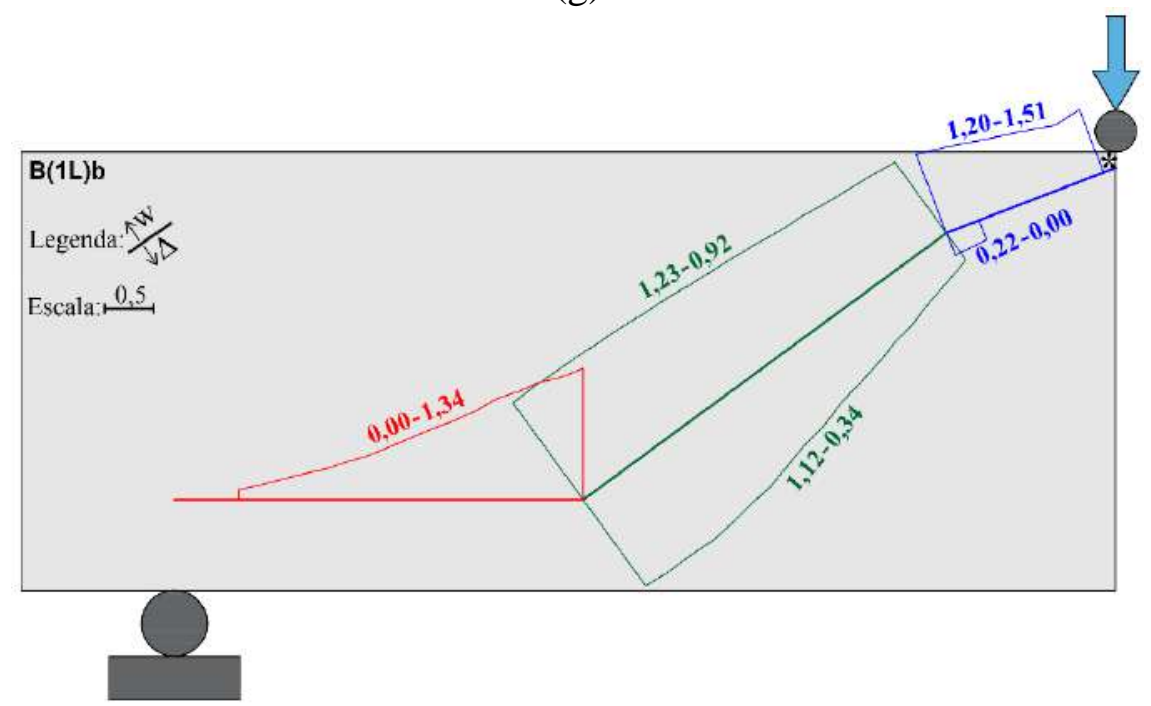

(h)

Figura 4.64 (continuação) - Deslocamentos relativos, em mm, ao longo da fissura correspondentes a $V_{u}$. Abertura $(w)$ e deslizamento $(\Delta)$ da fissura representados acima e abaixo, respectivamente, da fissura (trechos retilíneos mostrados na Figura 4.38): (a) B(0)a; (b) B(0)b; (c) B(0,5S)a; (d) B(0,5S)b; (e) B(1S)a; (f) $\mathrm{B}(1 \mathrm{~S}) \mathrm{b}$; (g) B(1L)a; (h) B(1L)b. * Indica região sem possibilidade de análise dos deslocamentos.

\subsection{2}

\section{Análises dos mecanismos resistentes}

Para a avaliação do comportamento à força cortante das vigas via seus mecanismos resistentes, foi utilizada a forma e os resultados da cinemática da fissura simplificada (Figura 4.58) e adotados os procedimentos listados a seguir. 
a) Parcela de força cortante conferida pelo efeito de pino $\left(V_{d}\right)$

Esta parcela foi calculada conforme o modelo proposto no item 4.1.2 (eq. 4.11, p. 148). A abertura de fissura de fendilhamento de controle $w_{D}$ foi tomada como sendo a abertura num segmento do trecho 1 imediatamente ao lado do encontro dos trechos 1 e 2 (Figura 4.65) e o comprimento $b$ (Figura 4.10, p. 144) foi considerado igual ao deslocamento relativo na direção horizontal no encontro desses trechos. A partir daí seguiram-se os passos descritos no final do item 4.1.2 (p. 148).

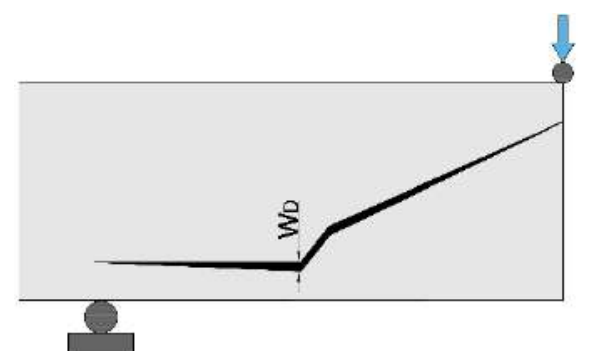

Figura 4.65 - Posição da abertura de fissura $w_{D}$ nas vigas.

b) Parcela de força cortante conferida pelo engrenamento dos agregados $\left(V_{a g}\right)$

Esta parcela foi obtida pela eq. 4.41 (Figura 4.66):

$$
V_{a g}=b_{w}\left[\int_{0}^{l_{c r}} \tau_{r} \operatorname{sen}\left(\alpha_{c r}\right) d l-\int_{0}^{l_{c r}} \sigma_{r} \cos \left(\alpha_{c r}\right) d l\right]
$$

onde

$b_{w}$ é a largura da alma da viga

$\tau_{\mathrm{r}}$ (eq. 4.21, p. 176) e $\sigma_{\mathrm{r}}$ (eq. 4.20, p. 176) são, respectivamente, as tensões de cisalhamento e normal referentes ao engrenamento dos agregados, conforme proposto no item 4.2.3.

$\alpha_{c r}$ é o ângulo entre o segmento $d l$ analisado e o eixo longitudinal da viga $l_{c r}$ comprimento total do trecho da fissura analisado. 


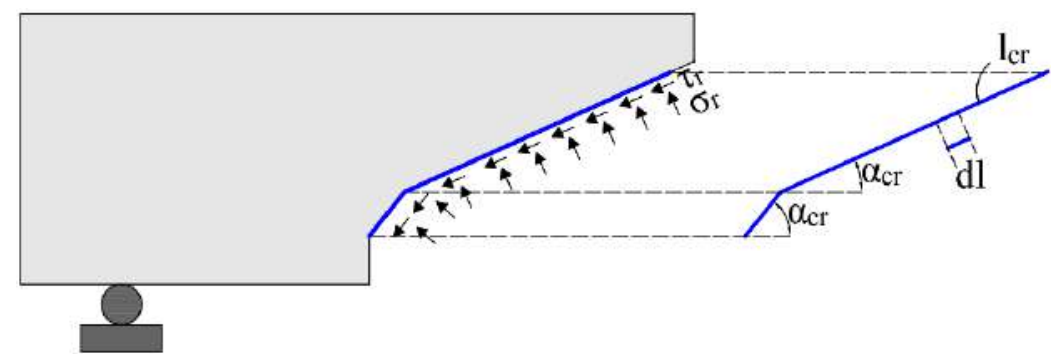

Figura 4.66 - Tensões de cisalhamento e normal resistentes correspondentes ao engrenamento dos agregados nas vigas.

c) Parcela de força cortante conferida pelas fibras $\left(V_{f i b}\right)$

Esta parcela foi obtida pela eq. 4.42 (Figura 4.67):

$$
V_{f i b}=b_{w}\left[\int_{0}^{l_{c r}} \tau_{f} \operatorname{sen}\left(\alpha_{c r}\right) d l+\int_{0}^{l_{c r}} \sigma_{f} \cos \left(\alpha_{c r}\right) d l\right]
$$

onde

$b_{w}$ é a largura da alma da viga

$\sigma_{\mathrm{f}}$ (eq. 4.30 , p. 183 ) e $\tau_{\mathrm{f}}$ (eq. 4.31 , p. 183) são, respectivamente, as tensões normal e de cisalhamento conferidas pelas fibras, conforme proposto no item 4.2.3. $\alpha_{c r}$ é o ângulo entre o segmento $d l$ analisado e o eixo longitudinal da viga $l_{c r}$ comprimento total do trecho da fissura analisado.

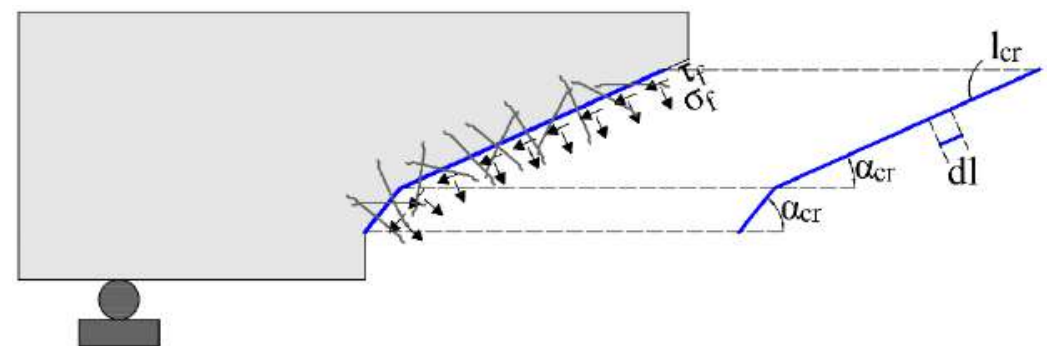

Figura 4.67 - Tensões de cisalhamento e normal correspondentes ao efeito das fibras nas vigas.

Diferentemente dos experimentos nos espécimes do tipo pushoff, em que houve uma definição prévia do plano de ruptura, a região de formação e desenvolvimento da fissura crítica nas vigas é livre para seguir o caminho de menor resistência do material. Portanto, é razoável de se esperar que a quantidade de fibras por $\mathrm{mm}^{2}\left(\eta_{\mathrm{f}}\right)$ seja inferior a um valor médio de sua distribuição e, portanto, menor do que o valor adotado para os espécimes pushoff. Para levar isto em consideração, 
foi considerado um valor inferior a $\eta_{\mathrm{f}}$, denominado $\eta_{\mathrm{f}, \text { viga. }} \mathrm{O}$ valor de $\eta_{\mathrm{f}, \text { viga }}=0,5 \eta_{\mathrm{f}}$ foi escolhido para uma melhor correlação com os resultados experimentais.

d) Parcela de força cortante conferida pelo concreto comprimido não fissurado $\left(V_{c z}\right)$

Para estimar $V_{c z}$, foi adotada a eq. 4.43 (item 2.2.4, p. 77), obtida a partir da distribuição de tensão de cisalhamento de Mörsch (1909). Além de simples, análises da literatura indicaram ser ela capaz de levar a uma boa estimativa de $V_{c z}$ (Sherwood, 2008).

$$
V_{c z}=\frac{2}{3} \frac{h_{c z}}{\left(d-\frac{h_{c z}}{3}\right)} V
$$

onde

$h_{c z}$ é a altura do concreto comprimido não fissurado medida junto à seção transversal de aplicação de carga (análise fotogramérica)

$d$ altura útil

$V$ força cortante experimental no estágio analisado

e) Parcela de força cortante conferida pela resistência à tração residual do concreto $\left(V_{\text {res }}\right)$

Esta parcela foi obtida pela eq. 4.44 (Figura 4.68):

$V_{\text {res }}=b_{w} \int_{0}^{l_{c r}} \sigma_{r e s} \cos \left(\alpha_{c r}\right) d l$

sendo $\sigma_{\text {res }}$ a resistência à tração residual do concreto.

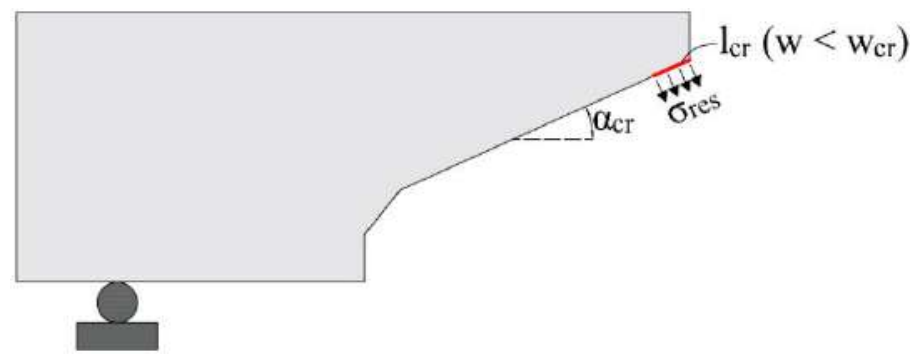

Figura 4.68 - Resistência à tração residual do concreto na fissura crítica das vigas $\left(w<w_{c r}\right)$. 
Dentre as equações de $\sigma_{\text {res }}$ apresentadas na revisão da literatura (item 2.2.3, p. 73), foi escolhida a de Hordijk (1992). Em geral, para uma determinada abertura de fissura, ela leva a valor de $\sigma_{\text {res }}$ intermediário entre os obtidos usando as outras equações da literatura listadas (Figura 2.41a, p. 76), e tem sido usual sua adoção para análises do comportamento à força cortante de vigas de concreto (Campana et al., 2013, Huber et al., 2016; Cavagnis et al., 2018a). Para estimar a energia de fratura $\left(\mathrm{G}_{\mathrm{F}}\right)$, parâmetro utilizado para obter $\sigma_{\text {res, }}$, foi utilizada a formulação do FIB MC 2010 (2013) (Quadro 2.2, p. 75), obtendo-se valor de $w_{c r}$ em torno de 0,24 mm para os concretos das vigas. Considerou-se que as fibras só seriam ativadas quando $w>w_{c r} \mathrm{e}$, por conta disso, adotou-se o mesmo procedimento para todas as vigas.

Em nenhum dos trechos de fissura analisados considerou-se simultaneamente as contribuições $V_{\text {res }}$ e $V_{a g}$ ou $V_{\text {res }}$ e $V_{f i b}$. Levou-se em conta $V_{\text {res }}$ somente se $w<w_{c r}$, caso contrário, considerou-se $V_{a g}$, e contabilizou-se $V_{f i b}$ apenas quando $w>w_{c r}$.

Com as equações para avaliar a contribuição de cada mecanismo resistente definidas, pôde-se obter a força cortante resistente da viga $\left(V_{R}\right)$ :

$$
V_{R}=V_{d}+V_{a g}+V_{f i b}+V_{c z}+V_{r e s}
$$

Nas vigas sem fibras, observou-se que a soma das parcelas dos mecanismos resistentes pós-formação da fissura crítica não foi capaz de descrever satisfatoriamente o comportamento experimental, havendo, em geral, subavaliação da força cortante, como mostrado na Figura 4.69 para a viga B(0)a. Posição e desenvolvimento da fissuração dessas vigas, para $V<V_{u}$, se deram sempre abaixo de uma linha fictícia ligando as seções de aplicação de carga e de apoio (linha vermelha na Figura 4.70), levando a crer em alguma transferência direta de força para o apoio, o que dificulta a análise comparativa entre a força cortante experimental e a resistida via os mecanismos resistentes considerados (Figura 4.69). Já nas vigas com fibras, a proximidade dos valores de $V_{R}$ e $V$ ao longo do ensaio leva a crer que a transferência direta de força para o apoio nestes elementos foi menos relevante. 


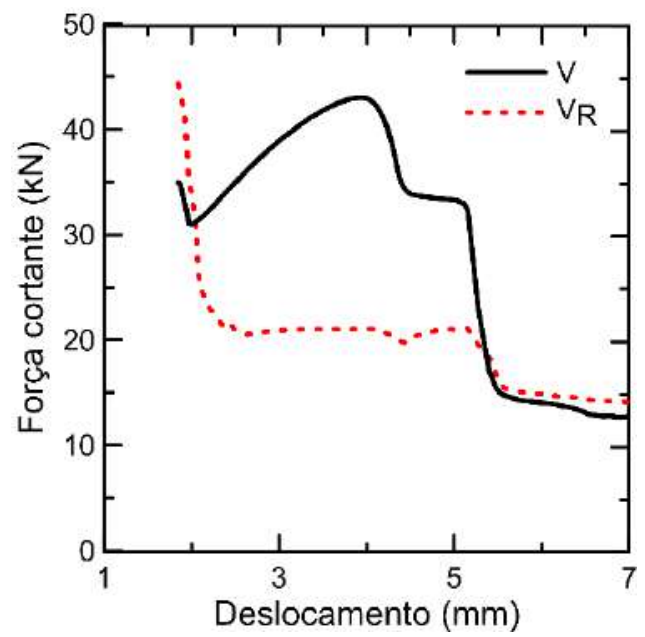

Figura 4.69 - Curva força cortante experimental $(V)$ e resistente $\left(V_{R}\right.$, eq.4.45) da viga $\mathrm{B}(0)$ a versus seu deslocamento vertical.

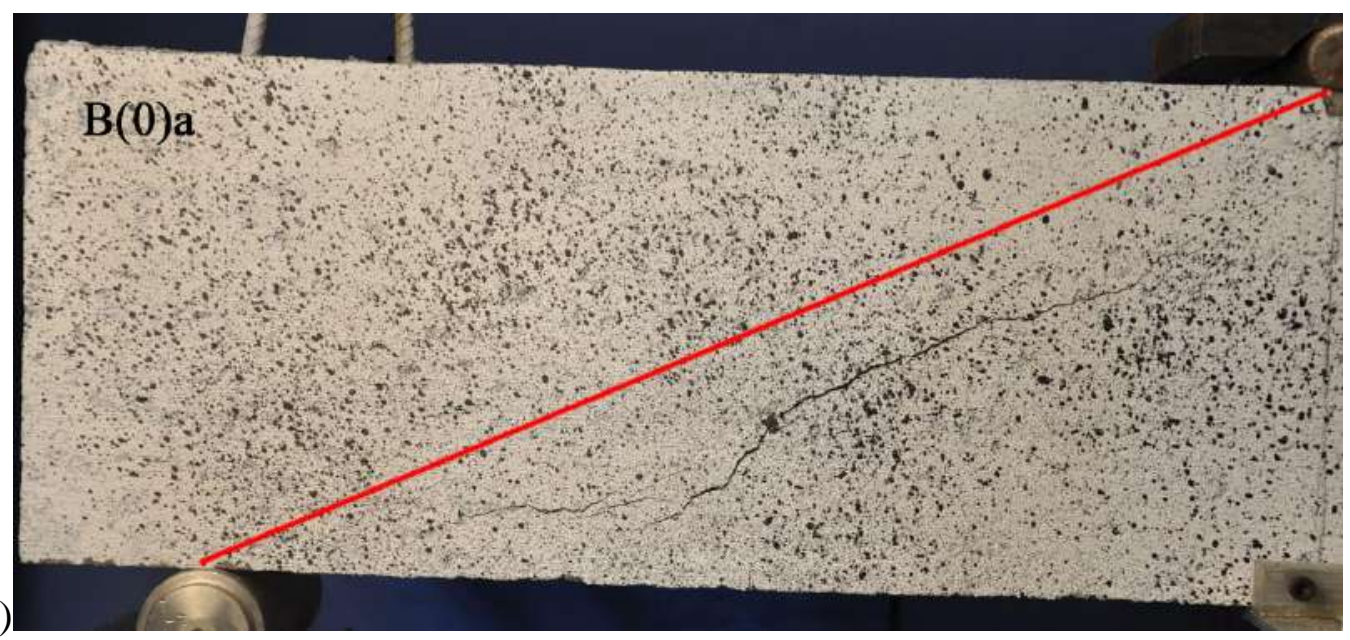

(a)

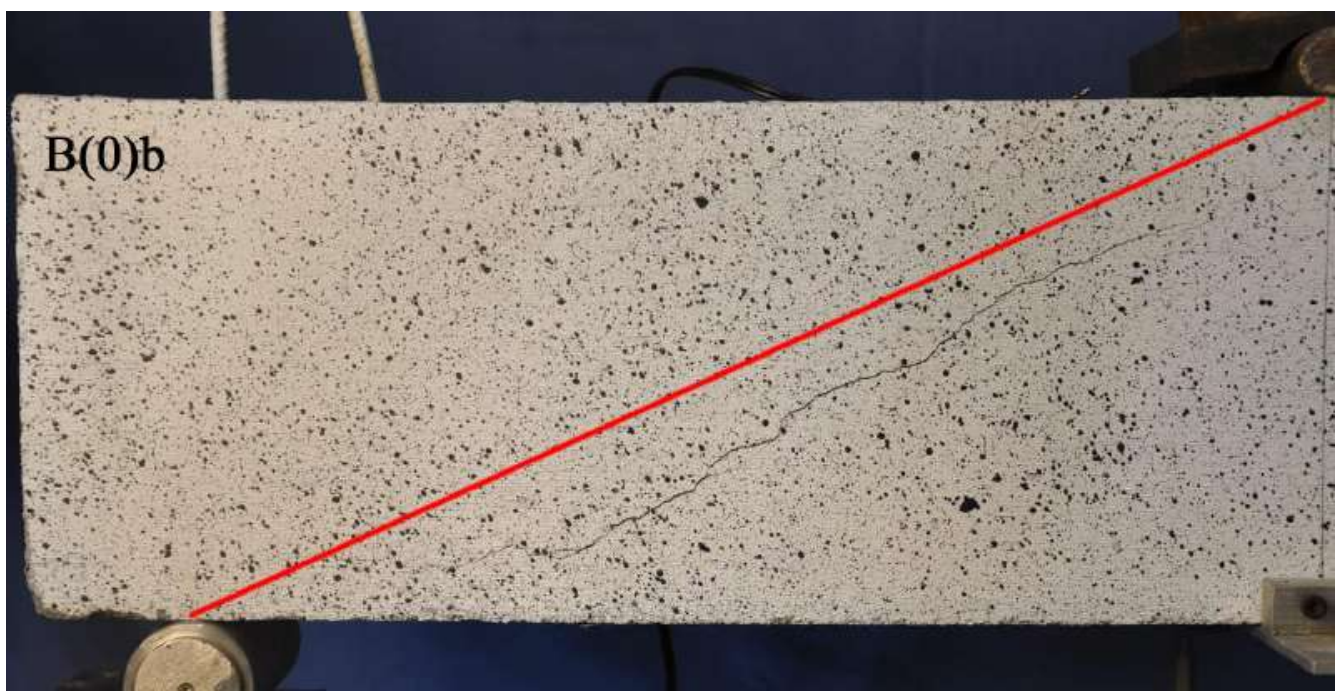

(b)

Figura 4.71 - Imagem das vigas sem fibras sob a atuação de $V$ próximo a $V_{u} \mathrm{com}$ uma linha vermelha ligando as seções de apoio e de aplicação de carga: (a) B(0)a;

(b) $\mathrm{B}(0) \mathrm{b}$. 
Para o melhor entendimento das contribuições dos mecanismos resistentes ao longo dos estágios de carregamento das vigas com fibras, considerou-se, além do seu somatório (eq. 4.45), cada uma delas em separado. Isto é mostrado nas Figuras 4.72 a 4.77 , que relacionam força cortante e deslocamento.

Na Figura 4.78 é mostrada a contribuição de cada mecanismo resistente em relação à força cortante da viga $\left(V_{i} / V\right)$ entre o início da fissura crítica $\left(V_{c r}\right)$ e a ruptura da viga $\left(V_{u}\right)$. O valor de $V_{c r}$ para cada viga é o menor dos valores de $V$ para ela listados na Tabela 4.7. Por fim, a faixa de variação de todas as relações $V_{i} / V$ observadas na Figura 4.78 são agrupadas por tipo de mecanismo resistente e apresentadas na Figura 4.79. 


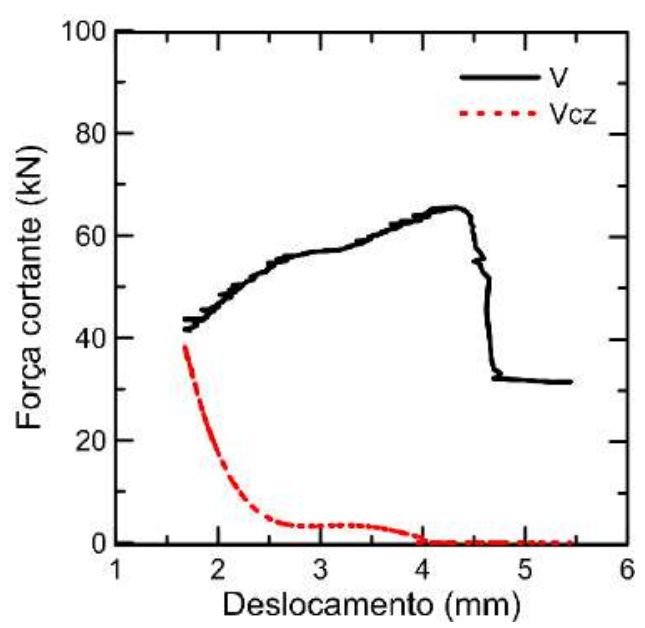

(a)

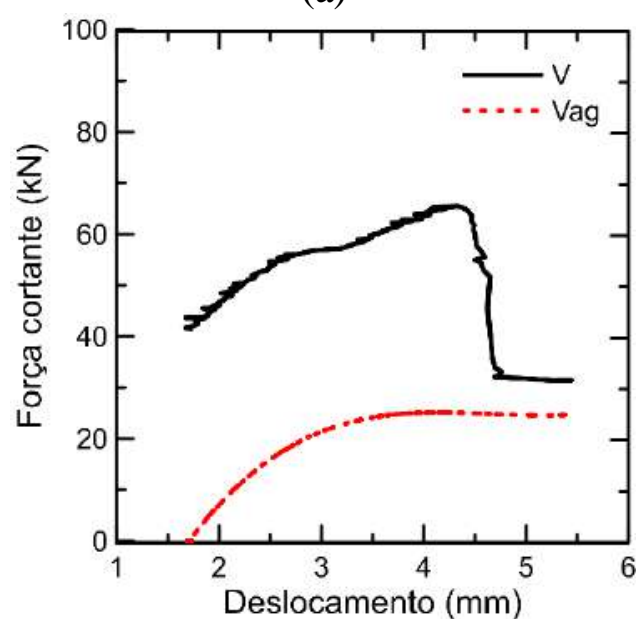

(c)

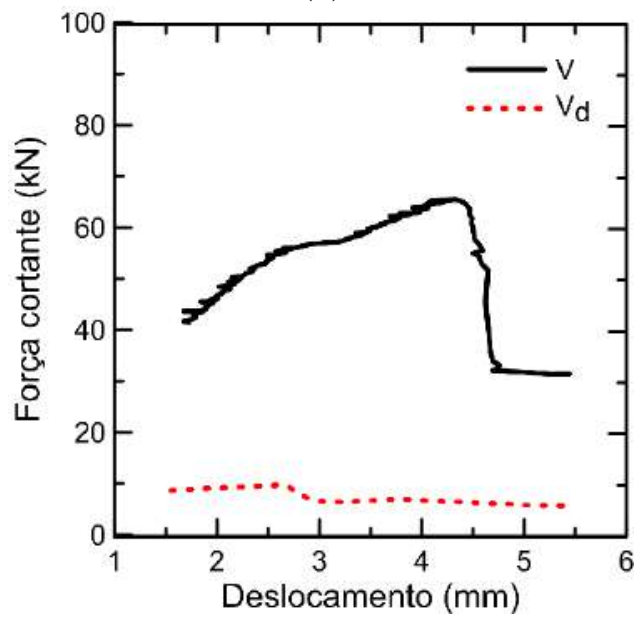

(e)

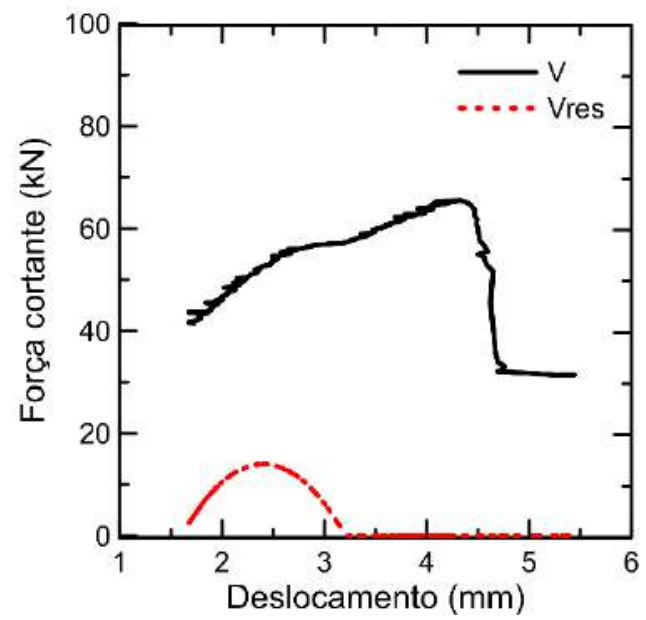

(b)

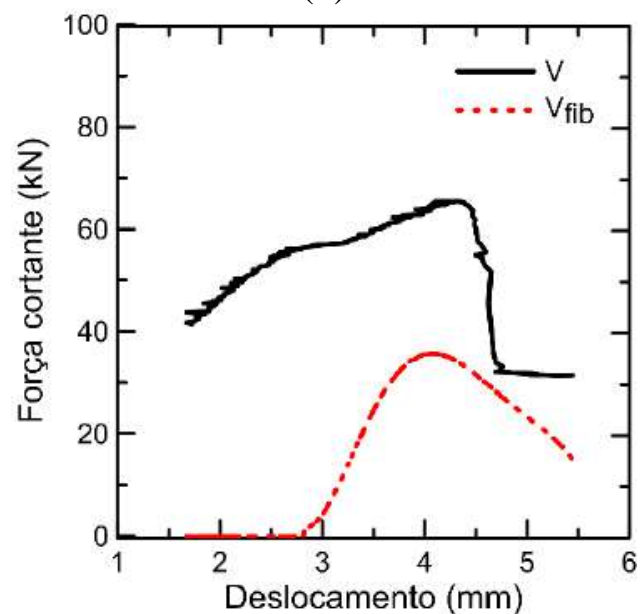

(d)

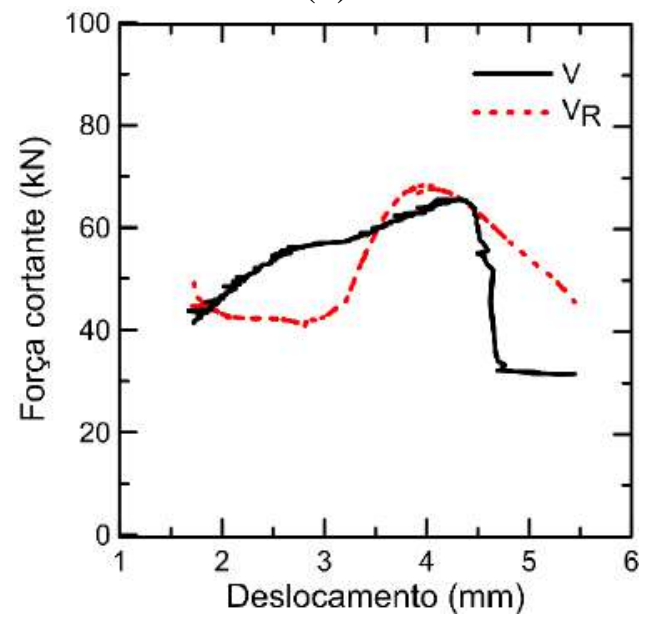

(f)

Figura 4.72 - Curva força cortante experimental $(V)$ ou contribuição dos mecanismos resistentes versus deslocamento vertical da viga $\mathrm{B}(0,5 \mathrm{~S}) \mathrm{a}\left((\mathrm{a}) V_{c z}\right.$;

(b) $V_{r e s}$; (c) $V_{a g}$; (d) $V_{f i b}$; (e) $V_{d}$; e (f) $V_{R}$ ). 


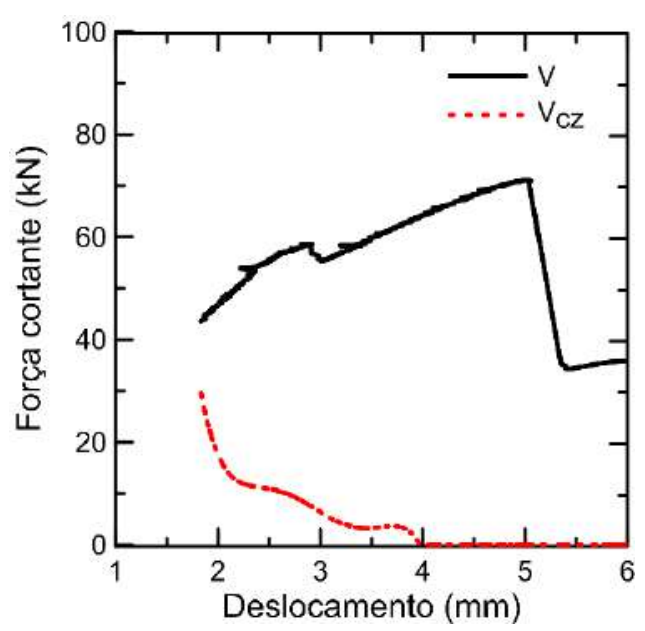

(a)

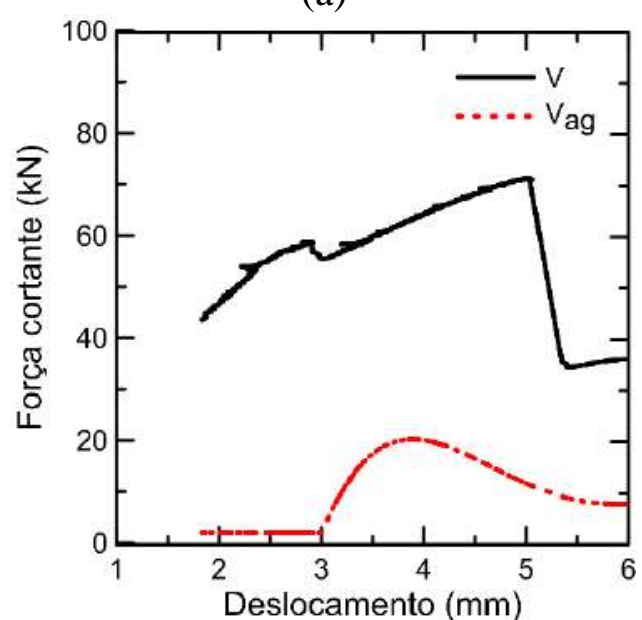

(c)

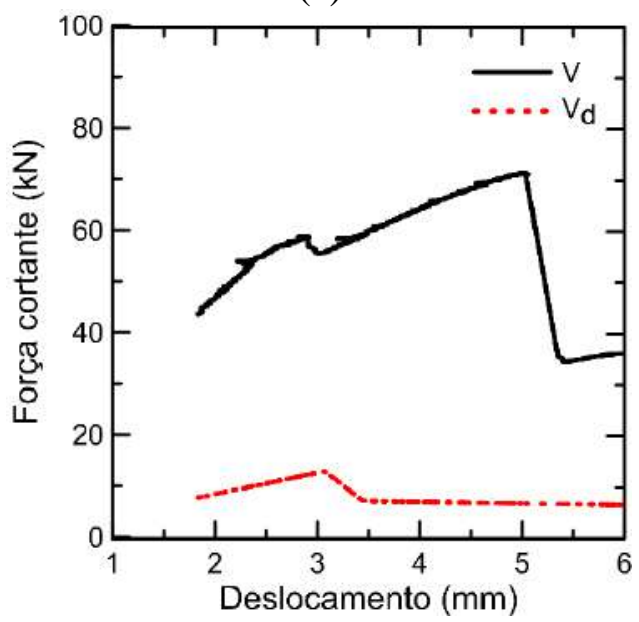

(e)

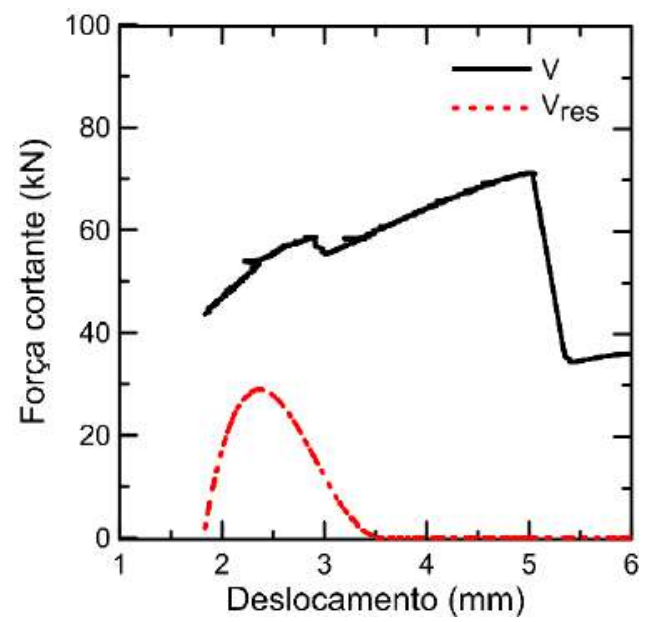

(b)

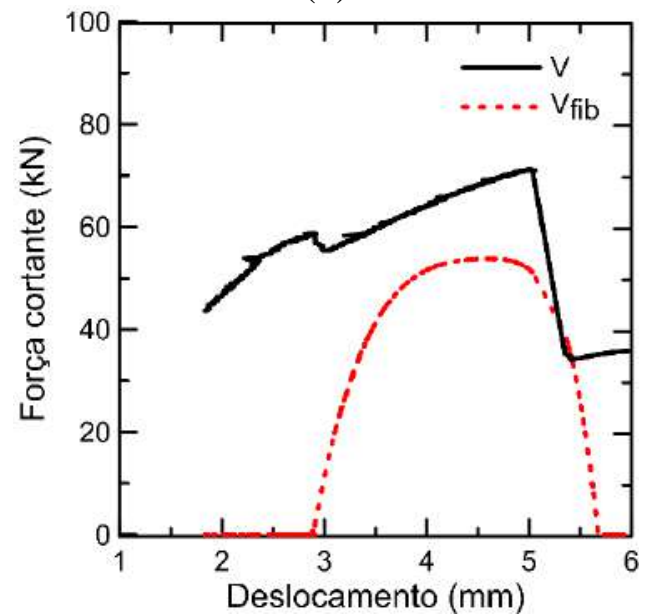

(d)

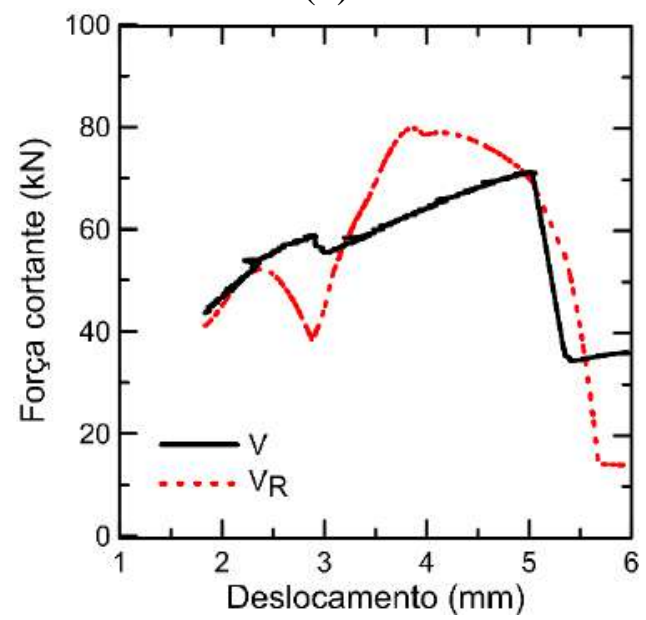

(f)

Figura 4.73 - Curva força cortante experimental $(V)$ ou contribuição dos mecanismos resistentes versus deslocamento vertical da viga $\mathrm{B}(0,5 \mathrm{~S}) \mathrm{b}\left((\mathrm{a}) V_{c z}\right.$; (b) $V_{r e s}$; (c) $V_{a g}$; (d) $V_{f i b}$; (e) $V_{d}$; e (f) $V_{R}$ ). 

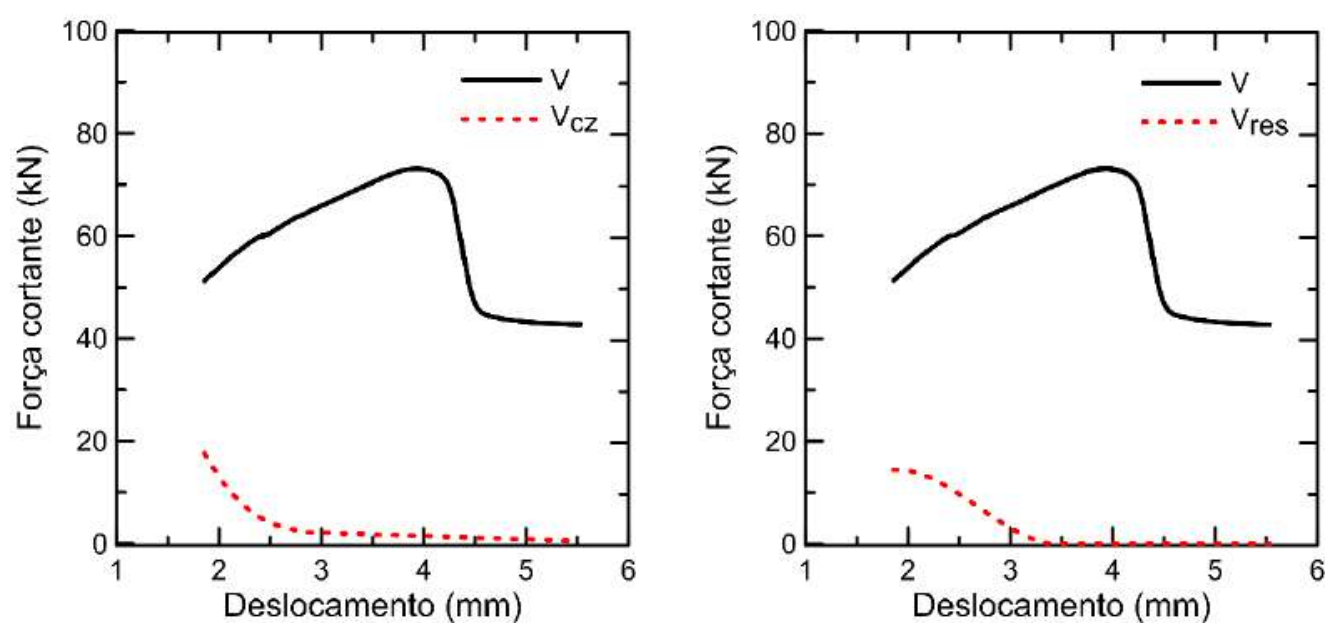

(a)

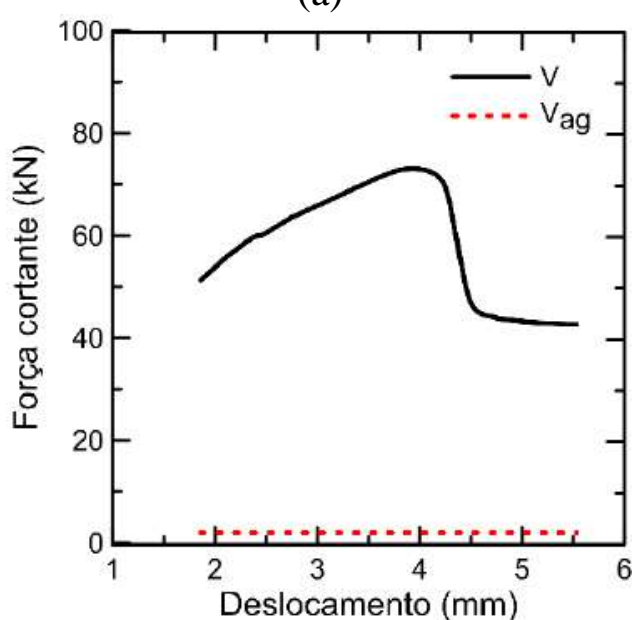

(c)

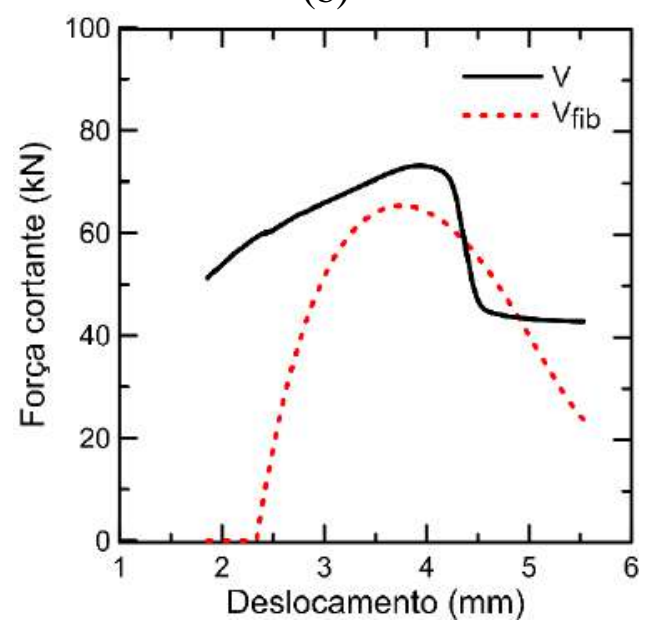

(d)

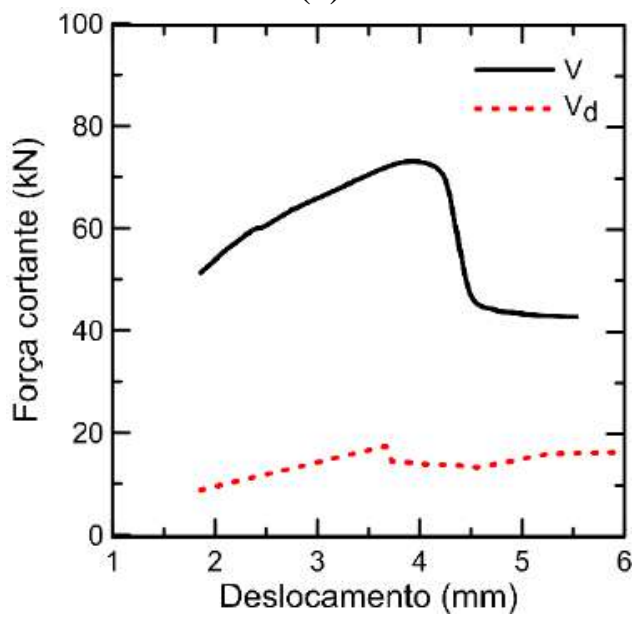

(e)

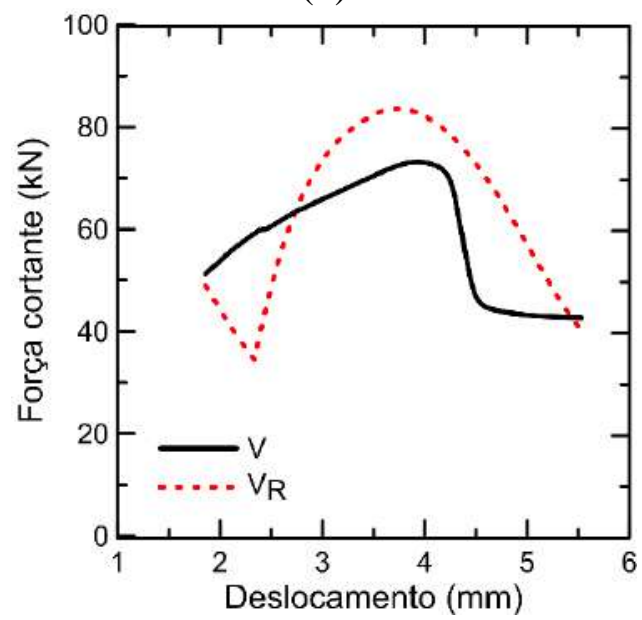

(f)

Figura 4.74 - Curva força cortante experimental $(V)$ ou contribuição dos mecanismos resistentes versus deslocamento vertical da viga $\mathrm{B}(1 \mathrm{~S})$ a ((a) $V_{c z}$; (b) $V_{r e s}$; (c) $V_{a g}$; (d) $V_{f i b}$; (e) $V_{d}$; e (f) $V_{R}$ ). 


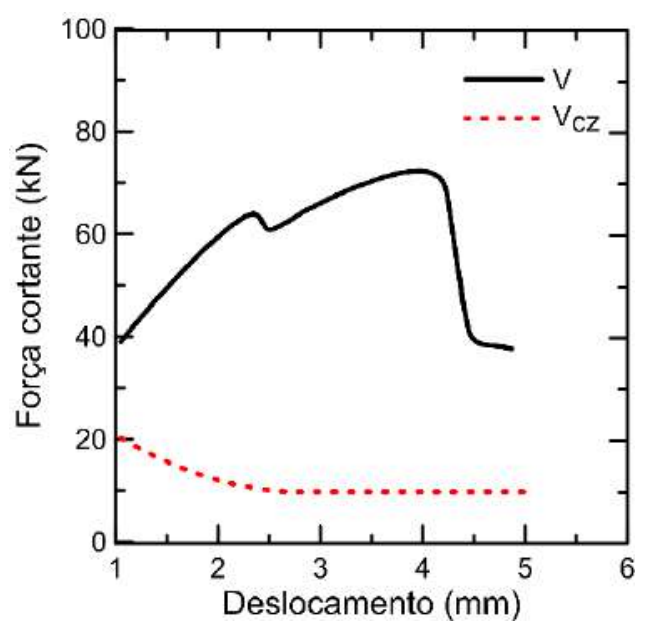

(a)

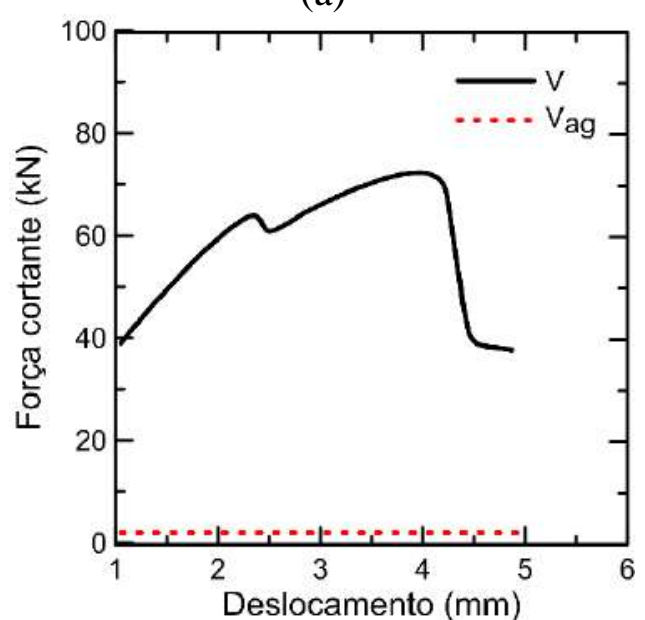

(c)

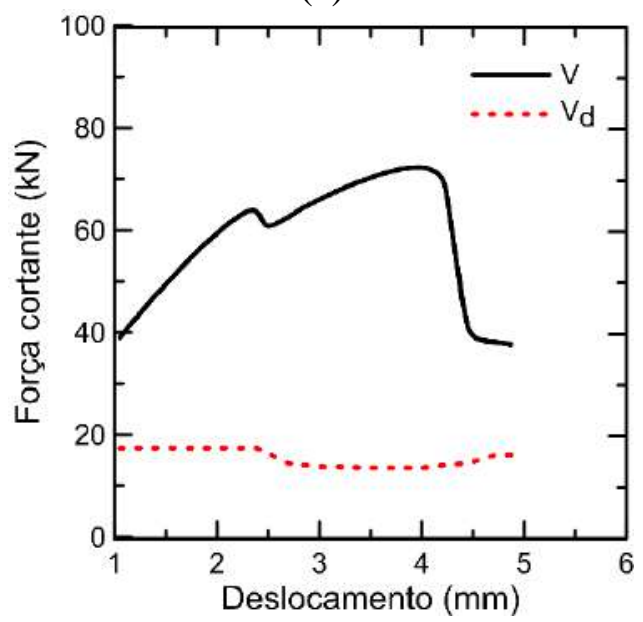

(e)

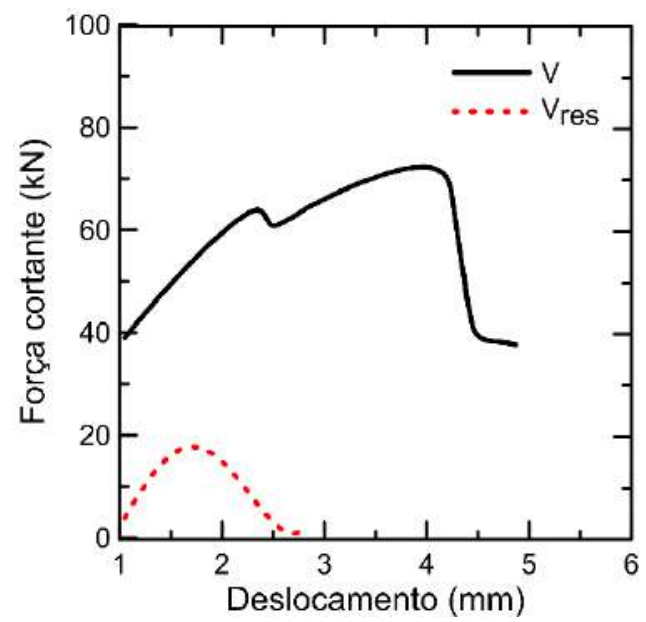

(b)

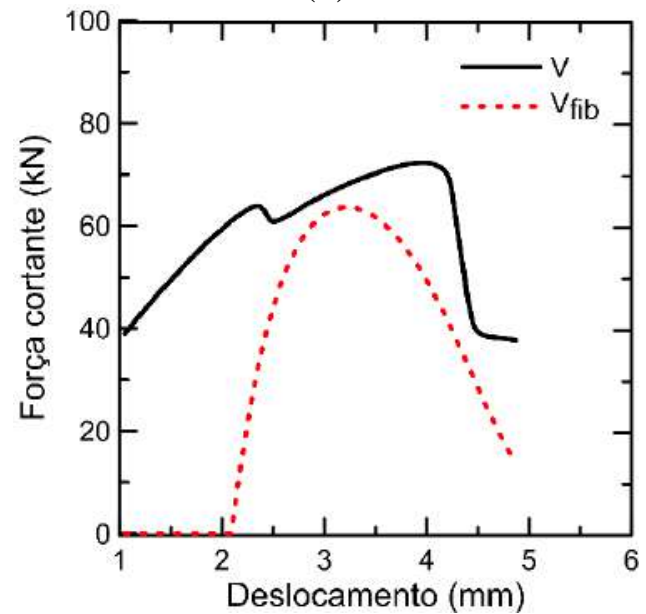

(d)

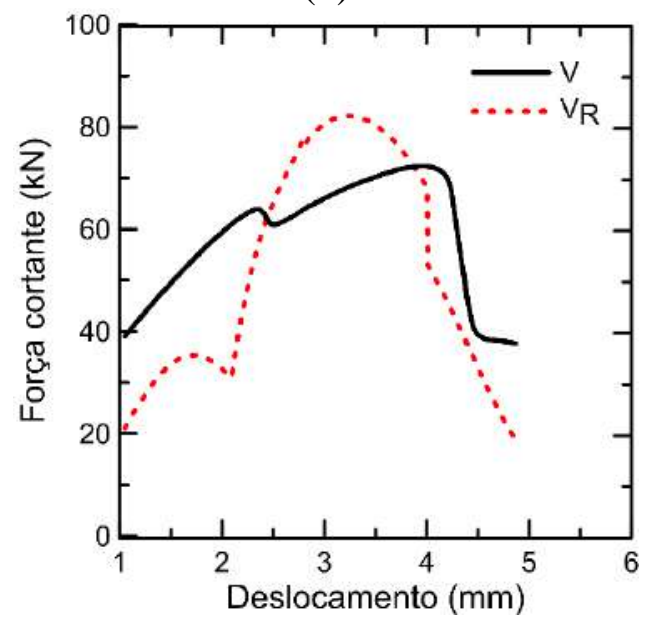

(f)

Figura 4.75 - Curva força cortante experimental $(V)$ ou contribuição dos mecanismos resistentes versus deslocamento vertical da viga $\mathrm{B}(1 \mathrm{~S}) \mathrm{b}$ ((a) $V_{c z}$; (b) $V_{r e s}$; (c) $V_{a g}$; (d) $V_{\text {fib }}$; (e) $V_{d}$; e (f) $V_{R}$ ). 

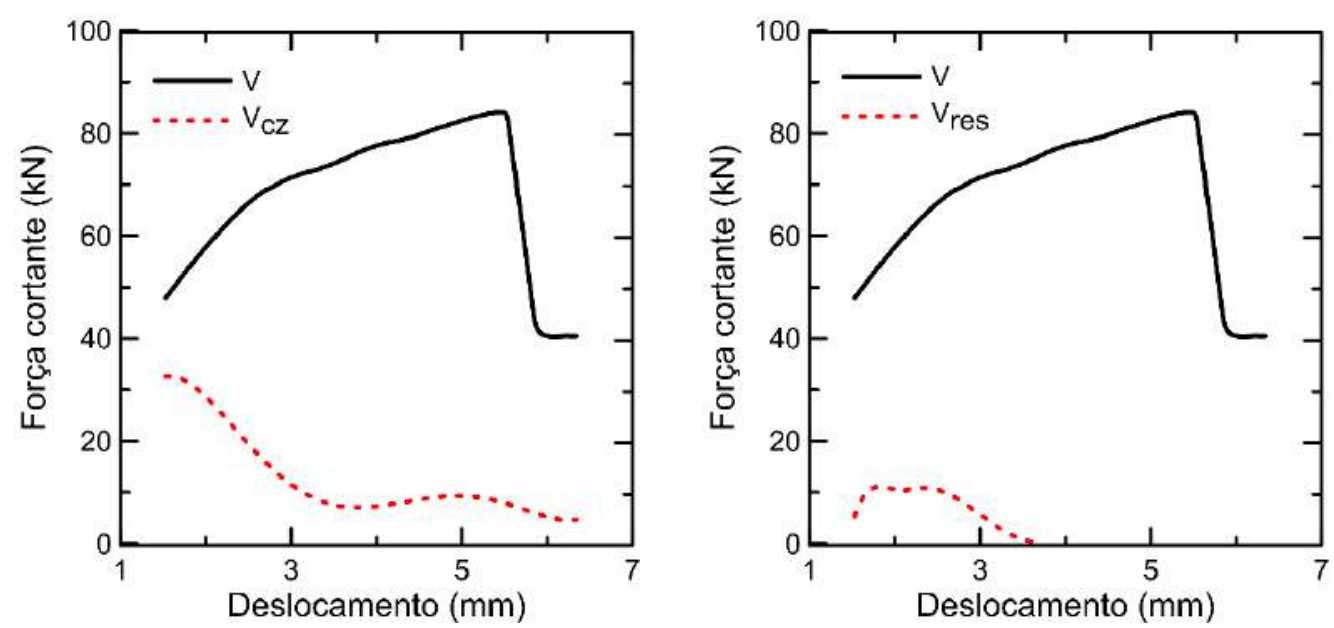

(a)
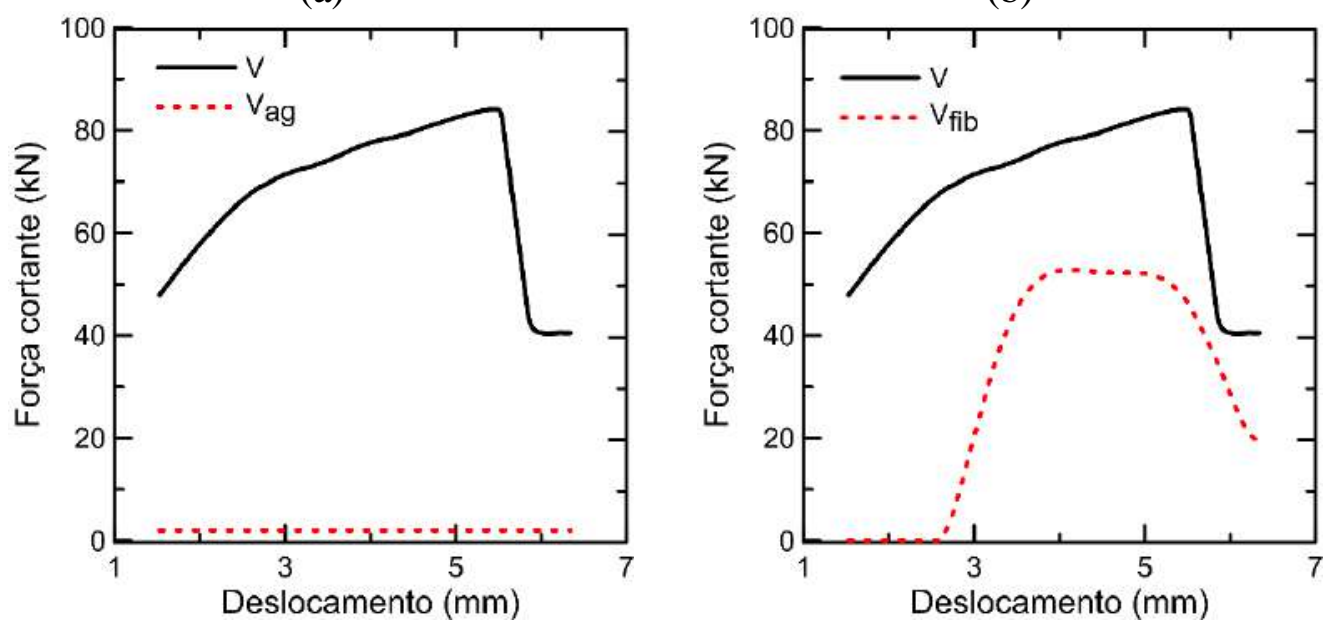

c)

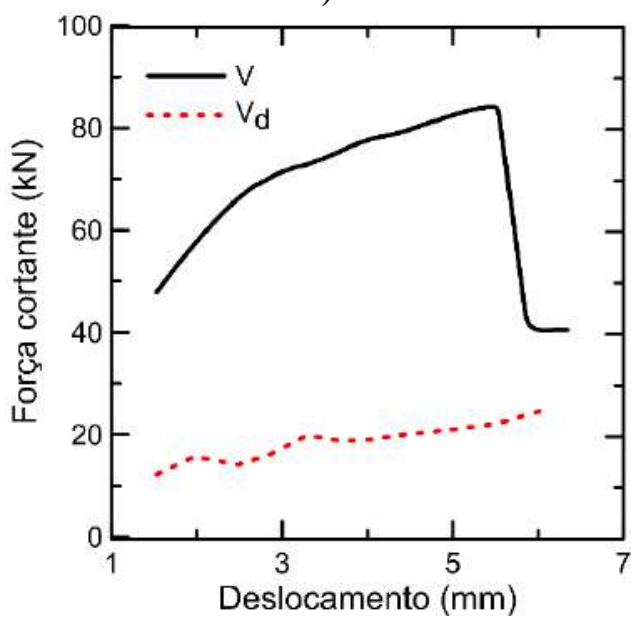

(e)

(d)

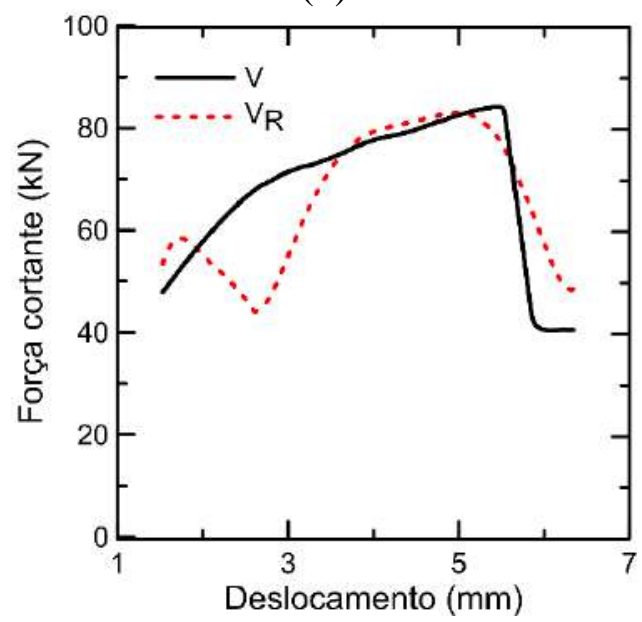

(f)

Figura 4.76 - Curva força cortante experimental $(V)$ ou contribuição dos mecanismos resistentes versus deslocamento vertical da viga $\mathrm{B}(1 \mathrm{~L}) \mathrm{a}\left((\mathrm{a}) V_{c z}\right.$; (b) $V_{r e s}$; (c) $V_{a g}$; (d) $V_{f i b}$; (e) $V_{d}$; e (f) $V_{R}$ ). 

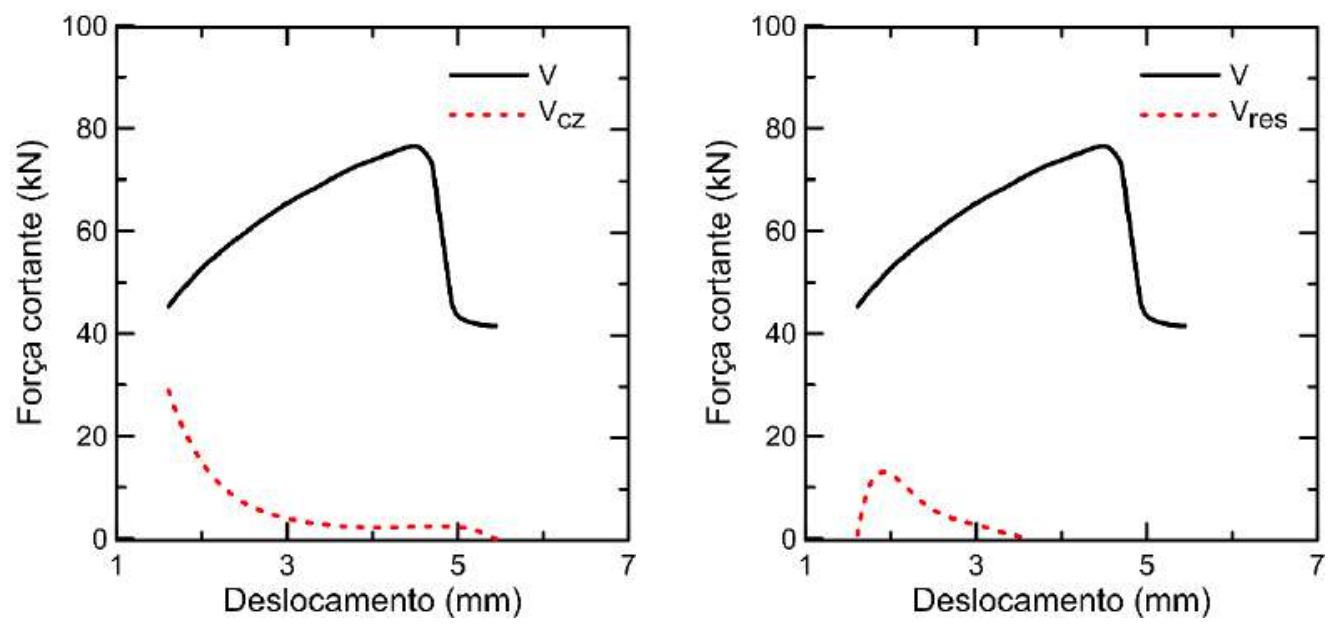

(a)
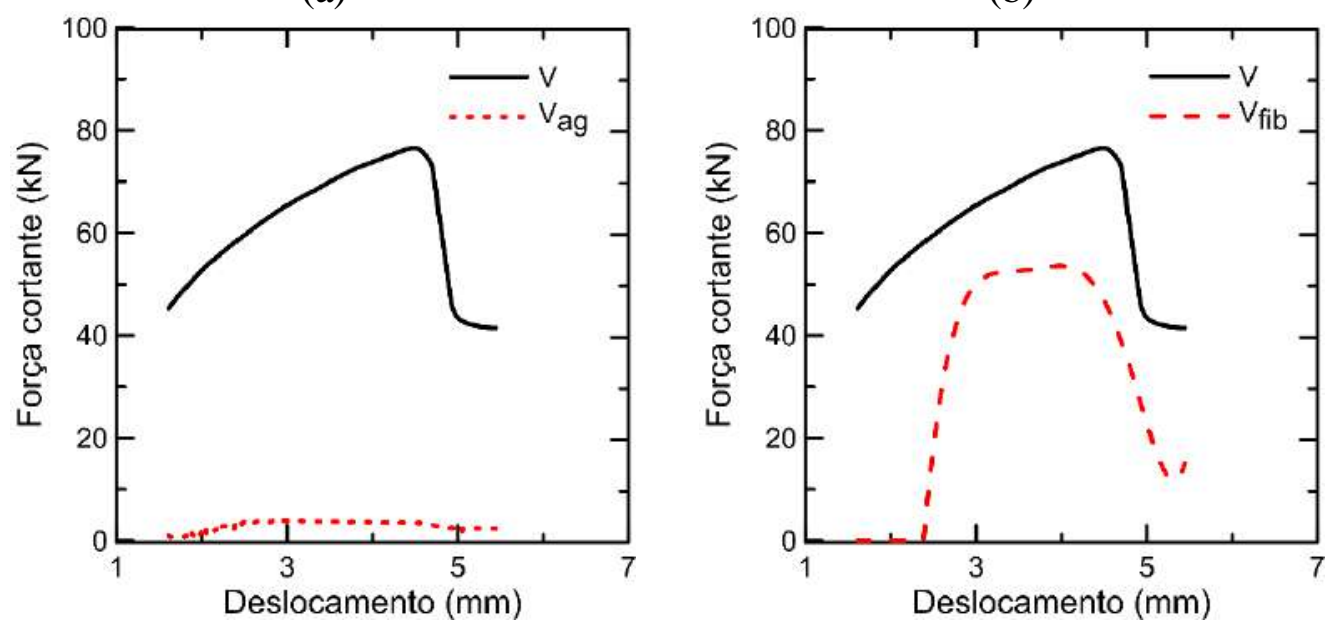

(c)

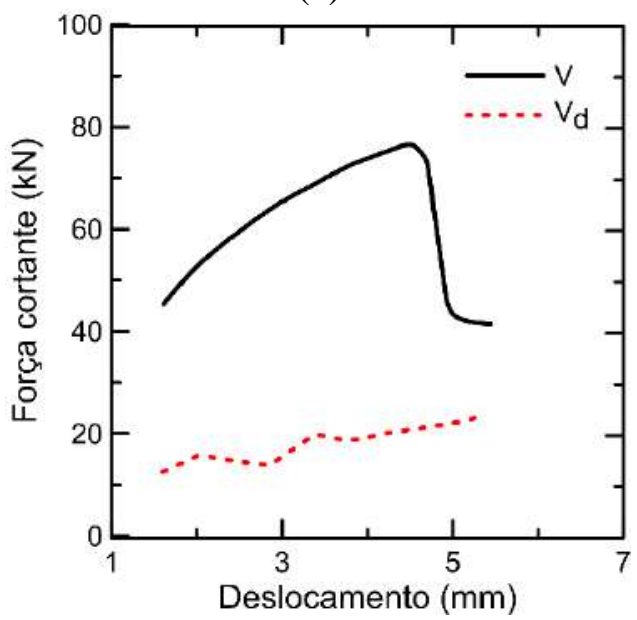

(e)

(d)

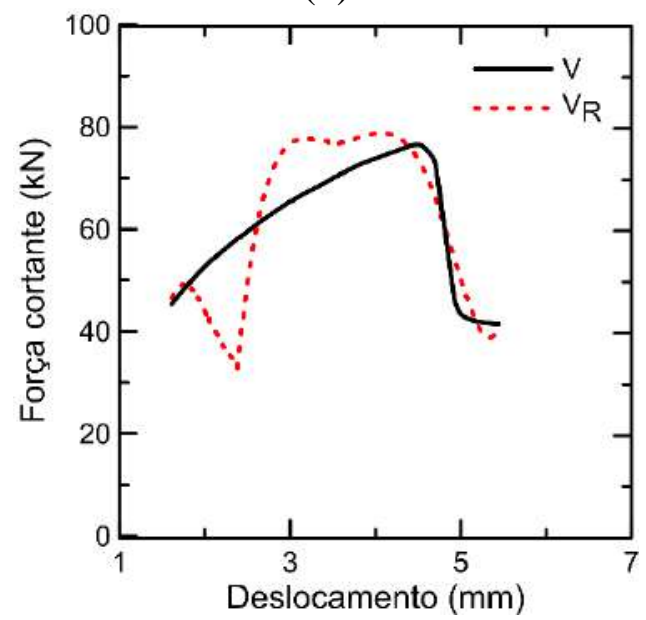

(f)

Figura 4.77 - Curva força cortante experimental $(V)$ ou contribuição dos mecanismos resistentes versus deslocamento vertical da viga $\mathrm{B}(1 \mathrm{~L}) \mathrm{b}\left((\mathrm{a}) V_{c z}\right.$; (b) $V_{r e s}$; (c) $V_{a g}$; (d) $V_{f i b}$; (e) $V_{d}$; e (f) $V_{R}$ ). 

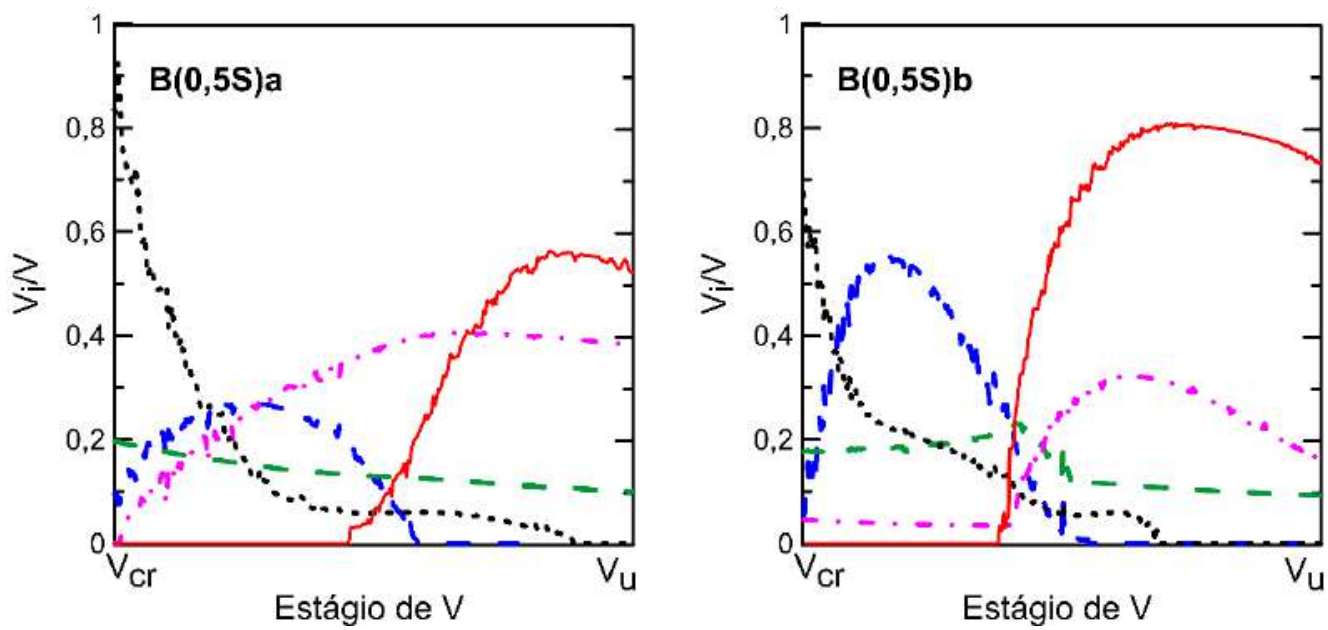

(a)

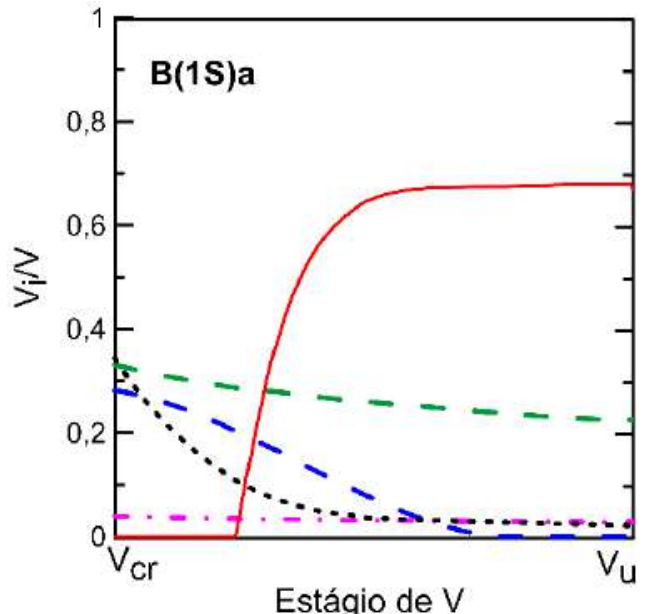

(c)

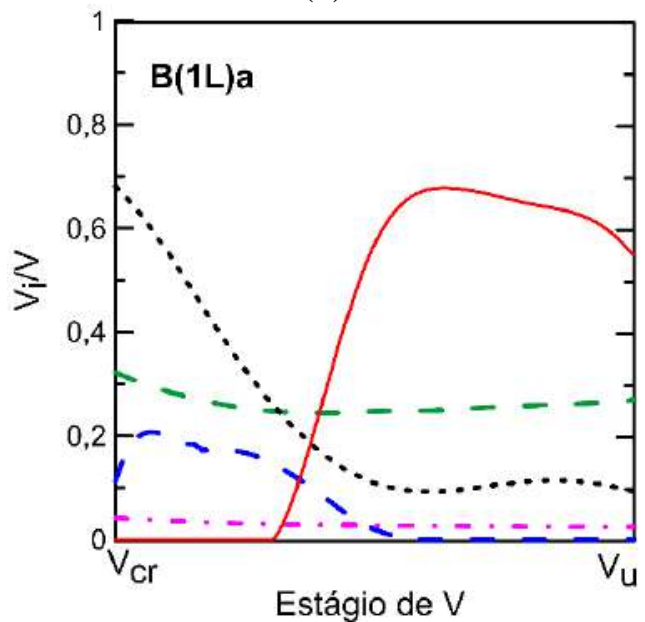

(e)

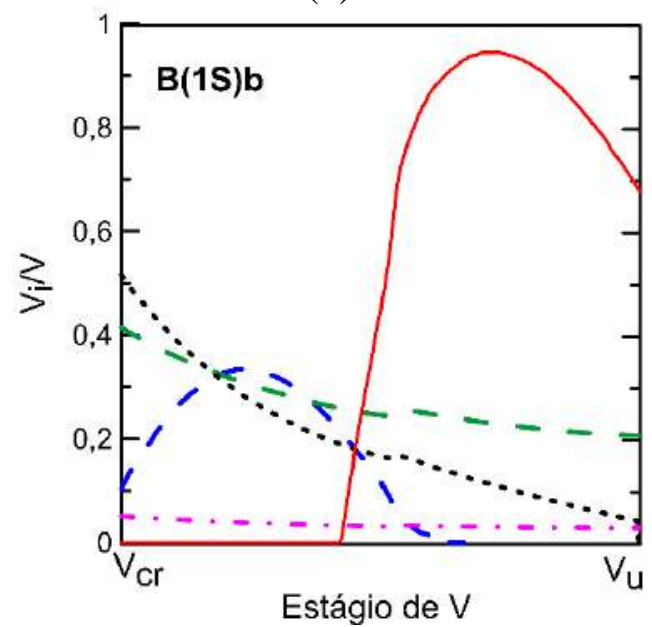

(d)

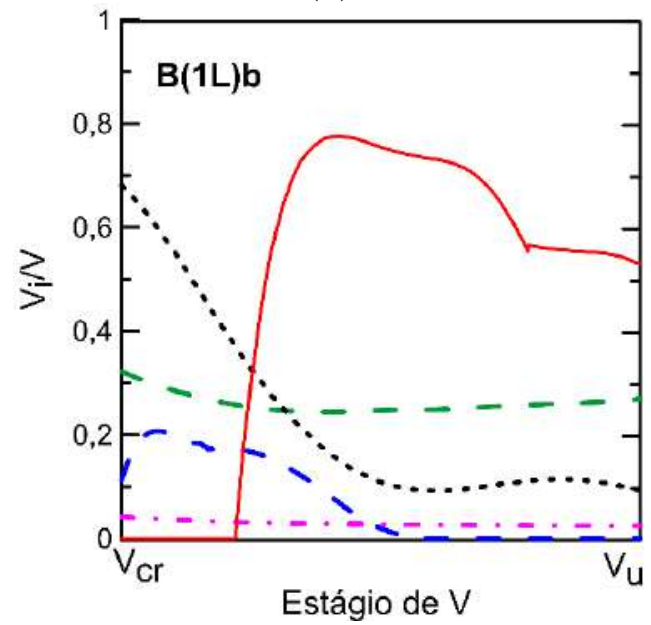

(f)

$$
\begin{gathered}
\text { Legenda } \\
\ldots . . v_{c z}--v_{\text {res }}-\cdot-v_{a g}-v_{\text {fib }}--v_{d}
\end{gathered}
$$

Figura 4.78 - Curvas de contribuição de cada mecanismo resistente $\left(V_{i}\right)$ em relação à força cortante da viga $(V)$ entre o início da fissura crítica $\left(V_{c r}\right)$ e a ruptura da viga $\left(V_{u}\right)$ : (a) $\mathrm{B}(0,5 \mathrm{~S}) \mathrm{a}$; (b) $\mathrm{B}(0,5 \mathrm{~S}) \mathrm{b}$; (c) $\mathrm{B}(1 \mathrm{~S}) \mathrm{a}$; (d) $\mathrm{B}(1 \mathrm{~S}) \mathrm{b}$; (e) $\mathrm{B}(1 \mathrm{~L}) \mathrm{a}$;

(f) $\mathrm{B}(1 \mathrm{~L}) \mathrm{b}$. 


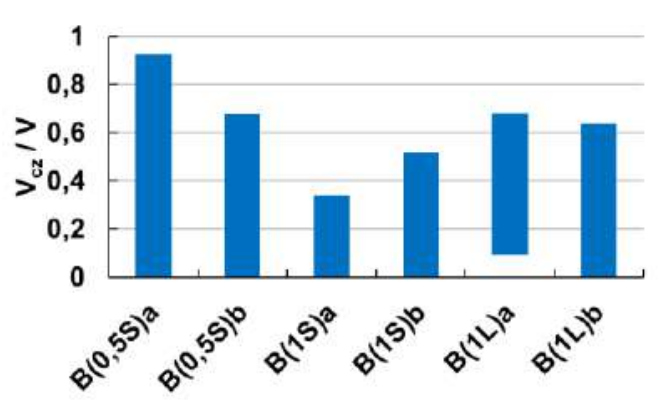

(a)

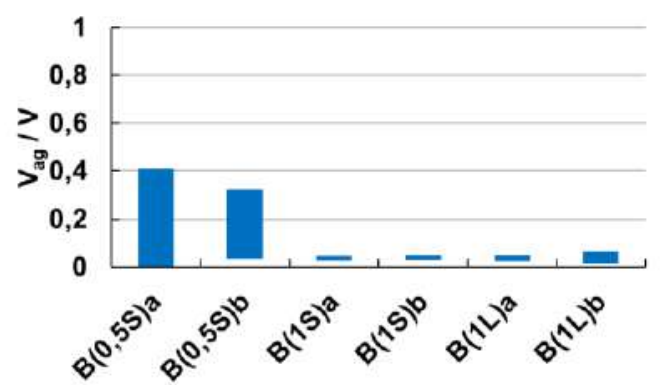

(c)

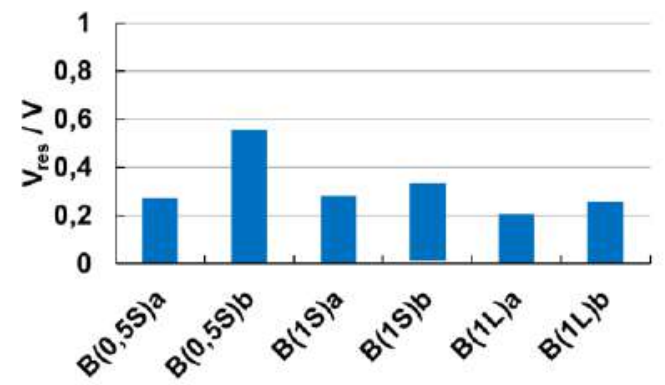

(b)

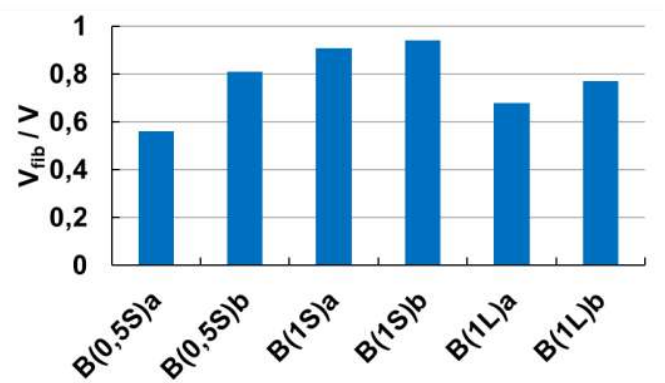

(d)

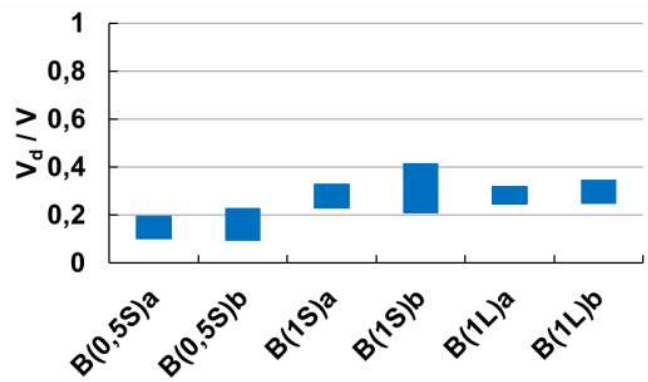

(e)

Figura 4.79 - Faixa de variação da relação $V_{i} / V$ entre $V_{c r}$ e $V_{u}$ : (a) $V_{c z} / V$; (b) $V_{\text {res }} / V$; (c) $V_{a g} / V$; (d) $V_{\text {fib }} / V$; (e) $V_{d} / V$.

A parcela de efeito de pino se mostrou menos efetiva nas vigas sem fibras, uma vez que a fissura de fendilhamento $\left(w_{D}>0\right)$ ocorreu simultaneamente com a formação da fissura crítica (Tabela 4.7) e o modelo adotado considera, para esse caso de vigas, $\mathrm{V}_{\mathrm{d}} \approx 0$ quando $\mathrm{w}_{\mathrm{D}}>0$. Já nas vigas com fibras, essa parcela aumentou com o aumento do teor de fibras $V_{f}$, tendo-se $9 \% \leq V_{d} / V \leq 23 \%$ e $21 \% \leq V_{d} / V \leq 42 \%$ para $V_{f}=0,5 \%$ e $V_{f}=1 \%$, respectivamente. Embora não tenha sido evidenciada influência do fator de forma das fibras na faixa de variação de $V_{d} / V$ (Figura 4.79e), quando da ruptura das vigas, observou-se tendência de maior relação $\left(V_{d, u} / V_{u}\right)$ com o aumento de $V_{f}\left(l_{f} / d_{f}\right)$ (Figura 4.80). A variação de $V_{d} / V$ foi menos acentuada que as de $V_{f i b} / V, V_{c z} / V$ e $V_{r e s} / V$ entre $V_{c r}$ e $V_{u}$ (Figura 4.78). 


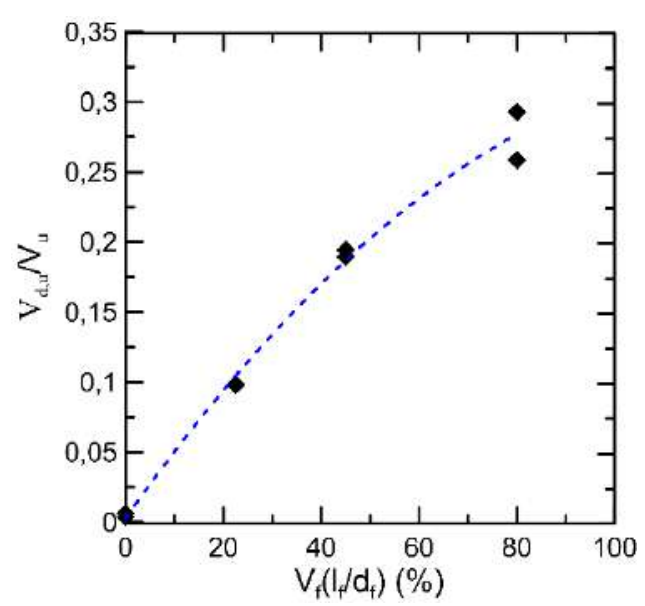

Figura 4.80 - Parcela de efeito de pino no estágio de ruptura em função de $V_{f}\left(l_{f} / d_{f}\right)$.

Uma vez que os deslocamentos relativos da fissura tenderam a ser maiores na direção de aplicação de carga (vertical) do que na direção horizontal e como, em geral, a fissura crítica apresentou pequena inclinação em relação ao eixo longitudinal das vigas, observou-se a preponderância de $r<1$, o que levou a tensões correspondentes ao engrenamento dos agregados $\sigma_{\mathrm{r}}$ e $\tau_{\mathrm{r}}$ próximas de zero (Figura 4.35, p. 178) e, consequentemente, baixos valores de $V_{a g}$. As exceções foram as vigas com menor teor de fibras, $\mathrm{B}(0,5 \mathrm{~S})$, para as quais constatou-se variação de $V_{a g} / V$ entre $V_{c r}$ e $V_{u}$ e maiores valores para essa relação $\left(0 \leq V_{a g} / V \leq 41 \%\right)$, enquanto para as demais vigas $V_{a g} / V$ ficou aproximadamente constante e não passou de $7 \%$ (Figuras 4.78 e 4.79).

A Figura 4.78 aponta que a ação das fibras não ocorreu imediatamente após o surgimento da fissura crítica, mas passando posteriormente a ser o principal mecanismo resistente, sendo sua contribuição de até $94 \%$ de $V$. Embora este mecanismo resistente não tenha tido uma contribuição majoritária ao longo de todo o trecho entre $V_{c r}$ e $V_{u}$, sua relevância é evidenciada nas Figuras 4.78 e 4.79.

O mecanismo resistente que apresentou maior contribuição na força cortante resistida pela viga no início da formação da fissura crítica foi o do concreto comprimido acima do final da fissura crítica $\left(V_{c z}\right)$, sendo de até $92 \%$ de $V$ para a viga $\mathrm{B}(0,5 \mathrm{~S})$ a e de até $68 \%$ de $V$ para as demais. À medida que a fissura crítica se desenvolveu, a contribuição desta parcela diminuiu (Figura 4.78).

Com relação à parcela referente à resistência à tração residual do concreto, observou-se aumento de $V_{\text {res }} / V$ para valores de $V$ próximos de $V_{c r}$, decrescendo 
posteriormente até chegar a valor próximo de zero. A menos da viga $\mathrm{B}(0,5 \mathrm{~S}) \mathrm{b}$, para a qual chegou-se a valor maior, teve-se $V_{\text {res }} / V \leq 32 \%$ (Figuras 4.78 e 4.79 ).

É interessante observar que, embora as vigas com fibras de mesmo teor e tipo de fibras tivessem tido curvas força cortante - deslocamento vertical próximas entre si, como as das vigas $\mathrm{B}(1 \mathrm{~S})$ reproduzidas na Figura 4.81, elas não tiveram campos de deslocamentos semelhantes. Isto, por sua vez, acarretou diferenças na evolução de $V_{i} / V$ (Figura 4.78). Ou seja, os resultados mostraram que é possível que, em vigas semelhantes, os campos de deslocamentos do vão de cisalhamento de ruptura e a fissura crítica assumam formas diferentes, tendo-se variações na contribuição de cada mecanismo resistente entre $V_{c r}$ e $V_{u}$ apesar de ter-se, para um determinado valor de deslocamento vertical das vigas, valores de força cortante próximos.

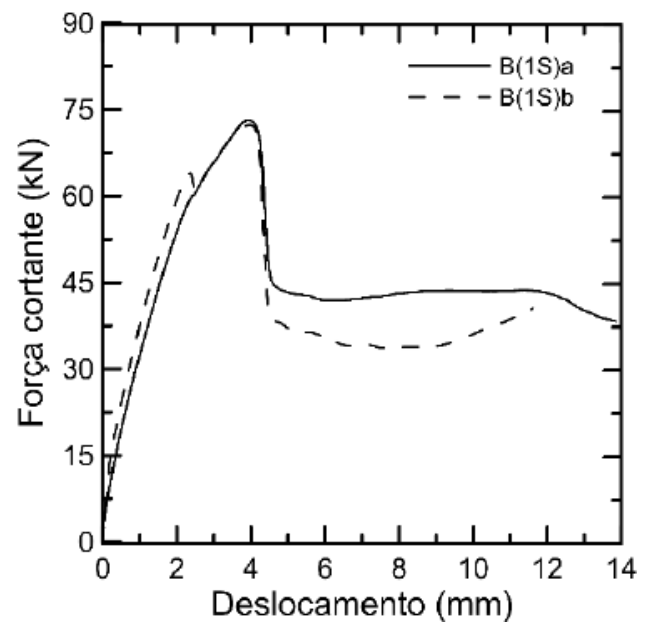

Figura 4.81 - Curvas força cortante-deslocamento vertical das vigas $\mathrm{B}(1 \mathrm{~S})$.

Embora sejam desconhecidas as características reais da superfície da fissura crítica, a partir das análises feitas foi possível ter um melhor entendimento do comportamento à força cortante das vigas em diferentes estágios de carregamento, assim como do porquê do aumento da resistência à força cortante de vigas com fibras de aço com o aumento de $V_{f}\left(l_{f} / d_{f}\right)$. 


\section{5 \\ Conclusões e sugestões para trabalhos futuros}

No estudo aqui descrito buscou-se investigar a contribuição de mecanismos resistentes para a resistência à força cortante de vigas esbeltas sem estribos e de concretos com resistência à compressão em torno de $40 \mathrm{MPa}$, dando enfoque particular aos efeitos de pino, de engrenamento de agregados e de fibras de aço.

A fotogrametria, técnica que vem sendo usada na investigação do comportamento de elementos de concreto armado, forneceu informações relevantes, que não poderiam ser obtidas por meio de instrumentação convencional.

A seguir são resumidas conclusões que puderam ser tiradas a partir do estudo realizado e dos desenvolvidos por outros pesquisadores.

\section{1 \\ Conclusões}

No estudo sobre o efeito de pino, constatou-se que $V_{d, \max }$ aumenta com o aumento de $V_{f}\left(l_{f} / d_{f}\right)$. Verificou-se também que ela aumenta com o aumento do diâmetro das barras de aço, fato que, para o caso de vigas sem fibras de aço, foi observado por Taylor $(1969,1974)$ e Baumann \& Rüsch (1970), mas contestado por outros autores.

Os espécimes sem fibras ensaiados não mostraram o comportamento quase plástico relatado por Baumann e Rüsch (1970) nem a relação entre $V_{d}$ e $\Delta$ sugerida por Taylor $(1969,1974)$, que considera uma súbita perda de resistência após fissuração e estabilização para valor de $V_{d}$ igual a $V_{d, c r} / 2$ e $\Delta=0,17 \mathrm{~mm}$.

O valor de $\Delta_{\max }$ também aumentou com o aumento de $V_{f}\left(l_{f} / d_{f}\right)$, mas em maior proporção que $V_{d, \max }$, notando-se uma relação aproximadamente linear entre de $\Delta_{\max }$ e $V_{f}\left(l_{f} / d_{f}\right)$.

Ao contrário do que ocorreu nos espécimes sem fibras de aço, nos com fibras houve aumento de $V_{d}$ após o aparecimento da fissura ao longo da armadura longitudinal, o que deve ser resultado da melhoria do comportamento do concreto 
à tração e do controle da abertura e do desenvolvimento dessa fissura providos pelas fibras.

O modelo proposto para analisar o efeito de pino nos espécimes ensaiados descreve satisfatoriamente o comportamento observado ao longo do carregamento e leva a valores de $V_{d, \max }$ próximos dos experimentais.

O estudo sobre engrenamento de agregados evidenciou a limitação dos diferentes modelos já propostos para analisar esse mecanismo; eles podem levar a resultados bem diferentes entre si e bem diferentes dos experimentais.

Os resultados dos ensaios pushoff mostraram aumento de $\tau_{\max }$ com o aumento de $V_{f}\left(l_{f} d_{f}\right)$. Nos espécimes sem fibras, notou-se dimiuição de $\tau$ com a formação e aumento da abertura de fissura na seção de cisalhamento. Nos com fibras, depois da ocorrência da fissuração, houve aumento de $\tau$ antes que ocorresse a diminuição contínua dessa tensão.

A análise das superfícies de ruptura dos espécimes sem fibras levou a crer que o coeficiente de atrito nessas superfícies não seja desprezível e nem a sua macrorugosidade, contrariando hipóteses adotadas em modelos propostos por outros autores.

Foi proposto modelo para análise dos ensaios pushoff realizados, baseado no de Li \& Maekawa (1989), mas levando em conta atrito entre as unidades de contato e a função densidade de contato obtida a partir das superfícies de ruptura dos espécimes sem fibras, que se mostrou bem diferente da adotada por Li \& Maekawa (1989). As relações entre tensões e deslocamentos relativos dadas pelo modelo nem sempre se mostraram satisfatórias, principalmente no caso dos espécimes com fibras, possivelmente em decorrência do número de fibras por unidade de área adotado não traduzir a situação real e do modelo não considerar adequadamente a interação entre o engrenamento dos agregados e a ação das fibras.

Nas vigas, verificou-se também aumento da força cortante última com o aumento de $V_{f}\left(l_{f} / d_{f}\right)$.

Com base na cinemática da fissura diagonal crítica das vigas, procurou-se avaliar a contribuição dos diferentes mecanismos para a resistência à força cortante das vigas. A parcela $V_{c z}$ foi estimada por meio da fórmula de Mörsch (1909), que estudo anterior mostrou fornecer valores adequados, e a parcela $V_{\text {res }}$ por meio da relação entre tensão normal residual e abertura de fissura proposta por Hordijk 
(1992). As demais parcelas foram avaliadas considerando resultados dos ensaios deste estudo e modelos a partir deles propostos.

Nas vigas sem fibras, parece ter havido alguma transmissão direta da carga para o apoio, o que tendeu a levar à obtenção de valores de $V_{R}=V_{d}+V_{a g}+V_{c z}+V_{\text {res }}$ menores que os de $V$ verificados nos ensaios.

Nas com fibras, as avaliações de $V_{R}=V_{d}+V_{a g}+V_{f i b}+V_{c z}+V_{\text {res }}$ realizadas indicam que, próximo à ruptura, a parcela $V_{f i b}$ é a dominante e, a menos das vigas com menor teor de fibras, a segunda maior parcela é a $V_{d}$. Nas vigas com menor teor de fibras (vigas $\mathrm{B}(0,5 \mathrm{~S})$ ), a segunda maior parcela é a $V_{a g}$ e a $V_{d}$ é a terceira.

Zarrinpour \& Chao (2017), que também se propuseram a avaliar as contribuições de diferentes mecanismos para a resistência à força cortante de vigas com fibras de aço com características diferentes das deste trabalho e seguindo diferente metodologia da aqui adotada para avaliar essas contribuições, concluíram que a parcela referente ao engrenamento dos agregados é deprezível e que a parcela $V_{c z}$ é a preponderante, seguida da $V_{f i b}$ e da $V_{d}$. Há, portanto, discordância entre as conclusões desses autores e as deste trabalho principalmente com relação à relevância da parcela $V_{c z}$, mas também em relação à parcela $V_{a g}$, que parece não ser sempre desprezível.

Neste e em outros estudos, verificou-se que a contribuição dos diferentes mecanismos resistentes, além das caracteríticas das vigas, depende das posição e forma da fissura diagonal crítica, que podem variar mesmo em vigas semelhantes.

\section{2}

\section{Sugestões para trabalhos futuros}

Há ainda muito o que investigar para que se tenha uma melhor compreensão acerca do comportamento à força cortante de vigas sem e com fibras de aço. Face ao limite de tempo, neste estudo considerou-se um número restrito de variáveis e seria desejável ampliá-lo, levando em conta mais variáveis, e sempre com o uso de fotogrametria.

Nos ensaios visando investigar o efeito de pino, poderiam ser considerados mais diâmetros e camadas da armadura longitudinal de tração, além de variações quanto aos teores e tipos de fibras. Os para estudo do engrenamento dos agregados, 
poderiam incluir diferentes teores, dimensões e tipos de agregados graúdos e também de fibras.

A interação entre engrenamento dos agregados e o efeito das fibras ao longo da fissura diagonal crítica de vigas precisa ser melhor entendida; investigações experimentais e teóricas que levem a um modelo mecânico mais realista são desejáveis.

A contribuição da região comprimida para a resistência à força cortante merece estudos específicos. Para eles, e também para investigar o efeito de escala em vigas com fibras de aço, são necessários ensaios de vigas com maiores dimensões.

Por fim, uma investigação do caminho de forças resistentes em função das respostas dos mecanismos resistentes e da posição e geometria da fissura crítica poderia contribuir para um melhor entendimento do comportamento à força cortante de vigas de concreto. 


\section{6 Referências bibliográficas}

ADVISORY COMMITTEE ON TECHNICAL RECOMMENDATIONS FOR CONSTRUCTIONS - CNR, Guide for the Design and Construction of FiberReinforced Concrete Structures - CNR-DT 204/2006, Roma, Itália, 2007. AGUADO, A.; LARANJEIRA, F. Presentación del Anejo de Hormigón com Fibras de la EHE y Ecuación Constitutiva del Hormigón con Fibras. In: Jornada sobre Aplicaciones Estructurales de Hormigón con Fibras. Barcelona, Espanha. p. 1-32, 2007.

ALBAJAR, J. S. The influence of aggregate fracture on the shear strength of reinforced concrete beams. Londres (Inglaterra), 2008, 409p. Tese de Doutorado - Imperial College London.

AMERICAN CONCRETE INSTITUTE. ACI 318-14: Building Code Requirements for Structural Concrete - and Commentary. Farmington Hills, EUA, 2014.

AMERICAN CONCRETE INSTITUTE. ACI445R-99: Recent approaches to shear design of structural concrete. ACI-ASCE Committee 445, 55 p. 1999. ASSOCIAÇÃO BRASILEIRA DE NORMAS TÉCNICAS. NBR 7480: aço destinado a armaduras para estruturas de concreto - especificações. Rio de Janeiro, 2007.

ASSOCIAÇÃO BRASILEIRA DE NORMAS TÉCNICAS. NBR 7809: agregado graúdo - determinação do índice de forma pelo método do paquímetro - método de ensaio. Rio de Janeiro, 2019.

ASSOCIAÇÃO BRASILEIRA DE NORMAS TÉCNICAS. NBR NM 248: agregados - determinação da composição granulométrica. Rio de Janeiro, 2003. ASSOCIAÇÃO BRASILEIRA DE NORMAS TÉCNICAS. NBR 7211: agregados para concreto - especificações. Rio de Janeiro, 2009.

ASSOCIAÇÃO BRASILEIRA DE NORMAS TÉCNICAS. NBR NM 67: concreto - determinação da consistência pelo abatimento do tronco de cone. Rio de Janeiro, 1998 
ASSOCIAÇÃO BRASILEIRA DE NORMAS TÉCNICAS. NBR 8522: concreto - determinação dos módulos estáticos de elasticidade e de deformação à compressão. Rio de Janeiro, 2017.

ASSOCIAÇÃO BRASILEIRA DE NORMAS TÉCNICAS. NBR 7222: concreto e argamassa - determinação da resistência à tração por compressão diametral de corpos de prova cilíndricos. Rio de Janeiro, 2011.

ASSOCIAÇÃO BRASILEIRA DE NORMAS TÉCNICAS. NBR 5739: concreto - ensaio de compressão de corpos de prova cilíndricos. Rio de Janeiro, 2018.

ASSOCIAÇÃO BRASILEIRA DE NORMAS TÉCNICAS. NBR 8953: concreto para fins estruturais - classificação pela massa específica, por grupos de resistência e consistência. Rio de Janeiro, 2015.

ASSOCIAÇÃO BRASILEIRA DE NORMAS TÉCNICAS. NBR ISO 6892-1: materiais metálicos - ensaio de tração. Rio de Janeiro, 2013.

BARRAGÁN, B. et al. Shear failure of steel fiber-reinforced concrete based on push-off tests. ACI MATERIALS JOURNAL, v. 103, n. 4 , p. 251-257, jul-ago 2006.

BAUMANN, T.; RUSCH, H. Versuche zum stadium der verdubelungswirkung der biegezugbewehrung eines stahlbetonbalkens. Deutscher Ausschuss fur Stahlbeton, Heft 210, Berlim, Alemanha, p. 45-83, 1970.

BAZANT, Z. P.; GAMBAROVA, P. G. Rough crack models in reinforced concrete. ASCE - Journal of Structural Engineering, v. 106, n. 4, p. 819-842, 1980.

BELBACHIR, A. et al. Size effect on the contribution of the aggregate interlock mechanism in reinforced concrete beams without shear reinforcement. European Journal of Environmental and Civil Engineering, 18 p. 18 de maio de 2018.

BELGO BEKAERT ARAMES. Catálogo de fibras de aço Dramix 3D 45/30BL e 80/60BG. Disponível em: < http://www.belgobekaert.com.br $>$. Acesso em: 20 de mar. 2018.

BOULEKBACHE, B. et al. Influence of yield stress and compressive strength on direct shear behavior of steel fibre-reinforced concrete. Construction and Building Materials, v. 27, p. 6-14, 2012.

CAMPANA, S. et al. Analysis of shear-transfer actions on one-way RC members based on measured cracking pattern and failure kinematics. Magazine of Concrete Research, v. 65, n. 6, p. 386-404, 2013. 
CAVAGNIS, F.; RUIZ, M. F.; MUTTONI, A. Shear failures in reinforced concrete members without transverse reinforcement: An analysis of the critical shear crack development on the basis of test results. Engineering Structures, v. 103, p. 157$173,2015$.

CAVAGNIS, F. Shear in reinforced concrete without transverse reinforcement: from refined experimental measurements to mechanical models. Suíça: Tese de doutorado - École Polytechnique Fédérale de Lausanne, 201 p. 2017.

CAVAGNIS, F.; RUIZ, M. F.; MUTTONI, A. An analysis of the shear-transfer actions in reinforced concrete members without transverse reinforcement based on refined experimental measurements. Structural Concrete, v. 19, p. 49-64, 2018a. CAVAGNIS, F.; RUIZ, M. F.; MUTTONI, A. A mechanical model for failures in shear of members without transverse reinforcement based on development of a critical shear crack. Engineering Structures, v. 157, p. 300-315, 2018 b.

CHANA, P. S. Some aspects of modelling the behaviour of reinforced concrete under shear loading. Cement and Concrete Association. n. 543, 22 p. 1981.

CHOI, S.; SHAH, S. P. Measurement of deformations on concrete subjected to compression using image correlation. Experimental Mechanics, v. 37, n. 3, p. $307-$ 313, 1997.

CHOI, S.; SHAH, S. P. Fracture mechanism in cement-based materials subjected to compression. Journal of engineering mechanics, v. 124, n. 1, p. 94-102, 1998. CORRELATED SOLUTIONS: NON-CONTACTING MEASUREMENT SOLUTIONS. VIC-2D e VIC-3D. Disponível em: < https://www.gomcorrelate.com/>. Acesso em: 04 de set. 2018.

CRAMMOND, G.; BOYD, S. W.; DULIEU-BARTON, J. M. Speckle pattern quality assessment for digital image correlation. Optics and Lasers in Engineering, v. 51, p. 1368-1378, 2013.

CUENCA, E. On shear behavior of structural elements made of steel fiber reinforced concrete. Valência, Espanha: Tese de doutorado - Universitat Politècnica de València, 422 p. 2012.

DENG, Q.; YI, W.; TANG, F. Effect of coarse aggregate size on shear behavior of beams without shear reinforcement, ACI Structural Journal, v. 114, n.5, p. 1131$1142,2017$. 
DINH, H.; PARRA-MONTESINOS, G. J.; WIGHT, J. K. Shear behavior of steel fiber-reinforced concrete beams without stirrup reinforcement. ACI Strucutral Journal, v. 107, n. 5, set-out. 2010.

DUTTON, M. Digital image correlation for evaluating structural engineering materials. Canadá: Tese de doutorado - Queen's University, 233 p. 2012.

ECHEGARAY-OVIEDO, J. Upgrading the push-off test to analyze the contribution of steel fiber on shear transfer mechanisms. Valência, Espanha: Tese de doutorado - Universitad Politecnica de Valencia, 219 p. 2014.

EUROPEAN STANDARD. EN 14651: Test method for metallic concrete measuring the flexural tensile strength (limit of proportionality (LOP), residual). Bruxelas, Bélgica, 2005.

FAYYAD, T. M.; LEES, J. M. Application of digital image correlation to reinforced concrete fracture, Procedia Materials Science, v. 3, p. 1585-1590, 2014.

FEDERATION INTERNATIONALE DE LA PRECONTRAINTE. Technical report: Shear at the interface of precast and in-situ concrete. FIP, Lausanne. 1978. FENWICK, R. C.; PAULAY, T. Mechanism of shear resistance of concrete beams", Journal of Structural Division, Proceedings of the American Society of Civil Engineers. v. 94, n. ST10, p. 2325-2350, 1968.

GALI, S.; SUBRAMANIAM, V. L. Investigation of the dilatant behavior of cracks in the shear response of steel fiber reinforced concrete beams. Engineering Structures, v. 152, p. 832-842, 2017.

GAMBAROVA, P. G.; KARAKOÇ, C. A new approach to the analysis of the confinement role in regularly cracking concrete elements. In: Proceeding of $7^{\text {th }}$ International Conference on Structural Mechanics in Reactor Technology, Chicago (EUA), v. H, p. 251-261, 1983.

GETTU, R.; GARDNER, D. R.; SALDÍVAR, H.; BARRAGÁN, B. E. Study of the distribution and orientation of fibers in SFRC specimens. Materials and Structures, v. 38, p. 31-37, 2005.

GOM: Precise Industrial 3D METROLOGY. GOM CORRELATE. Disponível em: 〈https://www.gom-correlate.com/>. Acesso em: 04 de set. 2018.

GONZÁLES, G. L. G. Medição de deformações elastoplásticas em regiões de concentração de tensões utilizando métodos sem malha e visão computacional. 
Rio de Janeiro, Brasil: Tese de doutorado - Pontifícia Universidade Católica do Rio de Janeiro, 2014.

GUIDOTTI, R. Poinçonnement des planchers-dalles avec colonnes superposées fortement sollicitées (em francês). Tese de doutorado - École Polytechnique Fédérale de Lausanne, 446 p. 2010.

HAMADI, Y. D.; REGAN, P. E. Behaviour in shear of beams with flexural cracks. Magazine of Concrete Research, v. 32, n. 111, p. 67-78, 1980.

HETÉNYI, M. Beams on elastic foundation: Theory with application in the fields of civil and mechanical engineering. $11^{\mathrm{a}}$ ed. Michigan: Universidade de Michigan, EUA, 1979.

HILlERBORG, A.; MODÉER, M.; PETERSSON, P-E. Analysis of crack formation and crack growth in concrete by means of fracture mechanics and finite elements. Cement and Concrete Research, v. 6, p. 773-782, 1976.

HORDIJK, D. A. Tensile and tensile fatigue behaviour of concrete; experiments, modelling and analyses. Heron, Faculty of Civil Engineering, Delft University of Technology, v. 37, n. 1, 79p, 1992.

HOULT, N. A. et al. Measuring crack movement in reinforced concrete using digital image correlation: Overview and application to shear slip measurements. Proceeding of the IEEE, v. 104, n. 8, p. 1561-1574, 2016.

HUBER, P.; HUBER, T.; KOLLEGGER, J. Investigation of the shear behavior of $\mathrm{RC}$ beams on the basis of measured crack kinematics. Engineering Structures, v. 113, p. 41-58, fevereiro 2016.

HTUT, T. N. S. Fracture processes in steel fibre reinforced concrete. Austrália: Tese de doutorado - The University of New South Wales, 400 p. 2010.

INTERNATIONAL DIGITAL IMAGE CORRELATION SOCIETY (iDICs). A good practices guide for digital image correlation - standardization, good practices, and uncertainty quantification committee. 94 p. 2018.

INTERNATIONAL FEDERATION FOR STRUCTURAL CONCRETE (FIB). FIB Model Code for Concrete Structures 2010, Wilhelm Ernst \& Sohn, Berlim, 2013.

ISLA, F.; RUANO, G.; LUCCIONI, B. Analysis of steel fibers pull-out. Experimental study. Construction and Building Materials. v.100, p. 183-193, 2015. 
JAPAN SOCIETY OF CIVIL ENGINEERS. JSCE-SF6: Method of test for shear strength of steel fiber reinforced concrete. Tokyo, 1990.

JELIC, I.; PAVLOVIC, M. N.; KOTSOVO, M. D. A study of dowel action in reinforced concrete beams. Magazine of Concrete Research, v. 51, n. 2, p. 131141, abril 1999.

KHAJA, M, N.; SHERWOOD, E. G. Does the shear strength of reinforced concrete beams and slabs depend upon the flexural reinforcement ratio or the reinforcement strain?. Canadian Journal of Civil Engineering, 36 p. 2013.

KHALOO, A. R.; KIM, N. Behavior of steel fiber reinforced concrete under direct shear. ACI MATERIALS JOURNAL, v. 94, n. 6, p. 592-601, nov-dez 1997.

KHANLOU, A. et al. Shear performance of steel fibre-reinforced concrete. In: Australian Structural Engineering Conference, Australia, Julho 11-13 2018, 8p.

KIM, J-K.; PARK, Y-D. Prediction of shear strength of reinforced concrete beams without web reinforcement. ACI Materials Journal, v. 93, n. 3, p. 213-223, maijun. 1996.

KIM, Y. H. et al. Shear characteristics and design for high-strength selfconsolidating concrete. Journal of Structural Engineering, v. 136, n. 8, p. 9891000, Agosto 2010.

KREFELD, W.; THURSTON, C. W. Contribution of longitudinal steel to shear resistance of reinforced concrete beams, ACI Journal Proceedings, v. 63, n. 3, p. 325-344, março 1966.

KUPFER, H.; HILSDORF, H. K.; RUSCH, H. Behavior of concrete under biaxial stresses. ACI Journal Proceedings, v. 66, n. 8, p. 656-666, 1969.

KWAN, A. K. H.; Ng, P. L.; LAM, J. Y. K. Modelling dowel action of discrete reinforcing bars in cracked concrete strucutures. In: AIP Conference Proceedings 1233, p. 701-706, 2010.

LANTSOGHT, E. O. L. Database of shear experiments on steel fiber reinforced concrete beams without stirrups. Materials, v. 12, n. 6, 36 p. 2019.

LECOMPTE, D. et al. Quality assessment of speckle patterns for digital image correlation. Optics and Lasers in Engineering, v. 44, p. 1132-1145, 2006.

LEE, S.; CHO, J.; VECCHIO, F. J. Simplified diverse embedment model for steel fiber-reinforced concrete elements in tension. Materials Journal, v. 110, n. 4, p. 403-412, 2013. 
LI, B.; MAEKAWA, K. Contact density model for cracks in concrete. In: IABSE Colloquium, Delft, p. 51-62, 1987.

LI, B.; MAEKAWA, K.; OKAMURA, H. Contact density model for stress transfer across cracks in concrete. Journal of the Faculty of Engineering - The University of Tokyo, v. 40, n. 1, p. 9-52, 1989.

LIM. S.; RAJU, R. M.; MATSUDA, M.; OKAMOTO, T.; AKIYAMA, M. Structural behavior prediction of SFRC beams by a novel integrated approach of $\mathrm{x}$ ray imaging and finite elemento method. Construction and Building Materials, v. 170, p. 347-365, 2018.

LUO, G.; CHUTATAPE, O.; FANG, H. Experimental study on nonuniformity of line jitter in CCD images. Applied Optics, v. 40, n. 26, p. 4716-4720, 2001. MARAR, K.; EREN, O.; ROUGHANI, H. The influence of amount and aspect ratio of fibers on shear behavior of steel fiber reinforced concrete. KSCE Journal of Civil Engineering, v. 21, n. 4, p. 1393-1399, 2017.

MARÍ, A. et al. Shear-flexural strength mechanical model for the design and assessment of reinforced concrete beams subjected to point or distributed loads. Frontiers of Structural and Civil Engineering, v. 8, n. 4, p. 337-353, 2014.

MARCUS, H. Load carrying capacity of dowels at transverse pavements joints. Journal of the American Concrete Institute, v. 48, n. 2, p. 169-184, 1951.

MATOS, L. M. P.; BARROS, J. A. O.; VENTURA-GOUVEIA, A.; CALÇADA, R. A. B. Constitutive model for fibre reinforced concrete by coupling the fibre and aggregate interlock resisting mechanisms. Cement and Concrete Composites, v. 111, p. 19, 2020.

MIRSAYAH, A. A.; BANTHIA, N. Shear strength of steel fiber-reinforced concrete. ACI Structural Journal, v. 99, n. 5, p. 473-479, 2002.

MÖRSCH, E. Der Einsenbetonbau (publicado em inglês como: Concrete-Steel Construction). The Engineering News Publishing Company, 368 p. 1909.

OSTROMECKI, R.; SUPRYNOWICZ, K. Research on the surface deformability of reinforced concrete beams with the use of digital image correlation method. Solid State Phenomena, v. 240, p. 25-30, 2015.

PAN, P. et al. Systematic errors in two-dimensional digital image correlation due to lens distortion. Optics and Lasers in Engineering, v. 51, p. 140-147, 2013. 
PANDA, S. S.; GANGOLU, A. R. Study of dowel action in reinforced concrete beam by factorial design of experiment. ACI Structural Journal, v. 114, n. 6, p. 1495-1505, nov-dez. 2017.

Parra-Montesinos, G. J.; et al. Use of steel fibre reinforcement for shear resistance in beams and slab-column connetions, Shear and punching shear in RC and FRC, FIB bulletin 57, p. 243-262, 2010.

PAULAY, T.; LOEBER, P. J. Shear transfer by aggregate interlock. ACI - Special Publication SP42, p. 1-15, 1974.

PEREIRA, E. V. Influência de fibras de aço no comportamento mecânico e nos mecanismos de fissuração de concretos autoadensáveis. Rio de Janeiro: Dissertação de mestrado - Pontifícia Universidade Católica do Rio de Janeiro (PucRio), 170 p. 2017.

PFYL, T. Tragverhalten von stahlfaserbeton. Suíça: Tese de doutorado Eidgenossiche Technische Hochschule, 139 p. 2003.

Prisco, M.; Plizzari, G.; Vanderwalle, L. MC 2010: Overview on the shear provisions for FRC, Shear and punching shear in RC and FRC, FIB bulletin 57, p.61-76, 2010.

RAJU, R. A.; LIM, S.; AKIYAMA, M.; KAGEYAMA, T. Effects of concrete flow on the distribution and orientation of fibers and flexural behavior of steel fiberreinforced self-compacting concrete beams. Construction and Building Materials, v. 262, 24p, 2020.

REGAN, P. Aspects of diagonal tension in reinforced concrete. Structural Concrete, v. 1, n. 3, p. 119-132, 2000.

REGAN, P. E.; et al. The influence of aggregate type on the shear resistance of reinforced concrete. The Structural Engineer, v.83, n. 23/24, p. 27-32, 2005.

REINHARDT, H. W. Fracture mechanics of an elastic softening material like concrete. Heron, v. 29, n. 2, 42 p. 1984.

RESENDE, T. L. Resistência à força cortante de vigas de concreto autoadensável. Rio de Janeiro: Dissertação de mestrado - Universidade Federal do Rio de Janeiro (UFRJ), 173 p. 2014.

REU, P. The art and application of DIC - Hidden components of DIC: Calibration and shape function - Part 1. Experimental Techniques, v. 36, p. 3-5, 2012.

REU, P. The art and application of DIC - All about speckles: speckle density. Experimental Techniques, v. 39, p. 1-2, 2015. 
RIBEIRO, E. M. Caracterização de agregados graúdos do Rio de Janeiro para concreto estrutural. Rio de Janeiro: Tese de doutorado - Universidade Federal do Rio de Janeiro (COPPE/UFRJ), 355 p. 2006.

RILEM TC162-TDF: Test and design methods for stell fibre reinforced concrete recommendations, Materials and Structures, v. 33, p. 75-81, mar. 2000.

RODRIGUES, L. D. Aplicação da técnica DIC a espécimes com diferentes formas, materiais e gradientes de deformação. Rio de Janeiro, Brasil: Tese de doutorado - Pontifícia Universidade Católica do Rio de Janeiro, 2014.

RUIZ, M. F.; MIRZAEI, Y.; MUTTONI, A. Post-punching behavior of flats slabs. ACI Structural Journal, v. 110, n. 5, p. 801-811, 2013.

RUIZ, M. F.; MUTTONI, A.; GAMBAROVA, P. G. Relationship between nonlinear creep and cracking of concrete under uniaxial compression. Journal of Advanced Concrete Technology, v. 5, n. 3, p. 1-11, 2007

RUIZ, M. F.; PLUMEY, S.; MUTTONI, A. Interaction between bond and deviation forces in spalling failures of arch-shaped members without transverse reinforcement. ACI Structural Journal, v. 107, n. 3, p. 346-354, 2010.

SAGASETA, J.; VOLLUM, R. L. Influence of beam cross-section, loading arrangement and aggregate type on shear strength. Magazine of Concrete Research, v. 63, n. 2, p. 139-155, 2011 a.

SAGASETA, J.; VOLLUM, R. L. Influence of aggregate fracture on shear transfer through cracks in reinforced concrete. Magazine of Concrete Research, v. 63, n. 2, p. 119-137, 2011 b.

SANTOS, A. H. A.; PITANGUEIRA, R. L. S. Concrete modulus of elasticity assessment using digital image correlation, IBRACON Structures and Materials Journal, v. 9, n. 4, p. 587-594, 2016.

SARKAR, S.; ADWAN, O.; BOSE, B. Shear stress contributions and failure mechanisms of high strength reinforced concrete beams. Material and Structures, v. 32, p. 112-116, março 1999.

SHERWOOD, E. G. One-way shear behaviour of large, ligthly-reinforced concrete beams and slabs. Toronto, Canadá: Tese de doutorado - University of Toronto, 2008.

SHOAIB, A.; LUBELL, A. S.; BINDIGANAVILE, V. S. Size effect in shear for steel fiber-reinforced concrete members without stirrups. ACI Structural Journal, v. 111, n. 5 , set-out. 2014. 
SINGH, B.; CHINTAKINDI, S. An appraisal of dowel action in reinforced concrete beams. Proceedings of Institution of Civil Engineers, Structures and Buildings, n. SB5, p. 257-267, maio 2013.

SOETENS, T.; MATTHYS. Shear transfer across a crack in steel fibre-reinforced concrete. Cement and Concrete Composites, v. 82, p. 1-13, 2017.

SOLTANZADEH, F.; BARROS, J. A. O.; SANTOS, R. F. C. High performance fiber reinforced concrete for the shear reinforcement: experimental and numerical research. Construction and Building Materials, v. 77, p. 94-109, 2015.

F. Soltanzadeh, J.A.O. Barros, R.F.C. Santos, High performance fiber reinforced concrete for the shear reinforcement: experimental and numerical research, Construct. Build. Mater. 77 (2015) 94-109, https://doi.org/10.1016/j. conbuildmat.2014.12.003. [13] T. Pfyl, Tragverhalten von s

SOROUSHIAN, P.; LEE, CHA-DON. Distribution and orientation of fibers in steel fiber reinforced concrete. ACI Structural Journal, v. 87, n. 5, p. 433-439, 1990. SURYANTO, B.; TAMBUSAY, A.; SUPROBO, P. Crack Mapping on shearcritical reinforced concrete beams using open source digital image correlation software. Civil Engineering dimension, v. 19, n. 2, p. 93-98, 2017.

SUSETUO, J.; VECCHIO, F. J. Effectiveness of steel fiber as minimum shear reinforcement: panels tests, FIB bulletin 57, p. 227-241, 2010.

SUTTON, M. A. et al. Determination of displacements using an improved digital correlation method. Image and Vision Computing, v. 1, n. 3, p. 133-139, 1983.

SUTTON, M. A.; ORTEU, J. J.; SCHREIER, H. W. Image correlation for shape, motion and deformation measurements - basic concepts, theory and applications. $1^{\mathrm{a} e d,}$ New York: Springer, 2009.

TAMBUSAY, A.; SURYANTO, B.; SUPROBO, P. Visualization of shear cracks in a reinforced concrete beam using the digital image correlation. International Journal on Advanced Science Engineering Information Technology, v. 8, n. 2, 2018. 
TAYLOR, H. P. J. Investigation of the dowel shear forces carried by the tensile steel in reinforced concrete beams. Cement and Concrete Association, Technical Report 431, 24 p. 1969.

TAYLOR, H. P. J. The fundamental behavior of reinforced concrete beams in bending and shear. ACI Special Publication, v. 42, p. 43-77, 1974.

ULAGA, T. Betonbauteile mit Stab- und Lamellenbewehrung: Verbund- und Zuggliedmodellierung (em alemão). Zurique, Suíça: Tese de doutorado - ETHZ, 160 p. 2003.

VASSOLER, J. M.; FANCELLO, E. A. Error analysis of the digital image correlation method. In: XXIX Mecánica Computacional, 2010, Argentina, p. 61496161.

VECCHIO, F. J.; COLLINS, M. P. The modified compression-field theory for reinforced concrete elements subjected to shear. ACI Journal Proceedings, v. 83, n. 2, p. 219-231, 1986.

VINTZELEOU, E. N.; TASSIOS, T. P. Mathematical models for dowel action under monotonic and cyclic conditions. Magazine of Concrete Research, v. 38, n. 134, p. 13-22, março 1986.

VOLLUM, R. L.; FANG, L. Shear enhancement near supports in RC beams. Magazine of Concrete Research, v. 67, n. 9, p. 443-458, 2015.

VOO, J. Y. L.; FOSTER, S. J. Variable engagement model for the design of fibre reinforced concrete structures, In: Advanced Materials for Construction of Bridges, Buldings anb Other Structures III, P05, ECI Sypmposium series, 2003, Estados Unidos da América, 11 p.

WALRAVEN, J. C. Aggregate interlock: A theoretical and experimental analysis. Delft (Holanda), 1980, 197p. Tese de Doutorado - Delft University.

WALRAVEN, J. C.; REINHARDT, H. W. Theory and experiments on the mechanical behavior of cracks in plain and reinforced concrete subjected to shear loading. Heron, Dept. of Civil Engineering, Delft University of Technology, v. 26, n. 1A, 68p, 1981.

WIGHT, J, K.; MACGREGOR, J. G. Reinforced Concrete - Mechanics and

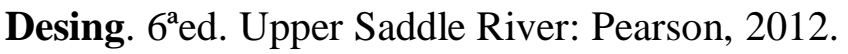

XIA, J. et al. Dowel action and shear strength contribution of high strength rebar embedded in ultra-high performance fiber reinforced concrete. Engineering Structures, v. 83, p. 223-232, 2015. 
YANG, Y. Shear behaviour of reinforced concrete members without shear reinforcement - a new look at na old problem. Delft: Tese de doutorado Universidade Técnica de Delft, 344 p. 2014.

YAOFENG, S.; PANG, J. H. L. Study of optimal subset size in digital image correlation of speckle pattern images. Optics and Lasers in Engineering, v. 45, p. 967-974, 2007.

YU, Q.; BAZANT, Z. P. Can stirrups suppress size effect on shear strength of RC beams?, Journal of Structural Engineering, v. 137, n. 5, p. 607-617.

ZARRINPOUR, M. R.; CHAO, S. Shear strength enhancement mechanisms of steel fiber-reinforced concrete slender beams, ACI Structural Journal, v. 114, n. 3, mai-jun. 2017.

ZIRGULIS, G.; SVEC, O.; GEIKER M. R.; CWIRZEN. A.; KANSTAD. Influence of reinforcing bar layout on fibre orientatiton and distribution in slabs cast from fibre-reinforced self-compacting concrete (FRSCC). Structural Concrete, v. 17, n. 2, p. 245-256, 2016. 


\section{Apêndice A \\ Técnica óptica de correlação de imagem digital (CID)}

Um dos grandes desafios do estudo da resistência à força cortante de vigas de concreto é o entendimento do comportamento da fissura diagonal crítica. Devido aos fatos da região de formação e desenvolvimento desta fissura não ser previsível e da instrumentação clássica para medição de deslocamentos e deformações (por exemplo, transdutores de deslocamentos e extensômetros elétricos) demandar a definição prévia de locais específicos para sua instalação, este tipo de investigação sempre foi trabalhosa e limitada (Taylor, 1974; Sherwood, 2008).

Com o advento da técnica óptica de correlação de imagem digital (CID), desenvolvida no início da década de 1980 (Sutton et al., 1983), com aplicações iniciais na mecânica da fratura do concreto em meados da década de 1990 (Choi \& Shah, 1997 e 1998) e, mais recentemente, em investigações sobre resistência à força cortante de vigas de concreto (Cavagnis, et al., 2015 e 2018a; Ostromecki \& Suprynowicz, 2015; Huber et al., 2016; Gali \& Subramaniam, 2017; Zarrinpour \& Chao, 2017; Belbachir, et al., 2018; Tambusay et al., 2018), passou a ser possível acompanhar não somente a cinemática da fissura crítica, como também de toda a região do vão de ruptura.

A técnica de correlação de imagem digital consiste no registro e rastreamento de imagens da superfície de interesse, previamente preparada de modo a ter um conjunto padrão de pontos (speckles) espaçados aleatoriamente. Para o registro destas imagens, pode-se utilizar apenas uma câmera para medições na superfície do espécime, para o caso de análises no plano dessa superfície, ou mais câmeras, quando se deseja obter informações nas três dimensões (Sutton et al., 2009). Logo, como o comportamento ao esforço cortante de vigas de concreto é essencialmente bidimensional, uma câmera pode ser suficiente para sua análise, embora o guia de boas práticas de CID da iDICs (2018) recomende a análise 3D para quaisquer situações. Dos cinco trabalhos sobre força cortante em vigas de concreto com uso de CID analisados no item 2.3, dois valeram-se da análise 2D (ver Tabela A.1, p. 250). 
Para uma adequada aquisição de dados, alguns cuidados devem ser tomados; entre outros: exposição da superfície à luz difusa e posicionamento da câmera ortogonalmente a ela (Pan et al., 2013). Na Figura A.1 é mostrada uma viga de concreto preparada para ser ensaiada utilizando a técnica de CID.

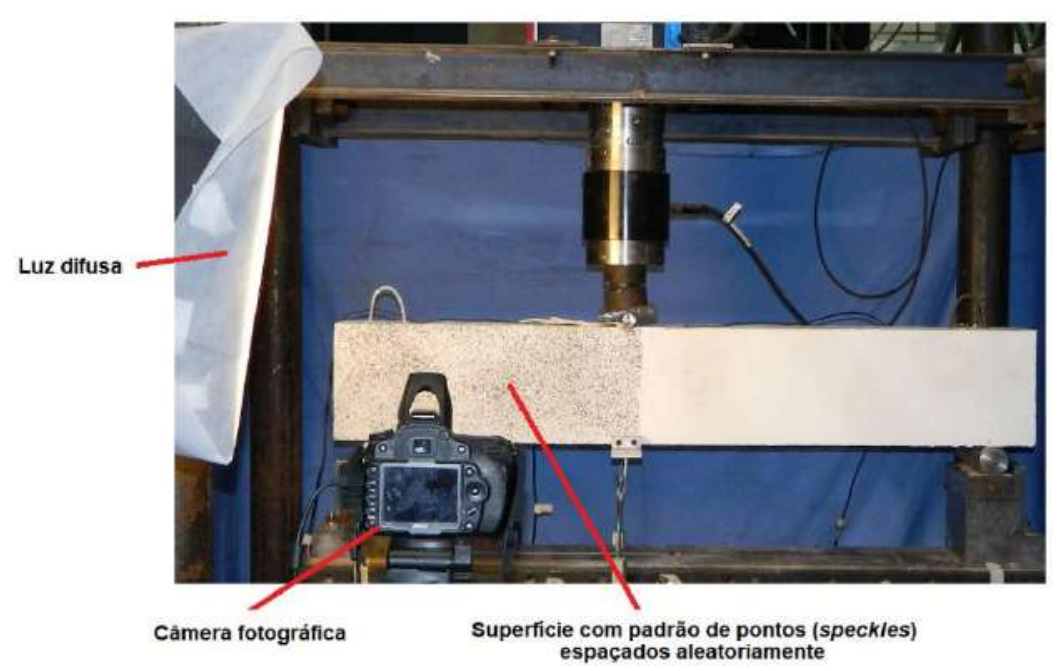

Figura A.1 - Viga preparada para ensaio utilizando a técnica de CID.

A ideia básica desta técnica consiste em, a partir da imagem digital da superfície investigada para a situação inicial de teste (imagem de referência) e de outra para situação de carregamento e deformação de interesse (imagem a ser comparada com a de referência), determinar o campo de deslocamentos na região desejada do espécime (e de deformações, a partir do de deslocamentos), por meio das análises das diferenças entre essas imagens.

Sendo a imagem composta por um conjunto de pixels, que são pequenas células sensíveis à luminosidade e com o armazenamento de sua intensidade na escala de cinza variando do valor entre 0 e 255 , é realizado o processo de correlação de subconjuntos de pixels (denominado subsets ou facetas) entre a imagem de referência e as outras, conforme ilustra a Figura A.2. O deslocamento resultante da média dos deslocamentos dos pixels que compõem um subset é expresso em seu centro, a partir do qual é aplicado um "passo" (step), definido pelo número de pixels deslocado do centro deste subset até o do próximo a ser investigado (Lecompte et al., 2006; Gonzáles, 2014; Rodrigues, 2014). Para o processamento das imagens, existem alguns softwares consolidados no mercado, como VIC-2D/3D (Correlated Solutions, 2018) e GOM Correlate (GOM, 2018). 


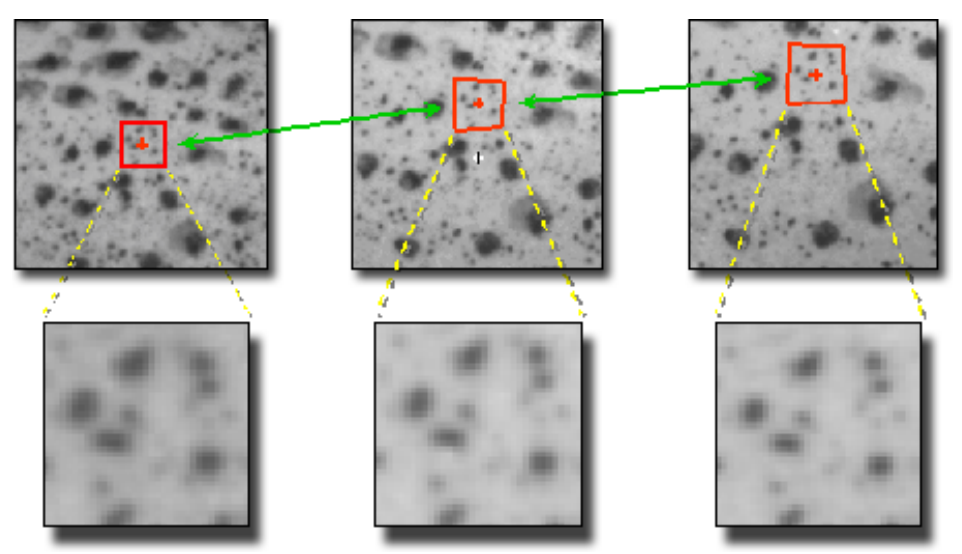

Figura A.2 - Princípio da técnica CID. Quadriláteros em vermelho indicam subsets. (Correlated Solutions, 2018)

Para se garantir a identidade única do subset, é imprescindível que a superfície analisada tenha um padrão não repetitivo, isotrópico e de alto contraste, sendo usual para isto a aplicação de um fundo branco fosco sob um padrão de pontos pretos foscos (speckles) espaçados aleatoriamente, sendo possível também a aplicação contrária destas cores (Lecompte et al., 2006; Crammond et al., 2013; iDICs, 2018).

Rodrigues (2014), a partir de sua revisão bibliográfica, concluiu que devem ser almejados maior densidade e o menor tamanho de speckles discernível pelas lentes utilizadas, de modo a permitir uma maior flexibilidade na escolha do tamanho dos subsets e passos de análises. Reu (2012) afimou que o tamanho ótimo de speckles é garantido quando o tamanho das áreas em branco e em preto são de 3 a 5 pixels.

No que se refere à aplicação em investigação experimental da resistência à força cortante em vigas de concreto, Zarrinpour \& Chao (2017) comentaram a importância de que os speckles tivessem no mínimo de 3 a 5 pixels para que as análises de deformações tivessem suficiente acurácia. Ostromecki \& Suprynowicz (2015) buscaram criar speckles contendo no mínimo 5 pixels, com base na relevante redução de erro de deslocamento absoluto observado nas análises realizadas por Vassoler \& Fancello (2010) ao alterar o tamanho dos speckles de aproximadamente 1 pixel para 4 ou 5 pixels. Cavagnis et al. (2015 e 2018a) reportaram que adotaram speckles de tamanho de 3 a 5 pixels.

Segundo Vassoler \& Fancello (2010), o subset pode variar desde poucos pixels até cem, o que pode mudar consideravelmente a precisão das análises. Subset menor é preferível devido ao menor esforço computacional; entretanto, é necessário 
que o padrão tenha suficiente densidade e quantidade / tamanho de speckles (no mínimo 3 por subset), para uma adequada correlação (Lecompte et al., 2006; Yaofeng \& Pang, 2007; Vassoler \& Fancello, 2010; iDICs, 2018). De acordo com Reu (2015) a densidade ótima de speckles é alcançada para a condição em que a cor do padrão de pintura da área do subset analisado é igualmente dividida entre branca e preta.

Logo, a escolha do tamanho do subset está diretamente relacionada à qualidade do padrão de pintura. Segundo Reu (2012), para um padrão de speckles de tamanho entre 3 a 5 pixels e densidade de cores semelhantes, um subset com dimensões aproximadas de $(20$ x 20) pixels é adequado. Uma forma de avaliar a escolha do tamanho do subset é por meio da análise do número e tamanho de regiões onde ocorrem erros (Figura A.3). Em seus trabalhos sobre força cortante em vigas de concreto, Huber et al. (2016) e Gali \& Subramaniam (2017) utilizaram subsets de dimensões ( 15 x 15$)$ pixels e ( 35 x 35$)$ pixels, respectivamente.

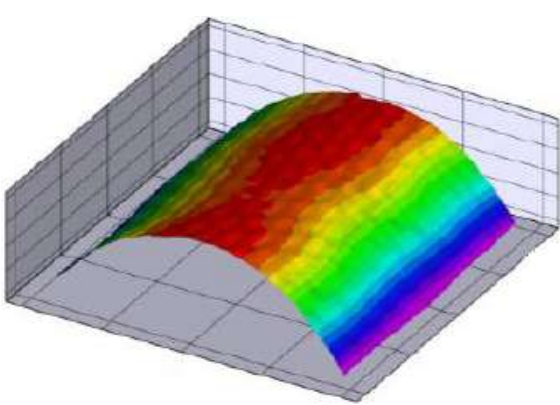

(a)

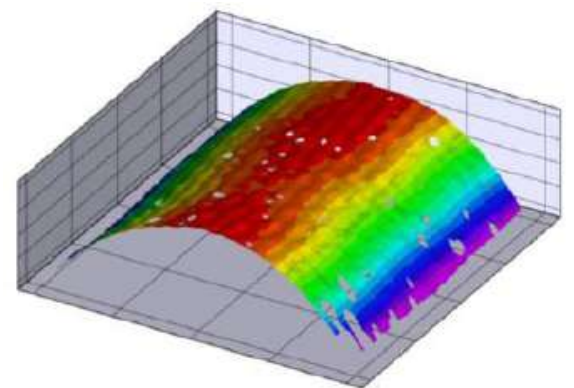

(b)

Figura A.3 - Variação do tamanho dos subsets para análise do mesmo espécime: (a) subsets de 53 pixels (adequado); e (b) subsets de 37 pixels (não adequado regiões com vazios). Adaptado Rodrigues (2014)

Nos trabalhos de Yaofeng \& Pang (2007), Vassoler \& Fancello (2010) e Lecompte et al. (2006), observou-se que o aumento do tamanho dos subsets acarretou melhor acurácia nos deslocamentos. Rodrigues (2014), a partir de seu trabalho e referências bibliográficas consultadas, também observou que o aumento do subset tendeu a menos indicações de erro por parte do software, porém ressaltou que quando se trabalha com gradientes de deformação, o tamanho do subset deve ser reduzido e condizente com tais gradientes. Reu (2012) também ressaltou a importância do tamanho pequeno do subset para se analisar campos de deformações. A adoção de subsets menores minimiza os erros de deformações 
devido à manutenção da ordem da função de correlação do subset em comparação com a utilizada para as análises de deslocamentos, função esta que nem sempre é informada pelo software (Reu, 2012).

De acordo com Rodrigues (2014), a determinação dos passos (steps) com que o programa fará o rastreamento para as correlações tem maior influência na acurácia do que o tamanho do subset. Das observações experimentais, o autor notou que nem sempre um menor passo leva a resultados mais exatos, e que a escolha de melhores passos está relacionada ao grau de uniformidade das deformações e ao padrão de speckles, conforme é ilustrado na Figura A.4. De acordo com o guia de boas práticas de CID (iDICs, 2018), de maneira geral, recomendam-se passos com tamanho de $1 / 3$ a 1/2 do tamanho do subset. Rodrigues (2014) sugere como uma das formas de otimização da escolha do passo a avaliação do aspecto e dos valores encontrados para as zonas de comportamento mais uniforme (o que implica em resultados do campo uniforme) ou até mesmo a comparação pontual com resultados obtidos com extensômetros. Em nenhuma das referências bibliográficas sobre força cortante em vigas de concreto com o uso de CID consultadas foi indicado o tamanho do passo.

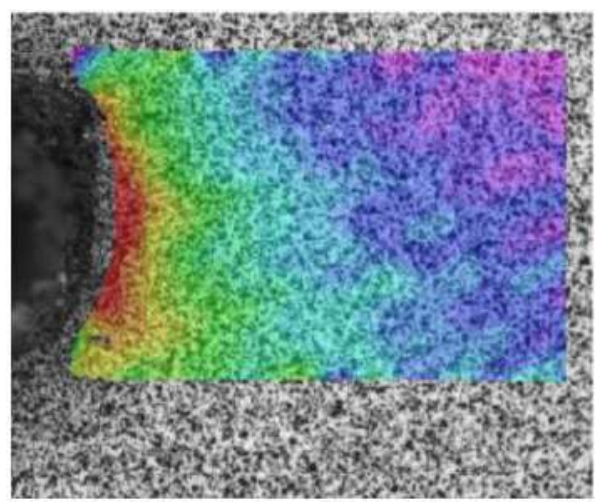

(a)

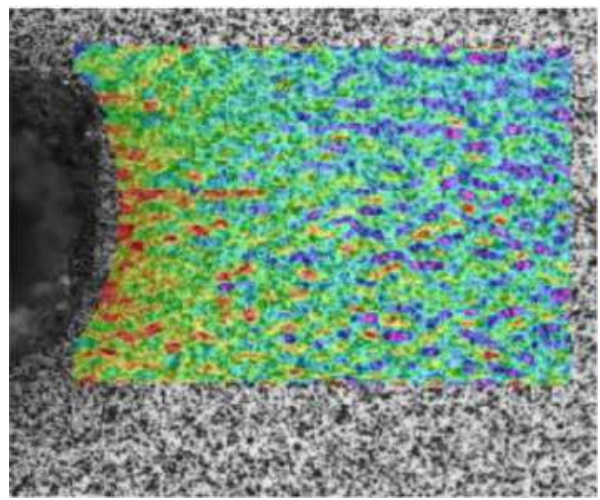

(b)

Figura A.4 - Variação do tamanho do passo e sua relação com o campo de deformações para o mesmo espécime: (a) 15 pixels - maior homogeneidade no campo de deformações; e (b) 4 pixels - campo de deformações com relevante heterogeneidade, o que não representa o comportamento real do espécime.

(Rodrigues, 2014)

Rodrigues (2014) relatou também que, embora tenha havido tentativas de uniformizar as pinturas dos padrões, os melhores resultados foram obtidos de maneira artesanal, adaptando-se a metodologia conforme a situação de análise. O guia iDICs (2018) recomenda o treinamento prévio da execução da pintura e 
simulação desta superfície como a do elemento a ser testado, em condições iguais à real, a fim de validar o padrão de pintura. A partir do tamanho da região de interesse de análise, da qualidade e posicionamento da câmera (relação mm/pixel da imagem), é possível estimar o tamanho ideal dos speckles.

Nos trabalhos sobre resistência à força cortante em vigas de concreto, observou-se tanto o uso da técnica manual de aspersão dos speckles por spray de tinta preta sobre a superfície previamente pintada de tinta branca (Ostromecki \& Suprynowicz, 2015; Gali \& Subramaniam, 2017), quanto a de método mais sofisticado, como a utilizada por Cavagnis et al. (2015 e 2018a), em que um padrão aleatório pré-definido por software é impresso em um cartão e colado na superfície do espécime, de modo a obter speckles de tamanho pequeno e constante, arredondados e não sobrepostos.

Em variadas aplicações em corpos-de-prova de concreto, a técnica óptica de CID tem se mostrado confiável (Choi \& Shah, 1997; Fayyad \& Lees, 2014; Santos et al., 2016; Cavagnis et al., 2015 e 2018a; etc.). Uma das formas de se estimar de maneira aleatória a qualidade (precisão e acurácia) das informações geradas pelo software de correlação de imagens é por meio da comparação entre duas imagens para o mesmo carregamento (geralmente nulo) e situação real de ensaio (posicionamento da câmera, luminosidade, etc.), sendo a variação das medições encontradas entre estas duas imagens utilizadas para esta estimativa. Uma forma de fazer uma verificação localizada é, a partir de uma região específica de interesse, comparar o resultado fornecido pelo software de correlação e o obtido por uma instrumentação clássica.

Choi \& Shah (1997) estimaram a acurácia de deslocamento medido em corpos-de-prova de concreto submetidos à compressão usando três diferentes procedimentos e obtiveram um erro médio entre 0,014 pixels e 0,064 pixels, que corresponderam a $1,20 \times 10^{-3} \mathrm{~mm}$ e $5,50 \times 10^{-3} \mathrm{~mm}$. Em trabalhos sobre resistência à força cortante em vigas de concreto, Cavagnis et al. (2015 e 2018a) e Gali \& Subramaniam (2017) obtiveram um erro de deslocamento de aproximadamente 0,02 pixels (que corresponderam em seus trabalhos a um valor entre $4,0 \times 10^{-3} \mathrm{~mm}$ a $12,0 \times 10^{-3} \mathrm{~mm}$ e $2,00 \times 10^{-3} \mathrm{~mm}$ a $2,83 \times 10^{-3} \mathrm{~mm}$, respectivamente), enquanto que para a deformação específica Gali \& Subramaniam (2017) tiveram resolução de $0,017 \times 10^{-3}$ e Zarrinpour \& Chao (2017) uma acurácia de $0,1 \times 10^{-3}$. Huber et al. (2016) não conseguiram analisar o campo de deformações na região comprimida 
não fissurada devido à falta de acurácia suficiente causada pelo tamanho de imagem escolhido para obtenção das medições.

$\mathrm{Na}$ teoria, qualquer tipo de câmera pode ser utilizada para o registro de imagens; entretanto, Hoult et al. (2016) ressaltaram alguns aspectos a considerar na escolha, como: desvio de fase da imagem (“jitter"), qualidade da lente da câmera e da imagem. O guia da iDICs (2018) apresenta recomendações mais detalhadas sobre a escolha e operação dos equipamentos de aquisição de imagens.

$\mathrm{O}$ desvio de fase da imagem refere-se a movimentos da imagem que não correspondem à realidade, que podem chegar a $\pm 0,4$ pixel (Luo et al., 2001). No caso das análises de deslocamentos relativos, como abertura e deslizamento entre faces de fissura, esta movimentação não influi nos resultados (Hoult et al., 2016).

A qualidade da lente da câmera está diretamente relacionada com a intensidade da inerente distorção da imagem proveniente da lente, a qual pode ser avaliada e corrigida por ensaio e algoritmo específicos, como apresentado por Pan et al. (2013). Para o caso de análise 2D, o guia da iDICs (2018) recomenda o uso de uma lente telecêntrica bilateral a fim de reduzir os erros de translação ou rotação fora do plano do elemento ensaiado. Se este tipo de lente não estiver disponível, é recomentado o uso de lente de grande comprimento focal. Embora Hoult et al. (2016) tenham comentado sobre esta fonte de erro, eles desconsideraram este efeito em sua verificação da cinemática da fissura crítica de cisalhamento, sem comentar sua consequência.

A qualidade da imagem em termos de pixels está relacionada com a resolução da câmera e o tamanho da área a ser monitorada. Para uma mesma relação entre as dimensões e número de pixels da imagem ( $\mathrm{mm} /$ pixel), uma área maior demanda uma câmera mais próxima da região a ser fotografada ou de maior resolução. Para as investigações de resistência à força cortante em vigas de concreto, verificou-se o uso de câmera fotográfica com resolução desde 4 megapixels (Huber et al., 2016), passando por 5 megapixels (Gali \& Subramaniam, 2017; Zarrimpour \& Chao, 2017; Belbachir, et al., 2018) e chegando até 36,3 megapixels (Cavagnis, et al., 2015 e 2018a). A relação mm/pixel ficou entre 0,100 e 0,143 para Gali \& Subramaniam (2017), de 0,182 a 0,382 para Belbachir et al. (2018) e de 0,20 a 0,60 para Cavagnis et al. (2015 e 2018a).

No geral, nos trabalhos sobre resistência à força cortante de vigas de concreto utilizando a CID notou-se escassez de informações sobre os parâmetros que influem 
na acurácia das análises (relação mm/pixel, tamanho dos speckles, subsets e do passo, etc.).

A Tabela A.1 resume alguns parâmetros usados para a CID em alguns trabalhos sobre resistência à força cortante em vigas de concreto. 
Tabela A.1 - Resumo de alguns parâmetros adotados em alguns trabalhos sobre força cortante em vigas de concreto com o uso da CID.

\begin{tabular}{|c|c|c|c|c|c|c|c|c|c|c|}
\hline \multirow{3}{*}{ Trabalho } & \multirow{3}{*}{$\begin{array}{c}\text { câmera } \\
\text { megapixels }\end{array}$} & \multirow{2}{*}{\multicolumn{2}{|c|}{$\begin{array}{l}\text { captura da } \\
\text { imagem }\end{array}$}} & \multirow{3}{*}{$\begin{array}{l}\text { Superfície } \\
\text { analisada } \\
\text { cm }^{2}\end{array}$} & \multirow{3}{*}{$\begin{array}{l}\text { relação } \\
\mathrm{mm} / \text { pixel }\end{array}$} & \multirow{3}{*}{$\begin{array}{c}\text { speckles } \\
\text { (pixels) }\end{array}$} & \multicolumn{4}{|c|}{ Análises } \\
\hline & & & & & & & \multirow{2}{*}{ software } & \multirow{2}{*}{$\begin{array}{l}\text { subset } \\
\text { (pixels) }\end{array}$} & \multirow[b]{2}{*}{ Tipo } & \multirow{2}{*}{ qualidade } \\
\hline & & modo & $\begin{array}{l}\text { frequência } \\
\qquad(\mathrm{Hz})\end{array}$ & & & & & & & \\
\hline 1 & 4 & $3 \mathrm{D}$ & 0,2 a 5,0 & $\begin{array}{c}1750 \mathrm{a} \\
1200\end{array}$ & - & - & Aramis & $15 \times 15$ & des & 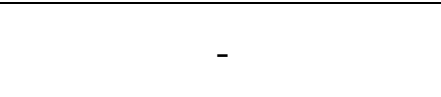 \\
\hline $2^{*}$ & 5 & $2 \mathrm{D}$ & - & 1000 & $\begin{array}{c}0,100 \mathrm{a} \\
0,143\end{array}$ & - & VIC-2D & $35 \times 35$ & des/def & $\begin{array}{l}\text { erro des: }(2,00 \text { a } 2,83) 10^{-3} \\
\text { mm } \\
\text { resolução def: } 0,017 \times 10^{-3}\end{array}$ \\
\hline 3 & 5 & $3 \mathrm{D}$ & - & $\begin{array}{c}10668 \mathrm{a} \\
44797\end{array}$ & - & 3 a 5 & - & - & des/def & acurácia def: $0,1 \times 10^{-3}$ \\
\hline 4 & 5 & $2 \mathrm{D}$ & 1,0 & $\begin{array}{c}1250 \mathrm{a} \\
9750\end{array}$ & $\begin{array}{c}0,182 \mathrm{a} \\
0,382\end{array}$ & - & - & - & des & - \\
\hline 5 & $\begin{array}{c}36,3^{+} \\
5^{-}\end{array}$ & $3 \mathrm{D}$ & $1,0-2,0$ & $\begin{array}{l}6300 \mathrm{a} \\
33600\end{array}$ & $\begin{array}{c}0,35 \mathrm{a} \\
0,60^{+} \\
0,2^{-}\end{array}$ & 3 a 5 & VIC-3D & - & des/def & $\begin{array}{c}\text { erro des }{ }^{+}:(7,00 \mathrm{a} \\
12,0) 10^{-3} \mathrm{~mm} \\
\text { erro des- } 4,00 \times 10^{-3} \mathrm{~mm}\end{array}$ \\
\hline
\end{tabular}

${ }^{1}$ Huber et al. (2016); ${ }^{2}$ Gali \& Subramanian (2017); ${ }^{3}$ Zarrinpour \& Chao (2017); ${ }^{4}$ Belbachir et al. (2018); ${ }^{5}$ Cavagnis et al. (2018a)

des: deslocamento; def: deformação; ${ }^{*} a / d=1,8 ;{ }^{+} \mathrm{e}^{-}:$relativo a câmera para análise de deslocamentos e deformações, respectivamente. 